\title{
ANDREA AMRI-HENKEL
}

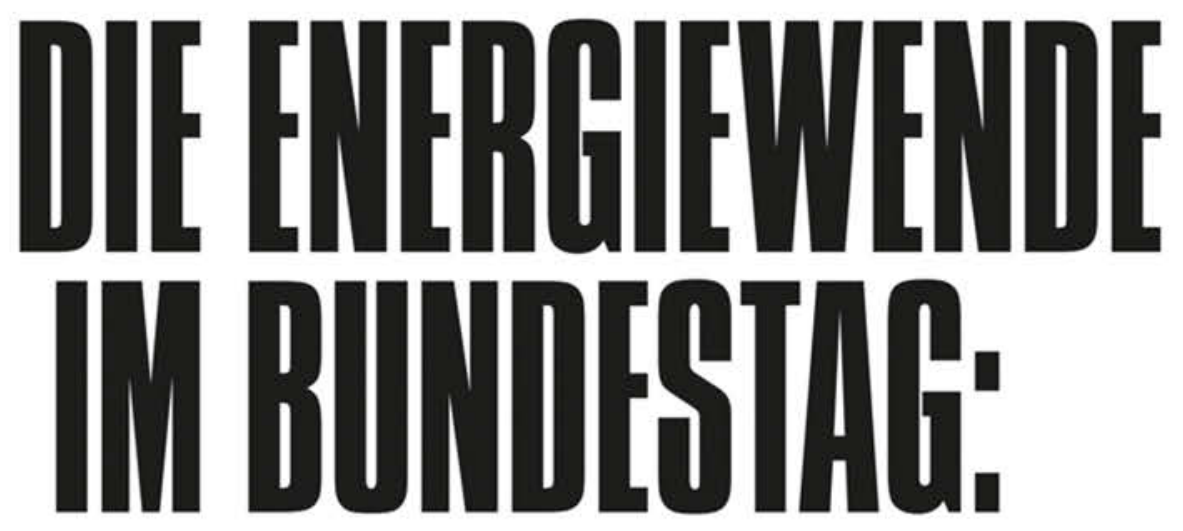

EIN POLITISCHES TRANSFORMATIONSPROJEKT?

Eine Diskursanalyse aus feministischer und sozial-ökologischer Perspektive
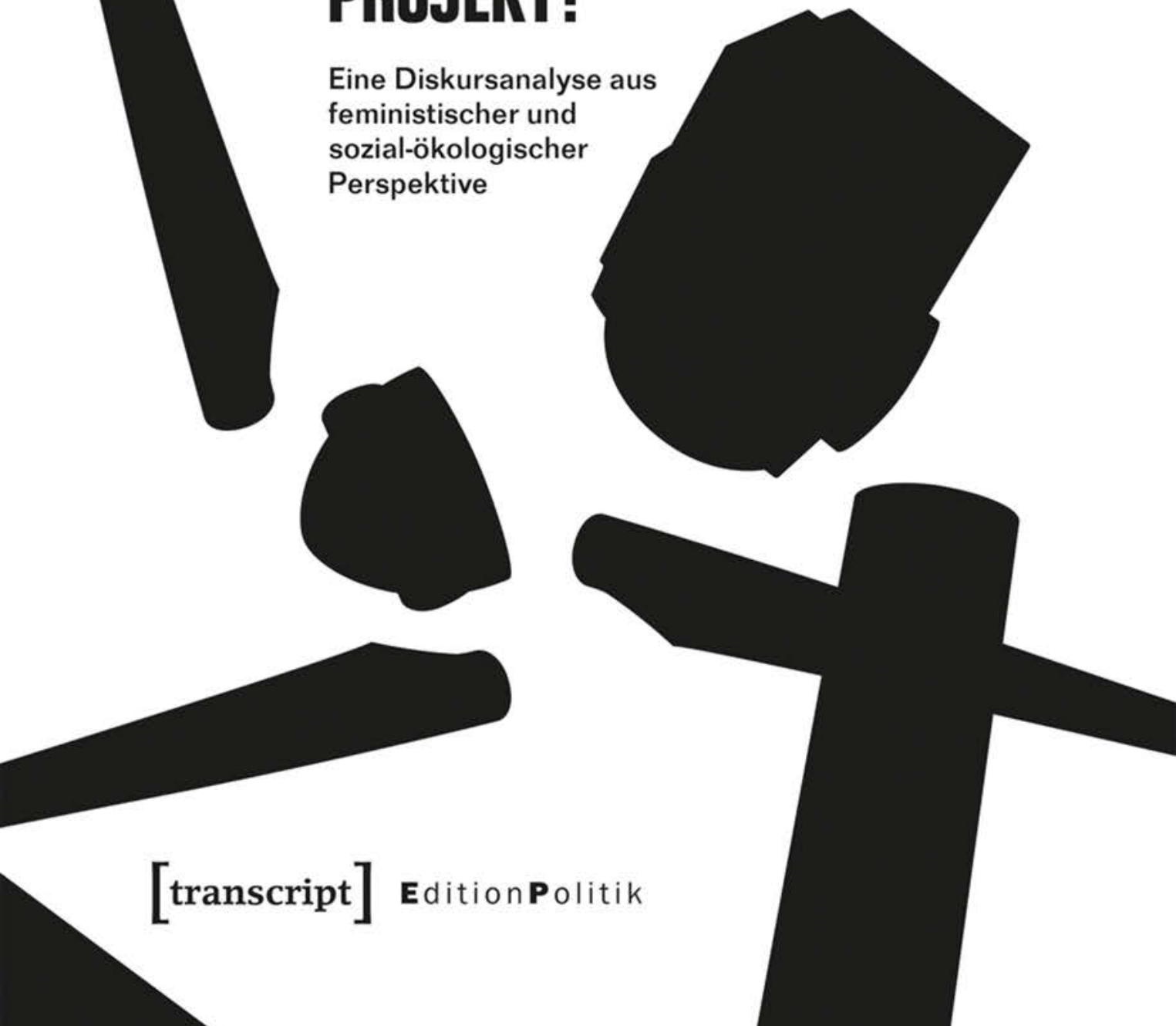
Andrea Amri-Henkel

Die Energiewende im Bundestag: ein politisches Transformationsprojekt?

Edition Politik | Band 106 
This open access publication has been enabled by the support of POLLUX (Fachinformationsdienst Politikwissenschaft)

\section{POLLUXX Informationsdienst}

and a collaborative network of academic libraries for the promotion of the Open Access transformation in the Social Sciences and Humanities (transcript Open Library Politikwissenschaft 2020)

This publication is compliant with the "Recommendations on quality standards for the open access provision of books", Nationaler Open Access Kontaktpunkt 2018 (https://pub.uni-bielefeld.de/record/2932189)

\author{
Universitätsbibliothek Bayreuth | \\ Universitätsbibliothek der Humboldt- \\ Universität zu Berlin | Staatsbibliothek \\ zu Berlin | Universitätsbibliothek FU \\ Berlin | Universitätsbibliothek Bielefeld \\ (University of Bielefeld) | Universitäts- \\ bibliothek der Ruhr-Universität Bochum \\ | Universitäts- und Landesbibliothek | \\ Sächsische Landesbibliothek - Staats- und \\ Universitätsbibliothek Dresden | Universi- \\ tätsbibliothek Duisburg-Essen | Univer- \\ sitäts- $u$. Landesbibliothek Düsseldorf | \\ Universitätsbibliothek Erlangen-Nürnberg \\ | Universitätsbibliothek Johann Christian \\ Senckenberg | Universitätsbibliothek \\ Gießen | Niedersächsische Staats- und Uni- \\ versitätsbibliothek Göttingen | Universitäts- \\ bibliothek Graz | Universitätsbibliothek der \\ FernUniversität in Hagen | Martin-Luther- \\ Universität Halle-Wittenberg | Staats- und \\ Universitätsbibliothek Carl von Ossietzky, \\ Hamburg | Technische Informations- \\ bibliothek Hannover | Gottfried Wilhelm \\ Leibniz Bibliothek - Niedersächsische
}
Landesbibliothek | Universitätsbibliothek Kassel | Universitäts- und Stadtbibliothek Köln | Universität Konstanz, Kommuni- kations-, Informations-, Medienzentrum | Universitätsbibliothek Koblenz-Landau | Universitätsbibliothek Leipzig | Zentral- $u$. Hochschulbibliothek Luzern | Universitäts- bibliothek Mainz | Universitätsbibliothek Marburg | Ludwig-Maximilians-Universität München Universitätsbibliothek | Max Planck Digital Library | Universitäts- und Landesbibliothek Münster | Universitäts- bibliothek Oldenburg | Universitätsbiblio- thek Osnabrück | Universitätsbibliothek Passau | Universitätsbibliothek Potsdam | Universitätsbibliothek Siegen | Universitäts- bibliothek Vechta | Universitätsbibliothek der Bauhaus-Universität Weimar | Universi- tätsbibliothek Wien | Universitätsbibliothek Wuppertal | Universitätsbibliothek Würz- burg | Zentralbibliothek Zürich | Bundes- ministerium der Verteidigung - Bibliothek | Landesbibliothek Oldenburg

Andrea Amri-Henkel , geb. 1987, ist Nachhaltigkeitswissenschaftlerin und hat an der Leuphana Universität Lüneburg promoviert. Ihre Arbeitsschwerpunkte liegen in den Bereichen Energie- und Mobilitätswende, Politik, Transformation und Gender. 
Andrea Amri-Henkel

\section{Die Energiewende im Bundestag: ein politisches Transformationsprojekt?}

Eine Diskursanalyse aus feministischer und sozial-ökologischer Perspektive 
Lüneburg, Leuphana Universität Lüneburg, Fakultät Nachhaltigkeit, Dissertation, Disputation: 29.10.2020, Urspr. Titel: Die »Energiewende« im Bundestag: ein politisches Transformationsprojekt? Dekonstruktion und Bewertung. Diskursanalyse von Bundestagsdebatten zur Energiewende zwischen der 14. und 18. Legislaturperiode unter Anwendung einer Analyseperspektive Vorsorgenden Wirtschaftens.

Gutachterinnen: Prof.in Dr. Sabine Hofmeister, Prof.in i.R. Dr. Adelheid Biesecker, Prof.in Dr. Ines Weller

\section{Bibliografische Information der Deutschen Nationalbibliothek}

Die Deutsche Nationalbibliothek verzeichnet diese Publikation in der Deutschen Nationalbibliografie; detaillierte bibliografische Daten sind im Internet über http:// dnb.d-nb.de abrufbar.

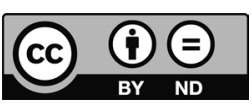

Dieses Werk ist lizenziert unter der Creative Commons Attribution-NoDerivatives 4.0 Lizenz (BY-ND). Diese Lizenz erlaubt unter Voraussetzung der Namensnennung des Urhebers die Vervielfältigung und Verbreitung des Materials in jedem Format oder Medium für beliebige Zwecke, auch kommerziell, gestattet aber keine Bearbeitung. (Lizenztext:

https://creativecommons.org/licenses/by-nd/4.o/deed.de)

Um Genehmigungen für Adaptionen, Übersetzungen oder Derivate einzuholen, wenden Sie sich bitte an rights@transcript-publishing.com

Die Bedingungen der Creative-Commons-Lizenz gelten nur für Originalmaterial. Die Wiederverwendung von Material aus anderen Quellen (gekennzeichnet mit Quellenangabe) wie z.B. Schaubilder, Abbildungen, Fotos und Textauszüge erfordert ggf. weitere Nutzungsgenehmigungen durch den jeweiligen Rechteinhaber.

\section{() 2021 transcript Verlag, Bielefeld}

Umschlaggestaltung: Max Weinland

Lektorat: David Amri

Satz: Daniel Schulz

Druck: Majuskel Medienproduktion $\mathrm{GmbH}$, Wetzlar

Print-ISBN 978-3-8376-5479-0

PDF-ISBN 978-3-8394-5479-4

EPUB-ISBN 978-3-7328-5479-0

https://doi.org/10.14361/9783839454794

Gedruckt auf alterungsbeständigem Papier mit chlorfrei gebleichtem Zellstoff. Besuchen Sie uns im Internet: https://www.transcript-verlag.de Unsere aktuelle Vorschau finden Sie unter www.transcript-verlag.de/vorschau-download 


\section{Inhalt}

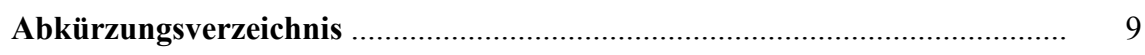

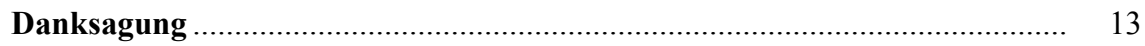

1 Einleitung und Forschungsstand ...................................................... 15

1.1 Gegenstand und Forschungsfragen .................................................. 19

1.2 Positionierung und theoretische Verortung.......................................... 27

1.3 Struktur der Arbeit .............................................................. 37

2 Diskurstheorie ..................................................................................... $\quad 39$

2.1 Gesellschaftspolitische Bedeutung und Entwicklung von Diskurstheorien........................................................................ $\quad 39$

2.2 Verortung der Diskurstheorie nach Laclau/Mouffe .............................. 41

2.3 Der Diskursbegriff nach Laclau/Mouffe ............................................... 44

2.4 Grundbegriffe der Diskurstheorie nach Laclau/Mouffe .......................... 49

2.5 Gesellschafts-, Hegemonie- und politische Theorie nach Laclau/Mouffe........................................................................ 53

2.6 Radikale Demokratie und Kritik ..................................................... 61

3 Vorsorgendes Wirtschaften als kritisch-emanzipatorische Perspektive im Kontext von Transformation ............................................................... 65

3.1 Theoretische Verortung des Transformationsbegriffes ......................... 66

3.1.1 Transformatives Verständnis von Zeitlichkeit........................... 66

3.1.2 Integrative Krisenbetrachtung ............................................ $\quad 70$

3.1.3 Diskurstheoretische Verortung
sozial-ökologischer Transformation ..................................... 72

3.2 Positionierung: Vorsorgendes Wirtschaften als sozial-ökologisches Transformationskonzept ................................................................ $\quad 75$

3.2.1 Handlungsprinzipien............................................................... 79

3.2.2 Weitere Bewertungskriterien Vorsorgenden Wirtschaftens........ 86

3.2.3 Potenziale einer diskurstheoretischen Perspektive Vorsorgenden Wirtschaftens ................................................... 100

4 Methodik: Diskursanalyse und Vorsorgendes Wirtschaften als Forschungsprogramm ................................................................... 103

4.1 Gegenstand: Plenardebatten im Bundestag ......................................... 105

4.2 Operationalisierung der Diskurstheorie nach Laclau/Mouffe ................ 109

4.2.1 Computerbasiertes diskursanalytisches Verfahren ..................... 110

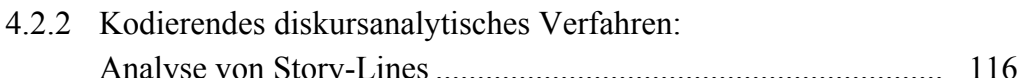

4.2.3 Klassifikation fantasmatischer Narrative ................................ 122 
4.3 Operationalisierung einer kritisch-emanzipatorischen

Analyseperspektive Vorsorgenden Wirtschaftens.

4.4 Kritische Reflexion des Forschungsansatzes und Forschungsdesigns

5 Dekonstruktion Teil I: Diskursanalyse der Bundestagsdebatten zur „Energiewende“ nach Laclau/Mouffe

5.1 Ergebnisse des computerbasierten Verfahrens

5.1.1 Zeitlicher Diskursverlauf: Frequenzanalyse

5.1.2 Kollokations- und Konkordanzanalyse von der 14. bis zur 18. Legislaturperiode.

5.1.3 Diskussion: Regelmäßige Differenzbeziehungen von

„Energiewende“ in Auseinandersetzung um Hegemonie.

5.2 Story-Lines im Diskurs um „Energiewende“

5.2.1 Übersicht über die Entwicklung der politischen Einordnung von „Energiewende“

5.2.2 Förderung und Ausbau erneuerbarer Energien als gemeinsames Ziel

5.2.3 Der erneuerbare Energiebereich als Wirtschaftsfaktor.

5.2.4 Marktorientierung als Bedingung erneuerbarer Energiepolitik und ,Energiewende“

5.2.5 ( $\mathrm{Zu})$ Hohe Kosten erneuerbarer Energien und „Energiewende“"

5.2.6 Deutschland als Vorreiter und „Energiewende“ als nationales Gemeinschaftswerk

5.2.7 Strominfrastruktur als zentrale Herausforderung der „Energiewende“

5.2.8 Rolle der Bürger*innen im Kontext von Akzeptanz und Konsens.

5.2.9 Wissenschaft als Schlüssel zum Gelingen der „Energiewende“

5.2.10 Die ,großen Vier' als Repräsentanten des herkömmlichen Energiesystems

5.3 Fantasmatische Narrative im Kontext des Diskurses um „Energiewende“

5.3.1 Ökologische Modernisierung.

5.3.2 Marktwirtschaftliche Energiepolitik

5.3.3 Sozial-ökologischer Umbau.

5.4 Zusammenführung und Diskussion: Post-Politik der „Energiewende“.. 246

6 Dekonstruktion Teil II: Der „Energiewende“-Diskurs im Bundestag aus Perspektive Vorsorgenden Wirtschaftens

6.1 Vorsorgende „Energiewende“?

6.2 Kooperative „Energiewende“?

6.3 Am guten Leben orientierte „Energiewende“? 
6.4 Externalisierung als Prinzip im Diskurs um „Energiewende“

6.5 Potenziale für eine herrschaftsärmere Zukunftsgestaltung im Diskurs um „Energiewende“

7 Fazit: Die bundespolitische „Energiewende“ im Kontext marktwirtschaftlicher Beharrung

7.1 Beantwortung der Forschungsfragen über zentrale Zeitabschnitte ........ 311

7.2 Schlussfolgerungen für den gesamten Betrachtungszeitraum ................ 322

7.3 Ausblick und weiterer Forschungsbedarf............................................ 326

7.4 Rückbindung an die Theorie:

Ansatzpunkte zur Überwindung des Post-Politischen.

7.5 Kritische Reflexion

Literatur

Anhang 



\section{Abkürzungsverzeichnis}

5R 5L

Abb.

AfD

AKW

BGB

BIP

BMBF

BMU

BMWI

bspw.

ca.

CCS

CDA

CDM

CDU

CSU

SPD

CJA

$\mathrm{CO}_{2}$

COSMAS

DDR

DIP

DIW

EEG

EEWärmeG

EnBW

EnLAG

etc.

EU
5 Wörter Rechts, 5 Wörter Links (Abstand zum Knotenpunkt)

Abbildung

Alternative für Deutschland

Atomkraftwerk

Bürgerliches Gesetzbuch

Bruttoinlandsprodukt

Bundesministerium für Bildung und Forschung

Bundesministerium für Umwelt, Naturschutz und nukleare Sicherheit

Bundesministerium für Wirtschaft und Energie

beispielsweise

circa

Carbon Capture and Storage

Critical Discourse Analysis

Clean Development Mechanismus

Christlich Demokratische Union

Christlich Soziale Union

Sozialdemokratische Partei Deutschlands

Climate Justice Action

Kohlenstoffdioxid

Corpus Search, Management and Analysis System

Deutsche Demokratische Republik

Dokumentations- und Informationssystem für Parlamentarische Vorgänge

Deutsches Institut für Wirtschaftsforschung

Erneuerbare-Energien-Gesetz

Erneuerbare-Energien-Wärmegesetz

Energie Baden-Württemberg

Energieleitungsausbaugesetz

et cetera

Europäische Union 


\begin{tabular}{|c|c|}
\hline FADA & Feminisms and Degrowth Alliance \\
\hline FDP & Freie Demokratische Partei \\
\hline FONA & Forschung für Nachhaltige Entwicklung \\
\hline $\begin{array}{l}\text { freq/rel. freq/ } \\
\text { min freq }\end{array}$ & frequency/relative frequency/minimum frequency \\
\hline GenG & Genossenschaftsgesetz \\
\hline GG & Grundgesetz \\
\hline $\begin{array}{l}\text { GmbH } \\
\text { \& Co KG }\end{array}$ & $\begin{array}{l}\text { Gesellschaft mit beschränkter Haftung und Compagnie Komman- } \\
\text { ditgesellschaft }\end{array}$ \\
\hline IDS & Institut für Deutsche Sprache \\
\hline IG BCE & Industriegewerkschaft Bergbau, Chemie, Energie \\
\hline KDA & Kritische Diskursanalyse \\
\hline KernbrStG & Kernbrennstoffsteuergesetzes \\
\hline km & Kilometer \\
\hline KWIC & key word in context \\
\hline Kwp & kilowatt peak \\
\hline LKW & Lastkraftwagen \\
\hline Log & Logarithmus \\
\hline Lp & Legislaturperiode \\
\hline MW & Megawatt \\
\hline NGO & Non-Governmental Organization \\
\hline $\mathbf{P}$ & probabilitas \\
\hline p.a. & pro anno (pro Jahr) \\
\hline PDS & Partei des Demokratischen Sozialismus \\
\hline PolMine & Project for corpus-assisted political research \\
\hline GermaParl & German parliamentary corpus \\
\hline POS & Part of Speech \\
\hline PV & Photovoltaik \\
\hline $\mathbf{q m}$ & Quadratmeter \\
\hline RWE & Rheinisch-Westfälisches Elektrizitätswerk \\
\hline s.o. & siehe oben \\
\hline s.u. & siehe unten \\
\hline SÖF & Sozial-Ökologische Forschung \\
\hline TNS Emnid & $\begin{array}{l}\text { Taylor Nelson Sofres (TNS) Erforschung der öffentlichen Mei- } \\
\text { nung, Marktforschung, Nachrichten, Informationen und Dienst- } \\
\text { leistungen (Emnid) }\end{array}$ \\
\hline TraVo & $\begin{array}{l}\text { Vorsorgendes Wirtschaften. Transformationen in Ökonomie und } \\
\text { Politik }\end{array}$ \\
\hline u.a. & unter anderem \\
\hline UBA & Umweltbundesamt \\
\hline UNU-WIDER & $\begin{array}{l}\text { World Institute for Development Economics Research der Verein- } \\
\text { ten Nationen }\end{array}$ \\
\hline US & United States \\
\hline
\end{tabular}


usw.

VDMA

vgl.

WASG

WBGU

WCED

WWF

XML/TEI

z.B.

zit. in

ZK und so weiter

Verband Deutscher Maschinen- und Anlagenbau

vergleiche

Wahlalternative Soziale Gerechtigkeit

Wissenschaftlicher Beirat der Bundesregierung globale Umweltveränderungen

World Commission on Environment and Development

World Wildlife Fund

Extensible Markup Language/Text Encoding Initiative zum Beispiel

zitiert in

Zentralkomitee der SED 



\section{Danksagung}

Diese Arbeit hat einen langen Weg hinter sich, an dem viele Menschen einen Anteil hatten. Zunächst möchte ich meinen beiden Doktormüttern Prof.in Dr. Sabine Hofmeister und Prof.in Dr. Adelheid Biesecker für die Unterstützung während meiner gesamten Promotionszeit danken. Vielen Dank für viele inhaltlich spannende Diskussionen, dafür, dass ihr mir mit Rat und Tat zur Seite gestanden habt und, dass ihr mich zum Vorsorgenden Wirtschaften gebracht habt! Im Austausch mit euch habe ich meine Positionierung als kritische und feministische Nachhaltigkeitsforscherin entwickeln können.

Mein Partner David Amri hat mich während meiner Promotionszeit nicht nur moralisch unterstützt, sondern gemeinsam haben wir diese Forschungsarbeit immer wieder reflektiert und dadurch weitergebracht. Er hat zudem in umfangreicher Detailarbeit das Lektorat übernommen, wofür ich sehr dankbar bin! Großer Dank geht an Max Weinland, der mit seiner grafischen Gestaltung nicht nur den Umschlag dieses Buches ,besonders` gemacht hat, sondern auch die Grafiken im Text. Daniel Schulz hat mit seiner detaillierten und mühevollen Formatierungsarbeit einen großen Beitrag dazu geleistet, dass diese Doktorarbeit am Höhepunkt des ersten Lockdowns der Corona-Pandemie Anfang April 2020 bei der Universität eingereicht und am Höhepunkt des zweiten Lockdowns druckfertig gemacht werden konnte. Vielen Dank für die in dieser schwierigen Zeit so wichtigen Unterstützung!

Ich danke außerdem meinen lieben Kolleg*innen und Freund*innen Katharina Kapitza, Janina Dannenberg, Jenny Schmidt, Esther Meyer, Sebastian Heilmann, Beate Friedrich, Gudrun Harms, Laura Elger und Laura Welle für die Diskussionen, die Unterstützung und ganz besonders dafür, dass ihr mich durch all die Höhen und Tiefen der letzten Jahre begleitet habt!

Vielen Dank an meine Familie, besonders an meine Kinder, die mir kontinuierlich ,Denkpausen“ verschafft haben und deren pure Existenz mir geholfen hat, den Blick für das ,Wesentliche‘ zu schärfen.

Ich danke der Rosa Luxemburg Stiftung, die mein Promotionsprojekt durch ein Stipendium ermöglicht hat. Diese Finanzierung gab mir die Freiräume, die nötig sind, um intensive Forschungs- und Denkarbeit mit Familienerweiterung und Sorgearbeit zu verknüpfen. 



\title{
1 Einleitung und Forschungsstand
}

\author{
„Die Energiewende ist ein Transformationsprojekt, \\ das mehr ist als technologische und wirtschaftliche \\ Innovation. Sie bedeutet einen grundlegenden Um- \\ bau, nicht nur in der Energieerzeugung, sondern auch \\ in den Städten und im Verkehr, in der Industrie und \\ in den Haushalten.“ \\ www.bmwi.de - Energiepolitik
}

Die Ansprüche, die mit der „Energiewende ${ }^{1 ، “}$ in Verbindung gebracht werden, sind hoch - auch von Seiten der Bundesregierung, wie das obige Zitat verdeutlicht. Dabei bleibt aber häufig unklar, was mit „Energiewende“ oder Transformation genau gemeint ist. Transformation ist ein vieldeutiger Begriff mit historisch vielfältiger Verwendung: Er wurde sowohl im Sinne des Übergangs zu einer Vernunft geleiteten Gesellschaftsgestaltung in den Debatten der Französischen Revolution verwendet als auch später zur Bezeichnung der Übergangsperiode zum sowjetischen Sozialismus. Polanyi („The Great Transformation“) verwendete ihn wiederum für den Übergang zur kapitalistischen Marktwirtschaft (Polanyi 1995). Aber auch in Zusammenhang mit Demokratisierungsprozessen autoritärer Regime, bspw. in Südeuropa und Lateinamerika taucht der Begriff auf. Aktuell ersetzt der Begriff der Transformation in

1 In der vorliegenden Arbeit schreibe ich „Energiewende“ in Anführungszeichen, um zu verdeutlichen, dass ich nicht von einem bestimmten Verständnis oder einer Definition von „Energiewende“ ausgehe, sondern von „Energiewende“ als Diskurs spreche. Ich hebe dadurch die zentrale Bedeutung von „Energiewende“ für meine Arbeit hervor. Zudem verdeutliche ich das prozessorientierte Verständnis von „Energiewende“, das sich in ständigem Wandel befindet. Ebenso setze ich „Fukushima“ in Anführungszeichen, um die diskursiv konstituierte Symbolik des Ereignisses für den deutschen Diskurs um „Energiewende" hervorzuheben. Aus Gründen der besseren Lesbarkeit verzichte ich bei den zahlreichen weiteren Begriffen, die vor dem Hintergrund der diskurstheoretischen Perspektive meiner Arbeit ebenfalls als diskursiv bestimmt verstanden werden, auf diese Hervorhebung. Bspw. sind in diesem Verständnis Natur, Nachhaltigkeit, Transformation erneuerbare Energien, Atomausstieg, Klimaschutz, Umwelt, Kultur, Entwicklung sowie zahlreiche weitere Begriffe ebenso diskursiv bestimmt. In ihrer Verwendung adressiere ich somit die jeweilige im Diskurs zugewiesene Bedeutung. Insofern ich diese Begriffe vor dem Hintergrund meiner eigenen wissenschaftlichen Positionierung verwende, geht dies aus dem Kontext hervor. 
den wissenschaftlichen Debatten sowie in der wissenschaftlichen Politikberatung zunehmend das Leitbild nachhaltiger Entwicklung (Brand 2017: 24) oder wird ergänzend zu diesem verwendet, um die Notwendigkeit struktureller Veränderungen hervorzuheben (Brand/Wissen 2017: 28ff.). Nachhaltigkeit wird dabei weiterhin als Ziel von Transformation benannt ${ }^{2}$ (vgl. z.B. WBGU 2011a; www.umweltbundesamt.de Transformation; Umweltbundesamt 2018), bleibt aber über einen Verweis auf die Brundtland-Kommission hinaus meist ebenso unbestimmt wie der Transformationsbegriff selbst. ${ }^{3}$ Insbesondere in Folge des Hauptgutachtens des WBGU von 2011 „Welt im Wandel: Gesellschaftsvertrag für eine große Transformation“ gewann die Debatte um Transformation in Deutschland an Bedeutung (WBGU 2011b).

In Deutschland stellt die „Energiewende“ laut Müller (2012: 30f.) einen „wichtigen Kristallisationspunkt gesellschaftlicher Kämpfe“ dar, da sie historisch im Kontext sozialer Bewegungen wie einer starken Anti-Atomkraft- und Umweltbewegung seit den 70er Jahren entstand. Mit Veröffentlichung der vom Umweltbundesamt UBA finanzierten und vom Öko-Institut veröffentlichten Studie „Energie-Wende: Wachstum und Wohlstand ohne Erdöl und Uran“ (Krause u.a. 1980) fand der Begriff „Energiewende ${ }^{4 “}$ in den 1980er Jahren Eingang in die gesellschaftlichen Debatten. ${ }^{5}$ Die „Energiewende“ gilt dabei als „Prüf- und Testfeld“ für oder gegen gesellschaftlichen Wandel, beziehungsweise Transformation (Reißig 2012: 20f.). Auch im WBGU Gutachten wird Energie als einem von drei zentralen Transformationsfeldern, ,an denen die Politik zur Transformation ansetzen sollte“ ein herausragender Stellenwert

2 „Unter Großer Transformation versteht der WBGU die weltweite Veränderung von Wirtschaft und Gesellschaft in Richtung Nachhaltigkeit“ (WBGU 2011a: 1).

3 So definiert der WBGU nachhaltige Entwicklung wie folgt: „1987 von der BrundtlandKommission [(World Commission on Environment and Development)] als Entwicklung definiert, die den Bedürfnissen der heutigen Generation entspricht, ohne die Möglichkeiten zukünftiger Generationen zu gefährden, ihre eigenen Bedürfnisse zu befriedigen und ihren Lebensstil zu wählen. Heute existiert eine Vielzahl von Nachhaltigkeitsdefinitionen. Allen gemeinsam ist der Anspruch, dass ökonomische, soziale und umweltverträgliche Entwicklung gleichzeitig voran getrieben werden müssen“ (WBGU 2011b: 419). Gottschlich (2017: 22ff.) untersucht verschiedene Diskursstränge über Nachhaltigkeit und plädiert dafür, den Begriff der Nachhaltigkeit nicht aufzugeben, sondern ihn als diskursiven Begriff zu verwenden. Diesem Verständnis von Nachhaltigkeit als Diskurs schließe ich mich hier an und bewege mich auf Grundlage der in der vorliegenden Arbeit vorgenommenen Positionierung auf spezifische Weise innerhalb dieses Diskurses.

4 Krause u.a. (1980: 23ff.) verbanden mit „Energiewende“ zunächst überwiegend Forderungen nach einer technischen Umstellung der Energieversorgung sowie einer Reduktion des Energieverbrauchs, u.a. durch „,bessere Energienutzung“. Sie verbanden diese Forderungen aber auch mit einer Infragestellung bedingungslosen materiellen Wachstums und vertraten die These der Möglichkeit einer Entkoppelung von Wirtschaftswachstum und Energieverbrauch.

5 Laut einer Untersuchung von Dernbach (2015) zeigen sich die ersten Treffer für „Energiewende“ in der COSMAS-Datenbank des Instituts für Deutsche Sprache IDS, eine „der umfangreichsten Textdatenbanken“ für die deutsche Sprache, in der bspw. Zeitungs-, Fach-, und Sachartikel sowie Literatur gesammelt werden, im Jahr 1986 (Dernbach 2015: 27). 
beigemessen (WBGU 2011: 3). In Deutschland beträgt der Anteil der energiebedingten Treibhausgasemissionen an den Gesamtemissionen ca. 85\% (Letzte Aktualisierung des UBA aus 2019 mit Daten aus 2017; www.umweltbundesamt.de - Treibhausgasemissionen). Um das 2-Grad-Ziel noch zu erreichen, sei laut WBGU eine globale „Energiewende“ sowie eine Abkehr vom auf „fossilen Energieträgern basierenden Wirtschaftswachstum“ im Rahmen einer großen Transformation dringend erforderlich (WBGU 2011: 3). Der WBGU verdeutlicht an dieser Stelle den Zusammenhang zwischen dem industriellen Wirtschaftssystem und seinen ökologischen Auswirkungen und verweist auf die Tragweite des notwendigen Transformationsprozesses (Biesecker u.a. 2015: 5).

„Indem der Beirat diesen Zusammenhang herstellt, geht er über die bisherige Debatte zur Energiewende hinaus: Wird hier [gemeint ist in der bisherigen Debatte] die Umstellung der Energiebzw. Stromversorgung noch auf technisch ökonomische Aspekte verkürzt diskutiert, so wird im Hauptgutachten [WBGU 2011b] mit Verweis auf die drei zentralen Transformationsfelder schon deutlich, dass eine Wende hin zur Nutzung ,neuer Energien' in ,alten (gesellschaftlichen) Verhältnissen` nicht gelingen wird [...]“ (Amri-Henkel u.a. 2017: 13).

Doch finden solche Verständnisse von „Energiewende“ und Transformation auch Eingang in die Bundespolitik? Oder: Was genau ist politisch gemeint, wenn von „Energiewende“ als einem Transformationsprojekt die Rede ist? Welche politischen Ziele werden im Zusammenhang mit „Energiewende“ adressiert? Dies sind grundlegende Fragen der vorliegenden Arbeit.

Im Zentrum der politischen Problematisierung von „Energiewende“ scheinen zwei Anliegen zu stehen: Den Energieverbrauch zu senken und den Anteil erneuerbarer Energien zu erhöhen. Laut Umweltbundesamt ist der Endenergieverbrauch in Deutschland seit 1990 aufgrund von „Wirtschaftswachstum und Konsumsteigerungen" allerdings trotz Effizienzsteigerungen kaum gesunken (www.umweltbundes amt.de - Energieverbrauch). Darüber hinaus ist die Debatte um die „Energiewende“ in Deutschland auf den Strombereich fixiert, obwohl de facto die Steigerung des Anteils der erneuerbaren Energien in anderen Energiebereichen deutlich niedriger ausfällt. Der Anteil erneuerbarer Energien am Bruttoendenergieverbrauch beträgt 2018 16,6\%, am Stromverbrauch 37,8\% (www.umweltbundesamt.de - erneuerbare Energien). Zum einen scheint sich das vielfach mit „Energiewende“ verbundene Versprechen der Möglichkeit einer Entkoppelung von Wirtschaftswachstum und Energieverbrauch (vgl. z.B. Krause u.a. 1980: 23) also nicht einzulösen. Zum anderen bleibt in Anbetracht der Zahlen selbst die bloße technische Umstellung des Energiebereichs auf erneuerbare Energien offensichtlich weiterhin eine anspruchsvolle Herausforderung.

Darüber hinaus stellt sich die Frage, ob und inwiefern sozial-ökologische $\mathrm{Zu}$ sammenhänge von den politischen Akteur*innen adressiert werden. Im WBGUGutachten steht nach einer Analyse von Biesecker u.a. (2015) nicht das ,sozialökologische Ganze“ im Fokus. Vielmehr wird der „gesellschaftliche Umgang mit Energie“ hauptsächlich in Bezug auf ,nachhaltigere[...] Konsumstrukturen, effizientere[...] Produktionsstrukturen und erneuerbare[...] Energieträger aufgegriffen“ (Biesecker u.a. 2015: 16), ohne eine sozial-ökologische und soziokulturelle Einbettung vorzunehmen. Biesecker u.a. (2015) kritisieren, dass dem Kapitalismus inhären- 
te, sozial-ökologische Externalisierungsprozesse nicht identifiziert werden - dass Macht- und Herrschaftskritik ausbleiben. Dem folgend sind auch die darin präsentierten Lösungsansätze letztlich in weiten Teilen als eher technikorientiert zu bewerten (Biesecker u.a. 2015: 16f.). Trotz des politischen Beschlusses zur „Energiewende“ sind die Herausforderungen zur Umstellung der fossilen auf eine erneuerbare Energieversorgung nach wie vor also enorm - während sich gleichzeitig die Frage aufdrängt, ob eine mangelnde Thematisierung des sozial-ökologischen Zusammenhangs der „Energiewende“ der Bewältigung dieser Herausforderungen im Wege steht.

Zweifellos birgt eine „Energiewende“ transformative Potenziale, schon allein aufgrund ihrer historischen Initiierung als Bottom-up Prozess. Mautz (2017) arbeitet heraus, dass eine expandierende soziotechnische Nische nicht nur Kräfteverschiebungen im Energiesektor bewirken konnte, sondern, dass gleichzeitig ein gesellschaftlicher Umbruch stattfand, in dem die für die „Energiewende“ maßgeblichen Akteur*innen unter einer breiten bürgerschaftlichen Beteiligung zu einer neuartigen Basis des Energiesektors wurden (Mautz 2017: 196f.). Ein Ziel war für viele Akteur*innen dabei auch die Demokratisierung der Energieversorgung sowie eine sozial gerechtere Energieproduktion. Dies sollte u.a. durch Energie in Bürger*innenhand erreicht werden (Radtke 2018: 284). Thomas (2012) zeigt auf, wie die „Energiewende“ kommunalpolitische Handlungsspielräume (wieder) erweitern und dadurch zu einer Demokratisierung auf kommunaler Ebene beitragen kann. Die Beteiligung an der Energieproduktion und -versorgung als öffentlichem Gut oder damit zusammenhängende Rekommunalisierungen können „Aushandlungsmöglichkeiten über öffentliche Güter wieder in die Hände der Bürger legen“ und Beteiligung auf lokaler Ebene als wesentlichen „Ansatzpunkt für Lernprozesse“ ermöglichen (Thomas 2012: 5f).

In Bezug auf transformative Prozesse im Rahmen der „Energiewende“ sind darüber hinaus veränderte räumliche Strukturen $\mathrm{zu}$ nennen, u.a. durch eine mit der „Energiewende“ zusammenhängende Hybridisierung von Stadt und Land. ${ }^{6}$ Diese kann mit der Veränderung gesellschaftlicher Naturverhältnisse einhergehen, wie Hofmeister/Scurrell (2016) und Kanning u.a. (2016) herausarbeiten. Die zentralen Raumbeziehungen der fossilen Energiewirtschaft werden demnach vermehrt durch dezentrale, in der Fläche ausgedehnte und sichtbare Produktionsstrukturen ersetzt neue „Energielandschaften“ entstehen. Zudem bestimmen im Zuge des Ausbaus erneuerbarer Energien zunehmend die Produktionszeiten natürlicher Systeme die Energieversorgung (bspw. über die Verfügbarkeit von Wind und Sonne) - gesellschaftliche Naturverhältnisse verändern sich hier also auch in zeitlicher Dimension. Dadurch ist eine postfossile Gesellschaft verstärkt gezwungen „sich der raum- und zeitlichen Kontextgebundenheit ihres Energiesystems [...] - und mithin auch der bislang im Ökonomischen abgespaltenen Dimension der Naturproduktivität" (Amri-Henkel u.a. 2017: 17) bewusst zu werden. Auch aus Geschlechterperspektive sind die mit der

6 Hofmeister/Scurrel (2016: 188) beschreiben dies u.a. folgendermaßen: „Diese Transformation der Raummuster in eine StadtLandschaft wird in den letzten zehn Jahren durch die sogenannte Energiewende forciert: Dabei gehen wesentliche Impulse von den ,ländlichen“ Gebieten in der Region aus, die durch neue innerstädtische Flächennutzungen, mit denen ,Natur“ in die Städte hineingeholt wird, flankiert werden“. „Ländliche und städtische Räume werden als ein Kontinuum mit verschiedenen Schwerpunkten sichtbar“ (ebenda: 195). 
„Energiewende“ einhergehenden strukturellen Veränderungen interessant: So wird die geschlechtshierarchische Trennung zwischen öffentlich und privat zumindest irritiert, indem aus Konsument*innen Produzent*innen werden, wie der Begriff der Prosument*innen verdeutlicht. ${ }^{7}$

„Indem also andere materiell-physische Prozesse und neue technische Systeme auf gesellschaftliche Prozesse einwirken („Doing Nature“), verändern sich gesellschaftliche Natur- und Geschlechterverhältnisse (,Doing Gender“)“(Kanning u.a. 2016: 223). ${ }^{8}$

Die Transformation des Energiesystems birgt also zumindest das Potenzial, dass hierarchische Trennungsstrukturen an Bedeutung verlieren, dass das vormals Abgespaltene sichtbar wird. Doch wird die bundespolitische Gesetzgebung diesen Potenzialen gerecht oder steht sie ihnen eher entgegen?

Vor dem Hintergrund des sich hier abzeichnenden Problemfeldes führe ich im vorliegenden Kapitel in den Gegenstand meiner Arbeit sowie in die der Arbeit zugrunde liegenden Forschungsfragen (1.1) ein, nehme eine theoretische Verortung meiner Arbeit sowie damit zusammenhängend eine Positionierung vor (1.2) und präsentiere die Struktur der Arbeit (1.3). Der zugrunde liegende aktuelle Forschungsstand fließt dabei in alle Unterkapitel mit ein.

\subsection{GEGENSTAND UND FORSCHUNGSFRAGEN}

In einer Befragung von 54 Expert*innen aus dem Bereich der Energiepolitik kommen Joas u.a. (2014, 2016) zu dem Schluss, dass die politischen Ziele der „Energiewende" sowie ihre Rangordnung unklar seien. Während die Befragten überwiegend Klimaschutz priorisierten, werde in den politischen Debatten des Bundestags vor allem „das energiepolitische Zieldreieck aus Wirtschaftlichkeit [bzw. Bezahlbarkeit], Versorgungsicherheit und Umweltverträglichkeit“" hervorgehoben (Joas u.a. 2014: 7). Im Rahmen des Projektes „TraVo: Vorsorgendes Wirtschaften. Transformationen in Ökonomie und Politik“ wurde anhand von 7 Leitfaden gestützten Interviews ${ }^{9}$ mit Expert*innen, die Zugang zu parlamentarischen Entscheidungsprozessen haben, eine Sondierungsstudie durchgeführt (vgl. Amri-Henkel u.a. 2017). Diese kam zu dem Schluss, dass die interviewten Politikexpert*innen zwar alle von der Notwendigkeit

7 Auf den theoretischen Hintergrund gesellschaftlicher Natur- und Geschlechterverhältnisse wird im Verlauf der Einleitung noch eingegangen.

8 Ob dabei allerdings neue Geschlechterhierarchien entstehen bleibt gemäß den Autorinnen zunächst noch offen.

9 Die Interviews wurden zwischen Ende 2015 und Anfang 2016 durchgeführt. Interviewt wurden Vertreter*innen aus einer Gewerkschaft, einem Umweltverband, einem Sachverständigenrat, einem Forschungsinstitut, einem industriellen Interessensverband, einem großen Energiekonzern sowie ein*e Politiker*in aus dem Bundestag. 
einer gesellschaftlichen Transformation ${ }^{10}$ im Zusammenhang mit einer „Energiewende" ausgingen, dies aber in den parlamentarischen politischen Entscheidungsprozessen nicht repräsentiert sahen. So seien sozial-ökologische Themenbereiche in den politischen Entscheidungsprozessen wenig präsent, während ein starker Fokus auf dem Strombereich sowie auf den Kosten erneuerbarer Energien liege - ein Fokus, der soziale Gerechtigkeit mitunter konterkariere. In aktuelleren politischen Entwicklungen, wie den Novellierungen des Erneuerbare-Energien-Gesetzes EEG 2014 und 2016/17 $7^{11}$, mit denen das sogenannte Ausschreibungsdesign ${ }^{12}$ eingeführt wurde, sahen die Interviewten eine Gefahr für die Errungenschaften der „Energiewende“, unter denen vor allem Bürger*innenbeteiligung und Dezentralisierung als maßgeblich benannt wurden. Während die Politik in der Wahrnehmung der Befragten in den ersten Jahren der „Energiewende“, die sie bundespolitisch im Zeitraum der rot-grünen Bundesregierung verorteten, eine gestaltendere Rolle eingenommen habe, „werden politische Entscheidungen nun zunehmend auf den Markt verlagert" (Amri-Henkel u.a. 2017: 14). Das politische Engagement der Befragten, d.h. ihre Einflussnahme auf parlamentarische Entscheidungsprozesse, konzentrierte sich in der Folge auf eine verfahrenspolitische ${ }^{13}$ Ebene, auf der versucht wurde, aktuelle parlamentarische Entscheidungsprozesse, bspw. im Kontext des EEG, zu modifizieren. Trotz ihrer Überzeugung von der Notwendigkeit einer grundsätzlicheren Transformation sahen sie demnach anscheinend keine Möglichkeit, entsprechende Wertvorstellungen einzubringen (ebenda).

„Wie kaum ein anderes Politikfeld war die deutsche Energiepolitik auch durch teilweise sehr heftige - Konflikte geprägt“ (Reusswig u.a. 2017: 1) heißt es im Abschlussbericht des Projektes „Energiekonflikte“, eines von 33 Projekten im Rahmen des FONA-Forschungsprogramms ,umwelt- und gesellschaftsverträgliche Transfor-

10 Dabei unterschied sich das Verständnis von Transformation zwischen den Interviewten. Unterschiede lagen bspw. in der Ablehnung oder Befürwortung von Wirtschaftswachstum oder der kapitalistischen Wirtschaftsweise insgesamt.

11 Das EEG 2017 (www.bmwi.de - EEG 2017) wurde im Bundestag zunächst unter der Bezeichnung EEG 2016 diskutiert (www.bmwi.de - EEG 2016). Im Juli 2016 wurde es in EEG 2017 umbenannt. Um Verwechslungen zu vermeiden, wähle ich im Folgenden die Bezeichnung EEG 2016/2017.

12 Das Bundesministerium für Wirtschaft und Energie BMWi schreibt 2016 zum Ausschreibungsmodell: „Mit dem Erneuerbare-Energien-Gesetz 2014 (EEG 2014) haben wir bereits grundlegende Weichenstellungen vorgenommen, um die Erneuerbaren planbar und verlässlich ausbauen und sie fit für den Markt zu machen. Das EEG 2017 läutet nun die nächste Phase ein - und die ist ein Paradigmenwechsel: Die Vergütungshöhe des erneuerbaren Stroms wird ab 2017 nicht wie bisher staatlich festgelegt, sondern durch Ausschreibungen am Markt ermittelt werden. Denn die erneuerbaren Energien sind erwachsen geworden und fit genug, sich dem Wettbewerb zu stellen“" (www.bmwi.de - EEG 2017; wettbewerbliche Vergütung).

13 Als verfahrenspolitisch werden im Folgenden politische Praktiken bezeichnet, die nicht auf einer Paradigmenebene zu verorten sind, sondern auf das Funktionieren, das Optimieren und die Verwaltung politischer Praktiken gerichtet sind, also bestehende Verhältnisse nicht grundsätzlich in Frage stellen. 
mation des Energiesystems“ (s.u.). Dies zeige sich u.a. in den wechselnden „Beschlusslagen zum sog. Atomausstieg auf Bundesebene seit 1998“, die eine Nachwirkung der vorausgegangenen gesellschaftlichen Konflikte um die Kernenergie seien (Reusswig u.a. 2017: 1). Ohlhorst u.a. (2014) kommen in einer Analyse der Governance-Strukur der „Energiewende“ im Mehrebenensystem zu dem Schluss, dass es „an einer eindeutigen Führungs- bzw. Koordinationsleistung des Bundes hinsichtlich der anvisierten Richtung der Systemtransformation“ fehle (ebenda: 96). „Im Wesentlichen sollen marktwirtschaftliche Instrumente die Systemintegration der Erneuerbaren vorantreiben“, während eine strategische Planung bspw. bezüglich einer Dezentralisierung nicht erkennbar sei (ebenda). Zahlreiche weitere Kritikpunkte an der politischen Umsetzung der „Energiewende“ lassen sich aus aktuellen Forschungsarbeiten ableiten: In einem 2014 zur Zukunft der deutschen „Energiewende“ veröffentlichten Artikel kritisiert ein Zusammenschluss von Forscher*innen der Helmholtz-Gemeinschaft eine reduktionistische Betrachtung der „Energiewende“ in der öffentlichen und politischen Debatte. So fokussiere diese auf den Strombereich, dabei insbesondere auf das EEG und die damit zusammenhängenden Kosten, obwohl eine langfristige systemische Perspektive politisch notwendig sei (Gawel u.a. 2014: 1): „This reductionism blocks our view both for the socioeconomic connections and for the real challenges to energy policy“ (ebenda: 2). Auch Biesecker/von Winterfeld (2016: 35) kritisieren, „dass die Energiewende meist in technologischer und kostenbasierter ökonomischer Perspektive betrachtet und auf diese reduziert wird“. Aus feministischer Perspektive hinterfragen sie, wie regenerativ die „Energiewende“ tatsächlich angelegt sei. Aus dieser Perspektive fordere das Prinzip der Nachhaltigkeit zum Sorgen auf. „Die Sorge um und für die Regenerationsfähigkeit der Lebensgrundlagen“ spiele jedoch außerhalb feministischer Arbeiten in der Debatte um „Energiewende“ kaum eine Rolle (ebenda). So werde „die soziale Dimension des Nachhaltigkeitsprinzips“" von den Vorsitzenden der Parteien CDU, CSU und SPD ausgeblendet (ebenda). Die aktive Beteiligung privater Akteur*innen an der „Energiewende“, z.B. als Stromproduzent*innen komme nicht in den Blick, stattdessen werden diese auf ihre Funktion als Marktakteur*innen (Kund*innen) reduziert oder als widerständige Bürger*innen als Hindernis für die „Energiewende“ konstituiert. Auch vorsorgende, intergenerationale Perspektiven kommen zu kurz (ebenda). Biesecker/von Winterfeld (2016: 36) fürchten, dass die „Energiewende“ in den bislang zum großen Teil unhinterfragten „sozialen, kulturellen, ökonomischen und politischen Traditionen und Strukturen“" stecken bleiben könne. Rosenkranz (2012) kritisiert, dass die schwarzgelbe Bundesregierung (2009-2013) die „Energiewende“ durch einen Fokus auf die Kostendebatte sowie eine ungerechte Verteilung der Kosten absichtlich diskreditiert habe, um ihre wahlstrategischen Interessen durchzusetzen. So konnte sich die Bundesregierung als Initiatorin der „Energiewende“ präsentieren, während sie diese gleichzeitig entleere: „Sie führen die Energiewende im Munde und bremsen sie gleichzeitig aus“ (ebenda: 101). Gleichzeitig wird der Bundespolitik bei der „Energiewende“ aber eine herausragende Rolle zugeteilt. Eine sprachlich-semantische Untersuchung über die mediale Berichterstattung zur „Energiewende“ in 121 Millionen Artikeln von Tages- und Wochenzeitungen zwischen 1986 und 2011 von Dernbach (2015: 28ff.) kommt zu dem Schluss, dass „Energiewende“ in den Medien überwiegend als Aufgabe der Politik gesehen wird. Nicht nur die hier exemplarisch genann- 
ten Untersuchungen werfen die Frage auf, ob die energiepolitische Gesetzgebung in Deutschland bisher diesem Anspruch gerecht wird.

Aus den beschriebenen Konfliktfeldern lässt sich bereits ableiten, dass eine Bestimmung des Begriffs „Energiewende“ weder einheitlich noch eindeutig erfolgt, obwohl es sich um ein erklärtes Ziel gesetzgeberischer Prozesse handelt. Ähnlich verhält es sich mit dem Begriff der ,Transformation', der - wie Czada/Radtke (2018: 70) zeigen - mit dem Begriff der ,Wende` zwar nicht identisch ist, aber dennoch häufig im Konzept von „Energiewende“ enthalten zu sein scheint. Die Spezifität des Begriffes „Energiewende“ im Deutschen zeigt sich auch dadurch, dass es keine adäquate Übersetzung ins Englische gibt. Weder, energy transition“ noch ,energy transformation“ sind bedeutungsidentisch, weshalb der Begriff „Energiewende“ häufig ins Englische übernommen wird. Angesichts der begrifflichen Unschärfe von „Energiewende" in der politischen Auseinandersetzung werfen Czada/Radtke (2014) die Frage auf, „ob die ,Energiewende“ wirklich existiert oder [...] nur eine magische Formel darstellt, eine gefallende Phrase, die mit hochgeschätzten aber weitgehend inhaltsleeren Handlungsorientierungen verbunden ist“" (ebenda: 46). Sie sehen politikwissenschaftlichen Forschungsbedarf nicht nur bezüglich von Diskurszusammenhängen und begrifflicher Schärfung, sondern auch bezüglich mit „Energiewende“ zusammenhängender politischer Praktiken ${ }^{14}$ (ebenda). An diesem Punkt knüpfe ich mit meiner Arbeit an und möchte zur Schließung dieser Lücke beitragen, wie ich im Folgenden näher ausführe.

Seit Veröffentlichung des WBGU-Gutachtens 2011 haben zahlreiche einzelne Arbeiten „Energiewende“ im Kontext von Transformation diskutiert (vgl. z.B. AmriHenkel/Hofmeister 2018; Graf u.a. 2018 ;Müller 2012; Göllinger/Gaschnig 2016; Haas 2017; Neukirch 2018; Czada/Radtke 2018; Mautz 2017; Hanke/Best 2013; Exner u.a. 2016; Flämig/De Maiziére 2016; Schlacke/Kröger 2015). Zwischen 2013 und 2016 erforschten darüber hinaus 33 Projekte im Rahmen des FONA-Forschungsprogramms des Bundesministeriums für Bildung und Forschung BMBF eine „umwelt- und gesellschaftsverträgliche Transformation des Energiesystems“. Förderthemen waren Entwicklungsoptionen für das Energiesystem, Partizipation und Governance (www.transformation-des-energiesystems.de). Sowohl „Energiewende“ als auch Transformation bleiben allerdings auch in neueren Forschungsarbeiten häufig begrifflich unbestimmt, ebenso bezüglich der Beziehung zwischen beiden Begriffen. So wird meistens „Energiewende“ als Bestandteil von Transformation implizit vorausgesetzt (auch umgekehrt ist es oft der Fall) und die begriffliche Unschärfe von „Energiewende“ zum Teil reproduziert. Dadurch können die Verhältnisse, in die sowohl „Energiewende“ als auch Transformation begrifflich eingebunden sind, nicht in den Blick kommen. Nur wenige Arbeiten leisten eine systematischere Analyse von „Energiewende“ als Teil von Transformation und nehmen dabei ihre Zusammenhänge (z.B. gesellschaftliche Naturverhältnisse) in den Blick (vgl. z.B. Grasselt 2016;

14 Als politische Praktiken bezeichne ich in der vorliegenden Arbeit - vor dem Hintergrund meiner in Kapitel 2 (Diskurstheorie) erläuterten diskurstheoretischen Perspektive - Praktiken, die sich aus dem politischen Diskurs ergeben und gleichzeitig Teil von ihm sind. In ihnen materialisiert sich der politische Diskurs, bspw. in Form von Gesetzen, Beschlüssen oder Handlungsweisen politischer Akteur*innen. 
Haas 2017; Neukirch 2018; Sander 2016). Haas (2017) untersucht mit einer politisch-ökonomischen Policy-Analyse der „Energiewende“ zentrale Parameter im Vergleich zwischen Spanien und Deutschland sowie der EU und kommt dabei zu dem Schluss,

„dass stabile ökonomische Kontextbedingungen, eine aktive Einbindung der Zivilgesellschaft bei gleichzeitiger Delegitimierung des alten, fossil- nuklearen Energiesystems und eine vergleichsweise große Responsivität der Staatsapparate gegenüber gesellschaftlichen Forderungen einen energetischen Wandel begünstigen“ (ebenda: 287).

So weise die „Energiewende“ in Deutschland wichtige Aspekte einer Transformation auf (ebenda: 289). Unter Transformation versteht er eine grundlegende „Transformation der bestehenden gesellschaftlichen Naturverhältnisse“ und betrachtet sie als für die „Herstellung guter Lebensverhältnisse“ notwendig (ebenda: 301). Gleichzeitig stellt er aber fest, dass die Krisenbearbeitung auf europäischer Ebene dafür nicht ausreiche und eher in Richtung eines autoritären Neoliberalismus weise, in dem sich „Elemente eines grünen Kapitalismus“ sowie vereinzelt „Elemente eines Green New Deals und einer sozial-ökologischen Transformation“ zeigen (Haas 2017: 301). Neukirch (2018) untersucht ,die Transformation des deutschen Energiesystems im Zeitraum 1974 - 2017 als einen Konflikt zweier Großkoalitionen“ (ebenda: 1). Er unterscheidet dabei zwischen Etablierten, die für das herkömmliche Energiesystem stehen und Herausforderern, die eine „Energiewende“ fordern. Neukirch (2018) nimmt eine akteurszentrierte Perspektive ein und sieht die „Energiewende“ als Ergebnis dieses Konflikts. Nach 2010 wandelte sich demnach die Koalition der „Etablierten“ und befürwortete nun die „Energiewende“, während Teile der Herausforderer sich ebenfalls mit etablierten Akteur*innen zusammenschlossen und eine „Green-Growth-Koalition“ bildeten. Die etablierte Koalition versuchte so alte Machtverhältnisse wiederherzustellen, was ihr zumindest teilweise auch gelang (ebenda: $25 \mathrm{ff}$.).

Hendrik Sander (2016) stellt in seiner Dissertation die Frage, ob mit „Fukushima“ tatsächlich ein Umbau des Energiesystems eingeleitet wurde und ob dies im Kontext eines grünen Kapitalismus interpretiert werden kann. Er führt dazu eine historisch-materialistische Policy-Analyse der 17. Legislaturperiode durch und fokussiert dabei insbesondere die Rolle von Bundeskanzlerin Angela Merkel. Sander kommt zu dem Schluss, dass die „Energiewende“ nicht im Kontext eines grünen Kapitalismus gesehen werden kann, da ein Interesse an einer Ökologisierung der Energieversorgung bei zentralen Akteur*innen nicht bestehe. Stattdessen sei es nach „Fukushima“ zu einer Festigung von Herrschaftsverhältnissen einhergehend mit einer Stärkung der Macht der Regierung Merkel gekommen. Der Regierung Merkel sei es gelungen den „Energiewende“ Begriff gemäß der eigenen politischen Interessen $\mathrm{zu}$ besetzen und so die „Deutungshoheit und Kontrolle über die Entwicklungsrichtung der Naturaneignung im Energiebereich zu übernehmen“ (ebenda: 260).

Die genannten Arbeiten leisten einen umfangreichen Überblick über die Akteur*innen der deutschen Energiepolitik, ihre Interessen und ihr Wirken im Kontext 
von Wandel. ${ }^{15}$ Um einen tiefergehenden Einblick in das Verständnis bzw. die Vorstellungen von „Energiewende“ und die Bedeutung dieser Vorstellungen für gesellschaftlichen Wandel oder auch Transformation sowie in zeitliche Veränderungen zu erhalten, sind Diskursanalysen hilfreich. Diskurse werden dabei in der vorliegenden Arbeit im Anschluss an Foucault (1974) als wirklichkeitskonstituierend begriffen, d.h. ihnen wird für die Möglichkeit von Veränderung eine zentrale Bedeutung beigemessen. ${ }^{16}$ Hermwille (2016: 237ff.) untersucht am Beispiel von EnergieNarrativen ${ }^{17}$ nach „Fukushima“ im Vergleich zwischen Japan, Deutschland und Großbritannien, welche Rolle Narrative im Kontext von Wandel spielen können. Während in Großbritannien kein entsprechendes Narrativ erfolgreich gewesen sei, habe sich in Deutschland das Narrativ, dass Atomkraft eine unkontrollierbare Gefahr darstelle, durchgesetzt. Grasselt (2016) analysiert den energiepolitischen Diskurs der schwarz-gelben Bundesregierung zwischen 2009 und 2013 sowie Medienbeiträge, die deren Energiepolitik adressieren. Sein Ziel ist es, die Argumentationen, mit denen die Regierung auf den energiepolitischen Diskurs einwirkte, zu identifizieren (ebenda: 29). Er stellt fest, dass sich die Bundesregierung auf „vergangenheitsbedingte Weichenstellungen und Leitbilder in den beteiligten Politikpfaden“ berief, die Politikwandel verhinderten, da ,andere Determinanten die Grundausrichtung des Handlungspfades prägen“ (ebenda: 428). Daher werden technologogische und ökonomische Lösungen mit „den damit verbundenen Rationalisierungen“ bevorzugt (ebenda). Lauber/Jacobsson (2016: 147ff.) untersuchen den Wandel des Diskurses um Kosten erneuerbarer Energien im Kontext des EEG und kommen zu dem Schluss, dass kurzfristige, reduktionistische Narrative in den letzten Jahren dominant wurden. Dadurch stehe die Last erneuerbarer Energien im Vordergrund, während externe Kosten konventioneller Energieversorgung ignoriert würden.

Was den Stand der Forschung betrifft, so ist festzustellen, dass die genannten Arbeiten auf einer Mischung aus inhalts- und diskursanalytischen ${ }^{18}$ Vorgehensweisen aufbauen und sich teilweise auf der Ebene von Sprach- und Kognitionsforschung verorten (Grasselt 2016: 43). Eine systematische Diskursanalyse des „Energiewende“-Diskurses im Kontext von Transformation steht vor dem Hintergrund poststruk-

15 Wenn in diesem Kapitel von Wandel gesprochen wird, so meint dies gesellschaftliche Veränderungen, die nicht unbedingt politisch gesteuert sind oder mit tiefgreifenderen strukturellen Veränderungen einher gehen. Wandel kann zum Beispiel durch Bewusstseinsveränderungen, bzw. Veränderungen von Ansichten oder Lebensstilen initiiert werden. Ähnlich der Begriffe „Energiewende“ und Transformation bleibt in der Transformationsforschung auch Wandel ein überwiegend vages Konzept, das häufig begrifflich gar nicht bestimmt wird.

16 Eine genauere Definition des der Arbeit zu Grunde liegenden Diskursbegriffes erfolgt in Kapitel 2.3.

17 Hermwille (2016: 238) definiert Narrative im Anschluss an Roe (1994) als „simple stories that describe a problem, lay out its consequences and suggest (simple) solutions“. In der vorliegenden Arbeit wird der Begriff Narrativ synonym mit ,sinnstiftender Erzählung‘ verwendet (vgl. auch www.duden.de).

18 Für eine Erläuterung des widersprüchlichen Verhältnisses poststrukturalistischer Diskurstheorie zur Inhaltsanalyse vgl. Kapitel 2 (Diskurstheorie). 
turalistischer Diskurstheorie noch aus. Die poststrukturalistische Diskurstheorie zeichnet sich dadurch aus, dass sie auf das Herausarbeiten von wirklichkeits- und identitätskonstituierenden Trennungsstrukturen fokussiert. ${ }^{19}$ In diesem Sinne erweitere ich unter der Anwendung der Diskurstheorie nach Laclau/Mouffe (2015) ${ }^{20}$ (vgl. Kapitel 2) das Forschungsspektrum im Bereich der Diskursanalysen zur „Energiewende".

Im Rahmen der im Projekt „TraVo“ (s.o.) durchgeführten Expert*inneninterviews wurde deutlich, dass sich zahlreiche außerparlamentarische bundespolitische Akteur*innen in ihrer Arbeit zur „Energiewende“ maßgeblich daran orientieren, was im Bundestag jeweils aktuell auf der Agenda steht (Amri-Henkel u.a. 2017). Der parlamentarische Diskurs hat demnach großen Einfluss auf gesamtgesellschaftliche Sagbarkeitsräume. Schwab-Trapp (2001: 271ff.) bezeichnet die Mitglieder des Deutschen Bundestags als „diskursive Eliten“. Sie verfügen über das „symbolische Kapital“, das ihnen Gehör und Gewicht verschaffe (ebenda: 272). Sie können somit Diskurse beeinflussen und zur Veränderung oder Verfestigung kollektiv anerkannter Sichtweisen beitragen (ebenda). Dem parlamentarischen Diskurs kommt auch dadurch eine besondere Bedeutung zu, dass sich die daraus folgenden Entscheidungen in Form von Gesetzen materialisieren und so Veränderungen unmittelbar herbeigeführt werden. Van Dijk (1992: 201) bezeichnet parlamentarische Diskurse aufgrund ihrer besonderen Funktion zudem als „Schaufenster-Diskurse“, da es sich nicht um Debatten im eigentlichen Sinn handelt. Die Abläufe sind hochgradig formalisiert und Redebeiträge im Parlament werden in der Regel in erster Linie nicht zum Austausch von Argumenten, sondern für eine breite Öffentlichkeit gehalten. Sprache wird hier hochgradig strategisch eingesetzt. Nach Hombach (1991) gehe es um die Definitionsmacht von Begriffen und um das Aufwerten eigener Positionen im Gegensatz zur Abwertung anderer. Ziel sei die positive oder negative Besetzung von Begriffen in Verbindung mit eigenen politischen Inhalten sowie die eigenen Deutungen auch in eine breitere Öffentlichkeit auszustrahlen (Hombach 1991: 34ff.). Die Art und Weise wie im Bundestag „Begriffe besetzt ${ }^{21 \text { “ }}$ werden hat dabei unmittelbare Wirkung auf die praktische Politik und somit auf die Lebenswelt aller in Deutschland lebenden Menschen ${ }^{22}$ (Klein u.a. 1991: 44ff.). Aufgrund der dargelegten herausragenden Stellung der Bundestagsdebatten zur Energiepolitik, stellen diese den Gegenstand meiner Diskursanalyse dar.

19 Weber (2018) analysiert vor dem Hintergrund der Diskurstheorie nach Laclau/Mouffe (2015) Konflikte um Landschaft im Kontext der „Energiewende“, dabei liegt der Fokus allerdings auf der Konstitution von Landschaft. Bedall (2014) analysiert Klimadiskurse mit Hilfe der Laclau/Mouffe'schen Diskurstheorie.

20 Ich beziehe mich dabei auf die 5. Auflage der deutschen Übersetzung des 1985 im Englischen erschienen Werkes, Hegemony and Socialist Strategy“.

21 Dass die Politiker*innen des Bundestags natürlich selbst nicht außerhalb des Diskurses stehen, sondern Teil von ihm sind, wird später noch ausgeführt (vgl. Kapitel 2 Diskurstheorie).

22 Klein u.a. (1991: 44ff.) verdeutlichen dies bspw. anhand der Begriffe ,Soziale Marktwirtschaft', ,Chancengleichheit', ,Gerechtigkeit‘, ,Anschluss“/BBeitritt” (der DDR zur Bundesrepublik), etc. 
Bereits Leipprand u.a. (2017) untersuchen die Entwicklung von energiepolitischen Diskursen und ihrer Story-Lines ${ }^{23}$ in deutschen Parlamentsdebatten zwischen 1980 und 2011 inhaltsanalytisch. Sie zeigen dabei wie sich der Diskurs gewandelt hat, wie er entradikalisiert wurde, sich in die vorherrschende ökonomische Logik einfügte und gerade deswegen so erfolgreich wurde (Leipprand u.a. 2017: 283ff.). Die Studie deutet darauf hin, dass der Begriff „Energiewende“ nach 2011 zwar Konsens im Parlament wurde, sich die „Stories ${ }^{24 ،}$ die unter diesem Begriff erzählt wurden, aber weiterhin unterschieden. Mitglieder von CDU/CSU/FDP schienen sich eher unwillig unter dem Begriff der „Energiewende“ zu versammeln, da dies nicht länger vermeidbar war. Leipprand u.a. (2017: 298ff.) verweisen hier auf weiteren Forschungsbedarf: Spiegelt der diskursive Wandel von CDU/CSU/FDP einen Wandel grundsätzlicher Wertvorstellungen im Bundestag wider? Adressieren neuere StoryLines die Konflikte, die sich unter dem Begriff der „Energiewende“ im Parlament verbergen? Diese Fragen greife ich in meiner Arbeit mit dem Ziel auf, die Erkenntnisse der Studie diskursanalytisch zu ergänzen und zu vertiefen.

Ich möchte dadurch zur begrifflichen Schärfung von „Energiewende“ beitragen und dekonstruiere zunächst die Verwendung des Begriffs im Bundestag diskursanalytisch nach Laclau/Mouffe (2015). Im zweiten Schritt analysiere ich die Wirkweise bzw. die Ausrichtung der identifizierten politischen Praktiken, indem ich die generierten Erkenntnisse im Kontext von Transformation ${ }^{25}$ interpretiere. Mit dieser (expliziten) transformationstheoretischen Einordnung und Reflexion möchte ich eine zusätzliche Ergänzung des Forschungsstandes zur „Energiewende“ leisten. Ich fokussiere dabei auf die Plenardebatten im Zeitraum zwischen der 14. und 18. Legislaturperiode (bzw. 1998-2017) ${ }^{26}$ als Forschungsgegenstand. Den Beginn der rot-grünen Regierungszeit (1998) wähle ich als Startpunkt meiner Untersuchung, weil diese überwiegend mit dem Start der „Energiewende“ auf der policy-Ebene assoziiert wird (vgl. z.B. Morris/Jungjohann 2016: 197). Überwiegend werden dabei die Plenarprotokolle ausgewertet, die ich vereinzelt um andere Dokumente ergänze (vgl. Kapitel 4 Methodik), was ich dann für jeden Einzelfall begründe. Plenarprotokolle bieten sich für eine diskursanalytische Untersuchung an, da es sich um vollständige Transkriptionen von Plenarsitzungen handelt, die auch Zwischenrufe beinhalten. Sie stehen zudem öffentlich zur Verfügung (www.bundestag.de/services/opendata). Die computerbasierte Erforschung von Plenardebatten hat sich in den letzten Jahren erst entwickelt und befindet sich in einem permanenten Weiterentwicklungsprozess. Maschinell verarbeitbare Versionen von öffentlichen Dokumenten stehen erst seit kurzem

23 Ebenso wie in der vorliegenden Arbeit definieren Leipprand u.a. (2017) den Begriff der ,Story-Line“ im Anschluss an Hajer (2004) als zusammenfassende, komplexitätsreduzierende Erzählung (vgl. dazu das Rahmenpapier der Dissertation von Leipprand, im Rahmen derer die Studie eingeordnet wird, Leipprand 2017: 4). Auf den Begriff der ,Story-Line“ wird in Kapitel 4.2.2 noch genauer eingegangen.

24 Der Begriff der ,Story“ wird dabei synonym zu ,Narrativ` verwendet (Leipprand 2017: 4).

25 Dabei orientiere ich mich an der Perspektive des Vorsorgenden Wirtschaftens, die ich in Kapitel 3 darlege.

26 In einem ersten quantitativen Schritt ziehe ich zudem die Jahre 1996-1998 zur Kontextualisierung hinzu, wie ich in Kapitel 4 (Methodik) begründe. 
zur Verfügung, was den Entwicklungsprozess der Dokumentenanalyse weiter beschleunigt. Der Vorteil einer computerbasierten Analyse liegt vor allem in einer dadurch möglichen Bearbeitung von großen Datenmengen (Blaette 2018). Die quantitative Erhebung, die ich im ersten Schritt methodisch verwende, dient der Sondierung der Datenlage und der Strukturierung des Forschungsgegenstandes in Form des parlamentarischen Diskurses. Meine Arbeit sehe ich daher auch als Beitrag zur methodischen Entwicklung und Fundierung einer computerbasierten Plenarforschung. Ich verwende den im Project for corpus-assisted political research PolMine erarbeiteten GermaParl-Korpus ${ }^{27}$ in der Version von 2017 (Blaette 2017). Die datenbasierte Vorstrukturierung des Forschungsgegenstandes dient der Präzisierung der anschlieBenden qualitativen Diskursanalyse (vgl. Kapitel 4 Methodik). Durch diese Methodenkombination trage ich zur methodischen Operationalisierbarkeit der Diskurstheorie nach Laclau/Mouffe (2015) und somit zur Weiterentwicklung der politischen Diskursforschung bei.

Meine Forschungsfragen, die ich im Folgenden vor dem Hintergrund meiner theoretischen Verortung und Positionierung fundiere, lauten:

(1) Welche Bedeutung(en) hat „Energiewende “ im Bundestag im Zeitverlauf?

(2) Kann die „Energiewende“ - vor dem Hintergrund dieser Bedeutung(en) - als ein bundespolitisches Transformationsprojekt gewertet werden?

\subsection{POSITIONIERUNG UND THEORETISCHE VERORTUNG}

In der vorliegenden Arbeit positioniere ich mich innerhalb der Diskurse um „Energiewende" und Transformation derart, dass ich von einer wechselseitigen Notwendigkeit ausgehe: Eine „Energiewende“ muss in eine umfassendere (noch zu definierende) Transformation eingebettet sein. Für eine solche Transformation wiederum ist eine „Energiewende“ notwendig. Dazu bedarf es einer aktiven politischen Gestaltung. Diese Positionierung bewerte ich als von der Kernaussage her anschlussfähig an das WBGU Gutachten (2011b). Allerdings liegt meiner Position ein anderes Transformations- und Politikverständnis zu Grunde, welches ich im Verlauf der Arbeit spezifiziere. ${ }^{28}$ Das WBGU Gutachten initiierte im deutschsprachigen Raum eine umfassende wissenschaftliche Debatte darüber, wie Transformation gestaltet sein kann (für eine Debatte dazu in der GAiA vgl. Bauriedl (2015); Biesecker/von Winterfeld (2013c); Brunnengräber (2014); Leggewie u.a. (2015); Unmüßig (2015)). Die wissenschaftlichen Beiträge beziehen sich dabei in unterschiedlicher Weise auf den Begriff der Nachhaltigkeit als Ziel von Transformation. Die Ansichten darüber, was genau Nachhaltigkeit bedeutet und damit zusammenhängend, wie tiefgreifend

27 Als Korpora werden in der Linguistik ,large bodies of naturally occurring language data stored on computers" (Baker 2006: 1) bezeichnet.

28 Einen Vergleich mit dem WBGU-Gutachten nehme ich dabei nicht vor. Für eine umfassende Analyse des WBGU Gutachtens und des darin enthaltenen Staats- und Transformationsverständnisses aus Perspektive Vorsorgenden Wirtschaftens vgl. Biesecker u.a. (2015). 
Transformation sein soll, was transformiert werden soll und was nicht, gehen erwartungsgemäß auseinander.

Es deutet sich an, dass sich die in Kapitel 1.1 beschriebenen reduktionistischen Betrachtungen von „Energiewende“ und Transformation nicht nur in der Politik, sondern auch in der Forschung widerspiegeln. Kanning u.a. (2016) kritisieren am Beispiel der „Energiewende“, dass der „Forschungs- und Politikfelder verbindende Blick“ auf die Krise gesellschaftlicher Naturverhältnisse (Becker u.a. 2011: 82ff.) im deutschsprachigen Raum, in dem technische und ökonomische Fragen im Fokus ${ }^{29}$ stehen, zu kurz komme (Kanning u.a. 2016: 216). Ebenso wird kritisiert, dass neben der gesellschaftlichen Dimension auch Geschlechterverhältnisse systematisch ausgeblendet werden. „[V]on seinen sozial-ökologischen Kontexten“ losgelöst erzeugtes Wissen fließe so „als vermeintlich universell gültiges Wissen in Politikkonzepte“ ein (ebenda). Die Autorinnen sehen Forschungspotenzial darin, die „Energiewende“ und den Klimawandel als Transformationsprozesse zu fassen, ,in denen sich die gesellschaftlichen Naturverhältnisse wandeln“ (ebenda) und in denen über die untrennbare Verbindung von Natur und Geschlecht (Schultz u.a. 2006) auch Geschlechterverhältnisse zum Ausdruck kommen (Kanning u.a. 2016: 216). Forschungsansätze zur (deutschen) „Energiewende“, in denen Geschlechterperspektiven integriert sind, bleiben nach aktuellem Forschungsstand außerhalb einer ausführlicheren Konsumforschung (Kleinhückelkotten/Neitzke 2016; Räty/Carlsson-Kanyama 2009， 2010; Weller 2004, 2012, 2013; Weller u.a. 2016), die bspw. auf einen aufgrund von gesellschaftlicher Arbeitsteilung geschlechterdifferenzierten Energiekonsum verweist, nur vereinzelt auffindbar (vgl. z.B. Clancy/Roehr 2003; Fraune 2015; Kanning 2013; Weller u.a. 2016). Gut dokumentiert sind dagegen geschlechterdifferenzierte Daten über Beschäftigungsverhältnisse in der Energiebranche (vgl. z.B. EIGE 2012; pwc 2014). Geschlechterforschung zu Energiefragen konzentriert sich bislang überwiegend auf den globalen Süden. Dabei wird der ungleiche Zugang zu Ressourcen in Verbindung mit patriarchalen Machtstrukturen, geschlechtsspezifischer Arbeitsteilung, Armutsverhältnissen oder der erhöhten Vulnerabilität von Frauen bezüglich des Klimawandels behandelt (vgl. z.B. Amigo-Jorquera u.a. 2019; Brownhill/Turner 2009; Ding u.a. 2014; Hemmati/Röhr 2009; Köhlin u.a. 2011; Mahat 2011; Marshall u.a. 2017; Ogwumike/Ozughalu 2014; Ryan 2014; Sikka 2019; Wamukonya/Skutsch 2002). Ein weiterer Fokus der Genderforschung im Energiebereich liegt auch auf der Nutzung traditioneller Biomasse, ihrer Gesundheitsfolgen sowie der positiven Effekte von erneuerbaren Energien in diesem Zusammenhang (vgl. z.B. Burke/Dundas 2015; Dash u.a. 2018; Matinga u.a. 2019; Menghwani u.a. 2019, 2019). Umfangreiche Forschungen gibt es im Querschnittsbereich Gender und Klima - einen ausführlichen Überblick über den Forschungsstand geben Spitzner u.a. (2020).

29 Dieser Fokus besteht, obwohl sich in den letzten Jahren auch eine umfangreichere sozialund politikwissenschaftliche Forschung zur „Energiewende“ entwickelt hat (vgl. z.B. Radtke/Hennig 2013; Kopatz 2015; Radtke 2016; Kopatz 2013; Mautz u.a. 2008; Giacovelli 2017; Di Nucci/Brunnengräber 2014; Schubert u.a. 2015; Gründinger 2017; Radtke/Kersting 2018; Flaute u.a. 2018; Holstenkamp/Radtke 2018; Schmid u.a. 2017; Radtke u.a. 2019). 
Eine genderspezifische Forschungslücke bezüglich der deutschen „Energiewende“ macht auch Haas (2017: 297) aus, indem er auf die Notwendigkeit einer ,,intersektional oder geschlechtertheoretisch fundierten Analyse der energiepolitischen Wandlungsdynamiken" verweist. Ziel einer solchen Analyse müsse es sein, zu identifizieren, wie sich „spezifische Dimensionen sozialer Ungleichheit“ im energiepolitischen Kontext abbilden oder im Rahmen der „Energiewende“ möglicherweise wandeln. Er hebt zudem die Notwendigkeit hervor, auch Dimensionen globaler Ungleichheit mit einzubeziehen, da eine postulierte Demokratisierung der Energieversorgung durch die „Energiewende“ deren Einbettung in globale Macht- und Herrschaftsverhältnisse ausblende (ebenda: 298).

Ähnlich wie Kanning u.a. (2016) kritisiert auch Wissen (2014), dass die für Macht und Herrschaft konstitutive Gestaltung gesellschaftlicher Naturverhältnisse in der bisherigen Transformationsforschung zu wenig Beachtung finde, und dass die Einsichten der Politischen Ökologie (vgl. z.B. Brand/Wissen 2011; Görg 2003; Becker 1999) verstärkt einfließen müssen (Wissen 2014: 50). Brand (2016: 25) plädiert dafür, Transformation verstärkt als analytischen Begriff zu verwenden, welcher auf die hierarchische Strukturierung von Gesellschaft verweise, „where social and power positions are constituted in line with social relations of class, gender and race and are inscribed in economic, political and cultural relations". Die Vorstellung von Transformation müsse grundlegender gefasst werden als dies bisher der Fall sei. Denn sie sei „weniger ein Problem der richtigen ,Governance“ bzw. der Initiierung und Diffusion von technischen Innovationen“, sondern betreffe grundsätzliche gesellschaftliche Organisationsprinzipien und stelle vorherrschende „Modi der Naturaneignung“" sowie damit verbundene Macht- und Herrschaftsverhältnisse zur Disposition (Wissen 2014: 50). Eine solche Lücke wird nicht nur in der deutschen, sondern auch in der englischsprachigen wissenschaftlichen Debatte ausgemacht (vgl. z.B. Rose/Cachelin 2018). Dabei ist zu beachten, dass der Begriff Transformation im Englischen von der Bedeutung her anders verwendet wird als im Deutschen und die wissenschaftliche Debatte sich im englischsprachigen Raum auf Transitionforschung fokussiert (Chappin/Ligtvoet 2014: 715). Seit einigen Jahren ist dabei auch von ,sustainability transitions“ die Rede (vgl. z.B. Markard u.a. 2012 sowie Loorbach u.a. 2017). Child/Breyer (2017) untersuchen die Verwendung der Begriffe in englischsprachigen wissenschaftlichen Publikationen und kommen zu dem Schluss, dass transition und transformation häufig synonym zur Bezeichnung vom Wandel soziotechnischer Systeme verwendet werden. Markard u.a. (2012) unterscheiden vier Rahmenkonzepte, die sich in den transition studies etabliert haben: „transition management $[\ldots]$, strategic niche management $[\ldots]$, the multilevel perspective on sociotechnical transitions [...], and technological innovation systems [...]“ (ebenda: 955). Untersuchungen des Forschungsfelds zeigen, dass technische Aspekte, wie ,grüne Innovationen' zwar mit gesellschaftlichen und auf der Ebene der Governance auch mit politischen Fragen verbunden werden (Markard u.a. 2012; Avelino u.a. 2016). Dabei geht es aber meist um eine Steuerung oder das Management von Transitionsprozessen innerhalb bestehender Verhältnisse, während die herrschaftliche Strukturierung bzw. Nicht-Nachhaltigkeit dieser Verhältnisse nicht im Fokus steht (vgl. z.B. von Winterfeld 2012). Kenis u.a. (2016: 568) arbeiten den post-politischen Charakter von transition management heraus: „To start with, transition management understands the relation transition initiatives adopt towards existing regimes not in politi- 
cal, but in market terms“. Einige Autor*innen haben die Kritik aufgenommen und fordern, Machtfragen mehr in den Blick zu nehmen (vgl. z.B. Geels 2014; Avelino u.a. 2016).

Gottschlich/Katz (2016) kritisieren, dass sich die Nachhaltigkeits- und Transformationsforschung zu selten als kritische Wissenschaft positioniere und sich zu selten gemäß der kritischen Theorie der Analyse von „Herrschaftsverhältnissen, Hierarchien und Ungleichheiten“" und somit deren Transformation widme (ebenda: 4). Dazu gehören auch die gesellschaftlichen Naturverhältnisse. Das ,instrumentelle und damit krisenverursachende Naturverständnis“ werde zu selten hinterfragt, Natur bleibe zu häufig ,,das Andere“ [...] Ressource und Kapital“ (ebenda: 3).

Ich verorte mich vor diesem Hintergrund in der vorliegenden Arbeit mit meinem Nachhaltigkeits- und Transformationsverständnis unter anderem im Konzept der gesellschaftlichen Naturverhältnisse der Sozialen Ökologie (Becker/Jahn 2006). Dabei werden Natur und Gesellschaft als miteinander vermittelt begriffen, wofür ,die Vorstellung eines unaufhebbaren Zusammenhangs von Natur und Gesellschaft, die Behauptung einer Differenz zwischen ihnen sowie die These der historischen Konstitution dieser Differenz“ (Jahn/Wehling 1998: 82) zentral sind. Sozial-ökologische Krisenphänomene sollen so - vor dem Hintergrund der Annahme komplexer Beziehungsmuster von Natur und Gesellschaft, sowohl in Bezug auf ihre Zusammenhänge als auch auf ihre Trennungen - wissenschaftlich bearbeit- und beschreibbar gemacht werden (ebenda: 80). Gemäß dem Konzept der gesellschaftlichen Naturverhältnisse nach Becker/Jahn (2006: 177) verwende ich den ,sozial-ökologischen Blick“ als „theoretische Brille“, die ich als Teil der Perspektive des Vorsorgenden Wirtschaftens $^{30}$, das ich später noch vorstellen werde, verstehe. Mithilfe dieser Brille können „gesellschaftliche Unterscheidungspraktiken, die eine Grenze zwischen dem Natürlichen und dem Gesellschaftlichen ziehen“, aufgedeckt werden „und wie mit den Relationen zwischen beiden umgegangen wird“ (ebenda). Die Soziale Ökologie geht also von einer konstitutiven Abhängigkeit von Gesellschaft und Natur und somit auch „von Gesellschafts- und Naturbegriffen“ aus (ebenda: 176). Görg (1999: 8f.) hebt hervor, dass moderne Gesellschaften das Soziale „mehr und mehr ,naturfrei““ „,als das ,Andere“ der Gesellschaft" gedacht und „die Grundbegriffe der Soziologie unter immer stärkerer Abstraktion von den materiell-stofflichen Bedingungen ihrer Existenz definiert“ haben. Gleichzeitig wurde ,die Definition von Natur und ihren Eigenschaften mehr und mehr den Naturwissenschaften überlassen, die aber wiederum immer stärker von einem praktisch-technischem Apriori geprägt sind“" (ebenda). Was unter Natur verstanden werde, wandle sich nicht nur historisch, es hänge ,,auch von den angenommenen Fähigkeiten von Gesellschaften zur Kontrolle der äußeren und inneren Natur“ ab (ebenda). „Naturbegriffe ${ }^{31}$ stehen in einem Wechselverhältnis zur

30 Wenn ich in der vorliegenden Studie vom Vorsorgenden Wirtschaften spreche, adressiere ich das Konzept, bzw. den Ansatz ,Vorsorgendes Wirtschaften' und nicht das Netzwerk Vorsorgendes Wirtschaften. Ich spreche vom Vorsorgenden Wirtschaften also auf einer inhaltlichen und nicht auf einer personellen Ebene, auch wenn sich diese kaum differenzieren lassen, wie ich im Folgenden noch zeige.

31 Die wechselseitige Konstitution von Gesellschaft und Natur verweist auch darauf, dass es nicht eine Natur, sondern vielfältige Natur/en gibt und der Begriff daher im Plural verwen- 
Fähigkeit der Naturbeherrschung und ihrer Bewertung, ohne davon völlig determiniert zu werden“ (ebenda).

Vor dem Hintergrund des sozial-ökologischen Blicks wird deutlich, „dass Umweltprobleme keine Probleme der Umwelt sind - und die ökologische Krise keine Krise der Natur", sondern dass es die Beziehungen zwischen Gesellschaft und Natur, die gesellschaftlichen Naturverhältnisse sind, die in die Krise geraten sind, die hier zu betrachten wären (Becker/Jahn 2006: 58) ${ }^{32}$ Lösungsversuche, die eindimensional sind und dies nicht in den Blick nehmen, werden als ungenügend bewertet und es wird kritisiert, dass sie lediglich Probleme von einem in den anderen Bereich verschieben (ebenda: 59). Ebenso wie es reduktionistisch sei gesellschaftliche Naturverhältnisse von der Naturseite her zu erfassen, gelte dies auch für eine Erfassung rein von der gesellschaftlichen Seite. Daraus leitet sich eine „doppelseitige Kritik“ ab: „Einerseits Kritik am Naturalismus und andererseits Kritik am Kulturalismus und Soziozentrismus“ (ebenda: 186f.). Der Begriff der Krise ist dabei für die sozialökologische Forschung zentral. Die ökologische Krise sei demnach nur als Verhältnis (Weltverhältnis) zwischen Mensch (als Individuum), Natur und Gesellschaft/Kultur begreifbar. Keines der Elemente bestehe für sich oder ,,ist unabhängig von den anderen denkbar" (ebenda: 34). Wie dieses Verhältnis gedacht und bestimmt wird, hänge von kulturell und historisch spezifischen Werten und Normen ab (Weltverständnis) (ebenda: 34). ${ }^{33}$ Für die Forschung bedeutet dies: „Der sozial-ökologische Blick richtet sich auf hybride Krisenphänomene, in denen gesellschaftliche und natürliche Pro-

det werden müsste, wie dies bspw. bei Hofmeister u.a. (2019) und Hofmeister (2008) praktiziert wird, wodurch „das Konzept von einer einzigen universellen Natur“ aufgebrochen wird (Hofmeister 2008: 822).

32 Becker/Jahn (2006: 55f.) betonen, dass es darüber hinaus ,nicht gleichgültig“ sei „ob öffentlich von Umweltproblemen, von einer ökologischen Krise oder von Naturzerstörung gesprochen wird“, da damit unterschiedliche Konflikte adressiert werden. „In der allgemeinen Öffentlichkeit werden Ökologie, Umwelt und Natur fast gleichbedeutend verwendet“, allerdings betone Ökologie ,stärker den unauflöslichen Zusammenhang zwischen den Menschen und der Natur“, während sich Umwelt ,in erster Linie auf die Natur als materielle Lebensgrundlage der Menschen, als Quelle von Rohstoffen und Senke für Abfälle und Schadstoffe“ beziehe. Natur habe unter den drei Begriffen „die weiteste Bedeutung“, ,ihr werden ein Eigensinn und Eigenqualitäten zugesprochen, das nicht von Menschen Gemachte und für sie nur begrenzt Verfügbare wird betont und die Normativität von Naturvorstellungen hervorgehoben (Görg 1999)“ (Becker/Jahn 2006: 55f.). Ob von Umwelt-, ökologischen Problemen, von ökologischer, multipler oder sozial-ökologischer Krise gesprochen wird, hat also maßgeblichen Einfluss darauf wie umfangreich und grundlegend die angestrebten Lösungen sind. Ich schließe mich in meiner Arbeit dem Verständnis der Sozialen Ökologie an und verwende den Begriff der Krise in diesem Sinne. An Stellen, an denen ich mich auf eine gängige alltagssprachliche Verwendung, bzw. die Verwendung bestimmter politischer Akteur*innen beziehe, spreche ich auch von Umwelt- oder ökologischen Problemen.

33 Das Weltverhältnis als ökologischen Krisenzusammenhang zu reformulieren erfordert nach Becker/Jahn eine grundlegende Revision der „Kategorien des Weltverständnisses“ (Becker/Jahn 2006: 37). 
zesse sich überlagern, interferieren und eine komplexe Krisendynamik entwickeln“ (ebenda: 169). Im Gegensatz zu eindimensionalen wissenschaftlichen Betrachtungen verändere sich durch die Krisenhypothese sowohl das Wissensobjekt, das erforscht wird, als auch der Zugang zu diesem (ebenda).

Feministische Forschungen arbeiten die Verwobenheit von gesellschaftlichen Natur- und Geschlechterverhältnissen seit den 80er Jahren (vgl. z.B. Scheich u.a. 1989) heraus, denn die Frage nach der Geschlechterdifferenz verweise immer schon auf das Verhältnis von Natur und Gesellschaft: „Im Ringen um eine Antwort darauf, was Frauen und Männer voneinander unterscheidet, ist der Bezug auf Natur und Körperlichkeit schon angelegt“" (Hofmeister u.a. 2013: 34). Die Frage nach den gesellschaftlichen Naturverhältnissen sei somit mit der Frage nach den Geschlechterverhältnissen verwoben und umgekehrt (ebenda). ${ }^{34}$ Die Natur-Kultur-Dichotomie wird in der Geschlechterforschung als zentrale, selbst geschlechtlich kodierte, „Ordnungskategorie hegemonial westlichen Denkens“ gesehen (Schultz u.a. 2006: 227).

„Sie ist mit einer aus der Evolutionsbiologie entnommenen Unterscheidung von $>$ männlich = aktiv $\prec$ und $>$ weiblich $=$ passiv $\diamond$ verbunden. Deren Übertragung auf moderne Entwicklungsvorstellungen führte letztlich zur Deutung einer als aktive Kulturgestaltung ausgelegten Männlichkeit (samt der als männlich codierten Personengruppen und Strukturen) in Abgrenzung zu einer als passive Naturzugehörigkeit definierten Weiblichkeit (samt der als weiblich codierten Personengruppen und Strukturen). Das Geschlechtliche, das mit dem Natürlichen und dem Weiblichen identifiziert wird, ist in diesem Muster idealtypisch immer als das Besondere im Verhältnis zum Allgemeinen der gattungsgeschichtlichen Entwicklung definiert“" (ebenda: 227f.).

Hofmeister u.a. (2013b) arbeiten vor diesem Hintergrund die Potenziale von Geschlechterperspektiven für die Nachhaltigkeitswissenschaft heraus. So sei „[d]as Interesse an der gesellschaftlichen Produktion und Reproduktion von ,Geschlecht ' [...] prinzipiell verbunden mit dem Interesse, Herrschaftsverhältnisse, die diese Prozesse ermöglichen und zu deren Stabilisierung sie beitragen, in kritischer Absicht aufzudecken“ (ebenda: 45). Dabei stehe nicht die Konstruktion von Geschlecht im Mittelpunkt, „sondern die Frage, wozu sie dient“ (ebenda). Die Geschlechterforschung geht somit weit über einen schlichten Fokus auf die Kategorie Geschlecht hinaus. Die Erkenntnis, dass moderne Gesellschaften auf der Herstellung dualistischer Hierarchisierungen beruhen, ist für die Geschlechterforschung zentral (ebenda). Sie macht Dichotomisierungsprozesse sichtbar, zielt auf Herrschaftskritik sowie auf die Transformation von Herrschaftsverhältnissen ,,im Interesse des Abgespaltenen und Abgewerteten" (ebenda).

Die feministische Perspektive ist dabei - neben ihrer positionierenden Funktion in meiner Arbeit vor allem auch eine Erkenntnisperspektive. So gehe es laut Gottschlich/Katz (2016) in der feministischen Nachhaltigkeitsforschung um „die Identifikation und kritische Analyse jedweder Form von Ungleichheitsverhältnissen und ihren Wechselwirkungen“ (ebenda 13). Die Geschlechterforschung hole dabei die Re-

34 Für eine ausführlichere Darstellung des Zusammenhangs sei auf den Sammelband „Geschlechterverhältnisse und Nachhaltigkeit“ Hofmeister u.a. (2013a) sowie auf Scheich u.a. (1989) verwiesen. 
lationalität in den Blick: „Die Wechselbezüge zwischen dem voneinander dualistisch Getrennten - Frauen und Männer, Natur und Kultur/ Gesellschaft, Privatheit und Öffentlichkeit - sind somit grundsätzlich eingelassen in ein Geflecht von Interessen an Herrschaft, an der Abwertung und Marginalisierung des einen Teils" (Hofmeister u.a. 2013: 45). Die feministische Perspektive ist aber nicht nur für die Bearbeitung wissenschaftlicher Problemstellungen, sondern bereits für die Stellung des Problems selbst relevant. Denn die mit Weiblichkeit verbundenen Problemstellungen werden in westlichen Gesellschaften, vor dem Hintergrund einer Etikettierung von Weiblichkeit als Untergeordnetes, nachrangig betrachtet und für Lösungsmöglichkeiten häufig nicht berücksichtigt. Dies kann zur Verschärfung sozial-ökologischer Krisen führen, wenn Probleme vor diesem Hintergrund definiert werden (Schultz u.a. 2006: 230).

„Das Vorrangigstellen und Abwerten betreffen dabei die mit der Natur-Kultur-Differenz verbundenen und geschlechtsspezifisch symbolisierten Basisunterscheidungen moderner westlicher Gesellschaften: dass öffentliche und wirtschaftliche Belange und Personen wichtiger sind als private, dass Produktions- und Technikbelange Vorrang haben vor Reproduktionsbelangen, dass bezahlte Arbeit mehr wert ist als unbezahlte Arbeit etc.“ (ebenda).

Die Geschlechterkategorie hat insofern eine reflexive Funktion für die Hierarchisierung von Problemstellungen, die sich nicht auf den Einbezug von Frauen bei sozialökologischen Problemlagen beschränkt, sondern mit der generell der „Einbezug gesellschaftlicher Alltagsakteure und der Sphäre des Privaten zugeordneter gesellschaftlicher Teilbereiche" geprüft werden kann (ebenda: 230). Die reflexive Funktion feministischer Wissenschaft bezieht sich aber nicht nur auf Problemstellung und Gegenstand. Die Reflexion des Forschungsgegenstandes setzt zudem „die Selbstreflexion der Forscher_in in Bezug auf das eigene Geschlecht und die eigene Rolle im Forschungsprozess voraus“ (Hofmeister u.a. 2013: 45). Gerade weil die Forschenden so die eigene normative Positionierung explizit machen, sich dem „situierten Wissen“ (Haraway 1988) bewusst sind, könne ,ein Höchstmaß an Objektivität in Bezug auf die Ergebnisse der Forschung“" gewährleistet werden (Hofmeister u.a. 2013: 45).

Eine kritische Nachhaligkeits- und auch Transformationsforschung in diesem Sinne sei auf die Transformation gesellschaftlicher Natur- und Geschlechterverhältnisse gerichtet und explizit herrschaftskritisch (ebena: 46). Gottschlich/Katz (2016) zeigen in ihrem Artikel, dass eine auf diese Weise kritische Nachhaltigkeits- und Transformationsforschung weiterhin marginalisiert ist. Dies sei problematisch, da bestehende Ungleichheitsverhältnisse, Ungerechtigkeiten und nicht-nachhaltige Verhältnisse so nicht reflektiert werden und das daraus hervorgehende Wissen diese möglicherweise reproduziere (ebenda: 12). In der deutschen Transformationsforschung hat sich in den letzten Jahren - teilweise mit Bezug zur Postwachstums-/bzw. Degrowthbewegung - eine kritische Transformationsforschung ${ }^{35}$ herausgebildet

35 Als kritisch bezeichne ich in der vorliegenden Arbeit Forschung, die sich kritisch gegenüber einer vermeintlichen Realität verhält, Ausschlüsse sowie hierarchische Trennungsstrukturen aufzeigt, explizit herrschaftskritisch ist, indem sie bestehende Verhältnisse in Frage stellt, denaturalisiert und auf die Transformation von Herrschaftsverhältnissen zielt. 
(Acosta/Brand 2018; AK Postwachstum 2016; Bauriedl/Wichterich 2014; Binswanger 1998; Brand u.a. 2013b; Brand 2014; Brangsch u.a. 2012; Brie 2014a, 2015b, 2015d, 2015c; Brie u.a. 2016; Burkhart u.a. 2017; Candeias 2010, 2013; Dellheim/Krause 2008; Dörre u.a. 2019; Sutterlütti u.a. 2018). Arbeiten, die sich auf das Konzept gesellschaftlicher Naturverhältnisse beziehen und meist einen kapitalismuskritischen Standpunkt vertreten, sprechen dabei häufig von einer sozial-ökologischen Transformation als Lösung multipler Krisen ${ }^{36}$ (Brand 2017: 24f.). Leider kommen aber auch in der kritischen Transformationsforschung feministische Perspektiven bislang zu kurz, bzw. werden nur randständig behandelt (vgl. z.B. Klein 2014). Die Feminisms and Degrowth Alliance FADA setzt sich seit 2016 für die Integration feministischer Perspektiven in die Degrowth-Debatte ein. Saave-Haarnack u.a. (2019: 29) kritisieren: „feminist reasoning is still not an integral part of the degrowth proposal“.

Als Nachhaltigkeitswissenschaftlerin positioniere ich mich innerhalb einer kritischen, feministischen, sozial-ökologischen Transformationsforschung und möchte mit der vorliegenden Arbeit einen Beitrag dazu leisten, diese auch innerhalb der Transformationsforschung noch marginalisierte Perspektive weiter zu stärken. Eine feministische, sozial-ökologische Forschung ist darüber hinaus aus ihrem Selbstverständnis heraus inter- und transdisziplinär (Schultz u.a. 2006: 230; Jahn 2005; Hofmeister u.a. 2013: 40ff.; Becker/Jahn 2006: 287; Becker/Jahn 2000). Ich verorte mich dabei mit Jahn (2005: 37) im „Horizont transdisziplinärer Forschung“, da die vorliegende Arbeit nicht als transdisziplinärer Forschungsprozess im Sinne einer Integration von Praxisakteur*innen sowie einer gemeinsamen Generierung des Gegenstandes angelegt ist. Der praktische und gesellschaftliche Problembezug bleibt aber bestehen, ebenso wie die kognitive Integrationsanforderung, sowohl hinsichtlich der Interdisziplinarität als auch der Integration von Praxisbezügen sowie alltagspraktischem Wissen. Neben wissenschaftlichen werden auch gesellschaftliche Problemlösungen erarbeitet (vgl. ebenda: 34ff.). Die feministische Perspektive ist insofern auch eine inter- und transdisziplinäre Perspektive, als dass ,,unter geschlechtsspezifischen Aspekten die wechselseitigen Verbindungen zwischen Wissenschaft und Gesellschaft reflektiert" werden (Schultz u.a. 2006: 230).

Innerhalb des Forschungsbereiches feministischer, sozial-ökologischer Transformationsforschung nehme ich eine weitere Positionierung vor, indem ich in meinem Transformationsverständnis wie bereits erwähnt an die Arbeiten des Vorsorgenden Wirtschaftens anknüpfe (vgl. Kapitel 3) und mit dieser Arbeit gleichzeitig auf spezifische Weise Teil des Diskurses um Vorsorgendes Wirtschaften ${ }^{37}$ bin. Das Vorsor-

Aufgrund der zahlreichen Forschungsarbeiten in diesem Gebiet befinden sich in der obigen Auflistung nur Arbeiten, die sich explizit auf Transformation beziehen.

36 Um im Rekurs auf die Soziale Ökologie die Zusammenhänge der Krisendimensionen zu verdeutlichen, wird häufig von einer multiplen Krise oder einer Vielfachkrise gesprochen (Brand 2009; Demirović u.a. 2011). Brand sieht den inneren Zusammenhang der vielfältigen Krise ,in der fossilistisch-kapitalistischen Produktions- und Lebensweise“ (Brand 2009: 2).

37 Da das Vorsorgende Wirtschaften ein offenes Konzept ist, das sich nicht auf feststehende Inhalte reduzieren lässt, ist jeder Beitrag zum Vorsorgenden Wirtschaften gleichzeitig ein Beitrag zur Konzeptentwicklung und positioniert sich somit in einer bestimmten Weise im 
gende Wirtschaften versteht sich als „kritischen Ansatz“, der die herrschaftliche Prägung gesellschaftlicher Natur- und Geschlechterverhältnisse zu einem Ausgangspunkt der eigenen Arbeit macht (Netzwerk Vorsorgendes Wirtschaften 2013: 10). Das Netzwerk Vorsorgendes Wirtschaften hat sich in der Folge einer oikos Konferenz im Jahr 1992 in St. Gallen gegründet, bei der sich eine Arbeitsgruppe von Frauen mit „Nachhaltigem Wirtschaften aus weiblicher Perspektive“ beschäftigte (www.vorsorgendeswirtschaften.de). 1994 wurden die ersten Arbeitsergebnisse in einem Sonderheft der Politischen Ökologie veröffentlicht (Busch-Lüty u.a. 1994). Es folgten weitere Publikationen des Netzwerks in den Jahren 2000 (Biesecker u.a. 2000) und 2013 (Netzwerk Vorsorgendes Wirtschaften 2013) (38 $^{38}$ sowie zahlreiche Arbeiten zum Vorsorgenden Wirtschaften von Einzelautorinnen. Zudem entstanden im Umfeld des Netzwerks Forschungsprojekte, wie das im Förderschwerpunkt der sozial-ökologischen Forschung SÖF des BMBF angesiedelte Projekt „Blockierter Wandel? Denk- und Handlungsräume für eine Nachhaltige Regionalentwicklung“ (20032006), bei dem aus feministischer Perspektive dichotome Muster und Hierarchisierungen sowie damit verbundene Blockaden für sozial-ökologische Transformationsprozesse analysiert wurden (Forschungsverbund „Blockierter Wandel?“ 2007). Zuletzt zielte das Forschungsprojekt „TraVo: Vorsorgendes Wirtschaften - Transformationen in Ökonomie und Politik“ auf die Verbindung der Debatten um ,sozialökologische Transformationen“ und „Nachhaltigkeit und Genderperspektiven“ und damit auf eine Erhöhung des Stellenwerts feministischer Perspektiven in den Transformationsdebatten (Biesecker u.a. 2015, 2016; Amri-Henkel u.a. 2017). Die vorliegende Arbeit knüpft - wie bereits erläutert - an einige Ergebnisse aus diesem Projekt an.

Ein Anliegen dieser Arbeit ist es dabei zu zeigen, dass sich eine methodische Anwendung der Diskurstheorie nach Laclau/Mouffe (2015) besonders für eine feministische, sozial-ökologische und kritische Transformationsforschung eignet. Zum einen, weil es sich um eine politische Theorie handelt, die eine Hegemonietheorie beinhaltet und die Herrschaftsverhältnissen eine zentrale Stellung zuweist ${ }^{39}$, indem sie zeigt wie die Konstitution von Identität parasitär auf dem Ausschluss des ,Anderen“ beruht. Zum anderen, weil ihr Diskursbegriff die Dichotomie zwischen sprachlich/geistig versus nicht-sprachlich/materiell subvertiert und so der doppelseitigen Kritik der Sozialen Ökologie Rechnung trägt, wie ich in Kapitel 2.3 ausführlich dar-

Diskurs Vorsorgendes Wirtschaften. In diesem Sinne verstehe ich auch meine Arbeit zum Vorsorgenden Wirtschaften, mit der ich die Ansätze des Vorsorgenden Wirtschaftens nicht einfach wiedergebe, sondern diese aus meiner dieser Studie zugrunde liegenden Perspektive interpretiere und weiterentwickle. Meiner Arbeit liegt also ein diskurstheoretisches Verständnis Vorsorgenden Wirtschaftens zugrunde.

38 In der Skizzierung Vorsorgenden Wirtschaftens konzentriere ich mich in der vorliegenden Arbeit hauptsächlich auf diese drei gemeinsamen Publikationen des Netzwerks. Darüber hinaus beziehe ich aber auch die Arbeiten von Einzelautorinnen ein, die für meine, der Arbeit zu Grunde liegenden Positionierung innerhalb des Netzwerks relevant sind. Wo dies gegenstandsbezogen notwendig erscheint, nehme ich darüber hinaus selbst theoretische Weiterentwicklungen vor, mache dies aber kenntlich.

39 Dies führe ich in Kapitel 2 (Diskurstheorie) genauer aus. 
lege. So kann dem „Dilemma zwischen Essentialismus und Konstruktivismus, zwischen Materialität einerseits und Diskursivität [...] andererseits“, mit dem sich auch die Nachhaltigkeitswissenschaft konfrontiert sieht (Hofmeister u.a. 2013: 46), entgegengewirkt werden. Die Diskurstheorie nach Laclau/Mouffe (2015) bewegt sich daher theoretisch innerhalb des „,neuen Denkraums“ der Sozialen Ökologie, in dem sozial-ökologische Probleme in ihrem Zusammenhang betrachtet werden können (Becker/Jahn 2006: 187). Dies werde ich im Verlauf der Arbeit zeigen (vgl. Kapitel 2), immer wieder kritisch reflektieren und dadurch einen Beitrag zur Theorieentwicklung leisten.

Feministische Forschung hat aber nicht nur einen dekonstruktiven, sondern auch einen re-konstruktiven Anspruch, der darin beruht, dichotome Strukturen zugunsten nachhaltigerer Verhältnisse aufzubrechen (Hofmeister u.a. 2013: 46). Auch hier zeigen sich Anknüpfungspunkte an die Diskurstheorie, in der die Dekonstruktion als Voraussetzung für Emanzipation gilt (Critchley 1998: 205). Eine vollständige Emanzipation bleibt für Laclau/Mouffe (2015) zwar unmöglich, da Ausschlüsse für gesellschaftliche Beziehungen konstitutiv sind, wie ich in Kapitel 2 (Diskurstheorie) ausführe. Stattdessen eröffnet die Anerkennung der Nicht-Naturgegebenheit und somit des politischen Charakters von Identität aber den Weg für eine herrschaftsärmere Zukunftsgestaltung, in der Machtverhältnisse transformiert werden können und Gesellschaft demokratischer gestaltet werden kann - Emanzipation als politische Zielsetzung bleibt somit erhalten, ist jedoch ein offener Prozess (Laclau/Mouffe 2015: 24f.). ${ }^{40}$ Der politische Anspruch der Diskurstheorie zeigt sich somit nicht nur anschlussfähig für eine feministische Forschung, sondern auch für die kritische Transformationsforschung. Diese Anschlussfähigkeit ${ }^{41}$ nutze ich, um die analytische Verknüpfung der Diskurstheorie mit dem Vorsorgenden Wirtschaften (bzw. einem diskurstheoretischen Verständnis Vorsorgenden Wirtschaftens) sowohl theoretisch als auch methodisch zu wagen. Damit zusammenhängend spreche ich von einer kritischemanzipatorischen Perspektive Vorsorgenden Wirtschaftens. Die kritische Perspektive Vorsorgenden Wirtschaftens beschreibt seine dekonstruierende Funktion, die ich mit der in Kapitel 4.3 vorgestellten Analyseheuristik generiere. Gleichzeitig beinhaltet das Vorsorgende Wirtschaften stets auch eine emanzipatorische Perspektive, indem es die Dekonstruktion in den Kontext alternativer, herrschaftsärmerer Zukunftsgestaltungen stellt, bzw. deren Möglichkeit aufscheinen lässt. An einigen Stellen hat sich darüber hinaus im Laufe des Forschungsprozesses eine diskurstheoretische Dis-

40 Unter Emanzipation verstehe ich daher in der vorliegenden Arbeit in Anschluss an Laclau/Mouffe (2015) und Laclau (2002) einen unvollendbaren aber dennoch handlungsleitenden Prozess, der auf das Aufbrechen von hierarchischen Trennungsstrukturen, Externalisierungen, Herrschaftsverhältnissen und somit eine herrschaftsärmere Zukunftsgestaltung zielt. Emanzipation wird hier also auf einer gesellschaftlichen und politischen Ebene betrachtet. Da Emanzipation niemals vollständig sein kann, es immer nur partielle Emanzipationen geben kann, spricht Laclau auch von Emanzipationen im Plural (Laclau 2002). Der Emanzipationsbegriff wird im Laufe von Kapitel 2 noch näher ausgearbeitet. Eine begriffliche Kontextualisierung mit dem Begriff der Transformation erfolgt in Kapitel 3.

41 Die Anschlussfähigkeit von Vorsorgendem Wirtschaften und Diskurstheorie wird in Kapitel 2 und 3 noch genauer diskutiert. 
kussion sowie eine gegenstandsbezogene Weiterentwicklung des Vorsorgenden Wirtschaftens als notwendig erwiesen, besonders im Hinblick auf die analytische Funktion des Ansatzes. So war es notwendig, die Kriterien Vorsorgenden Wirtschaftens nach Biesecker/von Winterfeld (2015) zu konkretisieren und um postkoloniale Perspektiven zu erweitern, da sich diese im Forschungsprozess als besonders wichtig erwiesen (vgl. Kapitel 3.2.2). Gleichzeitig ergibt sich durch die Verknüpfung von Diskurstheorie und Vorsorgendem Wirtschaften auch eine normative Erweiterung der Diskurstheorie, die deren emanzipatorischen Anspruch konkretisiert, die politische Ökonomie ${ }^{42}$ in den Blick holt und somit einen Beitrag leistet, dem materiellen Anspruch des Diskursbegriffes nach Laclau/Mouffe (2015) gerecht zu werden.

\subsection{STRUKTUR DER ARBEIT}

Im nachfolgenden Kapitel 2 erfolgt zunächst eine Einführung in die Diskurstheorie nach Laclau/Mouffe (2015). Dabei wird auch deren gesellschaftspolitische Bedeutung sowie ihr Potenzial für eine feministische Forschung herausgearbeitet. Dies geschieht in Abgrenzung zu anderen diskurstheoretischen Ansätzen. Der Diskursbegriff nach Laclau/Mouffe (2015) wird eingeführt (2.3) und mit Grundbegriffen der Diskurstheorie in Beziehung gesetzt (2.4). Vor diesem Hintergrund wird die Laclau/ Mouffe'sche Diskurstheorie ${ }^{43}$ als politische und als Hegemonietheorie präsentiert (2.5). In Kapitel 3 erfolgt zunächst eine theoretische Verortung des Transformationsbegriffes im Sinne sozial-ökologischer Transformation (3.1), die sich innerhalb eines Spannungsfeldes zwischen Revolution und Reform abspielt (3.1.3). Außerdem erfolgt eine Auseinandersetzung mit den zeitlichen Perspektiven von Transformation in Abgrenzung zu Fortschritt (3.1.1). Darauf aufbauend wird anschließend in das Vorsorgende Wirtschaften als sozial-ökologisches Transformationskonzept (3.2) und in seine Handlungsprinzipien (3.2.1) eingeführt. Über die Handlungsprinzipien hinaus konkretisiere ich das Vorsorgende Wirtschaften im Hinblick auf die spätere Analyse anhand weiterer Kriterien (3.2.2). In Kapitel 4 gehe ich zunächst genauer auf die Analyse von Plenardebatten als Gegenstand meiner Arbeit ein (4.1). Darauf folgend operationalisiere ich die Diskurstheorie nach Laclau/Mouffe (2015) anhand einer Kombination aus einem computerbasiertem Verfahren (4.2.1), einem kodierenden Verfahren (4.2.2) sowie der Klassifikation von dem Diskurs zugrunde liegenden Fantasien (4.2.3). Das Vorsorgende Wirtschaften operationalisiere ich anhand von Analyseheuristiken (4.3). Gegen Ende des Kapitels erfolgt eine kritische Reflexion des Forschungsansatzes, wobei ich auch auf die im vorherigen Unterkapitel beschriebene Positionierung und theoretische Verortung zurückkomme (4.4). Die Ergebnisse der Diskursanalyse nach Laclau/Mouffe (2015) präsentiere ich in Kapitel (5), wobei sich die Struktur des Kapitels an der Abfolge des methodischen Vorgehens orientiert. Die

42 Fraser (2001: 263) kritisiert, dass die Laclau/Mouffe'sche Diskurstheorie diese ausklammere, was ich in Kapitel 2.6 genauer erläutere.

43 Wenn ich im Folgenden von der Laclau/Mouffe'schen Diskurstheorie, bzw. von Laclau/ Mouffe spreche, beziehe ich mich auf das diskurstheoretische Grundlagenwerk der beiden, „Hegemonie und radikale Demokratie“ (Laclau/Mouffe 2015). 
Ergebnisse der computerbasierten Analyse (5.1) unterziehe ich in Kapitel 5.1.3 einer ersten qualitativen Diskussion. Gegen Ende dieses Ergebniskapitels (5.4) erfolgt eine Reflektion der Ergebnisse des methodischen Dreischritts insgesamt. In Kapitel 6 wird das im Laufe der Diskursanalyse generierte Material qualitativ aus kritisch-emanzipatorischer Perspektive Vorsorgenden Wirtschaftens analysiert, sodass im Fazit (7) alle Ergebnisse zusammengefügt und die Forschungsfragen beantwortet (7.1) werden können. Abschließend erfolgt eine Rückbindung an die Theorie (7.4) und es wird weiterer Forschungsbedarf aufgezeigt (7.3). 


\section{Diskurstheorie}

Die theoretische Grundlage meiner Methodologie bildet die Diskurstheorie nach Ernesto Laclau und Chantal Mouffe (Laclau/Mouffe 2015), die im Folgenden im Hinblick auf die in Kapitel 4 erarbeitete Methodik dargelegt und begründet wird. Ich zeige dabei sowohl vor dem Hintergrund des gesellschaftspolitischen Anspruchs, als auch vor dem Hintergrund des Diskursbegriffes und seiner hegemonietheoretischen Verortung, dass sich die Laclau/Mouffe'sche Diskurstheorie besonders für eine feministische, sozial-ökologische, politische Transformationsforschung eignet, wie sie in der vorliegenden Arbeit verfolgt wird.

Dabei wird ein feministischer Diskursbegriff herausgearbeitet, der die Multidimensionalität und Heterogenität von Geschlecht ${ }^{1}$ und anderen Identitätskategorien verdeutlicht. Epistemologisch ist er an eine feministische Wissenschaftskritik anschlussfähig und zeigt gleichzeitig strukturelle Ungleichheitslagen, Dichotomisierungsprozesse und Hierarchisierungen sowie die Prozesse, in denen Geschlecht und anderen Identitätskategorien sozial produziert und reproduziert werden, auf.

Darüber hinaus werden die für die Arbeit grundlegenden diskurstheoretischen Begriffe wie Subjekt, Identität, Gesellschaft, Politik, Macht und Hegemonie eingeführt. Da ich in der Methodik meiner Arbeit (vgl. Kapitel 4.2) einen Operationalisierungsvorschlag der Diskurstheorie nach Laclau/Mouffe (2015) von Georg Glasze, Annika Mattissek u.a. aufgreife, knüpfe ich bereits in meiner folgenden theoretischen Ausarbeitung an diese Arbeiten an (Glasze u.a. 2009; Glasze/Mattissek 2009b; 2009a; Glasze 2008; 2009).

\subsection{GESELLSCHAFTSPOLITISCHE BEDEUTUNG UND ENTWICKLUNG VON DISKURSTHEORIEN}

Diskurstheorien eignen sich besonders für eine (feministische) politische Analyse von Transformationsprozessen, wie sie Gegenstand meiner Arbeit ist: Poststrukturalistisch informierte Diskurstheorie widersetzt sich jedem Objektivitäts- und Universalitätsanspruch. Gleichzeitig ist sie gesellschaftspolitisch motiviert. In ihrem Zent-

1 Für eine vertiefte Auseinandersetzung mit Geschlecht als heterogener und multidimensionaler Kategorie im Rahmen verschiedener analytischer Perspektiven vgl. Hofmeister u.a. (2016); Hofmeister/Katz (2011); Hofmeister u.a. (2013a). 
rum steht die Kritik an gesellschaftlichen Verhältnissen, an Machtverhältnissen, an scheinbar objektiven Wahrheiten. Diskurstheorien liefern dazu Perspektiven und manchmal auch Methoden, die allerdings immer auf den Gegenstand anzupassen sind. So schreibt Foucault auf die Frage, welchen Kämpfen seine Arbeiten dienen:

\begin{abstract}
„Alle meine Bücher [...] sind [...] kleine Werkzeugkisten. Wenn die Leute sie aufmachen wollen und diesen oder jenen Satz, diese oder jene Idee oder Analyse als Schraubenzieher verwenden, um die Machtsysteme kurzzuschließen, zu demontieren oder zu sprengen, einschließlich vielleicht derjenigen Machtsysteme, aus denen diese meine Bücher hervorgegangen sind - nun gut, umso besser“ (Foucault 1976: 53).
\end{abstract}

Gerade für feministische Wissenschaftsperspektiven bietet sich die Arbeit mit Diskurstheorien an. Es sind unter anderem die Kritik am Objektivitätsanspruch herkömmlicher Wissenschaft, das Hinterfragen von vermeintlich ewig gültigen Wahrheiten, von Macht- und Herrschaftsverhältnissen, der Blick auf ,das Andere', das Ausgegrenzte sowie der emanzipatorische Anspruch, was die feministische Wissenschaft mit verschiedenen diskurstheoretischen Ansätzen eint - auch wenn eine explizite Auseinandersetzung mit dem Feminismus in diskurstheoretischen Ansätzen häufig fehlt. ${ }^{2}$

Laut Derrida $(1995,2003)$ ist Emanzipation „démocratie à venir“, ein quasi unerreichbarer Zustand, ein messianisches Versprechen. In ihrem Emanzipations- und Demokratieverständnis knüpfen Laclau/Mouffe hier an (Šumič-Riha 1998: 145). Im Sinne kommender Demokratie sind Emanzipation und „Demokratie die Zukunft der Dekonstruktion, aber diese Zukunft ereignet sich jetzt, sie ereignet sich indem das Jetzt das Kontinuum der Gegenwart durchbricht" (Critchley 1998: 205).

Eine in diesem Sinne entwickelte Diskurstheorie ist auf die Transformation der Verhältnisse gerichtet und leistet selbst einen Beitrag in Form von ,analytical activism“ (Lazar 2007: 145). Diskurstheorie ,untermauert damit Proteste und motiviert zu Protesten“ (Jäger 2012: 8). Die Schnittstellen zwischen feministischer Wissenschaft und poststrukturalistischer Diskurstheorie haben Potenzial für die Nachhaltigkeitsforschung, die sich häufig mit dem Vorwurf konfrontiert sieht, Machtverhältnisse auszublenden (Gottschlich 2017: 24).

\title{
Entwicklung von Diskurstheorien
}

Ferdinand de Saussure gilt als Begründer der strukturalistischen Sprachwissenschaft. Er betrachtet Sprache als ein Differenzsystem, in dem die Bedeutung eines Wortes aus der Beziehung zwischen dem Signifikanten (das Bezeichnende) und dem Signifikat (das Bezeichnete) entsteht. Isoliert sind sowohl Signifikant als auch Signifikat bedeutungslos. Demnach ist Sprache nicht in der Lage eine externe Realität positiv abzubilden, vielmehr wird die Bedeutung durch das Zeichensystem (aus Signifikat

2 Dies gilt nicht für Laclau/Mouffe, in deren für die Diskurstheorie zentralem Werk „Hegemonie und radikale Demokratie: Zur Dekonstruktion des Marxismus“ (Laclau/Mouffe 2015) Feminismus zwar nur eine Nebenrolle spielt, aber mitgedacht wird, wie Chantal Mouffe insbesondere in anderen Arbeiten vertieft (z.B. Mouffe 2001; Mouffe 1992). 
und Signifikant) erst hergestellt. Auch das Signifikat existiert also nicht unabhängig vom Sprachsystem (De Saussure 1967: 76ff.).

Allerdings betrachtet Saussure „Sprache als ein System von Differenzen ohne positive Bestimmungen“ in der wirklichen Welt (Laclau/Mouffe 2015: 147). Diese rein relationale Bedeutung von Begriffen, setzt allerdings voraus, dass der strukturelle Raum vollständig konstituiert ist (ebenda: 147; De Saussure 1967: 83ff.), „denn nur innerhalb eines solchen [geschlossenen Systems] ist es möglich derart die Bedeutung jedes Elements zu fixieren“ (Laclau/Mouffe 2015: 147). Im Gegensatz dazu arbeiten Roland Barthes und Jacques Derrida später die Nicht-Geschlossenheit von Strukturen sowie die Nicht-Fixiertheit von Bedeutung heraus und tragen dazu bei, die Konzepte des Strukturalismus hin zum Poststrukturalismus zu radikalisieren (Derrida 1988; Barthes 1987; vgl. auch Glasze 2008: 187f.). Bedeutung wird weiterhin als Effekt von Differenzbeziehungen konzeptualisiert. Allerdings sei Bedeutung nicht fixiert, nicht eindeutig, sondern entstehe durch sich ständig ändernde Verweise immer wieder neu (Derrida 1974; Derrida 1972; Glasze/Mattissek 2009b: 25; Lacan 1973). In den 60er/70er Jahren entwickelt Michel Foucault die Diskurstheorie weiter, indem er Diskursformationen, Diskurse als Aussagensysteme (Foucault 1974: 187ff.), in den Mittelpunkt seiner Betrachtungen stellt und damit den Schritt über das Individuum hinaus zu den „Regeln der Herstellung sozialer Wirklichkeit“ geht. Foucault geht davon aus, dass Strukturen historisch situiert sind, Wahrheitsfähigkeit und Wissensordnung immer wieder (neu) hergestellt werden (Glasze/Mattissek 2009b: 25).

„Jede Gesellschaft hat ihre eigene Ordnung der Wahrheit, ihre ,allgemeine Politik‘ der Wahrheit: d.h. sie akzeptiert bestimmte Diskurse, die sie als wahre Diskurse funktionieren läßt; es gibt Mechanismen und Instanzen, die eine Unterscheidung von wahren und falschen Aussagen ermöglichen und den Modus festlegen, in dem die einen oder anderen sanktioniert werden; es gibt einen Status für jene, die darüber zu befinden haben, was wahr ist und was nicht“ (Foucault 1978: 51).

\subsection{VERORTUNG DER DISKURSTHEORIE NACH LACLAU/MOUFFE}

In der sozialwissenschaftlichen Diskursforschung haben sich unterschiedliche diskurstheoretische Ansätze entwickelt, die sich aufgrund ihrer gesellschaftstheoretischen Annahmen unterscheiden und die diskursive Konstitution sozialer Wirklichkeit unterschiedlich konzeptualisieren, bzw. diese unterschiedlich weit denken (Glasze/ Mattissek 2009b: 31). Glasze/Mattissek (2009b: $31 \mathrm{ff}$.) unterscheiden dabei zwischen strukturalistischen, wissenssoziologisch orientierten sowie poststrukturalistischen Ansätzen, die hier im Hinblick auf die eigene theoretische Einordnung kurz skizziert werden.

Zur strukturalistischen Diskursforschung zählen beispielsweise die Arbeiten der critical discourse analysis CDA (van Dijk 1997; Fairclough 1995; Wodak/Chilton 2005; Wodak/Meyer 2009), die an die marxistische Ideologiekritik anschließen und von prädiskursiven Sozialstrukturen ausgehen, die den Diskurs determinieren. Durch die damit zusammenhängende Unterscheidung zwischen einerseits Ideologie/ 
Sprache/Diskurs und sozialen Praxen/Wirklichkeit auf der anderen Seite sind Untersuchungen häufig eher linguistisch orientiert. Kritisiert wird, dass diese Ansätze zum Teil den Eindruck erwecken, die Wissenschaft sei quasi exklusiv in der Lage hinter der Sprachfassade die ,wirkliche Wirklichkeit“ zu erblicken (Glasze/Mattissek 2009b: 31; Jäger 2012: 20). Einen eigenständigen Ansatz der Kritischen Diskursanalyse KDA hat für den deutschen Sprachraum der Sprachwissenschaftler Siegfried Jäger (Jäger 2012; Jäger/Zimmermann 2010) entwickelt. Jäger arbeitet dabei ebenfalls primär sprachwissenschaftlich, schließt aber enger als die CDA an Michel Foucault an und baut auf diskurstheoretische Arbeiten von Jürgen Link (Link 2005) auf. Die Herausforderung von Ansätzen, die sich eng an Foucault orientieren, liegt unter anderem in der Abgrenzung zwischen diskursiven und nicht-diskursiven Praktiken, die Foucault letztlich noch voneinander unterscheidet. Hierfür wird der Begriff des „Dispositivs“ verwendet, der sich auf heterogene Ensembles von Diskursen und nichtsprachlich bestimmten Handeln (Wissen), sozialen Praktiken, Institutionen, Vergegenständlichungen/Sichtbarkeiten bezieht (Foucault 1978). In diesem Sinne unterscheiden an Foucault orientierte Ansätze zwischen Diskurs- und Dispositivanalyse. Diese Unterscheidung ist allerdings nicht unproblematisch, denn wo Diskurs aufhört und die soziale Praxis/Wirklichkeit anfängt, ist häufig schwer abzugrenzen. Als Beispiel nennt Jäger (2012: 49) den ,neokonservativen Diskurs“, der die „neokonservative politische Praxis“ und damit „,die herrschende Wirtschafts- und Gesellschaftsordnung“ konstituiert. Wo hört da der Diskurs auf, wo fangen politische Praxis und Materialität an?

Die wissenssoziologische Diskursforschung (vgl. z.B. Hajer 1997; Keller 2011; Keller u.a. 2005; Schwab-Trapp 2001; Viehöver 2008) knüpft in ihren Überlegungen zur gesellschaftlichen Strukturierung an Bourdieu und Giddens (Bourdieu 1982; Giddens 1988) an (Glasze/Mattissek 2009b: 32). Sie vereint die hermeneutische Wissenssoziologie mit der foucaultschen Diskurstheorie. Die Arbeitsgruppe um Reiner Keller geht aber über den foucaultschen Diskursbegriff hinaus, indem sie „die Rolle der handelnden Akteure“ (Keller 2011: 12) betont. Diskurse werden dabei als Praktiken aufgefasst, die ,institutionell-organisatorisch reguliert[...]“ sind (ebenda). Diskurs sei eine Struktur, „welche die symbolische Praxis von Akteuren anleitet, von diesen allerdings auch beeinflusst wird und strategisch eingesetzt werden kann. In dieser Praxis wird der Diskurs reproduziert und transformiert" (Glasze/Mattissek 2009b: 32). Kritisiert wird an der wissenssoziologischen Diskursanalyse, dass die Situiertheit des*r Wissenschaftlers*in sowie das intentionale Subjekt unhinterfragt bleiben (Angermüller 2005).

Im Gegensatz zu strukturalistischen und wissenssoziologischen Ansätzen gehen poststrukturalistische Ansätze (vgl. z.B. Barthes 1987, 2010; Butler 1991, 2016; Derrida 1972, 1995; Laclau/Mouffe 2015; Marchart 1998a)

„weder von gesellschaftlichen Verhältnissen noch von handelnden Subjekten als Ursprung diskursiver Strukturen aus. Vielmehr betrachten sie beides als diskursiv konstituiert und nehmen damit keinen außerdiskursiven ,Grund' der Gesellschaft an - wie ihn bspw. marxistische Theorien in der ökonomischen Basis verorten“ (Glasze/Mattissek 2009b: 32f.).

Insofern stehen im Analyseinteresse nicht Subjekte oder Akteur*innen, die vermeintlich Diskurse hervorbringen, sondern die Frage wie Identitäten, Bedeutung und 
Strukturen $^{3}$ diskursiv konstituiert werden. Im Gegensatz zu den oben beschriebenen Ansätzen und zu Foucault gehen poststrukturalistische Ansätze in ihrem Diskursbegriff konsequenter über das Sprachliche hinaus - wenn auch in unterschiedlichem Ausmaß (ebenda). Dadurch verschwimmen die Grenzen zwischen Materialität und (sprachlichem) Diskurs, was sich bei Laclau/Mouffe (2015) in einem auf das Materielle erweitertem Diskursbegriff widerspiegelt.

\section{Verortung des diskurstheoretischen Ansatzes von Ernesto Laclau und Chantal Mouffe}

Die Diskurstheorie von Ernesto Laclau und Chantal Mouffe ist eng an das Konzept der Hegemonie gekoppelt, wodurch sie sich von anderen diskurstheoretischen Ansätzen unterscheiden. Sie orientieren sich dabei am Hegemoniebegriff Gramscis (s.u.), den sie radikalisieren. Sie etablieren Hegemonie als „Logik des Politischen“, die alle gesellschaftlichen und ökonomischen Bereiche durchdringt. Sie leisten damit erstmalig eine Verortung der Dekonstruktion im Feld der politischen Theorie, indem sie im Gegensatz zu marxistischen Ansätzen den Fokus von der ,ökonomischen Basis postmarxistisch auf das Politische“ verschieben (Marchart 1998a: 7). Durch ihre Verortung in der politischen Philosophie, ihren Beitrag zur Ontologie des Politischen und ihrer theoretischen Einordnung verschiedener politischer Phänomene, eignet sich die Diskurstheorie nach Laclau/Mouffe besonders für politische Analysen. Viele an Laclau/Mouffe orientierte Arbeiten untersuchen daher „die Entstehung und den Wandel politischer Diskurse“ (Nonhoff 2007: 173).

Ernesto Laclau und Chantal Mouffe setzen in ihrer Theorieentwicklung an einem Widerspruch im marxistischen Geschichtsverständnis an: Auf der einen Seite gehe Marx von Geschichte als objektivem Prozess aus, der durch die Abfolge verschiedener Systeme von Produktionsverhältnissen geprägt sei. Auf der anderen Seite betrachte Marx die Geschichte als permanente Geschichte der Klassenkämpfe. In diesem Widerspruch zwischen objektivem Prozess und der zentralen Stellung von Klassenkämpfen sieht Laclau eine Hauptursache der ,Krise des Marxismus“ (Laclau 2007: 25). Laclau/Mouffe lehnen die objektivistische Sichtweise auf Geschichte ab, weisen sozialen Antagonismen ${ }^{4}$ aber weiterhin eine zentrale Bedeutung $\mathrm{zu}-$ jedoch seien diese nicht mehr an den Orten fixiert, die ihnen durch das objektivistische Geschichtsverständnis zugewiesen worden waren (nämlich die Klassengrenzen). Nicht eine vermeintlich objektive Geschichte, sondern die antagonistischen Relationen selbst konstituieren das soziale Gewebe. In diesem Sinne verstehen Laclau/Mouffe sich als post-marxistisch (ebenda: 26). Wie im Marxismus gehen sie von einer fundamentalen Gespaltenheit der Gesellschaft aus, allerdings wird anders als im Gedanken des Klassenkampfes auf die Annahme einer „ontologisch privilegierten Stellung einer universalen Klasse“" verzichtet (Laclau/Mouffe 2015: 34). Dies wird teilweise als ein Verabschieden von der Kategorie Klasse missverstanden. Jedoch wird lediglich ihre universale Stellung aufgegeben; sie wird in die Komplexität und Vielschichtigkeit gesellschaftlicher Identitätsspiele und Machtverhältnisse eingebettet (Smith

3 Zur begrifflichen Bestimmung vgl. Kapitel 2.4.

4 Für eine genauere Auseinandersetzung mit dem Antagonismus-Begriff vgl. Kapitel 2.4. 
1998: 226). Der kämpferische Charakter der Politik bleibt bestehen (Distelhorst 2007: 71).

Im Gegensatz zu den teilweise heftigen Kritiken von marxistischer Seite in Reaktion auf ihre Veröffentlichungen, sahen Laclau/Mouffe ihre Diskurstheorie selbst eher als emanzipatorische Weiterentwicklung marxistischer Denkweisen:

„So können die Diskurse, die das Feld des klassischen Marxismus konstituieren, helfen, das Denken einer neuen Linken zu formen: durch Überliefern einiger ihrer Begriffe, Transformieren beziehungsweise Aufgeben anderer sowie durch ein Sich-Verdünnen in jene unendliche Intertextualität emanzipatorischer Diskurse, in der die Pluralität des Sozialen Gestalt annimmt“ (Laclau/Mouffe 2015: 35).

Von einer Sichtweise, die dem Klassen-Antagonismus eine zentrale Stellung zuweist, in der das Kapital als totale Kategorie die Gesellschaft strukturiert und das Soziale in der Ökonomie begründet ist, gelangen Laclau/Mouffe durch eine Radikalisierung Gramscis (vgl. Kapitel 2.5) „zu einer Sicht von Hegemonie, in der Machtverhältnisse Wiederholung, Kontingenz und Reartikulation unterworfen sind“ (Butler 1998b: 255). Strukturkategorien sind gemäß dieser Sichtweise kontingent und somit ohne Relation zu Zeit und Raum nicht denkbar. Gesellschaft ist demnach unbegründbar, bzw. letztlich immer offen, plural und kontingent. ${ }^{5}$ Mit dieser Perspektive dekonstruieren sie den ökonomischen Essentialismus des Marxismus, zeigen seine Brüche auf und decken auf, wie sich der Marxismus letztlich selbst der Hegemonie bediene, um den Eindruck der Kohärenz zu bewahren (bspw. in der Konstruktion einer vermeintlichen universellen Klassenidentität) (Distelhorst 2007: 70). ${ }^{6}$ Sie verfolgen einen deutlichen gesellschaftspolitischen Anspruch: Sie zeigen auf, dass und wie Strukturen mit Machtverhältnissen zusammenhängen, kontingent sind, also „das Ergebnis politischer Aushandlungsprozesse und damit prinzipiell veränderlich“ (Glasze/ Mattissek 2009a: 153). Das Aufdecken von vermeintlich natürlich Vorgegebenem, von Essentialismen, macht den Weg für eine emanzipatorische Praxis frei.

\subsection{DER DISKURSBEGRIFF NACH LACLAU/MOUFFE}

Laclau/Mouffe schließen in ihrem Diskursbegriff zwar an Foucault an, allerdings kritisieren sie die ihrer Meinung nach inkonsistente Unterscheidung Foucaults zwischen diskursiv und nicht-diskursiv und versuchen diese zu überwinden (Laclau/Mouffe 2015: 141). Foucault führt zur Unterscheidung von diskursiv und nicht-diskursiv den Begriff des „Dispositivs“ ein, kommt aber selbst bei der Abgrenzung in Schwierig-

5 Diese Sichtweise der beiden wurde auch entscheidend durch die Lebenserfahrung in lateinamerikanischen Gesellschaften beeinflusst, auf die das klassen-reduktionistische Denken des Marxismus schwer anwendbar ist (Torfing 1999: 15).

6 So würden nach Laclau/Mouffe im Marxismus Bewegungen wie der Feminismus „entweder als marginal beziehungsweise peripher in Bezug auf die Arbeiterklasse (dem aus orthodoxer Sicht fundamentalen Subjekt) oder als ein revolutionärer Ersatz für eine in das System integrierte Arbeiterklasse betrachtet [...]“ (Laclau/Mouffe 2015: 122). 
keiten und konstatiert, es sei „kaum von Bedeutung, zu sagen: das hier ist diskursiv und das nicht" (Foucault 1978: 125). Für Laclau/Mouffe gibt es kein dem Menschen direkt zugängliches Außerdiskursives. Ihr Diskursbegriff ist dabei sehr weit: Er „verwirft die Unterscheidung zwischen diskursiven und nicht-diskursiven Praxen und behauptet, dass [...] sich jedes Objekt insofern als Objekt eines Diskurses konstituiert, als kein Objekt außerhalb jeglicher diskursiver Bedingungen des Auftauchens gegeben ist“" (Laclau/Mouffe 2015: 140f.). Identität entstehe wie Bedeutung in Differenzbeziehungen, in Relationen zwischen Elementen - Identität ohne Relation, ohne Unterscheidung, sei nicht denkbar. Laclau/Mouffe betrachten auch das Soziale und das Politische als Differenzsysteme und fassen sie unter den Diskursbegriff. Damit soll nicht etwa ausgedrückt werden, dass alles Sprache sei oder sprachlich bestimmt werde, sondern, dass auch das Soziale und das Politische aus differentiellen Elementen bestehen, die nach den Regeln der strukturellen Linguistik untersucht werden können (Distelhorst 2007: 71f.). Laclau/Mouffe verwenden den Diskursbegriff also katachrestisch ,falsch ${ }^{67}$ : „That is to say, he [sic] 'creatively misapplies' the concept of discourse to encompass all dimensions of social reality and not just the usual practices of speaking, writing and communicating" (Howarth 2000: 116). Gleichzeitig wird so die Dichotomie zwischen sprachlich/geistig versus nicht-sprachlich/materiell subvertiert. Die weithin verbreitete Annahme ,eines geistigen Charakters des Diskurses“ wird verworfen und demgegenüber ,der materielle[...] Charakter jeder diskursiven Struktur bekräftig[t]“. Weder sei Diskurs der „reine[...] Ausdruck des Denkens“, noch gebe es ein nicht von sprachlichen Diskursen beeinflusstes „objektive[s] Feld“ (Laclau/Mouffe 2015: 142). Dabei verweisen sie auf Wittgenstein, dessen Sprachspiele sowohl Sprache als auch materielle Eigenschaften enthalten. So begründe sich die relationale Identität eines Bausteins nicht auf einer geistigen Idee von „Baustein“, sondern auf den Baustein als materiellen Gegenstand - mit der Idee eines Bausteins könne kein Haus gebaut werden. Sprachliche und Nicht-sprachliche Elemente stehen dabei nicht einfach nebeneinander, „sondern konstituieren ein differentielles und strukturiertes System von Positionen, das heißt einen Diskurs“ (ebenda: 143), wobei materielle Elemente in den differentiellen Positionen verstreut seien. Die materielle Welt ist demnach also nicht als dem Diskurs vorgelagert, nicht als Konstante außerhalb des Diskurses, zu sehen, sondern als Teil des Diskursbegriffs (ebenda: 142f.). Neben Sprache wird also auch die nicht-sprachliche materielle Welt als an Diskursen beteiligt betrachtet, wobei beide gleichzeitig auch vom Diskurs mit geformt werden und sich nicht außerhalb von diesem befinden.

Die Untergrabung der Dichotomie diskursiv/außerdiskursiv beinhalte also nicht, abzustreiten, dass es „,eine Welt außerhalb unseres Denkens gibt“, oder dass die Welt vor den Diskursen dagewesen wäre:

7 D.h. der Diskursbegriff wird bei Laclau/Mouffe absichtlich fehlerhaft, bzw. bedeutungsverschiebend verwendet. Castro Varela/Dhawan (2015: 154) beschreiben die Katachrese als diskursive Strategie: „Die Katachrese hingegen verschiebt spezifische Bilder und rhetorische Strategien innerhalb einer Erzählung, um sie dann zur Eröffnung neuer Bedeutungsfelder und -funktionen, die im Kontrast zu einem konventionellen Verständnis stehen, freizugeben". 
„Ein Erdbeben oder der Fall eines Ziegelsteins sind Ereignisse, die zweifellos in dem Sinne existieren, dass sie hier und jetzt unabhängig von meinem Willen stattfinden. Ob aber ihre gegenständliche Spezifik in der Form von ,natürlichen Phänomenen` oder als ,Zornesäußerung Gottes' konstruiert wird, hängt von der Strukturierung des diskursiven Feldes ab. Nicht die Existenz von Gegenständen außerhalb unseres Denkens wird bestritten, sondern die ganz andere Behauptung, dass sie sich außerhalb jeder diskursiven Bedingung des Auftauchens als Gegenstände konstituieren könnten“" (ebenda: 142).

Daraus folgt zum einen, dass Artikulation als Praxis kein rein sprachliches Phänomen ist, sondern eine materielle Dimension hat. Zum anderen wird ein Diskurs nicht auf ein begründendes Subjekt zurückgeführt, sondern es erfolgt die Annahme, dass Subjektpositionen in der ,diskursiven Formation verstreut“ seien, es also keine Konstitutionsebene außerhalb von Diskursen gebe (ebenda: 143). „Die wichtigste Konsequenz" der Untergrabung der Dichotomie diskursiv/außerdiskursiv sei „die Preisgabe des Gegensatzes von Denken und Wirklichkeit“ (ebenda: 144). Damit werde auch deutlich, dass herkömmlich dem Bereich des Denkens zugeordnete Kategorien tatsächlich dem Terrain des Sozialen zuzuordnen seien und dieses mit konstituieren. Denken, Diskurs und Wirklichkeit durchdringen sich gegenseitig (ebenda). Wo das eine aufhört und das andere anfängt, könne nicht festgestellt werden.

Hier verdeutlicht sich die potenziell fruchtbare Verbindung eines solchen Diskursbegriffes zum „,neuen Denkraum“ der Sozialen Ökologie (Becker/Jahn 2006: 187), auf die ich in Kapitel 1 verwiesen habe: Ein mit Laclau/Mouffe entwickelter Diskursbegriff beschränkt sich weder auf die sprachliche Welt, noch auf die außersprachliche materielle/physische Welt, er beinhaltet beides. Insofern geht er mit dem Anspruch des „Weder-nochs“ und „Sowohl-als-auchs“ der Sozialen Ökologie konform. ${ }^{8}$ Ebenso wie das „Weder-noch“ und „Sowohl-als-auch“ gegenüber dem methodischen Dualismus, mag ein solcher Diskursbegriff gegenüber einem sprachlichen Diskursbegriff zunächst weniger logisch oder gar widersprüchlich erscheinen. Einer solchen Kritik lässt sich analog zur Sozialen Ökologie begegnen: „Die Paradoxien und Widersprüche des Weder-noch und des daraus hervorgehenden Sowohl-als-auch sind in diesem Denkraum nicht Ausdruck einer begrifflichen Schwäche, sondern der Sache angemessene Formulierungen. Dadurch wird viel theoretische Phantasie freigesetzt [...]“ (ebenda). Ein solcher Diskursbegriff verkörpert von Anfang an die Widersprüchlichkeiten und Paradoxien dieses Zusammendenkens, er ist materiellsymbolisch geprägt und adressiert sowohl Deutung als auch Wirkung (vgl. ebenda). Er birgt nach meiner Auffassung somit besonderes Potenzial für die sozialökologische Forschung, indem Probleme als sozial-ökologische Probleme gestellt

8 Das „Weder-noch“ und „Sowohl-als-auch“ bezieht sich auf die eingangs formulierte (vgl. Kapitel 1) doppelseitige Kritik der Sozialen Ökologie am Naturalismus sowie am Kulturalismus/Soziozentrismus: „Sozial-ökologische Krisenphänomene [...] lassen sich weder als Vergesellschaftung der Natur noch als eine Naturalisierung der Gesellschaft angemessen beschreiben und verstehen. Sie fallen sowohl in den Bereich einer vergesellschafteten Natur als auch in den einer naturalisierten Gesellschaft. Wir versuchten also, das logisch so klare Entweder-oder des methodischen Dualismus durch die logisch wenig eindeutigen Formulierungen Weder-noch und Sowohl-als-auch zu ersetzen“ (Becker/Jahn 2006: 187). 
werden können und „nicht als voneinander getrennte ökologische und soziale“ (ebenda). ${ }^{9}$ Die Diskurstheorie nach Laclau/Mouffe ist also ,nicht primär eine Diskurstheorie [im herkömmlichen Verständnis], sondern eine Sozialtheorie und eine Politische Theorie, die das Soziale im Modus der Diskursivität verfasst sieht“ (Nonhoff 2007: 8). ${ }^{10}$

Für eine politische feministische Forschung erscheint ein nach Laclau/Mouffe entwickelter Diskursbegriff sehr produktiv: Zum einen hat seine Verwendung Folgen für den Blick auf Geschlechtsidentität selbst. Genauso wie ein Stein, der eben nicht als diskursive Fiktion betrachtet wird, besitzt auch die Geschlechterdifferenz bei Laclau/Mouffe ontologischen Status. „Die Besonderheit dieses ontologischen Status liegt jedoch darin, als eine unentwirrbare Mischung aus Natur und Kultur nicht erkannt werden zu können, was jeden Diskurs über die Geschlechterdifferenz [...] in eine Narration verwandelt“ (Distelhorst 2007: 142). Die Geschlechterdifferenz existiere, ist aber in ihrer Materialität für uns nicht direkt fassbar. Um ,auf die Ebene des Seins“ zu gelangen, müsse sie diskursiv eingebettet werden, wobei die Differenzrelationen mit der sie verknüpft werde, gleichzeitig darüber entscheiden, was sie sei (ebenda: 142f). Laclau/Mouffe weisen den Vorwurf des Idealismus zurück: Das Reale sei lediglich nicht direkt zugänglich, die Idee von Natur das Ergebnis einer langen historischen sozialen Konstruktion (Mouffe 2001: 14). An dieser Stelle kann mit dem materiellen Diskursbegriff von Laclau/Mouffe eine häufig an Judith Butler ${ }^{11}$ geäußerte Kritik konstruktiv gewandelt werden: Obwohl Butler wie Laclau/Mouffe der Anatomie ontologischen Status zuweist (vgl. Kapitel 2.5), also nicht die Körperlichkeit an sich abstreitet, sondern lediglich den direkten Zugang $\mathrm{zu}^{\mathrm{ihr}}{ }^{12}$ sowie die Möglich-

9 Dies ist zumindest in der Theorie der Fall. Welche Herausforderungen sich für eine forschungspraktische Anwendung eines solchen Diskursbegriffes zeigen, wird im späteren Verlauf der Arbeit reflektiert.

10 Hier gehen Laclau/Mouffe auch über die Diskurstheorie von Judith Butler hinaus, die zwar die Performativität von Diskursen und damit ihre materielle Wirkmächtigkeit hervorhebt, in ihrem Diskursbegriff im Anschluss an Foucault aber sprachfixiert bleibt (Butler 1995: 124f; 129; Distelhorst 2007: 59).

11 Zwischen beiden Ansätzen gibt es zahlreiche Gemeinsamkeiten aber auch Unterschiede (für eine vergleichende Auseinandersetzung vgl. Distelhorst 2007), die Autor*innen verbindet ein langer intellektueller Austausch. Mein Ziel ist es dabei nicht verschiedene Ansätze gegeneinander auszuspielen oder den teilweise erbittert geführten Kampf zwischen Poststrukturalismus, Strukturalismus und Kritischer Theorie zu reproduzieren. Ich plädiere vielmehr mit Nancy Fraser für ein vermittelndes Arbeiten mit dem Ziel ,„die besten Bestandteile eines jeden Paradigmas zu wahren, um dadurch den Boden zu bereiten für ihre fruchtbare Integration in feministische Theoriebildung" (Fraser 1995: 60).

12 „The body as posited as prior to the sign, is always posited or signified as prior. This signification produces as an effect of its own procedure the very body that it nevertheless and simultaneously claims to discover as that which precedes is own action. [...] This is not to say that materiality of bodies is simply and only a linguistic effect which is reducible to a set of signifiers. [...] To posit by way of language a materiality outside of language is still to posit that materiality, and the materiality so posited will retain that positing as its constitutive condition“ (Butler 1993: 30). 
keit daraus eine ,natürliche‘ Zweigeschlechtlichkeit, bzw. Geschlechtsidentität abzuleiten ${ }^{13}$ (Distelhorst 2007: 142f; von Redecker 2011: 67ff.; Butler 1991: 37ff., 1993: 28ff.), gerät durch die Sprachfixierung in der Dekonstruktion der Sex/Gender Dichotomie letztlich die Dimension der Körperlichkeit aus dem Blick. Dies brachte ihr z.B. von Barbara Duden in „die Frau ohne Unterleib“ den Vorwurf der „Entkörperung“, also der Beseitigung der Körperlichkeit insgesamt, ein (Duden 1993). Butler sei so nicht in der Lage, körperliche Artikulationen zu denken, ,die nicht aus dessen sozialdiskursiver Konstruiertheit herrühren"; sie umgehe das Problem der Körperlichkeit ständig (Distelhorst 2007: 37). ${ }^{14}$ Damit verbunden sei eine Überbetonung des sprachlichen Diskurses bei Butler sowie ein Vernachlässigen von Gerechtigkeitsthemen und eine Unmöglichkeit, politische Forderungen zu entwickeln, für deren Begründung die Vorstellung von (auch körperlichem) Leiden zentral seien (ebenda: 40). ${ }^{15}$ Durch die Untergrabung der Dichotomie diskursiv/außerdiskursiv bei Laclau/Mouffe dagegen wird die Körperlichkeit in den Diskursbegriff integriert. Welcher Teil einer Erfahrung aber körperlich bestimmt ist und welcher Teil sprachlich geprägt, sei nicht fassbar, sei unentwirrbar. Diese Sichtweise hat Sprengkraft, da sie (nicht nur sexuelle) Erfahrungen entnaturalisiert und politisiert. Die damit verbundenen Herausforderungen stellen sich weniger theoretisch als vielmehr in der forschungspraktischen Analyse, in der das Materielle häufig weniger zugänglich ist als das Sprachliche und daher erneut die Gefahr einer Sprachfixierung aufkommt (vgl. Kapitel 4.4 Kritische Reflexion).

13 „Ja, möglicherweise ist das Geschlecht (sex) immer schon Geschlechtsidentität (gender) gewesen [...]. Die Geschlechtsidentität umfasst auch jene diskursiven/kulturellen Mittel, durch die eine ,geschlechtliche Natur' oder ein ,natürliches Geschlecht‘ als ,vordiskursiv', d.h. als der Kultur vorgelagert oder als politisch neutrale Oberfläche [...] hergestellt und etabliert wird" (Butler 1991: 24).

14 Distelhorst merkt allerdings an, dass es Butler darum ginge die feministische Theorie aus einer Sackgasse zu holen, da sie es (zum damaligen Zeitpunkt) nicht schaffte „das eigene Postulat, Biologie sei kein Schicksal, zu Ende zu denken“ und Butlers Anliegen liege darin hier einen Befreiungsschlag zu vollziehen, um dem Feminismus seine Sprengkraft wiederzugeben. Vor diesem Hintergrund sei eine Überbetonung des Sprachlich-Diskursiven zunächst notwendig gewesen, um die Debatten zu beleben (Distelhorst 2007: 47).

15 Obwohl sie sich selbst in „Bodies that matter“ verstärkt mit dieser Kritik auseinandersetzt (Butler 1993: 28ff.): „Against the claim that poststructuralism reduces all materiality to linguistic stuff, an argument is needed to show that to deconstruct matter is not to negate or do away witht the usefulness of the term. And against those who would claim that the body's irreducible materiality is a necessary precondition for feminist practice, I suggest that that prized materiality may well be constituted through an exclusion and degradation of the feminine that is profoundly problematic for feminism. [...] To call a presupposition into question is not the same as doing away with it; rather, it is to free it from its metaphysical lodgings in order to understand what political interests were secured in and by that metaphysical placing, and thereby to permit the term to occupy and to serve very different political aims. To problematize the matter of bodies may entail an initial loss of epistemological certainty, but a loss of certainty is not the same as political nihilism“ (Butler 1993: $30)$. 
Darüber hinaus zeigt der Diskursbegriff nach Laclau/Mouffe auch über die Geschlechterdifferenz hinausgehende Trennungsstrukturen auf und verweist auf Wege, diese zu überwinden. Denn mit einem solchen Diskursbegriff lassen sich nicht nur herkömmlich dem Sozialen zugeordnete Grenzziehungsprozesse aufdecken und analysieren, sondern vermeintliche Naturalisierungen aufbrechen. Mit dem Diskursbegriff nach Laclau/Mouffe lassen sich „Gesellschaft/Umwelt- bzw. Mensch/NaturBeziehungen neu interpretieren“ und es kann analysiert werden, „wie jeweils die Grenze zwischen Mensch und Natur, bzw. Gesellschaft und Umwelt gezogen wird“, wie also in Abhängigkeit eines spezifischen diskursiven Kontextes Natur konstituiert wird (Glasze/Mattissek 2009b: 16f.). Eine um Geschlechterperspektiven erweiterte Diskurstheorie ermöglicht dabei die Analyse und das Aufdecken von Trennungsstrukturen und Hierarchisierungen in Verbindung mit Geschlechterverhältnissen. Sie verbindet die Kritik an diesen Strukturen mit integrativen Perspektiven, wie zum Beispiel dem dieser Arbeit zugrunde liegenden Konzept des Vorsorgenden Wirtschaftens.

Durch einen derartigen Diskursbegriff birgt die politische Diskursanalyse umfangreiche Potenziale für Analysen politischer Prozesse: Wenn Diskurse nicht nur sprachlich, sondern auch materiell und körperlich sind, wenn Diskurse das herstellen, was wir als Wirklichkeit wahrnehmen, ,dann ist die Frage, wie der Diskurs strukturiert ist, ausschlaggebend dafür, wie Menschen ihr Leben führen können“ (Distelhorst 2007: 54).

Die Eignung der Laclau/Mouffe'schen Diskurstheorie für eine feministische, sozial-ökologische Transformationsforschung sehe ich vor allem im dargestellten Charakter des Diskursbegriffes sowie seiner hegemonietheoretischen Verortung begründet. Bevor ich näher auf diese Verortung eingehe, werde ich im Folgenden in die Grundbegriffe der Diskurstheorie einführen.

\subsection{GRUNDBEGRIFFE DER DISKURSTHEORIE NACH LACLAU/MOUFFE}

\section{Momente und Elemente}

In ihrem Diskursbegriff schließen Laclau/Mouffe an Foucault und Derrida an und geben die Vorstellung der Möglichkeit, Bedeutung dauerhaft $\mathrm{zu}$ fixieren, auf (Laclau/Mouffe 2015: 139ff.). Diskurs ist für sie ein „System differentieller Entitäten“, die sie „Momente“ nennen (ebenda: 146). Die Bedeutung von „Momenten“ ist dabei in einem bestimmten Diskurs temporär fixiert, Elemente dagegen bezeichnen all jene Bedeutungen, die existieren oder existiert haben, beispielsweise in anderen Diskursen. Die Unterscheidung zwischen Elementen und Momenten dient also analytisch auch der Lokalisierung von Entitäten außerhalb oder innerhalb eines Diskurses (Glasze/Mattissek 2009a: 159). 


\section{Artikulation und Diskurs}

Artikulation ist ,jede Praxis, die eine Beziehung zwischen Elementen so etabliert, dass ihre Identität als Resultat einer artikulatorischen Praxis modifiziert wird. Die aus der artikulatorischen Praxis hervorgehende strukturierte Totalität nennen wir Diskurs“ (Laclau/Mouffe 2015: 139). In Diskursen geht es darum, Elemente in Momente umzuwandeln, indem ihre Bedeutung (temporär) fixiert wird.

\section{Identität}

Doch wie wird der Zusammenhang zwischen diskursiven Entitäten hergestellt, bzw. wie lassen sich Diskurse abgrenzen? Im Hinblick auf die Kohärenz einer diskursiven Formation beziehen sich Laclau/Mouffe auf Foucaults „Regelmäßigkeit in der Verstreuung“, wonach „die Verstreuung selbst zum Prinzip der Einheit“ wird. So werde durch ein regelmäßiges In-Beziehung-Setzen von Elementen der Eindruck eines ,natürlichen“ bzw. wirklichen Beziehungssystems erweckt (ebenda: 141). Identität ist dabei eine Struktur, die verschiedene artikulierte Elemente zumindest temporär verbindet und dadurch „Einheit und Zugehörigkeit vor dem Hintergrund der Vielschichtigkeit sozialer Bruchlinien schafft“ (Glasze/Mattissek 2009a: 162).

Der Übergang von Elementen zu Momenten könne aber niemals vollständig sein. „Der Status der ,Elemente“ ist der von flottierenden Signifikanten, die nicht gänzlich zu einer diskursiven Kette artikuliert werden können“ (Laclau/Mouffe 2015: 148). Dadurch scheine ein „Niemandsland“ hervor, das die Arena für die artikulatorische Praxis eröffne. Es gebe daher keine gesellschaftliche Identität, die vollständig abgeschlossen sei, die kein diskursives Äußeres habe, die nicht kontingent sei, die nicht jederzeit durch ein Äußeres umgeformt werden könne. Identität sei rein relational, sie könne nicht „,vollkommen konstituiert werden“ (ebenda: 145). Laclau/Mouffe konzeptualisieren die Identität von Gruppen also nicht essentialistisch, sie verzichten auf die Vorstellung naturalisierter Wesensmerkmale (Glasze 2008: 5). Ein Schwerpunkt der Diskurstheorie von Laclau/Mouffe liegt daher auf der Untersuchung der Art und Weise der diskursiven Konstitution von Identitäten, welche als „,maßgeblich für die Frage" betrachtet wird, welche Themen wie politisch verhandelt werden und welche nicht oder welche sozialen Grenzziehungen stattfinden (Glasze/Mattissek 2009a: 153f.). Sie berufen sich dabei auf Althussers Konzept der Anrufung (Althusser 1977), wonach Individuen durch Institutionen, d.h. ideologische Staatsapparate, Subjektpositionen (wie Arbeiterin, Studentin etc.) zugewiesen werden. Die ideologischen Staatsapparate verdecken bei Althusser die ,wahren', ökonomisch determinierten, sozialen Beziehungen - das Ideologische verdecke die Realität. Laclau/Mouffe verwerfen die Vorstellung der ökonomischen Determinierung von Subjektpositionen und damit auch den marxistischen Ideologiebegriff und ersetzen ihn durch ihren Diskursbegriff. Individuen (die wie bei Althusser nicht als autonom betrachtet werden) werden von verschiedenen Diskursen ,,angerufen“ (z.B. Mann, Frau, weiß, schwarz, etc.) (Glasze/Mattissek 2009a: 162). „Identität ist für Laclau und Mouffe die Identifikation mit einer diskursiv konstituierten Subjektposition“ (ebenda: 162f.), die letztlich aber immer scheitere, da sie nur temporär fixiert werden könne. Eigentlich ideologisch sei es dagegen, eine soziale Ebene zu behaupten, die auf einer objektiven Wahrheit beruhe (Distelhorst 2007: 109). 


\section{Knotenpunkte und Äquivalenzkette}

Im „Feld der Diskursivität“ gibt es einen Bedeutungsüberschuss, der den Diskurs als „System differentieller Entitäten“ untergräbt, indem er die letztliche Unmöglichkeit seiner Schließung, der endgültigen Fixierung von Bedeutung, aufzeigt. Im „Feld der Diskursivität“ konstituiert sich die soziale Praxis, denn ,[j]edweder Diskurs konstituiert sich als Versuch, das Feld der Diskursivität zu beherrschen, das Fließen der Differenzen aufzuhalten, ein Zentrum zu konstruieren“ (Laclau/Mouffe 2015: 147).

Auf diese Art und Weise werden Knotenpunkte konstruiert, die privilegierte Signifikanten innerhalb einer Signifikantenkette darstellen und deren Bedeutung partiell fixieren. Laclau/Mouffe beziehen sich hier auf den Psychoanalytiker Jacques Lacan, der in diesem Zusammenhang die Vorstellung von „Stepp-Punkten“ verwendet, die so wie privilegierte Signifikanten die Bedeutung der Signifikantenkette partiell fixieren, das Polster einer Couch festhalten (ebenda). Die Signifikantenkette bezeichnen Laclau/Mouffe als Äquivalenzkette, da die Signifikanten in eine Äquivalenzbeziehung gebracht werden, obwohl sie keinen gemeinsamen essentiellen Wesenskern besitzen. Laclau/Mouffe wählen zur Verdeutlichung des Äquivalenzverhältnisses das Beispiel der Kolonisierung: Die Kolonialmacht sei durch Unterschiede in der Sprache, der Sitten oder der Hautfarbe etc. sichtbar. „,[J]eder dieser Inhalte [ist] mit den anderen durch ihre gemeinsame Unterscheidung vom kolonisierten Volk äquivalent“ (ebenda: 164), wodurch die Äquivalenz den Effekt der Auflösung der Differenzen zwischen den Inhalten erzeuge: Zwischen den vermeintlichen Eigenschaften der Kolonialmacht bestehe ein ,identisches Etwas', das nur in der Abgrenzung vom ,Anderen' bestehen kann. Das Äquivalenzverhältnis produziere demnach eine rein negative Identität, die Kolonialmacht werde diskursiv zum Nicht-Kolonisierten (ebenda). Gleichzeitig wird das ,identische Etwas` weniger konkret gesehen, je länger die Äquivalenzkette ist. „Im Grenzfall wird es zu reinem gemeinschaftlichen Sein, unabhängig von jeder konkreten Manifestation“, zur reinen Idee von Gemeinschaft, das Außen zur reinen ,Anti-Gemeinschaft‘, zum reinen Bösen (Laclau 2002: 72f).

Die Knotenpunkte einer Äquivalenzkette stellen gleichzeitig die Grenze des Diskurses dar. So kann beispielsweise der Signifikant Mann als Knotenpunkt innerhalb des Patriarchatsdiskurses gelten. Er wird in einer Äquivalenzkette mit Signifikanten wie Mut oder Stärke als privilegierter Signifkant mit Bedeutung aufgeladen, fixiert selbst die Bedeutung der Kette partiell und repräsentiert gleichzeitig die Grenze zum unbenannten diskursiven Außen (Glasze/Mattissek 2009a: 163). Der Knotenpunkt „bricht die Logik der Differenz und ermöglicht so die Logik der Gleichheit zwischen den Mitgliedern der Gruppe“ (Glasze 2008: 193). Dahinter steht in Anschluss an Lacan der stete Wunsch nach Ganzheit, die Vorstellung eines vollständigen, autonomen Subjekts, das aber unmöglich sei, da Identität nicht endgültig fixiert werden könne (Glasze/Mattissek 2009a: 164).

\section{Das konstitutive Außen und der Antagonismus}

Das Außen sei dabei sowohl Existenzbedingung für das Innen und gleichzeitig gefährdet es seine Identität, muss also ausgeschlossen werden. Laclau/Mouffe bezeichnen es daher im Anschluss an Derrida (1972) und Staten (1986: 16) auch als das 
,konstitutive Außen ${ }^{16}$ (Laclau 1990: 9; Mouffe 2000: 147). Identität oder Gemeinschaft konstituiert sich demnach also einerseits durch einen antagonistischen Ausschluss des ,Anderen', andererseits zeigt das Außen so die Kontingenz der eigenen Identität auf, da das Innen nur durch Abgrenzung vom Außen existiert. So verunmöglicht das Außen die letztliche Schließung von Identität (Glasze/Mattissek 2009a: 164). Identitätsbildung impliziert also auch immer das Errichten von Differenz, was häufig in Form von Hierarchien geschieht (z.B. Mann/Frau, weiß/schwarz, etc.) (Mouffe 2001: 15). Laclau/Mouffe konkretisieren die Vorstellung eines solchen Systems der diskursiven Abgrenzung mit dem Begriff des Antagonismus. ${ }^{17}$

Das Bedürfnis eines ganzen Ichs, einer vollkommenen Gemeinschaft könne also nicht gestillt werden weshalb es auf das antagonistische Außen projiziert werde. Da die Gemeinschaft/ die Identität nichts zusammenhalte als der gemeinsame Bezug auf den antagonistischen Gegner, würde sie zerfallen, wäre ein Sieg über das ,Andere‘ möglich oder würde sie aufhören sich vom ,Anderen“ abzugrenzen (Glasze/Mattissek 2009a: 164). Diese ,antagonistische Zweiteilung des diskursiven Feldes“ befeuert die Diskursproduktion - die „Gemeinschaft kann nicht aufhören, gegen ihr Anderes anzukämpfen bzw. sich immer wieder neue Andere zu suchen“(ebenda).

\section{Der leere Signifikant}

„Das zur eigenen Identität gehörende Lager lässt sich aufgrund der Präsenz der antagonistischen Kraft nicht um die eigene ontische Partikularität schließen: und so muss es sich einerseits durch eine Äquivalenzkette zwischen den eingeschlossenen Inhalten signifizieren und andererseits durch die Produktion eines leeren Signifikanten, der kein Signifikat hat, weil er die unmögliche Fülle der Gemeinschaft repräsentiert [...]“ (Laclau 2007: 31).

Dieser Signifikant, der gemäß des Zitates die Gemeinschaft repräsentiert, werde derart mit Bedeutung aufgeladen, dass er gleichzeitig jede spezifische Bedeutung verliere. Er stehe für das Universelle, obwohl er selbst partikular sei (Glasze 2008: 193). Als Beispiel nennt Laclau den Signifikanten ,Arbeiterkampf ${ }^{*}$, der im Zuge der russi-

16 Derrida verwendet diesen Begriff noch nicht. Staten (1986) entwickelt ihn in Anschluss an Derrida.

17 Laclau/Mouffe definieren den Begriff des Antagonismus in Abgrenzung zum Widerspruch und zur Realopposition: Im Falle des Antagonismus hindere mich „[d]ie Präsenz des „Anderen“ [...] daran, gänzlich Ich selbst zu sein. Das Verhältnis entsteht nicht aus vollen Totalitäten, sondern aus der Unmöglichkeit ihrer Konstitution. [...] Insofern es einen Antagonsismus gibt, kann ich für mich selbst keine vollständige Präsenz sein. Aber auch die Kraft, die mich antagonisiert, ist keine solche Präsenz: ihr objektives Sein ist ein Symbol meines Nicht-Seins und wird auf diese Art und Weise von einer Pluralität von Bedeutungen überflutet, die verhindern, dass es als volle Positivität fixiert wird. Realopposition ist ein objektives, also bestimmbares und definierbares Verhältnis zwischen Dingen; Widerspruch ist ein ebenso definierbares Verhältnis zwischen Begriffen; Antagonismus hingegen konstituiert die Grenzen jeder Objektivität, die sich als partielle und prekäre Objektivierung enthüllt. [...] Der Antagonismus entzieht sich der Möglichkeit, durch Sprache erfasst zu werden, da ja Sprache nur als Versuch einer Fixierung dessen existiert, was der Antagonismus untergräbt“" (Laclau/Mouffe 2015: 161f.). 
schen Revolution zur Einschreibungsfläche für sämtliche Befreiungskämpfe wurde, dabei aber seine ursprüngliche, spezifische Bedeutung verlor (Laclau 2002: 76f.). Der leere Signifikant bestimme letztlich die Gemeinsamkeit über die Abgrenzung zum Außen (Glasze 2008: 193). Dass ein zunächst partikularer Signifikant das Universelle repräsentieren könne, sei das Ergebnis eines hegemonialen Prozesses: „eine bestimmte Partikularität transformiert ihren eigenen Körper in die Repräsentation einer inkommensurablen Totalität“ (Laclau 2007: 30). Damit wird die „Präsenz leerer Signifikanten“ sogar als „die eigentliche Bedingung für Hegemonie“ betrachtet (Laclau 2002: 74). Welche Signifikanten, zu welcher Zeit und an welchem Ort mit welcher Bedeutung gefüllt werden, um als leere Signifikanten zu dienen, werde von hegemonialen Verhältnissen bestimmt (Glasze 2008: 193), „verschiedene politische Kräfte" konkurrieren darum ihre partikularen Ziele als universelle Erfüller eines Mangels zu repräsentieren (Laclau 2002: 76). „Hegemonisieren bedeutet genau diese Füllfunktion zu übernehmen“" (ebenda).

\subsection{GESELLSCHAFTS-, HEGEMONIE- UND POLITISCHE THEORIE NACH LACLAU/MOUFFE}

\section{Gesellschaft und Subjekt}

Aus diesem Identitätsverständnis folgen zentrale Annahmen für das Subjekt und die Gesellschaft. Laclau/Mouffe wenden sich von klassischen akteurs- bzw. gesellschaftszentrierten Ansätzen ab.

Während der Begriff der*s Akteur*in die aktive, also durch (selbstbestimmtes) Handeln geprägte, Dimension des Subjekts in den Vordergrund stelle, beinhalte ein diskurstheoretischer Subjektbegriff neben dem Subjekt, das artikuliert, auch das Subjekt, das artikuliert wird (Bedall 2014: 51; Nonhoff 2006: 172). ${ }^{18}$ Die Subjektkategorie wird als genauso unvollständig und offen wie jede diskursive Identität bewertet. Ein ,sinnstiftendes Subjekt“, das in der Lage wäre Identität zu stiften bzw. zu schließen, gebe es nicht, da dieses Subjekt genauso durchdrungen von Unsicherheit wäre wie die diskursive Totalität insgesamt. Die Subjektpositionen seien aber nicht bloß im Diskurs verstreut, sie lassen sich auch nicht eindeutig abgrenzen, da sie selbst diskursiv konstruiert und überdeterminiert seien. Verschiedene Subjekte können sich mit gleichen oder ähnlichen Subjektpositionen identifizieren, bzw. von einem Diskurs ,angerufen' werden. Dadurch scheine am Horizont eine (unmögliche) Totalität auf, die hegemoniale Artikulation ermögliche (Laclau/Mouffe 2015: 157).

Der Subjektbegriff hat sich bei Laclau im Laufe der Zeit gewandelt - von einer eher strukturalen Position hin zu einer psychoanalytischen Sicht im Anschluss an Lacan: Da sich Identität nicht schließen lasse, sie nur durch den Bezug auf ein konstitutives Außen bestehe, also nicht auf einen essentialistischen Wesenskern zurückgeführt werden könne, sei „das Subjekt ein Mangel an Sein, es trachtet auch danach, diesen Mangel zu beheben, indem es sich mit Positionen in der symbolischen Ord-

18 Der Begriff Akteur*in wird in der vorliegenden Arbeit dennoch verwendet, wird aber in diesem diskurstheoretischem Sinne verstanden. D.h. Akteur*innen stehen nicht außerhalb der diskursiven Struktur, sondern sind Teil von ihr. 
nung identifiziert, um zu einer Schließung seiner Identität zu gelangen“(Distelhorst 2007: 87). Aus dem Begehren heraus, diesen Mangel an Sein zu schließen, binde sich das Subjekt an leere Signifikanten, die „die Fülle der Gemeinschaft“ versprechen. Doch genau an diesem Punkt scheitere das Subjekt: Zwar finde es eine „relativ stabile Repräsentation“ (ebenda), doch der leere Signifikant sei nicht in der Lage, seiner Singularität gerecht zu werden. So befinde sich das Subjekt in einem steten Teufelskreis, denn weder könne der Mangel an Sein je behoben, noch sein Begehren nach Vollständigkeit erfüllt werden, weshalb es stets seine zum Scheitern verurteilten Identifikationsprozesse von Neuem aufnehme (ebenda).

Das Subjekt wird also als nicht fest angesehen, weshalb es in der Diskursanalyse als sinnvoll erachtet wird, von Subjektpositionen und nicht von Subjekten zu sprechen, da alle Erfahrungen, die Subjekte machen, wiederum von den „diskursiven Bedingungen ihrer Möglichkeit“ (Laclau/Mouffe 2015: 150) abhängen. Subjekte seien nicht „der Ursprung sozialer Verhältnisse“, da sie selbst von diskursiven Strukturen abhängen (Laclau/Mouffe 2015: 150).

In diesem Zusammenhang wird an Laclau/Mouffes Theorie verschiedentlich kritisiert, dass sie politisches Handeln für den Feminismus verunmögliche, da ,die Frau“ als handelndes Subjekt verloren gehe (für eine umfassende Auseinandersetzung mit dieser Kritik vgl. Butler/Scott 1992). Eine Frauenbewegung erfordere Kohärenz von Identität mit definierbaren homogenen Interessen und nicht Kontingenz, wie bei Laclau/Mouffe, die feministischer Politik den Boden entziehe (Mouffe 1992: 381). Chantal Mouffe entgegnet dieser Kritik, dass ihre Sicht auf Identität emanzipatorisches Potenzial für die feministische Bewegung biete, da sie erst zum Verständnis ihres Kampfes beitrage. Denn erst, wenn sich die Kategorie ,Frau' nicht mehr auf eine homogene Wesenheit beziehe, gehe es nicht mehr darum ,eine Natur der Frau' im Gegensatz zum Mann herauszudestillieren, sondern darum zu analysieren, wie die Kategorie ,Frau', wie Geschlechterdifferenz, kulturell verschieden diskursiv konstruiert wird, wie dadurch Unterordnungsverhältnisse geschaffen werden, welche Rolle Machtverhältnisse spielen (Mouffe 2001: 18f.). Dadurch werden die historischen Bedingungen sichtbar, unter denen ,Frau' als Kategorie konstruiert werde. Individuen seien weder rational handelnd, noch sich selbst transparent, sie seien in ihren Positionen nicht homogen, in ihren Beziehungen vielschichtig. Ein Individuum könne sowohl herrschend und in einer anderen Beziehung Herrschaft unterworfen sein. Werde die Vorstellung einer homogenen Wesenheit ,Frau“ im Gegensatz zu einer homogenen Wesenheit ,Mann“ aufgegeben, werde „[d]as ganze falsche Dilemma ,Gleichheit gegen Differenz ${ }^{6}[\ldots]$ auseinandergesprengt“, rücke die „Vielfalt gesellschaftlicher Beziehungen" in den Blick, in denen Geschlechterdifferenz auf unterschiedliche Weise konstruiert werde und Unterdrückungsverhältnisse auf unterschiedliche Weisen bekämpft werden müssen (ebenda). „Unterordnung“ sei kein einfacher Mechanismus oder „Ausdruck eines unveränderlichen weiblichen Wesens“ (Laclau/Mouffe 2015: 153), sondern werde durch die verschiedenen gesellschaftlichen Praxen, die weibliches Geschlecht (sex) mit gesellschaftlicher Frauenrolle (gender) verbinden, hergestellt (Laclau/Mouffe 2015: 153; Mouffe 1992). Wo sex aufhört, gender anfängt und umgekehrt sei daher immer auch diskursiv bestimmt.

Obwohl Subjekte von diskursiven Strukturen abhängen, bedeute das nicht, dass sie handlungsohnmächtig seien; es komme ihnen dennoch eine politische Rolle zu. Sie seien lediglich nicht dazu in der Lage, die diskursiven Strukturen vollständig zu 
verlassen und von ihnen unabhängig zu agieren. Das heiße nicht, dass Kategorien, wie ,Klasse“ oder ,Frauen', etc. verworfen werden müssen. Vielmehr heiße das, dass die Erkenntnis, dass ihre Einheit nicht auf einer zugänglichen gemeinsamen Wesenheit basiere, sondern durch partielle Fixierung entstehe, also nicht a priori vorhanden sei, emanzipatorisches Potenzial habe, da sie zum Verständnis verschiedenster Macht- und Unterordnungsverhältnissen beitrage und Ausschlüsse sichtbar mache (Mouffe 1992: 373f.; 382). Aus dieser Sicht seien vielfältige Formen von Einheit und gemeinsamen Handeln vorstellbar, auch im Rahmen eines feministischen Kampfes (ebenda: 382). Soziale Beziehungen werden politisiert, durch „erlebte Identität“ entstehen prekäre Bündnisse „,im Kampf um politische Artikulation“ (Wöhl 2007: 141). Die Kritik an Essentialismen sei daher nicht ,an obstacle to the formulation of a feminist democratic project [but] is indeed the very condition of its possibility" (Mouffe 1992: 382). Laut Chantal Mouffe bestehe ein häufiges Missverständnis der antiessentialistischen Position darin, dass die Kritik essentialistischer Identität automatisch zur Ablehnung von Identität im Allgemeinen führe (ebenda: 381).

Aus der Unmöglichkeit der Schließung von Identität, der Unvollständigkeit jeder Totalität folge die letztliche Unmöglichkeit von Gesellschaft. „Gesellschaft kann niemals vollständig Gesellschaft sein, weil alles in ihr von ihren Grenzen durchdrungen ist, die verhindern, dass sie sich selbst als objektive Realität konstituiert“ (Laclau/Mouffe 2015: 163). Soziale Praxis könne daher nicht Moment einer Totalität sein, sie sei immer auch artikulatorisch, da sie die letztlich unmögliche Gesellschaft mit konstituiere (ebenda: 148). Gesellschaft sei somit nicht vollständig objektiv vorhanden, sich nicht selbst transparent, sie sei weder vollkommen möglich noch vollkommen unmöglich (ebenda: 166). Im Gegensatz zum Marxismus gibt es bei Laclau/Mouffe kein einfaches Grundprinzip, das die Gesellschaft strukturiert, und keine feststehenden Strukturen - die sozialen Brüche sind vielseitig. Institutionen aber auch ökonomische Strukturen werden nicht als objektiv gegebene Fakten betrachtet, sondern als Ergebnis von politischen Auseinandersetzungen, „sedimentierte Diskurse“ (Glasze 2008: 194). „Nationen, Ethnien, politische Gruppen, Sprachgemeinschaften“ erscheinen nicht mehr als natürlich vorhanden, sondern als ,vorgestellte" Gemeinschaften (ebenda).

\section{Dislokationen}

Gesellschaftliche Strukturen formieren sich nach dieser Auffassung also ständig neu, sie sind instabil, genauso wie die mit ihnen zusammenhängenden Gemeinschaften. Dies verdeutlicht noch einmal die Unmöglichkeit von permanenter und universeller sozialer Wirklichkeit innerhalb dieses Konzeptes; Widersprüche und Heterogenitäten können nur temporär verdeckt werden (Glasze/Mattissek 2009a: 160). Dislokationen können eine determinierende Struktur unterminieren (Laclau 1990 39ff.). Damit gemeint sind Ereignisse, die nicht in der bestehenden Struktur symbolisiert werden können, weil sie aus der von ihr produzierten sozialen Wirklichkeit ausbrechen (Glasze/Mattissek 2009a: 160) (z.B. das Ereignis „Fukushima“ für die Behauptung ,Atomkraft ist sicher'). Dislokationen können nicht nur Großereignisse sein, sondern sie seien auch ein permanentes Phänomen, insofern es immer etwas gebe, das nicht in einer bestehenden Struktur symbolisiert werden könne, das widerständig sei (Torfing 1999: 149). „Dislocation is the traumatic event of 'chaos' and 'crisis' that ensures the incompleteness of the structure; it is precisely this incompleteness, this lack of objec- 
tivity, that deprives the structure of its determining capacity“ (ebenda). Eine Dislokation könne also ein kritisches Moment, ein Moment der Politisierung sein, da es die Kontingenz des Diskurses demonstriere. Das Sein werde dabei mit seinem ,Anderen konfrontiert (Bedall 2014: 57). Je umfassender die strukturelle Dislokation, desto größer seien die Möglichkeiten zur Reartikulation. Das bedeute aber nicht, dass dieser Spielraum unendlich wäre, denn immer noch bestimmen sedimentierte Diskurse die soziale Wirklichkeit und legen darüber auch den Rahmen dessen fest, was sagbar und verfügbar sei, bzw. was überhaupt gehört werde und als glaubwürdig gelte (Glasze/Mattissek 2009a: 160). Eine mögliche Reaktion auf eine Dislokation sei die Herausbildung eines neuen Antagonismus, indem die Ursache eine*r antagonistischen Gegner*in zugeschrieben werde. Damit werde ein neuer „Mythos“ eine neue vermeintliche „Objektivität“" konstituiert (Glasze 2008: 193).

\section{Politik}

Der Antagonismus blockiere zwar die vollständige Möglichkeit von Gesellschaft, ermögliche sie aber gleichzeitig in prekärer Weise. Nur durch die Existenz eines Raums des Offenen, des Unabgeschlossenen, des Politischen sei auch ein Raum der „Entscheidung und partiellen Schließung“, der Politik, möglich (Marchart 1998b: 101). Dabei werden politische Positionen nicht als objektiv gegeben betrachtet, sondern als Ergebnis von Grenzziehungsprozessen. Das Politik-Verständnis nach Laclau/Mouffe ist anti-essentialistisch (Glasze/Mattissek 2009a: 154). In diesem Verständnis etabliert sich im Politischen die antagonistische Strukturierung von Gesellschaft, in der Politik wird mit dem Antagonismus aktiv umgegangen, werden politische Kämpfe ausgefochten, wird das Innen in Abgrenzung vom Außen konstituiert $^{19}$ (Marchart 1998b: 104). Das Soziale geht aus dem Feld des Politischen und der Politik hervor. Akteur*innen werden dabei nicht als Ausgangspunkt von Auseinandersetzungen betrachtet, sondern als selbst von politischen Aushandlungsprozessen geprägt. Die Politik formt auch das politische Subjekt. Ebenso erscheinen Identitäten und Machtverhältnisse politisch, da kontingent und veränderbar (Glasze/Mattissek 2009a: 156).

Mit der Diskurstheorie nach Laclau/Mouffe lässt sich die Geschlechterperspektive sinnvoll in einem breiteren Diskursverständnis politisch entfalten. Chantal Mouffe verfolgt dabei ein feministisches Politikverständnis, das auch Konsequenzen für die Konzeption von Bürger*innenschaft hat. Sie betont, sie argumentiere nicht dafür, Geschlechterdifferenzen total abzuschaffen - Gleichberechtigung erfordere nicht notwendigerweise vollständig gender-neutrale soziale Beziehungen, im Gegenteil führe Gleichbehandlung in manchen Fällen zu Ungleichberechtigung (man denke z.B. an die Gender-Medizin). Aber in Bezug auf Bürger*innenschaft sei Geschlecht keine dienliche Unterscheidung.

19 Politische Entscheidungen können aber widersprüchlich und uneindeutig sein, da sie auf eine Vielzahl von Referenzsystemen und Bedeutungszusammenhängen zurückgreifen. Diese Vielzahl führe zu einer Überdeterminierung, die Brüche und Instabilitäten hervorruft (Glasze/Mattissek 2009a: 156). 
„I am a tone with Pateman ${ }^{20}$ in criticizing the liberal, male conception of modern citizenship but I believe that what a project of radical and plural democracy needs is not a sexually differentiated model of citizenship in which the specific tasks of both men and women would be valued equally, but a truly different conception of what it is to be a citizen and to act as a member of a democratic political community“ (Mouffe 1992: 377).

In diesem Sinne sei feministische Politik keine Politik, die „die Interessen von Frauen als Frauen“ (ebenda: 382 [eigene Übersetzung]) verfolge, sondern die feministische Ziele in einen breiteren Kontext einbette. Es gehe dabei um „die Transformation von allen Diskursen, Praktiken und gesellschaftlichen Verhältnissen, in denen die Kategorie ,Frau“ in unterordnender Weise konstruiert wird“" (ebenda [eigene Übersetzung]) und nicht um die Gleichberechtigung einer ,natürlich bestimmten“, homogenen Gruppe ,Frauen“ (ebenda).

Laclau/Mouffe grenzen sich mit ihrem Politikverständnis vom Marxismus ab, der mit der Auflösung von Privateigentum an Produktionsmitteln den Antagonismus zwischen Arbeit und Kapital abzuschaffen glaubte und von einer dann harmonischen, einheitlichen Gesellschaft ausging, in der letztlich auch das Politische aufgelöst sei (Marchart 1998b: 95). Sie grenzen sich aber insbesondere auch von traditionellen liberalen Politikverständnissen ab, in denen sich selbst transparente rationale Individuen mit im Vorhinein voll entwickelten Identitäten Politik zur Maximierung ihres Eigennutzes betreiben, in denen Politik in einer ökonomischen Perspektive als ein Markt gesehen wird, auf dem es um Verteilung von Ressourcen geht. Aus der diskurstheoretischen Perspektive von Laclau/Mouffe werden die Ausschlüsse (z.B. menschliche Beziehungen, Kultur, Sprache, Emotionen, etc.) eines solchen Politikverständnisses sichtbar (Mouffe 2001: 16f.).

Mit ihrem Politikverständnis bietet die Diskurstheorie nach Laclau/Mouffe einen Rahmen, um politische Positionen, Wertvorstellungen, Leitbilder und Inhalte konzeptionell zu erfassen und in ihrer Konstituierung zu interpretieren. So können Konflikte zwischen verschiedenen Positionen herausgearbeitet und die Mechanismen der Bildung von Allianzen verdeutlicht werden. Die Theorie bietet ein Politikverständnis, das hilft, die Heterogenität sozialer Wirklichkeiten analytisch einzuhegen (Glasze/ Mattissek 2009a: 154). Der Fokus liegt auf der Frage, wie das Politische diskursiv konstituiert wird, wie Politik ,gemacht ${ }^{\star}$ wird $^{21}$, weswegen sie zur Analyse politischer Prozesse besonders geeignet erscheint.

\section{Macht}

Welche Bedeutung haben nun in einem solchen Politik- und Gesellschaftsverständnis, einem solchen Identitäts- und Subjektverständnis, Machtverhältnisse? Wenn es keine präkonstituierten Identitäten und Subjekte gibt, dann kann Macht keine Beziehung zwischen solchen Subjekten und Identitäten sein. Vielmehr werden in dieser Sichtweise die Identitäten selbst von Machtverhältnissen konstituiert und somit auch

20 Mouffe spielt hier auf Carole Patemen an, die in „The sexual contract“ die patriarchale Grundstruktur moderner Gesellschafts-Vertragstheorien herausarbeitet (Pateman 1988).

21 Der Fokus liegt demnach nicht auf gesellschaftlichen Produktions- oder Eigentumsverhältnissen, etc. sondern auf den diskursiven Prozessen, die diese ermöglichen und herstellen. 
das, was als Wirklichkeit wahrgenommen wird. Wenn das „,konstitutive Äußere stets im Inneren als seine stets reale Möglichkeit präsent ist" (Laclau/Mouffe 2015: 27) und das Innere somit kontingent sei, folge daraus auch: „die hegemoniale Anordnung kann keine andere Quelle der Gültigkeit für sich in Anspruch nehmen als die Machtbasis, auf der sie gegründet ist“ (ebenda). Es gebe keine „privilegierte ontologische Stelle“ (wie die Arbeiterklasse, oder ein König von ,Gottes Gnaden'), auf der die Legitimität von Macht begründet werden könne (ebenda), sie sei also stets politisch. Wie bei Foucault ist das Verhältnis von $\mathrm{Macht}^{22}$ und Diskurs komplex:

„Die Diskurse [...] sind ein für allemal der Macht unterworfen oder gegen sie gerichtet. Es handelt sich um ein komplexes und wechselhaftes Spiel, in dem der Diskurs gleichzeitig Machtinstrument und -effekt sein kann, aber auch Hindernis, Gegenlager, Widerstandspunkt und Ausgangspunkt für eine entgegengesetzte Strategie. Der Diskurs befördert und produziert Macht; er verstärkt sie, aber er unterminiert sie auch, er setzt sie aufs Spiel, macht sie zerbrechlich und unaufhaltsam“ (Foucault 1986: 122).

Eine vollständige Auflösung von Machtverhältnissen, eine vollständige Emanzipation und somit eine vollständige Realisierung von Demokratie ist nach Laclau/Mouffe nicht möglich, da Machtverhältnisse und Ausschlüsse für gesellschaftliche Beziehungen als konstitutiv angesehen werden (es gibt kein ,wir ${ }^{6}$ ohne ,sie') (Laclau/ Mouffe 2015: 24f.; Mouffe 1992). Dies widerspricht dem klassischen sozialistischen Verständnis, in dem ,eine Gesellschaft umso demokratischer [ist], je weniger Macht für soziale Verhältnisse konstitutiv ist" (Laclau/Mouffe 2015: 25). Sowohl bei Foucault als auch bei Laclau/Mouffe bleibt die Definition von Macht vage, bzw. Wandlungen unterworfen. Macht entsteht bei Laclau/Mouffe in Abgrenzungsprozessen, bzw. antagonistischen Verhältnissen, entsteht im Wechselspiel zwischen innen und außen, befeuert diese Prozesse aber gleichzeitig auch - Macht zeigt sich demnach stets in Verhältnissen. Auch wenn Identitäten als durch Machtverhältnisse konstituiert betrachtet werden, so wird ihnen - und damit zusammenhängend Subjekten - gleichzeitig durch dieses Wechselspiel Macht zugeschrieben. Sie agieren selbst machtvoll im Diskurs aber nie unabhängig vom Diskurs, d.h. nie unabhängig vom Machtgefüge. Ein Subjekt hat also keine Macht aus sich heraus. Macht ist dabei nicht per se negativ (z.B. über andere), sie kann auch (positiv) produktiv eingesetzt werden. Wo sich Macht in der Weise konzentriert, dass sie sich dauerhaft strukturell verhärtet und spontane Veränderungen verunmöglicht entsteht Herrschaft. Diese materialisiert sich bspw. in ökonomischen Verhältnissen, Geschlechterverhältnissen, von Rassismus geprägten Verhältnissen oder gesellschaftlichen Naturverhältnissen. Die Macht der/des ,Anderen` ist im herrschaftlichen Verhältnis minimiert.

22 Foucault definiert Macht dabei folgendermaßen: „die Macht ist nicht eine Institution, ist nicht eine Struktur, ist nicht eine Mächtigkeit einiger Mächtiger. Die Macht ist der Name den man einer komplexen strategischen Situation in einer Gesellschaft gibt“" (Foucault 1986: 114). 


\section{Hegemonie}

Wenn Identitäten durch Machtverhältnisse konstituiert werden, wenn die Objekte im Kern „etwas anderes als sich selbst“ - das konstitutive Außen - eingeschrieben haben, dann heißt das auch, dass das Sein keine reine Präsenz, keine Objektivität, sein kann, dass soziale Objektivitäten politisch durch Machthandlungen konstituiert sind und die Spuren ihrer Ausschließungsprozesse enthalten. Dieses Zusammenfließen von Macht und Objektivität nennen Laclau/Mouffe Hegemonie (ebenda: 26f.). In dieser Verbindung von Diskurs- und Hegemonietheorie liegt Potenzial der Theorie für eine politische feministische Diskursanalyse, weil es dadurch möglich wird, die Bedingungen der Konstitution von Identitäten und Objektivitäten mit einer Analyse von Machtverhältnissen zu verbinden. Leider bleibt der Hegemoniebegriff in vielen feministischen Ansätzen, wie auch bei Judith Butler, verschwommen (Distelhorst 2007: 65). Bei Laclau/Mouffe, besonders aber bei Laclau, ist Hegemonie die zentrale Kategorie politischer Analyse (Laclau 2000: 140). In „New Reflections on The Revolution of Our Time“ (Laclau 1990) entwickelt Laclau die Hegemonietheorie weiter. Über die Kategorie der Hegemonie grenzen sich Laclau/Mouffe von anderen konstruktivistischen Theorien ab. Für sie stellt in Übereinstimmung mit anderen konstruktivistischen Theorien ,die Kritik des Essentialismus zwar die notwendige theoretische Basis für eine politische Kritik“ (Mouffe 2001: 12) dar. Erst über die Hegemoniekonzeption konnte aber eine politische Auffassung erarbeitet werden, für die Machtverhältnisse, bzw. das Wesen der Macht, zentral sind (ebenda).

In ihrer Hegemonietheorie schließen Laclau/Mouffe an Gramsci (1991-2006) an, radikalisieren diesen nach eigener Aussage jedoch (für eine genauere Abgrenzung zu Gramsci's Hegemonietheorie vgl. Laclau/Mouffe 2015: 173ff.). Sie grenzen sich vom ökonomischen Determinismus Gramscis (dem Gramsci letztlich verpflichtet blieb) ab, aber auch von Ansätzen, die die strategische Rolle von Akteur*innen für die Hegemoniebildung in den Mittelpunkt stellen. Weder sei das Subjekt vollkommen durch die Struktur bestimmt, noch begründe das Subjekt das Soziale allein (vgl. auch Bedall 2014: 49). Wenn Macht nicht als grundlegend, sondern als in diskursiven Prozessen also „dem Sozialen innerlich durch die entgegengesetzten Logiken von Äquivalenz und Differenz" (Laclau/Mouffe 2015: 180) konstituiert betrachtet wird, kann die Hegemonietheorie nicht auf einer privilegierten Klasse oder einem dominanten Sektor aufbauen, ,die oder der das Zentrum einer hegemonialen Formation bildet, da sich uns ein solches Zentrum definitionsgemäß immer entziehen wird“ (ebenda). Ebenso wenig kann aber von einer Gleichverteilung oder einer Auflösung der Macht ausgegangen werden, da dies für Machtkonzentration blind machen würde (ebenda).

Hegemonie definiert Laclau folgendermaßen: „In my work, I have defined 'hegemony' as the type of political relation by which a particularity assumes the representation of an (impossible) universality entirely incommensurable with it" (Laclau 2000: 140). Hegemonie bezeichnet ein raum-zeitlich spezifisches politisches Verhältnis, in dem es einem partikularen Diskurs gelingt, eine temporäre Schließung zu verheißen, zum „dominanten Horizont sozialer Orientierung“ zu expandieren und somit eine spezifische Wirklichkeit zu naturalisieren. Damit verbunden ist die Marginalisierung alternativer Sichtweisen (Glasze/Mattissek 2009a: 159ff.).

Als Feld, auf dem sich Hegemonie bildet, wird das Feld der artikulatorischen Praxen betrachtet - denn wäre jede Bedeutung fixiert, wären feste Identitäten Teil eines geschlossenen Systems, gäbe es überhaupt keinen Raum für hegemoniale Praxis. 
Hegemoniale Praxis setze also dort an, wo Elemente noch nicht zu Momenten umgewandelt seien (Laclau/Mouffe 2015: 171). Ihre Bedingungen seien „die Präsenz antagonistischer Kräfte“ sowie „die Instabilität der sie trennenden Grenzen“ (ebenda: 173). Im Umkehrschluss heißt dies, dass nach dieser Sichtweise keine hegemoniale Logik vollständig das Soziale als Totalität begründen kann, denn damit hätte sich nach dem Verständnis von Laclau/Mouffe die Hegemonie selbst eliminiert. Hegemonie benötigt demnach die Offenheit des Sozialen (ebenda: 180). Die „Logik der Hegemonie“ ist also auch die „Logik der Artikulation“ und bestimmt als solche sogar „die Identität der hegemonialen Subjekte“ selbst (ebenda: 120).

In diesem Sinne sind es nicht Akteur*innen, Subjekte, Gruppen oder Staaten die hegemonial werden. Sie können aber Hegemonie durch Artikulation produzieren oder bekämpfen und sich über die gemeinsame Artikulation spezifischer Bedeutungen zu Gruppen, bzw. zu Diskurskoalitionen zusammenschließen (Bedall 2014: 52). Welche Akteur*innen sich zusammenschließen, bzw. welche Differenzen ,zentral und gegensätzlich [...] artikuliert werden“ (Glasze/Mattissek 2009a: 160) (Geschlecht, Klasse, Nationalität, etc.) stehe dabei nicht von vorne herein fest. Entsprechende Koalitionen werden immer wieder neu gebildet (ebenda). Diese stellen auch ein „Gefüge sozialer Kräfte“ dar, die unterschiedliche Wirkmächtigkeiten aufweisen (Bedall 2014: 48).

Mit ihrem Hegemoniebegriff gehen Laclau/Mouffe über Ansätze, die hauptsächlich auf Dekonstruktion fokussieren, hinaus - auch über Judith Butlers Ansatz, die zwar einen foucaultschen Zugang zu Machtverhältnissen hat, in ihrem Hegemoniebegriff aber vielleicht aufgrund des Fehlens eines marxistisch-gramscianischen Hintergrunds unscharf bleibt (Smith 1998: 225). Der Ansatz von Judith Butler ist zwar in der Dekonstruktion der Geschlechterdifferenz umfassender als der von Laclau/ Mouffe, die feministische Debatten zu sex und gender nur am Rande thematisieren (ebenda), er bleibe aber nach Distelhorst (2007) im Raum der Unentscheidbarkeit stehen und es gelinge ihm nicht, politische Mechanismen zu entwickeln. Durch die bei Laclau/Mouffe umfassender ausgearbeitete Hegemonietheorie sei es dagegen „möglich, den Sprung von der butlerschen Dekonstruktion der Geschlechterdifferenz in die politische Theorie zu schaffen und ihr dadurch neue Wege zu öffnen“ (Distelhorst 2007: 69). In einer Diskussion via E-Mail ${ }^{23}$ setzen sich Laclau und Butler mit „Gleichheiten und Differenzen“ auseinander und Butler äußert Zustimmung zu Laclaus Hegemonietheorie sowie deren politische Konsequenzen (Butler/Laclau 1998: 249). Butler hebt die Frage der Zeitlichkeit hervor und merkt an, dass diese durch die postmarxistische Wendung bei Laclau/Mouffe von einer „Auffassung, in der Kapital als soziale Verhältnisse auf relativ homologe Weise strukturierend verstanden wird, zu einer Sicht von Hegemonie, in der Machtverhältnisse Wiederholung, Kontingenz und Reartikulation unterworfen sind“" (Butler 1998b: 255), wieder

23 Trotz der Differenzen zielen Butlers und Laclau/Mouffes Werke in eine ähnliche Richtung und befruchten sich gegenseitig. Ernesto Laclau bezeichnet dies als „Konvergenz in offener Suche“ (Laclau 1998: 258): „Ich hoffe, daß der Austausch zwischen Judith Butler und mir als ein bescheidener Stimulus für andere dienen kann, an einer Unternehmung teilzunehmen und ihr beizutragen, deren Erfolg nur gesichert sein kann, wenn sie zu einer wirklich kollektiven wird“ (ebenda: 261). 
in den Blick komme. Im Anschluss an Laclau/Mouffes Hegemonietheorie sieht sie das Potenzial für den Feminismus auch darin, zu erkennen, „daß „Patriarchat“ oder „Systeme“ maskuliner Herrschaft keine systemischen Totalitäten sind, die Frauen in Positionen der Unterdrückung halten müssen, sondern vielmehr hegemoniale Machtformen, die ihre eigene Zerbrechlichkeit genau in dieser Operation ihrer Wiederholbarkeit enthüllen“ (ebenda: 256).

\subsection{RADIKALE DEMOKRATIE UND KRITIK}

Eine herrschaftsfreie Gesellschaft als Vision wird von Laclau/Mouffe nicht verworfen (auch wenn sie unerreichbar gilt), wird aber anders gedacht: Wenn die kontingenten Grundlagen von Hegemonie jederzeit sichtbar eingestanden und reflektiert werden, sich Institutionen also jederzeit für Veränderung öffnen, sei eine permanente Revolution der Institutionen möglich. Herrschaft entwickele sich, wenn diese Offenheit für Veränderung durch die Behauptung, ein politischer Zustand repräsentiere die Gesellschaft vollständig (also durch die Naturalisierung einer bestimmten Sichtweise), beendet werde und Ausschlüsse dadurch ignoriert und zementiert werden (Distelhorst 2007: 177). Wenn die Illusion, dass Macht aufgelöst werden könne, aufgegeben werde, sei die Hauptfrage radikaler demokratischer Politik nach Laclau/ Mouffe, wie mit pluralistischen demokratischen Werten vereinbarte Identitäts- und Machtformen gebildet werden und gleichzeitig herrschende Machtverhältnisse transformiert werden können - in diesem Kontext entwickelte vor allem Chantal Mouffe das Konzept der radikalen Demokratie (Laclau/Mouffe 2015: 25). Vor dem Hintergrund der Erkenntnis, dass es keine objektiven ewigen „Wahrheiten gibt, sei es [...] notwendig, den Dissens anzuerkennen“ (Glasze/Mattissek 2009a: 168). Wenn sowohl vollständige Äquivalenz als auch vollständige Differenz als unmöglich erkannt werden, dann könne nur die „Anerkennung der Vielfalt sozialer Logiken und der Notwendigkeit ihrer Artikulation“ (Laclau/Mouffe 2015: 29), also ein radikaler Pluralismus, demokratisch sein. Insofern könne auch keine demokratische Geschlechterpolitik Macht auflösen, aber sie könne „die Strukturierung der Geschlechterdifferenz als Herrschaftsverhältnis“ (Distelhorst 2007: 177) überwinden. Geschlechtshierarchisch verfasste Dichotomien wie öffentlich/privat, Kultur/Natur, etc. seien als Ergebnis hegemonialer Artikulation zu werten und ihre Grenzziehungen als von Machtverhältnissen abhängig. Zentraler Bestandteil ihrer Konzeption des Ökonomischen sei daher eine Subversion der Dichotomien öffentlich/privat, bürgerliche/politische Gesellschaft, die im Rahmen des neo-konservativen Diskurses den Bereich des Politischen beschränken (ebenda: 224). Dies würde letztlich dann auch zu einer Auflösung der Dichotomie Ökonomie/Gesellschaft, bzw. Ökonomie/Politik führen.

Mit der Zentralität von Machtverhältnissen in ihrer Vorstellung von radikaler Demokratie grenzen Laclau/Mouffe sich eindeutig von liberalen und einigen postmodernen Vorstellungen pluralistischer Demokratie ab, die für Machtverhältnisse und Ausschließungen blind sind. Im Gegensatz dazu wollen Laclau/Mouffe Unterordnungsformen, die auf Ausschluss beruhen, zerstören. Solche liberalen und postmodernen Vorstellungen von Demokratie beruhen auf der Abschaffung des Antagonismus (z.B. durch die Behauptung der Gleichheit aller) und damit einem scheinbaren Verschwinden des Politischen. Mit der zentralen Stellung von Antagonismus und 
Machtverhältnissen haben Laclau/Mouffe versucht, konsequent mit der Erkenntnis umzugehen, dass es keine totale, sondern nur partielle Emanzipationen geben könne (ebenda: 24f.).

Nancy Fraser kritisiert an der Theorie radikaler Demokratie, dass sie die politische Ökonomie ausklammere, hauptsächlich als Gegengewicht zur Identitätspolitik diene, durch den Fokus auf Anerkennung von Vielfältigkeit Fragen nach Verteilungsgerechtigkeit ausklammere und dadurch ihren emanzipatorischen Anspruch konterkariere (Fraser 2001: 263). Diese Kritik halte ich für teilweise gerechtfertigt. Auf der einen Seite fokussiert die Theorie auf die Dekonstruktion von Identität und sozialen Verhältnissen und es liegt daher weniger auf der Hand, die Theorie zu nutzen, um derzeitige Verteilungsverhältnisse aufzuzeigen. Sie kann aber die Diskurse (und über den erweiterten Diskursbegriff auch soziale Praktiken) analysieren, die eine solche Verteilung ermöglicht/hervorgerufen haben und weiterhin ermöglichen sowie die damit verbundenen Machtverhältnisse offenlegen. Dabei geht es Laclau/ Mouffe auch darum, nach dem Zusammenbruch des ,real existierenden Sozialismus“ eine Analyse für dessen Scheitern zu liefern und neue Perspektiven für die politische Linke zu eröffnen. Politisch ökonomisch schließen sie daher an den Sozialismus an, denken diesen aber neu bzw. weiter: „Wie gesagt enthält jedes Projekt für radikale Demokratie notwendigerweise eine sozialistische Dimension (die Abschaffung kapitalistischer Produktionsverhältnisse); es verwirft jedoch die Vorstellung, dass aus dieser Abschaffung notwendig die Beseitigung aller Ungleichheiten folgt" (Laclau/ Mouffe 2015: 232). ${ }^{24}$ Sozialismus sei daher ,einer der Bestandteile eines Projekts für radikale Demokratie, nicht umgekehrt“ (ebenda: 216). In der Anerkennung der Vielfältigkeit politischer Kämpfe und Diskurse, der Pluralität von politischen Räumen, sehen sie die Bedingung der Verwirklichung des sozialistischen Ideals (ebenda: 232). Eine „Konzentration von Macht und Wissen“ sei damit unvereinbar (ebenda: 216). Auch Laclau/Mouffe halten demnach - ebenso wie Nancy Fraser - die politische Ökonomie für einen wesentlichen Bestandteil radikaler Demokratie. Allerdings ist die Kritik von Nancy Fraser insofern berechtigt, als dass die politische Ökonomie im Gegensatz zur Dekonstruktion in der Diskurstheorie von Laclau/Mouffe eher einen Nebenschauplatz darstellt. Es bleibe daher „unklar, wie das Projekt einer radikalen Demokratie eine kulturbetonte Politik der Anerkennung mit einer Sozialpolitik der Umverteilung [und Gerechtigkeit] verbinden kann“ (Fraser 2001: 263f.). Die Theorie verfüge darüber hinaus nicht über eine Grundlage, mit der man ,gerechte von ungerechten Differenzen unterscheiden“ könne (ebenda: 264). Nancy Fraser lehnt die antiessentialistische Diskurstheorie aber nicht $a b$, sondern sieht in ihrem Verständnis der Konstruktion von Identität und Differenz einen Erkenntnisgewinn. Politik sollte nach ihrer Auffassung aber nicht ausschließlich dekonstruktiv sein. Die Herausforderung liege darin, die Dekonstruktion mit einer egalitären Sozialpolitik (Fraser 2001:

24 Die sozialistische Vorstellung der Arbeiterselbstverwaltung von Produktionsmitteln wird abgelehnt, da die Konstruktion von „Arbeiterinteressen“ auf Ausschluss beruhe, bspw. von „ökologische[n] Forderungen oder Forderungen anderer Gruppen“ (Laclau/Mouffe 2015: 217) und daher die ,wahre Partizipation aller Subjekte an Entscheidungen über das, was produziert, wie es produziert und über die Formen, in denen das Produkt verteilt werden soll, auf dem Spiel steht“" (ebenda: 216f.). 
273) sowie sozial-ökologischer Gerechtigkeit zu verbinden. Diesem Mangel der Diskurstheorie begegne ich in den Kapiteln 3 und 4 mit einer theoretischen, methodischen und positionierenden Verknüpfung mit dem Vorsorgenden Wirtschaften. 



\section{Vorsorgendes Wirtschaften als kritisch-emanzipatorische Perspektive im Kontext von Transformation}

In Kapitel 1 habe ich dargestellt, dass ich einen Forschungsbeitrag meiner Arbeit in der Verbindung von Diskurs- und Transformationstheorie sehe. Ich habe mich mit dieser Arbeit in der kritischen, feministischen Transformationsforschung sowie im Konzept der gesellschaftlichen Naturverhältnisse verortet. Im vorangehenden Kapitel habe ich gezeigt, dass sich die Diskurstheorie nach Laclau/Mouffe (2015) aufgrund ihres Diskursbegriffes, ihres Charakters als politische Theorie sowie ihrer Verbindung zur Hegemonietheorie für eine feministische, sozial-ökologische und kritische Transformationsforschung eignet. Eine kritische, feministische Transformationsforschung beschränkt sich nicht auf die Dekonstruktion derzeitiger nicht-nachhaltiger Verhältnisse, sondern ist explizit auf deren Transformation ausgerichtet. Transformationstheorien können dabei die Diskurstheorie um wichtige normative und politischökonomische Orientierungen ergänzen, wie ich im Folgenden zeigen werde.

Ich positioniere mich dabei im Folgenden auf spezifische Weise innerhalb der Transformationsforschung, indem ich in Anschluss an das Emanzipationsverständnis ${ }^{1}$ nach Laclau (2002) und Laclau/Mouffe (2015) (vgl. Kapitel 1 und 2) von einem emanzipatorischen Transformationsverständnis ausgehe, das eine herrschaftsärmere Zukunftsgestaltung zum Ziel hat. Eine begriffliche Einordnung von Emanzipation im Kontext von Transformation erfolgt in Unterkapitel 3.1.3.

Dazu braucht es emanzipatorische, möglichst herrschaftsarme ${ }^{2}$ Perspektiven, die ich ergänzend zu meiner feministischen, sozial-ökologischen und diskurstheoretischen Forschungsperspektive in der vorliegenden Arbeit mit dem Vorsorgenden Wirtschaften konkretisiere. Der Transformationsbegriff wird zunächst im Gegensatz zum Fortschrittsbegriff erarbeitet (3.1.1) und dann als sozial-ökologischer Transfor-

1 Für eine Definition von Emanzipation vgl. Fußnote 40 sowie die Erläuterungen im vorigen Kapitel 2.

2 Ich spreche hier von ,herrschaftsarm ' und nicht von ,nicht-herrschaftlich', da - wie im vorigen Kapitel dargestellt - mit Laclau/Mouffe (2015) eine vollständige Emanzipation nicht möglich ist und Macht für gesellschaftliche Beziehungen konstitutiv ist. Einen nichtherrschaftlichen Anspruch zu verfolgen, birgt die Gefahr, diese Machtstrukturren unzureichend zu reflektieren. 
mationsbegriff im Spannungsfeld zwischen Revolution und Reform diskurstheoretisch verortet (3.1.3). Trotz dem ich das Vorsorgende Wirtschaften in meiner Arbeit als emanzipatorische Perspektive verwende und somit die Dekonstruktion mit einer positiven Vision von Zukunft verbinde, steht die kritische Funktion - insbesondere mit Blick auf das spätere analytische Vorgehen (vgl. Kapitel 4 Methodik) - im Mittelpunkt: Anhand dessen, was sein könnte, wird aufgezeigt was nicht ist, und umgekehrt. Dazu stelle ich im zweiten Teil des Kapitels 3.2.1 zunächst die Handlungsprinzipien Vorsorgenden Wirtschaftens vor und erweitere diese im Hinblick auf die spätere Analyse um weitere Kriterien in Kapitel 3.2.2.

\subsection{THEORETISCHE VERORTUNG DES TRANSFORMATIONSBEGRIFFES}

\subsubsection{Transformatives Verständnis von Zeitlichkeit}

Vorherrschende Perspektiven auf, Verständnisse von und Formen von Zeit spielen eine zentrale Rolle für die Frage, ob, und wenn ja in welcher Weise, Transformation möglich ist. Denn Transformation hat stets mit Zeitlichkeit zu tun, sie bezieht sich auf Vergangenheit, Gegenwart und Zukunft zugleich. Daher erfolgt hier zunächst eine Auseinandersetzung mit Zeitlichkeit als Voraussetzung für Transformation.

Der Zugriff auf die Zukunft (bzw. Zukünfte) ist ein ,zentrales Element von Macht“, das Brie (2014a: 8) als das „Futuring der Herrschenden“ bezeichnet. Die neoliberale ${ }^{3}$ Erzählung von Zeit impliziert die Vorstellung absoluter individueller Zeitautonomie - jeder Mensch könne zu jeder Zeit über seine*ihre Zeit und Zukunft frei entscheiden und verfügen. Dieser Annahme folgend sei nach Rilling (2014: 34f.) der Zugriff auf die Zeit und damit auf die Zukunft seit den 1970er Jahren weitgehend privatisiert und den Vorstellungen des homo oeconomicus sowie der Organisation des Marktes unterworfen worden. Planung finde seitdem auf betrieblicher, lokaler, regionaler, nationaler und internationaler Ebene marktorientiert statt, auf individueller Ebene seien Eigenverantwortlichkeit und rationale Nutzenorientierung zentral.

3 Der Begriff des "Neoliberalismus“ wird in dieser Arbeit im Anschluss an Gottschlich (2017) und Ptak (2008) als in der Tradition von Klassik und Neoklassik stehende, ,dominante Ideologie des Kapitalismus seit dem Ende des 20. Jahrhunderts, mit der die Marktgesellschaft langfristig durchgesetzt und dauerhaft stabilisiert werden soll“, verwendet (Gottschlich 2017: 22). Die ordoliberale „Soziale Marktwirtschaft“ sieht Ptak (2008) als deutsche Variante des Neoliberalismus (Ptak 2008: 72f), die sich vor allem in der „ordnungspolitischen Macht des Staates“ zur „Organisierung der Wettbewerbsordnung“ mit dem Ziel der Annäherung an das neoklassische Ideal der vollständigen Konkurrenz sowie dem „Zugeständnis einer liberalen Gesellschaftspolitik“ vom angloamerikanischen Neoliberalismus unterscheide (ebenda: 76; 81). Ptak wertet die „Soziale Marktwirtschaft“ als ein Triumph des Neoliberalismus, indem sie über die vermeintliche „Betonung des Sozialen“ als Zugeständnis an die kapitalismuskritische Öffentlichkeit der Bundesrepublik der Nachkriegszeit auftrat, aber dabei gleichzeitig die Vorstellung etablierte „eine gut funktionierende Marktwirtschaft sei aus sich selbst heraus sozial“ (ebenda: $84 \mathrm{f}$.). 
Rilling (2014: 35) bezeichnet diesen bereits in den 1950er Jahren einsetzenden Prozess als „neoliberale Transformation der Zeitlichkeitskultur“, verbunden mit einer „Reduktion auf die Unmittelbarkeiten des Gegenwärtigen oder gar dem Ende der Temporalität" (ebenda). Zukünftige Generationen seien in dieser Zeitvorstellung nicht vorgesehen, in diesem Horizont erscheine nur noch der ,unendlich dauernde[...] Utopismus des Marktes“ (ebenda). „Oft - und erst recht nach 1989 - ist dies dann als ,Ende der Geschichte“ und somit auch als Erschöpfung eines letzten Zukunftszyklus verstanden worden“ (ebenda: 35). Nowotny (1989: 34f.) spricht von der „Illusion der Gleichzeitigkeit“", die über die Anschlusszwänge des Technosystems vermittelt werde und der Ungleichheit „eine zusätzliche zeitliche Dimension“ verleihe, indem diejenigen, die nicht anschlussfähig sind, als zeitlich rückständig erscheinen.

Westlichen Industriegesellschaften liegen nach Adam (2013: 116) verschiedene implizite Annahmen über Zeit zu Grunde. Die Messung von Zeit durch Kalender und Uhren ermöglichte die Quantifizierung von Zeit. Die mit dieser Messung verbundene Einteilung von Zeit strukturiere das sozio-ökonomische und sozio-ökologische Handeln. Zeit werde über den Globus rationalisiert und kommodifiziert (ebenda: 116f.):

„There is no doubt either that time is a personal and public resource with a use value on the one hand and an economic resource with an exchange value on the other. Finally, it is an acknowledged ,fact ' that time is money and associated with the assumption that speed means progress, efficiency, productivity and cost effectiveness: the more that can be produced in a given period the higher will be the profit" (ebenda: 117).

Das Ergebnis der Kommodifizierung der Zeit sei eine einzige Zeitform: Die lineare, quantitativ messbare (Uhr-)Zeit. Zeitqualität spiele dabei zunächst keine Rolle. Gleichzeitig sei Zeit ebenso unbewusst assoziiert mit „life, change and difference“, Diese Lebenszeiten stehen in zahlreichen Widersprüchen zur quantifizierten Zeit, sie werden der Natur sowie körperlicher Erfahrung zugeordnet und ins Private verschoben (ebenda). Es bestehe eine „unhinterfragte Hierarchie zwischen kommodifizierter Zeit und gelebter Zeit [eig. Übersetzung]“" (ebenda: 118). Aus dieser Hierarchisierung ergeben sich sozio-ökologische Folgen, da sie zu einer Missachtung der Regenerations- und Lebenszeiten sowohl bezüglich der Produktivitäten von Natur als auch im sozialen Bereich, bspw. der für Pflege und Sorge benötigte Zeit führe (ebenda: 118f.). Die Missachtung dieser Produktivitäten und der dafür erforderlichen Zeiten führe zu Ausbeutung und festige nicht-nachhaltige Verhältnisse.

Daraus ergibt sich für die Transformationsforschung die Notwendigkeit des Nachdenkens über Zeitlichkeit. Eine Aufgabe sei es dabei, meist implizit zu Grunde liegende und naturalisierte Annahmen über Zeit explizit zu machen, herauszufordern und für die Debatte zu öffnen (ebenda: 118).

Einige der von Adam (2013) angesprochenen impliziten Annahmen über Zeit stehen in enger Verbindung mit dem Fortschrittsbegriff der Aufklärung, die den Glauben an eine durch wissenschaftliche Erkenntnisse objektiv beherrschbare Natur, mit der stetige Verbesserungen und dadurch ein stetiger Vernunft geleiteter Fortschrittsprozess erwirkt werden können, begründete. Dieses Modell der rationalen Gesetzeserkenntnis wurde über den Glauben an ,eine objektivistische Beherrschbarkeit der Gesellschaft“ im Zuge der folgenden ökonomischen Entwicklung „,von der Natur auf die Gesellschaft übertragen“ (Demirović 2014: 423f.). Eine Gesellschaft, die 
nicht ständig fortschreitet, wird heute demnach als arm empfunden. Gemessen wird der Fortschritt überwiegend rein quantitativ oder technologisch, beispielsweise über das Wachstum des Bruttoinlandsproduktes BIP. Die Entwicklung, die ein solcher Fortschritt adressiert, ist als lineare Entwicklung, die über den Markt organisiert und von der profitorientierten Akkumulation angetrieben wird, zu betrachten. Dabei gerate das Lebendige, nicht marktlich Orientierte, aus dem Blick. Es „herrscht die Statik des Immergleichen“ (ebenda: 426), denn die sozialen Verhältnisse und die gesellschaftlichen Naturverhältnisse bleiben unangetastet, bzw. herrschaftlich strukturiert:

„Denn das aufklärerische Moment darin, das in Versöhnung mit der Natur terminiert, indem es den Schrecken der Natur beschwichtigt, ist verschwistert mit dem der Naturbeherrschung. Modell des Fortschritts [...] ist die Kontrolle außer- und innermenschlicher Natur. Die Unterdrückung, die durch solche Kontrolle geübt wird, [...] reproduziert den Antagonismus. Je mehr Identität durch den herrschaftlichen Geist gesetzt wird, desto mehr Unrecht widerfährt dem Nichtidentischen. Das Unrecht erbt sich fort an dessen Widerstand [...]. Alles schreitet fort in dem Ganzen, nur bis heute das Ganze nicht“" (Adorno 1984: 101).

Ein solcher Fortschritt verursache nach Demirović (2014: 426) multiple Krisen, denn er sei eben nicht an einer Beseitigung von Ausbeutung, Sexismus, Rassismus, Armut oder ökologischer Krisen interessiert. ${ }^{4}$ Im Gegenteil, er basiert auf Ausbeutung, indem er Haushalts- und Naturproduktivität kostenlos aneignet (Lang 1994: 47ff.). Ein solcher Fortschrittsbegriff normalisiert Ausbeutungsverhältnisse.

„Die Tradition der Unterdrückten belehrt uns darüber, daß der ,Ausnahmezustand“, in dem wir leben, die Regel ist. Wir müssen zu einem Begriff von Geschichte kommen, der dem entspricht. Dann wird uns als unsere geschichtliche [Herv. i. O.] Aufgabe die Herbeiführung des wirklichen Ausnahmezustands vor Augen stehen [...]“ (Benjamin 2010: 19),

formulierte Walter Benjamin 1940 im Angesicht des Nationalsozialismus. Benjamin (2010) kritisiert auch den sozialdemokratischen Fortschrittsbegriff. Dieser baue auf einem von Naturbeherrschung und moralischer Überhöhung geprägten Arbeitsbegriff auf, der Arbeit als Quelle allen Reichtums und aller Kultur vermittle, in dem die Arbeiterschaft von der technischen Entwicklung angetrieben werde, was die Illusion vermittelt habe, Fabrikarbeit alleine stelle bereits „eine politische Leistung“ dar (ebenda: 21f.). Die damit verbundene Vorstellung eines „unabschließbare[n]“ und „unaufhaltsame[n]“ Fortschritts sei eng verbunden mit der Vorstellung des Fortgangs durch „eine homogene und leere Zeit“ (ebenda: 23f.).

In diesem Sinne braucht es eine andere Logik des Fortschritts und der Zeitlichkeit, oder mit Adorno:

„Fortschritt heißt: aus dem Bann heraustreten, auch aus dem des Fortschritts, der selber Natur ist, indem die Menschheit ihrer eigenen Naturwüchsigkeit innewird und der Herrschaft Einhalt

4 Auch wenn dies in den Debatten um Fortschritt immer wieder behauptet wird, wenn der Fortschritt über eine Verbesserung der Lebensbedingungen für alle gerechtfertigt wird (Demirović 2014: 426). 
gebietet, die sie über Natur ausübt und durch welche die der Natur sich fortsetzt. Insofern ließe sich sagen, der Fortschritt ereigne sich dort, wo er endet“ (Adorno 1984: 103).

Eine solche andere Logik könnte auch im Transformationsbegriff gefunden werden. Für ein ,transformatives Transformationsverständnis“ ist nach Michael Brie ein „Gegen-Futuring“ (Brie 2014c: 8) notwendig, ein gegen-hegemoniales Zeitlichkeitsverständnis.

Barbara Adam sieht die Notwendigkeit, die der kapitalistischen Struktur innewohnende Hierarchie zwischen kommodifizierter Zeit und lebendiger Zeit aufzuheben, denn diese führe dazu, dass Nachhaltigkeit nicht verwirklicht werden könne (Adam 2013: 118f.). ${ }^{5}$ Zentraler Bestandteil einer transformativen Logik von Zeitlichkeit ist mit Barbara Adam zudem die Art und Weise, wie auf die Zukunft Bezug genommen wird. Denn Transformation hat mit Zukunftsverantwortung zu tun, der Bezug auf die Zukunft ist also ein anderer als im Fortschrittsbegriff. Barbara Adam unterscheidet im Anschluss an ihre gemeinsame Arbeit mit Chris Groves (Adam/ Groves 2007) drei verschiedene Zukunftskonzepte, die sie später im Hinblick auf das Vorsorgende Wirtschaften ausarbeitet (Adam 2013). Sie unterscheidet zwischen Zukunft als ,vergangener Zukunft', Zukunft als ,gegenwärtiger Zukunft' und Zukunft als ,zukünftiger Gegenwart‘. Das Konzept der ,vergangenen Zukunft' verdeutliche, dass es keine „leere Zukunft“, keine vollständig offene Zukunft gebe (Adam 2006: 6f.). Dies steht im Widerspruch zum von Benjamin (2010) kritisierten Verständnis ,leerer Zeit` im Fortschrittsbegriff und damit auch zum kapitalistischen Zeitverständnis, das zumindest auf individueller Ebene eine offene Zukunft verspricht, in der jede*r alles erreichen kann (wenn er*sie nur will). Im Gegensatz dazu zeigt das Konzept der , vergangenen Zukunft“, dass „,[d]ie Zukunft ein besetztes Land [ist], das immer und notwendigerweise schon von unseren Vorgängern vorbeschattet, d.h. eingenommen und bearbeitet worden ist“ (Adam 2006: 8). Gleichzeitig sei „gegenwärtige Zukunftspolitik größtenteils Aufarbeitung der vergangenen Zukunft“ (ebenda: 7). Die Zukunft gehöre aber nicht uns, denn auch andere, z.B. unsere Nachkommen seien von ihr betroffen, wir seien „Unbefugte - trespassers - auf dem Territorium der Zukunft" (ebenda). Moralisch seien wir aber dazu verpflichtet, das Leben der Mitlebewesen nicht zu gefährden oder zu verkürzen. Das Konzept der , gegenwärtigen Zukunft' frage danach, was die Zukunft für uns tun könne. Es stehe für ein Zukunftsverständnis, in dem Probleme und Risiken in die Zukunft verschoben werden (bspw. Atommüll) (Adam 2013: 123). Dies sei das Zukunftsverständnis, das sich im Fortschrittsbegriff widerspiegele: Man gehe davon aus, dass sich die gegenwärtigen Probleme durch den technologischen Fortschritt in Zukunft quasi von selbst lösen werden. Im Gegensatz dazu bedürfe es eines Verständnisses von Zukunft als ,zukünftiger Gegenwart', das danach frage, was wir für die Zukunft tun können. Es ist eng verbunden mit dem Handlungsprinzip der Vorsorge des Netzwerks Vorsorgendes Wirtschaften (siehe Kapitel 3.2.1) - „[it] is the primary domain of Vorsorge“ (ebenda): „Vorsorge, with its caring concern for what lies ahead, thus seeks to ac-

5 „Wherever the time-is-money and speed-is-profit combination is applied, it tends to lead to a high through-put, high waste system with obvious consequences for sustainability“ (Adam 2013: 119). 
company present decisions and actions through their latent and invisible phases to their potential time-space distantiated impact" (ebenda: 125). Vorsorge berücksichtig gemäß dem Vorsorgenden Wirtschaften die Zeiten der Natur und des sozial Weiblichen in den unterschiedlichen Phasen des (Re)Produktionsprozesses ${ }^{6}$ (Biesecker/Hofmeister 2006).

Vor dem Hintergrund meiner Forschungsperspektive hinterfragt eine Transformationsforschung in diesem Sinne nicht nur implizite Annahmen über Zeit, sondern baut auf solchen konzeptionell innovativen Zeitverständnissen auf (vgl. Adam 2013: 124). Sie entwickelt eine prozesshafte Zeitperspektive, die sich neben der Gegenwart auch für Vergangenheit und Zukunft öffnet. Während die konventionelle Ökonomie den Standpunkt ,gegenwärtiger Zukunft einnehme und sich auf Produkte, Produktion und Produktivität konzentriere, verschiebe eine vorsorgende Perspektive diesen Fokus vom Produkt zum Prozess, von der Produktivität zur (Re)Produktivität (ebenda: 125f.), „which entails opening out the temporal perspective to encompass, in the present, open pasts and futures in their im/material facticity“ (ebenda: 126).

\subsubsection{Integrative Krisenbetrachtung}

Neben unterschiedlicher Vorstellungen von Zeitlichkeit unterscheiden sich die mit dem Transformationsbegriff verbundenen Vorstellungen und Konzepte auch dadurch, inwiefern sie die Lösung im Zusammenhang mit Transformation gestellter Herausforderungen innerhalb oder außerhalb des Kapitalismus sowie gegenwärtig vorherrschender sozialer Verhältnisse und gesellschaftlicher Naturverhältnisse verorten. ${ }^{7}$ Unabhängig des Ortes, an dem sie geführt werden (z.B. Universität oder Parlament), sind Debatten über Transformation somit stets auch politische Debatten. ${ }^{8}$ So

6 Für eine Klärung des Begriffs der, (Re)Produktivität‘ vgl. Kapitel 3.2.

7 Dies verdeutlicht sich bereits am Begriff, der für die Herausforderungen, die eine Transformation notwendig machen, verwendet wird, ob bspw. rein vom Klimawandel, von Umweltproblemen, ökologischen Problemen, der ökologischen Krise oder der sozial-ökologischen bzw. multiplen Krise die Rede ist. Die Verwendung einer spezifischen Bezeichnung geschieht stets vor dem Hintergrund bestimmter Weltbilder und unter der Voraussetzung bestimmter Epistemologien. Die Bezeichnung als Umwelt- oder ökologische Probleme geht häufig von einzelnen, isolierbaren Problemen aus, die lokalisier- und (für sich) lösbar sind (Becker/Jahn 2006: 56), wie in Kapitel 1 deutlich wurde (vgl. auch Fußnote 32). Sie werden zwar vielfach als Folge industrieller Produktion oder menschlicher Lebensweisen interpretiert, dabei werden aber meist punktuelle Lösungen angestrebt (z.B. Grenzwerte, technische Verbesserungen, etc.).

8 Deutlich wird dies beispielsweise in den Diskussionen der Enquete Kommission „Wachstum, Wohlstand, Lebensqualität: Wege zu nachhaltigem Wirtschaften und gesellschaftlichem Fortschritt in der Sozialen Marktwirtschaft": Während die damaligen Regierungsparteien (CDU, CSU, FDP) das grundsätzliche Wirtschaftssystem als gesetzt sahen und lediglich eine Anpassung ,des wirtschaftlichen und gesellschaftlichen Systems an die Änderungen der globalen Welt“ (Bundestag 2013: 26) für notwendig hielten, plädierten die Oppositionsparteien (SPD, GRÜNE und LINKE) in einem Sondervotum für eine ,sozialökologische Transformation“, die grundlegendere Änderungen in der Wirtschaftsweise notwendig 
steht beispielsweise in Green-Growth-Ansätzen die Ökologisierung der kapitalistischen Produktions-, Konsum- und Lebensweise im Vordergrund, während der Transformationsbegriff in linken Ansätzen eher kapitalismusüberwindend verwendet wird (vgl. z.B. Brie 2015a: 9ff.; Brand/Wissen 2017: 28ff.).

Der WBGU hält das „kohlenstoffbasierte Weltwirtschaftsmodell“ für einen „,normativ unhaltbare[n] Zustand“, weil es „die Stabilität des Klimasystems“ gefährde. Der Strukturwandel des fossilen ökonomischen Systems wird „vom WBGU als Beginn einer ,Großen Transformation“ zur nachhaltigen Gesellschaft verstanden, die innerhalb der planetarischen Leitplanken der Nachhaltigkeit verlaufen muss“ (WBGU 2011b: 1). Doch so zukunftsweisend das Gutachten des WBGU in manchen Punkten auch klinge, so Biesecker u.a. (2015: 15f.), versäume es, die zentralen und vielfältigen Krisen unserer Zeit in einen Zusammenhang zu setzen - es fehle eine grundlegende Betrachtung des kapitalistischen ökonomischen Systems und seiner Externalisierungsstruktur.

Im Vorsorgenden Wirtschaften ${ }^{9}$ wird der Zusammenhang ökologischer und sozialer Krisen, die gemeinsam als ,die Krise des Reproduktiven' bezeichnet werden, in der dualistischen und (geschlechts-)hierarchischen Trennungsstruktur der kapitalistischen Ökonomie, die zwischen produktiven und reproduktiven Bereichen trennt, verortet. Nach diesem Verständnis ist die Ökonomie ist für ihre lebendigen Grundlagen blind, da in ihr nur das am Markt Handelbare gesehen und bewertet wird, während die Natur und die gesellschaftlich den Frauen zugeschriebene Sorgearbeit als reproduktiv und wertlos abgespalten sowie unreflektiert angeeignet werden (Biesecker/ Hofmeister 2013a: 144). Vor dem Hintergrund der Externalisierung von Natur- und sozial weiblicher Produktivität wird auch der Fortschrittsbegriff kritisiert, dem so manches angerechnet werde, ,was in Wahrheit auf die Produktivität der Natur oder der privaten Haushalte zurückzuführen sei“ und, der so kein „Instrument für das ,gute Leben“" sei (Lang 1994: 47f.).

Die systemisch begründete Trennungsstruktur, die Biesecker/von Winterfeld (2014) als „Externalisierungsstruktur“ bezeichnen, ermögliche „Herrschaft in vielfältiger Weise: Als Kapitalverhältnis, als patriarchales Verhältnis und als hegemoniales Verhältnis, in dem sich aktiv Mitgestaltende ,drinnen“ von denen ,da draußen“ distanzieren“ (Biesecker/von Winterfeld 2014: 1). Dies sei unter anderem im „Rückzug aus der Solidargemeinschaft" durch die höheren Einkommensschichten sichtbar (ebenda).

Aus dieser Perspektive ist eine Transformationsforschung notwendig, die sich für die Analyse dieser Trennungsstrukturen öffnet, da es sonst nicht gelingt, die gegen-

mache (Bundestag 2013: 116ff.). Jede Seite bediente sich für ihre Argumentation der entsprechenden wissenschaftlichen Sachverständigen.

9 Wie ich in der Einleitung dieser Arbeit (vgl. Kapitel 1) bereits verwiesen habe (vgl. Fußnote 37) ist das Vorsorgende Wirtschaften kein homogenes Konzept. Dies beinhaltet auch, dass es zu verschiedenen Inhalten, wie hier der „Krise des Reproduktiven“ verschiedene Ansichten innerhalb des Netzwerkes gibt. Aus forschungspraktischen Gründen differenziere ich innerhalb des vorliegenden Textes nicht zwischen diesen Ansichten, sondern wähle aus den gemeinsamen Publikationen des Netzwerkes die Arbeiten aus, die meiner eigenen Positionierung im Diskurs, Vorsorgendes Wirtschaften“ am ehesten entsprechen. 
wärtigen multiplen ökonomischen, ökologischen und sozialen Krisen in einen $\mathrm{Zu}$ sammenhang zu bringen und umfassende Alternativen zu entwerfen. Die mangelnde integrative Betrachtung gegenwärtiger Krisen, die Dominanz marktfixierter Ansätze und die damit zusammenhängende hierarchische Unterordnung der vermeintlich reproduktiven Bereiche bietet auch eine Erklärung dafür, warum ökologische und soziale Krisen in den Hintergrund treten, sobald sich (scheinbar) ökonomische Krisen anbahnen. Dies wurde in der Finanzkrise sowie der darauffolgenden Schulden- und Staatskrise deutlich: „Krisenmanagement soll die Verdichtung der Krisen verhindern, Zeit verschaffen. Doch wie erwartet, bereitet die Form der Bearbeitung der Krise jeweils die nächste Krisenkonjunktur vor“ (Candeias 2013: 2). Laut Candeias (2013: 9) gelinge es dem Neoliberalismus dadurch aber immer weniger, marginalisierte Interessen einzubeziehen und somit den Konsens über das ökonomische System aufrechtzuerhalten - als Reaktion verstärke er seine autoritäre Form. Gleichzeitig verstärke sich die Konkurrenz von Beharrungs- und Erneuerungskräften, die die Ursachen und Lösungen der Krisen in unterschiedlicher Weise interpretieren (ebenda).

\subsubsection{Diskurstheoretische Verortung sozial-ökologischer Transformation}

In Kapitel 1 wurde der dieser Arbeit zugrunde liegende Transformationsbegriff als sozial-ökologischer Transformationsbegriff eingeführt. Es wurde darauf verwiesen, dass sich dieser Begriff seit einiger Zeit für Ansätze etabliert, „die in der kapitalistischen und imperialen Dynamik - die neben der Produktionsweise auch die Lebensverhältnisse der Menschen umfasst - die Ursachen der gegenwärtigen Probleme sehen, nicht deren Lösung“ (Brand: 2012: 270) und - u.a. im Anschluss an die Soziale Ökologie - den Zusammenhang der Krisendimensionen hervorheben (vgl. z.B. Brand 2014; Becker/Jahn 2000; Brand 2017). In der kritischen Transformationsforschung, an die ich mit meiner Arbeit anknüpfe, verweist er auf einen anspruchsvollen Transformationsbegriff, der auf dem Weg ,aus der kapitalistischen Vergesellschaftung heraus- und zu einer friedlichen, nachhaltigen und demokratischen Weltgesellschaft" (Demirović 2014: 429) prozessorientierte Politik mit sozial-ökologischen Kämpfen und Bewegungen verbindet und dabei ein offenes Konzept bleibt. Demokratisierung, nicht nur in Form von demokratischer Teilhabe an Entscheidungsprozessen, sondern auch an der Produktion, an der Öffentlichkeit, am gesellschaftlichen und individuellen Leben, ist dabei in vielen Ansätzen ein zentrales Element. „GesellschaftsTransformationen bedeutet Wandel des Wirtschafts-, Produktions- und Sozialmodells, der System- und der Lebenswelt“ (Reißig 2014: 73) und „umfasst den Wandel der Produktions- und Lebensweisen, der Macht- und Eigentumsstrukturen sowie der individuellen und gesellschaftlichen Deutungsstrukturen“ (ebenda: 75). Aus Perspektive Vorsorgenden Wirtschaftens steht dabei insbesondere auch der Wandel gesellschaftlicher Natur- und Geschlechterverhältnisse im Fokus wissenschaftlicher Betrachtung. 
Indes entwickeln (bislang) soziale Bewegungen, die für eine sozial-ökologische Transformation kämpfen, kaum einen größeren Einfluss ${ }^{10}$, bzw. verfügen nicht über die notwendige Repräsentation in politischen Entscheidungsgremien (bspw. Parteien). Zahlreiche sozial-ökologische Transformationsansätze und -konzepte stammen aus der gesellschaftlichen Linken. Diese erscheint allerdings in vielen Fragen uneinig und zersplittert. Teilen von ihr falle es schwer, sich von Vorstellungen wie ,der ideologischen Zentralität der Arbeiterklasse“ (Laclau/Mouffe 2015: 31), dem mit ihr verbundenen universellen Anspruch oder ,,der Rolle der Revolution als dem begründenden Moment im Übergang von einem Gesellschaftstyp zu einem anderen“ (ebenda) zu verabschieden. Zum Teil werde weiterhin das emanzipatorische Potenzial verkannt, das von der Ausweitung der Konfliktivität, bzw. der Betrachtung von Unterdrückungsstrukturen, auf die vielfältigen sozialen Bewegungen, wie dem Feminismus, der ethnischen und sexuellen Minderheiten, der marginalisierten Bevölkerungsteile, der Öko- oder der Anti-Akw-Bewegung ausgehe (ebenda: 32). Zwar werden Transformationsansätze in der deutschen Linken seit einiger Zeit, bspw. im Zusammenhang der kritischen Transformationsforschung (s.o.), erarbeitet, aber weder ist der Begriff der Transformation unumstritten, noch gibt es breiter anerkannte strategische Konzepte (Brie 2015a: 9ff.). „Noch ist die Verwendung des Terminus Transformation eher eine Absage an orthodoxe sozialdemokratische wie kommunistische Orientierung auf Reform bzw. Revolution als ein eigenständiger wirkungsvoller Ansatz" (ebenda: 12).

Mit ihrer Beitragsreihe zur „kritischen Transformationsforschung“ (www.rls.de) will das Institut für Gesellschaftsanalyse der Rosa Luxemburg Stiftung zur Schließung dieser Lücke beitragen. Der Transformationsbegriff wird dabei „[i]m Spannungsverhältnis von Reform und Revolution“ (Brie 2015a: 12) verortet. So habe es in linken Bewegungen von Anfang an einen „Widerspruch zwischen reformerischen und revolutionären Ansätzen“ gegeben. Waren diese anfänglich von Pluralität geprägt, so verengte sich der Konflikt Anfang des 20. Jahrhunderts auf den Kampf zwischen kommunistischer (bewaffneter) Revolution und sozialdemokratischer Reform (ebenda: 13). „Seit den 1980er Jahren trat der Widerspruch zwischen diesen großen Ansätzen hinter der Gemeinsamkeit ihres Scheiterns zurück“ (ebenda: 14). Weder Revolution noch Reform haben offensichtlich ,den Horizont für eine langfristige und radikal gedachte Emanzipation [...] weit genug geöffnet“ (Demirović 2014: 429). Nach Laclau/Mouffe (2015: 216) beinhalte Revolution in einem klassischen Verständnis die Institution eines Punktes der Wissens- und Machtkonzentration (verkörpert z.B. in der Diktatur des Proletariats) ,,von dem aus die Gesellschaft ,rational ‘ reorganisiert werden könnte“. Das Versprechen der Revolution fungiert demnach mit Opratko (2012: 248f.) als „säkularisiertes Jenseits“, in das gegenwärtig unerreichte/unerreichbare Emanzipationsversprechen hineinprojiziert werden können. Auf diese Art und Weise diente und diene bis heute das Versprechen der Revolution auch dazu, „Forderungen, Interessen und Bedürfnisse, die etwa Fragen der Geschlechterverhältnisse, der Sexualität oder der Alltagskultur betreffen, auf die ,Zeit danach` zu

10 Auch wenn Bewegungen wie Fridays for Future sicher einige Aspekte sozial-ökologischer Transformation adressieren, so fokussieren sie in ihrer Zielsetzung doch eher einzelne Elemente, wie bspw. Klimaschutz (vgl. z.B. www.fridaysforfuture.de - Forderungen). 
vertrösten und die damit verbundenen Anliegen und Kämpfe zu delegitimieren“ (ebenda). Eine solche Perspektive ist nach Laclau/Mouffe (2015: 216f.) aber mit dem Anspruch radikaler Demokratie, der Pluralität und der Offenheit unvereinbar - auch wenn es immer nur partielle Emanzipationen geben kann. Nach Laclau (2002: 41) ist die Anerkennung der Unmöglichkeit einer vollständigen Emanzipation die Voraussetzung für demokratische Politik, denn „Unvollständigkeit und Vorläufigkeit gehören zur Essenz der Demokratie“. So sei Demokratie nur möglich, „wenn kein objektiver Weg vorgezeichnet, kein endgültiger Zustand erreicht werden kann, wenn also etwas entschieden werden kann“ (Flügel-Martinsen 2017: 19). Laclau/Mouffe (2015: 216f.) plädieren daher für die „Vervielfachung politischer Räume“ und betonen den „Prozesscharakter jeder radikalen Transformation“, von dem der revolutionäre Akt (in einem prozessorientierten Verständnis) dann ein ,,inneres Moment“ sein kann. In diesem Verständnis verorte ich den Transformationsbegriff diskurstheoretisch im Sinne der , démocratie à venir' (Derrida 1995, 2003). Derrida unterscheidet die ,démocratie à venir' von der zukünftigen Demokratie, in der die Zukunft das noch-nichtPräsente als Modalität der Gegenwart darstellt. Demokratie ereigne sich nicht morgen, die „Temporalität der Demokratie ist Kommen, sie ist jetzt stattfindende Ankunft“ (Critchley 1998: 205). Die ,démocratie à venir“ wird also als ein Prozess der Demokratisierung betrachtet.

Ein in dieser Weise verstandener emanzipatorischer Begriff von Transformation reflektiert, wie Demirović (2014: 429f.) fordert, den emanzipatorischen Mangel von Revolution und Reform, die negativen historischen Erfahrungen des Staatsozialismus, seine Selbstillusionierungen und seine autoritären Folgen und „zeugt von einer neuen Bereitschaft, die alten Gräben zu überwinden, sich der Pluralität alternativer Ansätze zu stellen und in den realen Kämpfen einen offenen Such- und Lernprozess einzuleiten [...]“" (Brie 2015a: 14).

Nach Reißig (2015: 108f.) verkörpere der Transformationsbegriff „,die Ereignisgeschichte, die Entstehung des ,Neuen“ im ,Alten“, die Kontingenz, die Offenheit des Prozesses, unterschiedliche Übergangsformen und den Verzicht auf Mystifizierung und Heilserwartungen“. In einem solchen Transformationsbegriff verschränken sich die Zeitperspektiven, das Morgen beginne im Heute (Demirović 2014: 430). Vor dem Hintergrund des Widerspruchs zwischen dem Zeitdruck eines grundsätzlichen Wandels und der anhaltenden Machtverhältnisse, die diesen blockieren (Klein 2014: 103), bewahre der Transformationsbegriff vor dem Verlust der Handlungsfähigkeit. Er verweise somit auch auf eine grundsätzlichen Änderung in der Logik gesellschaftlichen Wandels (Demirović 2014: 429). Er beschreibe einen tiefgreifenden Typ von Wandel, der sich auf allen Ebenen abspiele und auf alle Ebenen auswirke, der die Zeitverhältnisse politisiere (Rilling 2014: 42), der intentional, gestaltend und zugleich eigendynamisch, organisch-evolutionär sei (ebenda: 54), der - im Gegensatz zur weniger grundlegenden Reform - „durch Änderungen und Umformungen wesentlicher Prozessstrukturen, Institutionen, Kultur- und Ordnungsmuster, gesellschaftlicher Lebensweisen und der Neukonstitution und -konstruktion von Gesellschaftstypen und -modellen“ (Reißig 2014: 53) sowie damit zusammenhängend der Geschlechterverhältnisse und der Ökonomie gekennzeichnet sei.

Ein macht- und herrschaftskritischer Transformationsbegriff ist Grundlage für eine feministische Positionierung innerhalb der Transformationsforschung. Eine solche Positionierung wird in der vorliegenden Arbeit im Konzept des Vorsorgenden Wirt- 
schaften gefunden, das im Folgenden vorgestellt und diskurstheoretisch eingebettet wird.

\title{
3.2 POSITIONIERUNG: VORSORGENDES WIRTSCHAFTEN ALS SOZIAL-ÖKOLOGISCHES TRANSFORMATIONSKONZEPT
}

„Vorsorgendes Wirtschaften ist ein Weg zu einer nachhaltigen Ökonomie, der im Hier und Heute ansetzt, sich im Gehen festigt und weiter herausbildet und in diesem Prozess die kapitalistische Ökonomie hinter sich lässt" (Biesecker/Gottschlich 2012: 321). In dieser Prozessorientierung ist das Vorsorgende Wirtschafen ${ }^{11}$ an die ,kommende Nachhaltigkeit' sowie die ,démocratie à venir' anschlussfähig und weist perspektivisch über den Kapitalismus hinaus. Im Zentrum der Arbeit des Netzwerks Vorsorgendes Wirtschaften stand von Anfang an die Kritik an der Trennungsstruktur der kapitalistischen Marktökonomie und die damit verbundene Externalisierung des sogenannten Reproduktiven, also sozial weiblicher und unbezahlter Arbeit sowie der Produktivität der Natur.

\begin{abstract}
„Ausgehend hiervon wurde und wird für eine ökonomische Verfasstheit der Gesellschaft gestritten jenseits des für die Industriemoderne konstitutiven Trennungsverhältnisses zwischen in der ökonomischen Bewertung externalisierten sozial-ökologischen Prozessen auf der einen und der umfassenden Internalisierung der selben sozial-ökologischen Prozesse im materiellen Verwertungsprozess auf der anderen Seite“(Amri-Henkel u.a. 2017: 10).
\end{abstract}

Das Vorsorgende Wirtschaften zielt auf die Integration dieser Prozesse in das ,Ganze der Ökonomie' und einer damit verbundenen Wertschätzung und (nicht-kapitalistischen) politisch ökonomischen Inwertsetzung des bisher Externalisierten (AmriHenkel u.a. 2017: 10; Biesecker/Hofmeister 2013a: 138). Damit verbunden ist ein Perspektivenwechsel:

„Von den bisher als ,reproduktiv“ abgespaltenen Bereichen, der unbezahlten Tätigkeiten, von denen ein großer Teil sozial Frauen zugewiesene Sorge- oder Care-Arbeit ist, und der Natur aus wird auf die in modernen Industriegesellschaften kapitalistisch verfasste Marktökonomie ${ }^{12}$ geblickt“ (Biesecker/Hofmeister 2013a: 138).

Aus dieser Perspektive ist Ökonomie nicht mehr nur Marktökonomie, sondern die Versorgungsökonomie, die Natur, die staatlichen Bereiche sowie die Non-profit Ökonomie geraten als Handlungsräume in den Blick (Biesecker/Hofmeister 2006: 9). Die „Handlungsprinzipien, Strukturen und spezifische[n] Eigenschaften“ (Theorie-

$11 \mathrm{Zu}$ dem dieser Studie zugrundeliegenden diskurstheoretischen Verständnis Vorsorgenden Wirtschaftens vgl. Kapitel 1 und Fußnote 37.

12 Im Folgenden ist mit dem Begriff Marktökonomie/Marktwirtschaft vereinfachend die kapitalistisch verfasste Marktökonomie gemeint. Für die spezielle Bedeutung Sozialer Marktwirtschaft in Deutschland vgl. Fußnote 3 in Kapitel 3. 
gruppe Vorsorgendes Wirtschaften 2000: 27) der Versorgungswirtschaft werden sichtbar. Die Einnahme einer feministischen Analyseperspektive mit Hilfe der Kategorie Geschlecht ermöglicht die Kritik geschlechtsspezifischer Rollenverteilungen sowie der Geschlechterverhältnisse insgesamt (ebenda: 31). Kritisiert wird aber nicht nur die Trennungsstruktur der kapitalistischen Marktökonomie, sondern die auf der Neoklassik ${ }^{13}$ basierende ökonomische Theorie und Praxis sowie deren zugrunde liegenden Prämissen insgesamt. Das mechanistische, positivistische Weltbild, auf welchem diese Theorie zumindest implizit aufbaut, fußt auf der Annahme, dass Ökonomie, Gesellschaft und Natur strikten Gesetzmäßigkeiten folgen und konnotiert Naturbeherrschung gleichzeitig positiv (vgl. Kapitel 3.1.1). Im Vorsorgenden Wirtschaften dagegen werde die Welt als „vernetztes Ganzes“ gesehen (Theoriegruppe Vorsorgendes Wirtschaften 2000: 29), in der die Menschen nicht losgelöst von der Natur und den sozialen Beziehungen betrachtet werden, sondern eingebettet in vielfältige Beziehungen, in das System. Diese Sichtweise wirke sich sowohl auf das Rationalitätsverständnis als auch auf das Menschenbild aus: Wenn im Gegensatz zum Menschenbild des homo oeconomicus und dem damit zusammenhängenden methodologischen Individualismus ${ }^{14}$ der Neoklassik „die Grundfigur ökonomischen Handelns eine soziale Beziehung ist" (Biesecker/Kesting 2003: 171), der Mensch also nicht losgelöst von seinem Umfeld agieren könne, stelle individuelle Nutzenmaximierung keine geeignete Entscheidungsgrundlage dar (Theoriegruppe Vorsorgendes Wirtschaften 2000: 28ff.). Das Menschenbild des Vorsorgenden Wirtschaftens ist also ein positives: „Sorge und Vorsorge für sich und für andere sowie Verständigung

13 Als gemeinsame Charakteristika der frühen Neoklassik gelten nach Biesecker/Kesting (2003: 88f.): „,das Verständnis der Ökonomik als Naturwissenschaft“; „,er „,methodologische Individualismus“ (vgl. Fußnote 14), der universelle Anspruch der Theorie und damit verbunden „den Verlust der Geschichtlichkeit“" sowie die Annahme einer unveränderlichen „Natur des Menschen“ und letztlich „die Idee des Grenznutzens“.

14 Homo oeconomicus und methodologischer Individualismus: Der homo oeconomicus ist ein vom sozialen und ökologischen Lebensumfeld losgelöster reiner Wirtschaftsmensch (ein ,sozial männlicher Kapitalist'), der sich ausschließlich auf dem Markt betätigt, rational handelt und dabei seinen individuellen Nutzen maximiert (von Winterfeld u.a. 2012: 22ff.; Habermann 2008). Dieses Menschenbild findet seine Ursprünge im „Wohlstand der Nationen“ von Adam Smith: „Nicht vom Wohlwollen des Metzgers, Brauers und Bäckers erwarten wir das, was wir zum Essen brauchen, sondern davon, daß sie ihre eigenen Interessen wahrnehmen. Wir wenden uns nicht an ihre Menschen- sondern ihre Eigenliebe, und wir erwähnen nicht die eigenen Bedürfnisse, sondern sprechen von ihrem Vorteil“" (Smith 1974: 17). David Ricardo (1772-1823) beging das später so von Schumpeter (1965: 584) bezeichnete „Ricardianische Übel“ und übertrug diesen ausschließlich an der Verhaltensregel des Selbstinteresses orientierten abstrakten Wirtschaftsmenschen auf die Realität (Biesecker/Kesting 2003: 65; Hartfiel 1968: 82-87). Die Annahme, die Gesellschaft bestehe ausschließlich aus homines oeconomici, ermöglicht den Schluss vom Individuum auf die Gesellschaft, was als methodologischer Individualismus bezeichnet wird (Biesecker/ Kesting 2003: 130f.). Aus dem Menschenbild ergibt sich das Rationalitätsverständnis der Neoklassik, das als rational definiert, was auf individueller und gesellschaftlicher Ebene der Nutzenmaximierung dient und auf unternehmerischer Ebene der Gewinnmaximierung. 
und Kooperation bestimmen das Miteinander einer Gemeinschaft" (ebenda: 30). Dieses Menschenbild steht in Verbindung zu einem diskursorientierten, deliberativen Politikverständnis, das auf die Eröffnung von Aushandlungsräumen zielt. Hier setzt eine häufige Kritik am Vorsorgenden Wirtschaften an, das Menschenbild sei illusorisch, wobei Herrschafts- und Machtfragen zu kurz kämen (Gottschlich 2017: 263).

Konzeptionelle Einflüsse gewinnt das Vorsorgende Wirtschaften aus dem Institutionalismus, dem Bielefelder Subsistenzansatz, der Haushaltswissenschaft, der Ökologischen Ökonomie, der feministischen Wissenschaftstheorie und der Wirtschaftsethik. Mit dem Institutionalismus teilt das Vorsorgende Wirtschaften die Ansicht, dass Individuen nicht autonom agieren, sondern immer von institutionellen Regelungen, wie der Arbeitsteilung oder der Rechtsordnung beeinflusst werden. ${ }^{15}$ Institutionen sollten daher auf Chancengleichheit zielen und auf Verteilungsgerechtigkeit ausgerichtet sein (Theoriegruppe Vorsorgendes Wirtschaften 2000: 34f.). Der Bielefelder Subsistenzansatz stellt der Warenwirtschaft die Subsistenzwirtschaft entgegen. Ansatzpunkte für das Vorsorgende Wirtschaften sind u.a. in der Gebrauchswertorientierung, der Ausrichtung auf die Erhaltung und Ermöglichung des Lebens und dem vorausschauenden Handeln zu finden. An die Haushaltswissenschaft knüpft das Vorsorgende Wirtschaften mit der Kritik an der geschlechtsspezifischen Arbeitsteilung an, der Einbeziehung der Versorgungsökonomie sowie der Bedarfsorientierung in alläglichen Lebenszusammenhängen (ebenda: 37ff.). Im ökologischen Denken, das eine Wiederverortung im ökologisch-naturwissenschaftlichen Denken leiste, finden sich Orientierungen in der Ökologischen Ökonomie. Das Vorsorgende Wirtschaften verstehe sich aber ,als eine um die ethische und soziale Dimension erweiterte und gender-sensible Konzeption ökologischer Ökonomie“ (ebenda: 47ff.).

Der hierarchischen Strukturiertheit der Marktökonomie und der damit verbundenen Trennung zwischen produktiven und reproduktiven Bereichen setzen Adelheid Biesecker und Sabine Hofmeister die Kategorie der (Re)Produktivität ${ }^{16}$ entgegen, die auf die Auflösung dieser Trennung zielt (Biesecker/Hofmeister 2006). Sie ziele auf die Vermittlung von Produktion und Reproduktion, Erhalten und Gestalten, Herstellen und Wiederherstellen, die dann als Einheit, als „,der Natur und den Menschen immanente Kraft, Neues zu schaffen“ (Biesecker/Hofmeister 2013a: 138) erscheinen. Mit der Kategorie der (Re)Produktivität werde nicht nur die geschlechtsspezifische Arbeitsteilung aufgehoben, sondern auch die Trennung von Gesellschaft und Natur (ebenda: 143). Im Gegensatz zur ,Einäugigkeit‘ der marktökonomischen Produktivität verkörpere die Kategorie (Re)produktivität somit die ,[...] prozessuale, nicht durch Abwertungen getrennte Einheit aller produktiven Prozesse in Natur und Gesellschaft, bei gleichzeitiger Unterschiedenheit“ (Biesecker/Hofmeister 2006: 19). Das Ökonomische werde als politischer Raum zurückgewonnen, zum einen durch die

15 Aus diskurstheoretischer Perspektive wären diese Institutionen als sedimentierte Diskurse zu betrachten, die sowohl von Individuen beeinflusst werden, als auch diese selbst beeinflussen - die Individuen stehen nicht außerhalb des Diskurses.

16 Die Kategorie der (Re)Produktivität wird innerhalb des Netzwerks Vorsorgendes Wirtschaften kontrovers diskutiert. Ich ordne sie hier aber dem Vorsorgenden Wirtschaften zu, da sie auch in gemeinsamen Publikationen des Netzwerks eine Rolle spielt und ebenfalls Teil meiner Positionierung innerhalb des Netzwerks darstellt. 
Denaturalisierung der marktökonomischen Produktivität, zum anderen, indem die Kriterien für ein (Re)Produktivitätskonzept Gegenstand diskursiver Aushandlungsprozesse seien und nicht vermeintlich objektivistisch bestimmt werden (Biesecker/ Hofmeister 2013a: 152).

Produktion im marktökonomischen Sinne ,- wirtschaftstheoretisch bisher als der einzige produktive Akt gesetzt - erweist sich aus (re)produktionstheoretischer Perspektive als (oftmals verschwenderischer) Akt der Konsumtion lebendiger Produktivität“ (ebenda: 152). Während im von Externalisierung geprägten marktökonomischen Produktionsprozess eine dichotome Beziehung zwischen Bewertung und Verwertung bestehe, werden in einem (Re)Produktionsprozess Produktion und Konsumtion eingebettet in ökologische und soziale Prozesse, die als ebenso produktiv betrachtet werden. Natur werde ,,als Naturproduktivität zum Ausgangs- und als Naturprodukt zum Endpunkt“ (Hofmeister/Immler 1998: 28) dieses von Veränderung geprägten offenen Prozesses (Biesecker/Hofmeister 2006: 132ff.). Eine vorsorgende Ökonomie ist demnach also nicht wachstumsorientiert, sondern (re)produktionsorientiert, d.h. auf erhaltendes, bzw. erneuerndes Gestalten (Biesecker/Hofmeister 2013b: 241ff.) gerichtet. Im Ansatz der (Re)Produktivität verdeutlicht sich ein Potenzial der feministischen Perspektive auf Transformation: Sie kann über eine bloße Kritik an kapitalistischen Produktionsverhältnissen hinausgehen, indem sie das Produktivitätsverständnis an sich in Frage stellt. Der Ansatz der (Re)Produktivität bietet daher Ansatzpunkte für eine ,neue ' politische Ökonomie. Er setzt den notwendigen Umbruch der Geschlechterverhältnisse mit dem Umbruch der gesellschaftlichen Naturverhältnisse und ökonomischen Verhältnisse in einen Zusammenhang.

Während klassische umweltsoziologische Forschungsarbeiten entsprechend der neoklassischen ökonomischen Paradigmen (s.o.) häufig individuelles umweltorientiertes Verbraucherverhalten in den Mittelpunkt stellen, somit die Suffizienzfrage individualisieren und Verteilungsgerechtigkeit ausblenden, indem Umweltbewusstsein bspw. damit verbunden wird ,(a) mit weniger zufrieden zu sein und (b) dafür mehr zu bezahlen“ (Huber 2001: 302) macht das Vorsorgende Wirtschaften Suffizienz zur „gesellschaftlichen Gemeinschaftsaufgabe“ (von Winterfeld 2007: 51). Von Winterfeld (2007: 47) betont die kritische Dimension von Suffizienz, die in moralisierenden Apellen verloren gehe und darin liege, dass Suffizienz sich mit einer wachstumsorientierten kapitalistischen Gesellschaft insgesamt widerspreche. Nicht nur, aber ganz besonders vor dem Hintergrund einer globalen Perspektive, werfe Suffizienz die Frage nach Verteilungsgerechtigkeit auf. So beanspruche der europäische Lebensmittelkonsum nicht nur Flächen innerhalb Europas, sondern vor allem auch in Lateinamerika, Nordamerika und Westafrika, etc., z.B. für Futtermittelanbau (Soja, etc.), Kaffee, Kakao, etc. (ebenda: 49). „Der Stoff also, aus dem der Wohlstand des Nordens gemacht ist, ist nicht ungerechtigkeitsneutral“ (ebenda: 51). Suffizienz in einem kritischen Sinne richtet sich nicht nur an Konsument*innen, sondern auch an Unternehmer*innen und Politiker*innen, wodurch Suffizienz nicht mehr nur auf ein Weniger, sondern auch auf eine andere Art des Produzierens und der Politik verweist. „Nachhaltige Entwicklung bleibt ohne die Anstrengung einer grundlegenden Veränderung gesellschaftlicher Prämissen insuffizient" (ebenda: 54). Suffizienz sei eine politische Angelegenheit und zwar nicht in dem Sinne, dass der Staat sozialpolitische Verantwortung individualisiere und diejenigen zum Maßhalten aufruft, die immer schon Maß gehalten haben (z.B. wie es bei der Einführung von Hartz IV der Fall war), son- 
dern im Sinne einer auszuhandelnden Politik der Vorsorge, die nicht in irreparable Schäden investiere (bspw. Subventionierung von Atomkraft, Massentierhaltung, der Rüstungs- oder der Automobilindustrie), sondern in Prävention und Ermöglichung von Suffizienz (ebenda: 51ff.). Der Wachstumszwang der kapitalistischen Gesellschaft ist mit einem Konsumzwang verbunden, dem Biesecker/von Winterfeld (2013b: 268) die Suffizienzforderung entgegenstellen: „Niemand soll immer mehr haben wollen müssen“. Diese Forderung fragt nicht danach „wie viel genug ist (Pflicht zur Suffizienz), sondern nach dem, was zu viel ist (Recht auf Suffizienz)“ (ebenda: 268).

\subsubsection{Handlungsprinzipien}

Bereits in der ersten Publikation 1994 (Busch-Lüty u.a. 1994) wurden drei Handlungsprinzipien Vorsorgenden Wirtschaftens formuliert, die als Voraussetzungen für eine Vorsorgende Wirtschaftsweise gelten: „Vorsorge“, „Kooperation“ und „Orientierung am für das gute Leben Notwendigen ${ }^{17 “ “(J o c h i m s e n ~ u . a . ~ 1994: ~ 10) . ~ D i e ~ d r e i ~}$ Handlungsprinzipien stehen den ,in der Erwerbswirtschaft dominierenden Prinzipien Nachsorge, Konkurrenz und Orientierung an monetären Größen gegenüber[...]“ (Knobloch 2013: 36). Sie sind „Ausgangs- und Orientierungspunkt für die Theoriebildung“ und Bezugspunkt für unterschiedliche Disziplinen (Theoriegruppe Vorsorgendes Wirtschaften 2000: 52ff.).

\section{Vorsorge}

„Über das Handlungsprinzip Vorsorge verortet sich der vorsorgend Handelnde Mensch vorausschauend im Bewusstsein seiner eigenen räumlichen, zeitlichen, natürlichen und sozialen Beziehungen und Grenzen. Er verortet sich im Leben und in der Gesellschaft, indem er Zeit, Raum, die Mitmenschen und die natürliche Mitwelt, die ebenfalls in Zeiten und Räumen leben, in sein Blickfeld nimmt und in seine Handlungen einbezieht“" (Theoriegruppe Vorsorgendes Wirtschaften 2000: 50.).

Es beinhaltet „ein bewusstes Sich-In-Beziehung-Setzen des Menschen zu seinen Mitmenschen (einschließlich zukünftiger Generationen), zu seiner Mitwelt, von und zu sich selbst als menschlichem Lebewesen“ (ebenda: 58). Vorsorge setzt verschiedene prozessorientierte Kriterien voraus, welche sich bspw. in Langsamkeit, Vorsicht im Sinne von Fehlerfreundlichkeit und Bedachtsamkeit, Voraussicht bezüglich Handlungsfolgen, Umsicht bezüglich Nebenfolgen und Rückwirkungen, zeitlicher und räumlicher Übersicht sowie Rücksicht, ,die sich in der Begrenzung eigener Ansprüche und dem Bewußtsein von Gewordenem/Gewachsenen äußert“ (Jochimsen u.a. 1994: 9), konkretisieren (Theoriegruppe Vorsorgendes Wirtschaften 2000: 50). Dies beinhaltet auch eine kritische Bedürfnisreflexion, bei der „Schonung und Nicht-

17 Das Handlungsprinzip „Orientierung am für das gute Leben Notwendigen“ hieß anfangs „Orientierung am Lebensnotwendigen“ und wurde später umformuliert, um ein Missverständnis als Aufforderung ,zum Gürtel-enger-Schnallen, als ein nur auf Einschränkung zielendes Prinzip“ zu vermeiden (Biesecker/von Winterfeld 2013b: 272). 
Handeln“ als Optionen selbstgewählter Genügsamkeit in Betracht kommen (Jochimsen u.a. 1994: 9).

Der Begriff der Vorsorge verweist zudem auf Sorgebeziehungen und -tätigkeiten, da diese dem langfristigen Erhalt „sozialer und physischer Beziehungen des Menschen zu seiner Mitwelt" dienen (Theoriegruppe Vorsorgendes Wirtschaften 2000: 58). Sorgen wird weiterentwickelt zum Begriff des ,vorsorgenden Handelns‘. Während Sorgen sich zunächst nur auf Menschen im unmittelbaren Umfeld bezieht (bspw. Freund*innen, Familienmitglieder), bezieht sich der Begriff der ,Vorsorge“ auf alle vom Handeln Betroffene (bspw. zukünftige Generationen oder Menschen, die in anderen Weltregionen leben). Er bezieht sich aber nicht nur auf Menschen, sondern auch auf die natürliche Mitwelt - jetzt und in Zukunft (Biesecker/Kesting 2003: 169; Theoriegruppe Vorsorgendes Wirtschaften 2000: 58ff.). „,Vorsorge“ meint somit die Sorge für die zukünftige Gegenwart Anderer“ (Amri-Henkel u.a. 2017: 10). Sorgendes wird zu vorsorgendem Wirtschaften durch die Einbeziehung zukünftiger Betroffener (Hofmeister/Adam 2000: 238ff.). Mit dem Handlungsprinzip der Vorsorge zielt somit das Wirtschaften in der Gegenwart auf die (Re)Produktion seiner „sozial-ökologischen Voraussetzungen“ (Biesecker u.a. 2019: 121). Dies verdeutlicht die intertemporale, sozial-ökologische Perspektive des Handlungsprinzips, die bereits in Kapitel 3.1.1 eingeführt wurde und eine „Ökonomie in Zeiten“ (Adam 1998) impliziert, also „die Beachtung der verschiedenen Zeitskalen, Zeitmuster und qualitäten der verschiedenen am Wirtschaftsprozess beteiligten menschlichen und nichtmenschlichen Akteur*innen in der Gegenwart“ (Biesecker u.a. 2019: 122). Vorsorgendes Wirtschaften ist auch ein Wirtschaften im Zeitkontinuum, d.h., dass das gegenwärtige Wirtschaften nicht nur auf die zukünftige Gegenwart Anderer zielt, sondern gleichzeitig ,die physisch materiellen Resultate vergangener Wirtschaftsprozesse aufnimmt und transformiert" (ebenda; vgl. auch Adam/Groves 2007; Biesecker/Hofmeister 2013a: 148). Eine dafür notwendige vorausschauende „Langfristökonomie“ kann nur durch eine diskursive Entscheidungsfindung erreicht werden (Hofmeister/Adam 2000: 238ff.).

Während in der neoklassischen Theorie von einer Symmetrie der Ausgangsbedingungen ausgegangen wird (jede*r kann alles erreichen), setzt Vorsorge die Anerkennung von und den verantwortlichen Umgang mit Asymmetrien sowie den mit ihnen verbundenen Abhängigkeiten und Hierarchien voraus. Dies umfasst sowohl Asymmetrien zwischen Menschen, als auch zwischen Menschen und natürlicher Mitwelt (Biesecker 1996: 11). Sorgebeziehungen können keine Tauschbeziehungen sein, sie sind bedürfnisorientiert (Theoriegruppe Vorsorgendes Wirtschaften 2000: 59).

In der ,Ethik des Sorgens“ verdeutlicht sich der Gegensatz zum Menschenbild des isolierten homo oeconomicus. Ein vorsorgendes Handeln wird als wichtiger Schritt zur „Überwindung des Egozentrismus“ (Jochimsen u.a. 1994: 9) betrachtet. Zudem wird die Zentralität von Mensch-Ding-Beziehungen durch die Zentralität von Mensch-Mensch-Beziehungen ersetzt (Biesecker/Kesting 2003: 170).

Auch wenn sich die Inhalte des Handlungsprinzips Vorsorge prinzipiell auf die politische Ebene übertragen lassen (Lang 2000: 217f.), lag der Schwerpunkt in den anfänglichen Arbeiten des Vorsorgenden Wirtschaftens zunächst auf der individuellen Ebene, wodurch die individuelle (Eigen-)Verantwortung in den Vordergrund gerückt erschien. So formulierte das Netzwerk später selbstkritisch: „In den ersten Jah- 
ren der - auch theoretischen - Findungsphase hat sich das Netzwerk Vorsorgendes Wirtschaften mit der Frage nach Herrschaftsverhältnissen kaum auseinander gesetzt. Im Vordergrund stand zunächst, eigene Ansätze in Wissenschaft und Praxis zu finden“ (Theoriegruppe Vorsorgendes Wirtschaften 2000: 59). Für den Vorsorge-Begriff folgte daraus, dass dieser

„nicht nur - und möglicherweise auch nicht vor allem - im anscheinend herrschaftsfreien Raum privat sorgend handelnder Individuen anzusiedeln [ist]. Sondern es gilt zum einen, nach dem Prinzip der Vorsorge in der Erwerbsökonomie zu fragen und zum anderen auch den eigenen Kontrastbegriff auf Ambivalenzen hin abzuklopfen: ,Vorsorge' ist nicht automatisch herrschaftsfrei $[\ldots]$ “. (ebenda: 56 ).

In späteren Arbeiten, bspw. zu Gesellschaftsverträgen (z.B. Biesecker/von Winterfeld 2013a) oder zu (Re)produktivität (z.B. Biesecker/Hofmeister 2013a; Biesecker/Hofmeister 2006) wurde der Vorsorge-Begriff dann zunehmend im Politischen und im (überindividuell) Ökonomischen verortet und die herrschaftskritische Dimension vertieft (vgl. z.B. Forschungsverbund „Blockierter Wandel?“ 2007).

In der Entwicklung der Kategorie (Re)Produktivität knüpfen Biesecker/Hofmeister an die zentralen Elemente des mit dem Vorsorgeprinzip verbundenen Menschenbilds an und betten diese in ihr Konzept ein: Die Vorausschau auf Handlungsfolgen, ,die Verbindung von sozialen mit natürlichen Prozessen und die Eingebundenheit des wirtschaftlichen Handelns in Raum- und Zeitskalen von Gesellschaft und Natur" (Biesecker/Hofmeister 2013a: 151). Eine (re)produktive Ökonomie sei keine „lineare Durchflussökonomie“, der (Re)produktionsprozess sei ein Prozess in den „sozialen und ökologischen Zeiten“, der auch auf künftige Wirtschaftsprozesse vorausschaue (ebenda: 152).

Die zunächst mangelnde Übertragung des Vorsorgeprinzips auf die staatspolitische Ebene hängt möglicherweise mit dem uneinheitlichen Staatsverständnis innerhalb des Netzwerks zusammen, das ,von sozialstaatsinterventionistisch bis kommunitaristisch“ reiche (Gottschlich 2017: 268). Während in den Arbeiten von Biesecker/von Winterfeld das Gerechtigkeitspostulat und damit zusammenhängend die Gewährleistung von Möglichkeitsräumen, die staatlicher Leistungen und sozialstaatlicher Verantwortung (bspw. durch ein Bedingungsloses Grundeinkommen) bedürfen (z.B. Biesecker/von Winterfeld 2005), für das Staatsverständnis zentral sind, steht nach einem kommunitaristischen Verständnis (z.B. Lang 2004) die Rolle der Gemeinschaften für die Wohlfahrtsproduktion im Mittelpunkt (Gottschlich 2017: 268). ${ }^{18}$

\section{Kooperation}

„Mit der Formulierung dieses Handlungsprinzips betont das Netzwerk, dass die Herstellung von Gütern und Leistungen - im und jenseits des Marktes - grundsätzlich der Kooperation verschiedener marktlicher und nichtmarktlicher Akteure bedarf" (Amri-Henkel u.a. 2017: 11). Dabei wird nicht gegeneinander (also konkurrierend), sondern miteinander (also kooperierend) gewirtschaftet. Die Ziele und Wege, ebenso

18 Ich ordne mich mit meiner Arbeit dabei eher im Staatsverständnis von Biesecker/von Winterfeld ein und verorte die Handlungsprinzipien politisch und ökonomisch. 
wie die Normen des Wirtschaftens werden diskursiv ausgehandelt, ,[[k]ooperatives Wirtschaften ist nicht ziel-, sondern prozessorientiert“ und damit ergebnisoffen (Theoriegruppe Vorsorgendes Wirtschaften 2000: 51). Kooperation werde dabei nicht nur diskursiv koordiniert, sondern auch über Mitgefühl und Moral, d.h. das sozial Weibliche und bislang als nicht-rational, nicht-objektiv (und daher Fehl-amPlatz) Abgewertete werde für die Ökonomie zurückgewonnen, wodurch eine soziale „Feminisierung der Wirtschaft" erfolge (Biesecker 1994: 30). Während in der neoklassischen Theorie Kooperation nur strategisch gedacht werden kann und sich stets an Eigennutz orientiert, ist das Prinzip der Kooperation des Vorsorgenden Wirtschaftens auf Verständigung gerichtet (Theoriegruppe Vorsorgendes Wirtschaften 2000: 51). Das Gegenseitigkeitsprinzip ist somit ein anderes: Es beruht nicht auf einer materiellen Tauschbeziehung (,nur wenn Du mir gibst, geb“ ich Dir“), sondern auf Gegenseitigkeit in Form von Anerkennung, Sorge und Wertschätzung (ebenda: 51ff.). Auch dabei spielt der Umgang mit Asymmetrien eine Rolle - damit Kooperation funktioniert, müssen Machtverhältnisse reflektiert werden und andere trotz Ungleichheiten als gleichberechtigt wahrgenommen werden (Theoriegruppe Vorsorgendes Wirtschaften 2000: 60; Biesecker 1994: 29).

Solidarität als Voraussetzung kooperativen Wirtschaftens, ,entsteht unter anderem durch die Einsicht in eine gemeinsame Einbettung beispielsweise in die Gesellschaft, Gemeinschaft oder Natur“ (Jochimsen u.a. 1994: 9). Das Handlungsprinzip Kooperation trägt dazu bei „das ,Ganze des Wirtschaftens“ in den Blick zu nehmen“, denn ,alle Beteiligten sind Teil des Ganzen und nötig für das Ganze“ (Theoriegruppe Vorsorgendes Wirtschaften 2000: 60). Dazu zählen nicht nur die in der Gegenwart beteiligten Menschen, sondern auch momentan sprachlose Kooperationspartner*innen wie zukünftige Generationen oder die ,natürliche Mitwelt‘. Es handelt sich daher um eine ,verantwortliche Kooperation', in dem Sinne, dass die Lebensinteressen dieser Kooperationspartner*innen gleichermaßen berücksichtigt werden. Die zukunftsfähige Gestaltung des Wirtschaftens im Sinne von Lebensfreundlichkeit und ,Naturverträglichkeit‘ ist Aufgabe der Kooperation als Verständigungsprozess (ebenda: 51ff.). ${ }^{19}$ Als voraussetzende „Handlungs- und Verhaltensweisen“" sollen die Kooperierenden

,[s]olidarisch sein, sich miteinander verständigen, konsensbereit sein, offen sein und aktiv zuhören, Eigennutz zurückstellen können, sich Zeit nehmen und geduldig sein, Dinge, Erfahrun-

19 Biesecker/Kesting (2003: 180) unterscheiden bezüglich Kooperation zwischen drei Gruppen von Handlungstypen: „strategische Kooperation“, „verständige Kooperation“ und „,vorsorgend-verantwortliche Kooperation“. „Strategische Kooperationen sind [...] Kooperationen, die wirtschaftlich handelnde Individuen eingehen, um die je eigenen Ziele mit Hilfe von Anderen zu maximieren“. Sie ist auf Symmetrie begründet, ,,auf Kooperation unter Gleichen“ (ebenda: 180). „Verständige Kooperation“ dagegen berücksichtigt Machtverhältnisse und gründet auf dem Prinzip der Fairness. Die Handlungskoordination erfolgt diskursiv. „Vorsorgend-verantwortliche Kooperation“ beinhaltet das Einbeziehen aller, „sprachlosen“ Betroffenen, wie zukünftige Generationen und die natürliche Mitwelt. In den Verständigungsprozess wird der Gedanke der Sorge und des Vorsorgens integriert (ebenda: 180ff.). 
gen und Beziehungen bewahren und sorgfältig handeln, sich selbst beschränken können, [sich an Sachthemen statt Hierarchien orientieren], einsichtig sein“ (Jochimsen u.a. 1994: 9).

Auch hier scheint wieder ein anfänglich starker Fokus auf die individuelle Eigenverantwortung durch, der mit einem hohen moralischen Anspruch an den*die Einzelne*n verbunden ist und Machtverhältnisse noch wenig in den Vordergrund stellt. Dies mag mit der Absicht zusammenhängen, zunächst ein zum homo oeconomicus, der als einzigen Handlungsmodus die Konkurrenz kennt, kontrastives Menschenbild zu entwerfen. Gleichzeitig kam das Kooperationsprinzip, bspw. „als altes Prinzip haushälterischen Wirtschaftens“, historisch „zunächst außerhalb des Marktes“ zur Anwendung (Biesecker u.a. 2019: 122), weshalb seine politische, gesellschaftliche und ökonomische Einordnung möglicherweise erst im späteren Verlauf der Theoriebildung vorgenommen wurde.

„Das Prinzip der Kooperation muss sich deshalb in herrschaftskritischer Perspektive immer wieder fragen und [sic] fragen lassen, wie das Entstehen von Kooperationsfähigkeit gesellschaftlich organisiert werden kann. Kooperation spielt sich nicht automatisch friedvoll und gleichberechtigt ab, sondern bedarf der gesellschaftlichen Ermöglichungsräume“" (Theoriegruppe Vorsorgendes Wirtschaften 2000: 56f.).

Auch dieses Handlungsprinzip wurde in späteren Arbeiten stärker politisch und herrschaftskritisch verortet und zudem wurde über die Kategorie der (Re)Produktivität der Fokus auf die Mensch-Natur-Beziehung verstärkt. Werde die Natur als Kooperationspartnerin mit einbezogen, so werde die Aufgabe der Vermittlung zwischen Arbeits- und Naturproduktivität deutlich (Biesecker/Hofmeister 2006; Biesecker/Hofmeister 2013a). Dies subvertiert die gängige Auffassung von Natur als von Gesellschaft unabhängiger ,Kapitalstock“ (bspw. wenn es um ,planetarische Leitplanken“ geht) (Amri-Henkel u.a. 2017: 11), als möglichst konstant zu haltende Bestandsgröße, die allenfalls als Rohstoffquelle und Abfallsenke in den Blick kommt (insofern dies Kosten verursacht). Im Gegensatz dazu verweist das Kooperationskonzept des Vorsorgenden Wirtschaftens

„auf die Aufgabe der bewussten Vermittlung zwischen Arbeits- und Naturproduktivität mit Blick auf ein künftig als Quelle des Wirtschaftens taugliches Naturprodukt. Diese Sicht auf Natur erkennt an, dass schon die gegenwärtig genutzten Naturressourcen und -prozesse Resultat sozial-ökologischer Vermittlungsprozesse sind und dass es darauf ankommt, die Herstellung eines nachhaltigen Naturprodukts als eine aktive Vermittlungsaufgabe zwischen der vielfältigen menschlichen Arbeit und Naturprozessen zu verstehen“ (Biesecker u.a. 2019: 122f.).

Das Handlungsprinzip Kooperation in Verbindung mit der Kategorie (Re)Produktivität führt zu einem anderen Naturverständnis und zu anderen gesellschaftlichen Naturverhältnissen: Zum einen kommt die Zeitlichkeit von Naturproduktivität in den Blick, zum anderen wird die Natur/Gesellschaft Dichotomie belanglos, indem die Natur der Ökonomie und der Gesellschaft nicht mehr vorgelagert ist, sondern „alle menschlichen Tätigkeiten und die Naturleistungen [...] in das Ökonomische einbezogen, wertgeschätzt und bewertet“" werden (Biesecker/Hofmeister 2013a: 154). Die Kategorie (Re)Produktivität verdeutliche auch, dass sich Kooperation nicht nur auf 
den (bislang als einzig produktiv geltenden) Bereich der Erwerbsarbeit beziehe, sondern ebenso auf alle anderen Produktivitäten, die im derzeitigen System verwertet, aber nicht bewertet werden. „Das bedeutet eine Erweiterung des Begriffes Arbeit. In der Sprache der heutigen Debatten ist Arbeit dann nicht nur Erwerbsarbeit, sondern auch nicht-erwerbliche Arbeit, [Sorgearbeit], bürgerschaftliches Engagement und Eigenarbeit" (ebenda). Dies steht im Gegensatz zur heutigen Abhängigkeit und Unterwerfung aller Lebensbereiche unter den Arbeitsmarkt, an dessen Maßstäbe sich Beziehungen, Freizeit, Kleidung, Wohnung, Bildung und Erziehung etc. auszurichten haben und durch dessen „Strukturzwang“ nach Brie (2014b: 217ff.) der „Eigensinn der Lebenswelten“ kolonialisiert (vgl. Habermas 1985) werde. Mit der Neudefinition von Arbeit verbunden ist eine radikale Kürzung der Erwerbsarbeitszeit, bzw. mehr Zeit für , anderes' Arbeiten, das dadurch aufgewertet wird. Dafür wird die Umverteilung von Erwerbsarbeitseinkommen in andere Einkommensformen als notwendig erachtet (bspw. im Zusammenhang mit einem bedingungslosen Grundeinkommen). Mit der Kategorie (Re)Produktivität werde die geschlechtshierarchische Strukturiertheit der Ökonomie aufgelöst und die Dichotomisierung männlich vs. weiblich belanglos, ein „kooperatives Geschlechterverhältnis könnte entstehen“ (Biesecker/Hofmeister 2013a: 154), der „männliche Blick auf soziale Gerechtigkeit“ (Biesecker/ Hofmeister 2015: 82) verschwinde. Die Debatten um die ,Zukunft der Arbeit“ und die ,Zukunft der Natur' seien aus (re)produktiver Perspektive gemeinsam zu führen (ebenda: 83). ,(Re)Produzieren ist Kooperieren, der (Re)Produktionsprozess ein vielfach vernetzter Kooperationsprozess“ (Biesecker/Hofmeister 2013a: 152). Die politische Ausgestaltung dieser Prozesse werde ,eine zentrale Aufgabe demokratisch verfasster, nachhaltig wirtschaftender Gesellschaften sein“ (ebenda: 152).

\section{Orientierung am für das gute Leben Notwendigen}

Im Vorsorgenden Wirtschaften werden nicht Nutzenmaximierung oder rein monetäre/quantitative Größen als handlungsleitend erachtet. Die „Orientierung am für das gute Leben Notwendigen“ bezieht sich dabei nicht auf ein asketischen Existenzminimum, sondern auf alles für ein gutes Leben Erforderliche (Biesecker/von Winterfeld 2013b: 272). Es ist als viel-dimensionales Wohlfahrtskonzept angelegt, das einen Perspektivenwechsel vornimmt:

„Nicht das gute Leben hängt von Wachstum und Geld ab, sondern es hängt von der gesellschaftlichen Bestimmung guten Lebens ab, was wachsen oder schrumpfen kann, was mittels Geld geregelt werden kann und was nicht [...]. Geblickt wird dann von den Lebensprozessen der Menschen und der Natur auf die jetzt vielfältige Ökonomie“ (ebenda: 273).

Das Handlungsprinzip verweist somit direkt ,auf den gesellschaftlichen Diskurs, wie er im Modell des (Re)Produzierens als ein Bewertungs- und Entscheidungsprozess über die physische Verwertung angelegt ist“" (Biesecker/Hofmeister 2013a: 153). Denn was ein gutes Leben ist, bleibt bewusst offen. Es wird als nicht wissenschaftlich Bestimmbares betrachtet, das in einem gleichberechtigten, verständigungsorientierten, verantwortlichen, diskursiven Prozess ausgehandelt werden müsse (Theoriegruppe Vorsorgendes Wirtschaften 2000: 51ff.). Im Gegensatz zum auf monetäre Werte verengten dominierenden Wohlstandsverständnis wird deutlich, dass Lebensqualität nicht alleine von Gütern und Geldwerten abhängt, sondern z.B. von Bildung, 
Gesundheitsversorgung, zwischenmenschlichen Beziehungen, Sorge, vom Zustand natürlicher Lebensgrundlagen, von Zeit, Teilhabe und gesellschaftlichem Engagement, etc. Dadurch kommt die Sorgearbeit, aber auch andere bislang nicht bewertete Arbeitsformen sowie die Natur als Quellen gesellschaftlichen Reichtums in den Blick.

Die Diskussion um dieses Handlungsprinzip im Netzwerk verdeutlicht wie schwierig es ist, nicht in eine „,normative Falle zu tappen“ (Amri-Henkel u.a. 2017: 11). Denn ein ,gutes Leben“ könne nicht aufgeherrscht werden, weil es dadurch ,zugleich an sein Ende“ käme (ebenda). Andererseits ist aber eine normative Orientierung notwendig, um über das gute Leben zu sprechen und es somit politisch zu ermöglichen. Eine solche wird im Fähigkeitenansatz von Martha Nussbaum ${ }^{20}$ gefunden. Die Erfüllung bestimmter Grundfähigkeiten, Nussbaum (1999: 49ff.) in einer „Liste von miteinander zusammenhängenden Fähigkeiten (capabilities)“, einer Art „Minimaltheorie des Guten ${ }^{21 ، ~ z u s a m m e n f a s s t, ~ v e r s e t z e ~ d i e ~ M e n s c h e n ~ i n ~ d i e ~ L a g e, ~}$ „,ihre Fähigkeiten zur Gestaltung ihres eigenen Lebens zu entwickeln“ (Biesecker/ Hofmeister 2013a: 153). Diese zehn Grundfähigkeiten leitet Nussbaum aus den „konstitutiven Bedingungen des Menschen“ wie der Sterblichkeit, dem menschlichen Körper, der praktischen Vernunft oder der Verbundenheit mit anderen Menschen und der Natur ab. Unter anderem zählt sie dazu: Die Fähigkeit ein lebenswertes Leben in voller Länge und guter Gesundheit zu führen, eine Unterkunft zu haben, Bewegungsfreiheit, Freude erleben zu können, selbständiges Denken und Urteilen, Beziehungen einzugehen, Verbundenheit zu erkennen und in Verbundenheit zu leben, zu lieben, zu trauern, zu lachen, zu spielen, sich eine Vorstellung vom Guten zu machen und kritisch über die eigene Lebensplanung nachzudenken, politisch zu partizipieren, sein Umfeld zu gestalten, über einen menschenwürdigen Arbeitsplatz zu verfügen, etc. (Nussbaum 1999: 49ff.; Biesecker/Hofmeister Wirtschaften 2013: 153). Das Handlungsprinzip der Orientierung am für das gute Leben Notwendigen macht es zur

20 Martha Nussbaum entwickelte diesen Ansatz während ihrer Arbeit für das World Institute for Development Economics Research der Vereinten Nationen (UNU-WIDER), bei dem sie mit Amartya Sen zusammenarbeitete. Ihr Ansatz unterscheidet sich vor allem in der konkreten Ausgestaltung der ,Capabilities‘ von Sens Arbeit. Während Sen diese einem partizipativen Diskurs überlässt, geht Nussbaum von der Möglichkeit aus, universelle Grundfähigkeiten zu beschreiben: „The capabilities approach is fully universal: the capabilities in question are held to be important for each and every citizen, in each and every nation, and each person is to be treated as an end" (Nussbaum 2006: 78).

21 Aus diskurstheoretischer Perspektive ist diese nicht als eine Theorie des ,Guten an sich` zu verstehen, sondern ist die Grundlage für eine politische Positionierung, welche das Recht auf ein gutes Leben (und nicht die Definition eines vermeintlich ,Guten') in den Mittelpunkt stellt. In diesem Sinne interpretiere ich den Ansatz in der vorliegenden Arbeit und betrachte ihn gleichzeitig ein offenes Konzept. Nussbaums Vorstellung von essentiellen Eigenschaften des Menschseins teile ich dabei nicht (Nussbaum 1992: 207), sondern sehe ihre Einschätzung des Ansatzes aus späteren Arbeiten im Vordergrund: „The capapilities approach is a political doctrine about basic entitlements, not a comprehensive moral doctrine“ (Nussbaum 2006: 155). 
Aufgabe der Politik, die „Bedingungen für die Entwicklung dieser Fähigkeiten“ zu ermöglichen (Amri-Henkel u.a. 2017: 11f.).

„Vor diesem Hintergrund zielt das Handlungsprinzip auf die Ausgestaltung einer über das ,gute Leben“ ver- und aushandelnden Gesellschaft - eine Gesellschaft, die es versteht, prozessuale Anforderungen (Partizipation, ausgleichende Gerechtigkeitspolitiken) mit substanziellen Nachhaltigkeitszielen (Gestalten durch Erneuern) zu vermitteln“ (ebenda).

\subsubsection{Weitere Bewertungskriterien Vorsorgenden Wirtschaftens}

Adelheid Biesecker und Uta von Winterfeld haben in ihrer Analyse zu Gesellschaftsverträgen weitere Bewertungskriterien entwickelt (Biesecker/von Winterfeld 2015), die sie in der Analyse des WBGU-Gutachtens den positiv angelegten Handlungsprinzipien als kritische Kriterien zur Seite stellen und auch auf weitere Dokumente von Politikberatungsgremien zur „Energiewende“ anwenden (Biesecker u.a. 2015: 4). Anknüpfend an diese Arbeit verwende ich im Folgenden diese Kriterien als Kriterien Vorsorgenden Wirtschaftens. Dadurch erhalten Herrschafts- und Machtfragen innerhalb der für die vorliegende Studie wichtigen analytischen Funktion (vgl. Kapitel 1) des Vorsorgenden Wirtschaftens einen höheren Stellenwert und gleichzeitig erhöht sich die Operationalisierbarkeit des Konzeptes.

Das erste Kriterium fragt nach Externalisierungen ${ }^{22}$ und ist von Biesecker/von Winterfeld $(2014 ; 2015)$ detailliert ausgearbeitet worden. Das zweite Kriterium fragt nach dem emanzipatorischen Gehalt von Politiken (bei Biesecker/von Winterfeld (2015: 5) von Vertragsansätzen) und nach deren Potenzial für eine „herrschaftsärmere [...] Zukunftsgestaltung“ (ebenda). Gemeinsam verweisen die beiden Kriterien auf „emanzipatorische, nicht-externalisierende vorsorgende Gestaltungsperspektiven“ (ebenda). In diesen beiden Kriterien werden Parallelen in der Gesellschafts-, Ökonomie- und Herrschaftskritik zur Diskurstheorie nach Laclau/Mouffe (2015) besonders deutlich, wie im Folgenden gezeigt wird.

\section{Externalisierung als Prinzip}

Das Kriterium der ,Externalisierung als Prinzip“ verdeutlichen Biesecker/von Winterfeld (2015) anhand der Geschichte der klassischen Vertragstheorien (hier von Locke und Hobbes), die von einem fiktiven Naturzustand ausgehen und den Beginn der bürgerlichen Gesellschaft markieren. „Über die Festlegung von Politik- und Ökonomiekonzepten bestimmte und bestimmt ein Gesellschaftsvertrag darüber, wer wie zur Gesellschaft gehört, wer welche Rechten und Pflichten hat" (ebenda: 2). Dabei wirken Gesellschaftsverträge, als ,[d]ie Art, wie sich ein politisches Gemeinwesen, eine Gesellschaft, durch Regeln konstituiert“" ohne, dass es dafür der Zustimmung aller bedarf, als „Legitimationsformel politischer Herrschaft und ökonomischer Tätigkeiten und Strukturen“ (ebenda: 1). Dies verdeutlicht die Perfidität von Externalisie-

22 Auch außerhalb des Vorsorgenden Wirtschaftens gibt es zahlreiche Forschungsarbeiten zu Externalisierung (für aktuellere Arbeiten vgl. z.B. Brand/Wissen 2017; Lessenich 2018; 2016; Book u.a. 2019). Aufgrund des Fokus der vorliegenden Arbeit beschränke ich mich hier allerdings auf die Arbeiten zum Vorsorgenden Wirtschaften. 
rung, die zum großen Teil (mit Ausnahme der Verfassungen) implizit wirkt und naturalisiert erscheint. Biesecker und von Winterfeld beziehen sich dabei auf die Analyse von Pateman (1988), die herausarbeitet,

„,dass es freie und gleiche ,Brüder` sind, die sich die Verfügungsrechte über die Körper und die Arbeit von Frauen schon gesichert haben, bevor sie einen Vertrag miteinander schließen. Gleichwohl werden Frauen nicht einfach im Naturzustand zurückgelassen. Sondern sie werden als Abgespaltenes einbezogen, als das, was Männer nicht sind, was bürgerliche Gesellschaft nicht ist. Wenngleich also das, was Frauen sind und tun, nicht politisch ist, lebt die neue politische Herrschaft davon, dass die private Herrschaft im Haus (mit dem dominus als Vorstand) unangefochten bleibt. Wenngleich Frauen nicht zu dem beitragen, was als ökonomisch wertvoll gilt oder als Natur aneignende Arbeit die Grundlage für die Entstehung des Privateigentums ist (bei John Locke), lebt die neue ökonomische Verfassung davon, dass sie sich etwas Unsichtbares, dem Wirtschaften nicht Angehörendes ,kostenlos` aneignen kann“ (Biesecker u.a. 2015: 3f.).

Dies gelte nach Pateman (1988) nicht nur für Frauen, sondern auch für die Natur sowie in globaler Perspektive auch für Menschen, die in anderen (nicht-westlichindustrialisierten) Erdteilen leben (Biesecker/von Winterfeld 2015: 5) und bezeichnet im übertragenen Sinne das, was Biesecker/von Winterfeld Externalisierung als Prinzip nennen (Biesecker/von Winterfeld 2014).

Konzeptionell zeigt, das Externalisierte' Parallelen zum konstitutiven Außen bei Laclau/Mouffe (2015) im Anschluss an Derrida (1972) und Staten (1986: 16): Externalisierung bezeichnet einen Mechanismus, durch den „etwas Externes, Wertloses, Unsichtbares - ein [...] Schatten“ erzeugt wird, ,auf dessen Basis das interne, wertvolle, sichtbare Licht entsteht", wobei diese Konstruktion gleichzeitig als objektiv, als von Natur aus gegeben erscheine (Biesecker/von Winterfeld 2014: 4). Dieser Mechanismus ist bei Laclau/Mouffe (2015) zentral für die Konstitution von Identität (vgl. Kapitel 2). Biesecker/von Winterfeld (2014) berufen sich dabei auf Narr, der „Identifikation“ als „Prinzip von Herrschaft schlechthin“ (Narr 2015 zit. in Biesecker/von Winterfeld 2014: 5) bezeichnet. „Sie zieht sich durch die menschliche Geschichte und wird in ihrer gewalttätigen und gewalterzeugenden Ausprägung besonders in der Dialektik von Eigenem und Anderem sichtbar" (Biesecker/ von Winterfeld 2014: 4). Dabei wird wie im Begriff des ,konstitutiven Außen“ das Eigene über die Abgrenzung zum ,Anderen' konstituiert, wobei das ,Andere‘ aber gleichzeitig als Existenzbedingung für das Eigene gesehen wird. Identifikation erscheint somit immer als Prozess, der mit Ausschließung und Herrschaft zu tun hat. Biesecker/von Winterfeld (2014: 5f.) nennen hier in Anschluss an Debatten zum Postkolonialismus, insbesondere an Edward Said (Said 1979), das Beispiel der Abgrenzung vom ,Westen` zum ,Osten‘. Für die Identifikation des fortschrittlichen, zivilisierten, gebildeten und rationalen Westens sei gleichzeitig eine Konstruktion des Ostens als das ,Andere', als fremd, passiv, unterentwickelt, rückständig, weiblich notwendig. Es handele sich also nicht nur um eine Abgrenzung, sondern diese Abgrenzung werde mit Hierarchien, mit Abwertung, mit Herrschaft verbunden (Biesecker/von Winterfeld 2014: 5). Diese Vorstellung von Osten sei nicht ,der Osten' als solches, sondern eine westliche Artikulation von Osten, die von einem vermeintlich privilegierten Punkt aus erfolge und damit gleichzeitig die eigentliche 
Konstruktivität sowohl von ,Osten“ als auch von ,Westen“ verschleiere. Dieser Effekt verstärke sich durch Wiederholungen, durch „dichotome[...s] Sprechen“. „Das dichotome Muster westlicher, männlicher, kultureller... Überlegenheit verstärkt sich selbst"“ (ebenda: 6).

Biesecker/von Winterfeld (2014) nennen zwei weitere Aspekte des Identifikationsprinzips: Zum einen sei nicht nur das Verhältnis zwischen ,Eigenem“ und ,Anderem', zwischen ,Innen' und ,Außen' herrschaftlich, sondern auch das Innere selbst herrschaftlich organisiert. Als Beispiel nennen sie unter Bezug auf Narr (2015) den Nationalsozialismus. Zum anderen verdeutlichen sie, neben dem objektivierenden, und dualistischen Aspekt von Externalisierung, den instrumentellen, der eine zentrale Rolle für die Kapitalismuskritik spiele. Denn aus dieser Perspektive „wird deutlich, dass und wie das Abgetrennte für die Kapitalverwertung gebraucht wird, wie es für diesen Zweck vereinnahmt wird und wie dabei gleichzeitig neue Grenzlinien gezogen werden“ (Biesecker/von Winterfeld 2014: 7). Das betreffe beispielsweise sozial weibliche Arbeit und die Natur aber auch von Armut Betroffene (ebenda). Bereits Rosa Luxemburg verdeutlichte den instrumentellen Aspekt für die Kapitalakkumulation, die „soziale Formen“ (Luxemburg 1981: 315 zit. in Biesecker/von Winterfeld 2014: 7) und die Natur für ihre Bewegung benötige und diese ,aufsauge', sie ,als Nährboden“ (Luxemburg 1981: 363 zit. in Biesecker/von Winterfeld 2014: 7) brauche. Die „Beziehung zwischen kapitalistischer und nichtkapitalistischer Sphäre“ (Biesecker/von Winterfeld 2014: 7) sei gewaltvoll: „Ihr Schauplatz ist die Weltbühne. Hier herrschen als Methoden Kolonialpolitik, internationales Anleihesystem, Politik der Interessensphären, Kriege“ (Luxemburg 1981: 397f. zit. in Biesecker/von Winterfeld 2014: 7). Es gehe dabei nicht nur um die Erhöhung des Mehrwerts, sondern auch um die Generierung von Wert überhaupt - dem Kapitalismus sei ein „Externalisierungs- und Ausbeutungszwang“ inhärent (Biesecker/von Winterfeld 2014: 8). Während bei Rosa Luxemburg die vollständige Kapitalisierung aller nichtkapitalistischer Formen schließlich zur Aufhebung der Dialektik selbst, also zum Sozialismus führe, betonen Biesecker/von Winterfeld (2014: 8), „dass in dieser dialektischen Bewegung immer auch neue Grenzlinien entstehen, neue Verhältnisse von ,Drinnen“ und ,Draußen' $[\ldots]^{\text {“. }}$.

Externalisierung als Prinzip verweist auf die Konstruiertheit des Äußeren, des Abgespaltenen, das damit nicht wie bei Rosa Luxemburg als vorgefundene nichtkapitalistische Umgebung gesehen wird, sondern innerhalb des Kapitalismus ,gemacht' werde, um eine Aneignung als Abgespaltenes zu ermöglichen. ${ }^{23}$ Da der Kapitalismus sein Äußeres immer wieder neu zu erzeugen vermöge, komme er durch vollständige Kapitalisierung alles nicht-Kapitalistischen auch nicht ,zwangsläufig an sein Ende“ (ebenda: 11).

Zudem wird das Externalisierungsprinzip nicht als ausschließlich kapitalistisches Prinzip bewertet, denn bereits vor dem Kapitalismus habe es Ausbeutung von

23 Der Ansatz von Biesecker/von Winterfeld weist hier Ähnlichkeiten mit der ,LandnahmeThese ‘ von Klaus Dörre auf (Dörre 2009). Biesecker/von Winterfeld (2014: 9f.) kritisieren jedoch am Landnahme-Ansatz, dass dieser für eigene Externalisierungsstrukturen blind sei, denn die weibliche Sorgearbeit, als das ,Außen“ der Erwerbsarbeit, stehe weiterhin im „Schatten“. 
Mensch und Natur sowie auf Ausschluss beruhende Herrschaft gegeben (ebenda). Biesecker/von Winterfeld (2014) gehen hier also über den ökonomischen Determinismus von Luxemburg hinaus. Das Kapital wird nicht als ,die eine Struktur ' gesehen, die die Gesellschaft bestimmt. Sondern auch Identifikationsprozesse und damit einhergehend Externalisierung, die bereits vor dem Kapitalismus existierten, werden vom Kapitalismus in besonderer Weise befördert und benötigt.

Biesecker/von Winterfeld (2014: 4) stellen klar, dass die Externalisierung ,nicht mittels Internalisierung aufgelöst werden“ könne, weil das ökonomische und politische System nicht ohne die Ausbeutung des Wertlosen funktioniere und demnach auch weiterhin auf Externalisierung/Abspaltung beruhen werde. Sie sprechen hier von „abspaltendem Einbeziehen“ (ebenda: 14). Dies verdeutliche sich beispielsweise an der marktlichen Integration von Pflegearbeit, die auch im Markt abgewertet bleibe. Im Außen können sich aber widerständige Räume bilden, in denen eine andere Ökonomie, andere Geschlechter- und Naturverhältnisse gelebt werden. Durch Vermischung kritischer Stimmen aus dem Innen mit diesem Widerständigen entstehen Zwischenräume zwischen Innen und Außen, in denen die herrschenden mit den kritischen Vorstellungen und Bezogenheiten aufeinandertreffen (ebenda: 4f.). „In Aushandlungsprozessen und Machtkämpfen entscheidet sich, ob das Neue System verändernde Wirkungen entfalten kann oder Nische bleibt“" (ebenda: 5).

\section{Neokoloniale und nationale Externalisierung als Prinzip}

In ihren Ausführungen zur Externalisierung als Prinzip knüpfen Biesecker/von Winterfeld (2014) an den postkolonialen Theoretiker Edward Said (1979) an (s.o.) und verweisen somit auf globale Macht- und Herrschaftsverhältnisse sowie globale Ausgrenzungs- und kapitalistische Aneignungsprozesse. Im Vorsorgenden Wirtschaften ist diese Perspektive allerdings noch wenig vertreten. Die Bedeutung von Nord-SüdBeziehungen wird zwar immer wieder betont, allerdings kommen globale Machtverhältnisse eher selten in den Blick (Gottschlich 2017: 274f.). Insbesondere die Omnipräsenz (neo)kolonialer ${ }^{24}$ Verhältnisse, Muster, Effekte und Ausschlüsse, die nicht nur die ehemals kolonisierten Gebiete, sondern auch die sogenannte westliche Welt prägen, findet bislang wenig Beachtung. Dadurch bleibt die „historische Dimension krisenhafter gesellschaftlicher Naturverhältnisse“ bezüglich ihrer (neo)kolonialen Strukturen und Praktiken, die sich bis heute sozial-ökologisch auswirken, unscharf (Koch/Roth 2015: 43f.). ${ }^{25}$ Verknüpfungen zwischen einer Kritik der Moderne und einer Kritik des Kolonialismus bleiben im Vorsorgenden Wirtschaften größtenteils aus.

24 Ich verwende hier die Schreibweise (neo)kolonial, um einerseits das fortwährende Bestehen kolonialer Strukturen und Praktiken und andererseits ihre Aktualisierung in neuen Strategien und Strukturen zu verdeutlichen. ,Neokoloniale Externalisierung als Prinzip“ verwende ich in der vorliegenden Untersuchung ohne Klammer, da sich die vorliegende Untersuchung auf aktuelle diskursive Strategien und Strukturen beschränkt. Für eine Definition des Begriffes ,Neokolonialismus` vgl. Fußnote 28.

25 Dies ist nicht nur ein blinder Fleck im Vorsorgenden Wirtschaften, sondern in der Nachhaltigkeitsforschung insgesamt, wie Koch/Roth (2015) zeigen. 
Eine Erweiterung des Vorsorgenden Wirtschaftens um postkoloniale ${ }^{26}$ Perspektiven, die über die theoretische Anlage im Externalisierungsprinzip bei Biesecker/von Winterfeld hinaus geht, steht bislang noch aus. Hier ist weitere Forschungspraxis notwendig. In der Analyse der Debatten zur Energiepolitik zeigten sich allerdings in einem signifikanten Umfang neokoloniale Artikulationsmuster und nationale Erzählungen, weshalb sich die Notwendigkeit ergab, hier eine theoretische Erweiterung, bzw. Fundierung vorzunehmen. ${ }^{27}$ Ich verwende dafür in Erweiterung der genannten Arbeiten von Biesecker/von Winterfeld die Bezeichnung der ,neokolonialen ${ }^{28}$ und nationalen Externalisierung als Prinzip ' und betrachte diese in der vorliegenden Analyse als Spezialfall von Externalisierung. ${ }^{29}$ Dabei knüpfe ich in Ansätzen an die postkolonialen Theorien von Edward Said, Homi K. Bhabha und Gayatri C. Spivak an. ${ }^{30}$ Die vorliegende Arbeit kann nur erste Einblicke liefern, weitere Theorieschärfung sowie Forschungspraxis sind als notwendig zu erachten.

Eine Verknüpfung postkolonialer Theorie, feministischer Nachhaltigkeitsforschung und Diskurstheorie bietet sich auch aufgrund der wechselseitigen Anschlussfähigkeit an. Allen dreien ist es ein Anliegen ,,binäre und essentialistische Begriffspaare zu dekonstruieren, um dem damit ausgedrückten Machtgefüge entgegenzuwir-

26 Für eine kritische Auseinandersetzung mit dem Begriff ,postkolonial‘ vgl. Castro Varela/ Dhawan 2015: 15ff.

27 Diese theoretischen Erweiterungen und Fundierungen nehme ich im Folgenden im Hinblick auf den Untersuchungsgegenstand (deutsche parlamentarische Debatte) vor - die theoretische Erweiterung reflektiert also lediglich die Notwendigkeiten, die sich in der vorliegenden Analyse zeigten. Um postkoloniale Strukturen darüber hinaus zu untersuchen, ist sicherlich eine umfangreichere Erweiterung notwendig.

28 Ich verwende den Begriff des ,Neokolonialismus‘ hier, um die Nicht-Abgeschlossenheit des Kolonialismus und die Aktualität seiner spezifischen Unterdrückungsformen und Ausschlussprozesse zu verdeutlichen. Der Prozess der Dekolonisierung ist ein kontinuierlicher, durch den Begriff des ,Neokolonialismus“ wird gleichzeitig verdeutlicht, „dass der Kolonialismus immer neue Wege findet und Strategien entwirft, um sich die Ressourcen der vormals kolonisierten Länder zu sichern“ (Castro Varela/Dhawan 2015: 16). Der Begriff wurde vom ersten Präsidenten Ghanas, Kwame Nkrumah, geprägt, der in „Neo-colonialism: The Last Stage of Imperialism“ (Nkrumah 1965) herausarbeitete, dass „obwohl Länder wie Ghana technische Unabhängigkeit erreicht hatten, die ex-Kolonialmächte und die sich neu entwickelnden Supermächte wie die USA weiterhin eine entscheidende Rolle durch internationale Geldinstitutionen, durch die Bestimmung der Preise auf den Weltmärkten, multinationale Zusammenschlüsse und Kartelle sowie eine Vielzahl an Bildungs- und Kulturinstitutionen spielten. Tatsächlich, so argumentierte Nkrumah, sei der Neo-Kolonialismus heimtückischer und schwieriger aufzudecken und zu widerstehen als der ältere offene Kolonialismus“" (Ashcroft u.a. 2004: 162f. [eigene Übersetzung]).

29 Der Umfang der theoretischen Ausführungen des Spezialfalls ,neokolonialer und nationaler Externalisierung als Prinzip، ist daher im Vergleich zum bereits ausgeführten Teil von ,Externalisierung als Prinzip“ länger, weil dieser in der Theorie erst angelegt werden muss.

30 Diese drei Autor*innen zählen zu den bekanntesten Mitbegründer*innen postkolonialer Theorie (vgl. Castro Varela/Dhawan 2015). 
ken“ (Koch/Roth 2015: 47). ${ }^{31}$ Die Erzeugung von Differenz und Identität spielt in der postkolonialen Theorie eine besondere Rolle. Da die postkoloniale Theorie in vielen Punkten an die poststrukturalistische Diskurstheorie anschließt, ist dies nicht verwunderlich. Unter „Postkolonialität“ können diskursive Praktiken verstanden werden, „die Widerstand leisten gegen Kolonialismus, kolonialistische Ideologien und ihre Hinterlassenschaften“ (Castro Varela/Dhawan 2015: 17).

Spivak, die in ihrem Ansatz Marxismus, Dekonstruktivismus und feministische Theorie zusammenbringt, knüpft in der Betrachtung der Konstitution des ,Anderen“ an die Arbeiten von Said (s.o.), Lacan und Derrida an. Sie verwendet in ihrem Aufsatz „The Rani of Sirmur: An Essay in Reading the Archives“ als erste den Begriff des ,Othering ${ }^{32 ،}$ (different machen) systematisch (Spivak 1985) und macht ihn damit für die Diskursanalyse fruchtbar. „Othering describes the various ways in which colonial discourse produces its subjects“ (Ashcroft u.a. 2004: 171). Sie identifiziert verschiedene Dimensionen von ,Othering', bspw. die des ,Worlding', des ,Weltenmachen', in der das eurozentristische Selbst konsolidiert werde im Gegensatz zur gleichzeitig hergestellten „Dritten Welt“ und später dem globalen „Süden“ (Spivak 1985: 114). Europa wird als das ,Eigene“, das ,Normale“ (,the same“ (Spivak 1999: 113)) repräsentiert, von dem aus die koloniale Subjektivität der 'Anderen' als Untergebene produziert werde. ${ }^{33}$ Eine weitere Dimension würdige die ,Anderen' als statisch, pathologisch, primitiv und moralisch unterlegen herab, mache sie zu Objekten des Imperialismus - im Gegensatz zum fortschrittlichen, modernen Kolonialen ,Eigenen“. Die dritte Dimension stehe für die Trennung der einheimischen Staaten (,native states“) von der ,eigenen“ Kolonialregierung: „our [colonial] governments“ (Spivak 1985: 255). In allen drei Dimensionen wird Wissen und Technologie als Ei-

31 So ist aus dieser Perspektive auch die Einteilung der Welt in ,Industrieländer und ,Entwicklungsländer`/,Schwellenländer zu kritisieren (vgl. auch Post-development Ansatz). Nicht nur, weil dadurch ,nicht-westliche Lebensweisen als mangelhaft beschrieben“ (Koch/Roth 2015: 47) werden, sondern auch weil eine homogene lineare Entwicklung von Staaten hin zum Ideal eines westlichen Industriekapitalismus nicht haltbar ist. Die Ursachen der vielfältigen Realitäten dieser Länder sowie damit zusammenhängende globale Machtverhältnisse werden ausgeblendet (ebenda: 46ff.). Daher spreche ich in der vorliegenden Arbeit stets von ,sogenannten Entwicklungsländern‘.

32 Spivak unterscheidet dabei orthografisch zwischen dem kolonisierenden ,Other ${ }^{\circ}$ und dem kolonisierten ,other'. Ich unterscheide dies im Folgenden als das ,Eigene' und das ,Ande-

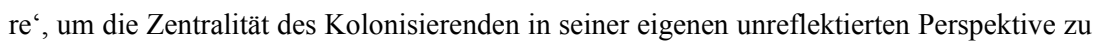
kennzeichnen.

33 Spivak (1985) macht gleichzeitig darauf aufmerksam, dass die imperialistische epistemische Herrschaft die „Dritte Welt“ in ein Zeichen verwandelt habe, dessen Ursprung als im ,worlding' Hergestelltes so vernebelt ist, dass das Weiterbestehen von Ausbeutungsstrukturen (auch in der Wechselwirkung zwischen Patriarchat und Imperialismus) nicht erkannt werden kann. „To think of the Third World as distant cultures, exploited but with rich intact heritages waiting to be recovered, interpreted, and curricularized in English translation helps the emergence of ,the Third World' as a signifier that allows us to forget that ,worlding', even as it expands the empire of the discipline“ (ebenda: 114). 
genheit des ,powerful empirical self“, des ,Eigenen“, im Gegensatz zum kolonialen ,Anderen' konstruiert (Jensen 2011: 64f.).

Spivak prägt im Anschluss an Gramsci (Gefängnishefte 1929-1935) und die South Asian Subaltern Studies group für die Position der radikalen Differenz zu den dominanten Gruppen den Begriff der ,Subalternität ${ }^{\circ}{ }^{34}$ Subalternität ist dabei als Gegenposition zur Hegemonie zu sehen. „Sie ist keine Identitätsbezeichnung, sondern eine Position und Differenz" (Castro Varela/Dhawan 2015: 187). In ihrem Aufsatz „Can the Subaltern speak?“ arbeitet Spivak (2011) heraus, dass es keinen Raum gibt, von dem aus die Subalternen sprechen können - aufgrund vielfältiger Herrschaftsverhältnisse haben sie keine Möglichkeit gehört zu werden. ${ }^{35}$ Dass die ,Subalternen` nicht gehört werden können hänge unter anderem mit der epistemologischen Einbettung und Wirkung des ,Othering' zusammen: So übe das imperialistische Projekt geplante „epistemic violence“ (Spivak 1985: 251) aus, die über eine hegemoniale eurozentristische Wissensordnung das Übernehmen von Wissensstrukturen und Epistemen erwirke oder aufzwinge und somit seine Vormachtstellung herstelle und reproduziere (ebenda: 255f.). ${ }^{36}$ Diese prägen maßgeblich das Selbst- und Fremdbild (z.B. der globale ,Süden` als unterentwickelt, hilfsbedürftig). Durch ,Othering ‘, d.h. indem von einem vermeintlichen Zentrum aus Verallgemeinerungen über das ,Andere` erzeugt werden, entstehe eine hegemoniale ,Realität ${ }^{\star}$, der sich auch die Subalternen ${ }^{37}$ nicht entziehen können (Koch/Roth 2015: 46ff.). Diese diskursive Wissensordnung materialisiere sich in verschiedenen Weisen. So zeigt Spivak (1985) „eine Komplizenschaft zwischen westlicher Wissensformation und internationalen Wirtschaftsinteressen“ (Castro Varela/Dhawan 2015: 193) auf.

34 „Gramsci entlieh den Begriff dem Vokabular militärischer Dienstgrade, wo dieser der Name für , untergeordnete Offiziere‘ ist. Er überträgt den Begriff `Subalterne`, um damit diejenigen zu bezeichnen, die keiner hegemonialen Klasse angehören - und fokussiert seine politischen Analysen auf diese [...]. Die subalternen Gruppen [...] können sinnvollerweise nur im Zusammenhang mit den dominanten Gesellschaftsgruppen verstanden werden. Letztere realisieren ihre historische Einheit im Staat, das heißt in der Kombination von politischer und ziviler Gesellschaft. Im Kontrast dazu bilden die subalternen Klassen eine fragmentierte Gruppierung, die durch mangelnde Autonomie, fehlende organische Intellektuelle und durch strukturelle und ökonomische Ausgrenzung gekennzeichnet ist“" (Castro Varela/Dhawan 2015: 186f.).

35 Spivak verfolgt dabei einen feministischen Ansatz und arbeitet dies überwiegend an Beispielen der Unmöglichkeit der Handlungsmacht von subalternen Frauen heraus.

36 „If the project of Imperialism is violently to put together the episteme that will ,mean“ (for others) and ,know' (for the self) the colonial subject as history's nearly-selved other, the example of these deletions indicate explicitly what is always implicit: that meaning/knowledge intersects power [...]. The narrative of imperialism-as-history is especially intelligible because planned; and here, contrary to Foucault's suggestion, the ,model of language [langue] and signs' is complicit with , that of war and battle“" (Spivak 1985: 255f.).

37 Der Subjektbegriff von Spivak ist dabei mit dem Subjektbegriff von Laclau/Mouffe (2015) kompatibel, da Subjekte nicht außerhalb des Diskurses stehen, also auch vom hegemonialen Diskurs beeinflusst werden. 
Die Ausschließungen, die eine subalterne Gruppe betreffen, werden als heterogen und vielfältig bewertet (ebenda: 186). Die Begriffe des ,Othering' und damit der Konstitution von ,Subalternität‘ beschreiben multidimensionale Prozesse, die verschiedenste Formen sozialer Differenzierung fassen und bieten sich daher für eine intersektionale (Crenshaw 1989) Perspektivenerweiterung an, die das Zusammenwirken verschiedener Ungleichheit generierender und legitimierender Kategorien in den Blick nimmt ohne diese rein additiv zu betrachten. ${ }^{38}$

In der Perspektive auf Zeitlichkeit, Fortschritt und Moderne zeigen sich zusätzliche Anknüpfungspunkte zwischen Vorsorgendem Wirtschaften, Transformationsund Diskurstheorie sowie Postkolonialer Theorie, sowie Potenziale für eine weitere Perspektivenerweiterung (s.o.). Homi Bhabha (1994) sieht die Beziehung zwischen Moderne und Kolonialismus als zentral an. Die Verdrängung der kolonialen und gewaltvollen Ursprünge der Moderne einerseits und ihr Fortschritts- und Rationalitätsnarrativ andererseits verdeutlichen die Ambivalenz der Temporalität und die Paradoxie der Moderne, an deren Aufdeckung Bhabha arbeitet (Castro Varela/Dhawan 2015: 251f.). Auch im Postmodernismus werde der Westen weiterhin als disziplinärer normativer Bezugspunkt gesetzt, weshalb die ,Anderen“ (Frauen, Indigene, Kolonisierte, Versklavte) wiederum unsichtbar (,people without a history“) werden (Bhabha 1994: 196f.). Er spricht von einer kolonialen Trennung (Disjunktion) moderner Zeiten von der Kolonial- und Sklavengeschichte, die auch dazu führe, dass mit der Erzählung einer moralischen modernen Geisteshaltung der Französischen Revolution und der Aufklärung die Erzählung des unzivilisierten primitiven ,Anderen“ (,the archaic racial factor") in den Kolonialgesellschaften nur befeuert werde (ebenda: 244). Durch einen Vergleich der Sklavenrevolten in Saint-Domingue mit der Französischen Revolution zeigt er auf, inwiefern die Werte der Aufklärung Emanzipation, Fortschritt, Freiheit - durch diese zeitliche Disjunktion für die kolonisierte Welt unerreichbar sind (Castro Varela/Dhawan 2015: 252). An unterdrückten Orten wie Saint-Domingue kann Fortschritt nur gehört, nicht gesehen werden. Die katachrestische, postkoloniale Übersetzung der Moderne führe folglich zu der Frage der Einführung subalterner Agency in die Frage der Modernität: „what is this ,now of modernity? Who defines this present from which we speak?" (Bhabha 1994: 244). An den Orten, an denen sich die Disjunktion in der Zeit offenbare, eröffne sich auch der Raum für eine postkoloniale Gegenmoderne, in der die westliche moderne Zeit nicht mehr als Maßstab gelten könne (ebenda: 244f.). Die enthistorisierte Figur des Menschen der westlichen Moderne funktioniere also nur auf Kosten der Externalisierung der ,Anderen' und stehe für eine lineare, teleologische Zeit, die Bhabha zu dekonstruieren versucht (Castro Varela/Dhawan 2015: 254).

Eng verbunden mit Bhabhas Kritik an moderner Zeitlichkeit ist seine Dekonstruktion der Nation ${ }^{39}$, die er in seinem Text „DisseminNation: Time, narrative and the margins of the modern Nation“ (Bhabha 1994: 139ff.) sowie in seinem Buch

38 Die intersektionale Diskriminierung ist mehr als die Summe von Diskriminierungskategorien (Crenshaw 1989: 140).

39 In der Analyse der energiepolitischen Debatte hat sich der Begriff der ,Nation` als relevant erwiesen, weshalb neokoloniale Externalisierung hier um nationale Externalisierung als Prinzip ergänzt wird. 
„Nation and Narration“ ausarbeitet (Bhabha 1990). So behaupte die Nation ihre Modernität, ,als eine autonome oder souveräne Form politischer Rationalität“", die aber aus postkolonialer Perspektive fragwürdig sei (Bhabha 1994: 141 [eigene Übersetzung]). Er zitiert Partha Chatterjee: „Nationalism... Seeks to represent itself in the image of the Enlightenment and fails to do so. For Enlightenment itself, to assert its sovereignty as the universal ideal, needs its Other; if it could ever actualise itself in the real world as the truly universal, it would in fact destroy itself" (Chatterjee 1986: 17, zit. in Bhabha 1994: 141). Die Nation sei eine relativ neue Erfindung, die Bhabha in einem spezifisch europäischen Umfeld verortet (Bhabha 1990: 9; Ashcroft u.a. 2004: 149). Die Entstehung moderner Nationalstaaten sieht er dabei untrennbar mit dem Aufkommen imperial-kapitalistischer Ökonomien in Europa verbunden. Diese waren auf Rohstoffe aus der sogenannten ,Neuen Welt' angewiesen. Ein neues Narrativ, welches die Interessen der neuen Handelsklassen (auch gegenüber der feudalen Aristokratie) konsolidierte und gleichzeitig die Basis für die Schaffung notwendiger neuer sozialer Formationen legte, war notwendig: Die Erzählung der Nation (Ashcroft u.a. 2004: 152). ${ }^{40}$ „The markets made possible by European imperial penetration motivated the construction of the nation-state at home [...]. The ,national idea', in other words, flourished in the soil of foreign conquest" (Bhabha 1990: 154). Bhabha dekonstruiert die Erzählung der modernen Nation, die ihre Geschichtlichkeit (,,in an ,immemorial past““ (ebenda: 45)) verdecke und ihre „Ursprünge in den Mythen der Zeit" (Castro Varela/Dhawan 2015: 257) verliere, sodass sie zeitlos und als Eins erscheine (,out of many one“ (Bhabha 1994: 142)). Er offenbart die Zeit der modernen Nation als homogen und leer. Aber sobald das Disjunktive/Trennende der Zeit der Moderne (s.o.) in den Blick komme, offenbare sich die Nation als Erzählung, die Ambivalenz von Nation. Die Rede von (nationaler) Kultur und Gemeinschaft verdecke die Risse der Gegenwart, indem sie eine nationale Vergangenheit konstruiere (ebenda). So legitimiere der Mythos einer nationalen Tradition nicht nur die Ausweitung einer partikularen Idee (z.B. Praktiken einer bestimmten Gruppe) auf das Universelle (das ,Volk'), sondern naturalisiere auch die Idee des Nationalstaates, in dem dann auch die Staatsmacht als natürlicher Ausdruck einer einheitlichen nationalen Geschichte und Kultur erscheine (Ashcroft u.a. 2004: 150). Die Nation als Erzählung beharre auf Gleichzeitigkeit und basiere ,parasitär‘ auf dem Ausschluss der ,Anderen“ sowie dem Dementieren von Vielfalt. „Kohärenz, Reinheit, Authentizität, Einstimmigkeit und Beständigkeit haben Vorrang vor Heterogenität, Hybridität, Kontaminierung, Uneinigkeit und allem Fluiden“ (Castro Varela/Dhawan 2015: 256). Analog zu Laclau/Mouffe (2015) wird das ,Andere“ als Gefahr für das nationale Selbst, die nationale Vollkommenheit, betrachtet, weshalb es einer permanenten Abwertung unterzogen werde, um die eigene Überlegenheit zu bestätigen (dabei wirken verschiedenste Diskriminierungsformen wie Sexismus, Rassismus und Klassismus ineinander) ${ }^{41}$ (Bhabha 1990: 4). Gleichzeitig (und ebenfalls analog zur Diskurs-

40 Ashcroft u.a. (2004: 151) heben dabei hervor, dass noch heute die Idee der ,Nation“ als ,natürliche‘ und unveränderbare Einheit in komplexer Weise mit der Idee der ,freien Märkte' im globalen Kapitalismus interagiere.

41 Varela/Dhawan (2015) verdeutlichen bspw. wie - basierend auf einer Verleugnung der Geschichtlichkeit der Nation - ,[d]ie Gegenwart postkolonialer Migranten und Migrantinnen 
theorie von Laclau/Mouffe) wird die Identität einer Nation als nie abgeschlossenes Konzept betrachtet, das somit auch nicht fixiert werden könne, trotz der Überzeugung von der eigenen Kohärenz. Daher werde das nationale Narrativ ständig „durch andere Identitäten nacherzählt, die die der Sexualität, Klasse oder ,Rasse verdrängen“ (Castro Varela/Dhawan 2015: 259) und die Hegemonie konsolidieren. Die nationale Identität beruhe also auch auf der Aneignung neuer identitärer Erzählungen, wodurch sich die Ausschließungsprozesse verschieben. In Anschluss an die Arbeiten von Lacan erklärt Bhabha den Willen zur Nation mit dem Wunsch nach Ganzheit und Gemeinschaft (ebenda: 256). Er arbeitet zwei Dimensionen des nationalen Narrativs heraus: Eine Pädagogische ${ }^{42}$, welche die Historizität von Nation und Volk behaupte aber deren Ambivalenz gleichzeitig verdränge. Und eine Performative, welche durch die nie abgeschlossene Identitätsbildung von Subjekten entstehe. Nationale Identität sei (zumindest erscheine sie) somit sowohl „statisch“, also Pädagogik -,,etwas, was wir gelernt haben“-, als auch offen, also Performanz -,,etwas, was wir durch unser tägliches Tun verändern“" (ebenda: 257f.).

Um die Möglichkeiten zur Operationalisierung des Vorsorgenden Wirtschaftens in der Transformationsforschung zu erhöhen, bietet eine postkoloniale Theorieentwicklung Vorsorgenden Wirtschaftens sowie eine diesbezügliche Schärfung von Externalisierung als Prinzip Potenziale, da es zu einer Perspektivenerweiterung kommt: Durch

„den Blick auf koloniale und machterhaltende Konstruktionsprozesse ,des Anderen` gegenüber ,dem Selbst ${ }^{*}[\ldots]$ sowie die Erweiterung der Perspektive um die räumlich-globale und zeitlichhistorische Dimension von Machtverhältnissen in ihrer jeweiligen Verschränkung mit dem Lokalen und Gegenwärtigen“ (Koch/Roth 2015: 50)

entsteht eine neue Qualität. Das Zusammenwirken verschiedener Ungleichheitskategorien wird intersektional erkennbar. Durch die Kritik der Nation gelangen weitere Externalisierungsprozesse in den Blick. Nicht zuletzt ermöglicht eine „Infragestellung der eigenen Komplizenschaft mit den Prozessen der Subalternisierung“ - wie von Spivak (2011) gefordert (Castro Varela/Dhawan 2015: 201) - eine (selbst-)reflexivere Perspektive Vorsorgenden Wirtschaftens.

\section{Potenziale für eine herrschaftsärmere Zukunftsgestaltung}

Nachdem nun das Kriterium der ,Externalisierung als Prinzip‘ eingeführt und um eine neokoloniale und nationale Perspektive erweitert wurde, gehe ich auf das zweite

[...] von den Ländern im globalen Norden als Bedrohung wahrgenommen [wird], weil sie zur eigenen Sinnerhaltung von eben diesen Anderen abhängig sind. Die Untersuchung nationaler Narrative - insbesondere die dominanten offiziellen Erzählungen - verdeutlichen rasch, wie andere Identitätsgruppen zum Schweigen gebracht werden“ (ebenda: 256).

42 Sie zeigt sich beispielsweise, wenn öffentliche Personen nationale Identität vorleben, aber auch in ,nationalistischen Ritualen, Gedenktagen, nationalen Feiertagen, militärischen Paraden“ oder der Anerkennung der Gründungstexten der Nation (Verfassung, Landkarten etc.) sowie der Repräsentant*innen der Nation (Nationalhelden, „Gründungsväter“, etc.) (Castro Varela/Dhawan 2015: 256). 
Kriterium ein, das Biesecker/von Winterfeld (2015) vorschlagen und das ich hier als ,Potenziale für eine herrschaftsärmere Zukunftsgestaltung', nach denen das Kriterium fragt, bezeichne. Es zielt in der Betrachtung der Gesellschaftsverträge bei Biesecker/von Winterfeld (2015: 5) zunächst auf die Rolle des Staates ab und wurde vor dem Hintergrund der Analyse des WBGU-Gutachtens entwickelt. Da es bisher nur in diesen Zusammenhängen angewandt wurde (Biesecker u.a. 2015; Biesecker/von Winterfeld 2015), ist es theoretisch bislang weniger ausgearbeitet. Um das Kriterium für die Analyse politischer Debatten in meiner Untersuchung anwendbar $\mathrm{zu}$ machen, ist also eine weitere theoretische Fundierung und Erweiterung notwendig, die ich im Folgenden vornehme. Das Ziel einer herrschaftsärmeren Zukunftsgestaltung (als Zieldimension von Emanzipation) verbinde ich dabei im Anschluss an Nancy Fraser (2001) mit Gerechtigkeit (vgl. auch Knobloch/von Winterfeld 2018) und der Frage nach Eigentum (vgl. auch Biesecker/von Winterfeld 2011). Das Kriterium spielt für meine Arbeit eine wichtige Rolle, da es die oben beschriebene Kritik von Fraser (2001: 263) an der Diskurstheorie aufgreift und die Frage bearbeitet wie sich Herrschaft im Kontext politischer Praktiken der „Energiewende" politisch ökonomisch materialisiert, bzw. wie materialisierte herrschaftliche Verhältnisse im Zuge dieser Praktiken abgebaut werden.

Das Kriterium der ,Potenziale für eine herrschaftsärmere Zukunftsgestaltung، fragt zum einen nach dem Selbstverständnis von Politik: Zeigen sich Potenziale für eine herrschaftsärmere Zukunftsgestaltung (Biesecker/von Winterfeld 2015: 5), bzw. für die Gestaltung möglichst wenig herrschaftlicher Verhältnisse? Welche Rolle kommt dabei der für die vorliegende Arbeit relevanten Politik im Bundestag zu spielt sie eine aktive Rolle, verlässt sie sich auf die Marktwirtschaft, trägt sie autoritäre Züge? Hier wird die Verwobenheit mit dem Kriterium der ,Externalisierung als Prinzip ‘ deutlich: Politische Praktiken können nur emanzipatorische Wirkung entfalten, wenn sie nicht auf Herrschaft bauen oder diese herstellen. Sie wirken emanzipatorisch, wenn sie aktiv mit Externalisierungen umgehen, diesen entgegenwirken und somit Herrschaft abbauen. Wird, wie in dieser Arbeit, ein emanzipatorischer Transformationsbegriff zugrunde gelegt, zielt Transformation also vor allem auf den Abbau bestehender Herrschaftsverhältnisse. Das verweist unmittelbar auf die Frage nach Gerechtigkeit als Legitimation von politischen Praktiken, die auf eine herrschaftsärmere Zukunftsgestaltung zielen. Da der Aspekt der Externalisierung bereits mit dem vorigen Kriterium behandelt wurde, möchte ich mich hier auf die Frage der Gerechtigkeit konzentrieren. Das Gerechtigkeitsverständnis des Vorsorgenden Wirtschaftens ist dabei wiederum ein transformatives, welches davon ausgeht, dass zur Herstellung von Gerechtigkeit Strukturen verändert werden müssen (Knobloch/von Winterfeld 2018; Netzwerk Vorsorgendes Wirtschaften u.a. 2018). Es verweist zudem auf das Leitbild Nachhaltiger Entwicklung und dabei insbesondere auf das Postulat interund intragenerationaler Gerechtigkeit. Verschiedene Aspekte davon wurden bereits aufgegriffen, bspw. Generationengerechtigkeit im Zusammenhang mit dem Handlungsprinzip der Vorsorge (Kapitel 3.2.1). Das Vorsorgende Wirtschaften legt zudem ein besonderes Augenmerk auf Gerechtigkeit in den gesellschaftlichen Naturverhältnissen (sozial-ökologisches Gerechtigkeitsverständis) sowie auf Geschlechtergerechtigkeit (Netzwerk Vorsorgendes Wirtschaften u.a. 2018). Um das Kriterium der ,Potenziale für eine herrschaftsärmere Zukunftsgestaltung ‘ für die Diskursanalyse anwendbar zu machen, geht es nun darum, Gerechtigkeit auf einer übergeordneten 
strukturell-politischen Ebene zu fassen: Wie wird Gerechtigkeit im politischen Diskurs gefasst? Handelt es sich um ein emanzipatorisches Gerechtigkeitsverständnis? Handelt es sich also um eines, das auf den Abbau von Herrschaft zielt?

Fraser (2001: 27f.) unterscheidet zwei Arten von Ungerechtigkeit: Zum einen „sozioökonomische Ungerechtigkeit ${ }^{43}$, die in den politisch-wirtschaftlichen Strukturen der Gesellschaft ihren Grund hat" und zum anderen kulturell-symbolische Ungerechtigkeit, die ,in sozialen Mustern der Anerkennung, Interpretation und Kommunikation ihren Grund" habe. ${ }^{44}$ Daher erfordere Gerechtigkeit sowohl Umverteilung als auch Anerkennung (ebenda: 24). Ökonomische Benachteiligung und kulturelle Nichtachtung seien miteinander verflochten, weshalb sie auch politisch so zu adressieren seien, dass sie gemeinsam gelöst werden können. Sie sieht Umverteilungs- und Anerkennungspolitik jedoch auch teilweise in einem Widerspruch, den sie als „Umverteilungs-Anerkennungs-Dilemma ${ }^{45 ، ~(e b e n d a: ~ 27) ~ b e z e i c h n e t . ~ E i n e ~ e n t s c h a ̈ r f e n d e ~}$ Antwort darauf findet sie im Ansatz von ,Affirmation“ und ,Transformation“:

„Mit affirmativen Maßnahmen gegen Ungerechtigkeit meine ich solche Mittel, die darauf abstellen, ungerechte Folgewirkungen auszugleichen, ohne den zugrundeliegenden Rahmen anzutasten, der diese Verhältnisse hervorbringt. Unter transformativen Maßnahmen verstehe ich dagegen Mittel, die beabsichtigen, ungerechte Folgewirkungen zu beheben, indem man gerade die zugrundeliegenden Voraussetzungen dieser Verhältnisse neu strukturiert“ (ebenda: 47).

Transformative Maßnahmen verknüpft Fraser (2001) auf der Anerkennungsebene mit der Dekonstruktion, bspw. von Dichotomien. Sie verändern die ,zugrundeliegende kulturell-evaluative Struktur“ der Missachtung (ebenda: 48) und weichen Differenzierungen auf. Dagegen festigen affirmative Maßnahmen bestehende Differenzierungen - bspw. würden die Klassendifferenzierungen durch affirmative Umverteilungs-

43 Sie beruft sich dabei nicht auf eine bestimmte Theorie von Gerechtigkeit. Es genüge die Zustimmung zu ,einem groben und allgemeinen Verständnis sozioökonomischer Ungerechtigkeit [...], das von einer Verpflichtung auf den Egalitarismus geprägt ist“" (Fraser 2001: 28). Dieser Einschätzung schließe ich mich hier an und nehme daher keine darüber hinausgehende theoretische Bestimmung von Gerechtigkeit vor.

44 Sie weist aber gleichzeitig darauf hin, dass sich diese beiden Formen der Ungerechtigkeit in Wirklichkeit kaum trennen lassen, sondern, dass sie miteinander verwoben sind. Die Trennung ergebe aber aus analytischen Gründen Sinn (Fraser 2001: 26). Aus diesen analytischen Gründen schließe ich mich der Trennung an.

45 Gemeint ist hier die Annahme, „daß die Politik der Anerkennung und die Politik der Umverteilung offenbar häufig widersprüchliche Ziele verfolgen. Neigt erstere dazu, die Gruppendifferenzierung zu fördern, ist die zweite bestrebt diese zu untergraben. Die zwei Anspruchsarten stehen folglich in einem Spannungsverhältnis zueinander, sie können sich beeinträchtigen oder sogar gegeneinander arbeiten“ (Fraser 2001: 33). Bspw. in Bezug auf Rassismus: „Wie können Antirassisten zugleich dafür kämpfen, ,Rasse‘ als Faktor aufzuheben und die kulturelle Besonderheit von Gruppen aufzuwerten, die als untergeordnete ,Rasse“ eingestuft werden?“ (ebenda: 46). Das Dilemma könne nicht völlig aufgelöst werden. 
maßnamen im liberalen Wohlfahrtstaat letztendlich gestärkt. ${ }^{46}$ Affirmative Maßnahmen streben zwar einen Ausgleich von Ungerechtigkeit an, ,aber die Tiefenstrukturen“, die die Benachteiligung erzeugen, „bleiben unangetastet“ (ebenda: 52).

„Deshalb müssen die oberflächlich vorgenommenen Umverteilungen ständig wiederholt werden. Dies führt dazu, daß die am stärksten benachteiligte Klasse das Kennzeichen angeheftet bekommt, sie sei von Natur aus unzulänglich und unersättlich und brauche deshalb immer mehr Hilfe. Mit der Zeit kann sogar der Eindruck entstehen, eine solche Klasse werde begünstigt, sei Empfänger [...] unverdienter Großzügigkeit. Auf diese Weise kann ein Ansatz, dessen Ziel der Ausgleich von Ungerechtigkeiten in der Verteilung ist, dabei enden, Ungerechtigkeiten in den Anerkennungsbeziehungen zu schaffen“" (ebenda). ${ }^{47}$

Dies bedeutet jedoch nicht, dass affirmative Maßnahmen von vorne herein abzulehnen wären. Es geht hier nicht darum eine generelle Wertung dieser Maßnahmen vorzunehmen, sondern vor allem die Richtung ihrer praktischen Wirkweisen im Hinblick auf Transformation analysierbar zu machen.

Im Gegensatz zu affirmativen Maßnahmen verringern transformative Maßnahmen soziale Ungleichheit, „ohne jedoch stigmatisierte Klassen verwundbarer Menschen hervorzubringen, die als Nutznießer besonderer Großzügigkeit wahrgenommen werden“ (ebenda: 53). Sie fördern Solidarität und Wechselseitigkeit in den Anerkennungsverhältnissen. Im Spannungsfeld zwischen Affirmation und Transformation sowie Umverteilung und Anerkennung, klassifiziert Fraser (2001) die Umverteilungsmaßnahmen des Wohlfahrtsstaats als affirmative Umverteilung und den Multikulturalismus (der auf der Behauptung kultureller Differenz beruht) als Beispiel für affirmative Anerkennung, wohingegen sie den Sozialismus, der die Grundstruktur der Produktionsverhältnisse neuordne, als transformative Umverteilung und die Dekonstruktion (bspw. vermeintlicher kultureller Differenzen) als transformative Aner-

46 „Ganz allgemein haben sie [die affirmativen Maßnahmen des Wohlfahrtsstaates, bspw. Sozialversicherung] die Konsequenz, daß sich die Aufmerksamkeit von der Einteilung in eine Arbeiter- und eine Kapitalistenklasse auf die Einteilung in beschäftigte und arbeitslose Fraktionen der Arbeiterklasse verschiebt. Die Sozialhilfeprogramme machen die Armen nicht nur zur ,Zielgruppe` der Unterstützung, sondern auch der Feindseligkeit. Denn derartige Maßnahmen sorgen zwar zweifellos für die benötigte materielle Hilfe. Sie bewirken aber auch eine stark emotional aufgeladene, antagonistische Differenzierung von Gruppen“ (Fraser 2001: 51f.).

47 Diese Wirkung entfaltet sich durch affirmative Maßnahmen im liberalen Wohlstandsstaat nicht nur auf die Klassendifferenzierung, sondern lässt sich auch bei anderen Differenzierungen feststellen, bspw. der Geschlechterdifferenzierung durch affirmative Maßnahmen der Gleichstellungspolitik. So könne am Ende der Eindruck entstehen „Frauen seien privilegiert" oder Empfängerinnen einer besonderen Behandlung, wodurch der Ansatz, der ursprünglich zum Ziel hatte, Ungerechtigkeiten auszuräumen „reaktiven Ungerechtigkeiten“ erst Nahrung gibt (Fraser 2001: 59). Aktuell zeigt sich dies im Erstarken rechter Angriffe auf die Gleichstellungspolitik. 
kennung einstuft (ebenda: 55). ${ }^{48}$ Sie verbindet somit die Dekonstruktion als Mittel der Umstrukturierung kultureller Anerkennungsverhältnisse mit der Forderung nach sozialer Gleichheit (die bei ihr als Umverteilung gedacht ist), wodurch in der Kombination beider Ansätze (Dekonstruktion und transformative Umverteilung) Frasers (2001: 263) oben (vgl. Kapitel 2.6) dargestellter Kritik an der Diskurstheorie nach Laclau/Mouffe (2015) konstruktiv begegnet werden kann. ${ }^{49}$

Die Forderung nach Gerechtigkeit, sowie nach Umverteilung als ein Aspekt davon, rückt die Frage nach dem Eigentum in den Blick, die im Vorsorgenden Wirtschaften bislang selten behandelt, aber von einzelnen Autor*innen aufgegriffen wird. ${ }^{50}$ Ich möchte hier nicht genauer auf den Begriff des Eigentums und seine grundsätzliche Bedeutung im Vorsorgenden Wirtschaften eingehen, jedoch kurz seine Relevanz im Zusammenhang mit Emanzipation und Gerechtigkeit verdeutlichen. Denn die Frage nach Eigentum hat insbesondere auch mit Herrschaftsverhältnissen zu tun. Biesecker/von Winterfeld (2011) bezeichnen Herrschaft im Anschluss an Binswanger (1998) als Qualifikation des Eigentums: Die Herrschaft des Eigentums

„,ist zunächst eine Herrschaft über Ressourcen. Da mit den Eigentumsrechten jedoch auch geregelt ist, was Nicht-Eigentümern untersagt ist, geht es auch um Herrschaft über Menschen. Eigentumsrechte bestimmen nicht nur die Beziehungen von Eigentümern zu Ressourcen, sondern sie definieren soziale Verhältnisse - Verhältnisse, in denen das Eigentum der einen andere von der Nutzung ausschließt“" (Biesecker/von Winterfeld 2011: 140).

Ein solches ausschließendes Eigentum bezeichnen Biesecker/von Winterfeld (2011: 140) im Anschluss an Binswanger (1998) als „Herrschafts-Eigentum“ (Biesecker/von Winterfeld 2011: 140). Eigentumsrechte könnten zwar „begrenzt oder mit Verpflichtungen verbunden werden“, bspw. mit sozial-ökologischen Verantwortlichkeiten der Eigentümer*innen, stattdessen werde aktuell aber das Privateigentum im Sinne von Herrschafts-Eigentum eher ausgedehnt (ebenda). Dies zeige sich bspw. in der Klimapolitik, wenn Luftverschmutzungsrechte in Privateigentum umgewandelt und an Märkten verkauft werden, wodurch die Ökonomisierung der Natur vorangetrieben werde (Biesecker/von Winterfeld 2011: 140; vgl. auch Brand u.a. 2013). Die Klimakrise solle somit auf individueller Ebene mit eben der (Profit)Rationalität gelöst werden, die in ihrer Summe auf globaler Ebene die Klimakrise mit ausgelöst habe (Biesecker/von Winterfeld 2011: 137).

48 „Ich habe hier dargelegt, daß eine sozialistische Wirtschaftspolitik kombiniert mit dekonstruktiver kulturalistischer Politik die besten Ergebnisse erzielen wird, wenn man das [Umverteilungs-Anerkennungs-] Dilemma [...] kleinarbeiten will [...]“ (Fraser 2001: 63).

49 Vor dem Hintergrund des sozial-ökologischen Ansatzes meiner Arbeit sowie des sozialökologischen Gerechtigkeitsverständnisses des Vorsorgenden Wirtschaften wende ich dabei die Begriffe Anerkennung, Umverteilung, Affirmation und Transformation nicht nur auf soziale Verhältnisse, sondern auch auf gesellschaftliche Naturverhältnisse an.

50 So beschreiben Biesecker/von Winterfeld (2011) die Entstehung der bürgerlichen Gesellschaft als Eigentümergesellschaft. 
„Diese Art Eigentum befördert keine nachhaltige Entwicklung. Sie ist verbunden mit Ausschluss, Unterwerfung, Ausbeutung. Die Vereigentümlichung ganz neuer Bereiche bedeutet Aneignung von ehemals öffentlichem oder von Gemeinschaftseigentum und damit Enteignung aller anderen“ (ebenda: 141).

Ein emanzipatorisches Eigentumsverständnis, das auch im Sinne des Vorsorgenden Wirtschaftens wäre, dürfe nicht ausschließend, herrschaftlich oder ausbeuterisch sein (ebenda). Maßnahmen transformativer Gerechtigkeit zielen in Bezug auf Eigentum also nicht auf „die Internalisierung des bislang Externen in herkömmliche Eigentumsmodelle“ sondern auf die Einbindung von Eigentum ,,in durchlässige und vernetzte soziale und ökologische Umwelten und Wirklichkeiten" (O'Hara 2000: 229; Biesecker/von Winterfeld 2011: 141).

\subsubsection{Potenziale einer diskurstheoretischen Perspektive Vorsorgenden Wirtschaftens}

Das Konzept Vorsorgendes Wirtschaften hat in der vorliegenden Studie eine analytische und eine normativ positionierende Funktion, wie ich eingangs erläutert habe (vgl. Kapitel 1.2). In Kapitel 2.6 bin ich auf einen zentralen Kritikpunkt an der poststrukturalistischen Diskurstheorie eingegangen, dass diese eine politische Positionierung, bzw. ein politisches Handeln verunmögliche (vgl. Butler/Scott 1992). Dem begegne ich, in dem ich dahingehend argumentiere, dass das Anliegen der Diskurstheorie im Gegenteil selbst ein Politisches ist, was ich ebenfalls in Kapitel 2 dargelegt und begründet habe. Scherer (2014: 920) argumentiert zudem, „daß die Einsicht in die letztendliche Unbegründbarkeit der eigenen Überzeugungen keinen Hinderungsgrund dafür darstellen muß, dennoch ,unerschrocken" für sie einzustehen". Aus sozial-ökologischer Perspektive bietet die Diskurstheorie nach Laclau/Mouffe (2015) als Metatheorie außer der Anerkennung radikaler Kontingenz allerdings kein zureichendes Kriterium ,anhand dessen entschieden werden kann, welche Politik wünschenswert ist und welche nicht“ (Distelhorst 2007: 177). Dass sich nach meiner Auffassung die forschungspraktische gemeinsame Anwendung von Vorsorgendem Wirtschaften und Diskurstheorie also nicht widerspricht, sondern in vielen Punkten ergänzt und Potenziale für eine kritische, sozial-ökologische Transformationsforschung bietet, habe ich im bisherigen Verlauf dieser Arbeit bereits mehrfach thematisiert. Die einzelnen Argumentationsstränge, derer ich mich dabei bediene, möchte ich in diesem Kapitel zusammenführen, um ein abschließendes Bild über das theoretische Grundgerüst dieser Arbeit zu vermitteln und zu begründen.

Das Vorsorgende Wirtschaften hat einen macht- und herrschaftskritischen Anspruch (Netzwerk Vorsorgendes Wirtschaften 2013: 10) und erweitert die Transformationsdebatten um eine feministische Perspektive. Ähnlichkeiten zwischen der Betrachtung von Externalisierung im Vorsorgendem Wirtschaften und der diskursiven Konstitution von Identitäten bei Laclau/Mouffe (2015) wurden in Kapitel 3.2.2 (Externalisierung als Prinzip) bereits ausgeführt. Während der Fokus der Diskurstheorie auf der Identitäts-, der Hegemonie- und der Demokratietheorie liegt, entwickelt das Vorsorgende Wirtschaften ausgehend von einer feministisch ökologischen Kritik am vorherrschenden Wirtschaftsmodell eine positive Vision. Eine Verbindung von Vor- 
sorgendem Wirtschaften und Diskurstheorie hat so das Potenzial, die Diskurstheorie nach Laclau/Mouffe (2015) um politisch ökonomische Aspekte zu ergänzen und der Kritik an der Diskurstheorie durch Fraser (2001) bezüglich einer Ausklammerung eben solcher Aspekte sowie der allgemeinen Kritik einer (vermeintlich) fehlenden politischen Positionierung entgegenzuwirken. Analytisch spiegelt sich dies in den Handlungsprinzipien Vorsorgenden Wirtschaftens (Vorsorge, Kooperation, Orientierung am für das gute Leben Notwendigen) sowie in den dargestellten weiteren Kriterien (Externalisierung als Prinzip, herrschaftsärmere Zukunftsgestaltung), welche die Grundlage für die Operationalisierung Vorsorgenden Wirtschaftens im folgenden Kapitel darstellen.

Eine diskurstheoretische Perspektive Vorsorgenden Wirtschaftens verstärkt darüber hinaus dessen Reflexivität, da die Parteilichkeit sichtbar wird. Sie hilft zudem verschiedene Positionen, Ambivalenzen und Widersprüche innerhalb des Ansatzes zu erkennen. Vorsorgendes Wirtschaften in diesem Sinne ist keine Vision mit universellem Geltungsanspruch, sondern hat politischen Gehalt. Die Diskurstheorie nach Laclau/Mouffe (2015) ermöglicht zudem eine erweiterte hegemonietheoretische Fundierung der Analyseperspektive Vorsorgenden Wirtschaftens. Da Machtverhältnisse und Herrschaftskritik in beiden Ansätzen auf jeweils eigene Weise eine zentrale Rolle spielen, rücken diese innerhalb einer gemeinsamen methodologischen Verbindung noch stärker in den Fokus, wodurch in der praktischen Anwendung die Erklärkraft beider Ansätze erhöht wird. So konnten im Laufe der Diskursanalyse Möglichkeiten gefunden werden, die theoretische Konzeption zu verfeinern und neue Gesichtspunkte - wie zum Beispiel (neo)koloniale Herrschaftsstrukturen und deren Ausdruck auf der Ebene nationaler politischer Diskurse - in das Vorsorgende Wirtschaften zu integrieren. Letztlich konnten also durch die theoretische Verbindung von Vorsorgendem Wirtschaften und Diskurstheorie beide Ansätze theoretisch und analytisch verfeinert werden. Im folgenden Kapitel arbeite ich die methodische Verbindung beider Ansätze innerhalb des Forschungsdesigns heraus (Abbildung 4).

Die Untergrabung der Dichotomie sprachlich/materiell im Diskursbegriff von Laclau/Mouffe (2015) kann dabei nicht nur zur Weiterentwicklung der feministischen Theoriebildung insgesamt beitragen (vgl. Kapitel 2.3), sondern ergänzt sich in Bezug auf das Vorsorgende Wirtschaften auch mit (Re)Produktivität als vermittlungstheoretischer Kategorie (vgl. auch Amri-Henkel 2020). Dies bietet neue Potenziale für die Arbeit mit dem Vorsorgenden Wirtschaften als Perspektive auf Transformation. Biesecker/Hofmeister (2006) verstehen unter Vermittlungstheorien in Anlehnung an Kropp (2002) „Ansätze, die Gesellschafts-Natur-Beziehungen [...] weder zur Seite der Natur noch zur Gesellschaft hin auflösen - also weder naturalistisch noch soziozentristisch argumentieren“ (Biesecker/Hofmeister 2006: 147). Dies gelingt - wie in Kapitel 2 (Diskurstheorie) gezeigt - bei Laclau/Mouffe (2015) durch die katachrestische ,Falschanwendung des Diskursbegriffes als materiellen Diskursbegriff, der ebenso wie der (Re)Produktivitätsansatz auf die „Auflösung des tradierten Gegensatzverhältnisses Gesellschaft/Kultur vs. Natur“ zielt und dies „mit politischen Konsequenzen“" verbindet (ebenda: 147). Der materielle Diskursbegriff von Laclau/Mouffe (2015) verweist stets auf die Vermitteltheit von Sprache, sozialer Praktiken und Materialität und eignet sich daher aus feministischer Perspektive besonders für die Dekonstruktion solcher Gegensatzverhältnisse (vgl. auch AmriHenkel 2020). 
Feministische Nachhaltigkeitsforscher*innen fordern die ,(Re)Integration von Materialität in die feministische Theoriebildung“ (Hofmeister u.a. 2013: 48). Für eine Nachhaltigkeitsforschung, bei der die „Wechselbeziehungen zwischen Materialität und sozialer Konstruktion" (ebenda) im Zentrum der Analyse stehen, bietet sich eine Kombination des Diskursbegriffs nach Laclau/Mouffe (2015) mit dem Vorsorgenden Wirtschaften daher an. Diese Kombination kann somit einen Ausweg aus folgendem methodologischen Dilemma der Gender- und der Nachhaltigkeitsforschung aufzeigen:

„Wie lassen sich Natur- und Geschlechterverhältnisse als soziale Konstruktionen je für sich und in ihren wechselseitigen Bezügen zueinander beschreiben, wenn zugleich an Materialität, an lebendigen Naturen und an lebendigen, vergeschlechtlichten Körpern (die als physische Identitäten die für beide Forschungsfelder konstitutiven Grenzbegriffe darstellen) - aus feministischer Sicht festgehalten werden will und muss?“ (ebenda: 76).

Diskurstheorie, Transformationstheorie und Vorsorgendes Wirtschaften in der vorliegenden Analyse der bundespolitischen Debatten um „Energiewende“ zusammenzuführen erweist sich methodologisch als sinnvoll, da das Vorsorgendes Wirtschaften als Analyseperspektive durch die oben genannte Ergänzung um politisch ökonomische Aspekte dabei hilft, die Materialität im Laufe der Analyse dann tatsächlich auch im Blick zu behalten. Die Zusammenführung von Diskurstheorie und Vorsorgendem Wirtschaften leistet somit einen Beitrag zur methodologischen und theoretischen Weiterentwicklung sozial-ökologischer Transformationsforschung, da gesellschaftliche Natur- und Geschlechterverhältnisse vermittlungstheoretisch gedacht werden und ihre Analyse hegemonietheoretisch fundiert wird. 


\section{Methodik: Diskursanalyse und Vorsorgendes Wirtschaften als Forschungsprogramm}

Wie in den vorangegangenen Theoriekapiteln deutlich wurde, kann der methodische Anspruch einer poststrukturalistisch informierten Diskursforschung nur postpositivistisch sein. Insofern wird der hier vorgestellte methodische Ansatz vor dem Hintergrund der theoretischen Annahmen sowie des spezifischen Gegenstandes erarbeitet und ebenso wie der Gegenstand selbst als nicht objektiv vorliegend erachtet. Der Anspruch des methodischen Vorgehens besteht also nicht darin, in vermeintlicher Objektivität ,wahre‘ Erkenntnisse über den Gegenstand zu erzeugen, sondern möglichst plausible Erklärungen und Theorien zu entwickeln (Glynos/Howarth 2007: 33). Dieser Prozess beinhaltet auch die Konstruktion des Forschungsobjektes selbst. Die Artikulationen von „Energiewende“ und damit zusammenhängender Inhalte im Bundestag werden als wissenschaftliches Problem konstituiert und auf einem bestimmten Komplexitäts- und Abstraktionsniveau betrachtet, womit bereits eine Eingrenzung des Untersuchungsgegenstandes einher geht (vgl. ebenda: 167). Ein solches post-positivistisches Vorgehen bezeichnen die ehemaligen Laclau-Schüler ${ }^{1}$ Glynos/Howarth (2007: 18f.) im Anschluss an Charles Sanders Peirce (1967) als Retroduktion/retroduktive Erklärung - im Gegensatz zu deduktiven oder induktiven Forschungsansätzen. Die Retroduktion ist ein zirkelhaftes Verfahren, das mit der Beobachtung eines Phänomens in der Gegenwart beginnt. Das Phänomen wird also von der*m Forschenden auf eine bestimmte Weise problematisiert, wodurch sich die anfänglichen Wahrnehmungen und Verständnisse bereits ändern. Folglich werden (retroduktive) Erklärungen gesucht, die das Phänomen verständlicher machen. Es entwickelt sich eine zirkelhafte Bewegung zwischen Phänomen/Problematisierung, Erklärung und schließlich Rechtfertigung der Erklärung, das Überzeugen anderer von ihrer Akzeptabilität und damit zusammenhängender theoretischer und praktischer Interventionen (Glynos/Howarth 2007: 33f.). Im Gegensatz zu induktiven und deduktiven Verfahren können sich also Theorien im Laufe des Forschungsprozesses verändern oder weiterentwickeln. Im Anschluss an Foucault bedeute Problematisieren im Politischen, das Politische daraufhin zu befragen, was es zu den Problemen, mit denen es konfrontiert wird, zu sagen habe (Glynos/Howarth 2007: 167). Im Folgenden ent-

1 Laclau bezeichnet das Werk der beiden als „the most significant attempt so far at elaborating a general framework for social research from a poststructuralist perspective" (Laclau in Glynos/Howarth 2007) 
wickle ich eine retroduktive, diskurstheoretische Forschungsmethodik, innerhalb derer das Phänomen „Energiewende“ im Rahmen der Bundestagsdebatten mit verschiedenen methodischen Verfahren, auf verschiedenen Ebenen und aus verschiedenen Perspektiven jeweils erneut problematisiert und erklärt wird. Die in Abbildung 1 dargestellten methodischen Schritte innerhalb dieses retroduktiven Prozesses sind Gegenstand des vorliegenden Kapitels.

\section{Abbildung 1: Einbindung der Methodik im retroduktiven Forschungsprozess}

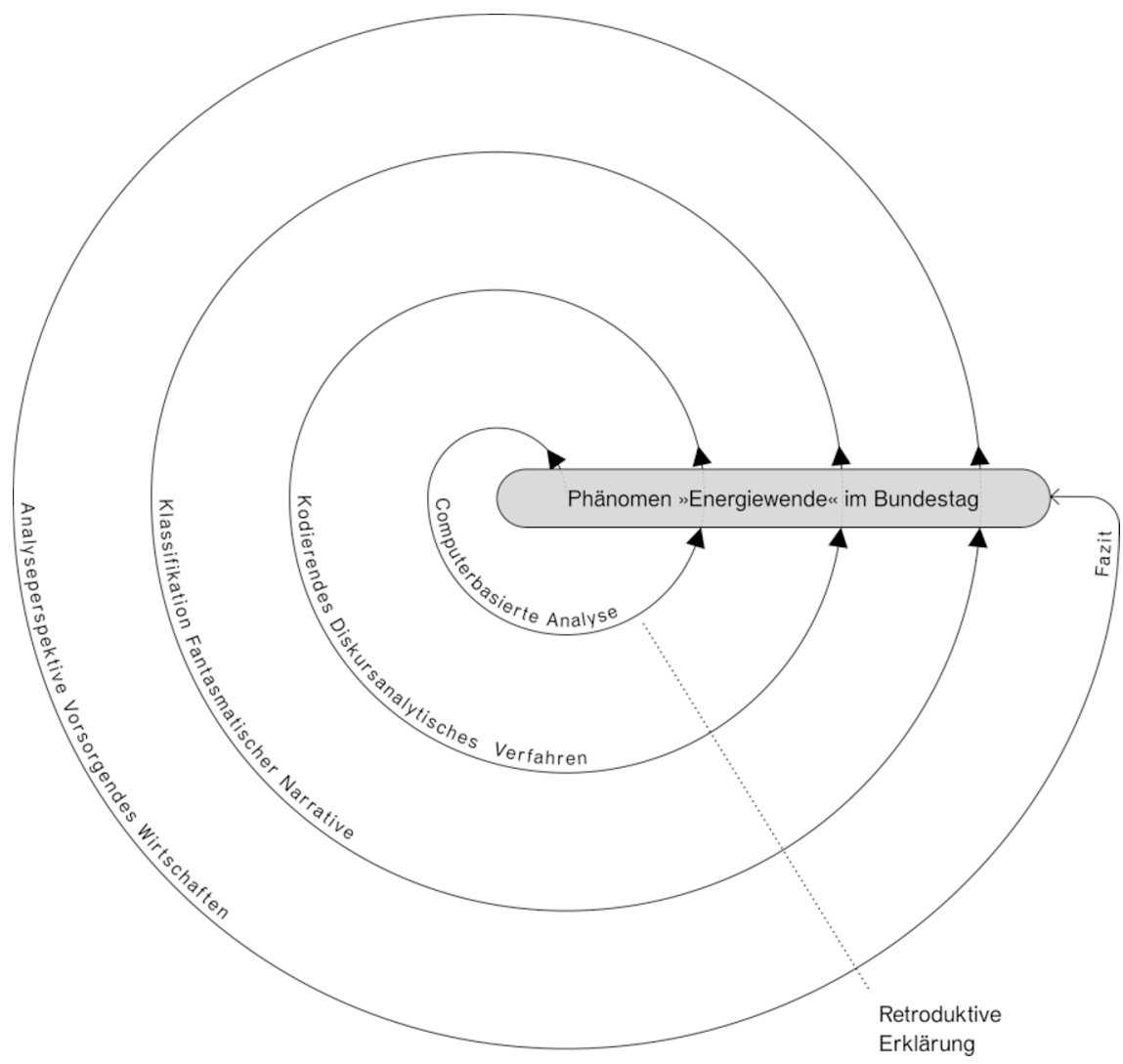

Quelle: eigene Darstellung

In Kapitel 2 (Diskurstheorie) wurde deutlich, dass sich die Diskurstheorie von Laclau/Mouffe auf die theoretische und philosophische Ebene konzentriert und sie ihre forschungspraktische Anwendbarkeit zunächst außen vor lässt - wozu sich Laclau als „happily guilty“ (Laclau 2004: 324) bekennt. Nonhoff (2007: 174) bezeichnet dies als für die politische Diskursforschung

„bedauerlich, weil Laclau und Mouffe somit zwar einerseits ein anspruchsvolles Angebot für die Schnittstelle von politischer Theorie und Diskurstheorie machen, weil aber andererseits kein ausgereiftes methodologisches Programm zur diskursanalytischen Überprüfung und Fortschreibung der Diskurstheorie besteht“. 
Die Herausforderung besteht also in einer konkreten methodischen Operationalisierung der Diskurstheorie, mit der die Gefahr umgangen wird, den Gegenstand einfach nur an eine abstrakte Theorie anzupassen. Daher greife ich Operationalisierungsvorschläge von Glasze (2008), Dzudzek u.a. (2009), Glasze u.a. (2009) sowie Glynos/ Howarth (2007) auf und entwickle sie gegenstandsbezogen weiter. Dadurch mache ich die Diskurstheorie als politische Theorie für meinen Forschungsgegenstand forschungspraktisch anwendbar.

Die normative und politisch ökonomische Dimension, durch die die Diskurstheorie mit Hilfe des Vorsorgenden Wirtschaftens erweitert wird, habe ich bereits im Rahmen der theoretischen Verortung meiner Arbeit in Kapitel 3 erläutert und in der Einleitung durch eine Positionierung innerhalb der Transformationsforschung kenntlich gemacht. Das Vorsorgende Wirtschaften erfüllt in der Methodik zudem aber auch eine analytische Funktion, indem es als kritisch-emanzipatorische Perspektive dient, mit der die diskursanalytischen Untersuchungsergebnisse qualitativ reflektiert und bewertet werden. Das methodische Vorgehen anhand heuristischer Fragestellungen wird im vorletzten Teil des Methodenkapitels erläutert. Zunächst gehe ich aber auf die methodische Erschließung des Forschungsgegenstandes ein und vertiefe dann die bereits angedeutete methodische Operationalisierung der Diskurstheorie nach Laclau/Mouffe (2015) in einem dreistufigen Verfahren. Nachdem diese methodisch durch dem Vorsorgenden Wirtschaften entlehnte analytische, qualitative Forschungskomponenten ergänzt wird, unterziehe ich im letzten Teilkapitel dieses Methodenteils meinen Forschungsansatz insgesamt einer kritischen Überprüfung.

\subsection{GEGENSTAND: PLENARDEBATTEN IM BUNDESTAG}

In Kapitel 1 habe ich die Bedeutung politischer Prozesse im Bundestag für den deutschen „Energiewende“-Diskurs aufgezeigt. Im Rahmen der im Projekt „TraVo“ durchgeführten Expert*inneninterviews hat sich gezeigt, dass sich außerparlamentarische bundespolitische Akteur*innen in ihrer Arbeit zur „Energiewende“ maßgeblich daran orientieren, was im Bundestag jeweils aktuell auf der Agenda steht (vgl. Amri-Henkel u.a. 2017). ${ }^{2}$ Daran anknüpfend habe ich begründet, warum ich in meiner Arbeit auf die Bundestagsdebatten als Untersuchungsgegenstand fokussiere. Argumentiert habe ich dabei unter anderem mit Schwab-Trapp (2001), der die Wortführerschaft ${ }^{3}$ der Mitglieder des Bundestages betont: „Diskursive Eliten sind vor allem deshalb Eliten, weil sie im Bourdieuschen Sinne über ein ,symbolisches Kapital ‘ verfügen, das sie in diskursiven Auseinandersetzungen einsetzen können und das ihren Deutungsangeboten Gewicht verleiht“ (ebenda: 272). Im Falle von Bundestagsabgeordneten leitet sich dieses Kapital aus der allgemeinen Anerkennung des Amtes an sich sowie der diesem in einer repräsentativen Demokratie explizit zugeschriebenen Repräsentationsfunktion ab, die ein öffentliches Sprechen für spezifische politische

2 Zumindest gilt dies für den Betrachtungszeitraum 2015/2016.

3 Auch wenn sie aus poststrukturalistischer Perspektive nicht außerhalb des Diskurses stehen, sondern Teil von ihm sind - also selbst vom Diskurs beeinflusst sind. 
und soziale Milieus nicht nur legitimiert, sondern auch erfordert. ${ }^{4}$ Die allgemeine Anerkennung der Repräsentationsfunktion des Amtes führt wiederum zu einer medialen Berichterstattung, die den Politiker*innen gesellschaftliches Gehör verschafft. Sie können also Öffentlichkeit herstellen, den öffentlichen Diskurs über „Energiewende“ in eine bestimmte Richtung lenken, initiieren, zu seiner Institutionalisierung beitragen und somit kollektiv anerkannte Sichtweisen verändern oder bestärken (vgl. Schwab-Trapp 2001: 272).

Auch habe ich auf die Rolle der Plenardebatten als formalisierte „SchaufensterDiskurse“ (van Dijk 1992: 201), die in erster Linie auf eine strategische Außenwirkung abzielen, hingewiesen. Bei den Plenardebatten handelt es sich nicht um Debatten im Sinne eines mehr oder weniger spontanen Meinungsaustausches, d.h. ihr Ablauf ist von vorne herein genau festgelegt, die Redezeiten berechnen sich nach der Fraktionsgröße (www.bundestag.de - Geschäftsordnung). So steht auch das Abstimmungsverhalten üblicherweise bereits vor den Debatten fest. Redebeiträge erfolgen also nicht (oder nur zu einem geringen Anteil) als Reaktion/Antwort auf Vorredner*innen, sondern legen den Standpunkt der Fraktion (oder einer Gruppe innerhalb der Fraktion) zum jeweils aktuellen Thema dar. Zielgruppe sind dabei in erster Linie nicht andere Abgeordnete, sondern die außerparlamentarische Öffentlichkeit. Die Redebeiträge der Fraktionen werden zum großen Teil strategisch platziert, sie sollen die jeweils eigene Deutungsweise möglichst gut in der Öffentlichkeit darstellen, um Einfluss auf die Meinungsbildung und gesellschaftliche Bedeutungskämpfe zu üben. Gleichzeitig ist davon auszugehen, dass gesellschaftliche Bedeutungskämpfe auch Einfluss auf die Redebeiträge im Bundestag haben, die durch ihre Öffentlichkeit ,politisch und moralisch äußerst stark unter Kontrolle stehen“ (van Dijk 1992: 201).

Alle Bundestagsdebatten werden in Plenarprotokollen erfasst, welche die Reden sowie Zwischenrufe vollständig wiedergeben und somit die Haltungen, Argumente und Deutungen sowie die Positionierungen der verschiedenen Fraktionen in den Bedeutungskämpfen um „Energiewende“ über die Zeit beinhalten. Allein aus diesem Grund bieten sie sich für die diskursanalytische Untersuchung politischer Prozesse im Bundestag besonders an. Darüber hinaus bleibt der Raum, in dem der Diskurs stattfindet, also der Kommunikationskanal, gleich - ebenso wie das parlamentarische Prozedere und die Zielgruppe des Gesprochenen. Da somit die „Bedingungen der Aussageproduktion möglichst stabil gehalten werden“ (Dzudzek 2009: 238), können Veränderungen des Diskurses methodisch sauber über längere Zeiträume nachvollzogen werden. Plenardebatten werden transkribiert und auf den Internetseiten des Deutschen Bundestages öffentlich digital zur Verfügung gestellt, was einen leichten Zugang zur Datenbasis ermöglicht (www.bundestag.de/services/opendata). Diese Originalprotokolle enthalten neben dem gesprochenen Wort auch die zu Protokoll gegebenen Reden, die ich in meiner Arbeit ebenfalls mit einbeziehe, da sie aufgrund der „Schaufenster-Funktion“ (van Dijk 1992: 201) des Bundestages Aufschluss über Deutungen sowie die Entwicklung des Diskurses geben.

4 Aus poststrukturalistisch informierter diskursanalytischer Perspektive können Bundestagsabgeordnete die Deutungsmuster dieser Gruppen natürlich nicht abbilden, da es sich nicht um homogene Gruppen handelt. Ihnen kommt aber eine herausragende Funktion innerhalb von Bedeutungskämpfen, die mit diesen Gruppen in Verbindung stehen, zu. 
Für die vorliegende Arbeit wird der im PolMine Projekt erarbeitete GermaParlKorpus in der Version von 2017 verwendet (Blaette 2017). Das PolMine Projekt ist eine Initiative von Prof. Dr. Andreas Blätte und zielt darauf, von politischen Institutionen öffentlich bereitgestellten Text, in digital verarbeitbarer Form für die Forschung verfügbar zu machen (www.polmine.github.io). Der GermaParl-Korpus enthält alle vom Deutschen Bundestag veröffentlichten Plenarprotokolle zwischen 1996 und 2016 in XML/TEI ${ }^{5}$ Format. $^{6}$ Dies entspricht 1291 Plenarprotokollen. Eine Übersicht über die Größe und den Zeitraum des Datenmaterials gibt Tabelle 1.

Tabelle 1: Korpusdaten nach Legislaturperioden (Lp)

\begin{tabular}{|c|c|c|c|}
\hline Lp & $\begin{array}{c}\text { Anzahl an } \\
\text { Protokollen }\end{array}$ & Ab Jahr & $\begin{array}{c}\text { Teilkorpus-Größe } \\
\text { (Token-Anzahl }^{\mathbf{7}} \text { ) }\end{array}$ \\
\hline 13 & 163 & $1996^{8}$ & 11.676 .618 \\
\hline 14 & 253 & 1998 & 19.349 .263 \\
\hline 15 & 182 & 2002 & 12.785 .509 \\
\hline 16 & 233 & 2005 & 18.412 .812 \\
\hline 17 & 252 & 2009 & 23.418 .060 \\
\hline Gesamt & 1291 & $2013^{9}$ & 15.371 .446 \\
\hline
\end{tabular}

Quelle: in Anlehnung an www.polmine.sowi.uni-due.de

Wie bereits in Kapitel 1.1 erläutert, konzentriert sich die vorliegende Analyse auf die 14. bis 18. Legislaturperiode (1998 bis 2017). Der Beginn des Analysezeitraums wurde auf die 14. Legislaturperiode angesetzt, da hier zum ersten Mal eine rot-grüne Regierungskoalition auftritt, die bis heute in besonderer Weise mit „Energiewende“

5 TEI Text Encoding Initiative ist ein internationaler Standard zur Kodierung von Texten, welcher die digitale Datenverarbeitung erleichtert (www.tei-c.org). Innerhalb des PolMine Projektes wurden die Protokolle aus dem Online-Archiv des Deutschen Bundestages für die digitale Datenverarbeitung aufbereitet.

6 Für genauere Informationen zur Korpusgenerierung vgl. www.polmine.sowi.uni-due.de.

7 Die Token-Anzahl bezeichnet in der Linguistik die Anzahl der tatsächlich vorhandenen Wörter, im Gegensatz zur Type-Anzahl, in der eine spezifische Wortform nur einmal zählt, unabhängig von der Häufigkeit ihres Vorkommens. Die Größe eines Korpus wird in der Lingusitik stets über die Token-Anzahl angegeben.

8 Der GermaParl Korpus beinhaltet Protokolle ab 08.02.1996. Die 13. Legislaturperiode beginnt am 10.11.1994.

9 Der GermaParl Korpus beinhaltet Protokolle bis einschließlich 16.12.2016. Die 18. Legislaturperiode endet am 24.10.2017. 
assoziiert wird (vgl. z.B. Morris/Jungjohann 2016: 197). Die Eingrenzung auf das Ende der 18. Legislaturperiode erfolgt aus forschungspragmatischen Gründen, da die vorliegende Analyse Anfang 2018 durchgeführt wurde und spätere Daten noch nicht vorlagen. Der darüber hinaus im GermaParl-Korpus enthaltene Zeitraum von 1996 bis 1998 wird lediglich zur Kontextualisierung zeitlicher Häufigkeitsentwicklungen im ersten Schritt der computerbasierten Analyse (vgl. Kapitel 4.2.1) herangezogen.

Das Datenmaterial von GermaParl ist mit linguistischen Annotationen versehen: Für jedes Wort ist die Information zur Wortart (in der Linguistik: Part of Speech POS) sowie die Information zur Grundform des Wortes (in der Linguistik: Lemma) verfügbar. ${ }^{10}$ Der Vorteil dieser Lemmatisierung ${ }^{11}$ für die spätere Datenverarbeitung bei der Analyse ist, dass nun alle im Text vorhandenen Wortformen über die Suche nach ihrer Grundform gefunden werden können (bspw. wird bei der Suche nach ,erneuerbar' nun auch ,erneuerbare' oder ,erneuerbaren' gefunden). Zusätzlich zu linguistischen Informationen enthält der GermaParl-Korpus strukturelle Metadaten (sattributes), sodass diese für die Analyse verfügbar sind und zum Beispiel die Auswertung auf ein bestimmtes strukturelles Merkmal eingegrenzt werden kann. Es ist so bspw. möglich einen Teilkorpus einer bestimmten Person, Fraktion oder eines bestimmten Zeitraumes zu analysieren, was insbesondere angesichts der großen Datenmenge von Bedeutung ist (www.polmine.sowi.uni-due.de). Die in der vorliegenden Arbeit verwendeten strukturellen Metadaten sind in Tabelle 2 dargestellt.

Tabelle 2: Strukturelle Metadaten in GermaParl

\begin{tabular}{|l|l|l|}
\hline s-attribute & Beschreibung & Wert \\
\hline lp & Legislaturperiode & 13 bis 18 \\
\hline session & Sitzung & 1 bis 253 \\
\hline date & Datum der Sitzung & YYYY-MM-TT \\
\hline year & Jahr der Sitzung & 1996 bis 2016 \\
\hline interjection & Zwischenruf & TRUE/FALSE \\
\hline role & Rolle des*r Sprecher*in & presidency/mp/government/... \\
\hline speaker & Name & Name \\
\hline parliamentary_group & Fraktion & Fraktion des*r Sprecher*in \\
\hline party & Partei & Partei des*r Sprecher*in \\
\hline
\end{tabular}

Quelle: in Anlehnung an www.polmine.sowi.uni-due.de

10 Dafür wurde das Tool TreeTagger verwendet (www.cis.uni-muenchen.de).

11 Bei der Lemmatisierung werden die Wortformen (Flexionen) ihrer Grundform zugewiesen. 
Wie im nachfolgenden methodischen Vorgehen deutlich wird, liegt dem ersten Schritt der Analyse (4.2.1) der gesamte Korpus (1291 Plenarprotokolle) zu Grunde. Dies hat den Vorteil, dass für „Energiewende“ relevante Debatten aus dem gesamten Korpus heraus identifiziert werden können - also die zu analysierenden Debatten nicht aufgrund im Vorhinein getroffener Annahmen ausgewählt werden, sondern korpusbasiert (zum Vorgehen vgl. Kapitel 4.2.1). So wird die Gefahr reduziert, inhaltlich relevante Debatten zu übersehen. Dieses Vorgehen ist auch hilfreich, um einen ersten Überblick über den gesamten Diskurs zu erhalten und besonders relevante Dokumente zu identifizieren. Im zweiten und dritten Schritt der Analyse (vgl. Kapitel 4.2.2 und 4.2.3) wird die Datenbasis dann auf diese identifizierten Dokumente eingeschränkt. In diesem Teil arbeite ich mit den Originalprotokollen des Deutschen Bundestags, die ich mithilfe der in GermaParl enthaltenen Metadaten aus dem gemeinsamen Dokumentations- und Informationssystems von Bundestag und Bundesrat DIP herunterlade (www.dip21.bundestag.de). ${ }^{12}$ Da der GermaParl-Korpus nur Protokolle bis einschließlich 2016 beinhaltet, ziehe ich darüber hinaus Protokolle aus dem Jahr 2017 für die qualitative Analyse in Betracht, um diese bis zum Ende der 18. Legislaturperiode zu vervollständigen.

Darüber hinaus ergänze ich die Analyse der Plenarprotokolle im zweiten Teil um Koalitionsverträge und andere Dokumente (Beschlussempfehlungen, Eckpunktepapiere, Energiekonzepte), die für den Diskurs im Bundestag eine richtungsgebende Funktion haben. Dabei werden ausschließlich Dokumente mit einbezogen, die - auch wenn sie kein gesprochenes Wort enthalten - Aufschluss über den im Vorhinein ausgehandelten und für eine bestimmte Gruppe (meist betrifft dies die Mitglieder der Koalitionsfraktionen) geltenden ,Sagbarkeitsrahmen“ geben und somit direkten Einfluss auf die Konstitution der Bedeutung von „Energiewende“ sowie die Kämpfe darum im Bundestag üben. An dieser Stelle sei nochmals auf die Rolle der Plenardebatten als formalisierte „Schaufenster-Diskurse“ (van Dijk 1992: 201) verwiesen.

\subsection{OPERATIONALISIERUNG DER DISKURSTHEORIE NACH LACLAU/MOUFFE}

Im Folgenden gehe ich ausführlicher auf die bereits angedeutete Operationalisierung der Diskurstheorie von Laclau/Mouffe (2015) durch Triangulation dreier methodischer Verfahren ein: Eine computerbasierte Diskursanalyse im ersten Schritt, ein darauf folgendes kodierendes Verfahren zur Identifikation von Story-Lines im zweiten Schritt sowie im dritten Schritt die Identifikation und Klassifikation zu Grunde liegender Fantasien. Bei der Beschreibung der drei methodischen Verfahren gehe ich auch auf die unterschiedlichen Ebenen des Diskurses ein, auf die diese jeweils abzielen (vgl. dazu auch Abbildung 4).

Durch die Triangulation ergibt sich ein retroduktives Vorgehen, in dem sich die Theoriebildung als Prozess darstellt. So wie das Phänomen „Energiewende“ (als poli-

12 Für die Kennzeichnung von direkten Zitaten auch im ersten Teil der Analyse verwende ich ebenfalls Originalprotokolle, da in den Metadaten des GermaParl-Korpus keine Seitenzahlen enthalten sind. 
tischer Diskurs im Bundestag) auf verschiedenen Diskursebenen immer wieder aufs Neue betrachtet und problematisiert wird, so entwickelt sich in diesem Prozess auch die retroduktive Erklärung weiter. Die Plausibilität der gewonnen Erkenntnisse wird so auf den verschiedenen Diskurs-Ebenen geprüft, vertieft und weiterentwickelt.

\subsubsection{Computerbasiertes diskursanalytisches Verfahren}

Glasze (2008) und Dzudzek u.a. (2009) schlagen für die Operationalisierung der Diskurstheorie nach Laclau/Mouffe (2015) im ersten Schritt ein lexikometrisches Verfahren vor. „Lexikometrische Verfahren untersuchen die quantitativen Beziehungen zwischen lexikalischen Elementen ${ }^{13}$ in geschlossenen Textkorpora“ (Dzudzek u.a. 2009: 233). Mithilfe solcher Verfahren lassen sich großflächige diskursive Strukturen, also Strukturen der Bedeutungskonstitution sowie deren zeitliche Entwicklung erfassen (ebenda). Ich ergänze dieses quantitative Verfahren an mehreren Stellen um qualitatives Vorgehen und spreche daher in Bezug auf meine Arbeit von einem computerbasierten diskursanalytischen Verfahren.

Der Lexikometrie sowie der poststrukturalistischen Diskursforschung liegt die gemeinsame theoretische Annahme zu Grunde, „dass Bedeutung ein Effekt der Beziehung von (lexikalischen) Elementen zu anderen (lexikalischen) Elementen ist" (ebenda: 234). Nach Glasze (2008: 195) eignen sich daher lexikometrische Verfahren zur Operationalisierung der Diskurstheorie von Laclau/Mouffe (2015), da sie untersuchen, „wie Bedeutungen durch Beziehungen zwischen lexikalischen Elementen hergestellt werden“. Die Lexikometrie betrachtet zunächst die Elemente (vgl. Kapitel 2.4) eines Diskurses, die in ihr ,als lexikalische Formen gefasst“ werden (Glasze 2008: 196). Ihre temporäre Fixierung zu Momenten des Diskurses um „Energiewende“ entsteht durch regelmäßige Differenzbeziehungen, d.h. der regelmäßigen Verknüpfung der lexikalischen Elemente mit „Energiewende“ im Rahmen bestimmter Beziehungen von Temporalität, Äquivalenz oder Differenz. Die Lexikometrie ermöglicht, diese Differenzbeziehungen zunächst herauszuarbeiten, bevor in den nächsten Schritten die politischen Kämpfe um Bedeutungskonstitution genauer analysiert und interpretiert werden. Sie untersucht den Gegenstand auf der obersten Ebene, indem sie sich zunächst auf seine lexikalischen Manifestationen konzentriert. Das hier beschriebene computerbasierte diskursanalytische Verfahren skizziert gewissermaßen den ,Sagbarkeitsrahmen“ von „Energiewende“ und zielt auf die Analyse einer oberen Diskursebene, auf der zunächst die tatsächlich artikulierten Elemente und ihre Verknüpfungen betrachtet werden. Über die Identifikation von Regelmäßigkeiten kann das Muster des Diskurses um „Energiewende“ eingefangen werden. Über die zeitliche Betrachtung werden die Kontingenz und Dynamik der Bedeutung von „Energiewende" dargestellt.

Nach Glasze (2008: 201) sind die ,drei wichtigsten Methoden der Lexikometrie für Arbeiten, die sich auf die Diskurstheorie nach LACLAU und MOUFFE beziehen [...] Frequenzanalysen, Analysen von Charakteristika [...von Teilkorpora ] und Analysen von Kookkurenzen [im Folgenden: Kollokationen]“. Mit der Kollokationsana-

13 Lexikalische Elemente sind Wörter oder Wortformen, die aus ihrem Textzusammenhang isoliert betrachtet werden. 
lyse können Wörter, die überzufällig häufig im Kontext eines bestimmten Wortes auftreten, identifiziert werden - sie misst die Signifikanz einer Bedeutungsbeziehung. Als Kollokationen werden also die Wörter bezeichnet, die für die Bedeutungskonstitution eine besondere Relevanz haben. ${ }^{14}$

Ich passe Glaszes (2008) Methodensammlung an mehreren Stellen gegenstandsbezogen an und ergänze sie bspw. um das korpuslinguistische Verfahren der Konkordanzanalyse (s.u.), mit der der breitere Kontext von Kollokationen analysiert wird. Das Vorgehen in meiner Arbeit kombiniert dabei über ein rein lexikometrisches Vorgehen hinaus quantitative mit qualitativen Techniken (vgl. auch Baker 2006: 2). Zwar beruhen Frequenz- und Kollokationsanalyse auf quantitativen Berechnungen, mit Hilfe der Konkordanzanalyse werden allerdings auch qualitative Beziehungen zwischen Elementen sichtbar gemacht und analysiert. Ebenso können die berechneten Aussagenmuster nur qualitativ interpretiert werden.

Für die Analyse verwende ich das Toolset polmineR (v.0.7.6), das innerhalb des PolMine Projektes zur gemeinsamen Verwendung mit dem GermaParl-Korpus entwickelt wurde (www.polmine.sowi.uni-due.de). PolmineR ist ein Toolset in R, das die qualitative und quantitative Analyse großer Datenmengen ermöglicht. Es beinhaltet bspw. die Möglichkeit von Frequenzanalysen, Verteilungen, Kollokationsanalysen, Konkordanzanalysen sowie die Betrachtung von Volltext. Dabei gehe ich wie folgt vor:

\section{(1) Frequenzanalyse}

Die Frequenzanalyse gibt Aufschluss darüber ,wie absolut oder relativ häufig" eine bestimmte lexikalische Form in einem Teil des Korpus oder im Gesamtkorpus auftritt (Dzudzek u.a. 2009: 240). Dieser erste Schritt dient zunächst dazu, einen groben Überblick über den Korpus, bzw. den Diskurs um „Energiewende“, sowie seine zeitliche Entwicklung zu erhalten. Zunächst untersuche ich die absolute und relative Häufigkeit (freq/rel. freq) von „Energiewende*15“ sowie die Häufigkeitsverteilung über die Zeit des gesamten Korpus (1996 bis Ende 2016). ${ }^{16}$ Da der Diskurs über „Energiewende“ historisch im Kontext von Atomausstieg* stattfindet führe ich zusätzlich einen Abgleich mit Atomausstieg* sowie weiteren relevanten Elementen wie Klimaschutz*, erneuerbar* oder Energie* durch. Um Zusammenhänge zwischen zeitlichen Trends in den Daten erkennen zu können, sind Korrelationsanalysen hilfreich, mit denen der Grad des Zusammenhanges zwischen zwei Variablen (bspw. der zeitli-

14 Baker (2006: 95f.) definiert Kollokation wie folgt: „All words co-occur with each other to some degree. However, when a word regularly appears near another word, and the relationship is statistically significant in some way, then such co-occurrences are referred to as collocates and the phenomena of certain words frequently occurring next to or near each other is collocation".

15 *: Der Stern verweist darauf, dass hier eine Buchstabenfolge maschinell untersucht wird. Eine Buchstabenfolge erfasst dabei auch andere Flexionsformen desselben Wortes sowie Wortkombinationen (z.B. Energiewende-Debatte). Dies ist ausschließlich für die computerbasierte Analyse relevant und taucht daher nur in diesem Zusammenhang auf.

16 Wie in Kapitel 4.1 erläutert, werden die Jahre 1996-1998 hier zur zeitlichen Kontextualisierung der Häufigkeitsentwicklungen herangezogen. 
chen Entwicklung von „Energiewende*“ und Klimaschutz*) beschrieben werden kann (vgl. z.B. Hilpert/Gries 2009: 388f.). Als statistisches Maß verwende ich dabei den Spearman-Korrelationskoeffizienten (Spearman's Rho). ${ }^{17}$

Im Hinblick auf das kodierende Verfahren im nächsten Schritt meiner Arbeit (vgl. Kapitel 4.2.2) nutze ich die Frequenzanalyse auch, um einen Überblick darüber $\mathrm{zu}$ erhalten, in welchen Bundestagssitzungen wie viel über „Energiewende“ gesprochen wurde, und um so relevante Plenarprotokolle zu identifizieren.

\section{(2) Charakteristika von Teilkorpora, Kollokations- und Konkordanzanalyse}

In diesem Schritt unterteile ich den GermaParl-Korpus zunächst in Partitionen, die den einzelnen Legislaturperioden entsprechen, da für die Untersuchung des „Energiewende"-Diskurses vor allem auch der zeitliche Bedeutungswandel unter Berücksichtigung der verschiedenen Regierungskoalitionen von Interesse ist. Ich fokussiere dabei ab diesem methodischen Schritt, wie in Kapitel 4.1 beschrieben, auf den dieser Arbeit zugrunde liegenden Betrachtungszeitraum der 14. bis 18. Legislaturperiode. ${ }^{18}$ Die Spezifika der einzelnen Legislaturperioden arbeite ich dann über Kollokationsund Konkordanzanalysen heraus, wodurch sich die Entwicklung der Bedeutungskonstitution über die Zeit darstellen lässt. Wie erwähnt geht sowohl die Linguistik als auch die poststrukturalistische Diskursforschung davon aus, dass die Bedeutung eines Wortes im Kontext, also in den Beziehungen zu anderen Wörtern, entsteht. Dies kann darüber hinaus zu positiver oder negativer Konnotation eines Wortes führen. Die Kollokationsbeziehung ist ein Maß für die Signifikanz einer solchen Beziehung. Kollokationen können auf Grundlage der Diskurstheorie von Laclau/Mouffe (2015) als Knotenpunkte von Äquivalenzketten interpretiert werden, da sie in der Bedeutungsgenerierung temporär fixiert wurden (vgl. Kapitel 2.4). Die Kollokationsanalyse ist also in besonderer Weise dafür geeignet, regelmäßige Differenzbeziehungen, also diskursive Muster, zu erfassen.

Für die Berechnung von Kollokationen ist die gewählte Größe des Kontextes um einen Schlüsselpunkt ${ }^{19}$ herum entscheidend. Üblicherweise wird dabei ein Kontext von 5 Wörtern rechts und 5 Wörtern links (5R 5L) des Schlüsselpunktes (z.B. „Energiewende“) gewählt (Baker 2006:100) - ein Vorgehen, dem ich mich hier anschließe. ${ }^{20}$ Dabei werden auch Vorfälle von Wörtern jenseits von Satzgrenzen mit einbezo-

17 Der Korrelationskoeffizient (rho) liegt zwischen -1 und 1, wobei 1 eine perfekte positive Korrelation, 0 keine Korrelation und -1 eine perfekte negative Korrelation anzeigt. Der Test ist signifikant, wenn $\mathrm{p}<0,05$ ist.

18 Dies geschieht aus den in Kapitel 4.1 genannten Gründen. Darüber hinaus zeigt sich aber bereits in der Frequenzanalyse, dass „Energiewende“ vor 1998 begrifflich kaum eine Rolle spielt (vgl. Kapitel 5.1.1).

19 Als Schlüsselpunkte werden im Folgenden zentrale Knotenpunkte in der Äquivalenzkette bezeichnet, auf die sich die vorliegende Analyse konzentriert (z.B. „Energiewende*“, erneuerbar*).

20 Ein größeres Fenster liefert mehr Kollokationen, die möglicherweise aber nicht mehr in direkter Verbindung zum Knotenpunkt stehen. Ein kleineres Fenster birgt die Gefahr nicht direkt folgende oder bevorstehende Wörter auszuschließen (Baker 2006:103). 
gen. Um festzustellen, ob die Differenz der Vorfälle eines Wortes innerhalb dieses Kontextes im Vergleich zu seinen Vorfällen im gesamten Korpus signifikant ist, es also überzufällig häufig im Kontext des Schlüsselpunktes auftaucht und damit eine Rolle für seine Bedeutungskonstitution spielt, ist ein statistischer Test notwendig. PolmineR verwendet dafür den log-likelihood Test. ${ }^{21}$ In meiner Analyse werden alle Kollokationen mit einem log-likelihood- Wert $<10,83$ maschinell aussortiert. Damit werden nur Kollokationen betrachtet, die innerhalb des 99,9\%-Perzentils liegen ( $\mathrm{p}<$ 0,001), also mit 99,9\%iger Wahrscheinlichkeit nicht zufällig auftreten. ${ }^{22} \mathrm{Um}$ die Aussagekraft der Ergebnisse zu gewährleisten, werden üblicherweise nur Kollokationen betrachtet, die in der betrachteten Datenbasis mindestens 5 mal mit dem Schlüsselpunkt zusammen auftreten (ebenda: 151). Für die 14. bis 16. Legislaturperiode setze ich diesen Mindestwert aufgrund der geringen Anzahl an Kollokationen auf 2 herab, was die Aussagefähigkeit entsprechend reduziert. ${ }^{23}$ Mit der Funktion des POStagging (vgl. Kapitel 4.1) innerhalb des polmineR können die Wörter zudem direkt anhand ihrer grammatischen Kategorie/Wortartklasse sortiert, bzw. aussortiert werden. So werden Wortarten, denen meist keine oder nur eine geringe lexikalische Bedeutung zukommt ${ }^{24}$, wie Artikel, Konjunktionen, Präpositionen, Pronomen, Adverben, Hilfsverben, Modalverben, Interjektionen, aber auch Sonder- und Satzzeichen sowie Zahlen maschinell aussortiert, sodass nur Adjektive (attributive und adverbiale Adjektive), Substantive und Vollverben mit lexikalischer Bedeutung betrachtet werden. Dabei gehe ich in Anlehnung an Baker 2006 (119f.) wie folgt vor:

a) Kollokationsanalyse: Zunächst wird nach Kollokationen des Schlüsselpunktes „Energiewende*25“ gesucht. Mit polmineR wird eine Liste der 100 Kollokationen mit dem höchsten Signifikanzwert erstellt und betrachtet. In der nachfolgenden Analyse erweist sich für die Eingrenzung eine Reduktion auf die nach der Reihenfolge der Signifikanz bemessenen rangersten $40-45^{26}$ Kollokationen als sinn-

21 Der log-likelihood Test ist ein Signifikanztest, der auf einer Binomialverteilung (also einer diskreten Wahrscheinlichkeitsverteilung) basiert. Für eine genauere Darstellung seiner Berechnung vgl. Dunning (1993: 65ff.). Für eine Auseinandersetzung der Vor- und Nachteile verschiedener statistischer Tests in der Korpuslinguistik vgl. Baker (2006): 101ff.

22 Ein $p$-Wert $<0,001$ impliziert eine weniger als 0,1\%ige Wahrscheinlichkeit, dass eine Verteilung zufällig auftritt.

23 Für eine kritische Einordnung dieser Vorgehensweise vgl. Kapitel 5.1.

24 Es wurden also Wortarten aussortiert, denen eine überwiegend grammatische Funktion zukommt. Die Sinnhaftigkeit dieser Einschränkung der Untersuchung wurde vorab in mehreren Testdurchläufen geprüft.

25 Zwar könnte „Energiewende“ auch über andere Artikulationen, z.B. eine ,Wende in der Energiepolitik' adressiert werden; ich interessiere mich aber in der vorliegenden Arbeit für die Bedeutungskonstitution und den -wandel von „Energiewende“, weshalb eine Eingrenzung auf diesen Begriff sinnvoll ist.

26 Die Sinnhaftigkeit dieser Anzahl ergibt analog zu Baker (2006: 119) aus der Analyse, da sich herausstellt, dass nachfolgende Kollokationen häufig inhaltliche Wiederholungen darstellen oder/und in den Konkordanzprofilen der ersten 40-45 Kollokationen bereits mitanalysiert werden. 
voll. Diese werden dann thematisch geclustert und unter gemeinsame Überschriften gefasst (bspw. „Kosten“, „,bezahlbar“, „Nulltarif“ unter der Überschrift „Kosten").

b) Positionsanalyse: Da Kollokationsanalysen von diskursiv etablierten Schlüsselpunkten (wie hier „Energiewende“) überwiegend auf Mainstream-Diskurse verweisen (da sie die stärksten Assoziationen messen) (ebenda: 118f.), ist eine Betrachtung möglicherweise herausfordernder Diskurse ebenfalls notwendig. Dafür können, wo nötig, die Kollokationsprofile einzelner Fraktionen erstellt und verglichen werden. So können auch unterschiedliche, möglicherweise marginalisierte, politische Positionen sichtbar gemacht werden.

c) Konkordanzanalyse: Bei der Konkordanzanalyse wird in polmineR eine Liste erstellt, die die identifizierten Knotenpunkte in ihrem Kontext darstellt (üblicherweise wird diese Darstellungsform als key word in context KWIC bezeichnet). Auch hier wird die Größe des Kontextes zuvor festgelegt. Ich analysiere dabei zunächst ein Fenster von 5 Wörtern rechts und 5 Wörtern links (5R 5L) eines Knotenpunktes, weite dieses Fenster aber aus, wenn es für das Verständnis notwendig ist. Dadurch kann nach Mustern im Kontext und nach Hinweisen auf dominante Diskurse gesucht werden. Auch die Qualität der Bedeutungsbeziehung zwischen zwei Knotenpunkten kann betrachtet werden (bspw.: Beziehen sie sich positiv oder negativ aufeinander? Stehen sie in einem temporalen oder kausalen Zusammenhang? Etc.). Eine Spezifizierung der Konkordanzliste in polmineR nach Datum und Fraktion (vgl. Abbildung 2) ermöglicht die Betrachtung zeitlicher Entwicklung sowie die Differenzierung und Interpretation politischer Positionen. Dazu wird - wo dies notwendig erscheint - auch nach herausfordernden Konkordanzlinien gesucht.

\section{Abbildung 2: KWIC Fenster in polmineR; Beispiel}

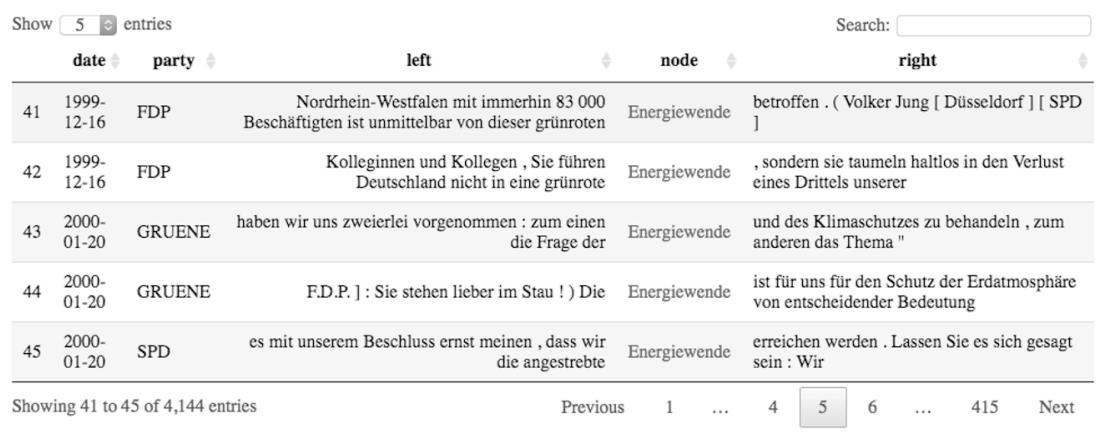

Quelle: eigene Darstellung

d) Um eine spezifischere, bzw. vergleichende Interpretation der Ergebnisse vornehmen zu können, führe ich zum Vergleich die Kollokations- und Konkordanzanalyse für die Schlüsselpunkte ,erneuerbare Energien' (Suchwort: ,erneuerbar*`) und ,Atomausstieg*‘ durch. Dies erfolgt aufgrund der besonderen Bedeutung dieser Schlüsselpunkte für den „Energiewende“-Diskurs, die sich in einer ersten 
sondierenden Kollokationsanalyse gezeigt hat, aber auch historisch bedingt ist, wie in Kapitel 1 gezeigt wurde.

\section{(3) Diskussion über alle Legislaturperioden im Kontext von Hegemonie}

Bereits in dieser Phase der Analyse wird das computerbasierte Verfahren einer qualitativen Bewertung unterzogen. Der Wandel des Diskurses über die einzelnen Legislaturperioden, die in der quantitativen Erhebung als Teilkorpora voneinander abgegrenzt wurden, wird analysiert. Die gewonnenen Erkenntnisse werden im Kontext von Hegemonie interpretiert (vgl. auch Nonhoff 2007). Denn diskurstheoretisch betrachtet sind es nicht in erster Linie nur Parteien und ihre jeweiligen Fraktionen im Parlament, die Einfluss auf die Bedeutungsgenerierung üben - diese befinden sich nicht außerhalb der diskursiven Struktur. Sie prägen sie mit und werden von ihr mitgeprägt. Insofern erscheint es sinnvoll die Entwicklung und Stellung von Elementen im diskursiven Raum auf einer Ebene quer zu den Parteigrenzen zu betrachten, um weitergehende Erkenntnisse zu generieren. Wichtig ist dabei vor allem in Betracht zu ziehen, dass Hegemonie sich nicht im Kampf um einen einzelnen Begriff wie „Energiewende“ herum entscheidet, sondern, dass dafür die „(An-)Ordnung des symbolischen Raums in seiner Gänze“ entscheidend ist (Nonhoff 2006: 236). Der Kampf um „Energiewende“ ist also als ein Teil eines umfassenderen Kampfes um Hegemonie $\mathrm{zu}$ verstehen, der auch außerhalb des Forschungsgegenstandes der Plenardebatten stattfindet.

Um die Bedeutung diskursiver Elemente für Kämpfe um Hegemonie zu verdeutlichen, bezeichnet Laclau diese Elemente auch als Forderungen ${ }^{27}$, einen Begriff, den ich hier methodisch einbinden möchte. Er verdeutlicht ihre unterschiedliche Bedeutung für die hegemoniale Ordnung des diskursiven Raumes, indem er zwischen demokratischen, popularen ${ }^{28}$ und affirmativen/flottierenden Forderungen unterscheidet (Laclau 2005). Demokratischen und popularen Forderungen wird dabei eine kritische Stellung zum hegemonialen Diskurs zugeordnet, während affirmative/flottierende Forderungen diesen stützen (vgl. auch Bedall 2014: 62f.). Diese Klassifizierung übertrage ich auf die im Zuge der Kollokationsanalyse identifizierten Knotenpunkte von „Energiewende“. Demokratische Forderungen ${ }^{29}$ verweisen dabei auf einen Mangel

27 Für eine kritische Auseinandersetzung mit dem Begriff der ,Forderung ‘ vgl. z.B. Nonhoff 2007: 176.

28 Es sei darauf hingewiesen, dass Laclau (2005) dabei einen positiven Populismus-Begriff zugrunde legt.

29 Der Begriff „,demokratische Forderung“ mag verwirrend erscheinen. Laclau erklärt seine Verwendung: „Let me say, in the first place, that by ,democratic“ I do not mean, in this context, anything related to a demoacratic regime [...]. A Fascist regime can absorb and articulate democratic demands as much as a liberal one. Let me also say that the notion of ,democratic demands' has even less to do with any normative judgement concerning their legitmacy [...]. The only features I retain from the usual notion of democracy are: (1) that these demands are formulated to the system by an underdog of sorts - that there is an equalitarian dimension implicit in them; (2) that their very emergence presupposes some kind of exclusion or deprivation (what I have called ,deficient being ')“ (Laclau 2005: 125). 
(oder anders formuliert: einen politischen Missstand), treten aber isoliert auf - d.h. sie sind noch nicht oder kaum mit anderen Forderungen verbunden (Laclau 2005: 74). Populare Forderungen stehen in einer antagonistischen Beziehung zum hegemonialen Diskurs und sind durch äquivalentielle Artikulation verbunden. Eine der Voraussetzungen für ihren Erfolg sei die Vereinigung verschiedener Forderungen „whose equivalence, up to that point, had not gone beyond a feeling of vague solidarity“ - in ein stabiles Signifikationssystem (ebenda: 74). Demokratische Forderungen können sich durch äquivalentielle Artikulation mit anderen Forderungen, die eine kritische Positionierung zum hegemonialen Diskurs aufweisen (denkbar wäre bspw. eine Artikulation von „Energiewende“ mit „sozial-ökologischer Transformation“), zu popularen Forderungen entwickeln. Geschehe dies nicht, wird aber auch eine Vereinnahmung durch den hegemonialen Diskurs als möglich erachtet (ebenda: 82). Der hegemoniale Diskurs könne also auch bewirken, dass die antagonistische Grenze verschwimme, indem er kritische Forderungen in seine eigene Äquivalenzkette einbinde. Er könne so bspw. die populare Äquivalenzkette durchbrechen, indem er einige ihrer Forderungen mit eigenen Forderungen verbinde. Auf demokratische Forderungen könne so auch Druck von rivalisierenden Diskursen ausgeübt werden. Die Bedeutung solcher Forderungen ,ist zwischen den äquivalentiellen Grenzen unbestimmt[eig. Übers.]“, sie ,hängt gewissermaßen über" (,,is suspended“) zwischen Hegemonie und Gegen-Hegemonie (ebenda: 132). Laclau bezeichnet solche Forderungen als ,flottierende Forderungen' (ebenda).

Demnach klassifiziere ich die identifizierten Knotenpunkte von „Energiewende“ als Forderungen, um dadurch die Entwicklung der hegemonialen Ordnung des diskursiven Raumes darzustellen und analytisch einzuordnen.

\subsubsection{Kodierendes diskursanalytisches Verfahren: Analyse von Story-Lines}

Während mit dem computerbasierten diskursanalytischen Verfahren regelmäßige Differenzbeziehungen identifiziert wurden, sollen nun komplexere Verknüpfungen in Bedeutungssystemen herausgearbeitet und kodiert werden. Dabei werden weniger die Elemente selbst, sondern ihre Verknüpfungen, d.h. Artikulationen, fokussiert. Nach Laclau/Mouffe (2015) beinhaltet Artikulation als Praxis der Bedeutungskonstitution dabei nicht nur die Verknüpfung von Elementen, sondern auch ,vielfältige Verbindungen und vielschichtige Relationen oberhalb der Wort- und Satzebene, häufig sogar oberhalb der Ebene einzelner konkreter Texte“ (Glasze u.a. 2009: 293). Dieser Analyseschritt zielt also auf eine tieferliegende Diskursebene (vgl. Abbildung 4). So kann herausgearbeitet werden, wie die mit der „Energiewende“ in Zusammenhang stehenden sozialen Praktiken konstituiert und herausgefordert werden, wie also die damit verbundene soziale Wirklichkeit hergestellt wird bzw. aus welchen politischen Kämpfe diese hervorgeht. Wurden durch die computerbasierte Analyse bereits Hinweise auf Verschiebungen und Brüche des Diskurses über den Zeitverlauf identifiziert (vgl. auch Glasze u.a. 2009: 297), wird nun genauer betrachtet, wie es zu diesen Brüchen kam.

Dafür wende ich ein kodierendes Verfahren in Anlehnung an Glasze u.a. (2009) an. „Das Ziel des Kodierens als Teilschritt einer Diskursanalyse ist es, Regelmäßig- 
keiten im (expliziten und impliziten) Auftreten (komplexer) Verknüpfungen von Elementen in Bedeutungssystemen herauszuarbeiten“ (Glasze u.a. 2009: 293). Ähnlich wie in interpretativ-hermeneutisch orientierten Verfahren der qualitativen Inhaltsanalyse (Mayring 1995) oder der grounded theory (Glaser/Strauss 1980) dient das Kodieren der Klassifizierung und der Bündelung des Materials (Glasze u.a. 2009: 294). Allerdings unterscheidet sich der konzeptionelle Stellenwert: Während Codes im inhaltsanalytischen Verfahren als Indikatoren für den Inhalt ,an sich' interpretiert werden, verweisen die Codes im diskursanalytischen Verfahren auf die Regeln der Bedeutungskonstitution, auf eine sich in der Datenbasis materialisierende Sicht auf die Wirklichkeit (Glasze u.a. 2009: 294; Diaz-Bone/Schneider 2008: 507ff.).

Kodiert werden also nicht einzelne Elemente, sondern regelmäßige Artikulationen, d.h. Verknüpfungen zwischen Elementen, die auch als Artikulationsmuster oder narrative Muster bezeichnet werden können (Glasze u.a. 2009: 296). Ich wähle in meiner Arbeit in Anschluss an Hajer (2004: 272f.) die Bezeichnung ,Story-Line', um die Rolle von Erzählungen/Narrationen für die Konstruktion und Einordnung politischer Probleme oder Themen hervorzuheben (vgl. auch Glasze 2008). ${ }^{30}$ Erzählung/Narration meint in einem diskursanalytischen Sinne ${ }^{31}$ „eine ,Kette von Äußerungen", die darauf zielt, ein Phänomen zu beschreiben“" und dabei eine spezifische Sichtweise einnimmt (Hajer 2004: 276). Die Verwendung des Begriffes ,Erzählung‘ soll verdeutlichen, dass ein politisches Problem/Thema nicht von außen beschrieben werden kann, also objektiv vorliegt, sondern, dass diejenigen, die es thematisieren, gleichzeitig Teil seiner Konstruktion sind, also das Problem/Thema auf eine spezifische Weise erzählen. In diesem Verständnis gibt es bspw. verschiedene Erzählungen von „Energiewende“ oder verschiedene Erzählungen des Problems Energieversorgung. Narrationen/Erzählungen können im Anschluss an Laclau/Mouffe (2015) als Artikulationen bezeichnet werden, ,die eine Beziehung zwischen Elementen herstellen, Grenzen etablieren, auf diese Weise eine temporäre Fixierung leisten, Bedeutung und damit Identität konstituieren"(Glasze 2008: 205). Dabei gehe es in der Diskursanalyse nicht wie in der strukturalistischen Erzählforschung, die sich vorwiegend mit literarischen Texten beschäftigt, ,um die Entwicklung einer systematischen Erzählgrammatik und einer Poetik der Erzählkunst“ (Nünning/Nünning 2002: 23) ${ }^{32}$, sondern vielmehr um eine Dekonstruktion des Erzählens, bzw. von Erzählungen auch außerhalb von literarischen Texten, die nicht einfach Bedeutung wiedergeben, sondern diese auch konstituieren (ebenda: 8). Erzählungen werden als grundlegendes Mittel für die Kommunikation und das Verständnis zwischen Menschen erachtet, als sinngebend und grundlegend für politische Entscheidungen und damit für Transfor-

30 Ein ähnliches Vorgehen anhand der Kodierung von Story-Lines in ihrer Diskursanalyse von Bundestagsdebatten zu Energie wählen auch Leipprand u.a. (2017), vgl. Kapitel 1.

31 Im Gegensatz zu anderen Verständnissen von Erzählung, bspw. im literaturwissenschaftlichen Sinne.

32 In der jüngeren Erzähltheorie entstanden aber auch vielfache neue Ansätze, bspw. die feministische Narratologie oder die postkoloniale Narratologie, etc. (Nünning/Nünning 2002: 8), die ihren Fokus nicht auf den literarischen Text als Träger von Inhalt, sondern auf die von der zeitlichen und räumlichen Positionierung abhängigen „Prozesse der Rezeption, Analyse und Bedeutungskonstitution“ richten (ebenda: 24f.). 
mation. Erzählungen spiegeln jeweils bestimmte Verständnisse von politischen und sozialen Beziehungen wider (Feldman u.a. 2004: 147).

Wenn Phänomene erzählt werden, findet in der Regel eine Komplexitätsreduktion statt, d.h. es wird ein spezifischer Aspekt genauer beleuchtet (bspw. die Kosten der „Energiewende“). Findet eine solche Zusammenfassung regelmäßig in ähnlicher Weise statt, wird also ein Phänomen oder Problem regelmäßig auf ähnliche Weise reduziert, bezeichne ich dies als Story-Line (vgl. auch Hajer 2004: 277). Story-Lines sind Bestandteile von Erzählungen. Sie haben großen Einfluss auf die Rahmung von politischen Problemen. Sie können sich zu „endlos wiederholten Sprachfiguren“ (ebenda: 292) festigen, die zu einer diskursiven Strukturierung der Welt beitragen, indem auf eine bestimmte Art und Weise Bedeutung zugewiesen wird (ebenda: 277ff.). Sie können das öffentliche Verständnis eines bestimmten Aspekts eines Phänomens dominieren und zur Naturalisierung bestehender Ordnungen beitragen (ebenda: 291). Story-Lines spielen also eine wichtige Rolle für die Entstehung von Hegemonie. Für die Analyse von Story-Lines spielt auch das Nicht-Gesagte eine Rolle, da so Abgrenzungen und implizite Annahmen deutlich werden.

Das kodierende Verfahren in meiner Arbeit gliedert sich in folgende Schritte, die zum Teil parallel ablaufen:

\section{(1) Datensammlung}

Erforderte die computerbasierte Analyse einen geschlossenen Korpus, kann in diesem Schritt ein offener Korpus zu Grunde gelegt werden. „Da zu Beginn des Forschungsprozesses vielfach nicht das gesamte zu untersuchende Diskursfeld überblickt werden kann“ (Glasze u.a. 2009: 299) schlagen Glasze u.a. (2009: 298f.) vor, im Anschluss an das theoretical sampling der grounded theory (Strauss/Corbin 1996: 25f.) die Datensammlung so lange fortzusetzen bis keine neuen Erkenntnisse mehr generiert werden. Für die vorliegende Arbeit wähle ich zunächst die Plenarprotokolle aus, in denen das Element „Energiewende“ auf Grundlage der computerbasierten Analyse in den einzelnen Legislaturperioden am häufigsten auftritt. Dadurch wird eine zu starke thematische Einschränkung der Datenbasis aufgrund von Vorannahmen vermieden. $^{33}$

Darüber hinaus füge ich die für das Erneuerbare-Energien-Gesetz EEG und seine Novellierungen zentralen Debatten der Datenbasis hinzu: Erneuerbare Energien gelten gemeinhin als „eine zentrale Säule der Energiewende“, das EEG als das ,zentrale Steuerungsmoment“ für ihren Ausbau (www.bundesregierung.de - Energiewende). In der computerbasierten Analyse zeigt sich der Stellenwert des EEG innerhalb des „Energiewende“-Diskurses u.a. dadurch, dass ab der 16. Legislaturperiode in den Plenardebatten um das EEG überdurchschnittlich häufig von „Energiewende“ gesprochen wird.

33 Bei ähnlichen Häufigkeiten von „Energiewende“ wird das Dokument ausgewählt, dessen Themenbereich am wenigsten durch andere Dokumente abgedeckt ist oder das in einen durch andere Dokumente nicht abgedeckten Zeitraum fällt. Eine Einschränkung der Anzahl der aufgrund von Häufigkeit ausgewählten Dokumente ergibt sich dann auf Grundlage der Gesamtzahl der untersuchten Dokumente, die in einem untersuchbaren Rahmen (hier: 31 Dokumente) bleiben muss. 
Neben dem EEG wird auch der Atomausstieg mit der „Energiewende“ in Verbindung gebracht - dies zeigt sich ebenfalls in der computerbasierten Analyse. Daher werden Dokumente, die sich im Zuge der Analyse für den Atomausstieg als besonders richtungsweisend zeigen, wie die Debatte zum Atomausstieg 2001, die Vereinbarung vom 14. Juni $2000^{34}$ oder die Debatte zur Laufzeitverlängerung vom 28.10. 2010, der Datenbasis hinzugefügt. In der Häufigkeitsverteilung von „Energiewende“ (vgl. Kapitel 5.1) zeigt sich deutlich, dass der Reaktorkatastrophe von „Fukushima“ eine richtungsweisende Funktion zukommt, weshalb den in diesem Zeitraum stattfindenden Debatten besondere Beachtung zukommt.

Aufgrund ihrer richtungsweisenden Funktion für die Plenardebatten wähle ich zudem die Koalitionsverträge der jeweiligen Legislaturperioden aus. Die Auswahl der übrigen Dokumente ergibt sich im Laufe des kodierenden Verfahrens, weil bspw. in den Debatten häufig Bezug auf diese Dokumente genommen wird (z.B. das Energiekonzept $\left.2010\left(17 / 3049 ; 17 / 3050^{35}\right)\right)$, sie einen Themenbereich abdecken, der noch nicht ausreichend untersucht werden konnte (z.B. energetische Gebäudesanierung (Plenarprotokoll 13.12.2012) und/oder sie eine besonders richtungsweisende Funktion für die Debatten um „Energiewende“ haben.

Tabelle 3: Anzahl an Plenarprotokollen nach Legislaturperioden, die ,Energiewende*“enthalten

\begin{tabular}{|l|c|c|c|c|c|}
\hline Legislaturperiode & 14. & 15. & 16. & 17. & 18. \\
\hline $\begin{array}{l}\text { Anzahl der Plenarprotokolle, } \\
\text { die „Energiewende*6 enthalten }\end{array}$ & 42 & 21 & 39 & 138 & $\begin{array}{c}127 \\
\text { (bis } \\
\text { Ende } \\
2016)\end{array}$ \\
\hline
\end{tabular}

Quelle: Daten aus polmineR; eigene Darstellung

Die Anzahl der ausgewählten Dokumente differiert zwischen den einzelnen Legislaturperioden, da „Energiewende“ nicht in allen Legislaturperioden die gleiche Rolle spielt (vgl. Tabelle 3). So kommt „Energiewende“ bspw. in der 15. Legislaturperiode nur in 21 Bundestagsdebatten vor, während sie in der 17. Legislaturperiode in 138 Debatten eine Rolle spielt. Bei der Auswahl der Dokumente wird zudem auf die zeitliche Verteilung geachtet, um innerhalb der Legislaturperioden stattfindende Brüche und Verschiebungen zu erfassen. Der Analyse liegen 31 Dokumente zu Grunde (vgl. Tabelle 4).

34 Die Vereinbarung vom 14. Juni 2000 wird umgangssprachlich als ,Atomkonsens ' bezeichnet. Es ist die schriftliche Vereinbarung zwischen der rot-grünen Bundesregierung und den Energieversorgungsunternehmen zum Atomausstieg.

35 Die Nummern beziehen sich hier auf die Drucksachen-Nummern im Archiv des Deutschen Bundestags. 
Tabelle 4: Dem kodierenden Verfahren zugrunde liegende Dokumente

\begin{tabular}{|c|c|c|c|c|c|}
\hline $\begin{array}{r}\begin{array}{r}\text { Legislatur- } \\
\text { periode } \\
\text { (ab Jahr) }\end{array} \\
\text { Auswahl- } \\
\text { kriterium }\end{array}$ & 14. Lp (1998) & 15. Lp (2002) & 16. Lp (2005) & 17. Lp (2009) & 18. Lp (2013) \\
\hline $\begin{array}{l}\text { Häufigkeit von } \\
\text { „Energiewende“ } \\
\text { (freq) }\end{array}$ & $\begin{array}{l}25.11 .1999^{36}(10) \\
27.06 .2002(9)\end{array} \mid$ & $\begin{array}{l}28.05 .2004(5) \\
09.09 .2004(3)\end{array}$ & 02.07 .2009 (8) & $\begin{array}{l}13.06 .2013(83) \\
30.06 .2011(59)\end{array}$ & $\begin{array}{l}10.04 .2014(69) \\
01.06 .2016(73)\end{array}$ \\
\hline EEG & $25.02 .2000(1)$ & & 06.06 .2008 (3) & 29.03.2012(38) & $27.06 .2014(33)^{37}$ \\
\hline $\begin{array}{l}\text { „Atomausstieg“ } \\
\text { bzw. } \\
\text { „Fukushima“ }\end{array}$ & $\begin{array}{l}14.12 .2001(6) \\
\text { Vereinbarung } \\
\text { vom 14. Juni } \\
2000\end{array}$ & & & $\begin{array}{l}28.10 .2010(6) \\
17.03 .2011(5) \\
24.03 .2011(11) \\
09.06 .2011(21) \\
30.06 .2011(59)\end{array}$ & \\
\hline $\begin{array}{l}\text { Sonstige } \\
\text { Dokumente }\end{array}$ & $\begin{array}{l}\text { Koalitionsvertrag } \\
\text { zwischen SPD } \\
\text { und GRÜNEN } \\
\text { (Aufbruch und } \\
\text { Erneuerung - } \\
\text { Deutschlands } \\
\text { Weg ins } 21 . \\
\text { Jahrhundert); } \\
\text { Beschluss- } \\
\text { empfehlung des } \\
\text { Wirtschaftsaus- } \\
\text { schusses zum } \\
\text { EEG-Entwurf } \\
14 / 2776\end{array}$ & $\begin{array}{l}\text { Koalitionsvertrag } \\
\text { zwischen SPD } \\
\text { und GRÜNEN } \\
\text { (Erneuerung- } \\
\text { Gerechtigkeit- } \\
\text { Nachhaltigkeit) }\end{array}$ & $\begin{array}{l}\text { Koalitionsvertrag } \\
\text { zwischen } \\
\text { CDU,CSU und } \\
\text { SPD (Gemeinsam } \\
\text { für Deutschland - } \\
\text { mit Mut und } \\
\text { Menschlichkeit); } \\
\text { Eckpunktepapier } \\
\text { der Bundesregie- } \\
\text { rung für ein inte- } \\
\text { griertes Energie- } \\
\text { und Klimapro- } \\
\text { gramm 2007 } \\
\text { (BMU 2007) }\end{array}$ & $\begin{array}{l}\text { Koalitionsvertrag } \\
\text { zwischen } \\
\text { CDU,CSU und } \\
\text { FDP (Wachstum. } \\
\text { Bildung. Zu- } \\
\text { sammenhalt); } \\
\text { Antrag der Frak- } \\
\text { tionen der } \\
\text { CDU/CSU und } \\
\text { FDP: Energie- } \\
\text { konzept umsetzen } \\
\text { - Der Weg in das } \\
\text { Zeitalter der er- } \\
\text { neuerbaren Ener- } \\
\text { gien (17/3050); } \\
\text { Energiekonzept } \\
\text { für eine umwelt- } \\
\text { schonende, zu- } \\
\text { verlässige und } \\
\text { bezahlbare Ener- } \\
\text { gieversorgung } \\
\text { (17/3049); } \\
\text { 13.12.2012 (44) }\end{array}$ & $\begin{array}{l}\text { Koalitionsvertrag } \\
\text { zwischen } \\
\text { CDU,CSU und } \\
\text { SPD (Deutsch- } \\
\text { lands Zukunft ge- } \\
\text { stalten); } \\
29.06 .2017(30)^{39}\end{array}$ \\
\hline $\begin{array}{l}\text { Anzahl } \\
\text { untersuchter } \\
\text { Dokumente }\end{array}$ & 7 & 3 & 4 & 12 & 5 \\
\hline
\end{tabular}

Quelle: eigene Darstellung

36 Datumsangaben beziehen sich auf jeweils analysierte Plenardebatten.

37 Diese Debatte bezieht sich auf das EEG 2014. Für das EEG 2016/2017 wurde keine zusätzliche Debatte ausgewählt, da dieses bereits in der Debatte vom 01.06.2016 abgedeckt ist.

38 Ich bezeichne die Fraktion BÜNDNIS 90/DIE GRÜNEN im Folgenden als die GRÜNEN.

39 Die Plenardebatte 29.06.2017 wurde ausgewählt, um das Bild für die 18. Legislaturperiode zu vervollständigen (der GermaParl-Korpus geht bis Ende 2016). Die Relevanz des hier verhandelten Themas „Mieterstrom“ zeigte sich darüber hinaus bereits in der Analyse vorheriger Dokumente. 


\section{(2) Entwicklung des Kategoriensystems}

Bei der Entwicklung des Kategoriensystems gehe ich induktiv vor, d.h. die Kategorien werden in einem offenen Prozess während der Analyse entwickelt (Mayring 1995; Glasze u.a. 2009: 196f.). Dursucht wird das Datenmaterial nach Story-Lines, also nach mehr oder weniger komplexen Artikulationsmustern, die auf „Energiewende“ - explizit oder implizit - einen regelmäßig ähnlichen Bezug nehmen. Es werden auch Story-Lines kodiert, die „Energiewende“ nicht direkt adressieren aber Aufschluss darüber geben, wie ggf. vermieden wird über „Energiewende“ zu sprechen - d.h. Story-Lines, die in einem impliziten Kontrast zu „Energiewende“ stehen. Nach Feldman u.a. 2004 werden kontroverse Prämissen häufig nicht expilzit gemacht, da sie Dissens erzeugen und die Zustimmung des Hörers zur Erzählung verringern (Feldman u.a. 2004: 152). ${ }^{40}$ Dennoch spielen sie eine Rolle für den Diskurs um „Energiewende“, da sie Aufschluss darüber geben, wie „Energiewende“ ggf. dem Außen zugewiesen wird oder Abgrenzungen gezogen werden. Die identifizierten Story-Lines werden mit einem Code/einer Kategorie markiert und so das Material gebündelt. Das sich unter einer Kategorie befindliche Material wird über den Zeitverlauf sortiert, sodass chronologische Verschiebungen sichtbar werden, und in einer Liste gesammelt.

Durch die formalen Bedingungen im Bundestag, durch welche die Redezeiten nach Fraktionsgröße bestimmt werden, liegt zu den größten Fraktionen das meiste Datenmaterial vor. Es ist daher davon auszugehen, dass sich von diesen Fraktionen bediente Diskurse und Story-Lines am deutlichsten zeigen. Dieser Effekt entspricht dem Ziel der Analyse, besonders erfolgreiche Story-Lines zu identifizieren, die aufgrund ihrer diskursiven Verbreitung besonders wirkmächtig sind, denen es also am besten gelingt, ihre Perspektive zu naturalisieren. Solche Story-Lines können auf hegemoniale Diskurse verweisen. Durch die Analyse der Koalitionsverträge sowie weiterer Dokumente der jeweiligen Regierungskoalitionen bzw. Bundesregierung wird dieser Effekt verstärkt. Gleichzeitig werden jedoch auch herausfordernde StoryLines identifiziert, wodurch politische Kämpfe sichtbar werden. Eine geringe Verbreitung einer Story-Line im Material lässt Rückschlüsse auf ihre Marginalität zu, aber nicht jede herausfordernde Story-Line ist auch marginalisiert. Marginalisierte Story-Lines bergen das Potenzial, in der computergestützen Analyse identifizierte Hinweise auf Brüche und Verschiebungen vertieft zu analysieren und das ,Außen“ hegemonialer Diskurse in den Blick zu holen ,und so Hinweise auf die Ursache für dessen Dislokation liefern" (Glasze 2008: 206) zu können. Die Datensammlung wird so lange fortgesetzt bis keine neuen Story-Lines mehr identifiziert werden können.

\section{(3) Interpretation}

In diesem Schritt werden die kodierten Story-Lines zusammengefasst, geordnet und interpretiert. Dabei werden Entwicklungen über den Zeitverlauf herausgearbeitet. Dadurch zeigt sich zum einen, wie sich die ,politische Rahmung“ von „Energiewende“ über den Zeitverlauf ändert. Es zeigt sich aber auch, welche Story-Lines eine

40 Danach wäre es bspw. weniger zu erwarten, dass sich im Material Äußerungen finden wie „Eine Energiewende ist schlecht, weil...“, sondern eher Äußerungen wie „Wir befürworten Kohleenergie, weil diese günstig ist.“ 
besondere Konstanz über die Legislaturperioden aufweisen. Diese Story-Lines verweisen, sofern sie gleichzeitig eine hohe Verbreitung zeigen, auf hegemoniale Diskurse. Sie spielen eine große Rolle für die Strukturierung des Diskurses „Energiewende", da sie in einer zeitlichen Kontinuität Bedeutung immer auf dieselbe Weise zuordnen. Abschließend interpretiere ich die Ergebnisse quer über alle Legislaturperioden und diskutiere sowie analysiere sie im Kontext von Hegemonie (vgl. Kapitel 5.1.3).

\subsubsection{Klassifikation fantasmatischer Narrative}

Nach Glynos/Howarth (2007) ist es die Rolle der Fantasie, die radikale Kontingenz des Sozialen zu verdecken, soziale Praktiken zu naturalisieren und somit zu entpolitisieren. Glynos/Howarth (2007) entwickeln einen Analyseansatz, in dem sie der Fantasie als grundlegender Logik erklärenden Gehalt für die diskursive Konstitution sozialer Praktiken zuweisen. Gehe es um die Logik einer Praxis oder eines Regimes von Praktiken, gehe es darum, zu begreifen, wie diese Praxis ,ticke', nicht in dem Sinne zu ihrem essentialistischen Kern zu gelangen, sondern darum, die zeitlich und räumlich kontextualisierten Möglichkeiten und Möglichkeitsbedingungen von Phänomenen zu untersuchen (ebenda: 134f.). „More positively, then, we could say that the logic of a practice comprises the rules or grammar of the practice, as well as the conditions which make the practice both possible and vulnerable“ (ebenda: 136).

Fantasmatische Logiken helfen zu verstehen, warum Subjekte von spezifischen Praktiken und Regimen,ergriffen“ werden (,why specific practices and regimes ,grip“ subjects") (ebenda: 145); oder mit Laclau: Fantasmatische Logiken beziehen sich auf die Kräfte hinter den Signifikationsprozessen (Laclau 2005: 101 zit. in Glynos/Howarth 2007: 145) und agieren somit auf einer „quasi-transzendentalen“, ontologischen Diskursebene (Glynos/Howarth 2007: 137). Nach Lacan bedürfe die politische Realität der Fantasie, um sich zu konstituieren. Glynos/Howarth zufolge sei die Rolle der Fantasie dabei nicht in erster Linie, ein ,falsches Bild der Welt ${ }^{`}$ zu zeichnen, sondern vielmehr aktiv sicherzustellen, dass die Kontingenz und damit die Nicht-Naturgegebenheit sozialer Realität sowie die politische Dimension einer Praxis unsichtbar oder unterdrückt werden (ebenda: 145). „In this regard, the logic of fantasy, which is predicated on the Lacanian category of enjoyment (jouissance), shows how subjects are rendered complicit in concealing or covering over the radical contingency of social relations“ (ebenda: 15). Fantasmatische Logiken helfen insbesondere dabei, Wandel oder Beharrung zu erklären: „Thus, aspects of a social practice may seek to maintain existing social structures by pre-emptively absorbing dislocations, preventing them from becoming the source of a political practice" (ebenda: 146f.). Fantasmatischen Logiken können über die Funktion der Schließung, der Verdeckung von Kontingenz, des ,Nähens' des Sozialen definiert werden. Dadurch strukturiere die Fantasie den Genuss (,jouissance') eines Subjektes als Genuss an der Schließung (,enjoyment of closure`). Dagegen sei aber ethisch gesehen die Akzeptanz von bzw. die Offenheit gegenüber Kontingenz erstrebenswert, also der Genuss an der Offenheit (ebenda: 151).

Die Fantasie entfaltet diskurstheoretisch Wirksamkeit durch „fantasmatische Narrative“, also durch ,große sinnstiftende Erzählungen“ auf der Ebene der Fantasie (ebenda: 147f.). Diese liegen innerhalb des vorliegenden Forschungsdesigns ,hinter 
den Story-Lines, sie sind also als Kräfte hinter den Bedeutungssystemen beziehungsweise auf der untersten Eben des Diskurses zu verorten (vgl. Abbildung 4). Durch ihr Herausarbeiten kann aufgezeigt werden, wie die Kontingenz oder NichtNaturgegebenheit sozialer Realität verdeckt oder herausgefordert wird. Die Identifikation fantasmatischer Narrative könne auch zum Verständnis der Geschwindigkeit und der Richtung von Wandel beitragen (,the 'vector' of political practices“) (ebenda: 145).

Fantasmatische Narrative verheißen entweder eine kommende Erfüllung (,fullness-to-come“), unter Benennung oder Implizierung eines Hindernisses/einer Gefahr, oder einer kommenden Katastrophe, falls das Hindernis/die Gefahr nicht überwunden werden könne. Glynos/Howarth sprechen dabei von einer glücksverheißenden(,beatific") und einer schreckensverheißenden- (,horrific“) Dimension der Fantasie (Glynos/Howarth 2007: 147f.). Diese Dimensionen nutze ich, um mit „Energiewen$\mathrm{de}^{\mathrm{c}}$ in Verbindung stehende fantasmatische Narrative $\mathrm{zu}$ identifizieren (vgl. auch Bedall 2014: 60).

Glynos/Howarth (2007) unterscheiden zwischen populistischen/revolutionären und institutionalistischen/reformistischen politischen Praktiken. ${ }^{41}$ Im Kontext populistischer/revolutionärer politischen Praktiken können sich fantasmatische Logiken durch ein Narrativ zeigen, welches das Glück in der Zukunft verheiße und dies durch eine interne Gefahr (also bspw. strukturelle Ursachen) verhindert sehe. Im Kontext institutionalistischer/reformistischer politischer Praktiken dagegen können fantasmatische Logiken durch ein Narrativ artikuliert werden, welches das Glück im Jetzt verorte und dieses durch eine externe Gefahr bedroht sehe (also strukturelle Ursachen ausblendet) (ebenda: 150f.).

Ich halte allerdings eine nicht binäre Einteilung für die Klassifikation fantasmatischer Narrative für analytisch fruchtbarer. So sind bspw. fantasmatische Narrative vorstellbar, die die Gefahr zumindest teilweise intern verorten (bspw. Klimawandel als Folge der Ökonomie), aber nach reformistischen Lösungen suchen (bspw. Green Economy). Zudem gibt es fantasmatische Narrative, die das Glück eher weniger im Jetzt verorten, sondern eine imaginierte Vergangenheit idealisieren - die damit verbunden politischen Praktiken bezeichne ich hier als reaktionär. Ich schlage daher eine Klassifikation anhand eines Vektors (vgl. Abbildung 3) statt einer binären Einteilung vor. Dies entspricht der Idee fantasmatischer Logiken zum „Verständnis von Widerstand gegen Wandel sozialer Praktiken [...] aber auch der Geschwindigkeit und Richtung von Wandel [eig. Übersetzung]“ beizutragen (ebenda: 145). Ein fantasmatisches Narrativ, das auf die Zukunft gerichtet ist und die Gefahr intern verortet, also eher an der strukturellen Ebene ansetzt, bezeichne ich dabei als transformativ, ein fantasmatisches Narrativ, welches das Glück im Jetzt verheißt und die Gefahr extern verortet bezeichne ich als beharrend. Ein fantasmatisches Narrativ, welches eine Mischung aus beidem darstellt, wäre demnach als reformistisch zu klassifizieren. ${ }^{42}$

41 Für eine Definition politischer Praktiken vgl. Fußnote 14 in Kapitel 1.

42 Fantasmatische Narrative zeigen sich nach Glynos/Howarth (2007) im Zusammenhang mit politischen Praktiken, weshalb sich die Begriffe hier teilweise nur schwer differenzieren lassen, bzw. in einem Spannungsverhältnis stehen. Gegenstand der Untersuchung sind hier aber in erster Linie fantasmatische Narrative, die über die Dimensionen des Glücks/der Ge- 
Abbildung 3: Klassifikation der Wirkrichtung fantasmatischer Narrative anhand der schreckens- sowie der glücksverheißenden Dimension

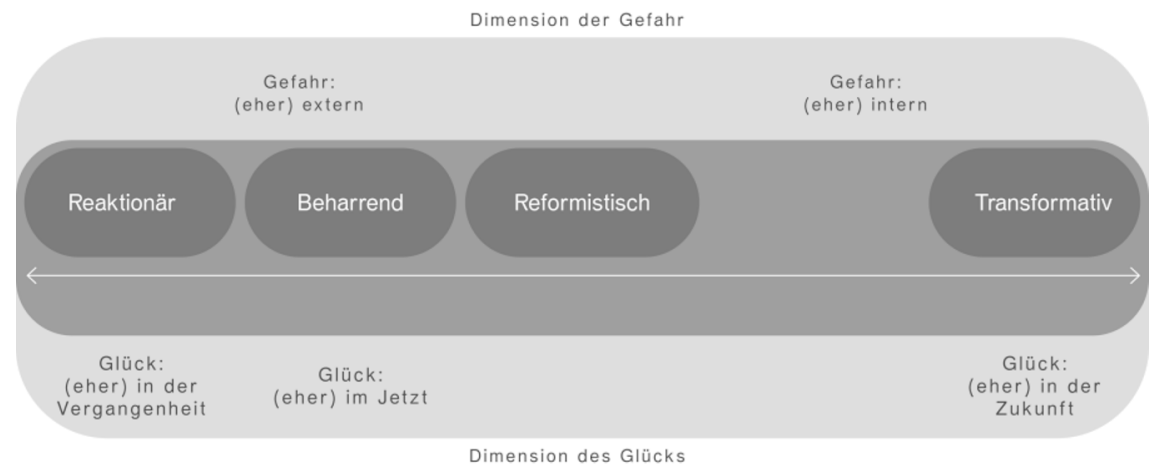

Quelle: eigene Darstellung

Methodisch gehe ich folgendermaßen vor:

1. Verortung der glücksverheißenden- (,beatific“) und der schreckensverheißenden(„horrific“) Dimension der Fantasie (ebenda: 147f.): Um den Story-Lines zugrunde liegende fantasmatische Narrative zu identifizieren, gehe ich das im vorherigen Schritt nach Story-Lines kodierte Material zunächst erneut durch und suche nach Artikulationen, die entweder Glück und/oder eine Katastrophe (bzw. etwas Entsetzliches, „horrific“) unter Benennung einer Gefahr verheißen. Die Auswertung erfolgt also quer zum vorherigen Verfahren. Diese Artikulationen werden anschließend danach sortiert, wie sie die Gefahr, die im schlimmsten Fall zur Katastrophe führt, verorten (extern oder intern) und in welcher Zeit sie das Glück verorten (Vergangenheit, Gegenwart, Zukunft).

2. Identifikation und Bezeichnung fantasmatischer Narrative: Im nächsten Schritt ist zu bewerten, ob die Dimensionen des Glücks und der Katastrophe sowie die Verortung der Gefahr ausreichend ausgeprägt sind, als dass von einem fantasmatischen Narrativ gesprochen werden kann. Werden Glücksverheißung, Katastrophe und Gefahr auf immer wieder ähnliche Weise adressiert? Welche Widersprüche oder Ambivalenzen zeigen sich ${ }^{43}$ Wenn ja, auf welche zentrale Aussage lässt sich das Narrativ reduzieren und wie lässt es sich demzufolge bezeichnen?

3. Implizite Annahmen und Klassifikation: Fantasmatischen Narrativen liegen stillschweigend geteilte Annahmen zugrunde, sie sind aufgeladen mit unsichtbaren, unausgesprochenen Bedeutungen, die häufig nicht ausgesprochen werden, da sie

fahr klassifiziert werden. Fantasmatische Narrative verweisen zwar auf (in diesem Fall reaktionäre, beharrende, reformistische oder transformative) politische Praktiken, mir geht es hier aber analytisch zunächst um die Richtung, in welche das jeweilige fantasmatische Narrativ politisch wirksam wird.

43 Fantasmatische Narrative zeichnen sich nach Glynos/Howarth (2007: 147f.) häufig gerade durch ihre Widersprüchlichkeit aus. 
Dissens erzeugen (vgl. auch Feldman u.a. 2004: 50). Stillschweigend geteilte Annahmen liefern Hinweise auf die Abgrenzung zu anderen Fantasien. Sie sind daher für die Einordnung relevant und werden in diesem Schritt, sofern möglich, identifiziert.

Anhand der Verortung der Dimensionen der Gefahr und des Glücks kann zuletzt das Verhältnis der bezeichneten Narrative zur Richtung ihrer politischen Wirksamkeit bestimmt werden (vgl. Abbildung 3). Handelt es sich um reaktionäre, beharrende, reformistische oder transformative fantasmatische Narrative, bzw. im Kontext welcher politischer Praktiken treten die jeweiligen Narrative zum Vorschein?

\subsection{OPERATIONALISIERUNG EINER KRITISCH- EMANZIPATORISCHEN ANALYSEPERSPEKTIVE VORSORGENDEN WIRTSCHAFTENS}

Nachdem wie beschrieben die Diskurstheorie anhand des „Energiewende“-Diskurses operationalisiert wurde, erfolgt im Sinne des retroduktiven Vorgehens meiner Arbeit (vgl. Abbildung 1) eine erneute Überprüfung und Erweiterung der diskursanalytisch entwickelten Erklärungen vor dem Hintergrund des Vorsorgenden Wirtschaftens. Dabei kommt seine analytische Funktion zum Tragen. Wie erwähnt begegne ich damit der in den Kapiteln 2.6 und 3.2.3 dargelegten Kritik an der fehlenden politischen Positionierung sowie eines mangelnden politisch ökonomischen Gehalts der Diskurstheorie, indem ich die Ergebnisse der Diskursanalyse aus Perspektive des Vorsorgenden Wirtschaftens erneut befrage und dadurch die Materialisierungen des Diskurses noch stärker in den Blick nehme.

Das Vorsorgende Wirtschaften ist dabei als kritisch-emanzipatorische Analyseperspektive zu verstehen; Kritisch, weil die Dekonstruktion weiterhin im Zentrum der Analyse steht. Ziel dieser Arbeit ist es nicht, einen politischen Gegenentwurf zur „Energiewende“ zu leisten oder umfassende politische Empfehlungen zu geben. Die Kritik steht im Zentrum der Arbeit. Allerdings verbindet sich die Kritik mit einem rekonstruktiven und emanzipatorischen Anspruch in dem Sinne, dass Emanzipation als „die Zukunft der Dekonstruktion“ verstanden wird (Critchley 1998: 205). Das Erkennen von Externalisierungsstrukturen und Ausgrenzungen, von Naturalisierungen, wird für eine emanzipatorische Politik und Praxis vorausgesetzt. Der emanzipatorische Anspruch ist dabei auch eine Konsequenz des dem Vorsorgenden Wirtschaften zu Grunde liegenden feministischen Theorieverständnisses. Kritik erfüllt demnach keinen Selbstzweck, sondern aus ihr heraus scheinen immer wieder emanzipatorische, nicht-externalisierende Gestaltungsperspektiven auf (Biesecker/von Winterfeld 2015: 5). Ziel der Kritik ist es, die Möglichkeit einer herrschaftsärmeren Zukunftsgestaltung in den Blick zu holen.

Vor diesem Hintergrund wird das Vorsorgende Wirtschaften als kritisch-emanzipatorische Analyseperspektive anhand von heuristischen Fragestellungen operationa- 
lisiert, mit denen ich die Ergebnisse der Diskursanalyse ${ }^{44}$ befrage. Die Fragestellungen leiten sich dabei direkt aus der in Kapitel 3 dargestellten Theorie ab, wobei ich die Handlungsprinzipien sowie die weiteren Kriterien Vorsorgenden Wirtschaftens zu Grunde lege und deren Gehalt gegenstandsbezogen bestmöglich abbilde. Ich verknüpfe hier also mein retroduktives Vorgehen insofern mit einem deduktiven Vorgehen, als dass die Fragestellungen sich aus der Theorie heraus ergeben. Diese werden aber gegenstandsbezogen angepasst, sodass sie sich im Laufe der Analyse verändern und weiterentwickeln können, sofern dies notwendig erscheint (so wurde bspw. das Kriterium der ,neokolonialen und nationalen Externalisierung als Prinzip ‘ erst im Laufe der Analyse entwickelt). Um die Operationalisierung des Vorsorgenden Wirtschaftens als Analyserahmen bestmöglich nachvollziehbar zu machen, habe ich mich für eine tabellarische Darstellung der heuristischen Fragestellungen entschieden. So ist eine vollständige Übersicht über die der Analyse zugrunde liegenden Fragestellungen am ehesten zu gewährleisten. Um eine bessere Lesbarkeit der Ergebnisse sicherzustellen erfolgt die Beantwortung der aufgelisteten Fragen in Kapitel 6 im Fließtext. Zur etwaigen Vermeidung von Redundanzen werden Aspekte, die für verschiedene Handlungsprinzipen/bzw. Kriterien relevant sind, der Heuristik zugeordnet, für die sie in dieser Untersuchung die höchste Relevanz haben. Gleiches gilt für Redundanzen, die sich im Laufe der Auswertung ergeben.

\section{Analyseheuristik Vorsorge}

(abgeleitet aus Kapitel 3.1.1 und 3.2.1)

Allgemein:

- Wie werden Mensch-Mensch und Mensch-Natur-Beziehungen, bzw. gesellschaftliche Naturverhältnisse konstituiert?

- Welche Rolle spielt Suffizienz?

- Welche Rolle spielen Vorsicht, Voraussicht, Weitblick, Fehlerfreundlichkeit?

- Spielt vorsorgendes Handeln eine Rolle?

- Welche Rolle spielen zukünftige Generationen?

- Zielt das Wirtschaften in der Gegenwart auf die (Re)Produktion seiner „sozialökologischen Voraussetzungen“ (Biesecker u.a. 2019: 121)?

\section{Zeitlichkeitsverständnis:}

- Welche Vorstellungen von Zeit zeigen sich?

- Wie wird auf die Zukunft Bezug genommen (gemeint ist hier die Unterscheidung zwischen Zukunft als ,vergangener Zukunft', Zukunft als ,gegenwärtiger Zukunft' und Zukunft als ,zukünftiger Gegenwart' nach Adam 2013)?

- Welche Rolle spielt Langfristigkeit?

- Zeigt sich eine hierarchisch strukturierte Dichotomie zwischen kommodifizierter Zeit und lebendiger Zeit?

- Spielen qualitative Unterschiede von Zeit eine Rolle oder geht es um lineare

44 Also die Ergebnisse der computerbasierten Analyse, das nach Story-Lines kodierte Material sowie die fantasmatischen Narrative. 
Zeitlichkeit?

- Werden unterschiedliche Zeiten der am Wirtschaftsprozess Beteiligten berücksichtigt?

- Welche Rolle spielt Fortschritt?

2. Analyseheuristik Kooperation (abgeleitet aus Kapitel 3.2.1)

- Wird Kooperation als Modus ökonomischer Zusammenarbeit explizit oder implizit thematisiert? Wenn ja...

- Wer kooperiert? Beruht die Kooperation nur auf marktlichen oder auch auf nichtmarktlichen Akteur*innen? Werden auch Naturleistungen ,einbezogen, wertgeschätz und bewertet“" (Biesecker/Hofmeister 2013a: 154)? Wird im Sinne von (Re)Produktivität zwischen Arbeits- und Naturproduktivität vermittelt (Biesecker/Hofmeister 2006)?

- Ist die Kooperation auf Eigennutz oder auf Verständigung gerichtet?

- Handelt es sich um eine verantwortliche Kooperation in dem Sinne, dass die Lebensinteressen auch sprachloser Akteur*innen gleichermaßen mitberücksichtigt werden?

- Wenn über Wirtschaften gesprochen wird, wird dieses als ziel- oder prozessorientiert konstituiert? Werden Ziele, Wege und Normen des Wirtschaftens diskursiv ausgehandelt?

- Welche Rolle spielen Konkurrenz und Wettbewerb?

- Wird Wirtschaften über Rationalität koordiniert? Welche Rolle spielen Mitgefühl, Moral, Emotionalität?

- Welches Gegenseitigkeitsprinzip liegt dem/n Ökonomieverständnis/sen zu Grunde?

- Werden Asymmetrien reflektiert? ${ }^{45}$

- Was für ein Arbeitsbegriff zeigt sich in den Debatten? Werden ,andere‘ Produktivitäten außerhalb von Erwerbsarbeit (z.B. Sorgearbeit) in die Kooperation einbezogen?

\section{Analyseheuristik Orientierung am für das}

Gute Leben Notwendigen (abgeleitet aus Kapitel 3.2.1)

- Welche Vorstellungen von Wohlstand lassen sich identifizieren?

- Wird Wohlstand als Mittel zum Zweck für ein gutes Leben oder als Selbstzweck definiert?

- Was wird unter Lebensqualität verstanden?

- Welche ökonomischen Zielsetzungen lassen sich identifizieren?

Werden diese als offen für Aushandlungen konstituiert?

45 Diese Frage ist auch für das Vorsorge-Prinzip relevant, wird hier aber, um Redundanzen zu vermeiden dem Kooperationsprinzip zugeordnet. 
- Wird die Ökonomie als Mittel oder Zweck eingeordnet?

- Wie wird entschieden, was gesellschaftlich be- und verwertet wird?

- Welche Perspektiven auf die Entwicklung der 10 Grundfähigkeiten nach Nussbaum (1999: 49ff.) zeigen sich im Material?

\section{Analyseheuristik Externalisierung als Prinzip}

(abgeleitet aus Kapitel 3.2.2)

Allgemein:

- Zeigen sich diskursive Praktiken, durch die etwas Externes erzeugt wird, ,auf dessen Basis das interne, wertvolle, sichtbare Licht entsteht“", wobei diese Konstruktion gleichzeitig als objektiv, als von Natur aus gegeben erscheint? (Biesecker/von Winterfeld 2014: 4)

- Welche hierarchisch strukturierten Dichotomien werden dadurch erzeugt?

- (Wie) wird der eine Teil diskursiv abgewertet?

- Welche Herrschaftsverhältnisse entstehen/zeigen sich?

- (Wie) zeigt sich der instrumentelle Aspekt von Externalisierung?

Wird „das Abgetrennte für die Kapitalverwertung gebraucht“ (ebenda)?

- Wann, wie und warum werden neue diskursive Grenzlinien gezogen?

Wird bspw. das Abgespaltene internalisiert, dabei aber weiterhin abgewertet (,abspaltendes Einbeziehen“ (ebenda: 14))?

Neokoloniale und nationale Externalisierung als Prinzip:

- Wird die historische Dimension krisenhafter gesellschaftlicher Naturverhältnisse, bspw. bezüglich (neo)kolonialer Strukturen und Praktiken thematisiert?

- Zeigt sich die ambivalente/disjunktive Temporalität der Moderne?

Z.B.: Werden einerseits die kolonialen und gewaltvollen Ursprünge der Moderne verdrängt und andererseits ihr Fortschritts- und Rationalitätsnarrativ betont?

- Zeigen sich Dimensionen von ,Othering (z.B. ,Worlding`) im Diskurs um „Energiewende“, wenn ja welche (Spivak 1985: 114)?

- Lassen sich Elemente der Erzeugung von Subalternität identifizieren?

- Welche Rolle spielt Wissen im Diskurs?

- Wird Wissen und Technologie als Eigenheit des ,Eigenen“, im Gegensatz zum kolonialen ,Anderen' konstruiert?

- Zeigt sich „epistemische Gewalt“, bzw. die Überschneidung von Wissen und Macht, wenn ja wie (Spivak 1985: 255f)?

- Wie prägt dieses Wissen das Selbst- und Fremdbild?

- Wie materialisiert sich die diskursive Wissensordnung?

- Wie wird die Nation im Zusammenhang mit „Energiewende“ erzählt? Z.B.:

- (Wie) wird nationale Identität im „Energiewende“-Diskurs konstruiert?

- Was ist das ,Andere“ der nationalen Gemeinschaft?

- Inwiefern konsolidiert das nationale Narrativ kapitalistische Interessen? 
- Welche Dimensionen des nationalen Narrativs zeigen sich (pädagogische/ performative)?

\section{Analyseheuristik Potenziale für eine herrschaftsärmere Zukunftsgestaltung (abgeleitet aus Kapitel 3.2.2)}

Allgemein:

- Geht Politik aktiv mit Externalisierungen um? Baut sie Herrschaft auf oder ab?

- Welche Rolle kommt der Politik zu? (z.B.: aktiv? Starker Staat oder autoritärer Staat oder laissez-faire?)

- (Wie) werden dominante Diskurse herausgefordert, zeigen sich Brüche im hegemonialen Diskurs, welche emanzipatorischen Potenziale zeigen sich in gegenhegemonialen Diskursen?

\section{Gerechtigkeit:}

- Wie wird Gerechtigkeit im „Energiewende“-Diskurs gefasst?

- Werden soziale und ökologische Gerechtigkeitsaspekte verbunden?

- (Wie) werden affirmative und/oder transformative Gerechtigkeit adressiert (Fraser 2001: 47ff.)?

- Welche Aspekte von Gerechtigkeit werden adressiert? (Anerkennung/Umverteilung - ökonomische Gerechtigkeit)

- Auf welcher Ebene werden Ungerechtigkeiten adressiert (z.B. strukturell)?

- Werden Asymmetrien produziert oder aufrechterhalten oder wird Asymmetrien entgegen gewirkt?

- Welche Rolle spielen dabei gesellschaftliche Naturverhältnisse?

- Welche Eigentumsverhältnisse werden mit der Energiepolitik hergestellt?

- Wo/wie zeigen sich herrschaftliche Eigentumsverhältnisse, also HerrschaftsEigentum, das andere von der Nutzung ausschließt?

\subsection{KRITISCHE REFLEXION DES FORSCHUNGSANSATZES UND FORSCHUNGSDESIGNS}

Neben der bereits in Kapitel 2 und 3 reflektierten Kritik an der Diskurstheorie sowie am Vorsorgenden Wirtschaften ergeben sich aus dem forschungspraktischen Verfahren meiner Arbeit folgende Herausforderungen:

Die erste Herausforderung liegt im Verhältnis zwischen der Diskurstheorie nach Laclau/Mouffe (2015) und dem vorliegenden Gegenstand begründet. Wie in Kapitel 2 erläutert, besteht ein wesentliches Potenzial der Diskurstheorie darin, die Trennung von sprachlicher und materieller Welt im Diskursbegriff aufzulösen, indem das Materielle ,katachrestisch“ in den Diskursbegriff hineingeholt und ,der materielle [...] Charakter jeder diskursiven Struktur bekräftig[t]“ (ebenda: 142) wird. Diesem Diskursbegriff gilt es in der Forschungspraxis gerecht zu werden. Die Datenbasis meiner Arbeit besteht aus Bundestagsdebatten und -dokumenten, der Gegenstand liegt also 
in Form von Sprache vor. Soziale Praktiken oder materielle Manifestationen im Kontext von „Energiewende“, wie sie sich außerhalb des im Bundestag Besprochenen zeigen, werden nicht betrachtet. ${ }^{46}$ Insofern liegt der Fokus der Untersuchung zumindest vordergründig auf Sprache. Dies lässt sich nach dem Diskursbegriff nach Laclau/Mouffe (2015) allerdings nicht nur mit der wirklichkeitsproduzierenden Funktion von Sprache begründen, sondern auch dadurch, dass sich Debatten im Bundestag in besonderer Weise unmittelbar materialisieren, bzw. in politischen Praktiken manifestieren: Nämlich in Beschlüssen und Gesetzen, die eine unmittelbar materielle Wirkung entfalten. Die materielle Dimension von „Energiewende“, die sich in diesen Beschlüssen, Gesetzen und politischen Praktiken zeigt (bspw. bestimmte Fördersätze von Solarenergie), ist somit ebenfalls als Teil der vorliegenden Diskursanalyse zu verstehen.

Nicht Teil der Arbeit ist der den Bundestagsdebatten vorgelagerte politische Prozess, der aus Ausschusssitzungen, Fraktionssitzungen, Kabinettssitzungen, Anhörungen, der Erarbeitung von Vorlagen durch die Ministerien oder Treffen der verschiedenen Gremien oder Ministerien mit Interessensvertreter*innen aus Wirtschaft und Zivilgesellschaft, etc. besteht. Möglicherweise wird „Energiewende“ hier anders verhandelt als dies in den Plenardebatten der Fall ist. Dies wäre in einer eigenen Forschungsarbeit zu analysieren.

Eine zweite Herausforderung dieser Arbeit liegt im Verhältnis von Diskurstheorie und Methode begründet. So sehen sich korpuslinguistische, quantitative und computerbasierte Verfahren häufig mit der Kritik konfrontiert, einen Objektivitätsanspruch $\mathrm{zu}$ verfolgen, der mit einem poststrukturalistischen und feministischen Wissenschaftsverständnis unvereinbar wäre (Jäger 2012: 134; Baker 2006: 5ff.). Daher werden solche Verfahren bislang kaum in diskursanalytischen Arbeiten eingesetzt (Dzudzek u.a. 2009: 234). In der Beschreibung meines methodischen Vorgehens habe ich dargelegt, wie mir das Einbinden computerbasierter Verfahren in diskursanalytische Forschungsdesigns als sinnvoll erscheint und dies begründet. Zentral ist dabei der zu Grunde liegende Anspruch, mit dem solche Verfahren angewandt werden: Weder ergibt sich aus der großen Datenbasis ein Anspruch auf Repräsentativität, noch sind quantitativ erhobene Daten ,objektiver'. Die Wahl eines computerbasierten Verfahrens ergibt sich in der vorliegenden Arbeit zum einen aus der Sinnhaftigkeit der Kombination verschiedener methodischer Ansätze im Forschungsdesign, innerhalb dessen sich Muster und Regelmäßigkeiten im Diskurs mit dem computerbasierten Verfahren relativ einfach herausarbeiten lassen. Zum anderen wurden die Vorteile der Verwendung einer großen Datenbasis, wie sie GermaParl darstellt und deren Bearbeitung nur computerbasiert möglich ist, bereits ausgeführt. Ein Nachteil großer Datenmengen ist allerdings, dass Fehler in der Datenbasis schwerer aufzudecken

46 Es ist davon auszugehen, dass sich soziale Praktiken von „Energiewende“ außerhalb des Bundestags zeigten, weit bevor eine Debatte im Bundestag darüber entstand. Dies ist allerdings nicht Gegenstand dieser Arbeit, die ausschließlich danach fragt wie sich „Energiewende" im Bundestag konstituiert. 
sind, da eine Einzelfallüberprüfung zu aufwendig wäre. So sind auch in GermaParl Fehler enthalten, die in einigen Fällen entdeckt und behoben werden konnten. ${ }^{47}$

Baker (2006: 11) schließt für den Anspruch quantitativer korpuslinguistischer Verfahren: „So we need to be aware that our research is constructed, but we shouldn't deconstruct it out of existence“".

Dieser Anspruch gilt selbstverständlich nicht nur für das computerbasierte Verfahren, sondern liegt der gesamten Arbeit zu Grunde und erfordert die eigene Positionierung stets zu reflektieren. Die Diskurstheorie sowie das Vorsorgende Wirtschaften liefern dabei nicht mehr und nicht weniger als eine spezifische Art zu denken und zu forschen - vor dem Hintergrund einer anderen Art zu denken würden zweifellos andere Ergebnisse generiert. Es geht also nicht darum ,wahre Erkenntnisse' zu generieren, sondern darum, an den aus dieser Perspektive aufgedeckten vermeintlichen Wahrheiten, Kritik zu üben (vgl. auch Jäger 2012: 78). Diese Arbeit verstehe ich demnach als Teil der diskursiven Kämpfe um „Energiewende“, „,sowohl im wissenschaftlichen Spezialdiskurs als auch im politischen Diskurs“ (ebenda: 145).

Das Forschungsdesign, welches der vorliegenden Arbeit zu Grunde liegt, führe ich abschließend in Abbildung 4 zusammen. Dabei nehme ich nochmals auf die verschiedenen Ebenen der Dekonstruktion, die in den einzelnen methodischen Schritten benannt wurden, Bezug. Es wird so deutlich, dass die Analyse im ersten Teil der Dekonstruktion von Methodenschritt zu Methodenschritt jeweils eine tieferliegende Diskursebene adressiert. Im zweiten Teil der Dekonstruktion werden die Ergebnisse des ersten Teils aus kritisch-emanzipatorischer Perspektive Vorsorgenden Wirtschaftens reflektiert. Ziel jedes Schrittes ist es auch immer wieder die Richtung der politischen Wirkweisen analysierter Einheiten des Diskurses (wie Forderungen, StoryLines oder fantasmatische Narrative) im Spannungsfeld zwischen Reaktion, Beharrung und Transformation zu reflektieren, was ich hier anhand von Vektoren darstelle. Die materielle Wirkung der damit verbundenen politischen Praktiken kommt so zunehmend in den Blick. Im zweiten Teil der Dekonstruktion wird dieser materiellen Wirkweise durch das Einfließen verstärkt politisch ökonomischer Aspekte zusätzlich Rechnung getragen.

47 So sind in einigen wenigen Fällen die Metadaten des Korpus fehlerhaft. Fehler, die entdeckt wurden, enthielten bspw. als Redebeiträge nach Parteizugehörigkeit kodierte Redebeiträge von Bundestagspräsident*innen, falsche Datumsangaben oder doppelte Kodierungen einzelner Textstellen. Da die aus polmineR entnommenen Zitate in der vorliegenden Arbeit anhand der Originalprotokolle überprüft wurden, konnte der Fehleranteil gering gehalten werden. 


\section{Abbildung 4: Ebenen der Dekonstruktion im Forschungsdesign}

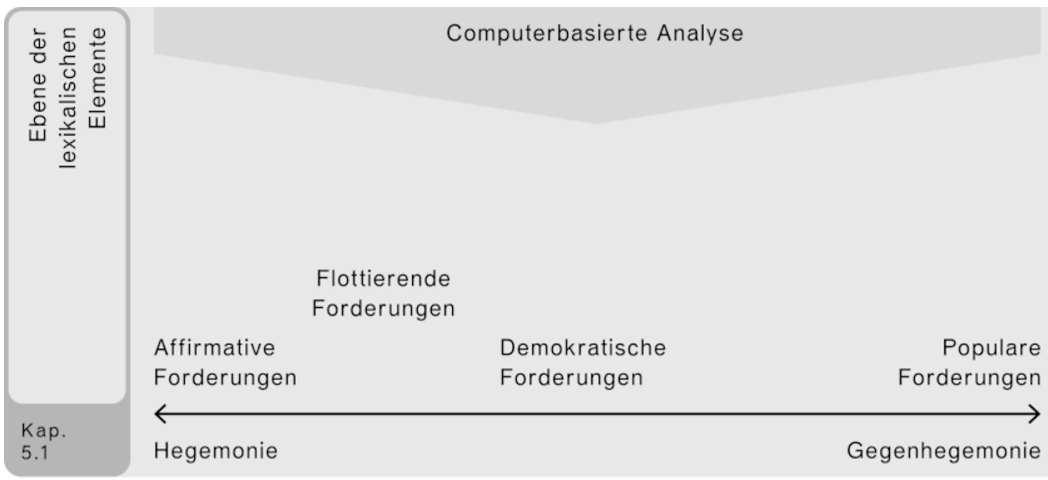

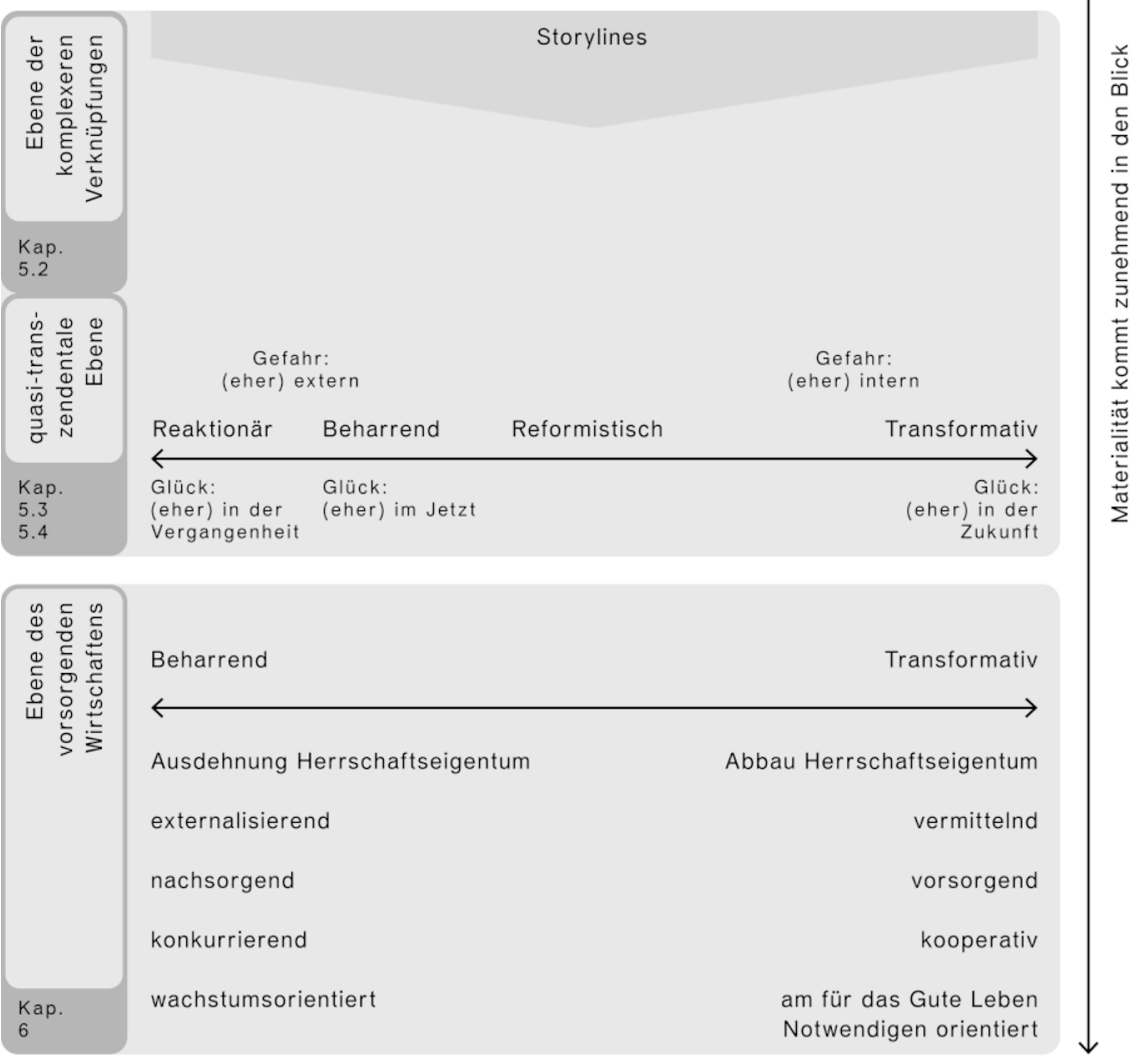

Bewertung

Beharrend

Transformativ

Quelle: eigene Darstellung 


\section{Dekonstruktion Teil I: Diskursanalyse der Bundestagsdebatten zur „Energiewende“ nach Laclau/Mouffe}

Im vorliegenden Kapitel werden die Ergebnisse des ersten Teils der Analyse vorgestellt. Der Fokus des Kapitels liegt auf der Bedeutungskonstitution von „Energiewende“ im Bundestag, deren zeitlicher Dynamik sowie der damit in Zusammenhang stehenden Kämpfe um Hegemonie.

Korrespondierend zur in Kapitel 4 entwickelten Methodik gliedert sich das Kapitel in vier Abschnitte, innerhalb derer - im Sinne des retroduktiven Vorgehens meiner Arbeit - „Energiewende“ auf verschiedenen Diskursebenen problematisiert und erklärt wird. Der erste Abschnitt zielt gemäß dem Forschungsdesign auf die oberste Ebene des Diskurses, auf die lexikalischen Elemente und die durch ihre Verknüpfung entstehenden Muster des Diskurses (Kapitel 5.1). Dieser Abschnitt ist nach Legislaturperioden gegliedert. Im zweiten Abschnitt (5.2) werden komplexere Bedeutungsbeziehungen auf einer tieferen Diskursebene betrachtet, indem durch explizite oder implizite Artikulationen entstehende Verknüpfungen nach Story-Lines kodiert werden. Dadurch zeigt sich, inwiefern „Energiewende“ auf komplexitätsreduzierende Weise erzählt wird oder gerade nicht erzählt wird. Der dritte Abschnitt (5.3) widmet sich der quasi-transzendentalen Diskursebene der Fantasie. Hier werden den StoryLines zugrunde liegende fantasmatische Narrative identifiziert und anhand ihres Verhältnisses zur politischen Praxis als reaktionär, affirmativ, reformistisch oder transformativ klassifiziert. Im letzten Teil des Kapitels (5.4) werden die Ergebnisse der Analyse zusammengeführt und vor dem Hintergrund von Hegemonie bewertet. Dieses Verfahren führt mich zu der (vorläufigen) Hypothese, dass sich „Energiewende“ im parlamentarischen Raum von einem vor-politischen zu einem post-politischen Diskurs entwickelt hat, was ich abschließend genauer erläutern werde.

\subsection{ERGEBNISSE DES COMPUTERBASIERTEN VERFAHRENS}

Um die Beziehungen zwischen einzelnen Elementen des „Energiewende“-Diskurses herauszuarbeiten, erfolgt - wie in Kapitel 4 beschrieben - zunächst eine computergestützte Analyse mit polmineR. Ziel ist es, den Prozess der Bedeutungskonstitution 
von „Energiewende“ zu fassen und gemäß der Diskurstheorie von Laclau/Mouffe (2015) temporäre Fixierungen von Elementen herauszuarbeiten.

Zunächst verschafft die Frequenzanalyse einen Überblick über den Diskursverlauf. Dann werden regelmäßige Differenzbeziehungen zwischen Elementen über die Legislaturperioden mittels Kollokations- und Konkordanzanalysen herausgearbeitet, durch die überzufällig häufig mit „Energiewende“ auftretende Elemente identifiziert und so Aussagenmuster erfasst werden. Abschließend wird ein erster Bezug zur Hegemonietheorie hergestellt, vor dessen Hintergrund eine qualitative Untersuchung der Ergebnisse des computerbasierten Verfahrens über alle Legislaturperioden erfolgt.

\subsubsection{Zeitlicher Diskursverlauf: Frequenzanalyse}

Die Betrachtung der diachronen Häufigkeitsverteilung von „Energiewende*1“ sowie der Vergleich mit weiterer aus dem Diskurs identifizierter relevanter Elemente geben Aufschluss über den Stellenwert und die Relevanz des Themas sowie die zeitliche Veränderung des Diskurses. Abbildung 5 zeigt zunächst den Anteil der Buchstabenfolgen „Energiewende*“ und erneuerbar* Energie* an der Anzahl der Vorfälle von Energie* im Gesamtkorpus (1996-2016).

Abbildung 5: Anteile von „Energiewende*“ und erneuerbar*Energie* an Vorfällen von Energie* im Gesamtkorpus

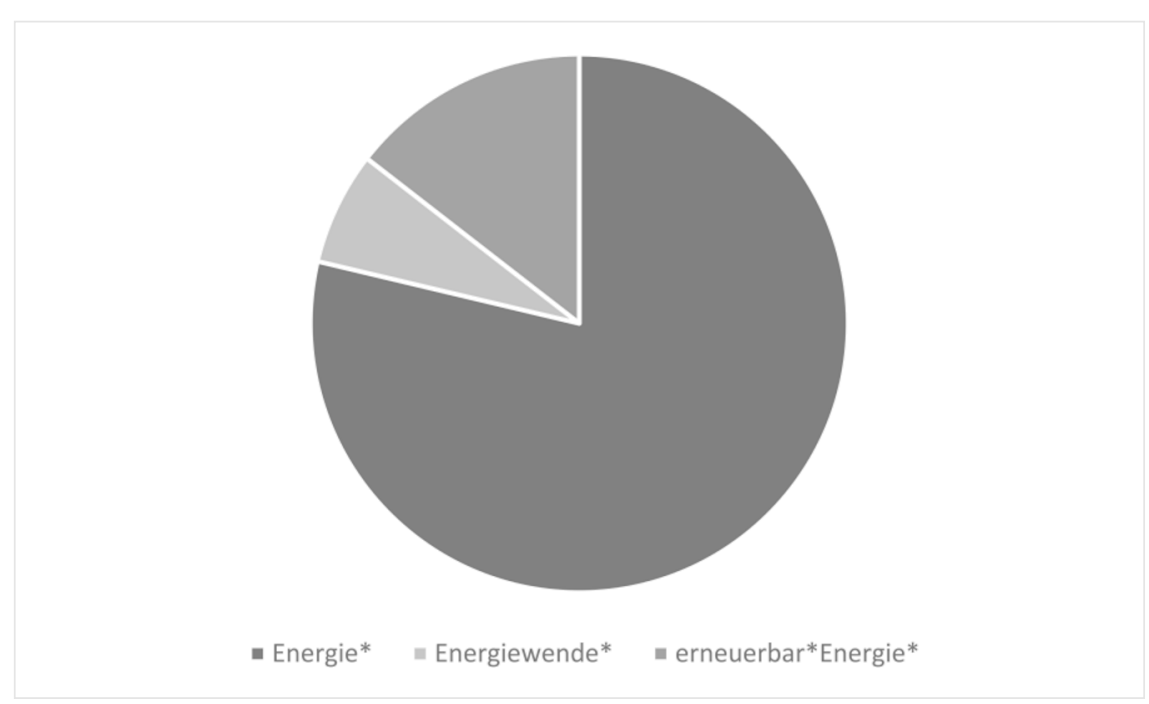

Quelle: eigene Darstellung

1 Zur Bedeutung des * vgl. Kapitel 4.2.1. Im Folgenden werden mit * markierte Elemente als ,Buchstabenfolgen“ bezeichnet, da es sich nicht unbedingt um bereits vollständige Wörter handelt. So kann eine Suche nach Energie* bspw. auch das Wort ,Energiewirtschaft' zum Ergebnis haben. Ich verwende die Schreibweise mit * dabei ausschließlich, wenn ich mich auf eine tatsächlich stattgefundene Analyse/Suche mit polmineR beziehe und nicht, wenn ich den Diskurs um „Energiewende“ allgemein adressiere. 
Insgesamt ist im GermaParl-Korpus 47.931 Mal in irgendeiner Form von Energie*2 die Rede, während „Energiewende*“ 4144 Mal vorkommt und erneuerbare* Ener-

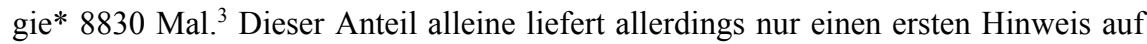
die Relevanz von „Energiewende“, da er ohne Betrachtung des Kontextes zunächst begrenzt aussagefähig ist. Denn auch in weiteren Vorfällen von Energie* kann in irgendeiner Form von erneuerbaren Energien oder „Energiewende“ die Rede sein bspw. wenn über Energiepolitik oder regenerativ* Energie* (986 Vorfälle) gesprochen wird. ${ }^{4}$ Um weitere Hinweise auf die Relevanz von „Energiewende“ sowie die zeitliche Entwicklung zu erhalten, wird die Häufigkeitsverteilung von „Energiewende*“ mit den Häufigkeitsverteilungen von erneuerbar* Energie*, Atomausstieg*, Klimaschutz* und Energie* verglichen (vgl. Tabelle 5) - Elemente, die einen Energiebezug aufweisen und, die häufig in Verbindung mit „Energiewende*" auftreten. ${ }^{5}$

Tabelle 5: Verteilung absoluter Häufigkeiten einzelner Schlüsselpunkte nach Jahren

\begin{tabular}{|c|c|c|c|c|c|}
\hline Jahr & $\begin{array}{c}\text { "Energie- } \\
\text { wende*6 }^{* 6}\end{array}$ & $\begin{array}{c}\text { erneuerbar* } \\
\text { Energie* }^{*}\end{array}$ & Atomausstieg* & Klimaschutz* & Energie* \\
\hline 1996 & 10 & 67 & 2 & 84 & 929 \\
\hline 1997 & 2 & 135 & 0 & 131 & 1307 \\
\hline 1998 & 2 & 25 & 4 & 116 & 743 \\
\hline 1999 & 28 & 200 & 90 & 294 & 1862 \\
\hline 2000 & 16 & 344 & 91 & 466 & 2403 \\
\hline 2001 & 31 & 154 & 64 & 338 & 1489 \\
\hline 2002 & 32 & 216 & 23 & 291 & 1210 \\
\hline 2003 & 12 & 479 & 16 & 241 & 1568 \\
\hline 2004 & 14 & 516 & 16 & 499 & 1749 \\
\hline
\end{tabular}

2 Diese Anzahl beinhaltet auch Vorfälle von Energie*, in denen nicht Energie im physikalischen Sinne gemeint ist - sondern bspw. im körperlichen Sinne, wie ,keine Energie haben`. Die Anzahl dieser Vorfälle ist aber angesichts der hohen Anzahl an Vorfällen von Energie* insgesamt zu vernachlässigen.

3 Groß- und Kleinschreibung wird dabei ignoriert.

4 Darüber hinaus können energiepolitische Themen auch ohne Verwendung der Buchstabenfolge Energie* adressiert werden, wenn bspw. von Kohlekraft* (1195 Vorfälle), Solarkraft* (18 Vorfälle) oder Kernkraft* (2538 Vorfälle) etc. die Rede ist. Allerdings ist es sehr wahrscheinlich, dass in diesen Debatten Energie* ebenfalls häufig vorkommt.

5 Dies zeigt sich während der Kollokationsanalyse in Kapitel 5.1.2. Dabei zeigt sich zudem das Element ,Klimaschutz' relevanter als ,Klimawandel', weshalb hier die Auswahl auf Klimaschutz* reduziert wird. 


\begin{tabular}{|c|c|c|c|c|c|}
\hline 2005 & 1 & 205 & 18 & 285 & 1086 \\
\hline 2006 & 5 & 388 & 45 & 303 & 2432 \\
\hline 2007 & 16 & 626 & 69 & 1283 & 2864 \\
\hline 2008 & 17 & 634 & 18 & 1209 & 3325 \\
\hline 2009 & 26 & 480 & 43 & 624 & 2238 \\
\hline 2010 & 29 & 1100 & 61 & 956 & 3889 \\
\hline 2011 & 392 & 790 & 155 & 571 & 3627 \\
\hline 2012 & 1256 & 748 & 79 & 367 & 4688 \\
\hline 2013 & 602 & 413 & 66 & 440 & 2259 \\
\hline 2014 & 924 & 704 & 58 & 949 & 4181 \\
\hline 2015 & 348 & 277 & 38 & 746 & 2345 \\
\hline 2016 & 381 & 329 & 61 & 796 & 1737 \\
\hline
\end{tabular}

Quelle: eigene Darstellung

Dabei zeigt sich, dass sowohl „Energiewende*“, als auch Atomausstieg* im Vergleich zu erneuerbar* Energie* und Klimaschutz* bis einschließlich 2010 relativ selten vorkommen. Während vor 2010 (mit Ausnahme von 2002) Atomausstieg* häufiger auftaucht als „Energiewende*“, dreht sich dieses Verhältnis ab 2011 um. Die Gründe hierfür sind einer quantitativen Analyse nicht entnehmbar und sind in den nächsten methodischen Verfahren genauer zu betrachten. Abbildung 6 veranschaulicht die Entwicklung der absoluten Häufigkeiten von „Energiewende*“, erneuerbar* Energie* und Klimaschutz* im Vergleich grafisch.

Es deutet sich an, dass die Korrelationsbeziehung zwischen der Häufigkeitsentwicklung von erneuerbar* Energie* und Klimaschutz* zumindest bis 2010 deutlich stärker ist, als die Korrelationsbeziehung zwischen erneuerbar* Energie* und „Energiewende*“ oder zwischen Klimaschutz* und „Energiewende*“. ${ }^{6}$ Ab 2011 verstärkt sich allerdings der Zusammenhang zwischen erneuerbar* Energie* und „Energiewende*“. 72012 war „Energiewende*“ mit 1256 Vorfällen erstmals quantitativ stärker vertreten als erneuerbar* Energie* mit 748 Vorfällen. Dies könnte ein Hinweis

6 Dies zeigt auch der Spearman-Korrelationskoeffizient, der für den Zusammenhang der Häufigkeitsentwicklung zwischen erneuerbar* Energie* und Klimaschutz* eine äußerst signifikante und starke Korrelation misst ( $r h o=0.73 ; p=0.00026)$. Die Korrelationen der Häufigkeitsentwicklungen zwischen erneuerbar* Energie* und „Energiewende*“ (rho $=0.493 ; \mathrm{p}=0.023)$ sowie Klimaschutz* und „Energiewende ${ }^{* “}$ sind im Vergleich betrachtet schwächer $($ rho $=0.516 ; \mathrm{p}=0.017)$.

$7 \quad($ rho $=0.657 ; \mathrm{p}=0.175)$ 
darauf sein, dass erneuerbare Energien vor 2011 eher zusammen mit Klimaschutz verhandelt wurden und weder erneuerbare Energien noch Klimaschutz zwingend als Teil einer „Energiewende“ besprochen wurden. Scheinbar gewinnt „Energiewende“ erst nach „Fukushima“ im Jahr 2011 an Relevanz, was auf die stark dislozierende Wirkung des Ereignisses verweist. Diese Entwicklung sowie die Qualität der hier identifizierten Korrelationen werden im weiteren Verlauf der Arbeit noch genauer betrachtet.

Abbildung 6: Verteilung absoluter Häufigkeiten von „Energiewende*“, erneuerbar* Energie* und Klimaschutz* zwischen 1996 und 2016

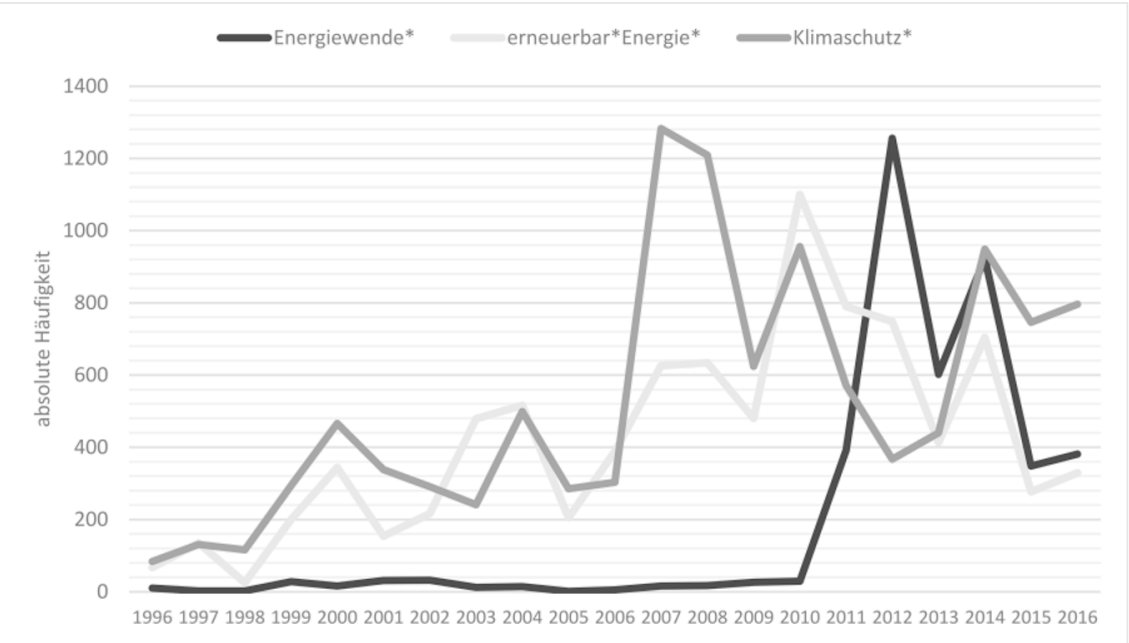

Quelle: eigene Darstellung

Um die Involvierung der verschiedenen Fraktionen in den Diskurs um „Energiewende" sichtbar zu machen, ist - aufgrund der nach Fraktionsgröße gestaffelten Redezeiten im Parlament - eine Betrachtung der relativen Häufigkeiten notwendig. ${ }^{8}$

Abbildung 7 zeigt, dass die GRÜNEN (außer in der 16. Legislaturperiode) im Vergleich betrachtet am häufigsten von „Energiewende“ sprechen. Dabei zeigt sich aber auch, dass vor der 17. Legislaturperiode das Thema „Energiewende“ von keiner Fraktion häufig aufgegriffen wurde. Es ist darüber hinaus erkennbar, dass die relative Häufigkeit der Nennungen durch die GRÜNEN von der 14. zur 15. Legislaturperiode abnimmt, das Thema also noch unter der rot-grünen Regierungszeit an Relevanz zu verlieren scheint.

8 PolmineR partitioniert dazu den Korpus nach Fraktionen, wodurch die Häufigkeit in Relation zu den Teilkorpora der einzelnen Fraktionen darstellbar wird. Die relativen Häufigkeiten bezeichnen hier die Anzahl der Vorfälle pro Wort. Wo angegeben, errechne ich daraus zur besseren Lesbarkeit die Anzahl der Vorfälle pro tausend Wörtern. 
Abbildung 7: Verteilung relativer Häufigkeiten von „Energiewende*“ über Parteien und Legislaturperioden

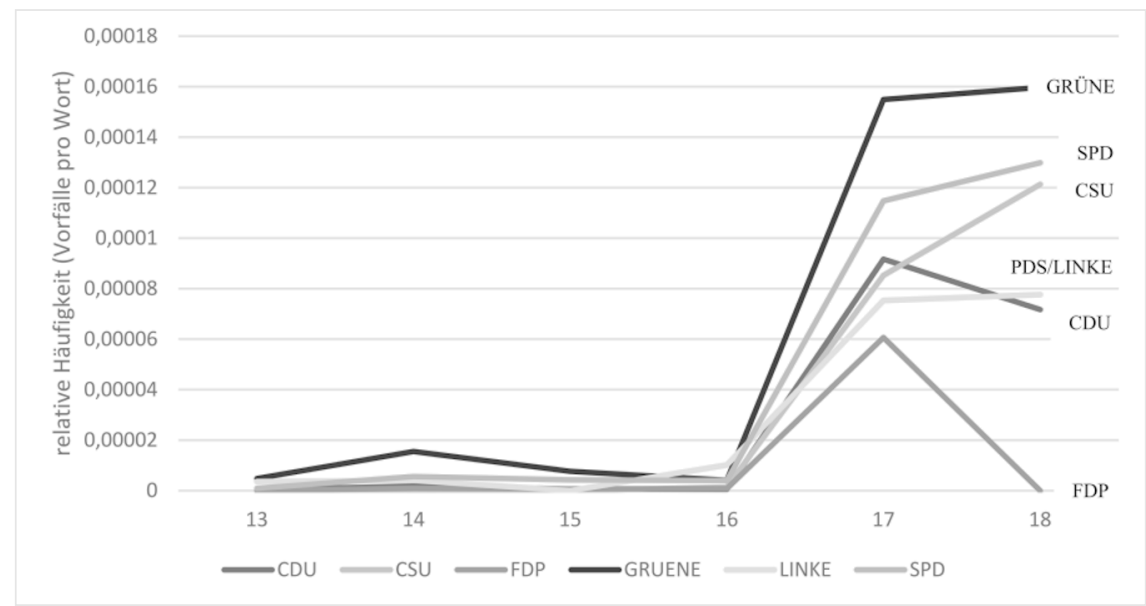

Quelle: eigene Darstellung

Im Gegensatz dazu ist die relative Häufigkeit der Nennungen von Klimaschutz* oder erneuerbar* Energien* durch die GRÜNEN konstant überdurchschnittlich hoch (Abbildung 8 und Abbildung 9). ${ }^{9}$

Abbildung 8: Verteilung relativer Häufigkeiten von erneuerbar* Energie* über Parteien und Legislaturperioden (Reihenfolge der Beschriftung entspricht Balkenreihenfolge)

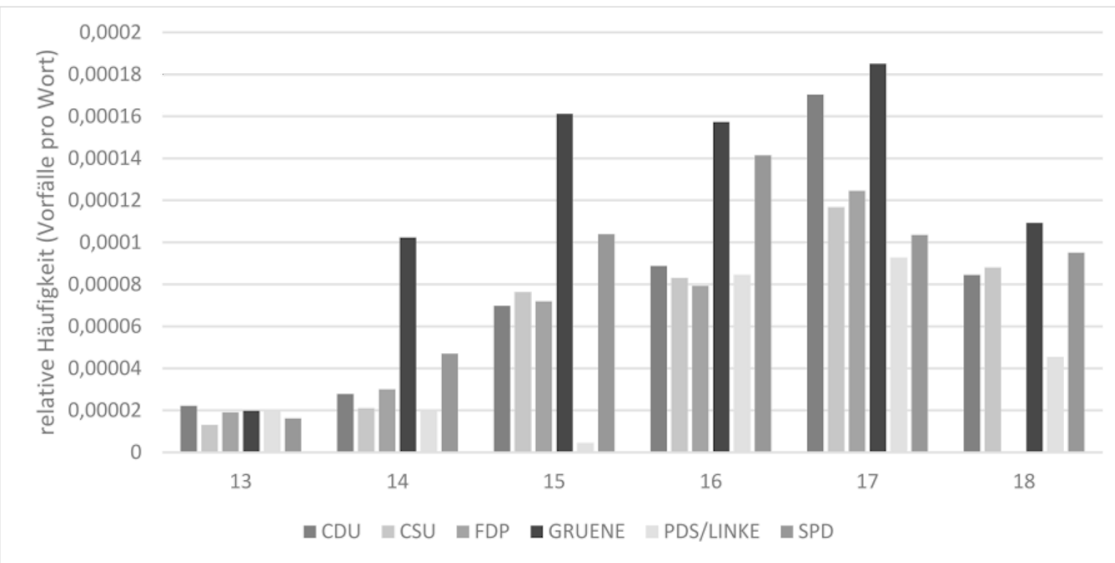

Quelle: eigene Darstellung

9 Auf eine Darstellung der relativen Häufigkeit von Atomausstieg* nach Fraktionen wird an dieser Stelle aufgrund der geringen absoluten Häufigkeit von Atomausstieg* verzichtet. Dies wäre grafisch schwer darstellbar. Die Involvierung der einzelnen Fraktionen in den Diskurs um Atomausstieg* wird aber im nächsten Unterkapitel 5.1.2 noch betrachtet. 
Abbildung 9: Verteilung relativer Häufigkeiten von Klimaschutz* über Parteien und Legislaturperioden (Reihenfolge der Beschriftung entspricht Balkenreihenfolge)

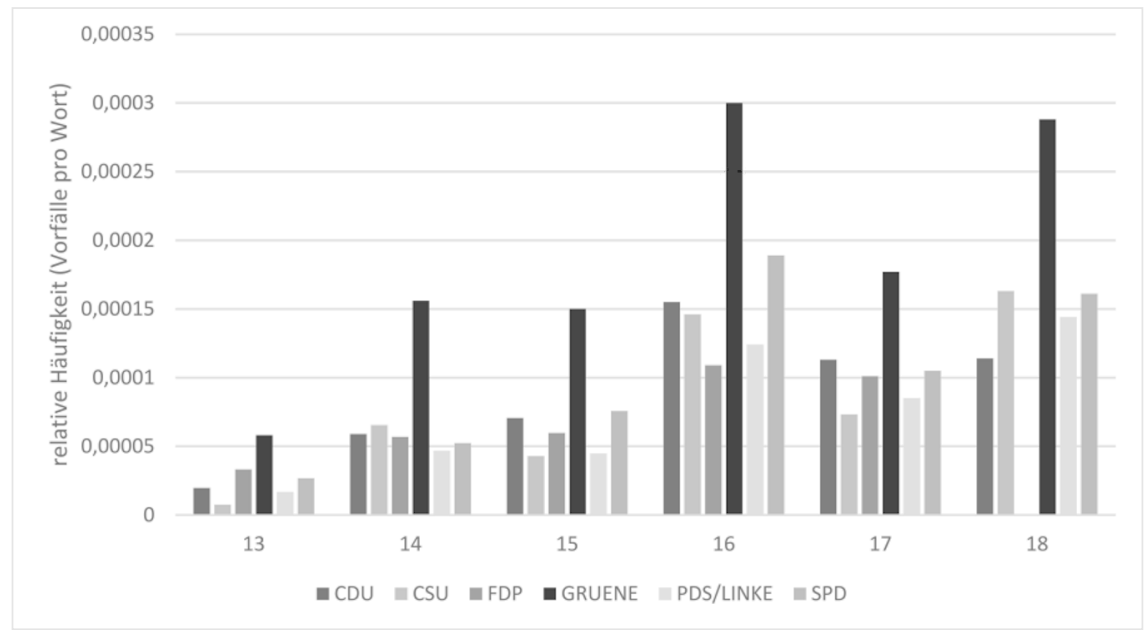

Quelle: eigene Darstellung

Die GRÜNEN scheinen die Diskurse um erneuerbare Energien und Klimaschutz stark zu initiieren, jedoch nicht zwingend mit „Energiewende“ zu verbinden. Auch die SPD greift „Energiewende“ erst ab „Fukushima“ verstärkt auf, involviert sich dann aber relativ häufig. Im Gegensatz zu „Energiewende“ scheint die Beteiligung an der Bedeutungsgenerierung von erneuerbaren Energien bereits vor „Fukushima“ über alle Fraktionen stetig zuzunehmen. In der 16. Legislaturperiode zeigen sich die relativ häufigsten Nennungen von „Energiewende*“ im Vergleich zwischen allen Fraktionen durch die LINKE, die neu im Bundestag vertreten ist (die PDS ist in der 15. Legislaturperiode nicht im Bundestag vertreten, bzw. nur mit Direktmandaten). Nach „Fukushima“ bleibt die relative Häufigkeit der Nennungen durch die LINKE aber annähernd konstant, „Energiewende“ scheint als Oppositionsthema für die LINKE im Vergleich zu den GRÜNEN nun weniger relevant. Die relativ seltensten Nennungen von „Energiewende“ zeigen sich bei der FDP, wobei diese in der 18. Legislaturperiode nicht im Bundestag vertreten ist.

Aus der relativen Häufigkeit der Nennungen von „Energiewende“ durch die einzelnen Fraktionen lässt sich allerdings noch nicht schließen, in welcher Art und Weise - bspw. positiv oder negativ - sich diese auf „Energiewende“ beziehen. Die Assoziations-, bzw. Äquivalenzbeziehungen ${ }^{10}$ und ihre Qualität werden im folgenden Kapitel genauer betrachtet.

10 Die Begriffe Assoziations- und Äquivalenzbeziehung werden synonym verwendet. 


\subsubsection{Kollokations- und Konkordanzanalyse von der 14. bis zur 18. Legislaturperiode}

Um genauere Aussagen über die Regeln des Diskurses um „Energiewende“ - also über regelmäßige Assoziations-, bzw. Äquivalenzbeziehungen von „Energiewende“ - treffen zu können, werden im Folgenden mit Hilfe einer Kollokationsanalyse diskursive Muster, zunächst im direkten Kontext von „Energiewende*“, über die einzelnen Legislaturperioden herausgearbeitet (vgl. Kapitel 4.2.1). Dadurch kann gezeigt werden, welche Kollokationen, die ich im Folgenden - wie in Kapitel 4.2 dargelegt - im Anschluss an Laclau/Mouffe (2015) als Knotenpunkte bezeichne, sich um den Schlüsselpunkt „Energiewende*“ herum bilden, in welche Äquivalenzketten sich also „Energiewende*“ einreiht und welche Elemente in der Bedeutungsgenerierung von „Energiewende“ temporär fixiert wurden. Zum Vergleich wird eine Kollokationsanalyse der Schlüsselpunkte ,erneuerbar* Energien“ und ,Atomausstieg*“ herangezogen. Diese spielen eine besondere Rolle für den Diskurs um „Energiewende*“, da sie häufig mit dieser in Verbindung stehen. ${ }^{11}$ Der Atomausstieg hat zudem auch eine historische Verbindung zur „Energiewende“, wie in Kapitel 1 gezeigt wurde. Die Bedeutung der Reaktorkatastrophe von „Fukushima“ für den Diskurs um „Energiewende“ hat sich bereits im vorigen Kapitel abgezeichnet.

\section{Legislaturperiode}

Tabelle 6: Rahmendaten der 14. Legislaturperiode

\begin{tabular}{|c|c|c|c|}
\hline $\begin{array}{c}\text { Erste und letzte Sitzung } \\
\text { der Legislaturperiode } \\
\text { im Bundestag }\end{array}$ & $\begin{array}{c}\text { Anzahl der } \\
\text { Sitzungen }\end{array}$ & $\begin{array}{c}\text { Regierungs- } \\
\text { koalition }\end{array}$ & $\begin{array}{c}\text { Bundes- } \\
\text { kanzler*in }\end{array}$ \\
\hline $26.10 .1998-16.10 .2002$ & 253 & $\begin{array}{c}\text { SPD/ BÜNDNIS } \\
\text { 90/DIE GRÜNEN }\end{array}$ & Gerhard Schröder \\
\hline
\end{tabular}

Quelle: eigene Darstellung

Insgesamt wird in der 14. Legislaturperiode $97 \mathrm{Mal}$ von „Energiewende*“ gesprochen. Aufgrund der geringen Anzahl an Nennungen von „Energiewende*“ lässt sich lediglich eine Kollokation (eingeleitet s.u.) identifizieren, die mindestens 5 Mal mit „Energiewende*“" auftaucht und deren Aussagefähigkeit somit als gesichert gelten kann (Baker 2016: 151). Um dennoch ein Bild über die Assoziations-, bzw. Äquivalenzbeziehungen von „Energiewende*“ zu erhalten setze ich - wie in Kapitel 4.2.1 erläutert - die minimale Häufigkeit für das Auftreten einer Kollokation in der 14. bis 16. Legislaturperiode auf 2 herab $(\min$ freq $=2) .{ }^{12}$ Es ist dennoch aufschlussreich die

11 Diese Erkenntnis ergab sich auch aus einer ersten Kollokationsanalyse.

12 Für die Kollokationsanalyse von Atomausstieg* gilt dieses Vorgehen für den gesamten Betrachtungszeitraum (14.-18. Legislaturperiode), während in der Kollokationsanalyse von 
Äquivalenzbeziehungen von „Energiewende“ in diesen Legislaturperioden zu betrachten, um zu sehen mit welchen Themen, bzw. Elementen, „Energiewende*“ auch wenn im Verhältnis zu aktuelleren Legislaturperioden selten von ihr gesprochen wird - in Verbindung gebracht wird. Allerdings müssen diese Assoziations-, bzw. Äquivalenzbeziehungen als brüchig angesehen werden. „Energiewende*“ wird also insgesamt nur schwach mit Bedeutung aufgeladen. An dieser - wenn auch schwachen - Bedeutungsaufladung beteiligen sich in der 14. Legislaturperiode überwiegend SPD (38 Vorfälle) und GRÜNE (42 Vorfälle), die anderen Fraktionen sprechen kaum von „Energiewende*“ (CDU: 8 Vorfälle, CSU: 0, FDP: 2 Vorfälle, PDS: 7 Vorfälle). Unter den genannten Bedingungen ergeben sich 13 Kollokationen, die in Tabelle 7 auf Grundlage einer Konkordanzanalyse thematisch gruppiert ${ }^{13}$ dargestellt sind.

Tabelle 7: Thematisch gruppierte 13 Kollokationen von „Energiewende*“ in der 14. Legislaturperiode

\begin{tabular}{|l|l|}
\hline Thematische Gruppierung & $\begin{array}{l}\text { Kollokationen (=Knotenpunkte) } \\
\left.\text { (freq/log likelihood }{ }^{14}\right)\end{array}$ \\
\hline Einstieg/Ausstieg & $\begin{array}{l}\text { eingeleitet }(8 / 88,66), \text { einzuleiten }(3 / 35,09), \text { Ein- } \\
\text { stieg }(4 / 38,88), \text { Atomausstieg }(2 / 20,74), \text { Ausstieg } \\
(3 / 25,71), \text { Weg }(4 / 17,67), \text { neue }(3 / 11,5), \text { beschwo- } \\
\text { rene }(2 / 26,43)\end{array}$ \\
\hline Umweltpolitische Themen & $\begin{array}{l}\text { Klimaschutz }(4 / 36,85), \text { Klimaschutzes }(2 / 23,12), \\
\text { Naturschutz }(3 / 22,69)\end{array}$ \\
\hline erneuerbare Energien & Energien $(3 / 22,84)$ \\
\hline Zeit & Zukunft $(3 / 12,04)$ \\
\hline
\end{tabular}

Quelle: eigene Darstellung

Wie in Kapitel 4.2.1 beschrieben sind Kollokationen von „Energiewende*“ Wörter, die überzufällig häufig im Kontext von „Energiewende*““ auftreten, während in der Konkordanzanalyse der Kontext dieses Auftretens qualitativ betrachtet wird.

erneuerbar* aufgrund der hohen Häufigkeit von Anfang an das Minimum von 5 gemeinsamen Vorfällen eingehalten werden kann.

13 Die Sinnhaftigkeit der thematischen Gruppierung der Kollokationen ergibt sich ausschließlich aus den Kontexten der Kollokationen, d.h. aus der Konkordanzanalyse - die Zuordnung erschließt sich daher auch in den folgenden Legislaturperioden nicht in jedem Fall auf den ersten Blick.

14 Wie in Kapitel 4.2.1 erläutert, bezieht sich freq hier auf die absolute Häufigkeit des Auftretens einer Kollokation. Der zweite Wert gibt den log-likelihood Wert an, wobei deutlich wird, dass alle angegebenen Werte deutlich über dem kritischen Wert von 10,83 (also p < $0,001)$ liegen und somit mit nahezu $100 \%$ iger Wahrscheinlichkeit nicht zufällig auftreten. 
Einstieg und Ausstieg zeigen sich auf Grundlage der Kollokationsanalyse als zentrale Themen im Kontext von „Energiewende*“ in der 14.Legislaturperiode. Atomausstieg* kommt mit 259 Vorfällen in den Bundestagsdebatten der 14. Legislaturperiode insgesamt deutlich häufiger vor als „Energiewende*“ (97 Vorfälle), allerdings wird eine direkte Beziehung zwischen Atomausstieg und „Energiewende*“ dennoch eher selten hergestellt (2 gemeinsame Vorfälle für „Atomausstieg ${ }^{15 ،,} 3$ gemeinsame Vorfälle für „Ausstieg“). Deutliche Aussagen wie die Folgende sind eher selten zu finden: „Aus unserer Sicht gibt es keinen Ausstieg ohne eine Energiewende und ohne ein Klimaschutzkonzept; es gibt aber auch keine Energiewende ohne einen Ausstieg, und es gibt keinen Klimaschutz ohne Energiewende" (GRÜNE ${ }^{16} 25.11$. 1999: $\left.6746^{17}\right)$.

Die Knotenpunkte um „Energiewende*““ werden in ihrem Kontext mit weiteren Forderungen ${ }^{18}$ äquivalenziert, d.h. die „Energiewende“ soll mit anderen politischen Zielen und Programmatiken Hand in Hand gehen. So spricht die Regierungskoalition beispielsweise davon, die „Energiewende“ über die „marktwirtschaftliche Lösung“ „einzuleiten“ (SPD 13.10.2000: 12027). Als Ziel der „Energiewende“ sollen „neue“ Arbeitsplätze geschaffen werden (z.B.: GRÜNE 06.05.1999: 3345; SPD 16.05.2002: 23504) und in „Zukunft“ Kosten durch reduzierte Ölimporte eingespart werden (,Was wir nicht an Öl verbrauchen, müssen wir auch nicht bezahlen“ (SPD 13.10. 2000: 12027)).

Umweltpolitische Assoziationen werden hauptsächlich von den GRÜNEN gesetzt, die Kollokationen aus diesem Bereich gehen ausschließlich auf ihre Fraktion zurück.

Das Konfliktive im von der rot-grünen Bundesregierung initiierten Diskurs um „Energiewende“ wird von den anderen Fraktionen nur selten herausgearbeitet, was an den wenigen Vorfällen von „Energiewende*“ durch andere Fraktionen deutlich

15 Kollokationen/Knotenpunkte setze ich im Folgenden in doppelte Anführungszeichen, um sie im Fließtext erkennbar zu machen. Innerhalb eines Zitats setze ich sie in einfache Anführungszeichen.

16 Im Folgenden zitiere ich die Bundestagsreden nach Fraktionszugehörigkeit und verzichte auf die Nennung des Namens der*s jeweiligen Sprecher*in. Dabei ist zu beachten, dass innerhalb der Fraktionen durchaus verschiedene Meinungen vorherrschen, Fraktionen also nicht als homogene Konstrukte zu betrachten sind. Jedoch sprechen meist diejenigen Bundestagsmitglieder der Fraktionen, die in ihren Reden die Standpunkte der Fraktion vertreten - häufig sind dies die thematischen Sprecher*innen der Fraktion, z.B. energiepolitische Sprecher*innen. Es kommen aber auch abweichende Positionen zu Wort. Im Verlauf der Arbeit zeigt sich, dass von einzelnen Fraktionen artikulierte Positionen häufig ambivalent sind.

17 Bundestagsprotokolle werden im Folgenden stets mit Datum und Seitenzahl zitiert. Auf die Nennung der Protokollnummer verzichte ich aus Gründen der Übersichtlichkeit, zumal die Protokolle über die Datumsangabe exakt zugeordnet werden können. Ich verzichte bei der Zitation von Bundestagsdebatten zudem bei Wiederholungen auf die Bezeichnung (ebenda), um die Sichtbarkeit der zitierten Fraktion sowie des Datums zu erhalten.

18 Wie in Kapitel 4.2.1 ausgeführt, verwende ich hier den Begriff der ,Forderung' für die Elemente eines Diskurses (Laclau 2005: 74ff.). 
wird. Die PDS bestreitet ein ernsthaftes Interesse der Regierungskoalition an der „Energiewende“: Die Koalition habe nicht die „Energiewende ,eingeleitet““, sie habe sie vielmehr ,Zu Grabe getragen“ (PDS 25.01.2002: 21143). Die CDU stellt den Anspruch der Regierungskoalition, eine „Energiewende“ einzuleiten, mehrfach in Frage: „Die ,beschworene“ Energiewende, die heute Mittag gerade wieder eine Rolle gespielt hat, findet nicht statt“ (CDU 27.06.2002: 24770). Darüber hinaus äußert sie sich faktisch kaum zu einer möglichen „Energiewende“.

Während die Bedeutungsaufladung von „Energiewende“ in den Parlamentsdebatten der 14. Legislaturperiode schwach und die Äquivalenzkette in der Folge brüchig ist, zeigen sich Artikulationen um erneuerbare Energien deutlich häufiger (1010 Vorfälle von erneuerbar*). Die Forderung ${ }^{19}$,erneuerbare Energien“ wird dabei - wenn auch in unterschiedlichem Ausmaß - von allen Fraktionen geteilt (vgl. auch Abbildung 8). Im Gegensatz zu den Artikulationen um „Energiewende“ (diese wird von der CSU nicht adressiert) sind daher an der Artikulation erneuerbarer Energien alle Fraktionen beteiligt. Bei einer Betrachtung der nach Höhe des Signifikanzwertes (log likelihood) geordneten rangersten 40 Kollokationen ( $\min$ freq $=5$ ) von erneuerbar* in ihrem Kontext (Konkordanzanalyse), konnten diese den Themenbereichen Technologien, Marktorientierung, Förderung/Ausbau, Energieverbrauch und Energieerzeugung, Gesetze sowie Rolle in der Welt zuordnen werden (vgl. Tabelle 8).

In den Äquivalenzbeziehungen von erneuerbar* scheint es demnach weniger um einen grundsätzlichen Wandel in der Energiepolitik als um die „Markteinführung“ von „Technologien“ zu gehen, die überwiegend mit der Einführung des EEG im Jahr 2000 in Verbindung gebracht wird. Darüber hinaus geht es um technologische und ökonomische Aspekte von „Energieerzeugung“ und Energieverbrauch, z.B. im Sinne von „Energieeinsparung“. Auch wenn davon auszugehen ist, dass alleine die Forderung nach Einführung ,erneuerbarer Energien“ einen gewissen Wandel in der Energiepolitik adressiert, so bleibt eine Assoziation erneuerbarer Energien mit einem grundsätzlichen Wandel aus. Forderungen, die sich auf eine verfahrenspolitische Ebene beziehen und marktwirtschaftlich sowie technologisch orientiert sind, kommen deutlich häufiger vor (,Förderprogramm“, „Markteinführung“, „Technologien“ etc.) als Forderungen, die sich auf langfristige Ziele einer solchen Politik beziehen. Ein relativ häufig genanntes Ziel ist die Stärkung der deutschen Wettbewerbsfähigkeit: „Damit haben wir nach dem Gesetz zur ,Förderung' der erneuerbaren Energien ,weltweit" das beste Gesetz, das es auf dem Markt gibt“ (GRÜNE 12.10.2001: 18906). „Deutsche Anbieter verfügen über ,weltweit‘ führende ,Technologien“ zur Nutzung erneuerbarer Energien“ (SPD 28.02.2002: 21986). Die „Energiewende“ als konkretes Ziel der Einführung erneuerbarer Energien spielt dagegen eher eine untergeordnete Rolle (z.B. SPD 22.03.2002: 22603). Dies zeigt sich auch dadurch, dass „Energiewende“ unter den Kollokationen von erneuerbar* mit nur 2 gemeinsamen Vorfällen nicht als relevante Kollokation einzuordnen ist. ${ }^{20} \mathrm{Zu}$ umweltpolitischen

19 Analog Fußnote 18 in diesem Kapitel.

20 Obwohl die Kollokationsanalyse von „Energiewende*“ zeigt, dass „Energiewende“ mit erneuerbaren Energien assoziiert wird, handelt es sich dabei offensichtlich um eine asymmetrische Äquivalenzbeziehung, da erneuerbare Energien umgekehrt relativ selten mit „Energiewende" in Verbindung gebracht werden. 
Zielen wie Naturschutz oder Klimaschutz kann in der Kollokationsanalyse ebenfalls nur eine vergleichsweise schwache Äquivalenzbeziehung identifiziert werden. ${ }^{21}$

Tabelle 8: Thematisch gruppierte rangerste 40 Kollokationen von erneuerbar $* 22$ in der 14. Legislaturperiode

\begin{tabular}{|c|c|}
\hline Thematische Gruppierung & $\begin{array}{l}\text { Kollokationen (=Knotenpunkte) } \\
\text { (freq/log likelihood) }\end{array}$ \\
\hline Technologien & $\begin{array}{l}\text { Energien }(805 / 11594,11), \text { Energie }(17 / 123,84), \\
\text { Kraft-Wärme-Kopplung }(25 / 244,43), \text { Energieträ- } \\
\text { ger }(17 / 186,48 \text {, Energieträgern }(6 / 67,11), \text { Ener- } \\
\text { giequellen }(12 / 153,08), \text { Technologien }(11 / 87,33) \text {, } \\
\text { Solarenergie }(6 / 63,26), \text { Wind }(6 / 49,39), \text { Bereich } \\
(44 / 201,23), \text { Biomasse }(5 / 45,44)\end{array}$ \\
\hline Marktorientierung & $\begin{array}{l}\text { Markteinführung }(15 / 184,69), \text { Marktanreizpro- } \\
\text { gramm }(12 / 159,79)\end{array}$ \\
\hline Förderung/Ausbau & $\begin{array}{l}\text { Förderung }(136 / 1195,55), \text { Ausbau }(38 / 328,11) \text {, } \\
\text { Anteil }(41 / 310,5), \text { Anteils }(19 / 222,69), \text { Verdopp- } \\
\text { lung }(18 / 188,46), \text { fördern }(22 / 145,04), \text { Förderpro- } \\
\text { gramm }(12 / 135,59), \text { Förderprogramme }(5 / 45,92) \text {, } \\
\text { Programm }(11 / 48,42) \text {, verdoppeln }(9 / 81,11) \text {, am- } \\
\text { bitionierteste }(5 / 72,71), 1000 \text {-Dächer-Programm } \\
(7 / 70,29), \text { Millionen }(22 / 64,41), \text { Durchbruch }\end{array}$ \\
\hline Energieverbrauch & $\begin{array}{l}\text { Energieeffizienz }(17 / 191,36), \text { Energiesparen } \\
(6 / 67,65), \text { Energieeinsparung }(11 / 116,9), \text { Nutzung } \\
(28 / 228,12)\end{array}$ \\
\hline Energieerzeugung & $\begin{array}{l}\text { Energieerzeugung }(5 / 47,86), \text { Strom }(18 / 152,36) \text {, } \\
\text { Einsatzes }(6 / 47,53) \text {, Stromerzeugung }(22 / 262,33)\end{array}$ \\
\hline
\end{tabular}

21 Klimaschutz kommt in der 14. Legislaturperiode nur 4 Mal gemeinsam mit erneuerbar* vor und ist daher trotz des immer noch hohen Signifikanzwertes eine wenig aussagefähige Kollokation ( $\log$ likelihood $=19,26)$. Naturschutz ist keine Signifkante Kollokation von erneuerbar*.

22 erneuerbar* wird hier aus technischen Gründen isoliert, d.h. nicht in Form der Buchstabenfolge ,erneuerbar* Energie*‘, betrachtet, da dies in der Kollokationsanalyse nicht möglich ist. In mindestens 10.104 von 10.960 Vorfällen über den gesamten Betrachtungszeitraum bezieht sich erneuerbar* jedoch direkt auf Energie*, was durch eine Kontextsuche festgestellt werden konnte. In den meisten der übrigen Vorfälle besteht zudem ein indirekter Bezug auf Energie, indem bspw. von ,erneuerbaren Technologien“ oder ,Strom aus erneuerbaren Quellen` die Rede ist. Daher ist diese Vorgehensweise als aussagekräftig einzuschätzen. 


\begin{tabular}{|l|l|}
\hline Gesetze & $\begin{array}{l}\text { Gesetz }(35 / 152,2), \text { Stromeinspeisungsgesetz } \\
(6 / 58,14), \text { Ökosteuer }(13 / 49,22), \text { Stromsteuer } \\
(5 / 44,8)\end{array}$ \\
\hline Rolle in der Welt & Weltweit $(10 / 59,37)$ \\
\hline
\end{tabular}

Quelle: eigene Darstellung

Auch gemeinsam mit Atomausstieg* (vgl. Tabelle 9) wird ein energiepolitischer Wandel eher selten adressiert. ${ }^{23}$ Die Debatten fokussieren überwiegend auf den Energieträger Atomenergie - die Nutzung anderer fossiler Energieträger wie Kohle oder der Energieverbrauch werden gemeinsam mit Atomausstieg* nicht herausgefordert. Diese fehlende Kontextualisierung von Atomausstieg mit einer anderen Energiepolitik wird von der Opposition kritisiert: „Die Bundesregierung hat kein umweltpolitisches ,Gesamtkonzept ${ }^{`}$. Sie hat den Atomausstieg vereinbart, jedoch keine alternative Energiepolitik“ (CDU 14.09.2000: 11360).

In der Frage des Klimaschutzes geht es in Zusammenhang mit dem Atomausstieg* zunächst darum, ob diese überhaupt „,vereinbar“ seien, was von der CDU bestritten wird. Es handelt sich beim Knotenpunkt „Klimaschutz“ also um eine flottierende Forderung (vgl. Kapitel 4.2.1), der sowohl positiv mit Atomausstieg* äquivalenziert wird (v.a. von der rot-grünen Regierungskoalition), als auch in einem Widerspruch gesehen wird und somit Teil des Diskurses gegen den Atomausstieg* ist.

Bereits anhand der Beteiligung der Fraktionen an den Debatten wird deutlich, dass sie alle dem Atomausstieg* eine Relevanz zuweisen (CDU: 64 Vorfälle, CSU: 30 Vorfälle, FDP: 27 Vorfälle, PDS: 45 Vorfälle, SPD: 21 Vorfälle, GRUENE: 72 Vorfälle). Die starke Umkämpftheit des Themas zeigt sich vor allem an den zahlreichen Knotenpunkten, die den Atomausstieg*, wie er von der rot-grünen Bundesregierung konzeptualisiert wird, herausfordern: So sprechen sowohl CDU (z.B. 14.09.2000: 11356), FDP (z.B. 30.11.2000: 13407), als auch PDS (21.06.2001: 17269) mehrfach vom so ,genannten“ oder von einem „,,vermeintlichen“ Atomausstieg, der irgendwie nicht so recht stattzufinden scheint“" (CDU 06.04.2000: 9169). Die CDU fürchtet, dass ,,sich durch Ihre Politik des ,übereilten“ Atomausstiegs die Strompreise erhöhen“ (CDU 16.12.1999: 7267). Die PDS kritisiert dagegen den rotgrünen Atomkonsens: „Wo ist die Umsetzung der Forderung nach dem ,sofortigen“ Atomausstieg geblieben? Was auf dem Tisch liegt, ist eine Vereinbarung mit der Atomlobby“ (PDS 29.03.2001: 15718). Die GRÜNEN erklären, man werde notfalls „den Atomausstieg dann auch im ,Dissens“ durchziehen“ (GRÜNE 07.10.1999: 5446).

23 Wobei die Aussagefähigkeit der identifizierten Knotenpunkte aufgrund ihrer geringen Häufigkeit hier wiederum - analog zu den Knotenpunkten um „Energiewende ${ }^{* “}$ - gering ist $($ min freq $=2)$. Insgesamt ergeben sich unter den genannten Bedingungen 34 Kollokationen. 
Tabelle 9: Thematisch gruppierte 34 Kollokationen von Atomausstieg* in der 14. Legislaturperiode

\begin{tabular}{|c|c|}
\hline Thematische Gruppierung & $\begin{array}{l}\text { Kollokationen (=Knotenpunkte) } \\
\text { (freq/log likelihood) }\end{array}$ \\
\hline Allgemein & $\begin{array}{l}\text { Atomausstieg }{ }^{24}(4 / 39,17), \text { Ziel }(6 / 24,87), \text { Forde- } \\
\text { rung }(3 / 14,49), \text { Frage }(9 / 20,87), \text { Sachen }(3 / 20,61) \text {, } \\
\text { Konzentration }(2 / 16,7)\end{array}$ \\
\hline Dissens & $\begin{array}{l}\text { (so) genannten }(7 / 44,26) \text {, siehe }(4 / 41,49) \text {, ver- } \\
\text { meintlichen }(3 / 33,24) \text {, Debatte }(6 / 19,9) \text {, Dissens } \\
(2 / 18,45) \text {, schwieriger }(3 / 31,1) \text {, rückgängig } \\
(2 / 15,67) \text {, ernst }(3 / 13,16) \text {, angeblich }(2 / 12,58)\end{array}$ \\
\hline Umweltpolitische Themen & $\begin{array}{l}\text { Klimaschutz }(10 / 90,8) \text {, vereinbar }(3 / 28,75), \text { Um- } \\
\text { weltpolitik }(2 / 11,96)\end{array}$ \\
\hline $\begin{array}{l}\text { Energiepolitisches Gesamt- } \\
\text { konzept }\end{array}$ & $\begin{array}{l}\text { Energiewende }(3 / 32,15), \text { Gesamtkonzept } \\
(2 / 14,93)\end{array}$ \\
\hline Akteur*innen & $\begin{array}{l}\text { Bundesumweltminister }(2 / 17,87) \text {, Energiewirt- } \\
\text { schaft }(2 / 17,59) \text {, Bundesregierung }(8 / 12,43) \text {, rot- } \\
\text { grünen }(4 / 26,65)\end{array}$ \\
\hline Gesetze & $\begin{array}{l}\text { Ökosteuer }(17 / 114,84), \text { Entwurf }(3 / 12,24), \text { Lesung } \\
(2 / 11,54)\end{array}$ \\
\hline Zeitraum & $\begin{array}{l}\text { sofortigen }(5 / 61,29) \text {, übereilten }(2 / 28,47) \text {, schnel- } \\
\text { len }(2 / 17,43) \text {, Jahren }(6 / 13,2)\end{array}$ \\
\hline umsetzen & bewerkstelligen $(2 / 20,59)$, stattfinden $(2 / 12,28)$ \\
\hline Rolle in der Welt & international $(2 / 10,88)$ \\
\hline
\end{tabular}

Quelle: eigene Darstellung

24 Bei der Kollokationsanalyse kommt es vor, dass im Kontext eines Schlüsselpunktes (wie hier Atomausstieg) der Schlüsselpunkt selbst als Knotenpunkt auftaucht - es also zu zwei Vorfällen innerhalb des Betrachteten Kontextes kommt. Diese Fälle beziehe ich im Folgenden der Vollständigkeit halber mit ein, auch wenn ihre Aussagefähigkeit für den Schlüsselpunkt eher gering ist. 


\section{Legislaturperiode}

Tabelle 10: Rahmendaten der 15. Legislaturperiode

\begin{tabular}{|c|c|c|c|}
\hline $\begin{array}{c}\text { Erste und letzte Sitzung } \\
\text { der Legislaturperiode } \\
\text { im Bundestag }\end{array}$ & $\begin{array}{c}\text { Anzahl der } \\
\text { Sitzungen }\end{array}$ & $\begin{array}{c}\text { Regierungs- } \\
\text { koalition }\end{array}$ & $\begin{array}{c}\text { Bundes- } \\
\text { kanzler*in }\end{array}$ \\
\hline $17.10 .2002-17.10 .2005$ & 187 & $\begin{array}{c}\text { SPD/ BÜNDNIS } \\
\text { 90/DIE GRÜNEN }\end{array}$ & Gerhard Schröder \\
\hline
\end{tabular}

Quelle: eigene Darstellung

In der 15. Legislaturperiode nimmt die Anzahl der Nennungen von „Energiewende*“ deutlich ab (37 Vorfälle). Die relative Häufigkeit von „Energiewende*“، die aufgrund der differenzierenden Anzahl an Bundestagssitzungen einen besseren Vergleich mit der vorigen Legislaturperiode erlaubt, reduziert sich auf etwas mehr als die Hälfte (von 0,005 Vorfällen pro tausend Wörter auf 0,0029). Auch die rot-grüne Bundesregierung beteiligt sich kaum noch an der Bedeutungsgenerierung, obwohl sie weiterhin Initiatorin des Diskurses ist (GRÜNE: 14 Vorfälle, SPD: 20, CDU: 2, CSU: 0, FDP: 1). Die ohnehin schon schwache Bedeutungsaufladung reduziert sich weiter, „Energiewende*“ wird kaum noch in Äquivalenzbeziehungen gebracht. Es lassen sich lediglich 9 Kollokationen identifizieren, deren Aussagefähigkeit aufgrund der geringen Häufigkeit der gemeinsamen Nennungen mit „Energiewende*“ wie bereits in der 14. Legislaturperiode begrenzt ist. Sie wurden erneut basierend auf einer Analyse ihres Kontextes (Konkordanzanalyse) thematisch gruppiert (vgl. Tabelle 11).

Tabelle 11: Thematisch gruppierte 9 Kollokationen von „Energiewende*“ in der 15. Legislaturperiode

\begin{tabular}{|l|l|}
\hline Thematische Gruppierung & $\begin{array}{l}\text { Kollokationen (=Knotenpunkte) } \\
\text { (freq/log likelihood) }\end{array}$ \\
\hline Einstieg & eingeleitete $(2 / 31,32)$, eingeleitet $(2 / 20,85)$ \\
\hline Umweltpolitische Themen & Klimaschutz $(2 / 18,57)$ \\
\hline Allgemein & $\begin{array}{l}\text { Effizienz }(2 / 20,89), \text { konsequent }(2 / 18,65), \\
\text { Politik }(3 / 15,79)\end{array}$ \\
\hline Rolle in der Welt & $\begin{array}{l}\text { globale }(5 / 61,78), \text { weltweit }(3 / 28,27), \text { Ziel } \\
(2 / 11,29)\end{array}$ \\
\hline
\end{tabular}

Quelle: eigene Darstellung

25 Im Herbst 2005 kommt es zu vorgezogenen Neuwahlen, da Bundeskanzler Gerhard Schröder im Juli 2005 die Vertrauensfrage stellt, die negativ ausfällt. Die PDS scheitert 2002 an der 5\% Hürde und ist nicht im Bundestag vertreten. 
Die „Energiewende“ gilt für die SPD und die GRÜNEN als „eingeleitet“. Umweltpolitische Themen reduzieren sich auf den in diesem Kontext ausschließlich von den GRÜNEN gesetzten Knotenpunkt „Klimaschutz“. Mit Klimaschutz in Verbindung stehen dabei im Kontext von „Energiewende*“ aber nicht vordergründig klimaschutzpolitische Forderungen, sondern bspw. ein international gedachter Führungsanspruch: „Deutschland ist hier kein Schlusslicht, sondern Spitzenreiter beim ,Klimaschutz', bei der Energiewende und beim Atomausstieg“" (GRÜNE 03.12.2002: 795). „Klimaschutz“ und „Energiewende“ werden demnach zwar in einer (wenn auch brüchigen) Äquivalenzkette artikuliert, aber kaum mit gemeinsamen politischen Forderungen - die über eine Thematisierung der deutschen Rolle in der Welt hinausgehen - verbunden. Daneben spielt erneut „Effizienz“ als Ziel einer „Energiewende“ eine Rolle: „Die Energiewende hin zu mehr ,Effizienz“ und einer Steigerung des Anteils der erneuerbaren Energien ist keine Utopie“ (SPD 13.11.2003: 6425).

Während die Artikulationen von „Energiewende“ in der 15. Legislaturperiode auf nationaler Ebene zunehmend isoliert erscheinen, d.h. erstens kaum vorkommen und zweitens kaum mit weitergehenden politischen Forderungen verbunden werden, wird andererseits die Verantwortung einer „Weltgemeinschaft“ (SPD 10.04.2003: 3337) hervorgehoben: „Wir können es uns global nicht leisten, dass diese Länder - ich sage es einmal so - die gleichen Fehler begehen wie wir. Wir brauchen eine ,globale“ Energiewende. ,Ziel' ist eine ,weltweit" nachhaltige Energieversorgung“ (GRÜNE 02.12.2004: 13417). „Energiewende“ wird also stärker als noch in der 14. Legislaturperiode mit einem globalen Anspruch assoziiert (Kollokationen: „globale“, „weltweit", „Ziel“). Deutschland solle dabei als Vorbild dienen - „mit gutem Beispiel vorangehen. Energiewende - weltweit und bei uns“" (GRÜNE 26.06.2003: 4431).

Während „Energiewende*“ in der 15. Legislaturperiode an Bedeutung verliert, intensiviert sich der Diskurs um erneuerbare Energien (von 1010 auf 1409 Vorfälle, die relative Häufigkeit verdoppelt sich sogar ungefähr von 0,0521 auf 0,110 Vorfälle pro tausend Wörter). Die beiden Diskurse scheinen sich zumindest quantitativ weiter zu entkoppeln. Erneuerbare Energien und „Energiewende*“ treten im zugrunde liegenden Betrachtungsfenster (5R 5L) überhaupt nicht mehr zusammen auf, eine konkrete, als solche bezeichnete „Energiewende“ wird im Kontext erneuerbarer Energien kaum noch diskutiert. Dies wirft die Frage auf, ob hier die umfassende Forderung der „Energiewende“ zu Gunsten einer weniger umfassenden, bzw. untergeordneten, dafür aber breit geteilten Forderung, erneuerbare Energien“ aufgegeben wurde. Dies wird in Kapitel 5.2 (Story-Lines) analysiert.

Betrachtet man die Artikulationen um erneuerbare Energien über die 40 rangersten Kollokationen (vgl. Tabelle 12) in ihrem Kontext (Konkordanzanalyse), wird deutlich, dass sich die Themenbereiche - wie Technologien, Marktorientierung, Förderung/Ausbau, Energieverbrauch, Energieerzeugung sowie Rolle in der Welt zum großen Teil stabilisiert haben - hier konnte Bedeutung scheinbar temporär fixiert werden. ${ }^{26}$ „Klimaschutz“ als Knotenpunkt der Äquivalenzkette um erneuerbare Energien gewinnt darüber hinaus an Bedeutung. Mit der Kollokation „langfristig“ kommt

26 Zumal hier aufgrund der hohen Frequenz von erneuerbar* wie bereits in der 14. Legislaturperiode alle identifizierten Kollokationen aussagefähig sind, da sie eine Häufigkeit gröBer als 5 aufweisen. 
eine zeitliche Perspektive hinzu: „Nur eine Energieversorgung auf Grundlage erneuerbarer Energien ist , langfristig“ nachhaltig und zukunftsfähig“ (SPD 03.12.2002: 790). „Die FDP fordert die Bundesregierung auf, den erneuerbaren Energien endlich eine ,langfristig“ tragfähige Perspektive zu eröffnen“(FDP 13.11.2003: 6415).

Tabelle 12: Thematisch gruppierte rangerste 40 Kollokationen von erneuerbar* in der 15. Legislaturperiode

\begin{tabular}{|c|c|}
\hline Thematische Gruppierung & $\begin{array}{l}\text { Kollokationen (=Knotenpunkte) } \\
\text { (freq/log likelihood) }\end{array}$ \\
\hline Technologien & $\begin{array}{l}\text { Energien }(1113 / 14972,04), \text { Energie }(18 / 132,47), \\
\text { Energieträger }(11 / 104,97), \text { Energieträgern } \\
(5 / 47,99), \text { Energiequellen }(6 / 74,81), \text { Technologien } \\
(18 / 144,99), \text { Bereich }(78 / 389,55), \text { Windenergie } \\
(5 / 36,61)\end{array}$ \\
\hline Marktorientierung & $\begin{array}{l}\text { Marktanreizprogramm }(11 / 140,37), \text { Branche } \\
(9 / 57,32), \text { Exportes }(8 / 53,63), \text { Kosten }(14 / 53,37) \text {, } \\
\text { Strompreis }(5 / 50,71), \text { Wirtschaftlichkeit }(5 / 35,13)\end{array}$ \\
\hline Förderung/Ausbau & $\begin{array}{l}\text { Förderung }(136 / 1123,62), \text { Ausbau }(42 / 331,04) \text {, } \\
\text { Anteil }(55 / 415,18), \text { Anteils }(8 / 79,42), \text { Verdopp- } \\
\text { lung }(11 / 107,67), \text { fördern }(25 / 153,09) \text {, Steigerung } \\
(9 / 53,92) \text {, Einsatz }(13 / 53,09) \text {, Prozent }(27 / 44,69) \text {, } \\
\text { erreichen }(13 / 43,22)\end{array}$ \\
\hline Energieverbrauch & $\begin{array}{l}\text { Energieeffizienz }(27 / 297,24), \text { Energiesparen } \\
(5 / 58,98), \text { Energieeinsparung }(13 / 144,57), \text { Effizi- } \\
\text { enz }(13 / 95,32), \text { Nutzung }(27 / 202,79)\end{array}$ \\
\hline Energieerzeugung & $\begin{array}{l}\text { Strom }(22 / 200,21), \text { Stroms }(5 / 54,46), \text { Energiemix } \\
(9 / 84,27), \text { fossilen }(6 / 52,5), \text { Strombereich } \\
(6 / 69,94), \text { Energieversorgung }(8 / 63,62), \text { Stromer- } \\
\text { zeugung }(7 / 67,87)\end{array}$ \\
\hline Gesetze & Neuregelung $(6 / 35)$ \\
\hline Rolle in der Welt & Entwicklungsländern $(11 / 74,82)$ \\
\hline Umweltpolitische Themen & Klimaschutz $(10 / 56,46)$ \\
\hline Zeit & Langfristig $(7 / 37,39)$ \\
\hline
\end{tabular}

Quelle: eigene Darstellung

In den Artikulationen, die dem Themenbereich ,Marktorientierung' zugewiesen wurden, zeigt sich verstärkt ein internationaler Fokus: z.B. hinsichtlich „der Förderung des ,Exportes' erneuerbarer Energien (GRÜNE 17.02.2005: 14639)“. Verbunden mit 
einer verstärkten Exportorientierung gewinnt der Themenbereich, der die Rolle Deutschlands in der Welt adressiert, an Bedeutung - vor allem in Beziehung zu den sogenannten „Entwicklungsländern“. Dabei werden „Klimaschutz“, Armutsbekämpfung und Exportförderung in eine Äquivalenzbeziehung gebracht:

„eine halbe Milliarde Euro allein dafür in die Hand zu nehmen, dass erneuerbare Energien in den ,Entwicklungsländern` eine Zukunftschance erhalten. So packen wir drei Dinge zusammen: Armutsbekämpfung, Klimaschutz und ein Stück Standortpolitik für eine wachsende Branche in Deutschland“" (GRÜNE 29.10. 2002: 158).

Obwohl erneuerbare Energien weitgehend unabhängig von „Energiewende“ artikuliert werden, verläuft vor allem diese Fokussierung auf eine internationalen Ebene in beiden Kontexten parallel. Eine genauere Analyse hierzu erfolgt in Kapitel 5.2.

Ebenso wie „Energiewende*“ spielt auch Atomausstieg* mit nur noch 57 Vorfällen eine wesentlich geringere Rolle als noch in der 14. Legislaturperiode (259 Vorfälle), die relative Häufigkeit, welche diese Zahlen aufgrund der unterschiedlichen Anzahl an Bundestagssitzungen vergleichbar macht, sinkt auf ein Drittel des Wertes der Vorperiode (von 0,01339 auf 0,0045 Vorfälle pro tausend Wörter). Es lassen sich lediglich 8 Kollokationen mit geringer Aussagefähigkeit $(\mathrm{min}$ freq $=2)$ identifizieren (vgl. Tabelle 13).

Tabelle 13: Thematisch gruppierte 8 Kollokationen von Atomausstieg* in der 15. Legislaturperiode

\begin{tabular}{|l|l|}
\hline Thematische Gruppierung & $\begin{array}{l}\text { Kollokationen } \\
\text { (=Knotenpunkte) (freq/log likelihood) }\end{array}$ \\
\hline Allgemein & Beschlossen $(4 / 25,55)$, eingeleitet $(2 / 19,12)$ \\
\hline Bewertung & verantwortbar $(2 / 24,4)$, richtig $(3 / 13,55)$ \\
\hline $\begin{array}{l}\text { Energiepolitisches Gesamt- } \\
\text { konzept }\end{array}$ & Energien $(2 / 13,6)$, Nutzung $(2 / 16,59)$ \\
\hline Akteur*innen & rot-grüne $(2 / 15)$ \\
\hline Gesetze & Ökosteuer $(2 / 16,42)$ \\
\hline
\end{tabular}

Quelle: eigene Darstellung

„Der Atomausstieg ist gesetzlich ,beschlossen“ und der Fahrplan eindeutig festgelegt“" (SPD 24.09.2004: 11600). Diese Auffassung führt offensichtlich dazu, dass das Thema für nicht mehr so relevant erachtet wird. Außer, dass Atomausstieg* in einer Aufzählung mit erneuerbaren Energien auftaucht, gibt es kaum Überschneidungen zwischen Artikulationen von Atomausstieg* auf der einen, und erneuerbaren „Energien“ oder „Energiewende*“ auf der anderen Seite. Der Bedeutungsverlust von „Energiewende*“ und Atomausstieg* verläuft also in der 15. Legislaturperiode parallel. Die CDU fasst dies folgendermaßen zusammen: „Nachdem aus Ihrer Sicht das 
große Thema Atomausstieg - eigentlich ist es kein Atomausstieg; aber ich übernehme einmal Ihr Vokabular - erledigt ist, kommt nun die große umweltpolitische Leere; deshalb werden Sie nebulös“(CDU 29.10.2002: 167).

\section{Legislaturperiode}

Tabelle 14: Rahmendaten der 16. Legislaturperiode

\begin{tabular}{|c|c|c|c|}
\hline $\begin{array}{c}\text { Erste und letzte Sitzung } \\
\text { der Legislaturperiode } \\
\text { im Bundestag }\end{array}$ & $\begin{array}{c}\text { Anzahl der } \\
\text { Sitzungen }\end{array}$ & $\begin{array}{c}\text { Regierungs- } \\
\text { koalition }\end{array}$ & $\begin{array}{c}\text { Bundes- } \\
\text { kanzler*in }\end{array}$ \\
\hline $18.10 .2005-27.10 .2009$ & 233 & CDU/CSU/SPD & Angela Merkel \\
\hline
\end{tabular}

Quelle: eigene Darstellung

Auch in der 16. Legislaturperiode wird weiterhin selten von „Energiewende*“ gesprochen (62 Vorfälle). Die relative Häufigkeit (0,0034 Vorfälle pro tausend Wörter) nimmt im Vergleich zur 15. Legislaturperiode ( 0,0029 Vorfälle pro tausend Wörter) nur leicht zu. Es ergeben sich 18 Kollokationen (min freq = 2) mit einer aufgrund der geringen Häufigkeit von „Energiewende*“ erneut eingeschränkten Aussagefähigkeit. Allein 7 der 18 Kollokationen gehen auf vier Anträge im Bundestag zurück (vgl. Tabelle 15) und weisen daher eine ungleiche Verteilung über die Legislaturperiode auf.

Auffallend ist, dass sich in der 16. Legislaturperiode die GRÜNEN als vormalige (Mit-)Initiator*innen des „Energiewende“-Diskurses weiter zurückziehen - die Anzahl der absoluten Vorfälle reduziert sich in ihrer Fraktion von 14 auf 10, ihre relative Häufigkeit ungefähr um die Hälfte (von 0,0076 auf 0,004 Vorfälle pro tausend Wörter). Gleichzeitig tritt die $\mathrm{LINKE}^{27}$ als neue Initiatorin auf und bringt sich bedeutungsgebend in den Diskurs ein (24 Vorfälle). Mit einer relativen Häufigkeit von 0,01 Vorfällen pro tausend Wörtern spricht die LINKE in Relation zu ihrer Redezeit damit 2,5 Mal häufiger von „Energiewende*“ als die GRÜNEN und die SPD (rel. freq $=0,0039$ ) zusammen. Aufgrund des Rückzugs aller anderen Fraktionen aus dem Prozess der Bedeutungsgenerierung gelingt es ihr, eigene - wenn auch schwach fixierte - Knotenpunkte zu setzen („ökologische“, „radikalen“, „erneuerbaren“) und andere mitzuprägen („,nachhaltige“, „,konsequent/e“, „Vorschlag“, „Hinblick“). Dadurch artikuliert sie Knotenpunkte gemeinsam mit „Energiewende*“, die zuvor nicht vorkamen.

27 Aus von der Bundesregierung enttäuschten SPD-Mitgliedern und zivilgesellschaftlichen Akteur*innen geht 2005 die Partei Arbeit \& soziale Gerechtigkeit - die Wahlalternative WASG hervor. Bei der Bundestagswahl 2005 erreicht die Linkspartei.PDS als Bündnis mit der WASG 8,7\% der Stimmen. Erst 2007 verschmelzen WASG und Linkspartei.PDS zur neuen Partei DIE LINKE (www.die-linke.de). Zwischen Linkspartei.PDS und LINKE wird aus Gründen der Vereinfachung im Folgenden nicht weiter differenziert. 
Tabelle 15: Thematisch gruppierte 18 Kollokationen von „Energiewende*“ in der 16. Legislaturperiode

\begin{tabular}{|l|l|}
\hline Thematische Gruppierung & $\begin{array}{l}\text { Kollokationen (=Knotenpunkte) } \\
\text { (freq/log likelihood) }\end{array}$ \\
\hline Umweltpolitische Themen & $\begin{array}{l}\text { Klimaschutz }(2 / 12,85), \text { ökologische }(2 / 19,3), \\
\text { Nachhaltigen }(2 / 18,44), \text { nachhaltige }(2 / 15,97)\end{array}$ \\
\hline Allgemein & $\begin{array}{l}\text { konsequent }(2 / 16,25), \text { konsequente }(3 / 54,63), \text { ra- } \\
\text { dikalen }(2 / 28,02), \text { erneuerbaren }(2 / 15,17), \text { Hin- } \\
\text { blick }(2 / 12,85), \text { Vorschlag }(2 / 11,51), \text { Verbündeten } \\
(2 / 23,79)\end{array}$ \\
\hline Anträge ${ }^{28}$ & $\begin{array}{l}\text { Gewächshäusern }(3 / 59,5), \text { Bürgerinnen }(2 / 11,45)- \\
\text { und Bürgerbeteiligung }(3 / 44,22) / \text { umfassend } \\
(3 / 31,99) / \text { berücksichtigen }(3 / 26,17), \text { Energieau- } \\
\text { Benpolitik }(3 / 42,15) / \text { Militarisierung }(3 / 41,37), \\
\text { Atomausstieg }(2 / 23,74)\end{array}$ \\
\hline
\end{tabular}

Quelle: eigene Darstellung

Die LINKE kritisiert die Auffassung der Bundesregierung von Energiepolitik grundsätzlich: „Bezahlbare Energiepreise oder sogar eine ,ökologische“ Energiewende sind eben nicht das Ziel Ihrer Politik“ (LINKE 07.11.2007: 12711). Die Forderung einer „,radikalen“ „Energiewende“ wird als Gegensatz zur bisherigen „Energiewende“ konstruiert - und mit weiteren Forderungen verknüpft, wie „Menschenrechte“ (LINKE 02.07.2009: 25694), „,dem Ende des Krieges um Öl“ (LINKE 21.06.2006: 3591), „einem fairen Ausgleich“ für „Haushalte mit geringem Einkommen“ (LINKE 10.04.2008: 16148) und einer „,nachhaltige[n]“ Versorgung mit Energie“ (LINKE 02.07.2009: 25694). Dagegen blockiere die Atomenergie „eine Energiewende zu ,nachhaltigen“ dezentralen Erzeugungsformen aus Sonne, Wind, Wasser und Biomasse dauerhaft“ (LINKE 26.06.2008: 18375). Daher seien „die insgesamt 43 Milli-

28 Gewächshäusern: Alle drei Vorfälle von Gewächshäusern im Kontext von „Energiewende*“ beziehen sich auf einen Antrag der GRÜNEN aus dem Jahr 2007 „Programm Energiewende in Gewächshäusern auflegen“".

Bürgerinnen- und Bürgerbeteiligung/umfassend/berücksichtigen: Alle drei Vorfälle von Bürgerinnen- und Bürgerbeteiligung, umfassend und berücksichtigen beziehen sich auf einen Antrag der LINKEN aus dem Jahr 2009 mit dem Titel „Stromübertragungsleitungen bedarfsgerecht ausbauen - Bürgerinnen und Bürgerbeteiligung sowie Energiewende umfassend berücksichtigen“.

Energieaußenpolitik/Militarisierung: Alle drei Vorfälle beziehen sich auf einen Antrag der LINKEN aus dem Jahr 2008 mit dem Titel „konsequente Energiewende statt Militarisierung der Energieaußenpolitik“".

Atomausstieg: Beide Vorfälle von Atomausstieg beziehen sich auf einen Antrag der GRÜNEN aus dem Jahr 2009 „Energiewende vorantreiben - Atomausstieg fortsetzen“. 
onen Euro“ an Ausgaben für die Internationale Atomenergiebehörde „kein Ruhmesblatt im Hinblick auf eine, ökologische“ Energiewende“ (LINKE 28.03.2006: 2169).

Die GRÜNEN thematisieren umweltpolitische Themen im Kontext von „Energiewende*“ kaum noch, so sprechen sie im betrachteten Kontext von „Energiewende*“ (5R 5L) auch das Thema „Klimaschutz“ nicht mehr an. Für die SPD lassen sich 2 Vorfälle von „Klimaschutz“ im Zusammenhang mit „Energiewende*“ identifizieren: „Angesichts dieser Probleme kann es keinen Zweifel geben, dass ,Klimaschutz“ und Energiewende Teil, und zwar ein grundlegender Teil, des Weges aus der Krise sein muss“ (SPD 18.12.2008: 21182). Der SPD gehe es bspw. darum, „weltweit“ zu zeigen, dass „ein Energiesystem auch ohne Atomenergie“ möglich sei - „Dies sollte der Weg im Hinblick auf eine ,nachhaltige“ Energiewende sein“ (SPD 19.03.2009: 22757).

Wie bereits in den vorigen Legislaturperioden nehmen die Artikulationen um erneuerbare Energien erneut zu, von 1409 auf 2464 Vorfällen, die relative Häufigkeit steigt im Vergleich zur Vorperiode allerdings nur leicht (von 0,110 Vorfällen pro tausend Wörter auf 0,13). Auf Grundlage der Kollokationsanalyse (min freq $=5$ ) stehen unter den rangersten 40 Kollokationen weiterhin die Themenbereiche Technologien, Marktorientierung, Förderung/Ausbau, Energieverbrauch sowie Energieerzeugung im Mittelpunkt, wobei eine verstärkte Differenzierung zwischen Strom und Wärme auffallend ist und der Wärmebereich als energiepolitisches Handlungsfeld deutlich an Bedeutung gewinnt (vgl. Tabelle 16). Umweltpolitische Themen sind weiterhin nur über „Klimaschutz“ vertreten. Die Rolle Deutschlands in der Welt spielt zwar in der Diskussion einer Internationalen „Agentur“ für Erneuerbare Energien (International Renewable Energy Agency IRENA) weiterhin eine Rolle, die Bedeutung der Entwicklungsländer (Rang 241) sowie des Exportes (Rang 103) innerhalb des Themenbereichs Marktorientierung hat jedoch deutlich abgenommen. Dafür gerät das Thema der Umstellung auf erneuerbare Energien in den Fokus.

Die GRÜNEN sprechen von einer „,vollständigen“ (GRÜNE 08.03.2007: 8584) oder „kompromisslosen“ (GRÜNE 06.07.2007: 11293) „Umstellung“, während die CDU den GRÜNEN vorwirft, sie ignorieren ,wissentlich die natürlichen und ökonomischen Schranken, die einer so weitgehenden Nutzung von erneuerbaren Energien gesetzt sind“ (CDU 16.02.2006: 1388). Ein bis zu einem gewissen Maß begrenzter „Ausbau“ erneuerbarer Energien, der aber nicht zwingend mit einer grundsätzlichen Wende in der Energiepolitik einhergehen muss, wird weiterhin von allen Fraktionen geteilt. Es handelt sich demnach um eine flottierende Forderung (vgl. Kapitel 4.2.1), die sich in einem Spannungsfeld zwischen vollständiger und teilweiser „Umstellung“ der Energieversorgung bewegt. Die CDU beruft sich dabei auf eine Einschätzung des von Sigmar Gabriel (SPD) geführten Umweltministeriums aus 2006, „dass der ,Ausbau“ erneuerbarer Energien bei etwa 25 Prozent des Gesamtenergievolumens erschöpft sein dürfte“ (CDU 16.02.2006: 1388). Der größere diskursive Zusammenhang einer breit geteilten Befürwortung eines (begrenzten) „Ausbaus“ im Spannungsfeld mit einer „Umstellung“ auf erneuerbare Energien bei gleichzeitigem Bedeutungsverlust von „Energiewende“ wird in Kapitel 5.2 (Story-Lines) genauer analysiert. 
Tabelle 16: Thematisch gruppierte rangerste 40 Kollokationen von erneuerbar* in der 16. Legislaturperiode

\begin{tabular}{|c|c|}
\hline Thematische Gruppierung & $\begin{array}{l}\text { Kollokationen (=Knotenpunkte) } \\
\text { (freq/log likelihood) }\end{array}$ \\
\hline Technologien & $\begin{array}{l}\text { Energien }(1950 / 25497,92) \text {, Energie }(39 / 252,98) \text {, } \\
\text { Energiequellen }(9 / 90,06) \text {, Technologien } \\
(24 / 175,45) \text {, Bereich }(150 / 776,17) \text {, Kraft-Wärme- } \\
\text { Kopplung }(18 / 146,26)\end{array}$ \\
\hline Marktorientierung & $\begin{array}{l}\text { Marktanreizprogramm }(15 / 138,8), \text { Wärmemarkt } \\
(12 / 137,21), \text { Branche }(21 / 133,14), \text { Investitionen } \\
(20 / 71,92)\end{array}$ \\
\hline Förderung/Ausbau & $\begin{array}{l}\text { Förderung }(115 / 779,28), \text { Ausbau }(154 / 1346,02) \text {, } \\
\text { ausbauen }(14 / 95,4), \text { Anteil }(166 / 1405,75), \text { setzen } \\
(20 / 72,71) \text {, fördern }(32 / 168,04), \text { Einsatz } \\
(45 / 215,52), \text { Prozent }(111 / 369,89)\end{array}$ \\
\hline Energieverbrauch & $\begin{array}{l}\text { Energieeffizienz }(124 / 1301,74), \text { effiziente } \\
(10 / 74,44), \text { Energieeinsparung }(29 / 308,57), \text { Effi- } \\
\text { zienz }(23 / 168,04), \text { Primärenergieverbrauch } \\
(8 / 95,1)\end{array}$ \\
\hline $\begin{array}{l}\text { Umstellung der Energiever- } \\
\text { sorgung }\end{array}$ & Umstellung $(13 / 91,26)$ \\
\hline Energieerzeugung & $\begin{array}{l}\text { Strom }(58 / 468,13), \text { Stroms }(16 / 176), \text { Nutzung } \\
(78 / 622,66), \text { Energiemix }(10 / 78,5), \text { Strombereich } \\
(14 / 136,39), \text { Stromversorgung }(13 / 123,84), \\
\text { Stromsektor }(8 / 84,49), \text { Energieversorgung } \\
(13 / 81,08), \text { Wärme }(63 / 679,67), \text { Wärmebereich } \\
(28 / 327,06), \text { Wärmesektor }(10 / 118,19), \text { erzeugt } \\
(12 / 88,75), \text { Wärmegesetz }(9 / 84,97), \text { Stromerzeu- } \\
\text { gung }(29 / 281,62)\end{array}$ \\
\hline Rolle in der Welt & Agentur $(11 / 86,86)$ \\
\hline Umweltpolitische Themen & Klimaschutz $(30 / 144,85)$ \\
\hline
\end{tabular}

Quelle: eigene Darstellung

Der Atomausstieg scheint in der 16. Legislaturperiode wieder an Bedeutung zu gewinnen, die relative Häufigkeit der Vorfälle verdoppelt sich $(0,0045$ auf 0,0093 Vorfälle pro tausend Wörter). Im Gegensatz zu „Energiewende*“ beteiligen sich die GRÜNEN an den Artikulationen um Atomausstieg* stärker (50 von 171 Vorfällen gehen auf die GRÜNEN zurück). Auch die SPD greift mit 75 Vorfällen das Thema wieder verstärkt auf, die LINKEN bringen sich mit 21 Vorfällen etwa in gleichem 
Maße ein, wie in die Artikulation von „Energiewende*“ (CDU: 9, CSU: 4, FDP: 12). Atomausstieg* hat in der 16. Legislaturperiode 34 Kollokationen (vgl. Tabelle 17), deren Aussagefähigkeit erneut aufgrund der geringen Häufigkeit der gemeinsamen Nennungen begrenzt ist $(\min$ freq $=2)$.

Tabelle 17: Thematisch gruppierte 34 Kollokationen von Atomausstieg* in der 16. Legislaturperiode

\begin{tabular}{|l|l|}
\hline Thematische Gruppierung & $\begin{array}{l}\text { Kollokationen (=Knotenpunkte) } \\
\text { (freq/log likelihood) }\end{array}$ \\
\hline Allgemein & $\begin{array}{l}\text { Atomkraft }(3 / 28,45), \text { beschlossenen, festgeschrie- } \\
\text { ben }(3 / 27,54), \text { Fortsetzung }(3 / 24,85), \text { Ausstieg } \\
(2 / 16,57), \text { beschlossenen }(3 / 27,92), \text { Frage } \\
(6 / 14,09)\end{array}$ \\
\hline Umweltpolitische Themen & $\begin{array}{l}\text { Klimaschutz }(10 / 76,14), \text { Klimaschutzziele } \\
(2 / 19,8)\end{array}$ \\
\hline Bewertung & $\begin{array}{l}\text { ambitionierter }(3 / 41,52), \text { klar }(6 / 25,72), \text { Mehrheit } \\
(3 / 14,77)\end{array}$ \\
\hline Dissens & $\begin{array}{l}\text { wackeln }(3 / 49,25), \text { rückgängig }(4 / 46,5), \text { Beibehal- } \\
\text { tung }(3 / 31,62), \text { festzuhalten }(3 / 27,96), \text { unumkehr- } \\
\text { bar }(2 / 26,5), \text { gerüttelt }(2 / 26,35), \text { Laufzeitverlänge- } \\
\text { rung }(2 / 25,19), \text { ständig }(3 / 21,9), \text { Vereinbarung } \\
(3 / 16,57), \text { Vereinbarungen }(2 / 14,75), \text { vereinbart } \\
(2 / 11,23), \text { weitergehen }(2 / 14,42), \text { glauben } \\
(2 / 12,73), \text { Ablehnung }(2 / 12,32)\end{array}$ \\
\hline Akteur*innen & $\begin{array}{l}\text { Koalitionsvertrag }(4 / 26,13), \text { Grundgesetz (4/25,9) } \\
\text { erneuerbarer (3/27,12), innovativer }(2 / 23,15), \\
\text { Energiewende }(2 / 23,12), \text { Energien }(4 / 22,72), \text { Koh- } \\
\text { lekraftwerke }(2 / 17,8)\end{array}$ \\
\hline $\begin{array}{l}\text { Energiepolitisches Gesamt- } \\
\text { konzept }\end{array}$ & \begin{tabular}{l} 
SPD-Bundestagsfraktion $(3 / 27,69)$ \\
\hline
\end{tabular} \\
\hline
\end{tabular}

Quelle: eigene Darstellung

Neben einer stärkeren Rolle des „Klimaschutzes“ im Zusammenhang mit Atomausstieg* wird der Atomausstieg auch vermehrt im Kontext einer anderen Energiepolitik artikuliert (hier als energiepolitisches Gesamtkonzept bezeichnet) - zumindest was die Einbeziehung anderer Energieträger in die Debatte angeht (,dass bei einem geplanten Atomausstieg keine zusätzlichen ,Kohlekraftwerke“ benötigt werden“ (LINKE 29.05.2008: 17286)). Daneben erfolgt eine Repolitisierung der Debatte um den Atomausstieg*, hauptsächlich über dessen Sinnhaftigkeit und Ausgestaltung als politische Maßnahme. So kritisieren die LINKEN: „Der ohnehin windelweiche Atomausstieg wird ,ständig“ infrage gestellt“ (LINKE 06.04.2006: 2654). Dagegen argu- 
mentiert die FDP weiterhin gegen einen Atomausstieg: „Mit dem Atomausstiegsgesetz steht Deutschland allein in der Welt“" (FDP 06.04.2006: 2669).

\section{Legislaturperiode}

Tabelle 18: Rahmendaten der 17. Legislaturperiode

\begin{tabular}{|c|c|c|c|}
\hline $\begin{array}{c}\text { Erste und letzte Sitzung } \\
\text { der Legislaturperiode } \\
\text { im Bundestag }\end{array}$ & $\begin{array}{c}\text { Anzahl der } \\
\text { Sitzungen }\end{array}$ & $\begin{array}{c}\text { Regierungs- } \\
\text { koalition }\end{array}$ & $\begin{array}{c}\text { Bundes- } \\
\text { kanzler*in }\end{array}$ \\
\hline $27.10 .2009-22.10 .2013$ & 253 & CDU/CSU/FDP & Angela Merkel \\
\hline
\end{tabular}

Quelle: eigene Darstellung

\section{„Energiewende“}

„Energiewende*“ kommt in der 17. Legislaturperiode 2270 Mal vor und somit - gemessen an der relativen Häufigkeit - über 28,5 Mal so häufig wie noch in der 16. Legislaturperiode (die relative Häufigkeit steigt von 0,0034 auf 0,097 Vorfällen pro tausend Wörter). Die stark dislozierende Wirkung der Reaktorkatastrophe von „Fukushima“ zeigt sich bei der Betrachtung der Anzahl der Nennungen von „Energiewende*“ in einzelnen Plenarsitzungen (Abbildung 10).

Abbildung 10: Verteilung absoluter Häufigkeiten von "Energiewende" in einzelnen Plenarsitzungen der 17. Legislaturperiode

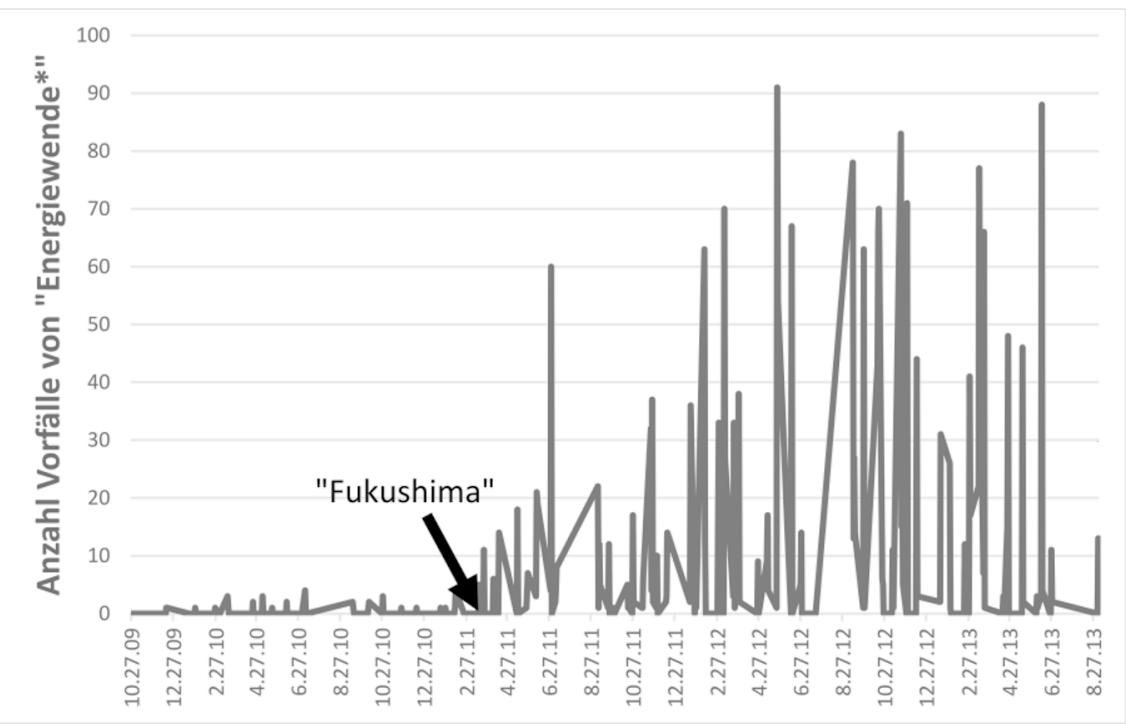

Quelle: eigene Darstellung

Deutlich wird: „Energiewende*“ ist erst seit „Fukushima“ eine breit artikulierte und relevante Forderung im Bundestag. Jetzt beteiligen sich auch CDU, CSU und FDP in 
einem nennenswerten Umfang an der Bedeutungsgenerierung (CDU: 562 Vorfälle, CSU: 192, FDP 239, GRUENE: 467, SPD: 582, LINKE: 225, für einen Vergleich der relativen Häufigkeiten vgl. Abbildung 7).

Auf Grundlage der methodischen Setzungen ergeben sich für „Energiewende*“ in der 17. Legislaturperiode 264 Kollokationen ( $\mathrm{min}$ freq $=2$ ), von denen hier die rangersten 44, die mit einer absoluten Häufigkeit über 5 auftreten, betrachtet werden ( $\min$ freq $=5$ ), also als aussagefähig zu betrachten sind (vgl. Tabelle 19). Vor dem Hintergrund der wesentlichen Erhöhung der Anzahl an Kollokationen lässt sich eine Ausdifferenzierung der Themenbereiche erkennen. Als Themenbereiche hinzu kommen vor allem soziale Themen, (Erfolgs)bedingungen, die Frage nach dem Subjekt und der Initialisierung der „Energiewende*“, Kosten und Herausforderungen. Erstmals lässt sich eine nennenswerte Zahl benannter Handlungsfelder differenzieren.

Während die Häufigkeitsanalyse nahelegt, dass „Energiewende*“ tatsächlich erst nach „Fukushima ${ }^{29 ،} \mathrm{zu}$ einem relevanten Thema wurde, ist die Bedeutung von „Fukushima“ für die „Energiewende“ unter den Fraktionen dennoch umstritten. „Fukushima“ wird so selbst zu einem wichtigen Element der Bedeutungskonstitution von „Energiewende“, da durch das Ereignis die Frage nach dem Zeitpunkt und dem Subjekt der Initialisierung von „Energiewende“ aufgeworfen wird (Kollokationen: „,voranzutreiben“, ,eingeleitet“, „vollzogen“, „,vollziehen“, „,beschlossen“, „Umsetzung"). Dieser Bedeutungskampf entfacht sich hauptsächlich zwischen CDU/CSU, FDP auf der einen und SPD, GRÜNEN auf der anderen Seite. Dabei konstruieren CDU und CSU „Fukushima“ als Initialmoment der „Energiewende“: „Zunächst einmal, finde ich, kann man festhalten, dass die Energiewende eine Reaktion auf die Erfahrung der Nuklearkatastrophe in Fukushima war“ (CDU 19.10.2011: 15576). „Die Energiewende ist die historische Konsequenz aus dem Unfall von - Fukushima“ (CSU 08.03.2012: 19554). SPD und GRÜNE betonen dagegen die Rolle der rotgrünen Regierung als Initiatorin der „Energiewende“: „Herr Rösler, bis Sie dran waren, gab es eine Energiewende“ (SPD 08.02.2012: 18794). „Sie haben die rot-grüne Energiewende nur geerbt“ (GRÜNE 20.11.2012: 25193). Die LINKE hebt dagegen die Bedeutung der sozialen Bewegungen hervor: „Fukushima war eine Zäsur; [...] Aber die Energiewende begann natürlich weit früher, und zwar unter dem Druck der Anti-AKW-Bewegung“ (LINKE 15.03.2013: 28644).

Innerhalb des Bedeutungskampfes um die Initialisierung der „Energiewende“ versuchen vor allem die Regierungsfraktionen diese als „Gemeinschaftswerk“ (z.B. FDP 14.09.2012: 23224), als im „Konsens“ (z.B. CDU 19.10.2011: 15572/ 08.03. 2012: 19548) ,gemeinsam“ (z.B. FDP 08.07.2011: 14275) und ,,auf einer breiten Basis“ (CDU 30.06.2011: 13384) ,beschlossen“ (Kollokation) zu konstituieren und so die vormals oder immer noch bestehenden Konflikte darüber zu verdecken. Konkrete, auf „Energiewende“ bezogene politische Forderungen stehen im Kontext dieser Knotenpunkte eher selten zur Diskussion. GRÜNE, SPD und LINKE weisen auf das Konflikthafte dieses Gemeinsamen hin. So hebt die SPD hervor: „Der ,Atomausstieg' stand im Gesetz. Die Energiewende war ,eingeleitet', gegen Ihren Widerstand“ (SPD 09.06.2011: 12964).

29 „Fukushima“ selbst belegt unter den inhaltlichen Kollokationen im betrachteten Fenster Rang 80 mit einer Häufigkeit von fünf und einem log-likelihood-Wert von $11=32,44$. 
Tabelle 19: Thematisch gruppierte rangerste 44 Kollokationen von „Energiewende*“ in der 17. Legislaturperiode

\begin{tabular}{|c|c|}
\hline Thematische Gruppierung & $\begin{array}{l}\text { Kollokationen (=Knotenpunkte) } \\
\text { (freq/log likelihood) }\end{array}$ \\
\hline Allgemein $^{30}$ & $\begin{array}{l}\text { Energiewende }(36 / 196,01) \text {, Projekt }(16,62,52) \text {, } \\
\text { Thema }(39 / 67,74) \text {, Atomausstieg }(18 / 144,02)\end{array}$ \\
\hline Umweltpolitische Themen & Klimaschutz $(34 / 204,97)$, Klimawandel $(11 / 65,6)$ \\
\hline Soziale Themen & sozial $(28 / 174,07) /$ soziale $(21 / 77,67)$ \\
\hline Erfolg(sbedingungen) & $\begin{array}{l}\text { Erfolg }(21 / 75,56), \text { erfolgreich }(15 / 56,6) / \text { erfolgrei- } \\
\text { che }(11 / 55,76), \text { Gelingen }(31 / 346,92) / \text { gelingen } \\
(27 / 182,78), \text { schaffen }(23 / 66,18), \text { Masterplan } \\
(22 / 231,11)\end{array}$ \\
\hline Stellenwert & ernst $(19 / 71,11)$ \\
\hline $\begin{array}{l}\text { Subjekt und Initialisierung } \\
\text { von „Energiewende“ }\end{array}$ & $\begin{array}{l}\text { voranzutreiben }(16 / 125,84) \text {, eingeleitet }(9 / 54,18) \text {, } \\
\text { vollzogen }(8 / 54,55) / \text { vollziehen }(7 / 53,19) \text {, be- } \\
\text { schlossen }(33 / 110,85) \text {, Umsetzung }(45 / 210,59)\end{array}$ \\
\hline Zeit & Schritt $(21 / 66)$ \\
\hline Kosten & $\begin{array}{l}\text { Kosten }(53 / 248,2)) \text {, bezahlbar }(11 / 81,58), \text { Nullta- } \\
\text { rif }(8 / 69,91) \text {, Verbraucherinnen }(14 / 62,38)\end{array}$ \\
\hline Herausforderung/Gefahr & $\begin{array}{l}\text { (vor die) Wand (fahren) }(17 / 132,05), \text { Herausfor- } \\
\text { derungen }(25 / 117,73) \text {, Bewältigung }(13 / 86,25)\end{array}$ \\
\hline Handlungsfelder/Mittel & $\begin{array}{l}\text { erneuerbare }(11 / 58,88) / \text { erneuerbaren }(15 / 56,92) \text {, } \\
\text { Energien }(22 / 80,32), \text { Gebäudebereich }(9 / 81,54), \\
\text { Energieeffizienz }(13 / 69,25), \text { Netzausbau } \\
(11 / 69,35), \text { Akzeptanz }(21 / 125,05), \text { Baustein } \\
(13 / 87,27), \text { Beitrag }(39 / 171,08), \text { leisten }(26 / 93,62) \text {, } \\
\text { Rahmen }(24 / 59,95)\end{array}$ \\
\hline Rolle in der Welt & $\begin{array}{l}\text { Klub }(20 / 231,16) / \text { Klubs }(5 / 56,2) \text { (der Energie- } \\
\text { wendestaate), Deutschland }(85 / 155,82)\end{array}$ \\
\hline
\end{tabular}

Quelle: eigene Darstellung

30 „Atomausstieg“ wird in der thematischen Gruppierung nun gemeinsam mit „Energiewende“ dem Themenbereich ,Allgemein“ zugeordnet, da „Atomausstieg“ nach „Fukushima“ wesentlich stärker mit „Energiewende“ äquivalenziert wird. 
Konfliktbeladen ist darüber hinaus die Frage, wie schnell die „Energiewende“ nun vollzogen werden solle, so wird vor allem von CDU, CSU häufig die Forderung „Schritt' für Schritt“ als impliziter Gegensatz zu einer schnellen „Energiewende“ verwendet (in 8 von 13 Vorfällen der Kollokation „Schritt“), z.B.: „Wir werden auch die Herausforderungen der Energiewende bewältigen, ,Schritt' für Schritt. ([Zwischenruf] Carsten Schneider [...] [ SPD ]: Ja ! In hundert Jahren ! [...]“ (CDU 11.09. 2012: 22863).

Eine Äquivalenzbeziehung zwischen „Klimaschutz“ und „Energiewende“ wird zwar in Relation zu ihrer Redezeit weiterhin überwiegend von den GRÜNEN hergestellt (16 von 43 Vorfällen), zum ersten Mal wird diese Beziehung nun aber auch von CDU, CSU und FDP artikuliert, die zuvor noch einen Widerspruch zwischen Klimaschutz und „Energiewende“ konstruiert hatten: „Die christlich-liberale Koalition hat ,Klimaschutz , Energiewende und Effizienzsteigerung zu zentralen Punkten der politischen Agenda gemacht" (CDU 28.02.2013: 28138). Dabei erscheint der Knotenpunkt „Klimaschutz“ meist in einer Aufzählung mit „Energiewende*“ - ohne, dass damit konkrete, weitergehende politische Forderungen verbunden werden. Ebenso wird die „Energiewende“ häufig als Herausforderung neben dem „Klimawandel“ aufgezählt, ohne konkrete damit verbundene politische Forderungen zu benennen, z.B. die ,großen gemeinsamen Herausforderungen: Energiewende, ,Klimawandel', demografischer Wandel“" (GRÜNE 12.05.2011: 12379). Eine Äquivalenzierung mit umfassenderen politischen Forderungen bleibt also aus.

In der 17. Legislaturperiode tritt „,sozial/e“ zum ersten Mal in einer Äquivalenzbeziehung mit „Energiewende*“ auf und wird so zu einem Knotenpunkt, der im Verhältnis zur Redezeit von der LINKEN überdurchschnittlich häufig artikuliert wird (24 von 49 Vorfällen). Dabei wird z.B. ein Verbot von „Stromsperren“ oder „,bezahlbare Strompreise“ (LINKE 21.03.2013: II;) gefordert. Die „Linken wollen die Energiewende mit einem sieben-Punkte-Programm ,sozial“ gestalten“ (LINKE 17.10. 2012: 23776). Aber auch SPD und GRÜNE artikulieren die Forderung einer ,sozialen“ „Energiewende“: Die SPD möchte „die Energiewende ,sozial“ gerecht und ökonomisch sinnvoll“ (SPD 17.10.2012: 23781) gestalten. Die GRÜNEN finden „,ür eine ,sozial' gerechte und ökologische Energiewende ist ein Regierungswechsel notwendig“ (GRÜNE 01.03.2013: 28303).

Auch „Erfolg“ wird ein zunehmend wichtiger Knotenpunkt in der Äquivalenzkette um „Energiewende*“ und spiegelt sich als Thema in verschiedenen Kollokationen („Erfolg“, „,erfolgreich“, „,erfolgreiche“, „Gelingen“, „gelingen“, „schaffen“) wider. Der Themenbereich wird überwiegend von der Regierungsfraktionen genutzt, um Erfolgsbedingungen $\mathrm{zu}$ artikulieren und sich gegen die Opposition abzugrenzen (z.B. „Wenn wir die Energiewende in Deutschland ,erfolgreich“ umsetzen wollen, dann müssen wir mit grünen Träumereien Schluss machen“ (FDP 24.11.2011: 17034)). In diesem Kontext ist auch die Frage, wie die „Energiewende“ „gelingen“ kann oder was zum „Gelingen“ der „Energiewende“ beiträgt, entscheidend - „Gelingen“ ist die rangerste Kollokation der 17. Legislaturperiode. Die genannten Erfolgsbedingungen für die „Energiewende“ sind dabei häufig marktwirtschaftlich oder technologieorientiert, z.B.: „Der ,Erfolg` der Energiewende ist abhängig von der Verbesserung der ,Energieeffizienz', vom Ausbau innovativer marktfähiger Erzeugungsanlagen für ,erneuerbare“ Energien, von Speicherlösungen“ (CDU 17.01.2013: 26945). 
Regierung und Opposition werfen sich gegenseitig vor, es mit der „Energiewende“ nicht ,ernst“ zu meinen und bestimmte Anforderungen nicht zu erfüllen. Häufig wird der Halbsatz verwendet ,,wer es (wirklich) ,ernst“ meint mit der Energiewende/ mit der Energiewende ,ernst“ meint, der [...]“. Bspw. betont die CSU: „Wenn es Ihnen ,ernst" ist mit der Energiewende, wenn Sie das Thema unterstützen - wollen, dann bitte ich Sie dringend: Hören Sie auf, die Tatsachen zu verdrehen!“(CSU 21.03.2013: 28800f.); dagegen die SPD: „Wer es ,ernst‘ meint mit der Energiewende, Kollege Döring, der muss die Energieversorgung in kommunaler Hand stärken“ (SPD 04.07.2011: 11761).

Darüber hinaus werfen vor allem die GRÜNEN der Regierungskoalition vor, die „Energiewende gegen die ,Wand““ (GRÜNE 22.03.2012: 20058) zu fahren.

In der 17. Legislaturperiode werden zudem häufig die „Kosten“ der „Energiewende" thematisiert (zweithäufigste Kollokation mit dem zweithöchsten log-likelihood-Wert), die somit zu einem der wichtigsten Themen (weitere Kollokationen: „bezahlbar“, „Nulltarif“, „Verbraucherinnen“) in der Debatte werden. Alle Fraktionen sprechen von den „Kosten“ der „Energiewende“ - allerdings aus unterschiedlicher Perspektive. CDU, CSU und FDP artikulieren mit dem Knotenpunkt „Kosten“ u.a. die Forderung einer marktwirtschaftlichen Orientierung, die die „Kosten“ begrenzen solle. Man benötige „Markt und mehr Marktintegration sowie eine permanente Kostenkontrolle, um eine Fehlallokation der Fördermittel zu vermeiden und die ,Kosten“ der Energiewende zu begrenzen“ (CDU 08.03.2012: 19559). Gleichzeitig betont vor allem die Regierungskoalition immer wieder die hohen „Kosten“ der „Energiewende“, bspw. durch die gemeinsame Artikulation von „Energiewende“ und „Nulltarif“: „[I]m Übrigen für die ganze linke Seite dieses Hauses. Ich sage Ihnen ganz offen: Wir haben zum Thema Energiewende immer klar gesagt, dass sie nicht zum ,Nulltarif‘ zu haben ist, dass das eine teure Operation wird" (CSU 21.03.2013: 28801). LINKE, SPD und GRÜNE heben dagegen das Konflikthafte und Widersprüchliche dieser Artikulationen hervor, indem sie kritisieren, dass die „Kosten“ ungerecht verteilt seien und die „Energiewende“ mit dem Argument zu hoher „Kosten“ absichtlich diskreditiert werde, z.B.: „In den letzten zwei Jahren wird nur noch gegen die angeblich hohen Kosten der Energiewende gehetzt“ (GRÜNE 13.06.2013: 31588).

Die mit „Energiewende*“ in Verbindung gebrachten Handlungsfelder sind überwiegend technologie-, marktwirtschaftlich und/oder verfahrenspolitisch ${ }^{31}$ ausgerichtet. Es handelt sich dabei häufig um flottierende Forderungen, die sowohl von Regierungs- als auch von Oppositionsfraktionen artikuliert werden, deren Bedeutung sich also in einem Spannungsfeld zwischen unterschiedlichen, teilweise gegensätzlichen Positionen generiert (Laclau 2005: 132). Als „Bausteine“ der „Energiewende“ werden bspw. genannt: „Energieeffizienz“, „die steuerliche Förderung der energetischen Gebäudesanierung“ (CDU 22.09.2011: 15046), „nachhaltige Bioenergienutzung“ (CDU 22.11.2011: 16815), die „Novelle des Kraft-Wärme-Kopplungsgesetzes“ (z.B. FDP 24.05.2012: 21519), „Die Reform des Mietrechtes“ (CDU 13.12.2012: 26290), „Contracting“ (CDU 27.09.2012: 23350), die „Rettung der einheimischen Solarindustrie“ (LINKE 13.06.2013: 31587) oder „Infrastruktur“ (z.B. CDU 25.04.2013:

31 Für eine Definition von verfahrenspolitisch vgl. Fußnote 13 in Kapitel 1. 
29722). Als Herausforderungen im „Rahmen“ der „Energiewende“ gelten z.B.: „Ausbau und Optimierung der Netze“ (GRÜNE 14.06.2012: 21915), „,Energieeffizienz“ und Energieeinsparung“ (SPD 14.06.2012: 21917), „Leitungsausbau“ (CDU 26.09. 2012: 23288) oder „schnelle An- und Abfahrvorgänge“ (FDP 18.10.2012: 24021) von Kraftwerken. Forderungen, die „soziale“ Aspekte adressieren, bleiben dabei marginalisiert, z.B. „eine Gerechtigkeitswende; denn sinkende Börsenstrompreise werden nicht an die Verbraucher weitergegeben, sondern nur an die Großindustrie" (SPD 14.03.2013: 28387). „Akzeptanz“ (21 Vorfälle) wird von allen Fraktionen als eine „Voraussetzung für das Gelingen der Energiewende“ (z.B. SPD 22.11.2012: 25363) artikuliert. Der Stellenwert von „Akzeptanz“ im Diskurs um „Energiewende“ wird in Kapitel 5.2.8 (Rolle der Bürger*innen) genauer beleuchtet.

Seit 2011 verstärkt sich zudem die Äquivalenzbeziehung zwischen „Energiewende*“ und „Deutschland“. „Deutschland“ ist die häufigste Kollokation (85 Vorfälle) von „Energiewende*“ in der 17. Legislaturperiode. Damit in Verbindung gebracht wird eine deutsche Vorreiterrolle: „,Deutschland“ übernimmt bei der Energiewende eine Vorreiterrolle für alle Industrienationen“ (CSU 14.03.2013: 28420). Die „Energiewende" solle vor allem auch gut für den deutschen Wirtschaftsstandort sein: eine „Energiewende im Sinne des Standortes ,Deutschland““ (SPD 19.01.2012: 18160). Die Äquivalenzbeziehung zwischen Deutschland und „Energiewende*“ wird von allen Fraktionen, außer von der LINKEN (1 Vorfall), umfangreich artikuliert.

\section{Positionsanalyse der Fraktionen im Vergleich}

Aufgrund der Beteiligung aller Fraktionen an der Artikulation von „Energiewende“ lassen sich in der 17. Legislaturperiode Differenzierungen zwischen den einzelnen Positionen herausarbeiten. ${ }^{32}$

Dabei wird deutlich, dass es eine große Übereinstimmung zwischen den Kollokationen der $\mathrm{CDU}^{33}$ mit dem fraktionsunabhängigen Kollokationscluster gibt. Das deutet zumindest rein quantitativ darauf hin, dass die CDU nun eine herausra-

32 Dabei wird für die Kollokationsanalyse der einzelnen Fraktionen der Mindestwert des Auftretens eines Knotenpunktes erneut auf 2 herabgesetzt. Da diese Analyse jedoch überwiegend dazu dient Gemeinsamkeiten und Differenzen zu den in dieser Legislaturperiode aussagefähigen fraktionsunabhängigen Kollokationen zu identifizieren, sind die Interpretationen, die sich aus dieser Relationen dennoch als aussagefähig zu betrachten, da sie zeigen welchen Anteil einzelne Fraktionen an der Bedeutungsgenerierung haben oder eben nicht haben. Innerhalb der Positionsanalyse der Fraktionen werden jeweils die rangersten 40 Kollokationen betrachtet.

33 Kollokationen CDU nach Rang (Häufigkeiten): Gelingen (12), gelingen (16), Energiewende (18), Schritt (15), Beschlossen (15), Stück (10), Baustein (7), Einstieg (7), Bezahlbar (6), Erfolg (11), Projekt (9), Klub (4), Kosten (10), gemeinsam (13), Akzeptanz (7), meistern (5), gestalten (7), Deutschland (23), Club (4), Beitrag (10), erfolgreich (8), Bewältigung (5), wichtiger (7), voranzutreiben (4), Herausforderungen (7), schaffen (9), Umsetzung (8), Fraktion (12), vorwegschicken (2), Rahmen (10), Masterplan (3), Konstruktiv (5), Mittelstandsinitiative (2), Stromsperren (2), Dimension (4), organisiert (4), mitarbeiten (3), Netze (4), Atomausstieg (3), Atomzeitalter (2). 
gende Rolle in der Bedeutungsgenerierung von „Energiewende*“ spielt, was im Laufe der Ergebnisauswertung aber immer wieder auch qualitativ evaluiert werden wird. ${ }^{34}$ Knotenpunkte, die nicht in direkter Verbindung zu weitergehenden, konkreten politischen Forderungen stehen, wie „G/gelingen“, „Erfolg“, „gemeinsam“, „gestalten“ sind dabei wichtig. Dagegen kommen umweltpolitische Themen in den ersten 40 Kollokationen der CDU nicht vor (im weitesten Sinne höchstens mit „Atomausstieg“ auf Rang 39). Auch Themen wie soziale Gerechtigkeit fehlen, der/die Bürger*in ist nur in der Kollokation „Akzeptanz“ vertreten.

Die diskursiven Muster der $\mathrm{CSU}^{35}$ erweisen sich als ähnlich - sie grenzt sich dabei aber deutlicher von der Opposition ab: „Wir wollen eine intelligente, eine bezahlbare Energiewende, eben keine ,rot-rot-grüne', sondern eine schwarz-gelbe Energiewende“ (CSU 29.03.2012: 20312). Sie wolle die „Wertschöpfung“ in den jeweiligen Regionen fördern und setzt den Knotenpunkt „Industrie“ in ein ambivalentes Verhältnis zu „Energiewende*“: ,[...] [O]b wir es trotz Energiewende schaffen, dass die ,Industrie“ das Rückgrat unserer Wirtschaft bleibt“ (CSU 16.05.2013: 30177), ist aus Sicht der CSU noch offen. Die CSU wolle die Energiewende nicht in erster Linie schnell, sondern ,sorgfältig, ,Schritt‘ für Schritt und mit Augenmaß vornehmen“ (CSU 14.06.2012: 22063).

Die FDP ${ }^{36}$ weist den „Herausforderung/en“ der „Energiewende“ einen hohen Stellenwert zu. Sie setzt das Motiv der „Deindustrialisierung“ in eine Äquivalenzbeziehung mit „Energiewende“ und zeichnet darauf aufbauend ein Gefahrenszenario, welches das eigene Verhältnis zur „Energiewende“ erkennbar ambivalent erscheinen lässt: „wir werden nicht zulassen - das sage ich vor allem Dingen in Richtung der Grünen -, dass die Energiewende zu einer ,Deindustrialisierung ‘ dieses Landes genutzt wird“ (FDP 24.11.2011: 17054). Die liberale Fraktion grenzt sich deutlich von der Opposition ab: „Hier zeigt sich das hässliche Gesicht der Dagegen-Partei. Die wahren ,Bremser' bei der Energiewende sind Sie, meine sehr

34 Der CDU als größter Fraktion kommt dabei auch die meiste Redezeit zu.

35 Kollokationen CSU nach Rang (Häufigkeit): Gelingen (11), Solarwirtschaft (3), rot-rotgrüne (2), Innovationen (3), Deutschland (10), sichern (4), Infrastruktur (4), Atomausstieg (2), Klimaschutz (3), Bezahlbarkeit (2), beschritten (2), Schritt (4), Biomasse (2), Modernisieren (2), Beitrag (4), deutsche (4), schaffen (4), Pläne (2), Wertschöpfung (2), Überschrift (2), sorgfältig (2), Meilenstein (2), Energieeffizienz (2), Bewältigung (2), Kosten (3), stärken (3), Erfolg (3), leisten (3), gestalten (2), Beschluss (2), Industrie (2), Beiträge (2), zeigen (2), Juni (2).

36 Kollokationen FDP nach Rang (Häufigkeit): Umsetzung (15), Herausforderungen (9), Beitrag (9), beschlossen (9), leisten (7), Masterplan (3), Nulltarif (3), Deutschland (13), erfolgreichen (4), vollziehen (3), Energiewende (4), Bewältigung (3), Bremser (2), guten (5), Kosten (5), Netzausbau (3), Deindustrialisierung (2), Finanzierung (4), Kasachstan (2), Atomkraft (2), gesellschaftlicher (2), Weg (7), Rolle (4), Bundesregierung (9), Atomausstieg (2), Herausforderung (3), vorankommen (2), notwendigen (3), voranzutreiben (2), liberale (2), Kontext (2), Thema (6), wichtiger (3), Händen (2), Baustein (2), Verbrauchern (2), erfolgreich (3), Rahmen (4), Energien (3), erneuerbare (2). 
verehrten Damen und Herren von den Grünen“ (FDP 08.02.2012: 18792).

Auch das Kollokationsprofil der SPD $^{37}$ zeigt deutliche Übereinstimmungen mit dem fraktionsunabhängigen Kollokationscluster, was ebenfalls auf eine starke Rolle in der Bedeutungsgenerierung von „Energiewende“ hindeutet, aber auch darauf, dass es Überschneidungen in den politischen Forderungen mit den Regierungsfraktionen gibt. Allerdings zeigen sich auch Forderungen, die eine kritische Positionierung zu den Knotenpunkten der Regierungskoalition aufweisen und, die im fraktionsunabhängigen Kollokationscluster marginalisiert sind. Die „Energiewende" steht häufiger als bei den Regierungsfraktionen in Verbindung mit politischen Forderungen, die den Bereich des Sozialen adressieren. Die „Energiewende ,sozial“ gerecht" zu gestalten (z.B.: SPD 17.10.2012: 23780) wird als Ziel artikuliert und die „Energiewende“ als „'gesamtgesellschaftliche“ Aufgabe“ (SPD 22.11.2012: 25363) gesehen. Auch „Ressourcenknappheit“ ist ein Thema.

Während bei der SPD „Klimaschutz“ unter den rangersten 40 Kollokationen nicht vorkommt, nimmt er im Kollokationsprofil der GRÜNEN ${ }^{38}$ den ersten Rang ein. Eine herausragende Rolle in den Artikulationen der GRÜNEN spielt zudem die Kritik an der Regierungskoalition, die die „Energiewende“ ,an die ,Wand““ (z.B.: GRÜNE 08.02.2012: 18805) fahre. Sie sprechen von „einer schwarz-gelben ,Konterrevolution“ gegen die Energiewende“ (GRÜNE 08.03.2012: 19540) und fordern die Regierungsfraktionen auf, „umzudenken“, werfen ihr vor, die Energiewende ,,in den Sand“ (z.B.: GRÜNE 11.09.2012: 22899) zu setzen, ihr Beitrag zur Energiewende sei „gleich ,null““ (z.B.: GRÜNE 07.09.2011: 14487). Die GRÜNEN fordern außerdem eine ,,,sozial ‘ gerechte und ökologische Energiewende“ (GRÜNE 01.03.2013: 28303).

„Kosten“ ist die rangerste Kollokation von „Energiewende*“ in den Artikulationen der LINKEN ${ }^{39}$ Allerdings adressiert die LINKE das Kostenthema aus einer

37 Kollokationen SPD nach Rang (Häufigkeit): Klub (12), Masterplan (11), Umsetzung (13), Kosten (11), Akzeptanz (7), Deutschland (21), Gelingen (4), Röttgen (7), einzuleiten (4), Wand (5), Ressourcenknappheit (3), ernst (8), Nulltarif (3), bewerkstelligen (3), Herausforderungen (6), sozial (5), Thema (13), Forschungsplattform (2), Management (3), Kraftwerkskapazitäten (2), intelligentere (2), verkorkste (2), blockieren (3), erfolgreiche (4), machbar (3), eingeforderte (2), gesamtgesellschaftliches (2), Nutzen (4), Wende (3), gemanagt (2), Atomzeitalter (2), Netzausbau (3), eingeleitet (3), Bewältigung (3), wichtigen (5), Standortes (2), finanziert (4), Energien (5), Erfolg (5).

38 Kollokationen GRÜNE nach Rang (Häufigkeit): Klimaschutz (15), Wand (9), sozial (7), Vorwand (4), finanzieren (7), Beitrag (8), voranzutreiben (5), Akzeptanz (6), solide (5), Schwarz-Gelb (8), Atomausstieg (5), finanziert (6), Deutschland (17), Kosten (9), Thema (12), ausfinanziert (3), voranzubringen (4), verstanden (6), Wirtschaftsminister (5), Energien (7), Gebäudebereich (3), Gebäudesanierung (4), umzudenken (2), Energiewende (6), Klimawandel (4), erneuerbare (4), Sand (3), Umsetzung (6), umzusetzen (4), demografische (3), Gelingen (2), Mieterrechte (2), Energieeffizienz (4), gerechte (3), Klub (2), Raumordnung (2), demografischer (2), Netze (3), Atomausstiegs (2), null (3).

39 Kollokationen LINKE nach Rang (Häufigkeit): Kosten (15), soziale (13), sozial (11), Energiewende (8), Gebäudebereich (4), Masterplan (4), Gelingen (4), Klimaschutz (5), 
herausfordernden Positionierung zum Diskurs der Regierungsfraktionen. Sie hebt dabei vor allem die „Verteilung“ hervor und kritisiert die Bundesregierung dafür, dass sie „die energieintensive Industrie von den ,Kosten“ der Energiewende“ befreie (LINKE 29.03.2012: 20277). Sie wirft der Bundesregierung vor, die „Energiewende" durch das Kostenthema negativ zu besetzen und aktiv andere gesellschaftlichen Konflikte zu verdecken: „Auf der anderen Seite ziehen Sie die Debatte über die Verteilung der ,Kosten' der Energiewende so auf, dass die erneuerbaren Energien unter Beschuss geraten, die Zukunftsenergien also, und nicht die soziale Schieflage oder die Profite, die damit vielerorts verdient werden“ (LINKE 15.03.2013: 28645). „Soziale“ Forderungen nehmen - gemessen an ihrer Häufigkeit - in den Artikulationen der LINKEN einen höheren Stellenwert als bei den übrigen Fraktionen ein: „Wir brauchen nicht nur eine Energiewende, sondern auch eine Kulturwende und eine ,soziale“ Wende“ (LINKE 09.06.2011: 12971). Mehrfach bringt die LINKE das Motiv einer „wirklichen“ „Energiewende“ ein. Dazu gehöre „nicht nur der Atomausstieg, sondern mittelfristig auch der Ausstieg aus der Verstromung der Braunkohle“ (LINKE 18.04.2013: 29364).

\section{Erneuerbare Energien und Atomausstieg}

Die Debatte um ,erneuerbare Energien“ intensiviert sich in der 17. Legislaturperiode noch einmal deutlich (von 2464 auf 3991 Vorfälle, die relative Häufigkeit steigt von 0,13 Vorfällen pro tausend Wörter auf 0,17). Es sind sich nun alle Fraktionen darüber einig, dass das „,Zeitalter“ der erneuerbaren Energien“ begonnen habe (104 Vorfälle). War in der 16. Legislaturperiode der Anteil der erneuerbaren Energien an der Energieversorgung noch umstritten, scheint dieser Konflikt nach „Fukushima“ zunächst beigelegt - es ist von „Vollversorgung“ (13 Vorfälle) die Rede. Alle Fraktionen sprechen nun vom „Umstieg“ in die erneuerbaren Energien (30 Vorfälle). Dabei wird deutlich: Auch in den Artikulationen um erneuerbare Energien gewinnt erst nach „Fukushima“ eine energiepolitische Wende an Bedeutung. Erneuerbare Energien werden zunehmend als Teil der „Energiewende“ artikuliert: „Die Energiewende hat zwei Beine: erneuerbare Energien und ,Energieeffizienz““ (CDU 08.02.2012: 18800). Allerdings wird dabei auch verstärkt die Notwendigkeit einer „Markt“- und „Systemintegration“ (14 Vorfälle) erneuerbarer Energien in den Fokus gerückt. Der Diskurs um erneuerbare Energien scheint zunehmend zum Bestandteil des „Energiewende"-Diskurses zu werden, die beiden Diskurse gleichen sich quantitativ (in Bezug auf die Häufigkeit der Nennungen) und qualitativ (in Bezug auf ihre Bedeutungsbeziehungen) an (vgl. Tabelle 20).

Beitrag (6), klar (8), Atomausstieg (4), Erfordernissen (3), sozialen (6), Baustein (3), voranzutreiben (3), Abfederung (2), Innovationen (3), Klub (2), wirklichen (3), Konzept (4), gerecht (4), bezahlen (4), Titel (4), ökologische (3), Klimaschutzes (2), ehrlichen (2), dringend (4), ehemaliger (2), regenerativen (2), notwendigen (3), Verkehrs (2), ITER (2), Wechsel (2), erfolgreiche (2), schnelle (2), Begriffen (2), Klimawandel (2), Entschuldigung (2), Vorgehen (2), Verteilung (2). 
Tabelle 20: Thematisch gruppierte rangerste 40 Kollokationen von erneuerbar* in der 17. Legislaturperiode

\begin{tabular}{|c|c|}
\hline Thematische Gruppierung & $\begin{array}{l}\text { Kollokationen (=Knotenpunkte) } \\
\text { (freq/log likelihood) }\end{array}$ \\
\hline Technologien & $\begin{array}{l}\text { Energien }(3035 / 38927,09), \text { Energie }(66 / 440,15) \text {, } \\
\text { Energiequellen }(15 / 162,93) \text {, Bereich } \\
(173 / 819,54), \text { fluktuierenden }(17 / 208,03), \text { Ener- } \\
\text { gieträger }(14 / 121,5)\end{array}$ \\
\hline Marktorientierung & $\begin{array}{l}\text { Marktanreizprogramm }(19 / 160,27), \text { Markt } \\
(35 / 170,97), \text { Systemintegration }(14 / 164,79), \\
\text { Branche }(25 / 135,64)\end{array}$ \\
\hline Förderung/Ausbau & $\begin{array}{l}\text { Förderung }(152 / 991,26) \text {, Ausbau }(409 / 3791,68) \text {, } \\
\text { Ausbaus }(32 / 326,56) \text {, auszubauen }(18 / 126,41) \text {, } \\
\text { ausbauen }(26 / 179,91) \text {, Anteils }(16 / 154,7), \text { Anteil } \\
(158 / 1219,28) \text {, fördern }(30 / 131,07), \text { Prozent } \\
(178 / 642,17) \text {, Einspeisevorrang }(25 / 286,71) \text {, Zu- } \\
\text { bau }(17 / 156,74) \text {, Investitionen }(39 / 187,21) \text {, Ein- } \\
\text { stieg }(26 / 182,54) \text {, Einspeisung }(14 / 143,81) \text {, errei- } \\
\text { chen }(43 / 162,93) \text {, Hauptanteil }(13 / 149,16)\end{array}$ \\
\hline Energieverbrauch & Energieeffizienz $(110 / 981,1)$ \\
\hline $\begin{array}{l}\text { Umstellung der Energiever- } \\
\text { sorgung }\end{array}$ & $\begin{array}{l}\text { Zeitalter }(96 / 1034,58), \text { Umstieg }(30 / 309,11) \text {, } \\
\text { Vollversorgung }(13 / 149,16), \text { Kernenergie } \\
(18 / 108,1)\end{array}$ \\
\hline Energieerzeugung & $\begin{array}{l}\text { Stroms }(37 / 410), \text { Strom }(89 / 727,34), \text { Erzeugung } \\
(24 / 218,8) \text {, Netze }(19 / 122,52), \text { Nutzung } \\
(79 / 573,8) \text {, Stromversorgung }(20 / 179,58), \text { Ener- } \\
\text { gieversorgung }(47 / 358,73), \text { Wärme }(37 / 372,5) \text {, } \\
\text { Stromerzeugung }(44 / 448,9)\end{array}$ \\
\hline
\end{tabular}

Quelle: eigene Darstellung

Auch die Debatte um Atomausstieg* intensiviert sich relativ an der Anzahl der Vorfälle gemessen in der 17. Legislaturperiode um mehr als das 1,5fache im Vergleich zur Vorperiode (von 0,0093 Vorfälle pro tausend Wörter auf 0,0156, absolut betrachtet von 171 auf 365 Vorfälle).

Im Herbst 2010 verabschiedet die schwarz-gelbe Regierungskoalition eine Verlängerung der Laufzeiten der Atomkraftwerke. Der Streit, der sich darum entfacht, lässt sich anhand zahlreicher Knotenpunkte nachzeichnen, die sich auf einen diesbezüglichen Dissens beziehen (vgl. Tabelle 21). 
Tabelle 21: Thematisch gruppierte 38 Kollokationen von Atomausstieg* in der 17. Legislaturperiode

\begin{tabular}{|c|c|}
\hline Thematische Gruppierung & $\begin{array}{l}\text { Kollokationen (=Knotenpunkte) } \\
\text { (freq/log likelihood) }\end{array}$ \\
\hline Allgemein & $\begin{array}{l}\text { Ausstieg }(8 / 68,28) \text {, beschlossen }(20 / 120,25) \text {, be- } \\
\text { schlossene }(3 / 26,18) \text {, beschlossenen }(6 / 56,37) \text {, } \\
\text { Atomprivileg }(5 / 86,71) \text {, Euratom-Vertrag } \\
(5 / 63,69) \text {, ändern }(5 / 25,77) \text {, beschließen }(7 / 51,85) \text {, } \\
\text { Fukushima }(4 / 39,05) \text {, voranbringen }(4 / 32,47), \text { for- } \\
\text { cieren }(3 / 32,18), \text { forciert }(2 / 20,88) \text {, beenden } \\
(4 / 26,81) \text {, Rückkehr }(3 / 25,69) \text {, organisieren } \\
(3 / 19,47) \text {, endgültigen }(2 / 19,28)\end{array}$ \\
\hline Zeit & $\begin{array}{l}\text { Jahre }(8 / 23,6) \text {, schnellstmöglichen }(4 / 59,94) \text {, so- } \\
\text { fortigen }(3 / 32,25) \text {, schnellen }(3 / 25,94)\end{array}$ \\
\hline Dissens & $\begin{array}{l}\text { rückgängig }(6 / 62,91) \text {, revidierbar }(3 / 47,87) \text {, Kon- } \\
\text { sens }(6 / 37,08) \text {, auszubremsen }(2 / 25,9) \text {, Nennens- } \\
\text { wertes }(2 / 29,67) \text {, Forderung }(5 / 22,96), \text { ernst } \\
(4 / 17,13) \text {, Rückfahrkarte }(2 / 34,68), \text { unumkehrbar } \\
(2 / 22,32) \text {, ehrlichen }(4 / 39,05)\end{array}$ \\
\hline $\begin{array}{l}\text { Energiepolitisches Gesamt- } \\
\text { konzept }\end{array}$ & $\begin{array}{l}\text { Energiewende }(21 / 168,46) \text {, Erneuerbare- } \\
\text { Energien-Gesetz }(2 / 16,15) \text {, Ausbau }(4 / 17,4), \mathrm{zu}- \\
\text { sammendenken }(2 / 29,67)\end{array}$ \\
\hline Rolle in der Welt & Deutschland $(14 / 26,34)$ \\
\hline Akteur*innen & $\begin{array}{l}\text { rot-grünen }(7 / 56,2), \text { Rot-Grün }(4 / 23,94), \text { Röttgen } \\
(3 / 17,31)\end{array}$ \\
\hline Forschung & Energieforschung $(2 / 19,24)$ \\
\hline Gesetze/Verträge & Gesetz $(7 / 22,31)$ \\
\hline
\end{tabular}

Quelle: eigene Darstellung

Insbesondere die LINKE kritisiert, dass der Atomausstieg unter rot-grün nicht ,unumkehrbar“ angelegt wurde (z.B.: LINKE 30.06.2011: 13390). Die SPD spricht davon, dass die Regierung „den gesellschaftlichen ,Konsens“ in der Frage des Atomausstiegs aufgekündigt“" habe (SPD 25.11.2010: 8221). Zur Diskussion steht zudem erneut der Zeithorizont, in dem ein Atomausstieg durchzuführen sei.

Auch in den Artikulationen um den Atomausstieg* scheint sich erst nach „Fukushima“ der Fokus auf eine energiepolitische Wende zu verstärken. „Energiewende" ist nicht nur die rangerste (bezogen auf die mit dem log likelihood Wert gemessene Signifikanz), sondern auch die häufigste Kollokation von Atomausstieg* (21 Vorfälle), was die zunehmende Verstrickung der Diskurse nach „Fukushima“ 
verdeutlicht. ${ }^{40}$ Insgesamt wird bereits in der computerbasierten Auswertung des Diskurses an dieser Stelle die Bedeutung von „Fukushima“ als dislozierendes Ereignis deutlich. Dies wird in Kapitel 5.2 genauer analysiert - ebenso wie die Bedeutung der Laufzeitverlängerung für den „Energiewende“"-Diskurs.

\section{Legislaturperiode}

Tabelle 22: Rahmendaten der 18. Legislaturperiode

\begin{tabular}{|c|c|c|c|}
\hline $\begin{array}{c}\text { Erste und letzte Sitzung } \\
\text { der Legislaturperiode } \\
\text { im Bundestag }\end{array}$ & $\begin{array}{c}\text { Anzahl der } \\
\text { Sitzungen }\end{array}$ & $\begin{array}{c}\text { Regierungs- } \\
\text { koalition }\end{array}$ & $\begin{array}{c}\text { Bundes- } \\
\text { kanzler*in }\end{array}$ \\
\hline $\begin{array}{c}22.10 .2013-24.10 .2017 \\
\text { (GermaParl Korpus endet } \\
\text { am 16.12.2016) }\end{array}$ & $\begin{array}{c}245 \\
(210 \text { in Germa- } \\
\text { Parl enthalten })\end{array}$ & CDU/CSU/SPD & Angela Merkel \\
\hline
\end{tabular}

Quelle: eigene Darstellung

\section{„Energiewende“}

Im betrachteten Zeitraum der 18. Legislaturperiode ist 1664 Mal von „Energiewende*“ die Rede. Die relative Häufigkeit von „Energiewende*“ steigt damit im Vergleich zur 17. Legislaturperiode nochmals leicht an - von 0,097 auf 0,11 Vorfälle pro tausend Wörter. Für „Energiewende*“ ergeben sich in der 18. Legislaturperiode 240 Kollokationen $(\min$ freq $=2$ ), von denen hier die aussagefähigen rangersten 45 , die mindestens 5 Mal gemeinsam mit „Energiewende*“ auftreten, betrachtet werden $($ min freq $=5)($ vgl. Tabelle 23).

In der 18. Legislaturperiode festigen sich viele Knotenpunkte von „Energiewen-

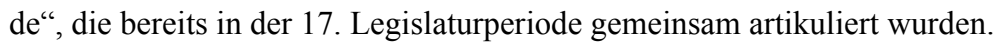

In Bezug auf den „Atomausstieg“ wird von einer „doppelte[n] Energiewende“ gesprochen „raus aus der Kernkraft und rein in erneuerbare Energie“ (SPD 10.04. 2014: 2450). Dieses Muster verdeutlicht die starke Äquivalenzbeziehung zwischen „Atomausstieg“ und „Energiewende*“" nach „Fukushima“.

40 Ebenfalls analog zu den Artikulationen um „Energiewende*“ gerät nach „Fukushima“ verstärkt die Rolle Deutschlands in der Welt in den Fokus, die häufig mit einer Vorreiterfunktion verbunden wird: „Als Erste überhaupt haben wir in Deutschland den Atomausstieg mit einem richtigen Konzept zum Ausbau der erneuerbaren Energien verbunden“ (CDU 15.03.2013: 28635).

41 Besonderheiten der 18. Legislaturperiode: Bei der Bundestagswahl 2013 scheitert die FDP an der 5\%-Hürde und ist damit nicht mehr im Bundestag vertreten. Während die CDU deutlich hinzugewinnen kann $(+7,7 \%)$ verlieren GRÜNE und LINKE jeweils über 20\% ihres Stimmanteils. Damit kommt die Mehrheitsgruppe auf $80 \%$ der Stimmanteile im Bundestag, während die Opposition nur über $20 \%$ verfügt - mit entsprechendem Einfluss auf die Redezeiten. Die AfD als neue politische Kraft scheitert mit 4,7\% an der 5\%-Hürde (www.bundeswahlleiter.de). 
Tabelle 23: Thematisch gruppierte rangerste 45 Kollokationen von „Energiewende*“ in der 18. Legislaturperiode

\begin{tabular}{|c|c|}
\hline Thematische Gruppierung & $\begin{array}{l}\text { Kollokationen (=Knotenpunkte) } \\
\text { (freq/log likelihood) }\end{array}$ \\
\hline Allgemein & $\begin{array}{l}\text { Energiewende }(22 / 106,93) \text {, Projekt }(14 / 67,31) \text {, } \\
\text { Atomausstieg }(7 / 53,37) \text {, Energiepolitik }(7 / 42,98)\end{array}$ \\
\hline Umweltpolitische Themen & Klimaschutz $(44 / 282,19)$ \\
\hline Erfolg(sbedingungen) & $\begin{array}{l}\text { Erfolg }(72 / 481,29) / \text { erfolgreiche }(17 / 118,02), \text { Ge- } \\
\text { lingen }(21 / 217,69) / \text { gelingen }(25 / 170,15), \text { schaffen } \\
(16 / 40,57), \text { führen }(27 / 108,06)\end{array}$ \\
\hline $\begin{array}{l}\text { Subjekt und Initialisierung } \\
\text { von „Energiewende“ }\end{array}$ & $\begin{array}{l}\text { voranzutreiben }(7 / 48,89) \text {, voranbringen } \\
(11 / 74,98) \text {, Umsetzung }(24 / 105,27) \text {, Bayern } \\
(13 / 55,83) \text {, Bürgerinnen }(15 / 52,96) \text { /Bürger } \\
(15 / 43,91)\end{array}$ \\
\hline Kosten & bezahlbar $(9 / 67,38)$, Nulltarif $(5 / 41,38)$ \\
\hline Herausforderung/Gefahr & Abrissbirne $(5 / 55,1)$ \\
\hline Handlungsfelder/Mittel & $\begin{array}{l}\text { erneuerbaren }(14 / 70,08) \text {, Energien }(15 / 65,67) \text {, } \\
\text { EEG }(7 / 39,79), \text { Gebäudebereich }(9 / 83,53), \text { Ener- } \\
\text { gieeffizienz }(23 / 162,98) \text {, Akzeptanz }(36 / 280,84) \text {, } \\
\text { Energieforschung }(7 / 67,32) \text {, Verkehr }(12 / 55,95) \text {, } \\
\text { Wärmebereich }(5 / 51,65) \text {, Ausbau }(12 / 47,91), \\
\text { Quartier }(5 / 40,67), \text { Digitalisierung }(29 / 193,15), \\
\text { Baustein }(10 / 62,35) \text {, zweite }(12 / 42,13), \text { Säule } \\
(13 / 85,35), \text { Beitrag }(19 / 61,89), \text { Rahmen } \\
(19 / 52,71), \text { Bestandteil }(9 / 50,2), \text { zentraler }(8 / 49,8)\end{array}$ \\
\hline Organisation & dezentrale $(7 / 66,2)$ \\
\hline Formalisierung & $\begin{array}{l}\text { Fortschrittsbericht }(6 / 53,58) \text {, Monitoringbericht } \\
(5 / 53,47)\end{array}$ \\
\hline Rolle in der Welt & $\begin{array}{l}\text { europäisch }(6 / 41,94) \text {, Deutschland }(89 / 221,98) \text {, } \\
\text { deutsche }(16 / 45,49)\end{array}$ \\
\hline
\end{tabular}

Quelle: eigene Darstellung

„Klimaschutz“ kommt weiterhin ein hoher Signifikanzwert für die Bedeutungsgenerierung von „Energiewende“ zu: „[W]ir haben in den Bereichen Klimaschutz und Energiewende eine Vorreiterrolle“ (CDU 03.12.2015: 13961).

„Erfolg“ ist in der 18. Legislaturperiode der Knotenpunkt mit dem höchsten Signifikanzwert. Der „Erfolg“ bzw. das „Gelingen“ (weitere thematisch verwandte Kol- 
lokationen: „erfolgreiche“, „gelingen“, „,schaffen“, „,ühren“) der „Energiewende*“ wird verstärkt mit nationalen Motiven verbunden, z.B. „Wenn diese Energiewende einem Land ,gelingen“ kann, dann ist das ,Deutschland“" (CDU 29.01.2014: 565). Die „,deutsche“ Energiewende“ ist zu einer festen Wendung geworden: „Man spricht von der ,German Energiewende“" (CDU 06.11.2014: 5854). Dabei geht es auch um die Stellung Deutschlands auf dem Weltmarkt. Die SPD möchte bspw. „die Energiewende so [...] gestalten, dass ,deutsche“ industrielle Produktion auf internationalen Märkten keine Chancen verliert“ (SPD 13.02.2014: 995). „Deutschland“ ist mit 89 Vorfällen die häufigste Kollokation dieser Legislaturperiode (Rang 4 bezüglich des Signifikanzwertes). „Energiewende“ scheint zum identitätsstiftenden Moment für „Deutschland“ zu werden - dies wird in Kapitel 5.2.6 (Deutschland als Vorreiter) noch genauer analysiert. Bei einer Kontextanalyse (Konkordanzanalyse) wir deutlich, dass dieses Moment mit ,Stolz' verbunden wird: ,,,Deutschland“ kann auf die Energiewende stolz sein“ (SPD 04.12.2014: 7024), „Wir haben in ,Deutschland“ die Energiewende beschlossen, und darauf sind wir stolz“ (CSU 26.03.2015: 9266). Im Kontext von „Energiewende*“ und „Deutschland“ wird ein Bild von ,der Welt" gezeichnet, die auf „Deutschland“ blicke: „ein zentrales Projekt der nachhaltigen Entwicklung in ,Deutschland' [ist] die Energiewende. In der Tat blickt die ganze Welt auf uns“ (SPD 04.12.2014: 7024). Die „Energiewende“" solle nicht nur in „Deutschland" stattfinden, sondern mindestens ,europäisch“ eingebunden werden.

Darüber hinaus nimmt der Stellenwert der „Bürgerinnen und Bürger“ als Subjekte der „Energiewende*“ in der 18. Legislaturperiode zu. Sämtliche Fraktionen beziehen sich positiv auf die Beteiligung von Bürgerinnen und Bürgern bei der „Energiewende*“: „Die breite Basis der Energiewende stellt die Beteiligung der ,Bürger“, die Bürgerenergie dar“ (CDU 01.06.2016: 16991). Dennoch scheint die Rolle der Bürger*innen für die „Energiewende“ stark umstritten, denn die Opposition wirft der Regierungskoalition vor, die Bürger*innenbeteiligung bei der „Energiewende“ zu torpedieren: „Lassen Sie die Energiewende in den Händen der ,Bürger“!“ (GRÜNE 29.01.2014: 582). „Die Union nimmt den ,Bürgern“ die Energiewende“ (LINKE 01.06.2016: 16986).

Die Kosten der „Energiewende“ sind in den Debatten der 18. Legislaturperiode weiterhin ein häufiges Thema (Kollokationen: „,bezahlbar“, „Nulltarif“). Im Mittelpunkt steht die Forderung, „dass die Energiewende ,bezahlbar" bleibt“ (CDU 19.03.2014: 1719). Ein diskursives Muster, das überwiegend von SPD und CDU artikuliert wird. Um auf die hohen Kosten der „Energiewende“ zu verweisen, wird die Formulierung „die Energiewende zum ,Nulltarif“ ist eine Illusion ${ }^{42 ، ~(z . B . ~ C S U ~}$ 08.05.2014: 2712; 19.03.2014: 1712) verwendet.

42 Dabei wird auf ein Zitat aus einem umstrittenen Interview verwiesen, das der damalige Vorsitzende des Wirtschafts- und Energieausschusses Peter Ramsauer (CSU) 2014 im Spiegel gegeben hatte. Ramsauer kritisierte dabei den Entwurf zur Novelle des EEG 2014, schloss ein „,zurück zur Atomkraft“ nicht aus, wenn „die Entwicklung aus dem Ruder läuft und wir uns die Energiewende so nicht leisten können und wollen“ - es dürfe „keine Einschnitte für die Wirtschaft geben“(www.spiegel.de). Die GRÜNEN beantragten hierzu eine aktuelle Stunde. 
Die in der 17. Legislaturperiode benannten Handlungsfelder der „Energiewen$\mathrm{de}^{* *}$ wiederholen sich in der 18. Legislaturperiode zum Teil, wobei „Energieforschung“, „Quartier“, „Wärmebereich“, „EEG“, „Digitalisierung“ und „Verkehr“ hinzukommen. „Energieeffizienz" solle neben den erneuerbaren Energien die „zweite“ „Säule“ der „Energiewende“ werden (8 Vorfälle, z.B.: CSU 05.02.2015: 8075). Die „Energiewende“ im „Verkehr“ gewinnt in der 18. Legislaturperiode an Bedeutung, wird aber überwiegend von der Opposition unter SPD und GRÜNEN eingebracht, z.B.: ,denn bisher hat sie [die Bundesregierung] die Energiewende im Wärmesektor und beim ,Verkehr“ völlig verschlafen“ (GRÜNE 18.12.2015: 14558); „die Elektromobilität ist entscheidend für eine erfolgreiche Energiewende im ,Verkehr", nicht zuletzt im Wirtschaftsverkehr“ (SPD 09.09.2016: 18642). Auch das „EEG“ gewinnt in im Kontext von „Energiewende*“" an Bedeutung, da seine Ausgestaltung - vor allem im Rahmen der Novellierungen 2014 und 2016/2017 - hochgradig umkämpft ist. So ist die Regierungskoalition der Überzeugung, „dass es einer Reform des ,EEG‘ bedarf, um die Energiewende [...] nicht zu gefährden. Da geht es um die Bezahlbarkeit für die ,Bürger' und um die Wettbewerbsfähigkeit unserer Unternehmen“ (CDU 08.05.2014: 2717). Dagegen argumentiert die Opposition, die Bundesregierung mache das „EEG“, „,bislang ein Segen für die Energiewende“, „zu einem Schreckgespenst“ (LINKE 27.06.2014: 3941); sie „säge[...]“ die erneuerbaren Energien als „,andere ,Säule“ der Energiewende [...] ab“ (GRÜNE 26.06.2014: 3853). „,[M]it dieser ,EEG'-Novelle zertrümmern Bundesregierung und Koalition alles, was die Energiewende demokratisch und, dezentral' macht, sie machen sich zu Lakaien der Konzerne und Großinvestoren“ (LINKE 24.06.2016: 17832). Das „EEG“ wird zu einem wichtigen, umkämpften Knotenpunkt von „Energiewende*“ - welche Rolle es genau für den Bedeutungskampf um „Energiewende“ spielt, wird im nächsten Kapitel 5.2 (Story-Lines) genauer betrachtet.

Eine zunehmend formale Expert*innen-Begleitung des Prozesses der „Energiewende“ zeigt sich in den Kollokationen „Monitoring“ und „Fortschrittsbericht“. Alle Fraktionen beziehen sich positiv auf das Hinzuziehen externer Expertise. Die GRÜNEN artikulieren jedoch auch die Gefahren einer Formalisierung, bspw. der Vernebelung tatsächlich getroffener politischer Entscheidungen: „Es wäre nicht so tragisch, wenn es nur darum ginge, ob Sie im Jahr 2020 in Ihrem ,Monitoringbericht` zur Energiewende, wenn Ihre Energiesparziele evaluiert worden sind, ein paar Häkchen machen können [...]. Es geht vielmehr um die Frage, ob Sie den ,Klimaschutz ernst nehmen“ (GRÜNE 05.02.2015: 8074).

Der Knotenpunkt „dezentrale“ gewinnt in der 18. Legislaturperiode zum ersten Mal an Bedeutung, taucht allerdings ausschließlich in einem negativen Bezug auf die Politik der Bundesregierung auf: „Damit machen Sie die Bürgerenergie, die ,dezentrale“ Energiewende kaputt“ (GRÜNE 23.05.2014: 3213), „Das sehen wir auch am ,EEG'-Entwurf, mit dem Sie die ,dezentrale‘ Energiewende torpedieren und durch Ausschreibungspflicht zentralistische Tendenzen unterstützen“ (LINKE 29.04.2016: 16607). Darüber hinaus bezeichnen die GRÜNEN „Sigmar Gabriel bei der Verabschiedung der ,EEG'-Novelle als ,Abrissbirne“ der Energiewende“ (GRÜNE 29.01.2015: 7764). Dieses Artikulationsmuster wird im Verlauf der Legislaturperiode immer wieder aufgegriffen (10 Vorfälle). 


\section{Positionsanalyse der Fraktionen im Vergleich}

Die CDU (337 Vorfälle) ${ }^{43}$ hat erneut einen hohen Einfluss auf die Bedeutungsgenerierung von „Energiewende“ im Bundestag, was sich an der hohen Übereinstimmung zwischen ihrem Kollokationsprofil ${ }^{44}$ und dem fraktionsunabhängigen Kollokationscluster zeigt. Stärker als andere Fraktionen bringt die CDU das Thema „Energieforschung“ ein, das sich in verschiedenen Kollokationen widerspiegelt. Die „Energieforschung“ solle auch der Konsensbildung dienen, bzw. der „Abstimmung mit Wirtschaft und Wissenschaft“: „Wir alle zusammen haben im letzten Frühjahr mit dem Forschungsforum Energiewende einen Dialogprozess gestartet“ (CDU 04.12.2014: 6875). Die CDU artikuliert darüber hinaus „Energiewende*" verstärkt mit Knotenpunkte, die eine ambivalente Bedeutungsbeziehung zu „Energiewende“ herstellen: So spricht sie von „Belastungen“, die „für die Unternehmen in Europa existenzbedrohend werden“ können (CDU 17.01.2014: 514). Sie skizziert „,zusätzliche finanzielle ,Belastungen“ durch die europäische Staatsschuldenkrise, die Energiewende und die Flutkatastrophe“ (CDU 11.04.2014: 2628).

Auch die CSU (193 Vorfälle) ${ }^{45}$ artikuliert verstärkt ambivalente Bedeutungsbeziehungen zu „Energiewende“. Sie hebt besonders die „Kosten“ der „Energiewende“ hervor: „Dass die Energiewende ,teuer“ ist, ist ja wohl Common Sense“ (CSU 19.03.2014: 1714). „Die ,durchschnittlichen“ ,Strompreise“ für Industriekunden“ seien in Deutschland im Vergleich hoch (CSU 24.04.2015: 9730). Die CSU spricht von der „Energiewende“ als „Generationenaufgabe“; Allerdings nicht im Sinne einer Verantwortung für kommende Generationen, sondern vielmehr, um

43 Kollokationen CDU nach Rang (Häufigkeit): Erfolg (16), Akzeptanz (8), gelingen (8), Energiewende (8), Energiepolitik (5), Energieforschungsprogramm (3), Digitalisierung (6), Energieeffizienz (5), bezahlbar (4), Umsetzung (7), Richtung (6), Deutschland (16), Klimaschutz (5), Gelingen (3), naturnahen (2), erfolgreiche (4), Hauseigentümer (2), Weg (9), Begleitforschung (2), Heizkosten (2), Kopernikus-Projekte (2), voranzutreiben (3), gestalten (4), meistern (3), Beitrag (6), Projekt (4), Quartier (2), absichern (2), breite (3), Energieforschung (2), Gebäudebereich (2), Baustein (3), Belastungen (3), gesamtgesellschaftlichen (2), vollständig (3), globalen (3), größte (3), größten (3), erneuerbaren(3), Aufgabe (5), Netzausbau (2), Basis (3).

44 Betrachtet werden in der Positionsanalyse - wie bereits in der 17. Wahlperiode - jeweils die 40 rangersten Kollokationen der Fraktionen, die mit einer Häufigkeit von mindestens 2 auftreten.

45 Kollokationen CSU nach Rang (Häufigkeit): Erfolg (10), Digitalisierung (6), Akzeptanz (5), Generationenaufgabe (3), Bestandteil (4), Nulltarif (3), Illusion (3), Energieeffizienz (4), gelingen (4), Umsetzung (5), zentraler (3), gefehlt (2), voranbringen (3), Baustein (3), Fortschrittsbericht (2), energiepolitischen (2), beschlossen (5), Säule (3), Rahmen (5), Akteur (2), Vorangekommen (2), Gelingen (2), durchschnittlichen (2), Strompreise (2), Umstellung (2), notwendiger (2), verbunden (3), Bürger (4), riesige (2), teuer (2), aktiven (2), Chancen (3), Bürgerinnen (3), stoppen (2), Herren (7), Damen (7), Klimapolitik (2), wichtigen (3), richtiger (2), Bedeutung (3). 
auf die Verantwortung kommender Generationen, z.B. bei der Finanzierung der Energiewende zu verweisen (CSU 08.05.2014: 2712). ${ }^{46}$ Die CSU erklärt, es gehe ihr „nicht darum, die Energiewende zu ,stoppen““, sondern „darum, sie rational und sinnvoll zu machen" (CSU 01.06.2016: 16980).

Auch das Kollokationsprofil der SPD (567 Vorfälle) $)^{47}$, die nun an der Regierung beteiligt ist, ähnelt in der 18. Legislaturperiode noch stärker dem fraktionsunabhängigen Kollokationscluster, was ihr Wirken innerhalb dominanter Muster der Bedeutungsgenerierung von „Energiewende“ verdeutlicht. Marginalisierte Positionen innerhalb des Diskurse vertritt sie anders als in der 17. Legislaturperiode dabei kaum noch, auch kaum kritischen Positionen zu den zentralen Knotenpunkten. Die SPD artikuliert mehrfach das Bild die „Energiewende vom ,Kopf auf die ,Füße““ stellen (z.B. SPD 08.05.2014: 2705) und impliziert damit, die „Energiewende“ hätte zuvor auf dem „Kopf“ gestanden. Sie grenzt sich nun explizit von GRÜNEN Positionen ab, indem sie diesen bspw. vorwirft, „mit Ihrem starren Beharren auf Überförderung der Energiewende einen ,Tort ${ }^{\star}$, an[zu]tun “" (SPD 10.04.2014: 2450). Dagegen sei der Vorwurf, dass die SPD die „Energiewende“ „ausbremsen“ wolle „ein Stück Propaganda seitens der GRÜNEN“ (SPD 27.06.2014: 3939). „In einem sich aufgrund der Energiewende schnell und radikal ,ändernden“ Marktumfeld“ wolle die SPD Versorgungssicherheit gewährleisten (SPD 29.01.2016: 15105). Die SPD wolle mit der „Energiewende“ „,anderen Ländern als Vorbild dienen“, „,Nachahmer“ finden“ (SPD 22.05.2015: 10310).

„Klimaschutz“ ist im Kollokationsprofil der GRÜNEN weiterhin die nach Signifikanzwert rangerste Kollokation (396 Vorfälle von „Energiewende*“) ${ }^{48}$

46 Gemeint ist ein kreditbasiertes Finanzierungsmodell für die „Energiewende“, das die Kosten in die Zukunft verlagert. Denn „,die Energiewende“ sei „eben nicht per Knopfdruck“ zu bewerkstelligen. Deshalb dürfe es keine „Denkverbote“ geben - ,[D]er Vorschlag, die Lasten der Energiewende über einen längeren Zeitraum zu strecken“ sei „nach wie vor diskussionswürdig“ (CSU 08.05.2014: 2712).

47 Kollokationen SPD nach Rang (Häufigkeit): Erfolg (42), Akzeptanz (16) Gelingen (12), Klimaschutz (14), führen (18), Deutschland (32), Digitalisierung (11), erfolgreiche (9), gelingen (9), Energieeffizienz (7), Verkehr (7), bezahlbar (5), Umsetzung (9), Energiewende (8), Wärmebereich (3), doppelte (4), Kopf (5), ineinandergreifen (3), Rahmen (9), Forschungsagenda (2), Energien (6), Verkehrssektor (3), Tort (2), Zuge (4), Klimaschutzes (3), Ziel (9), erneuerbaren (5), Projekt (5), muss (9), antun (2), gewandelten (2), Füße (3), ändernden (4), erfolgreich (5), Nachahmer (2), ausbremsen (2), Rahmenbedingungen (5), Ausbau (5), Ausbremsen (2).

48 Kollokationen GRÜNE nach Rang (Häufigkeit): Klimaschutz (22), Deutschland (27), Säule (6), Abrissbirne (4), Monitoringbericht (4), dezentrale (4), Bayern (7), angezogener (3), Handbremse (3), Kohleland (3), Digitalisierung (5), Wärmesektor (3), Energieforschung (3), Energien (6), Verkehr (5), Gegenteil (6), gelingen (4), Netzbetreiber (3), Akzeptanz (4), Bürgerinnen (6), Bürger (6), Bekenntnis (3), Energieeffizienz (4), Anschlag (3), zweite (5), Wärmebereich (2), bezeichnet (3), Investitionssicherheit (2), Projekt (4), erneuerbaren (4), exakte (2), Schwangerschaft (2), gesellschaftliche (3), Ausbau (4), vorangerbracht (2), Innovationen (3), profitieren (3), konsequent (3), ausgerichtet (2), werben (2). 
Darüber hinaus werden umweltpolitische Themen von den GRÜNEN im Kontext von „Energiewende“ selten artikuliert. Die GRÜNEN betonen die Rolle der „Bürger“*innen bei der „Energiewende“: „Die treibende Kraft hinter der Energiewende ist die große ,gesellschaftliche“ Unterstützung“ (GRÜNE 08.05.2014: 2711). Die Rolle Deutschlands in der Welt hat auch bei den GRÜNEN einen hohen Stellenwert. In 27 von 396 Vorfällen werden „Deutschland“ und „Energiewende*“ in eine Äquivalenzbeziehung gebracht, wodurch „Deutschland“ der Knotenpunkt mit der höchsten Häufigkeit (und signifikanter als bei allen anderen Fraktionen) ist. „Deutschland“ müsse „für die Energiewende im Ausland ,werben““ (GRÜNE 29.04.2016: 16576). Die Artikulationen der GRÜNEN sind darüber hinaus erneut stark auf eine kritische Herausforderung der Regierungskoalition gerichtet. „Das ist das ,exakte“ ,Gegenteil“ von Energiewende“ (GRÜNE 13.11.2014: 6209). Die Kritik bezieht sich unter anderem auf die aus Sicht der GRÜNEN mangelnde Geschwindigkeit der „Energiewende“, die „mit ,angezogener“ „Handbremse““ (z.B. GRÜNE 31.01.2014: 856) durchgeführt werde. „Das ,Bekenntnis“ zur Energiewende ist schön, davon allein kommt sie aber nicht“ (GRÜNE 02.07.2015: 11177). Darüber hinaus kritisieren die GRÜNEN den ausbleibenden Kohleausstieg: „Deutschland kann kein ,Kohleland“ bleiben und erfolgreich eine weltweit glaubwürdige Energiewende stemmen“ (GRÜNE 25.06.2014: 3699).

Die GRÜNEN und die LINKEN verbinden als einzige Fraktionen in signifikanter Weise „Energiewende*“ mit einer „dezentralen“ Organisation. Die LINKE (171 Vorfälle) ${ }^{49}$ setzt zudem die Knotenpunkte „ökologisch“ und „,nachhaltige“. „Wir als Linke wollen ,ökologische“, demokratische Stadtwerke als ,zentrale“ Akteure der Energiewende“ (LINKE 29.01.2016: 15117). Die LINKE bringt mehrfach „sozial“ und „ökologisch“ in eine Bedeutungsbeziehung: „Dann klappt es mit der Energiewende ,sozial“ und ,ökologisch““ (LINKE 08.07.2016: 18231). Sie artikuliert „Energiewende*“nicht nur als reines technik- und marktorientiertes Energiethema, sondern bringt sie auch in andere Kontexte ein: „demokratische Beteiligung und Bildungsthemen wie Energiewende, ,nachhaltige“ Lebensweise, Mobilität und biologische Vielfalt“ (LINKE 26.09.2014: 5127). Sie setzt „Energiewende*“ in einen breiteren Gesamtkontext: „,Nachhaltige“ Stadtentwicklung ist daher für das ,Gelingen“ der Energiewende genauso entscheidend wie für die Reduzierung der Flächen - und der Ressourceninanspruchnahme“ (LINKE 08.05.2015: 9954). Wie die GRÜNEN fordert die LINKE die Artikulationen der Regierungskoalition kritisch heraus: „Darum wird Energiewende ,absurd“ wohl fortgeführt: Ungebremste Kohlestrommengen trotz permanent wachsendem Ökostrom“ (LINKE 23.06.2016: 17730).

49 Kollokationen LINKE nach Rang (Häufigkeit): Gelingen (3), Gebäudebereich (3), Dezentrale (3), Zentrale (4), Energieeffizienz (3), Dezentralen (2), Akzeptanz (3), Fortschrittsbericht (2), Europäisch (2), Voranbringen (2), Wand (2), Erfolgreiche (2), Erneuerbare (2), Hinbekommen (2), Verankern (2), Atomausstieg (2), Ökologisch (2), Weltweiten (2), Beitrag (3), Finanzierung (3), Teuer (2), Bürgern (2), Nachhaltige (2), Gabriel (3), Experten (2), Wasser (2), Deutschland (6), Wichtigen (2), Fördern (2), Schlicht (2), Absurd (2), Erhöhen (2), Sozial (2). 


\section{Erneuerbare Energien und Atomausstieg}

Während sich die Debatte um „Energiewende“ in der 18. Legislaturperiode nochmals leicht intensiviert hat, sinkt die relative Häufigkeit von erneuerbaren Energien im Vergleich zur Vorperiode (1858 Vorfälle, relative Häufigkeit sinkt von 0,17 auf 0,12 Vorfälle pro tausend Wörter). Damit erfolgt eine weitere quantitative Angleichung der beiden Diskurse, die sich jetzt in der Anzahl der Vorfälle nur noch geringfügig unterscheiden. Die artikulierten Themenbereiche um erneuerbare Energien (vgl. Tabelle 24) ändern sich nur geringfügig im Vergleich zur vorigen Legislaturperiode.

Tabelle 24: Thematisch gruppierte rangerste 40 Kollokationen von erneuerbar* in der 18. Legislaturperiode

\begin{tabular}{|c|c|}
\hline Thematische Gruppierung & $\begin{array}{l}\text { Kollokationen (=Knotenpunkte) } \\
\text { (freq/log likelihood) }\end{array}$ \\
\hline Technologien & $\begin{array}{l}\text { Energien }(1289 / 17645,07) \text {, Energie }(25 / 137,03) \text {, } \\
\text { Bereich }(66 / 294,84) \text {, Bereichs }(13 / 145,3) \text {, Wär- } \\
\text { mebereich }(9 / 107,19) \text {, Stromsektor }(6 / 68,19) \text {, syn- } \\
\text { chronisieren }(5 / 60,6) \text {, Quellen }(7 / 55,88)\end{array}$ \\
\hline Marktorientierung & $\begin{array}{l}\text { Marktanreizprogramm }(6 / 67,1) \text {, Markt }(16 / 85,73) \text {, } \\
\text { Ausschreibungen }(12 / 103,84), \text { Investitionen } \\
(19 / 74,77), \text { Strommarkt }(8 / 72,07)\end{array}$ \\
\hline Förderung/Ausbau & $\begin{array}{l}\text { Förderung }(35 / 201,82) \text {, Ausbaus }(18 / 193,80) \text {, } \\
\text { Ausbau }(229 / 2357,22) \text {, ausbauen }(10 / 65,75) \text {, aus- } \\
\text { zubauen }(8 / 57,37) \text {, Anteil }(97 / 847,6), \text { Prozent } \\
(89 / 370,02), \text { Zubau }(11 / 106,1), \text { stärker }(15 / 66,19)\end{array}$ \\
\hline Energieverbrauch & Energieeffizienz $(64 / 610,35)$ \\
\hline $\begin{array}{l}\text { Umstellung der Energiever- } \\
\text { sorgung }\end{array}$ & $\begin{array}{l}\text { Zeitalter }(18 / 159,08) \text {, Energiewende }(20 / 101,47) \text {, } \\
\text { Umstieg }(11 / 120,63)\end{array}$ \\
\hline Energieerzeugung & $\begin{array}{l}\text { Stroms }(16 / 189,57), \text { Strom }(63 / 581,78), \text { Stromer- } \\
\text { zeugung }(17 / 174,56), \text { Stromproduktion }(7 / 72,01) \text {, } \\
\text { Erzeugung }(11 / 106,1) \text {, erzeugt }(8 / 61,97), \text { Nutzung } \\
(17 / 116,87), \text { Stromversorgung }(9 / 89,25), \text { Wärme } \\
(20 / 210,72) \text {, Wärmeversorgung }(5 / 57,72) \text {, decken } \\
(7 / 57,43), \text { fossilen }(8 / 61,97)\end{array}$ \\
\hline Gesetze & EEG $(13 / 95,23)$, Änderungen $(14 / 75,5)$ \\
\hline
\end{tabular}

Quelle: eigene Darstellung

Der Wärmebereich kommt wieder stärker in den Fokus. Zudem wird zunehmend eine Diskussion über den „Strommarkt“ geführt: „Nun müssen wir den ,Strommarkt“ fit für die Erneuerbaren und die Erneuerbaren fit für den ,Markt" machen“ (SPD 08.07. 2016: 18228). Im Zuge der „EEG“-Novellierung wird darüber diskutiert, die feste 
Einspeisevergütung abzuschaffen und stattdessen auf Direktvermarktungen und „Ausschreibungen“ zu setzen, z.B.: „Herr Gabriel sagt dieser Tage gerne, der Welpenschutz für erneuerbare Energien sei beendet, man müsse die Erneuerbaren jetzt durch ,Ausschreibungen“ in einen Wettbewerb bringen“ (LINKE 29.01.2016: 15101). Die erneuerbaren Energien sollen marktfähig werden - die CDU erklärt sie wolle „das ,EEG‘ in den kommenden Jahren Schritt für Schritt reformieren, stärker an den ,Markt' heranbringen und somit auch erneuerbare Energien wettbewerbsfähig machen[...]“ (CDU 17.01.2014: 551).

Die Artikulationen von Atomausstieg* reduzieren sich in der 18. Legislaturperiode (159 Vorfälle) im Vergleich zur Vorperiode bezogen auf die relative Häufigkeit um das 1,5fache (von 0,0156 Vorfällen pro tausend Wörter auf 0,0103). Der Dissens über den Atomausstieg scheint in großen Teilen beseitigt (vgl. Tabelle 25).

Tabelle 25: Thematisch gruppierte 34 Kollokationen von Atomausstieg* in der 18. Legislaturperiode

\begin{tabular}{|l|l|}
\hline Thematische Gruppierung & $\begin{array}{l}\text { Kollokationen (=Knotenpunkte) } \\
\text { (freq/log likelihood) }\end{array}$ \\
\hline Allgemein & $\begin{array}{l}\text { Euratom-Vertrag }(2 / 26,22), \text { reformieren }(2 / 18,03), \\
\text { Risiko-Reaktoren }(4 / 72,65), \text { Gronau }(4 / 60,62), \\
\text { Kelheim }(2 / 34,7), \text { beschlossen }(10 / 62,44), \text { be- } \\
\text { schlossenen }(4 / 42,65), \text { Fukushima }(4 / 53,11), \text { kon- } \\
\text { sequent }(6 / 50,86), \text { durchsetzen }(2 / 13.99), \text { Konsens } \\
(3 / 22,75), \text { Radioaktivität }(2 / 28,54), \text { möglichen } \\
(2 / 14,67), \text { internationalen }(3 / 14,57), \text { Großbritanni- } \\
\text { en }(2 / 13,85)\end{array}$ \\
\hline Zeit & $\begin{array}{l}\text { Jahre }(4 / 13,5), \text { beschleunigen }(5 / 56,34), \text { unverzüg- } \\
\text { lichen }(2 / 31,93)\end{array}$ \\
\hline Dissens & $\begin{array}{l}\text { Atomsubventionierung }(2 / 36,32), \text { Atomförderung } \\
(2 / 34,7), \text { Risiken }(6 / 48,79), \text { ernst }(3 / 17,47), \\
\text { Wehrpflicht }(2 / 23,07)\end{array}$ \\
\hline Kosten & $\begin{array}{l}\text { Klagen }(6 / 66,43), \text { Vattenfall }(2 / 21,23), \text { aufkom- } \\
\text { men }(2 / 21,23), \text { Kosten }(3 / 14,03), \text { verklagt } \\
(2 / 24,99)\end{array}$ \\
\hline $\begin{array}{l}\text { Energiepolitisches Gesamt- } \\
\text { konzept }\end{array}$ & $\begin{array}{l}\text { Energiewende (7/50,86) } \\
\text { deutschen }(5 / 23,04), \text { europäischen }(5 / 26,14), \text { eu- } \\
\text { ropaweiten }(2 / 36,32)\end{array}$ \\
\hline Deutschland $(23 / 103,11)$, Europa $(12 / 60,04)$, \\
\hline
\end{tabular}

Quelle: eigene Darstellung 
Strittig ist nun vor allem die Frage, wer die Kosten für den Atomausstieg zu tragen habe. So fordert die LINKE, dass diejenigen, „die sich jahrzehntelang eine goldene Nase mit der Atomenergie verdient haben, für die Milliarden Euro an Kosten des Atomausstiegs tatsächlich ,aufkommen“ [...]“ (LINKE 15.04.2016: 16266). „Vattenfall“ allerdings habe wegen „,des Atomausstiegs gegen die Bundessregierung geklagt und fordert eine Entschädigung in Höhe von 3,7 Milliarden Euro“ (GRUENE 21.05 .2014: 2954).

Genauso wie „Energiewende*“ wird nun auch Atomausstieg* verstärkt in eine Äquivalenzbeziehung mit dem Knotenpunkt „Deutschland“ gebracht. In einer Analyse des breiteren Kontextes dieser Vorfälle wird deutlich, dass dabei auch technischer Fortschritt und Wirtschaftswachstum als politische Ziele innerhalb der in dieser Äquivalenzkette artikulierten Forderungen eine Rolle spielen: „Klimaschutz schafft Wachstum. Dieses Wachstum hätten wir nicht ohne die erfolgreiche Umweltpolitik in ,Deutschland“, vom Atomausstieg über das EEG bis zur ,Energiewende“ und zu innovativen, ressourcenschonenden und treibhausgasarmen Produktionsprozessen “ (SPD 23.06.2016: 17598).

\subsubsection{Diskussion: Regelmäßige Differenzbeziehungen von „Energiewende“ in Auseinandersetzung um Hegemonie}

Insgesamt legt die Diskursanalyse in diesem ersten computerbasierten Anwendungsschritt nahe, dass die parlamentarische Debatte um „Energiewende“ vor „Fukushima“ - auch unter rot-grün - sehr schwach ausgeprägt war. Eine Fixierung von Knotenpunkten in einer Äquivalenzkette um „Energiewende“ gelingt daher vor 2011 kaum. Die wenigen Vorfälle von „Energiewende“ in den Jahren 1998 bis 2005 zeigen, dass die rot-grüne Bundesregierung das Thema „Energiewende“ selten direkt aufgreift. In der 16. Legislaturperiode tritt die LINKE verstärkt in der Debatte auf und setzt eigene Forderungen - „Energiewende“ bleibt aber aufgrund der geringen Zahl der Vorfälle marginalisiert. Vor allem CDU/CSU und FDP nehmen vor „Fukushima“ kaum an der Bedeutungsgenerierung von „Energiewende“ teil (vgl. Abbildung 7). Es gelingt vor 2011 also nur unzureichend, „Energiewende“ im parlamentarischen Raum mit Bedeutung aufzuladen, bzw. sind in dieser Hinsicht durch die Fraktionen im Bundestag kaum Bemühungen zu erkennen. Die rot-grüne Bundesregierung nutzt ihre Regierungszeit nicht, um „Energiewende“ im Bundestag zu politisieren. Erst nach „Fukushima“ findet eine Debatte um „Energiewende“ in nennenswertem Umfang statt - erst dann scheint es einen mehrheitlichen politischen Willen zu einer „Energiewende" zu geben, deren Bedeutung im parlamentarischen Raum jetzt erst generiert wird und gleichzeitig umkämpft ist.

Im Gegensatz dazu, scheint das Thema erneuerbare Energien von Anfang an breite parlamentarische Aufmerksamkeit zu genießen. Über eine prinzipielle Förderung erneuerbarer Energien, die nicht zwingend mit einer grundsätzlichen energiepolitischen Wende verbunden wird, scheinen sich bereits in der 14. Legislaturperiode alle Fraktionen einig zu sein. Anders sieht es beim Atomausstieg aus: Dieser wird zwar ebenfalls breit diskutiert, hier sind die politischen Lager allerdings deutlich gespalten in Befürworter*innen und Gegner*innen eines Ausstiegs. Atomausstieg und „Energiewende“ werden zwar vor „Fukushima“ vereinzelt in Beziehung zueinander ge- 
setzt, diese Verbindung ist jedoch schwach ausgeprägt. Auch hier deutet sich an, dass der Atomausstieg, wie er auf parlamentarischer Ebene diskutiert wird, anfangs nicht zwingend mit einer grundsätzlicheren energiepolitischen Wende verbunden wird. Während vor „Fukushima“ die Diskurse um „Energiewende“, erneuerbare Energien und Atomausstieg im parlamentarischen Raum also relativ unverbunden waren, scheint sich erst nach „Fukushima“ die „Energiewende“ als umfassende politische Forderung für Atomausstieg und erneuerbare Energien zu etablieren.

Wie kann nun die Bedeutung der mit „Energiewende“ in Verbindung stehenden diskursiven Elemente, also der regelmäßigen Differenzbeziehungen und Diskursmuster, für Kämpfe um Hegemonie, bzw. für die hegemoniale Ordnung des diskursiven Raumes, verdeutlicht und bewertet werden? Wie in Kapitel 4.2.1 ausgeführt, klassifiziert Laclau (2005: 74ff.) die Elemente des Diskurses als Forderungen und unterscheidet zwischen demokratischen, popularen und affirmativen/flottierenden Forderungen. Sowohl demokratische, als auch populare Forderungen weisen eine kritische Stellung zum hegemonialen Diskurs ${ }^{50}$ auf, während affirmative Forderungen diesen stützen (Bedall 2014: 62f.). Betrachtet man die parlamentarischen Debatten um „Energiewende“ vor dem Hintergrund dieser Klassifizierungen, wird deutlich, dass populare Forderungen zunächst wenig zu finden sind. Denn die „Energiewende“ wird kaum mit Forderungen aus verschiedenen gesellschafs- oder umweltpolitischen, bzw. sozial-ökologischen Bereichen verbunden. Eine starke Äquivalenzkette um „Energiewende“ bildet sich aufgrund der geringen Verwendung des Begriffes zwischen der 14. und 16. Legislaturperiode nicht heraus. Diese fehlende Verbindung (bzw. deren schwache Ausprägung) mit anderen Kämpfen gegen den Status quo (z.B. Anti-Akw, Naturschutz, Anti-Kapitalismus, Nachhaltigkeit, etc....) innerhalb des Parlaments und somit die anfangs fehlende Ausbreitung der Äquivalenzkette um „Energiewen$\mathrm{de}^{\text {“ }}$ steht dem Erfolg eines kritisch positionierten „Energiewende“-Diskurses entgegen. In der 16. Legislaturperiode bringt sich die LINKE verstärkt in den Diskurs ein und verbindet „Energiewende“ mit Forderungen, die als popular klassifiziert werden können, da Verbindungen mit anderen sozialen Kämpfen hergestellt werden. So bringt die LINKE „Energiewende“ in eine - wenn auch aufgrund der wenigen Vorfälle brüchige - Äquivalenzkette, die sich auf soziale Bereiche, wie Menschenrechte oder Frieden (s.o.) ausbreitet, indem sie diese mit Forderungen nach einer ,, radikalen “, ,,ökologischen“ und „,nachhaltigen“ „Energiewende“ verbindet. Die „Energiewende" ist in diesem popularen Diskurs als Teil einer umfassenderen Forderung nach Gesellschaftsveränderung zu verorten (vgl. auch Nonhoff 2007: 182). Durch die Forderungen einer ,, konsequenten “ und ,, radikalen “ Energiewende entstehen eine deutliche Abgrenzung gegenüber dem herkömmlichen Energiesystem sowie anderer, weniger umfassenderer, Vorstellungen von „Energiewende“. Die geringe Häufigkeit dieser Artikulationen ist auch dem verschuldet, dass andere Fraktionen sie kaum auf-

50 Unter einem hegemonialen Diskurs wird ein Diskurs verstanden, mit dem ein universaler Anspruch vertreten wird und der gleichzeitig eine hohe diskursive Verbreitung aufweist, d.h. ein Diskurs, dem es am besten gelingt, seine Perspektive und politische Positionierung als allgemein gültig zu konstituieren, vgl. Kapitel 2.5. Aufgrund der geringen diskursiven Verbreitung steht „Energiewende“ also zunächst außerhalb des hegemonialen Diskurses. 
greifen, was als Anzeichen für die Marginalisierung dieser popularen Forderungen zu werten ist.

Ein großer Teil der mit „Energiewende“ verbundenen Forderungen bleiben zwischen der 14. und 16. Legislaturperiode isoliert, treten also nur vereinzelt zusammen auf (z.B. Atomausstieg). Und wenn, dann sind sie meist nicht mit weitergehenden gesellschafts- oder umweltpolitischen Forderungen verbunden (z.B. wie die Forderung nach einer generell nachhaltigeren Lebensweise oder sozialer Gerechtigkeit). Diese Forderungen sind somit nach Laclau (2005) als demokratische Forderungen zu klassifizieren. Die „Energiewende“ wird nicht als starkes Identifikationsprinzip potenziell weitergehender Forderungen bedient, ist also kein Prinzip, das den Inhalt dieser Forderungen auf parlamentarischer Ebene auf einen gemeinsamen Nenner bringt und zu ihrem ,positiven symbolischen Ausdruck“ wird (ebenda: 82 [eigene Übersetzung]). So beinhalten die Forderungen ,Klimaschutz', ,Atomausstieg' oder ,erneuerbare Energien“ nicht zwingend die Forderung „Energiewende“, sondern treten auch häufig unverbunden auf. „Energiewende“ hat also auf parlamentarischer Ebene keine, bzw. nur eine schwache Repräsentationsfunktion. Nonhoff (2007: 187) bezeichnet „Repräsentation“ als hegemoniale Strategie, die hier demnach von der rot-grünen Regierungskoalition kaum verfolgt wird. Die Möglichkeit, den diskursiven Raum um „Energiewende“ politisch zu bestimmen, „Energiewende“ zu einer umfassenden Forderung zu erheben und sich somit von einem affirmativen energiepolitischen Diskurs abzugrenzen, wird von der rot-grünen Regierungskoalition weitestgehend nicht ergriffen. Während populare Forderungen die hegemoniale Formation ${ }^{51}$ an sich herausfordern, können demokratische Forderungen von einer sich ausbreitenden hegemonialen Formation aufgenommen werden (Laclau 2005: 82). Die überwiegende Verbindung mit demokratischen Forderungen sowie die geringe diskursive Verbreitung verdeutlichen also die Schwäche des „Energiewende“-Diskurses in seiner kritischen Funktion zwischen der 14. und der 16. Legislaturperiode.

Während „Energiewende“ durch die seltene Artikulation im Parlament kaum als gemeinsamer politischer Wille einer Mehrheitsgruppe erscheinen kann (Nonhoff 2007: 184), wird die Forderung erneuerbare Energien gleichzeitig von allen Fraktionen geteilt. Dies könnte als defensiv-hegemoniale Paradestrategie der Gegner*innen-

51 Diskursive Formationen zeichnen sich nach Laclau/Mouffe durch ,Regelmäßigkeit in der Verstreuung' aus. In diesem Sinne kann Hegemonie auch als hegemoniale Formation gefasst werden, der es durch besondere Verbreitung gelingt, ihre Perspektive zu naturalisieren, also als eine vorherrschende diskursive Formation. Nach Laclau/Mouffe (2015: 181f.) ist eine hegemoniale Formation eine ,artikulierte[...] Totalität von Differenzen“, die sich selbst bezeichnet, „indem sie eine Äquivalenzkette hervorbringt, die das was jenseits der inneren Grenzen ist, als das konstruiert, was sie nicht ist" (Laclau/Mouffe 2015: 181f.). Aufgrund der geringen diskursiven Verbreitung von „Energiewende“ sowie der expliziten Abgrenzung, die durch einige Fraktionen erfolgt (z.B. „beschworene“ „Energiewende“ (vgl. Kapitel 5.1.2), weise ich für die 14. Legislaturperiode bis „Fukushima“ den Teil des Diskurses, der sich durch seine gemeinschaftliche Abgrenzung von „Energiewende“ auszeichnet, bzw. diese durch Nicht-Nennung in ein ,Außen“ verweist, der hegemonialen Formation zu, deren Position ich vereinfachend als ,herkömmliches Energiesystem mit Förderung erneuerbarer Energien` beschreibe (vgl. Abbildung 11). 
schaft der „Energiewende“ interpretiert werden: Indem einzelne Forderungen, die mit „Energiewende“ verknüpft sind - wie erneuerbare Energien, Effizienz oder Klimaschutz - zu berechtigten Forderungen erklärt werden, aber ein Widerspruch im Energiesystem insgesamt negiert wird, wird der Antagonismus zwischen dem herkömmlichen Energiesystem und ihrem diffusem ,Anderen“, dem auch die „Energiewende“ zugewiesen wird, in gewisser Weise durchbrochen (vgl. auch Nonhoff 2006: 239). Erneuerbare Energien werden - auch durch ihre ungleich stärkere Thematisierung und Befürwortung - zu einem Identifikationsprinzip weiterer Forderungen, die zwar auch mit „Energiewende“ verknüpft werden (z.B. Effizienz oder spätestens ab der 15.Legislaturperiode Klimaschutz) - deren Verbindung zu erneuerbaren Energien aber wesentlich stärker ist. ${ }^{52}$ Auf diese Forderungen wird somit struktureller Druck von zwei Seiten ausgeübt: Sowohl von Gegner*innen als auch von Befürworter*innen der „Energiewende“. Die Bedeutung dieser Forderungen bleibt so zwischen den äquivalentiellen Fronten unbestimmt (Laclau 2005: 132), sie stehen im „Spannungsfeld zwischen Hegemonie und Gegen-Hegemonie“ (Bedall 2014: 62). Solche Forderungen, deren Bedeutung quasi zwischen Hegemonie und GegenHegemonie ,überhängt', bezeichnet Laclau als flottierende Forderungen. Die Art und Weise wie die Bedeutung dieser Forderungen oder ihrer Identifikationsprinzipien fixiert wird, ist noch offenes Ergebnis eines hegemonialen Kampfes (Laclau 2005: 132). Die hier erarbeitete Klassifizierung von Forderungen in Auseinandersetzung um Hegemonie ist für die 14.-16. Legislaturperiode in Abbildung 11 dargestellt.

52 So tritt beispielsweise (Energie)Effizienz zusammen mit „Energiewende“ in der 15. Legislaturperiode im betrachteten Fenster nur $3 \mathrm{Mal}$ auf (Effizienz freq=2; 11=20,88, Energieeffizienz freq=1; $11=11,27)$ und Klimaschutz $2 \mathrm{Mal}(11=18,12)$, während (Energie)Effizienz mit „erneuerbar(*)“ 40 Mal auftaucht (Energieeffizienz freq=27; 11=285,50, Effizienz freq=13; 1l=89,73) und „erneuerbar(.*)“ mit Klimaschutz 12 Mal (1l=64,38). 
Abbildung 11: Klassifizierung von Forderungen ${ }^{53}$ im Kontext von „Energiewende*" in Auseinandersetzung um Hegemonie zwischen der 14. und der 17. Wahlperiode vor „Fukushima“"

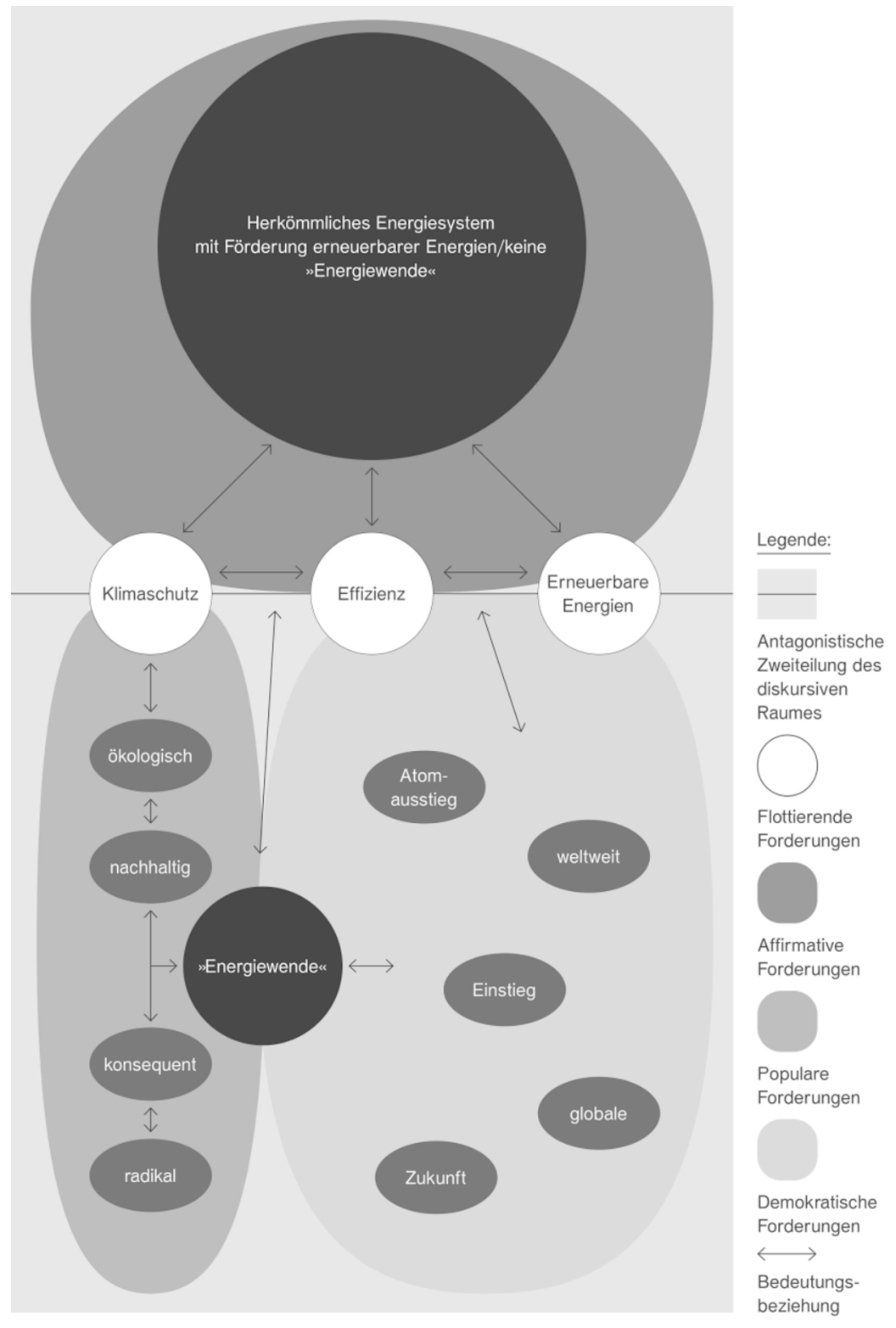

Quelle: eigene Darstellung

53 Die demokratischen und flottierenden Forderungen sind für die grafische Darstellung anhand einiger für den Diskurs besonders relevanter Knotenpunkte veranschaulicht und erheben keinen Anspruch auf Vollständigkeit. Für eine vollständige Darstellung der Kollokationen sei auf die vorige Analyse verwiesen. 
„Fukushima“ disloziert in besonderer Weise den Diskurs, der einen Widerspruch zwischen Klimaschutz und Atomausstieg konstruiert hatte und erneuerbare Energien lediglich bis zu einem begrenzten Maße als Teil des Energiesystems konstituierte. Nach „Fukushima“ erhöht sich der diskursive Verbreitungsgrad von „Energiewende“ schlagartig, was sicherlich auch als Erfolg der kritischen Diskurse zu werten ist, die diese Sichtweise herausgefordert hatten. Allerdings gelingt es den Gruppen, die zuvor einer „Energiewende“ ablehnend gegenüber standen (z.B. große Teile von FDP, CDU, CSU) relativ schnell „Energiewende“ in ihre Äquivalenzkette zu integrieren. Sie machen sich diese nun artikulatorisch zu eigen und erheben sie zur Repräsentantin ihres Politikwechsels. Dafür wird der Atomausstieg politisch akzeptiert. Der diskursiven Formation, die zuvor für das ,herkömmliche Energiesystem“ stand, gelingt es also ihre eigenen inneren Grenzen zu verschieben, den politischen Raum neu zu definieren und somit nach Laclau/Mouffe die ,allgemeinste Existenzbedingung jeder Formation“ zu erfüllen (Laclau/Mouffe 2015: 18). Aber auch aus den anderen Fraktionen wird die Forderung „Energiewende“ in einem relevanten Maße erst nach „Fukushima“ artikuliert. „Energiewende“ wird so in den Wahrheitshorizont und die Deutungsmuster einer sich ausbreitenden, mit den Fraktionsgrenzen nicht unbedingt identischen, hegemonialen Formation integriert. Dass diese sich ausbreitende hegemoniale Formation in erster Linie durch marktwirtschaftliche Deutungsmuster gekennzeichnet ist, wird in Kapitel 5.4 anhand der folgenden Analyseschritten weiter verdeutlicht, deutet sich aber bereits hier in der Betrachtung der nach „Fukushima“ relevanten Knotenpunkte an. Dabei steht insbesondere der wirtschaftliche „Erfolg“, auch für „Deutschland“ als Wirtschaftsstandort im Fokus, z.B.: „Der ,Erfolg“ der Energiewende muss sich schließlich auch daran messen lassen, dass ,Deutschland“ ein wettbewerbsfähiger Wirtschafts- und Industriestandort bleibt“" (CSU 23.05.2014: 3221). Die Verbindung von „Energiewende“ und „Deutschland“ scheint neben der Betonung der wirtschaftlichen Bedeutung für den Standort Deutschland, nach „Fukushima“ zunehmend zum identitätsstiftenden Moment zu werden, z.B.: „,Deutschland“ übernimmt bei der Energiewende eine Vorreiterrolle für alle Industrienationen“ (CSU 14.03.2013: 28421). Dies wird in Kapitel 5.2.6 (Deutschland als Vorreiter) noch genauer analysiert.

Die schnelle Aneignung von „Energiewende“ ist auch möglich, weil die Bedeutungsaufladung auf parlamentarischer Ebene vor „Fukushima“ schwach war und weil die hegemoniale Formation bereits zuvor Forderungen geteilt hat, die nun unter „Energiewende“ subsumiert werden: z.B. Erneuerbare Energien, Effizienz, Klimaschutz. Da auf bundespolitischer Ebene bislang kaum politische Bereiche zwingend mit „Energiewende“ verbunden sind, erscheint eine Konzentration auf wirtschaftspolitische und technologische Handlungsfelder nach „Fukushima“ nicht widersprüchlich. Es gelingt hier relativ einfach, den diskursiven Raum zu begrenzen. Gleichzeitig stehen „Energiewende“ aufgrund der geringen Bedeutungsaufladung vor „Fukushima“ zahlreiche Anschlussmöglichkeiten und „komplexitätsreduzierende Zugänge“ offen (Nonhoff 2006: 233). „Energiewende“ zeigt sich nach „Fukushima“ als ,außergewöhnlich interpretationsoffen[...]“ (ebenda). So steht „Energiewende“ gleichzeitig für Klimaschutz, wirtschaftlichen Erfolg und eine deutsche Vorreiterrolle, während sich die strukturellen Veränderungen auf den Strombereich konzentrieren. Die Kollokationen, die nach „Fukushima“ besondere Signifikanz aufweisen, wie „Erfolg“ oder „Gelingen“ sind nicht von vorne herein mit spezifischen politischen Inhal- 
ten verbunden. Gerade diese Deutungsoffenheit ist für die mit „Energiewende“ verbundene Identitätsstiftung zentral (vgl. auch Brodocz 2003: 60f.), denn damit ist eine soziale Integrationsleistung verbunden (Nonhoff 2006: 233), die es auch vormaligen Gegner*innen einer „Energiewende“ ermöglicht, dieser - auf der Grundlage ihrer eigenen Interpretation - zuzustimmen. Gleichzeitig erscheint die „Energiewende“ aber weiterhin auf ambivalente Weise als Zugeständnis an die politischen Gegner*innen, das nur unter gewissen Voraussetzungen gewährt wurde - nämlich vor allem der Begrenzung der „Kosten“ sowie der Vermeidung einer „Deindustrialisierung“, wofür eine marktwirtschaftliche Ausrichtung als zentral konstituiert wird (z.B.: FDP 11.09.2012: 22898).

Viele der nach „Fukushima“ mit „Energiewende“ neu verbundenen Forderungen werden auch von SPD und teilweise GRÜNEN geteilt (z.B. „Akzeptanz“, „Deutschland“, „Erfolg“), was erneut verdeutlicht, dass die Grenzen der hegemonialen Formation nicht mit den Parteigrenzen identisch sind (vgl. Abbildung 12).

Abbildung 12: Klassifizierung von Forderungen ${ }^{54}$ im Kontext von „Energiewende*“ in Auseinandersetzung um Hegemonie nach ,Fukushima“: ,Energiewende“ als Teil der hegemonialen Formation

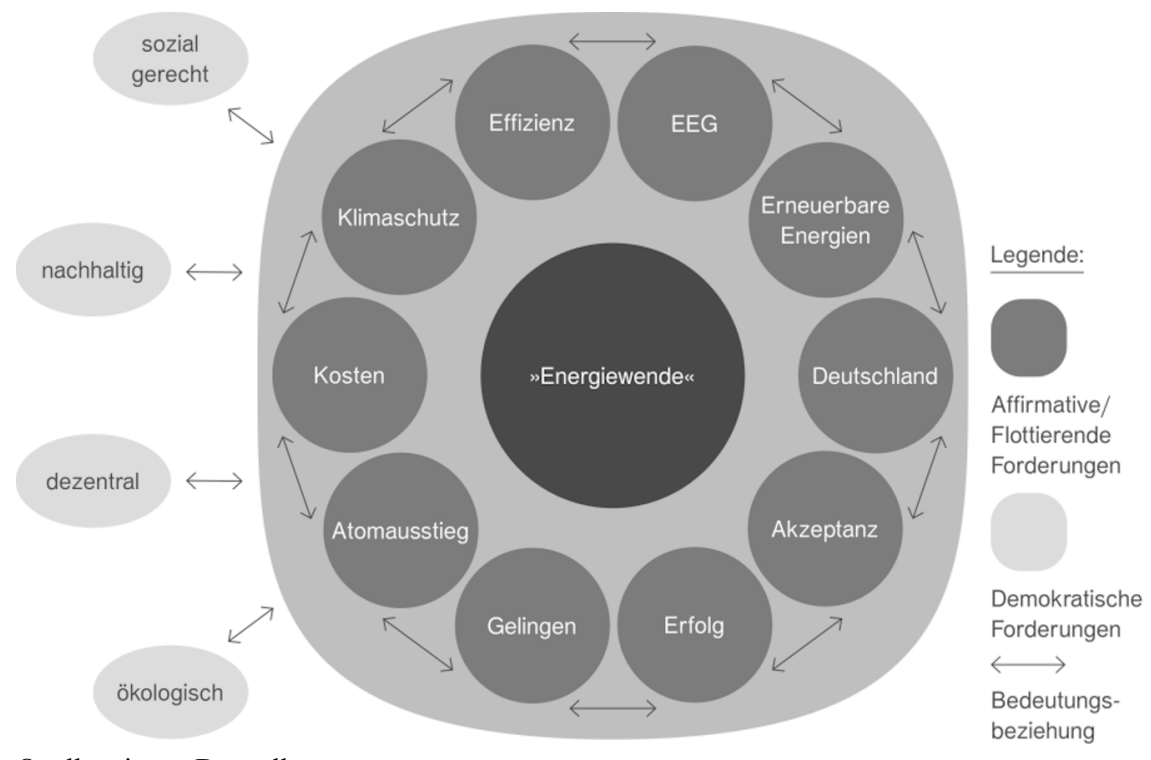

Quelle: eigene Darstellung

Außerhalb der hegemonialen Formation stehen im Zusammenhang mit „Energiewende" nur wenige - überwiegend von GRÜNEN und LINKEN artikulierte - Forderungen (,nachhaltig“, „ökologisch“, „,sozial“, „dezentral“), die aufgrund ihrer gerin-

54 Die in der Abbildung dargestellten Knotenpunkte entsprechen überwiegend den jeweils rangersten Knotenpunkten der 17. und 18 Wahlperiode. Für die demokratischen Forderungen wurden jeweils diejenigen ausgewählt, die die Klassifizierung am besten veranschaulichen. 
gen Verbreitung und der kaum noch stattfindenden Verbindung mit politischen Forderungen aus anderen sozialen Bereichen, nicht in einer starken Äquivalenzbeziehung stehen und somit hier vereinfachend als demokratische Forderungen klassifiziert werden ${ }^{55}$. Obwohl vor allem GRÜNE und LINKE immer wieder die „Energiewende"-Politik der Regierungskoalitionen kritisieren ${ }^{56}$, findet eine Artikulation einer grundlegend ,anderen“ „Energiewende“ kaum noch statt, was letztlich zu einer Ausbreitung der hegemonialen Formation führt - eine antagonistische Zweiteilung des diskursiven Raumes ist zumindest auf parlamentarischer Ebene kaum noch erkennbar.

Die hier aufgrund der bisherigen Datenlage interpretierten Trends im Diskurs über „Energiewende“ werden in den folgenden Analyseschritten weiter vertieft und qualitativ bewertet.

\subsection{STORY-LINES IM DISKURS UM „ENERGIEWENDE“}

Während im vorangehenden Kapitel regelmäßige Differenzbeziehungen von Elementen identifiziert wurden, werden nun komplexere Verknüpfungen in Bedeutungssystemen herausgearbeitet und nach Story-Lines kodiert. Um das genaue methodische Vorgehen in diesem Analyseschritt nachzuvollziehen, verweise ich auf Kapitel 4.2.2, in dem das Verfahren präzise aufgeschlüsselt ist. Auf eine erneute Wiedergabe der Methodik möchte ich daher an dieser Stelle verzichten.

Die im Folgenden beschriebenen Story-Lines reduzieren „Energiewende“ jeweils auf eine bestimmte Weise, sie ,erzählen“ also jeweils einen Teil von „Energiewende“ aus einer spezifischen, komplexitätsreduzierenden Perspektive. Da die Mitglieder des Bundestages als Teil der Konstruktion von „Energiewende“ betrachtet werden, sind die in Bundestagsdebatten identifizierten Story-Lines als grundlegend für die hier getroffenen politischen Entscheidungen anzusehen. Unter Story-Lines werden komplexe Artikulationen verstanden, die auch Verknüpfungen „oberhalb der Wort- und Satzebene“ (Glasze u.a. 2009: 293) beinhalten. D.h. im Gegensatz zum vorigen Kapitel, in dem die Beziehungen zwischen einzelnen spezifischen Elementen betrachtet wurden, können Story-Lines über verschiedene Elemente, sich im Zeitverlauf ändernde Elemente oder sogar über implizite Abgrenzung artikuliert werden. Von einer Story-Line wird gesprochen, wenn ein Teil von „Energiewende“ - ob explizit oder implizit - immer wieder auf ähnliche Weise gedeutet oder eingeordnet wird.

Im vorigen Kapitel 5.1 hat sich gezeigt, dass zwischen der 14. und 16. Legislaturperiode kaum von „Energiewende“ gesprochen wurde. Ich betrachte daher im Folgenden auch, welche - expliziten oder impliziten - Abgrenzungen zu „Energiewen$\mathrm{de}^{\text {“ }}$ in dieser Zeit stattfinden und wie sich diese erklären lassen. Darüber hinaus zeigt

55 Aufgrund der - wenn auch schwachen - Verbindung zu anderen politischen Bereichen, haben diese Forderungen sicherlich auch einen popularen Anteil, werden hier aber als demokratisch bezeichnet, um die Schwäche des kritischen Diskurses hervorzuheben.

56 Wie ich oben bereits verwiesen habe, kommt der Opposition unter GRÜNEN und LINKEN im Gegensatz zur Mehrheitsgruppe, die über 80\% der Mandate verfügt, nur ein geringer Redeanteil zu, was dies Positionen zusätzlich marginalisiert. 
sich, welche Story-Lines aus dieser Zeit für den „Energiewende“-Diskurs nach „Fukushima“" anschlussfähig sind, bzw. wie sich diese nach „Fukushima“ verändern.

Zunächst wird untersucht, wie über den Zeitverlauf direkt auf „Energiewende“ verwiesen wird (oder eben nicht verwiesen wird), also wie „Energiewende“ als ,großes Ganzes“ gedeutet/erzählt wird oder welche politischen Ziele „Energiewende“ direkt ersetzen. Ich bezeichne dies als die ,politische Einordnung' von „Energiewende“, da ausgehend von der politischen Schwerpunktsetzung der jeweiligen Regierungskoalitionen die einschneidensten Prägungen des „Energiewende“-Diskurses über die Legislaturperioden hinweg nachgezeichnet werden. Dieses erste Kapitel 5.2.1 dient einer Übersicht über den Diskursverlauf nach Legislaturperioden, bevor auf Deutungszusammenhänge quer zu diesen eingegangen wird.

Im weiteren Verlauf werden die Story-Lines zwischen der 14. bis 18. Legislaturperiode genauer betrachtet. Die in den Kapitelüberschriften 5.2.2 - 5.2.10 bezeichneten Story-Lines zeichnen sich jeweils durch ihre Dominanz im Datenmaterial aus ${ }^{57}$, sie werden überwiegend von den jeweiligen Regierungskoalitionen artikuliert. Herausfordernde Story-Lines werden eher aus der Opposition heraus artikuliert, machen politische Kämpfe sichtbar. Sie werden im Folgenden im Textverlauf von der Beschreibung der dominanten Story-Line formal durch einen Kasten abgegerenzt.

Insgesamt wird also im folgenden Kapitel nachgezeichnet, wie „Energiewende“ im Bundestag erzählt, bzw. gerade nicht erzählt wird und welche Bedeutungskämpfe stattfinden.

\subsection{1 Übersicht über die Entwicklung der politischen Einordnung von „Energiewende“}

Als Einstieg in die Untersuchung der Story-Lines werden nun wie beschrieben die unmittelbar mit „Energiewende“ in Verbindung stehenden Deutungszusammenhänge analysiert und über die Legislaturperioden herausgearbeitet. Dies dient dazu, sich zunächst einen Überblick über die zeitliche Entwicklung des Diskurses zu verschaffen. Es kann zudem gezeigt werden wie die diskursive Einordnung von energiepolitischen Problemen direkt mit der Konstitution politischer Praktiken zusammenhängt.

\section{4. und 15. Legislaturperiode: Energiepolitik im Rahmen von ökologischer Modernisierung und Atomausstieg}

Eine ökologische Modernisierung ist als eines der zentralen Ziele im Koalitionsvertrag der rot-grünen Regierungskoalition von 1998 festgeschrieben: „ökologische Modernisierung als Chance für Arbeit und Umwelt nutzen“ (Koalitionsvertrag 1998: 1). Unter dem Begriff der ,ökologischen Modernisierung‘ sollen wirtschaftliches Wachstum, technischer Fortschritt und umweltpolitische Ziele vereinbart werden. Sie bildet gewissermaßen den konzeptionellen Rahmen, innerhalb dessen die Energieversorgung in der 14. und 15. Legislaturperiode gestaltet werden soll. Während über den grundsätzlichen Ausbau und die Förderung erneuerbarer Energien Einigkeit herrscht, ist die Umsetzung einer umfassenden „Energiewende“ auch innerhalb der Regie-

57 Die Dominanz im Datenmaterial spiegelt dabei wie in Kapitel 4 erläutert aufgrund der unterschiedlichen Redezeiten meist die Kräfteverhältnisse im Bundestag wider. 
rungskoalition selbst umstritten. Differenzen zwischen SPD und GRÜNEN gibt es dabei vor allem bezüglich der Kohlepolitik: „Fakt ist, dass die SPD zur Kohlepolitik ein Stück weit eine andere Position als wir Grüne vertritt. Das ist doch keine Neuigkeit [...]. Jeder - auch wir - weiß, dass das so ist" (GRÜNE 14.12.2001: 20714). Statt Energiepolitik im Kontext einer „Energiewende“ zu debattieren, wird diese daher meist in den Rahmen einer ökologischen Modernisierung gesetzt, welche das Ausmaß der Umstellung der Energieversorgung zunächst offen lässt - es erfolgt also eine implizite Abgrenzung von „Energiewende“. Im Kontext ökologischer Modernisierung werden im parlamentarischen Diskurs umwelt- und energiepolitische Praktiken mit einer marktorientierten liberalen Arbeitsmarkt- und Wirtschaftspolitik konzeptionell verbunden: „Die Kosten für den Faktor Arbeit werden gesenkt. Im Gegenzug wird der Verbrauch von Energie und Rohstoffen verteuert“ (SPD 25.11.1999: 6740). Über „eine in zeitlich vorgegebenen Schritten kalkulierbare Belastung des Energieverbrauchs“, die Ökosteuer, sollen „die Sozialversicherungsbeiträge auf unter 40 Prozent" gesenkt werden (Koalitionsvertrag 1998: 12). Diese Verteuerung von Energie ist dabei hauptsächlich auf das private Verbraucher*innenverhalten ausgerichtet, während Teile der Industrie befreit werden: „Wegen der noch ausstehenden europäischen Harmonisierung der Energiebesteuerung wird in diesem ersten Schritt die energieintensive Wirtschaft bei Heizöl, Gas und Strom nicht belastet" (Koalitionsvertrag 1998: 12).

Der Atomausstieg, als zentrales energiepolitisches Thema der 14. Legislaturperiode, wird gleichzeitig teilweise als „Einstieg in eine andere Energiepolitik“ (SPD 25.11.1999: 6742) gewertet - wenn auch meist ohne diesen mit einer „Energiewende“ $\mathrm{zu}$ verbinden (vgl. Kapitel 5.1.2): „Die Atomenergie ist heute die größte Investitions- und Innovationsbremse beim Umstieg in eine Einspar- und Solarwirtschaft [...]“ (SPD 25.11.1999: 6742). Als Gründe für die Notwendigkeit eines „Atomausstiegs“ werden darüber hinaus das „Restrisiko“ für einen Unfall, das auch durch technischen Fortschritt nicht ausgeschlossen werden könne, nicht-vorhandene Endlager, die Entstehung „waffenfähigen Materials“, die Endlichkeit der Rohstoffe (Uran) sowie das Scheitern der Kernfusion/Transmutation genannt (SPD 14.12.2001: 20707). Erklärtes Ziel der rot-grünen Bundesregierung ist es, den „Atomausstieg“ im Konsens mit den Energieversorgungsunternehmen und „entschädigungsfrei“ zu regeln (Koalitionsvertrag 1998: 15f.). „Mit dem Dreiklang ,Energiesparen, rationeller Energieeinsatz und erneuerbare Energien“" solle die Energieversorgung nach dem „Atomausstieg“ „,auf neue Füße“ gestellt werden (SPD 14.12.2001: 20709). Es gehe auch darum, die „Energieversorgung nachhaltig [zu] machen“ und Arbeitsplätze zu schaffen (SPD 14.12.2001: 20709). Das EEG wird ebenfalls als Bestandteil einer ökologischen Modernisierungspolitik gesehen, die auch internationale Marktchancen eröffnen soll:

„Ich bin davon überzeugt, dass die gezielte Förderung der Stromerzeugung aus regenerativen Energiequellen angesichts der Chancen, die diese Technologien bieten, eine lohnenswerte Investition in die Zukunft ist, und zwar nicht nur in die Zukunft unseres Landes, sondern auch in die Zukunft internationaler Märkte [...]. Wir halten sie für einen wichtigen Schritt im Rahmen der Modernisierungspolitik der Bundesregierung“(SPD 25.02.2000: 8429). 
Anfangs wird dabei häufig der Begriff „Solarzeitalter“ verwendet: „Dieses Gesetz ist die Geburtsurkunde des Solarzeitalters“(GRÜNE 25.02.2000: 8441).

In der 15. Legislaturperiode wird „Energiepolitik“ weiterhin als einer „der zentralen Faktoren für die ökologische Modernisierung“ gesehen (GRÜNE 09.09.2004: 11252). „Energiewende“ wird nun auch explizit als Unterkapitel ökologischer Modernisierung im Koalitionsvertrag 2002 genannt. Der nachhaltige „Erhalt der natürlichen Lebensgrundlagen“ solle "Gerechtigkeit und Wachstum“ sichern (Koalitionsvertrag 2002: 7). Die „Energiewende“ solle helfen, „Lebensqualität und eine intakte Umwelt auch für unsere Kinder und Enkel zu bewahren“ (Koalitionsvertrag 2002: 10). Allerdings wird „Energiewende“ in den Bundestagsdebatten selbst dann kaum noch aufgegriffen. Ein Kohleausstieg steht zunächst nicht zur Debatte, Kohlekraftwerke sollen zunächst effizienter gemacht werden (vgl. z.B. GRÜNE 28.05.2004: 10237).

Wie schon in der 14. Legislaturperiode solle die ökologische Modernisierung die Ziele „Arbeit und Umwelt“ vereinbar machen, „Öko-Effizienz“ steigern, Kosten reduzieren, die Wettbewerbsfähigkeit verbessern, die Umwelt schützen und durch eine „Effizienzrevolution“ die Produktivität sowie den Export steigern (Koalitionsvertrag 2002: 36ff., GRÜNE 28.05.2004: 10238). Durch die wirtschaftlichen Erfolge habe sich auch das Image der „Umweltschützer“ verbessert - diese seien nun nicht mehr die „Miesmacher, Müsliesser“, sondern „die Wegbereiter zu neuem Optimismus in Wirtschaft und Gesellschaft“ (SPD 09.09.2004: 11256).

\section{Versus „Die beschworene Energiewende [...] findet nicht statt“}

Da die rot-grüne Bundesregierung trotz der verabschiedeten Gesetze zu erneuerbaren Energien und dem Atomausstieg in der 14. und 15. Legislaturperiode kein eigenes Energiekonzept vorlegt, kritisieren CDU/CSU und FDP deren Konzeptlosigkeit (z.B.: FDP 14.12.2001: 20714). Sie halten die Energiepolitik insgesamt nicht für schlüssig: „Für die Zukunftssicherung, die Entwicklung regenerativer Energien fehlt ein Konzept. Die Förderung im Bundeshaushalt insgesamt wird deutlich verringert [...]. Aber dieselbe Bundesregierung setzt zugleich auf Großkraftwerke auf der Basis von Kohle und Erdgas“ (CDU 25.11.1999: 6738). Die CDU/CSU glaubt nicht an eine vollständige Umstellung auf erneuerbare Energien und lehnt eine „Energiewende“ ab: „Der Bundesumweltminister und Teile der SPD setzen auf Energieeinsparung und regenerative Energien. Glauben Sie ernsthaft, daß sich der Energiebedarf allein aus Einsparungen, Solarenergie und Wasserkraft befriedigen läßt?“ (CDU 25.11.1999: 6738). „Das wird nicht in Zukunft, geschweige denn kurzfristig machbar sein“ (CDU 25.11.1999: 6738).

Die Atomenergie werde durch Kohleenergie ersetzt, was einer „Energiewende“ widerspreche: „Die beschworene Energiewende, die heute Mittag gerade wieder eine Rolle gespielt hat, findet nicht statt [...]“ (CDU 27.06.2002: 24770). Auch der Bundeskanzler spreche davon, dass ,es noch lange dauern wird, bis sich die Solarenergie durchsetzt, und dass erst einmal Großkraftwerke auf Steinkohleund Braunkohlebasis gebaut werden müssen“ (CDU 27.06.2002: 24770). Daher seien durch den Atomausstieg die Klimaziele nicht länger haltbar: „Mit dem Ausstieg aus der Kernenergie müssen Sie eine $\mathrm{CO}_{2}$-Reduktion in Höhe von rund 100 Millionen Tonnen ersetzen. Sie glauben, Sie könnten das allein durch eine Ener- 
giewende und eine Effizienzrevolution. Auch hier setzt der Wirtschaftsminister in seinem Bericht ein Fragezeichen [...]“ (CDU 14.12.2001: 20710). „Das geht voll zulasten des Klimaschutzziels“ (FDP 14.12.2001: 20714). „Wenn wir einen erfolgreichen Klimaschutz wollen, dann sind wir auch auf Kernenergie angewiesen“ (CDU 09.09.2004: 11254).

CDU/CSU und FDP lehnen darüber hinaus einen Kohleausstieg ab: „Ich sage in aller Deutlichkeit, dass wir weltweit sowohl Öl als auch Steinkohle und Braunkohle in absehbarer Zeit noch nutzen müssen“ (CDU 28.05.2004: 10236).

Hier deutet sich an, wie sich die Diskursformation, die ich oben (vgl. Kapitel 5.1.3) als hegemoniale Formation klassifiziert habe und deren Position ich vereinfachend als ,herkömmliches Energiesystem mit Förderung erneuerbarer Energien beschrieben habe, durch ihre gemeinschaftliche Abgrenzung von „Energiewende“ konstituiert.

\section{Versus Energiepolitik im Rahmen von ökologischem Umbau}

Die PDS spricht nicht von ökologischer Modernisierung, sondern von ökologischem Umbau, den sie von einer marktorientierten Umwelt- und Wirtschaftspolitik abgrenzt. Sie schlägt für den ökologischen Umbau im Energiebereich Maßnahmen vor: Sie fordert „32 Milliarden DM an ökologisch schädlichen Subventionen - das ist ein Volumen, das $30 \mathrm{mal}$ so groß ist wie der Umweltetat“ abzubauen, z.B. „im Verkehrsbereich und beim Kohlebergbau“, indem die „Kilometerpauschale“ umgewandelt werde. Im Kohlebergbau sollen die „freiwerdenden Mittel in den Strukturwandel der Bergbauregionen fließen“, um „alternative Arbeitsplätze“ zu schaffen (PDS 25.11.1999: 6749). Die „eingesparten Mittel“ sollen „quer über alle Haushalte, beispielsweise für die Altbausanierung, für eine ökologische Verkehrswende, für die Förderung erneuerbarer Energien sowie für die Umweltforschung und internationale Klimaschutzmaßnahmen verwendet“" werden, um eine ökologische Wende zu ermöglichen (PDS 25.11.1999: 6749).

Der Umstieg ins Solarzeitalter sei nur möglich, wenn deutlich mehr Energie eingespart würde, dafür müsse das EEG um entsprechende Maßnahmen ergänzt werden (PDS 25.02.2000: 8436). Allerdings sei ein Senken des Nettoverbrauchs in einer ,ständig wachsenden und nach Strom, Wärme und Sprit lechzenden Wirtschaft durch Energieeinsparungen dauerhaft" (PDS 25.02.2000: 8436) unrealistisch. „Ich denke, hier gibt es technisch-technologische Grenzen. Langfristig ist das Wachstumsmodell, welches auch die rot-grüne Koalition hochhält, eine Sackgasse“ (PDS 25.02.2000: 8436). Zudem müsse beim Energieverbrauch auch vielmehr der Strom-, Wärme- und Verkehrsbereich betrachtet werden, ,insbesondere der Schwer- und Flugverkehr“, was alle „erarbeiteten Reduktionsbestrebungen einreißen wird“" (PDS 25.02.2000: 8436).

In diesem Zusammenhang kritisiert die PDS auch eine Wirtschaftsorientierung der rot-grünen Modernisierungspolitik: „Einer nachhaltigen Energiepolitik steht die Wirtschaftspolitik Ihres Kanzlers und Ihres Wirtschaftsministers im Wege“ (PDS 27.06.2002: 24775). Die Ökosteuer habe keine ökologische Lenkungswirkung und sei sozial ungerecht: „Die Ökosteuer schafft keine zusätzliche Finanzierungsgrundlage für den ökologischen Umbau, weil deren Einnahmen aus den 
Energiesteuern fast vollständig für die Senkung der Lohnnebenkosten verwendet werden“ (PDS 25.11.1999: 6748).

Den Atomkonsens der rot-grünen Regierungskoalition hält die PDS für unzureichend: Das Atomausstiegsgesetz „,regelt im Grunde für 20 und mehr Jahre ein "Weiter so!"“ (PDS 14.12.2001: 20717). Auch die GRÜNEN hätten in ihrem Programm für die Bundestagswahl 1998 noch einen sofortigen Atomausstieg gefordert, da die Technologie , riskant und voller Zynismus gegenüber unseren Kindern und Kindeskindern“" sei (PDS 14.12.2001: 20716). Nun habe sich die Bundesregierung ,einer Energielobby unterworfen [...], die auf der Basis einer zentralistischen Großkraftwerkstruktur ihre Macht abgesichert" habe (PDS 14.12.2001: 20717). In Übereinstimmung mit den Umwelt- und Naturschutzverbänden fordere die PDS daher einen „schnellstmöglichen Ausstieg aus der Atomkraft“ (PDS 14.12.2001: 20717).

Hier wird deutlich, wie die PDS eine populare Äquivalenzkette um ökologischen Umbau aufbaut, indem sie diesen mit weitreichenden Forderungen aus verschiedenen sozialen Bereichen verbindet. Allerdings erfolgt eine Artikulation dieser Forderungen im Zusammenhang mit „Energiewende“ kaum (vgl. Kapitel 5.1.2), sodass diese nicht Teil der popularen Äquivalenzkette wird und somit im hier nachgezeichneten kritischen Diskurs noch kaum eine Rolle spielt.

\section{Legislaturperiode: ,breiter Energiemix“ statt „Energiewende“}

Im Koalitionsvertrag der 16. Legislaturperiode (CDU, CSU, SPD) kommt der Begriff der ,ökologischen Modernisierung ' nicht mehr vor. Stattdessen ist von ,Nachhaltigkeit‘ und ,Nachhaltiger Entwicklung“ die Rede. „CDU, CSU und SPD wollen eine nachhaltige Entwicklung“ (Koalitionsvertrag 2005: 17). Die Motive und genannten Zielsetzungen der im Koalitionsvertrag artikulierten Nachhaltigkeit entsprechen dabei weitgehend denen der ökologischen Modernisierung aus den Verträgen der vorangegangen rot-grünen Regierungskoalition. Eine klare Definition des Nachhaltigkeitsverständnisses oder eine Abgrenzung zur ökologischen Modernisierung findet allerdings nicht statt. Eine ,,ambitionierte Umweltpolitik“ solle „einen zentralen Beitrag zur Modernisierung unserer Gesellschaft" leisten und zum Motor für die Wirtschaft werden (Koalitionsvertrag 2005: 17f.).

„Deutschland und Europa brauchen deshalb einen neuen Aufbruch, der die Ziele erfolgreicher wirtschaftlicher Entwicklung und wirksamen Klima- und Umweltschutzes mit den sozialen Anliegen der Menschen im Sinne eines nachhaltigen Wirtschaftens im 21. Jahrhundert zusammenführt. Der wichtigste Schlüssel dazu ist eine Doppelstrategie zur Steigerung der Energie- und Ressourceneffizienz sowie zum Ausbau erneuerbarer Energien und nachwachsender Rohstoffe“ (Koalitionsvertrag 2005: 65).

Es erfolgt dabei eine implizite Abgrenzung zu „Energiewende“: Es ist nicht mehr von einer „Energiewende“ die Rede (dieser Begriff taucht weder im Koalitionsvertrag noch im späteren Eckpunktepapier der Bundesregierung für ein integriertes Energie- und Klimaprogramm (BMU 2007) auf), sondern von „eine[m] breiten Energiemix“, welcher „der erfolgversprechende Weg zur internationalen Wettbewerbsfähigkeit der deutschen Wirtschaft, zur Verringerung der Belastung von Verbrauchern 
und Unternehmen durch steigende Energie- und Rohstoffpreise und gleichzeitig zum Schutz der Erdatmosphäre und der Umwelt" sei (Koalitionsvertrag 2005: 65). Das Ziel sei eine in diesem Sinne „nachhaltige Energieversorgung“, die „wirtschaftliche[...] Preise“ mit „den Herausforderungen des weltweiten Klimawandels“ vereinbare (BMU 2007: 4).

Über die Gestaltung dieses „breiten Energiemixes“ bestehen zwischen CDU, CSU und SPD vor allem ,hinsichtlich der Nutzung der Kernenergie zur Stromerzeugung unterschiedliche Auffassungen“ (Koalitionsvertrag 2005: 50). So fordert die SPD beispielsweise: „Bestandteil einer modernen Energie- und Klimapolitik ist sicherlich nicht eine Renaissance der Atomenergie“ (SPD 02.07.2009: 25697). CDU und CSU befürworten hingegen weiterhin Atomenergie aus Klimaschutzgründen. Auch hier zeigt sich wieder deutlich, wie die die Einordnung energiepolitischer Probleme direkt mit der Konstitution politischer Praktiken zusammenhängt: Mit der Artikulation eines ,breiten Energiemixes' wird vom Fokus auf erneuerbare Energien abgerückt, hin zu verschiedenen Energieträgern. Die CDU spricht sich „,ür einen breiten Energiemix von den Erneuerbaren über Kohle und Öl bis hin zur Kernenergie aus“ (CDU 06.06.2008: 17734). „Irgendeine Quelle auszuschließen hieße eben, den Dreisatz ,sauber, sicher, sozial' aufzugeben. Das wollen wir nicht“ (CDU 06.06. 2008: 17741).

\section{Versus Vollständige Umstellung und radikale „Energiewende“}

Auch die GRÜNEN sprechen in der 16. Legislaturperiode kaum noch von „Energiewende“ (vgl. Kapitel 5.1.2), weshalb eine grundsätzliche Herausforderung der Artikulation eines ,breiten Energiemixes' kaum gelingt. Sie positionieren sich aber für eine ,vollständige Umstellung der weltweiten Energieversorgung auf erneuerbare Energien“ als „entscheidende Lösung, um das Klima zu schützen“ (GRÜNE 06.06.2008: 17737).

Die LINKE fordert in der 16. Legislaturperiode eine ,radikale Energiewende hin zu erneuerbaren Energien“ (LINKE 02.07.2009: 25694), die auch die sozialen Bedingungen und Auswirkungen in den Blick nehme. Die Arbeitsbedingungen in der Branche der erneuerbaren Energien seien schlecht: „Zwölfstundenschichten und schlechte Bezahlung sind keine guten Voraussetzungen für eine Zukunftsbranche. $\mathrm{Zu}$ Recht fordern die Gewerkschaften bessere Sozialstandards“ (LINKE 06.06.2008: 17736). Darüber hinaus habe eine radikale „Energiewende“ auch friedenspolitisches Potenzial:

„Die Umstellung auf eine nachhaltige Energieversorgung ist eine Überlebensfrage [...]. Wer heute auf erneuerbare Energien setzt und dieses Wissen mit Schwellen- und Entwicklungsländern teilt, wird sich morgen nicht an Kriegen um Öl und Gas beteiligen [...]“ (LINKE 02.07.2009: 25694).

Den mit diesen Artikulationen verbundenen Aufbau einer - wenn auch brüchigen - popularen Äquivalenzkette habe ich in Kapitel 5.1.3 dargestellt, ebenso wie die Marginalisierung des kritischen „Energiewende“-Diskurses, der die hegemoniale Formation herausfordert. 


\section{Legislaturperiode I: Zeitalter erneuerbarer Energien und Kernenergie als Brückentechnologie}

Die Energiepolitik der ersten Hälfte der 17. Legislaturperiode ist zunächst durch die diskursive Verknüpfung von „Kernenergie als Brückentechnologie“, Klimaschutz und Ausbau erneuerbarer Energien innerhalb eines „dynamischen Energiemix“ unter dem Oberziel des „Weges in das Zeitalter erneuerbarer Energien“ gekennzeichnet. Diese Verbindung wird vor allem im gleichzeitig mit der Laufzeitverlängerung verabschiedeten Energiekonzept der schwarz-gelben Regierung hergestellt (17/3049) ${ }^{58}$ und verdeutlicht erneut wie die diskursive Einordung der Energiepolitik unmittelbar politische Praktiken konstituiert. Sowohl im Energiekonzept, als auch im Koalitionsvertrag zwischen CDU, CSU und FDP ist keine Rede von „Energiewende“, wodurch erneut eine implizite Abgrenzung erfolgt. Nachhaltigkeit wird aber erneut als Prinzip genannt: „Das Prinzip der Nachhaltigkeit prägt unsere Politik“ (Koalitionsvertrag 2009: 25). „Wir wollen eine ideologiefreie, technologieoffene und marktorientierte Energiepolitik“ (Koalitionsvertrag 2009: 26; 17/3049: 2). Kohlekraft solle dabei weiterhin eine Rolle spielen, auch wenn der „Ausstieg aus dem subventionierten Steinkohlebergbau“ festgeschrieben sei (Koalitionsvertrag 2009: 28; 17/3049: 10). Der Glaube an technischen Fortschritt spielt für das Energiekonzept eine bedeutende Rolle: So solle Carbon Capture and Storage CCS weiter erforscht werden und zukünftig eine klimaneutrale Braunkohleverstromung ermöglichen (Koalitionsvertrag 2009: 28; 17/3049: 9). In der Fusionsforschung wird das Potenzial für die Erschließung ,eine[r] neue[n] umweltfreundliche[n] und sichere[n] Energiequelle" gesehen (Koalitionsvertrag 2009: 34). Deutschland solle bei ,hohem Wohlstandsniveau eine der energieeffizientesten und umweltschonendsten Volkswirtschaften der Welt werden“ (17/3049: 2). Das Energiekonzept ziele auf einen „Umbau“ der Energieversorgungsstrukturen. „Mit dem Energiekonzept“ beschreibe die Bundesregierung „erstmalig den Weg in das Zeitalter der erneuerbaren Energien“ (17/3049: 2). Die Kernenergie solle eine Brücke ,,auf dem Weg dorthin“ sein (17/3049: 2):

„Ein solcher Prozess benötigt nicht nur Zeit, sondern muss auch wirtschaftlich vernünftig ausgestaltet werden. Um diesen Übergang zu gestalten, brauchen wir noch zeitlich befristet die Kernenergie und werden deshalb die Laufzeiten um durchschnittlich zwölf Jahre verlängern“ (17/3049: 8).

Ohne die Kernenergie seien die Klimaziele und erträgliche Energiepreise nicht zu erreichen (Koalitionsvertrag 2009: 29). „[A]lle Forschungsinstitute im Bereich der Wirtschaft haben dargelegt, dass die Kernenergie“ einen „volkswirtschaftlichen Nutzen“ habe (CDU 28.10.2010: 7168). Durch die Laufzeitverlängerung entstehe daher ein Mehrwert: „Das ist ein Lastwagen voller Geld, der verbrannt wird. Wir wollen diesen Lastwagen voller Geld nicht verbrennen, sondern wir wollen das Geld für den schnelleren Umbau unseres Energieversorgungssystems nutzen“ (CDU 28.10.2010: 7168). Insofern sei das neue Energiekonzept „ein Marshallplan für den Umbau der

58 Die Laufzeitverlängerung wird im Rahmen der Änderung des Atomgesetzes verabschiedet, das am 28.10.2010 in zweiter und dritter Lesung verabschiedet wird. Die erste Lesung findet bereits am 01.10.2010 statt. 
deutschen Energiewirtschaft" (CDU 28.10.2010: 7168). Die schwarz-gelbe Regierungskoalition greift dabei immer wieder Artikulationsmuster der rot-grünen Regierungskoalition (ökologische Modernisierung) auf, ohne diese konkret zu benennen: Das Energiekonzept sei „das größte Modernisierungsprogramm für eine gesamte Volkswirtschaft“ und führe zu einer „Harmonisierung von Volkswirtschaft und Klimaschutz ohne Wohlstandsverluste“" (FDP 28.10.2010: 7201). So wird die Differenz dieser Politik zur rot-grünen Energiepolitik verdeckt:

„Das ist eine Revolution im Prozess. Das ist eine grundlegende Umgestaltung unseres Landes. Wir führen sie durch, weil wir glauben, dass sie dem Klimaschutz dient, und Klimaschutz ist unsere Lebensgrundlage. Wir führen diese Umgestaltung durch, weil wir überzeugt davon sind, dass damit eine technologische Modernisierung, eine Innovation, die Erschließung neuer Märkte und die Entstehung Hunderttausender von Arbeitsplätzen, die Stärkung der Wettbewerbsfähigkeit und Zukunftssicherung einhergehen“(CDU 28.10.2010: 7179).

Es handele sich um „eine grundlegende Umformung unserer Lebensweise“, die ,aber kein Verzichtsprozess“" sein solle, sondern ein Modernisierungsprozess, der die Sicherungen von Marktanteilen mit Technologieführerschaft und der Bewahrung der „Schöpfung“ verbinde (CDU 28.10.2010: 7182); Interessant ist, dass in dieser Debatte zum ersten Mal der Begriff der „Energiewende“ wieder aufgegriffen und in die Energiepolitik der Bundesregierung eingebunden wird: Eine „Energiewende ohne zu überfordern“ (CSU 28.10.2010: 7201).

\section{Versus Laufzeitverlängerung als energiepolitische Katastrophe}

Die Opposition unter SPD, GRÜNEN und LINKEN kritisiert dagegen die Laufzeitverlängerung, sie torpediere den von der Regierungskoalition skizzierten Weg in das Zeitalter erneuerbarer Energien. Die Verlängerung der Laufzeiten der Atomkraftwerke verhindere nicht nur Investitionen in erneuerbare Energien (GRÜNE 28.10.2010: 7340), es gehe auch insgesamt „um die Frage, ob wir die Energiewende hin zu den erneuerbaren Energien fortsetzen oder auf die alten Energiestrukturen setzen wollen“ (SPD 28.10.2010: 7218). ,[F]ür die Umwelt und das Klima“ brauche es „die Atomenergie nicht - weder ihr Geld noch den Strom“ (SPD 28.10.2010: 7173).

Die GRÜNEN argumentieren, schwarz-gelb mache „Lobby- und Klientelpolitik“ und trete „die Rechte von Minderheiten mit Füßen“ (GRÜNE 28.10.2010: 7177). Deutschland habe den „drittältesten Kraftwerkspark“ und nicht „die sichersten Atomkraftwerke der Welt" (GRÜNE 28.10.2010: 7177).

Die LINKE kritisiert, dass die Laufzeitverlängerung „den Kampf zwischen Atomenergie und erneuerbaren Energien“ zum Nachteil erneuerbarer Energien einläute (LINKE 28.10.2010: 7188). Auch der Strom werde nicht billiger, sondern die „Profite sacken die Konzerne ein“ (LINKE 28.10.2010: 7196). Die LINKE habe den „rot-grünen Kompromiss“ zwar stets kritisiert, aber diese Aufkündigung sei nun „eine wirkliche Katastrophe“ (LINKE 28.10.2010: 7175) und zwar nicht nur eine ökologische, sondern auch eine sozial- und arbeitsmarktpolitische, da Unternehmen der erneuerbaren Energien Branche gefährdet seien (LINKE 28.10. 2010: 7176). Die Koalition stelle ,absichtsvoll Unfrieden her“, verursache 
„schwere gesellschaftspolitische Auseinandersetzungen“ (LINKE 28.10.2010: 7175).

Es lässt sich hier ein starker kritischer Diskurs identifizieren, der die Laufzeitverlängerung herausfordert, sich aber zunächst nicht durchsetzen kann. Gleichzeitig wird die Forderung einer „Energiewende“ als positive Alternative mit der Energiepolitik der Regierungsfraktionen kontrastiert: „Mit der Laufzeitverlängerung dreht die Bundesregierung das energiepolitische Rad um zehn Jahre zurück und versucht, die Energiewende mit Atomausstieg und Ausbau der erneuerbaren Energien zu beenden“ (GRÜNE 28.10.2010: 7345).

\section{Legislaturperiode II: „Energiewende“ vor dem Hintergrund einer ,neuen Lage“ nach „Fukushima“}

Wie in Kapitel 5.1 dargestellt, disloziert „Fukushima“ den energiepolitischen Diskurs im Bundestag. Die schwarz-gelbe Regierungskoalition spricht von einer ,neuen Lage $^{6}$, die erst durch „Fukushima“ entstanden sei und aufgrund der nun ein Wechsel in der Energiepolitik notwendig sei:

„Und dennoch: Die Bundesregierung konnte und kann [...] nicht einfach zur Tagesordnung übergehen [...]. Deshalb haben wir im Lichte der Ereignisse in Japan veranlasst, dass alle deutschen Kernkraftwerke noch einmal einer umfassenden Sicherheitsprüfung unterzogen werden im Lichte der neuen Lage! Dazu setzen wir die Verlängerung der Laufzeiten der deutschen Kernkraftwerke aus, [...] indem wir für den Zeitraum eines dreimonatigen Moratoriums alle Kernkraftwerke, die 1980 und früher in Betrieb gegangen sind, vom Netz nehmen“ (Angela Merkel $^{59}$ 17.03.2011: 10884f.).

Das Abschalten der Kernkraftwerke wird nun von Angela Merkel zum ersten Mal im Bundestag direkt mit „Energiewende“ verknüpft:

„Nach dem dreimonatigen Moratorium werden wir über die endgültigen Konsequenzen für den Betrieb der Kernkraftwerke entscheiden [...]. Wir werden deshalb die bewusst ehrgeizig kurz bemessene Zeit des Moratoriums nutzen, um die Energiewende voranzutreiben und, wo immer möglich, zu beschleunigen. Denn wir wollen so schnell wie möglich das Zeitalter der erneuerbaren Energien erreichen - das ist unser Ziel [...]“ (Angela Merkel 17.03.2011: 10887).

Dennoch wird zunächst weiterhin von der Notwendigkeit der Kernenergie als Brückentechnologie gesprochen. Die Artikulationen von CDU, CSU und FDP sind dabei immer wieder von Ambivalenzen durchzogen. So plädiert nun auch die FDP für ein Moratorium: "Wenn sich die Fakten ändern, ändere ich meine Meinung" (FDP 24.03.2011: 11294), beschwört aber gleichzeitig die Gefahr einer Deindustrialisierung herauf: „Eine Deindustrialisierung, die gegen Arbeitsplätze und Wohlstand in

59 Ich zitiere im Folgenden Angela Merkel als Rednerin in den Bundestagsdebatten namentlich und hebe dadurch ihre besondere Stellung innerhalb der dargestellten Diskursentwicklung hervor. 
Deutschland gerichtet ist", sei mit schwarz-gelb nicht zu machen (FDP 24.03.2011: 11286).

Nach dem dreimonatigen Moratorium und dem Bericht der „Ethikkommission Sichere Energieversorgung" erfolgt am 09.06.2011 erneut eine Debatte im Bundestag nach einer Regierungserklärung von Angela Merkel: „Fukushima hat meine Haltung zur Kernenergie verändert“ (Angela Merkel 09.06.2011: 12960). Die Entscheidung in den 60er Jahren „maßgeblich auf Atomenergie zu setzen“ wird als „kollektiver Fehler" bezeichnet (CDU 30.06.2011: 13383), der Ausstieg in Bezug auf die Kraftwerksleistung als ,absolut verkraftbar“ angesehen (CDU 30.06.2011: 13369). Gleichzeitig mit dem Ausstieg aus der Kernenergie bekräftigt Angela Merkel ihre Absicht, die erneuerbaren Energien zur zentralen Säule der Energieversorgung machen zu wollen. Sie spricht mit Verweis auf das Energiekonzept 2010 von einem „tiefgreifenden Umbau unserer Energieversorgung“ (Angela Merkel 09.06.2011: 12961). Der „Ausstieg“ sei ohne einen „Umstieg“ nicht zu haben (Angela Merkel 09.06.2011: 12961). Für den Übergang seien aber fossile Kraftwerke notwendig, die daher schneller gebaut werden müssten (Angela Merkel 09.06.2011: 12962f.). „Im Gegensatz zu früheren Versuchen“ sei es nun gelungen „Ökologie und Ökonomie zu verbinden“ ohne sie ,wie in der Vergangenheit gegeneinander aus[zuspielen]“ (CDU 30.06.2011: 13403). Die ,erhöhten Wachstumszahlen“ machen „den zugegeben riskanten Weg dieser Energiewende“ leistbar (FDP 30.06.2011: 13396). Dass diese politische Einordnung von „Fukushima“ letztlich eine Ausbreitung der hegemonialen Formation ermöglicht, hat sich in Kapitel 5.1 .3 bereits angedeutet, und wird tiefgreifender in Kapitel 5.4 analysiert. Dabei arbeite ich auch heraus mit welchen politischen Praktiken diese Ausbreitung in Verbindung steht.

\section{Versus „Energiewende“ als Irrtumsbereinigung}

Die SPD kritisiert nicht die „,neuen Einsichten“, sondern „,das falsche Pathos“ und die „Unaufrichtigkeit“, mit der die Kanzlerin auftrete: „Es kann doch nicht sein, dass ausgerechnet Sie sich hier als die Erfinderin der Energiewende in Deutschland hinstellen“ (SPD 09.06.2011: 12964). Was die Regierung dem Bundestag vorlege sei kein Gesetz zur „Energiewende“, sondern ein „Irrtumsbereinigungsgesetz“ (SPD 09.06.2011: 12965). „Die Gesellschaft war immer schon weiter als Sie“ (SPD 09.06.2011: 12965). Die SPD spricht vom „Ende des Atomzeitalters“, das durch „Zwei tiefe Überzeugungen“ geprägt gewesen sei: „erstens, dass die Technik nie versagt, und zweitens, dass der Mensch nie versagt, und vor allen Dingen, dass nicht beides zum gleichen Zeitpunkt passiert“ (SPD 17.03.2011: 10890). Dennoch seien die „Risiken der Atomtechnologie“ bereits vor Japan bekannt gewesen (SPD 17.03.2011: 10890). Die SPD erinnert daran, dass die Laufzeitverlängerung „Kernbestandteil des sogenannten Energiekonzepts dieser Bundesregierung war“ (SPD 24.03.2011: 11279). ,[J]etzt auf einmal“" wolle die Regierung „einvernehmlich die Energiezukunft“ gestalten (SPD 24.03.2011: 11279).

Die GRÜNEN erklären, Angela Merkel beende „einen persönlichen Kampf“, den sie „gegen die Energiewende“ geführt habe (GRÜNE 09.06.2011: 12973) und, dass ,[d]ieser Schritt [...] diesen Menschen“ gehöre, die sich seit Jahren für die „Energiewende“ engagieren. Das „Gerede von einer Brückentechnologie“ sei nun widerlegt worden (GRÜNE 30.06.2011: 13380). Sie kritisieren aber auch, 
dass die Zielsetzungen für den Ausbau erneuerbarer Energien mit dem Atomausstieg nicht erhöht werden, dass Onshore-Windenergie und Repowering nicht ausreichend gefördert werden. Das zeige, dass die Bundesregierung „das Wesen der Energiewende immer noch nicht verstanden“ habe, denn dieses setze ,eine andere Struktur unserer Energieversorgung voraus, nämlich flexiblere und dezentralere Struktur“ (GRÜNE 09.06.2011: 12974). Die Menschen „,wollen nicht auf Kosten anderer Generationen leben“, weder durch die Kernenergie noch durch die „Kohleverstromung“" (GRÜNE 30.06.2011: 13381).

Es erfolgt hier also eine kritische Positionierung zur Politik der Regierungskoalition durch SPD und GRÜNE. Dieser kritische Diskurs wird allerdings dadurch geschwächt, dass die von der Regierungskoalition vorgeschlagene „Energiewende“ dennoch insgesamt positiv eingeordnet wird: „Jetzt geht es in Richtung Nachhaltigkeit“" (GRÜNE 30.06.2011: 13381). Die GRÜNEN erklären darauf achten zu wollen, „dass da nicht nur Energiewende draufsteht, sondern auch Energiewende drin ist" (GRÜNE 30.06.2011: 13392).

Die LINKE spricht über „Fukushima“ als „Zivilisationsbruch in der Geschichte des industriell-kapitalistischen Zeitalters“ (LINKE 17.03.2011: 10896). Daher fordert sie neben umfassenden Maßnahmen für einen endgültigen Atomausstieg auch „unverzüglich ein Energiekonzept der Zukunft, das mit unabhängigen Wissenschaftlerinnen und Wissenschaftlern, Umweltverbänden und kommunalen Energieversorgern erarbeitet werden muss, also nicht mehr die Handschrift der Energiekonzerne tragen darf" (LINKE 17.03.2011: 10898). Die LINKE fordert den „Atomausstieg [...] untrennbar mit einer Energiewende“ zu verbinden (LINKE 09.06.2011: 12970). Die Bundesregierung dagegen wolle die Energiewende nur „halbherzig“: „Im Kern gehen Sie auf das zurück, was SPD und Grüne mit der Atomlobby schon ausgehandelt und wir schon immer als halbherzig bezeichnet hatten. Das heißt, das, was Sie jetzt vorlegen, ist eine Korrektur der von Ihnen beschlossenen falschen Gesetze“ (LINKE 09.06.2011: 12969). Der „Atomausstieg“" sei bereits bis 2014 machbar (LINKE 09.06.2011: 12969). Gleichzeitig sei in den neuen Gesetzesentwürfen ,nicht eine einzige zusätzliche Fördermaßnahme“ verankert, sie begrenzen die „Macht der vier Konzerne“ nicht und enthalten keine einzige Maßnahme für eine soziale Gestaltung der Energiewende, eine gerechte Kostenverteilung oder faire Arbeitsbedingungen - die „Energiewende“ müsse daher mit einer sozialen Wende und einer „Kulturwende“ verbunden werden (LINKE 09.06.2011: 12971). „Die Energiewende funktioniert nur sozial, oder sie funktioniert gar nicht“" (LINKE 13.06.2013: 31295).

Die LINKE verbindet hier die Kritik an der Regierungskoalition mit einer Forderung nach einer umfassenderen „Energiewende“ und verbindet diese mit popularen Forderungen, die andere soziale Bereiche mit einbeziehen. Allerdings habe ich in Kapitel 5.1 gezeigt, dass diese von den LINKEN und teilweise auch von den GRÜNEN und der SPD artikulierten kritischen Forderungen, die eine ,andere „Energiewende“ in den Blick holen, schwach ausgeprägt sind. 


\section{Legislaturperiode:}

\section{,Vernünftige“, marktwirtschaftliche „Energiewende“}

In der 18. Legislaturperiode ist der „Energiewende“ im Koalitionsvertrag (2013) von CDU, CSU und SPD ein eigenes Kapitel gewidmet. Es ist das erste Mal seit 2002 und somit insgesamt das zweite Mal in der Geschichte der Bundesrepublik, dass „Energiewende“ in einem Koalitionsvertrag vorkommt. Von den Kernkraftwerksbetreibern werde die „Mitwirkung an der Energiewende“ erwartet, für die Beschäftigten sollen „sozialverträgliche Lösungen“ gefunden werden (Koalitionsvertrag 2013: 43). Gleichzeitig werden aber die „konventionellen Kraftwerke“ zum „Teil des nationalen Energiemixes“ und für „auf absehbare Zeit unverzichtbar“ erklärt (Koalitionsvertrag 2013: 40f.). Artikulationsmuster der ökologischen Modernisierung werden aufgegriffen und mit christlichem Anliegen verbunden:

„Die Energiewende ist ein richtiger und notwendiger Schritt auf dem Weg in eine Industriegesellschaft, die dem Gedanken der Nachhaltigkeit und der Bewahrung der Schöpfung verpflichtet ist. Sie schützt Umwelt und Klima, macht uns unabhängiger von Importen, sichert Arbeitsplätze und Wertschöpfung in Deutschland.“ (Koalitionsvertrag 2013: 36).

Ein zentrales Thema im Zusammenhang mit der „Energiewende“ der 18. Legislaturperiode ist die Novellierung des EEG - zunächst 2014 und dann 2016/2017. Die Novellierung zielt auch auf eine Reformierung der „Energiewende“ insgesamt, die verstärkt mit marktorientierten politischen Praktiken verbunden wird, also marktwirtschaftlicher und ,vernünftiger' organisiert werden solle (,mehr Markt und mehr Wettbewerb“ (CDU 27.06.2014: 3935)). So erklärt ein Abgeordneter der CDU [Michael Fuchs], der zuvor Befürworter der Atomenergie war:

„Heute ist für mich eine Premiere: Ich diskutiere über das EEG, ohne dass mir dabei gleich das Messer in der Tasche aufgeht [...]. Genau genommen habe nicht ich mich verändert, sondern das EEG hat sich verändert, und zwar in einer vernünftigen Weise [...]“ (CDU 27.06. 2014: 3935).

Mit dem EEG 2014 solle ,die Energiewende in Deutschland wieder auf ein festes Fundament" gestellt werden (SPD 27.06.2014: 3932). Gleichzeitig wird mit der Novellierung auch eine Reduktion des Tempos des Ausbaus erneuerbarer Energien im Rahmen der „Energiewende“ diskutiert - die Artikulationen von „Energiewende“ sind verstärkt von Ambivalenzen geprägt. Es reiche nicht, „,möglichst schnell erneuerbare Energien auszubauen", sondern es gehe vor allem um Planbarkeit und Berechenbarkeit (SPD 27.06.2014: 3932). Der Ausbau der erneuerbaren Energien gehe im Vergleich zum Netzausbau zu schnell (CDU 01.06.2016: 16984). Denn es gehe „nicht nur um den Ausbau der erneuerbaren Energien auf Teufel komm raus, sondern auch darum, [...] vernünftige wirtschaftliche Strukturen“ zu erhalten (SPD 01.06. 2016: 16978). Immer wieder ist von einem „Drahtseilakt zwischen Umweltverträglichkeit, Bezahlbarkeit und Versorgungssicherheit“ bei der „Energiewende“ die Rede, wobei man nicht allein auf Umweltverträglichkeit setzen dürfe (SPD 01.06. 2016: 16978). Die „Energiewende“ wird als „Modernisierungs- und Investititionsprojekt[...] mit großer internationaler Ausstrahlung“ konstituiert (SPD 29.07. 2017: 24986). Die CDU spricht vom „größte[n] Technologieprojekt unserer Zeit“ 
(CDU 29.06.2017: 24990). Eine „nüchternere[...]“ Betrachtung der „Energiewende“ gilt dabei als positiv, im Mittelpunkt stehen wirtschaftliche Erwägungen (CDU 29.06.2017: 24992). Es deutet sich an, dass es zu einer Konsolidierung der hegemonialen Formation, die sich in der 17. Legislaturperiode auf den Schlüsselpunkt „Energiewende“ ausgebreitet hat, gekommen ist. Diese Konsolidierung sowie die mit ihr in Verbindung stehenden politischen Praktiken werden in Kapitel 5.4 diskutiert.

\section{Versus Konterrevolution gegen die „Energiewende“}

Die GRÜNEN bewerten die Debatten um das EEG 2014 und 2017 als „eine unverfrorene Konterrevolution der alten, dreckigen Energiewirtschaft und deren Fürsprecher hier im Parlament" (GRÜNE 01.06.2016: 16974). Die Bundesregierung wolle „den Ausbau der erneuerbaren Energien [...] begrenzen, um den Kohledreckschleudern von RWE und Vattenfall einen Bestandsschutz zu geben“ (GRÜNE 01.06.2016: 16974). Durch den ausbleibenden Kohleausstieg komme es zu einem „Stromüberschuss“, Kohle- und Atomkraftwerke „,verstopfen das Netz“ (GRÜNE 01.06.2016: 16974). Die große Koalition sage „die Energiewende von unten wieder ab“ (GRÜNE 01.06.2016: 16974). Damit breche die Bundesregierung ihre Zusagen aus dem Pariser Klimaabkommen (GRÜNE 01.06.2016: 16974).

Auch die LINKE argumentiert, dass das Ausbremsen der „Energiewende“ dazu führe, dass 2020 die Klimaziele verfehlt werden: „Das ist wahrlich keine nachhaltige Politik. Diesen Pfusch können wir uns nicht mehr leisten“ (LINKE 29.06.2017: 24987f.). Die LINKE spricht im Zusammenhang mit dem EEG 2014 von einem „schwarze[n] Freitag für die erneuerbaren Energien“. In Wirklichkeit sei es keine „Reform“, sondern „die Beerdigung des Erneuerbare- EnergienGesetzes“ (LINKE 27.06.2014: 3940). Die Koalition wolle „den Ausbau der Erneuerbaren verzögern, um den Energiekonzernen Luft zu verschaffen, damit die fossil-atomare Energiewirtschaft noch eine Weile länger von ihrer dreckigen Kohleverstromung leben kann“" (LINKE 01.06.2016: 16977).

Hier wird deutlich, dass zwar ein kritischer Diskurs die politischen Praktiken der Regierungskoalition herausfordert, dieser Politik aber nur selten umfassende Forderungen im Zusammenhang mit einer , anderen“ „Energiewende“ entgegengestellt werden (vgl. auch Kapitel 5.1.3).

\subsubsection{Förderung und Ausbau erneuerbarer Energien als gemeinsames Ziel}

Wie in Kapitel 5.1 dargestellt ist die Förderung erneuerbarer Energien ein wichtiges erklärtes Ziel der rot-grünen Bundesregierung der 14. und 15. Legislaturperiode, das aber zunächst meist nicht direkt mit „Energiewende“ verknüpft wird. Als zentrales Moment im Diskurs um erneuerbare Energien ist von Anfang an das EEG mit seinen festen Einspeisevergütungen, die „Planungssicherheit“ gewährleisten sollen (SPD 25.02.2000: 8428), auszumachen. Dies wurde bereits in der computerbasierten Analyse deutlich und wird nun durch das Kodieren der Story-Line ,Förderung und Ausbau erneuerbarer Energien als gemeinsames Ziel' anhand der einschlägigen Dokumente qualitativ nachvollzogen. In der 15. Legislaturperiode solle die dem EEG zu- 
grunde liegende „Förderpolitik“ demnach weiter fortgeführt und „weiterentwickelt“ werden, ein Fokus liege nun auch auf der „Exportinitiative Erneuerbare Energien“ (Koalitionsvertrag 2002: 38). Hinsichtlich des Zieles des Ausbaus erneuerbarer Energien scheint dabei im Bundestag über alle Fraktionsgrenzen hinweg Einigkeit zu bestehen, was - wie in Kapitel 5.1.3 gezeigt - eine wichtige Voraussetzung für die spätere Ausbreitung der hegemonialen Formation darstellt.

„Die Bundesregierung und die sie tragenden Fraktionen haben einen Gesetzentwurf zur Förderung der erneuerbaren Energien vorgelegt, der in der Zielsetzung, den Anteil der erneuerbaren Energien in Deutschland zu verdoppeln, von uns unterstützt wird. In dem Ziel eines Ausbaus der Förderung von Energietechnologien, die einen wesentlichen Beitrag zur Klimapolitik darstellen und eine Brücke in die nächsten Jahrzehnte hinein bauen können, gibt es zwischen uns also im Grunde genommen keine Meinungsverschiedenheit“ (CDU 25.02.2000: 8429).

Auch CSU (z.B.: CSU 25.02.2000: 8439) und FDP stimmen dem Ausbau erneuerbarer Energien prinzipiell zu (z.B.: FDP 25.02.2000: 8433), wobei sie darauf bedacht sind, ihre Differenzen aufzuzeigen. Ein vollständiger Umstieg auf erneuerbare Energien steht im Bundestag allerdings kaum zur Diskussion und wird von CDU, CSU und FDP gar für unmöglich gehalten: „Wie sähe denn die deutsche Energiewirtschaft aus, wenn wir, erstens, auf Kernenergie verzichteten und wenn wir, zweitens, auf Kohle verzichteten? Das kann man doch mit regenerativen Energien gar nicht ausgleichen, erst recht nicht zu wettbewerbsfähigen Preisen“ (CDU 09.09.2004: 11254). Als weitere Differenz innerhalb der hier behandelten Story-Line lehnen CDU, CSU und FDP zudem das Konzept der festen Einspeisevergütungen, wie es im EEG verankert ist, ab und fordern eine Finanzierung über den Haushalt ähnlich der Braunkohle (z.B. FDP 25.02.2000: 8434). Die FDP grenzt sich dabei noch weiter ab und verbindet das Element des Wettbewerbs mit der Idee einer Quotenregelung:

„[...V]erlassen Sie die ausgetretenen Pfade der Subventionspolitik [...] und machen Sie den mutigen Schritt nach vorn zu der Vorgabe eines sich jährlich bis zum Anteil von 50 Prozent steigernden Prozentsatzes regenerativer Energien, die dann aber auch untereinander am Markt konkurrieren müssen“ (FDP 25.02.2000: 8443).

Die Förderung erneuerbarer Energien wird also von Anfang von allen Fraktionen als identitätsstiftendes Moment konstituiert, Differenzen zeigen sich dagegen vor allem in der Art der Förderung und dem Umfang des Ausbaus. Diese Differenzen werden insbesondere in den Debatten um die Ausgestaltung des EEG, in welchem sich der Diskurs über die Förderung der erneuerbaren Energien maßgeblich materialisiert, augenscheinlich.

In der 16. Legislaturperiode bekennen sich dann CDU/CSU gemeinsam mit der SPD im Koalitionsvertrag dazu, „das EEG in seiner Grundstruktur fort[zu]führen“ (Koalitionsvertrag 2005: 51). CDU und CSU grenzen sich nun von der FDP ab und revidieren ihre eigene Position zur festen Einspeisevergütung, die sie nun befürworten:

„In steter Regelmäßigkeit bieten Sie [die FDP] uns ein Quotenmodell als Ersatz für das EEG [...]. Wenn Sie sich damit ernsthaft befassten, könnten Sie im europäischen Vergleich sehen: 
Der Ausbau läuft überall dort besser, wo es ähnliche Modelle wie das unsrige gibt. Vor allem sind die erneuerbaren Energien dort sehr viel günstiger, wo es Einspeisegesetze gibt, als dort, wo es Quoten gibt““(CSU 06.06.2008: 17746).

Höhere Ausbauziele hält die SPD nun in Abgrenzung zu den GRÜNEN für unrealistisch (SPD 06.06.2008: 17743). Die prinzipielle Notwendigkeit der Förderung erneuerbarer Energien bleibt aber Konsens im Bundestag, das EEG nimmt über seine breite Anerkennung zunehmend eine Repräsentationsfunktion für den Diskurs um erneuerbare Energien ein, wird so zu einem zentralen Knotenpunkt und zu einem identitätsstiftenden Moment, zu dem sich die Fraktionen (mit Ausnahme der FDP) überwiegend positiv positionieren. Der Fokus des EEG auf den Strombereich wird dabei eher selten thematisiert, auch wenn ab der 16. Legislaturperiode der Wärmebereich zunehmend im Diskurs vorkommt. Im Eckpunktepapier 2007 heißt es: „Die Erneuerbaren Energien sind im Wärmemarkt der , schlafende Riese““ (BMU 2007: 27). ${ }^{60}$

In der schwarz-gelben Koalition der 17. Legislaturperiode gibt nun auch die FDP ihre kritische Positionierung in Bezug auf das EEG auf. Im Energiekonzept 2010 berufen sich die Regierungsfraktionen positiv auf die Förderpolitik des EEG, durch das die „Rahmenbedingungen“ für die internationale „Vorreiterrolle“ Deutschlands im erneuerbare Energien Bereich gelegt wurden (17/3049: 4), was noch einmal die Rolle des EEG als identitätsstiftendes Moment verdeutlicht. Unter Betonung des gemeinsamen Zieles der Förderung erneuerbarer Energien als „Weg in das Zeitalter erneuerbarer Energien“ (17/3049: 2) soll gleichzeitig die Laufzeitverlängerung der Kernenergie als „Brückentechnologie“ vermittelt werden. Der positive Bezug auf das EEG („Das EEG ist ein richtiges Gesetz“ (CDU 28.10.2010: 7183)) sowie das Versprechen einer weitgehenden Umstellung auf erneuerbare Energien (80\% bis 2050) gleichzeitig mit der Laufzeitverlängerung dient somit auch der Verdeckung gesellschaftlicher und politischer Konflikte über die Kernenergie. Die Betonung des allen Fraktionen gemeinsamen Zieles der Förderung erneuerbarer Energien bereits vor „Fukushima“, schwächt dessen dislozierende Wirkung ab - die Kernenergie sollte ja ohnehin nur „Brückentechnologie“ sein. Über die konsensuale Konstruktion der Förderung und des Ausbaus erneuerbarer Energien werden also verschiedene politische Programmatiken vermittelt, deren Konfliktivität über die Betonung des ,Gemeinsamen' verdeckt wird.

Während die SPD in der 17. Legislaturperiode noch auf diese Konfliktivität verweist (z.B.: ,Ihnen passt das EEG nicht. Ihnen passt der Umstieg auf die Erneuerbaren nicht. Insbesondere die PV ist doch Ihr Hauptangriffsfeld“ (SPD 29.03.2012: 20307)), gibt sie in der großen Koalition der 18. Legislaturperiode ihre kritische Diskursposition auf und nähert sich der CDU/CSU an: Mit dem der Äquivalenzierung von „Ausbaukorridor“ mit „erneuerbaren Energien“ wird eine Beschränkung und damit Verlangsamung des Ausbaus auf bestimmte festgelegte Ziele artikuliert (Koalitionsvertrag 2013: 38). Der „Ausbaukorridor“ solle im EEG festgelegt werden und dafür sorgen, dass „die Kosten im Rahmen bleiben“ (Koalitionsvertrag 2013: 38). Die SPD spricht vom Ende der „Zeit der Technologieförderung“ (SPD 27.04.2014:

60 Das EEWärmeG wird im Bundestag gemeinsam mit der EEG-Novelle am 06.06.2008 debattiert und verabschiedet. 
3932). Die Rolle des EEG für den „Energiewende“-Diskurs wird dadurch abgeschwächt.

\section{Versus Förderung erneuerbarer Energien kein gemeinsames Ziel (mehr)}

Die Opposition stellt spätestens ab der 18. Legislaturperiode den unter der StoryLine ,Förderung erneuerbarer Energien als gemeinsames Ziel` artikulierten Konsens im „Energiewende“-Diskurs deutlich in Frage und zeigt so die Brüche in den Artikulationen der Regierungskoalition auf:

Die GRÜNEN kritisieren eine Verlangsamung des Ausbaus erneuerbarer Energien durch die Politik der großen Koalition: „Sie legen hier eine EEG- Novelle vor, die die Erneuerbaren ausbremst, die Bioenergien abwürgt, die Solarenergie über die Sonnensteuer unwirtschaftlich macht, den Ausbau der Windenergie über

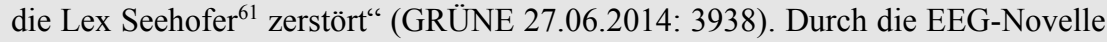
2016 werde der „Ausbau der erneuerbaren Energien um 70 Prozent reduziert“ (GRÜNE 01.06.2016: 16982f.).

Die LINKE kritisiert, durch die Novellierung 2014 werde „der Sinn des EEG in sein Gegenteil verkehrt“, statt erneuerbare Energien zu fördern, würden ,energieintensive Unternehmen subventioniert“ (LINKE 27.06.2014 3934). Die Reform „schaff[e] das EEG eigentlich ab“, es sei ein „Lex RWE“ (LINKE 27.06.2014: 3934).

\subsubsection{Der erneuerbare Energiebereich als Wirtschaftsfaktor}

Wie bereits dargelegt, werden in der 14. und 15. Legislaturperiode erneuerbare Energien vor allem durch die rot-grüne Regierungskoalition diskursiv in eine ökologische Modernisierung eingebettet, die Wirtschaftswachstum, Arbeitsplätze, technischen Fortschritt und Umweltziele vereinbaren solle. Dem erneuerbaren Energiebereich wird darüber hinausgehend eine besondere Bedeutung für die wirtschaftliche Entwicklung zugeschrieben, denn Energie stelle einen „Schlüsselfaktor für die Entwicklung gerade der deutschen Wirtschaft dar“ (SPD 27.06.2002: 24776). Erneuerbare Energien werden dabei nicht nur als Technologie konstituiert, sondern insbesondere auch als Wirtschaftsfaktor, ihnen wird für die Entwicklung der gesamten Volkswirtschaft eine hohe Bedeutung zugeschrieben. Entsprechend werden erneuerbare Energien mit wirtschafts- und technologieorientierten Knotenpunkten äquivalenziert und tragen noch wenig zur Bedeutungsgenerierung von „Energiewende“ bei. Schon bei der Einführung des EEG im Jahr 2000 stehen Exportmöglichkeiten im Fokus: „Die erneuerbaren Energien sind innovative Technologien, die neue Exportmöglichkeiten eröffnen und Arbeitsplätze vor allem im Mittelstand schaffen und sichern [...]“ (SPD 25.02.2000: 8428). Darüber hinaus solle der Gesetzesentwurf bewirken, „dass es in dieser Branche brummt" (GRÜNE 25.02.2000: 8432). Daher begrüße auch die Industrie das Gesetz, z.B. der Verband Deutscher Maschinen- und Anlagenbau VDMA

61 Einführung eines Abstandes von Windenergieanlagen von ca. $2 \mathrm{~km}$ zur Wohnbebauung in Bayern (2014) 
(Europas größter Industrieverband): „Der VDMA hält das Gesetz ebenfalls für hervorragend. Er sagt: Wir entwickeln mit diesem Gesetz eine Exportbranche mit großen Zukunftschancen“ (GRÜNE 25.02.2000: 8433). Zeitlich wird die Verabschiedung des EEG aus diesem Grund vor der Expo 2000 terminiert, die Konstitution des EEG als Wirtschaftsfaktor rechtfertigt dieses Vorgehen: „Es kommt uns darauf an, dieses Gesetz schnell zu verabschieden. Wir wollen es noch vor der Hannover-Messe landen [...]“ (SPD 25.02.2000: 8450). Die FDP bezeichnet das zu diesem Zeitpunkt als „eine knallharte Interessenpolitik“, es gehe der Regierungskoalition „nicht mehr primär um die Umwelt, sondern allein um Klientelpolitik“ (FDP 25.02.2000: 8442).

In der 15. Legislaturperiode festigt sich die Tendenz, den erneuerbaren Energiebereich als für die wirtschaftliche Entwicklung bedeutsam zu konstituieren - es gelingt eine temporäre Fixierung der erneuerbaren Energien als Wirtschaftsfaktor. „Die erneuerbaren Energien bringen Dynamik in den Arbeitsmarkt und steigern die Wettbewerbsfähigkeit“ (GRÜNE 28.05.2004: 10237). In diesem Kontext wird auch der Emissionshandel gesehen, er soll „Investitionen anreizen“ und „zu einer Jobmaschine“ werden (SPD 28.05.2004: 10250). Besonders betont werden zudem die Potentiale im internationalen Wettbewerb. Wegen der „technologische[n] Führerschaft“ Deutschlands setzen internationale Absatzmärkte wie China ,auf Deutschland als Partner“, wegen ihrem ,internationalen Erfolg“ und ihrer „Arbeitsplatzwirksamkeit“ sei die „Exportinitiative für erneuerbare Energien“ daher „außerordentlich vernünftig“ (SPD 09.09.2004: 11256).

\section{Versus rot-grüne Energiepolitik als Gefahr für den Standort Deutschland}

Vor allem die CDU/CSU aber auch die FDP konstruieren in der 14. und 15. Legislaturperiode die rot-grüne Energiepolitik als Gefahr für die wirtschaftliche Entwicklung: „Wie wirkt nun [...] die Energiepolitik dieser Koalition auf die wirtschaftliche Entwicklung? [...] Das, was Sie eingeleitet haben, führt zu einer ganzen Reihe von zusätzlichen Belastungen [...]“" (CDU 14.12.2001: 20710). Anscheinend herrsche auch innerhalb der Regierungskoalition keine Einigkeit über die wirtschaftlichen Auswirkungen des „Atomausstiegs“, eine abweichende Meinung werde bspw. vom Wirtschaftsminister vertreten: „Der Wirtschaftsminister hat zu Recht darauf hingewiesen, dass wir den Stromerzeugungsstandort Bundesrepublik Deutschland durch Ihre Vorgehensweise tendenziell gefährden“ (CDU 14.12.2001: 20711). Der Ausstieg aus der Kernenergie sowie „die Verdrängung heimischer Steinkohle und Braunkohle“ gefährde die Versorgungssicherheit, die Wettbewerbsfähigkeit, Arbeitsplätze sowie den „Produktionsstandort für Strom in der Bundesrepublik Deutschland“ (CDU 14.12.2001: 20711). In diesem Zusammenhang kündigt die CDU an, den „Atomausstieg“ zu revidieren: „Ich sage ganz klar und eindeutig: Herr Trittin, Sie freuen sich zu früh. Wir werden das, was Sie als dauerhaften Kernenergieausstieg bezeichnen, wieder rückgängig machen“ (CDU 14.12.2001: 20711). Durch erneuerbare Energien könne die Energieversorgung nicht sichergestellt werden, weshalb der „Atomausstieg“ die Abhängigkeit vom Ausland erhöhe. Diese gefährde die deutsche Energieversorgung: „Wir werden noch große Probleme bekommen. Lieber deutsche Ingenieure als verrückte Derwische in Nahost als Garanten unserer Energieversorgung!“ (FDP 09.09.2004: 
11229). Hier verdeutlicht sich die von Beginn an ambivalente Haltung in den Fraktionen von CDU, CSU und FDP zu den erneuerbaren Energien, auf die sie sich einerseits positiv beziehen, deren zu starke Ausbreitung sie aber als Gefahr für den Wirtschaftsstandort konstituieren. Diese ambivalente Haltung verdeutlicht nochmals wie die Bedeutung der Forderung ,erneuerbare Energien` zwischen Hegemonie und Gegen-Hegemonie flottiert, wie in Kapitel 5.1.3 deutlich wurde.

In der großen Koalition der 16. Legislaturperiode greifen CDU und CSU dann verstärkt die Artikulation von erneuerbaren Energien als Wirtschaftsfaktor auf und tragen somit wiederum zu einer Verfestigung dieser Story-Line bei. ${ }^{62}$ Erneuerbare Energien werden durch die Betonung ihrer positiven wirtschaftlichen Effekte beinahe mythenhaft aufgeladen. Die SPD spricht von einem „Jobwunder“, von erneuerbaren Energien als „volkswirtschaftliche Lebensversicherung“, von „Gründungswundern“ im Solarbereich, die an die industrielle Revolution erinnern (SPD 06.06.2008: 17730). In der 16. Legislaturperiode kommen zudem die erneuerbaren Energien als Wirtschaftsfaktor für den ländlichen Raum und dabei vor allem die Landwirtschaft/die Agrarindustrie in den Fokus: „Wir haben [...] mit dem EEG im Bereich der Bioenergien ein zusätzliches Standbein für die Landwirtschaft geschaffen" (SPD 06.06.2008: 17739). Die Argumentation der Stärkung der Landwirtschaft wird auch von der CSU aufgegriffen, die sich zum Ziel setzt, die „Konkurrenzfähigkeit der Landwirtschaft gegenüber den großen Playern [...] zu sichern [...]“ (CSU 06.06. 2008: 17747).

Mit der schwarz-gelben Koalition der 17. Legislaturperiode wird die Äquivalenzbeziehung zwischen den erneuerbaren Energien und ihren positiven wirtschaftlichen Effekten weiter gestärkt. Wie bereits die CDU/CSU in der 16. Legislaturperiode artikuliert nun auch die FDP erneuerbare Energien als Wirtschaftsfaktor und bedient somit diese Story-Line. Im Koalitionsvertrag wird der Ausbau der „Technologieführerschaft“ bei den erneuerbaren Energien als Zielsetzung genannt, „[d]ie Potentiale für Innovation, Wachstum und Beschäftigung beim Umbau unseres Energiesystems sind gewaltig“ (Koalitionsvertrag 2009: 27). Die bspw. durch das EEG „erzielte Investitionssicherheit“" habe ein ,massives Wachstum in allen Bereichen der erneuerbaren Energien erzeugt“, die sich dadurch „zu einem Treiber für Innovation und die Modernisierung der Energieinfrastruktur" entwickeln (17/3049: 4). Der positive Bezug auf erneuerbare Energien als Wirtschaftsfaktor durch schwarz-gelb erleichtert die diskursive Einbindung von „Fukushima“ und die Überwindung der dislozierenden Wirkung des Ereignisses. Der Wandel in der Positionierung weg von der Kernenergie als Teil des Wegs ins ,Zeitalters erneuerbarer Energien“ hin zu einer „Energiewende" wird ebenso wie zuvor die Laufzeitverlängerung mit den daraus resultierenden positiven wirtschaftlichen Effekten gerechtfertigt. Nach „Fukushima“ wird so die

62 Obwohl der Atomausstieg gleichzeitig weiterhin als Gefahr für den Standort Deutschland gesehen wird: „Die Russen haben Erdgas und Erdöl. Die Norweger haben Erdgas. Die Schweden haben Wasserkraft. Die Franzosen haben Atomkraft. Und wir Deutsche? Wir haben die Diskussion und in absehbarer Zeit eine veritable Stromlücke“ (CDU 02.07.2009: 25699). 
Story-Line ,erneuerbare Energien als Wirtschaftsfaktor“ auf die „Energiewende“ ausgeweitet und reartikuliert: Die deutsche Federführung werde eines Tages, wenn auch andere Staaten aus den konventionellen Energien aussteigen, „für unsere deutsche Wirtschaft“ „eine Chance sein (FDP 09.06.2011: 12968). Die „Energiewende“ solle ,zum Erfolg“ gemacht werden, „wegen des Klimaschutzes, aber auch wegen der wirtschaftlichen Perspektiven, die dahinterstehen“" (CDU 13.06.2013: 31290). Dass erneuerbare Energien innerhalb der vorliegenden Story-Line bereits vor „Fukushima“ als Wirtschaftsfaktor konstituiert wurden, erleichtert die Einbindung von „Energiewende“ in die hegemoniale Formation nach „Fukushima“.

Andererseits zeigen sich aber auch nach „Fukushima“" weiterhin ambivalente Artikulationen in Bezug auf erneuerbare Energien bzw. „Energiewende“ als Wirtschaftsfaktor. So wird der Positionswechsel zur „Energiewende“ zwar vor dem Hintergrund positiver wirtschaftlicher Effekte gerechtfertigt, es finden aber zunehmend Abgrenzungsprozesse statt. Bspw. gelten erneuerbare Energien als Wirtschaftsfaktor, solange die energieintensive Industrie nicht gefährdet werde: „Wenn Sie die energieintensive Industrie in diesem Land ihrer Basis berauben [...] dann vernichten Sie Arbeitsplätze“ (CDU 30.06.2011: 13383). An dieser Stelle wird deutlich, wie stark sich im Diskurs hegemoniale ökonomische Strukturen, in diesem Fall im Energiesektor, abbilden, bzw. was diskursiv einer politisch zu fördernden Ökonomie zugewiesen wird und was andererseits hiervon abgegrenzt wird. Der Branche der erneuerbaren Energien, insbesondere der Solarbranche, wird dieser Stellenwert nämlich nicht zugestanden. Hier ist es keine Forderung der Regierungsfraktionen, die in die Krise geratene Solarbranche als Wirtschaftsfaktor und in Verbindung mit den in diesem Bereich bestehenden Arbeitsplätzen zu erhalten, im Gegenteil: „Energiepolitik ist Wirtschaftspolitik“ - „Sozial- und Arbeitsmarktpolitik“ sei eben nicht Zweck des EEG: „Die Vergütung für Solaranlagen nach dem EEG kann nicht mit der Zielrichtung beibehalten werden, Arbeitsplätze in der Solarindustrie zu erhalten“ (CSU 13.06. 2013: 31584). „Wer nicht anpassungsfähig ist und wer den Strukturwandel nicht gestaltet, der wird sein Opfer" (CDU 29.03.2012: 20305). Die Forderungen der Opposition, die Branche zu retten, werden als „Besitzstandlobbyismus“ (CDU 29.03.2012: 20305) und „sozialistische [...] Industriepolitik“ bezeichnet (CSU 13.06.2013: 31585). Dabei zeigt sich deutlich, die zumindest teilweise stattfindende Reduktion von „Energiewende“ sowie der erneuerbaren Energien auf ihre Funktion als Wirtschaftsfaktor machen ihren wirtschaftlichen Erfolg gleichzeitig zu ihrer Bedingung:

„So hart das auch klingen mag: In diesen Unternehmen sind wertvolle Arbeitskräfte gebunden: Fachkräfte, die Unternehmen aus anderen Branchen derzeit händeringend suchen [...]. Die gesicherte Existenz der Solarindustrie in Deutschland unter einer Käseglocke aus Staatswirtschaft wird bald ein Ende haben. Die Tage des EEG sind gezählt, egal in welcher Konstellation wir im November hier wieder zusammenkommen“ (FDP 13.06.2013: 31586).

„Energiewende“ als Forderung wird von den Regierungsfraktionen zwar aufrechterhalten, aber gleichzeitig durch ambivalente Artikulationen zunehmend negativ eingebunden.

Unter der großen Koalition der 18. Legislaturperiode verstärken sich die Ambivalenzen der Artikulation von „Energiewende“ und erneuerbare Energien als Wirtschaftsfaktor: Einerseits wird die „Energiewende“ als Chance für die wirtschaftliche 
Entwicklung gesehen, andererseits wird sie aber auch immer wieder als Bedrohung konstruiert und vorherrschenden ökonomischen Strukturen untergeordnet. Ein starkes Motiv der 18. Legislaturperiode ist der Erhalt der Wettbewerbsfähigkeit deutscher Unternehmen und von Deutschland als Industrieland und -standort im Kontext der „Energiewende“. Damit Deutschland „beispielhaft zeigen“ könne, „dass Klimaschutz, Sicherung von Arbeitsplätzen und wirtschaftlicher Erfolg“ vereinbar seien, sei es wichtig ,die energieintensive Industrie vor einer steigenden EEG-Umlage zu schützen“ (SPD 27.06.2014: 3932). Schon heute gehen „die Investitionen in energieintensiven Branchen deutlich zurück“ und schon heute gingen deswegen Arbeitsplätze verloren (SPD 27.06.2014: 3933). Dabei werden Bedrohungsszenarien skizziert: „Wenn wir an der Stelle einen Fehler machen, dann gefährdet das - das muss jeder in diesem Haus wissen - unseren Industriestandort“ (CDU 27.06.2014: 3935). Immer wieder wird die Gefahr einer „Deindustrialisierung“ gezeichnet: „Wir wollen und werden dafür sorgen, dass Deutschland Industrienation bleibt [...]. Diese Koalition und dieser Minister lassen Deindustrialisierung in Deutschland nicht zu“ (SPD 27.06.2014: 3939f.). Dabei zeigt sich erneut eine implizite Abwertung der Branche der erneuerbaren Energien, die als für ihre wirtschaftliche Situation selbst verantwortlich konstituiert wird, gegenüber dem Rest der deutschen Wirtschaft, die „vor unzumutbaren Belastungen“ durch die „Energiewende“ zu schützen sei (SPD 10.04.2014: 2434). Die „Energiewende“ und ihrer Befürworter*innen werden somit immer wieder ins energiepolitische ,Außen“ verwiesen, wobei durch die Regierungskoalition auf ambivalente Weise weiterhin an der Forderung der „Energiewende“ festgehalten wird. Dies gipfelt zum Beispiel im Vorwurf an die GRÜNEN, dass sie an Firmen der erneuerbaren Energien Branche, selbst „massiv beteiligt“ seien und nur deswegen eine Politik zu deren Förderung betrieben. Die Branche der Erneuerbaren sei in Schwierigkeiten geraten, weil „es in dieser Branche unternehmerisches Missmanagement bis zum Gehtnichtmehr" gebe (CDU 01.06.2016: 16975). Die Solarindustrie habe „das süße Gift der Subvention genommen und damit ihre Wettbewerbsfähigkeit gegenüber chinesischen Herstellern verloren“ (CDU 27.06.2014: 3941).

\section{Versus das Ende der Solarindustrie als wirtschaftspolitischer Fehler}

Noch in der 17. Legislaturperiode hatte die SPD kritisiert, der Bundestag beschließe mit der Verabschiedung der EEG-Novelle 2012 „,das Ende der Solarindustrie in Deutschland“, die Koalition verspiele damit „,nicht nur die Energiewende und die Zukunft“, sondern auch deren ,gesellschaftliche Unterstützung“ (SPD 29.03.2012: 20292). In der Regierungsbeteiligung der großen Koalition der 18. Legislaturperiode argumentiert die SPD dann nicht mehr für die Rettung der Solarindustrie. Die GRÜNEN kritisieren daher, der Wirtschaftsminister (Sigmar Gabriel, SPD) kümmere ,sich um jeden Arbeitsplatz in der energieintensiven Industrie, wo die Arbeiter in der IG BCE organisiert sind, persönlich“, habe aber keine „Empathie für Arbeitsplätze in der Branche der erneuerbaren Energien“ (GRÜNE 01.06.2016: 16983).

GRÜNE und LINKE arbeiten die Ambivalenzen in den Artikulationen der Regierungsfraktionen heraus, ihre Positionen bleiben aber - auch aufgrund ihrer ge- 
ringen Redezeiten - marginalisiert. Die Regierungskoalition „treibe[...] diese Branchen mit Ihrer Politik aus dem Land“ (GRÜNE 27.06.2014: 3937). Die Bundesregierung ,zerstöre[...] Zukunftsbranchen“ und vernichte „Zigtausende Arbeitsplätze“, das sei „,wirtschaftspolitisch dumm“ (GRÜNE 01.06.2016: 16975).

Die LINKE bezeichnet die Nicht-Rettung der Solarindustrie als „Politikversagen und einen Skandal“. Der „Zusammenbruch“ führe zu einem „Niedergang ganzer Regionen in Ostdeutschland“ (LINKE 13.06.2013: 31587). Sie verwendet dafür ihrerseits in einem anderen Bedeutungszusammenhang den Knotenpunkt ,Deindustrialisierung‘: Die Regierung sehe ,unbeeindruckt zu, wie eine zweite Deindustrialisierung über den Osten Deutschlands hereinbricht" (LINKE 13.06. 2013: 31587). Das nütze lediglich den „Stromgroßkonzernen“. Dagegen seien die Autoindustrie und die Banken, „die mit halsbrecherischen Spekulationen das Geld ihrer Kunden leichtfertig aufs Spiel gesetzt haben“ mit „großer Selbstverständlichkeit“ „mit Milliarden Steuergeldern“ gerettet worden (LINKE 13.06.2013: 31586). Die LINKE kämpfe „um den Erhalt jedes Arbeitsplatzes“ und für die „Solarindustrie als Standortfaktor“"(LINKE 13.06.2013: 31587).

\subsubsection{Marktorientierung als Bedingung erneuerbarer Energiepolitik und "Energiewende“"}

Mit der Story-Line von erneuerbaren Energien als Wirtschaftsfaktor eng verknüpft ist eine marktorientierte Ausrichtung der Energiepolitik, die ein zentrales Element komplexitätsreduzierender Erzählungen erneuerbarer Energien und später der „Energiewende“ darstellt und daher hier als eigene Story-Line kodiert wird. In der 14. und 15. Legislaturperiode geht es zumeist um die Markteinführung der erneuerbaren Energien als Technologie - eine Verknüpfung zu einer „Energiewende“ bleibt zunächst aus. So wird das EEG als Instrument zur ,Markteinführung', als ,Marktanreizprogramm‘ konstituiert (z.B. GRÜNE 25.02.2000: 8442): „Ziel dieser Maßnahmen muss es sein, die Wirtschaftlichkeit der erneuerbaren Energien zu verbessern, damit sich für diese Technologien langfristig ein sich selbst tragender Markt entwickelt" (SPD 25.02.2000: 8428). Eine zumindest langfristige Marktorientierung der Energiepolitik wird so von Anfang an als Bedingung der Förderung erneuerbarer Energien konstituiert. Dennoch zeigen sich Ambivalenzen in den Artikulationen der rot-grünen Regierungskoalition, denn andererseits wird ein Widerspruch zwischen ,Markt ${ }^{\star}$ und ,Natur' konstruiert:

„Erneuerbare Energien können nicht nach dem traditionellen Bewertungsmuster von Wettbewerb eingeführt werden. [...] Sie können sie nicht gleichschalten, weil man die Natur nicht gleichschalten kann. Wenn man also das Potenzial erneuerbarer Energien nicht ausschließlich nach Marktprinzipien behandeln [...] will, wenn man den Ausbau in der Breite will, dann darf man sich nicht dem neuen Marktgesetz unterwerfen“ (SPD 25.02.2000: 8439).

Dagegen artikulieren CDU, CSU und FDP, die erneuerbaren Energien im EEG als zu „marktfern“ (CSU 25.02.2000: 8440). „Markwirtschaft“ wird mit „Effizienz“, „Kostensenkung“ (FDP 25.02.2000: 8443) sowie „Wettbewerb“ äquivalenziert. 
„Die Finanzierung, Förderung und Markteinführung der erneuerbaren Energien vom Marktgeschehen abzukoppeln ist ein Versagen hinsichtlich der zentralen Herausforderung an die erneuerbaren Energien, nämlich sich dem Wettbewerb zu stellen, ihm langfristig ausgesetzt zu sein, wettbewerbsfähig zu sein, damit wir auch unter dem Gesichtspunkt der Kosten die Energieversorgung in Deutschland sicherstellen können.“ (CDU 25.02.2000: 8430).

In der 15. Legislaturperiode intensiviert sich der Fokus auf eine Marktorientierung des Energiebereichs im Zuge der Debatte um den Emissionshandel. Der Emissionshandel solle als neues „marktwirtschaftliches Instrument“ eingeführt werden, das „am preisgünstigsten“ Emissionen vor allem im Energiebereich einspart (SPD 28.05.2004: 10248) und wird so als marktorientiertes Instrument der Energiepolitik konstituiert. Man wolle „gemeinsam noch mehr auf den Markt setzen“ (SPD 28.05.2004: 10248f.). Neue effiziente Anlagen sollen einen Wettbewerbsvorteil erhalten, weil sie Emissionsrechte ,,am Markt verkaufen“ können, während alte Anlagen Rechte zukaufen müssen (SPD 28.05.2004: 10248f.). Die Äquivalenzierung von Marktorientierung mit Klimaschutz und Energie findet Zustimmung über die Reihen der Regierungskoalition hinweg. Auch die CDU/CSU (z.B. CDU 28.05.2004: 10236) sowie die FDP begrüßen die Einführung von Emissionshandel, denn es gehe „um nicht weniger als die Umstellung in der Umweltpolitik von der bisherigen reinen Ordnungspolitik hin zu einem marktwirtschaftlichen Instrument“ (FDP 28.05.2004: 10239). Allerdings habe die rot-grüne Regierung daraus „ein bürokratisches Monstrum“ gemacht, die Investitionsanreize funktionieren nicht richtig (FDP 28.05.2004: 10239).

In der 16. Legislaturperiode nähern sich CDU, CSU einerseits und SPD andererseits in ihren Artikulationsmustern an. Die Marktorientierung als Bedingung für erneuerbarer Energien und Klimaschutz erlangt dadurch als komplexitätsreduzierende Erzählung noch mehr Gewicht. Der Klimaschutz und die Energiepolitik sollen mit dem Emissionshandel noch „ökonomisch effizienter“ gestaltet werden (Koalitionsvertrag 2005: 66). Im Zuge der Novelle des EEG 2009 sollen mit verringerten Vergütungssätzen (Degression) Marktanreize gesetzt werden, um „die Technologie zu verbessern“. Dies sei notwendig, damit „der Erfindergeist rege bleibt; denn die ausländische Konkurrenz ist längst aus den Startblöcken heraus“ (CDU 06.06.2008: 17742).

Die GRÜNEN kritisieren zwar die Degressionen in der EEG-Novelle als zu hoch, stützen sich dabei aber selbst auf eine marktorientierte Argumentation und artikulieren damit innerhalb der vorliegenden Story-Line: „[E]in schnell wachsender Markt braucht sensible Marktunterstützung und nicht auf Jahre hinweg starr festgelegte, drastische Vergütungssenkungen“"(GRÜNE 06.06.2008: 17738).

Während die LINKE die Demokratisierung des Strommarktes, im Sinne einer demokratischen behördlichen Kontrolle fordert (LINKE 02.07.2009: 25876), lehnen die anderen Fraktionen dies vor dem Hintergrund einer marktorientierten Einbindung der Energiewirtschaft ab: „Die Union hat den Wettbewerb im Blick und wird ihn weiter stärken. Wir sind die Partei der sozialen Marktwirtschaft [...]. CDU und CSU lehnen die sozialistische Lenkung der Energiewirtschaft und andere Formen des Kollektivismus ab.“ (CDU 02.07.2009: 25872). „Monopole, auch staatliche, sind aber der natürliche Feind des Fortschritts und damit auch der dringend erforderlichen Energiewende"(GRÜNE 02.07.2009: 25877). Hier zeigt sich somit die Hegemoniali- 
tät einer marktwirtschaftlichen Ausrichtung der Ökonomie im Diskurs um „Energiewende“.

In der 17. Legislaturperiode intensiviert sich unter schwarz-gelb der Fokus auf eine Marktorientierung als Bedingung erneuerbarer Energiepolitik weiter. Im Jahr 2010 verabschiedeten Energiekonzept geht es zunächst darum, den ,Weg in das Zeitalter erneuerbaren Energien“ marktorientiert zu gestalten: „Wir wollen den Wettbewerb und eine marktwirtschaftliche Orientierung auf den Energiemärkten stärken. Damit sichern wir nachhaltige wirtschaftliche Prosperität, zukunftsfeste Arbeitsplätze, Innovationen und die Modernisierung unseres Landes“ (17/3049: 2). Man setze auf eine „marktorientierte Energiepolitik“, die mit der Kernenergie als „Brückentechnologie“ äquivalenziert wird (17/3049: 2). Auf dem ,Weg in das Zeitalter erneuerbarer Energien“ soll vor allem auf die Initiative privater Unternehmen gesetzt werden: „Das ist die richtige Balance zwischen Markt und Staat. Das ist soziale Marktwirtschaft“ (FDP 28.10.2010: 7173). Auch das EEG solle in Zukunft „stärker am Markt orientiert werden und der weitere Ausbau der erneuerbaren Energien in stärkerem Maße marktgetrieben erfolgen“ (17/3049: 4). Dafür wird das ab diesem Zeitpunkt regelmäßig verwendete diskursive Muster „Schrittweise Markt- und Systemintegration der erneuerbaren Energien“" eingeführt (17/3049: 11). Die Marktintegration wird zunehmend als eine quasi-natürlichen Voraussetzung für die weitere Etablierung erneuerbarer Energien konstituiert. Die Naturalisierung des marktorientierten Ökonomieverständnisses ist dabei als identitätsstiftendes Moment seiner Befürworter*innen zu werten. Dieses prägt den Diskurs zunächst implizit, materialisiert sich dann aber immer wieder in entsprechenden Gesetzgebungen: So müsse das EEG geändert werden, ,,damit die erneuerbaren Energien im Markt ankommen und zukunftsfähig sind“ (CDU 28.10.2010: 7184). Das „Strommarktdesign der Zukunft“ solle ,im Kern marktwirtschaftlich ausgerichtet sein“ (17/3049: 8). SPD, GRÜNE und LINKE sprechen dagegen von einem „Systemkonflikt“ zwischen erneuerbaren Energien und konventionellen Kraftwerken, da durch die konventionellen Grundlastkraftwerke regelmäßig zu viel Strom im Netz sei. Erneuerbare Energien können daher nicht einfach in das bestehende System integriert werden (SPD 28.10.2010: 7207; GRÜNE 28.10.2010: 7192; LINKE 28.10.2010: 7188f.).

Da die Marktorientierung der Energiepolitik als eine zentrale Story-Line durch „Fukushima“ nicht disloziert wird, kann diese nach „Fukushima“ zu einer Grundlage des „Energiewende“-Diskurses werden. Durch eine Marktorientierung könne der Ausbau der erneuerbaren Energien nun „schneller“ als unter rot-grün voranschreiten (FDP 30.06.2011: 13375). Bereits in ihrer Regierungserklärung zum „Atomausstieg“ erklärt Angela Merkel „Kosteneffizienz und zunehmende Marktorientierung“ zur „Leitlinie“ des Umstiegs. „Diesem Ziel dient die Novelle des Erneuerbare-EnergienGesetzes“ (Angela Merkel 09.06.2011: 12962). Die Koalition betont „erstmalig Marktmechanismen [ins EEG] einbringen“ zu wollen (FDP 09.06.2011: 12986). Dazu brauche es „Marktprinzipien“, wie z.B. die „Marktprämie“, die als Knotenpunkte von „Subventionen und Regulierungen“ (FDP 30.06.2011: 13375) abgegrenzt werden. Die erneuerbaren Energien sollen ,,mit marktwirtschaftlichen Mitteln in den Markt“ eingeführt werden, das EEG „,so wirtschaftsfreundlich und industriefreundlich“" werden, ,wie es noch nie war“ (CDU 30.06.2011: 13370). Wie bereits im EEG 2009 soll durch Reduktion der Vergütungen die Wettbewerbsfähigkeit gefördert werden (CDU 29.03.2012: 20306). Mit dem EEG 2012 soll das „Marktintegrations- 
modell gesetzlich veranker[t...]“ werden (CDU 29.03.2012: 20306). Die Opposition dagegen habe den eigentlichen Sinn des EEG, „die Markteinführung“, vergessen (FDP 29.03.2012: 20308).

Die „Markt- und Systemintegration“ ist auch ein zentrales Thema der 18. Legislaturperiode. Das wird bereits im Koalitionsvertrag zwischen CDU/CSU und SPD deutlich: „Das EEG ist ein Instrument zur Markteinführung von erneuerbaren Energien. Sie sollen perspektivisch ohne Förderung am Markt bestehen“ (Koalitionsvertrag 2013: 39f.). Das EEG müsse „mehr Markt beinhalten“ (CDU 01.06.2016: 16984). Die erneuerbaren Energien sollten den Strommarkt bestimmen und könnten daher ,nicht dauerhaft in einem vom Markt abgeschotteten Sondersystem untergebracht werden“ (SPD 27.06.2014: 3932). Daher müsse man jetzt „den Systemwechsel hin zu Ausschreibungen vornehmen [...]. Wir müssen aber auch dafür sorgen, dass wir die Preise für erneuerbare Energien durch Markt und Wettbewerb - und nicht mehr im Deutschen Bundestag - festlegen“ (CDU 01.06.2016: 16984). Damit ließen sich alle Schwierigkeiten, wie „Überrenditen“ oder „die Tatsache, dass Bauern bis zu 40000 Euro pro vermieteter Fläche für Windkrafträder bekommen, usw. “ lösen (CDU 01.06.2016: 16979). Während die Regierungskoalition die erneuerbaren Energien in den Markt integriere, lebe die Opposition ,immer noch in der Welt der Markteintrittsinstrumente“ (CDU 01.06.2016: 16984). Die „Kompetenzen der Energiepolitik“ sollen zukünftig im Wirtschaftsministerium „gebündelt werden“ (SPD 10.04.2014: 2443). Auch hier wird im Kontext von Hegemonie deutlich, aus welchem Ökonomieverständnis heraus die „Energiewende“ maßgeblich mit Bedeutung aufgeladen wird.

\section{Versus Zwangsvermarktung und Gefährdung erneuerbarer Energien durch Marktorientierung}

Die GRÜNEN sprechen dagegen von „Zwangsvermarktung“, die vor allem die kleinen Produzent*innen (z.B. den „Familienvater") treffe, die gar keine Chance haben den „Solarstrom vom Hausdach an der Börse zu vermarkten“ - das wirke wie eine 10-20-prozentige Vergütungssenkung (GRÜNE 29.03.2012: 20203). Privatpersonen können keine Energieversorgungsunternehmen sein (GRÜNE 29.03. 2012: 20303). Die GRÜNEN kritisieren die EEG-Reform 2014 gestalte den Ausbau der erneuerbaren Energien nicht marktwirtschaftlich, sondern würge ihn ab (GRÜNE 10.04.2014: 2441).

Während die GRÜNEN eine Marktorientierung aber nicht grundsätzlich in Frage stellen, lehnt die LINKE eine solche generell ab, auch im Rahmen der Debatte um die EEG-Novelle 2012 (LINKE 29.03.2012: 20278). Sie sieht das EEG grundsätzlich durch eine Marktliberalisierung gefährdet: „Sie selbst zerstören das EEG mit dieser Reform (LINKE 27.06.2014: 3941). Die Regierungskoalition wolle mit der „Direktvermarktung und mit Ausschreibungen die Marktliberalisierung“ und gehe dabei weit über EU-Vorschriften hinaus (LINKE 27.06.2014: 3941).

Die Artikulation kritischer Forderungen in- und außerhalb marktorientierter Deutungsmuster im Kontext von Hegemonie wird in Kapitel 5.4 weiter diskutiert. 


\subsection{5 ( $\mathrm{Zu})$ Hohe Kosten erneuerbarer Energien und „Energiewende“}

Eine weitere Story-Line, die sich bereits im Rahmen der computerbasierten Datenanalyse abgezeichnet hat und sich nun in der qualitativen Auswertung der einschlägigen Dokumente bestätigt, ist die komplexitätsreduzierende Erzählung, die erneuerbare Energien und „Energiewende“ auf ihre vermeintlich hohen Kosten reduziert. In der 14. bis 15. Legislaturperiode spielen diese noch eine untergeordnete Rolle. ${ }^{63}$ Zwar werden in der 16. Legislaturperiode dann die Kosten der Energieversorgung im Kontext einer potenziellen Gefährdung der Wettbewerbsfähigkeit der energieintensiven Wirtschaft diskutiert (z.B. Koalitionsvertrag 2005: 85), andererseits ist die Einschätzung der großen Koalition diesbezüglich auch positiv: „Erneuerbare sind nicht umsonst; aber die Kosten bleiben im Rahmen und sind vorhersehbar[...]" (CDU 06.06.2008: 17735). Aufgrund der wachsenden Nachfrage nach Energie bei gleichzeitiger „Verknappung der fossilen Energieträgern“ komme es zu „dramatischen Preissteigerungen", die durch erneuerbare Energien abgemildert werden könnten (CDU 06.06.2008: 17741). Während die FDP weiterhin für eine marktwirtschaftliche Lösung für mehr Wettbewerb zur Reduktion der Kosten erneuerbarer Energien plädiert (FDP 06.06.2008: 17732), kontrastiert die CDU die Kosten des EEG mit den Folgekosten von Erderwärmung und Ressourcenknappheit:

„Es ist richtig - das adressiere ich insbesondere an die FDP -: Durch die erneuerbaren Energien wird Energie kurzfristig sicherlich nicht billiger. Wenn man aber über den Tellerrand hinausschaut, dann stellt man sehr schnell fest, dass wir, wenn wir jetzt nicht handeln, dieses Nichthandeln später teuer bezahlen müssen“ (CDU 06.06.2008: 17741).

Auch die SPD argumentiert, dass „die Beibehaltung der jetzigen Energiepolitik“ durch die Folgekosten des Klimawandels viel teurer sei als die Umstellung auf erneuerbare Energien (SPD 06.06.2008: 17744). Im Gegensatz dazu seien „für die Zukunft unserer Kinder und Enkelkinder 3 oder 5 Euro im Monat verdammt preiswert" (SPD 06.06.2008: 17744). „Zudem werden durch erneuerbare Energien „mindestens 400.000 Arbeitsplätze geschaffen“: „Es ist teurer, wenn diese Leute zum Arbeitsamt geschickt werden“" (SPD 06.06.2008: 17744).

Erst in der 17. und 18. Legislaturperiode werden erneuerbare Energien und „Energiewende“ zunehmend im Kontext von hohen Kosten artikuliert. Auch die Zusammenhänge der diskursiven Elemente verschieben sich: Wurden noch in der vorigen Legislaturperiode die Kosten des Ausbaus erneuerbarer Energien den Folgekosten des Klimawandels gegenüber gestellt, so werden die Kosten erneuerbarer Energien nun verstärkt isoliert artikuliert. So heißt es im Energiekonzept von schwarzgelb unter der Überschrift „kosteneffizienter Ausbau der Erneuerbaren“: „Ziel der Bundesregierung ist es, den Ausbau der erneuerbaren Energien weiter voranzutreiben und zugleich den Druck auf Innovationen und Kostensenkungen weiter zu verstär-

63 Debatten über die Kosten der Energieversorgung zwischen der 14. und 15. Legislaturperiode beziehen sich meist auf die Ökosteuer (z.B.: GRÜNE 09.09.2004: 11253). 
ken“ (17/3049: 4). Kostensenkungsbedarf wird dabei vor allem bei der Photovoltaik gesehen (17/3049: 4).

Nach „Fukushima“ gewinnen Äquivalenzierung der Knotenpunkte ,Kosten“ und ,erneuerbare Energien` weiter an Bedeutung, wobei die Kosten erneuerbarer Energien in den Debatten zunehmend mit den Kosten der „Energiewende“ gleichgesetzt werden. Bereits in der Regierungserklärung zum Atomausstieg, hat das Thema einen hohen Stellenwert. Dabei steht „vor allem die energieintensive Industrie“ und deren Belastung durch die Strompreise im Mittelpunkt (Angela Merkel 09.06.2011: 12962). „Die EEG-Umlage soll nicht über ihre heutige Größenordnung hinaus steigen“, langfristig sollen die Kosten gesenkt werden (Angela Merkel 09.06.2011: 12962). Auch für die FDP hat die „Bezahlbarkeit“ einen hohen Stellenwert, was sie von der Opposition unterscheide (FDP 09.06.2011: 12968; 29.03.2012: 20308). Gleichzeitig stellt die Betonung von Kostensenkungen ein einendes Moment zwischen Befürworter*innen und Gegner*innen erneuerbarer Energien innerhalb der eigenen Fraktion her. Mit den Kosten verbunden wird das Bedrohungsszenario des möglichen Verlusts von „Hunderttausende[n] von Arbeitsplätzen“ in der energieintensiven Industrie (CSU 09.06.2011: 12973; CDU 29.03.2012: 20282).

\section{Versus Befreiung der energieintensiven Industrie als Ursache für hohe Kosten und soziale Ungerechtigkeit}

GRÜNE, LINKE und SPD betonen dagegen, dass die Strompreise ,nicht wegen der Energiewende gestiegen“ seien, sondern ,trotz der Energiewende“ (SPD 29.03.2012: 20283) und verweisen damit auf Brüche in den Artikulationen der Regierungsfraktionen. Die Kosten der Atomenergie seien im Gegensatz zur „Energiewende“ kaum bezifferbar (GRÜNE 30.06.2011: 13381). Durch eine übermäßige Entlastung der energieintensiven Industrie komme es zu einer Umverteilung zwischen Privatverbraucher*innen und großen Unternehmen, die Kosten würden „auf immer weniger Schultern verteilt“ (SPD 29.03.2012: 20282): „Die Mehrkosten tragen die Privathaushalte und die kleinen Unternehmen: also der Rentner für das befreite Hotel, die Krankenschwester für das befreite Rechenzentrum, der Einkaufsmarkt um die Ecke für den Riesenmarkt auf der grünen Wiese und der Handwerker für die Fabrik“" (SPD 29.03.2012: 20283). Auch die GRÜNEN sprechen von einer Umverteilung von ,privaten kleinen Verbrauchern“ „,in Richtung Industrie“, die insgesamt „9 Milliarden Euro“ betrage (GRÜNE 29.03.2012). SPD und GRÜNE fordern zwar eine begrenzte Befreiung der energieintensiven Industrie: „Die energieintensive Industrie gehört zu Deutschland“, weshalb „diese Unternehmen im Land“ gehalten werden müssen (GRÜNE 29.03.2012: 20286). Es sei aber völlig intransparent ,wer genau welche Subventionen bekommt", über die Befreiung von der EEG-Umlage werde der Braunkohletagebau mit 40 Millionen Euro im Jahr subventioniert (GRÜNE 29.03.2012: 20286). Die GRÜNEN kritisieren, dass die ständige Betonung der Kosten der „Energiewende“ bei gleichzeitiger Nichtbetrachtung der Kosten des Klimawandels, diese subvertiere: „In den letzten zwei Jahren wird nur noch gegen die angeblich hohen Kosten der Energiewende gehetzt“, die aber „,keine Kosten, sondern Investitionen gegen den Klimawandel“ seien (GRÜNE 13.06.2013: 31588). Die LINKE betont, dass die Industrie diese strompreissenkenden Effekte für eine 
„Gewinnmacherei im Schatten der erneuerbaren Energien“ nutze, weshalb eine staatliche Preisaufsicht notwendig sei (LINKE 24.03.2011: 11308). So seien die Strompreise an der Börse um 2 Cent gesunken, während die EEG-Umlage nur um 1,5 Cent gestiegen sei - statt Preissenkungen habe es aber Preiserhöhungen gegeben (LINKE 24.03.2011: 11308) - „Das heißt, das Ganze ist eine Gelddruckmaschine“ (LINKE 30.06.2011: 13390) oder auch eine ,gigantische Umverteilungsmaschine“ (LINKE 29.03.2012: 20277), wie es in einer späteren Debatte heißt.

Während die SPD in der 17. Legislaturperiode die umfassenden Befreiungen der energieintensiven Industrie sowie die starke Betonung der Kosten durch schwarzgelb kritisiert, wechselt sie in der 18. Legislaturperiode ihre Diskursposition und wirkt affirmativ auf die Story-Line, die die „Energiewende“ auf ihre Kosten reduziert. Auch durch die starke Positionierung der Mehrheitsgruppe (80\%) im Bundestag kommt den Kosten dadurch ein noch höherer Stellenwert zu. Im Koalitionsvertrag ist von einem „energiepolitischen Dreieck[...]“ aus „Klima- und Umweltverträglichkeit, Versorgungssicherheit [und] Bezahlbarkeit" die Rede (Koalitionsvertrag 2013: 9). Diese Ziele seien gleichrangig. Der „Kosteneffizienz“ soll eine „höhere Bedeutung“ als bisher beigemessen werden (Koalitionsvertrag 2013: 36). Immer wieder ist von einem „Kostenanstieg“ die Rede, dessen „Ausmaß und Geschwindigkeit“ spürbar gebremst werden solle (Koalitionsvertrag 2013: 38f.). Gerade für die Rechtfertigung der Novellierungen des EEG 2014 und 2016/2017 spielt solche Artikulationsmuster eine Rolle: „Es gab beim EEG in wenigen Jahren Kostensteigerungen von mehr als 10 Milliarden Euro“ (SPD 27.06.2014: 3932). Durch die wiederkehrende Äquivalenzierung des Knotenpunktes ,Belastung“ mit „Energiewende“ entsteht der Eindruck, diese sei ,zu teuer‘. So sei die EEG-Umlage ,inzwischen zu einer massiven Belastung geworden“ (SPD 10.04.2014: 2435), „,niemand wird leugnen, dass wir hier auf der Kostenseite ein Problem haben“ (CDU 01.06.2016 16979). Die Ausgaben für erneuerbare Energien in Höhe von 24 Milliarden Euro im Jahr 2014 seien ,eine gewaltige Belastung für uns als Volkswirtschaft, für die Unternehmen, aber auch für die Familien“ (CDU 10.04.2014: 2439). Der Fokus auf Kosten wird diskursiv mit einem Bedrohungsszenario des Verlustes von Wirtschaftskraft verbunden: „Wir müssen die Frage der Energiekosten permanent adressieren [...]; Denn ansonsten werden große energieintensive Unternehmen Deutschland verlassen“ (CDU 10.04.2014: 2439). Die Energiekosten „,bestimmen die Wettbewerbsfähigkeit dieses Landes“ weshalb die Industrie zum Erhalt von Arbeitsplätzen entlastet werden müsse (SPD 10.04.2014: 2434). Die Äquivalenzbeziehung zwischen ,Kosten“ und „Energiewende“ erscheint zunehmend quasi-natürlich, weshalb die Artikulation dieser Verbindung zur Norm wird: „Frau Verlinden [GRÜNE], Sie haben das Wort ,Kosten“ - wir alle können das nachlesen - in Ihrer Rede nicht einmal verwandt“ (SPD 01.06.2016 16989).

\section{Versus die Kostendebatte diskreditiert die „Energiewende“ zu Unrecht}

Wie bereits in der 17. Legislaturperiode bestreiten GRÜNE und LINKE einen allein durch die „Energiewende“ verursachten Kostenanstieg, kritisieren mangelnde Kostengerechtigkeit und heben die Folgekosten von Umweltschäden hervor. Da- 
durch verweisen sie weiterhin auf die Brüche und Widersprüche in den Artikulationen der Regierungsfraktionen, ihre Wirkung auf den Diskurs bleibt aufgrund ihrer geringen Redezeit aber marginal. So argumentieren die GRÜNEN, es gebe „keine explodierende EEG-Umlage“, das sei eine „freie Propagandaerfindung“ (GRÜNE 01.06.2016: 16983). Auch die LINKEN kritisieren die ,unsägliche Kostendebatte“ (LINKE 01.06.2016: 16977). Es mache keinen Sinn die „Energiewende“ gegen ihre Kosten auszuspielen: „Ja, die Energiewende kostet Geld. Keine Energiewende ist um ein Vielfaches teurer“ (LINKE 01.06.2016: 16985). Mit dem Kostenargument werde ausgeblendet, dass „die Alternative viel teurer“ sei „und noch ganz andere Konsequenzen nach sich zieht“ (GRÜNE 01.06.2016: 16983). Zudem sei zwar die EEG-Umlage gestiegen, gleichzeitig sei aber der Börsenstrompreis durch die strompreissenkenden Effekte der erneuerbaren Energien deutlich gesunken (von 10 Cent je Kilowattstunde im Jahr 2008 auf 2,5 Cent je Kilowattstunde im Jahr 2016). Davon profitieren die Bürger*innen und Netzkunden durch die EEG-Umlage nicht, während die Preise für die energieintensiven Unternehmen, die von ihr befreit sind, deutlich gesunken seien: „Es ist eine Umverteilung von den Kleinen zu den Großen, die hier stattfindet“ (LINKE 01.06.2016: 16986). Es könne nicht sein, „dass die privaten Verbraucher zahlen und am Ende nur die Industrie profitiert. Das hat nichts mit Kostengerechtigkeit zu tun“ (GRÜNE 10.04.2014: 2441).

\subsubsection{Deutschland als Vorreiter und „Energiewende“ als nationales Gemeinschaftswerk}

Die bundespolitische Förderung erneuerbarer Energien wird von Anfang an mit dem diskursiven Muster der ,besonderen Rolle' Deutschlands als internationalem Vorbild verknüpft. Dies hat sich bereits im Rahmen der quantitativen Erhebung mit dem durchweg hohen Ranking von „Deutschland“ als häufige Kollokation abgezeichnet und bestätigt sich nun auch in der qualitativen Kodierung der wichtigsten StoryLines: „Ich bin mir ganz sicher, dass viele internationale Augen auf dieses Gesetz schauen werden und viele Erwartungen und Hoffnungen damit verbunden sind“ (SPD 25.02.2000: 8437). Die rot-grüne Regierungskoalition der 14. und 15. Legislaturperiode weist Deutschland im Klimaschutz eine Sonderrolle zu: „Wir setzen damit auch deswegen ein weltweites Signal, weil wir auf diese Weise die Frage des weltweiten Klima- und Umweltschutzes anders angehen, als es bisher bei den Weltklimakonferenzen leider der Fall war“" (SPD 25.02.2000: 8437). Die Förderung erneuerbarer Energien in Deutschland wird dabei auch direkt mit Entwicklungszusammenarbeit verknüpft, denn Deutschland als „Exportland“ trage Verantwortung: „Um sie aber dort [,,in der Dritten Welt"] wirksam werden zu lassen, müssen wir sie hier industriell mobilisieren, und zwar auch mithilfe dieses Gesetzes [...]" (SPD 25.02.2000: 8438). Die Äquivalenzierung der Förderpolitik mit Entwicklungszusammenarbeit sowie der Exportförderung findet auch Zustimmung bei CDU,CSU und FDP, da sie aus marktwirtschaftlicher Perspektive attraktiv erscheint - Deutschland solle die Technologie ,dort einsetzen, wo sie viel mehr und viel effizienter zum Klimaschutz beitragen kann [...]“" (CSU 25.02.2000: 8440). Die FDP möchte daher „,in Entwicklungs- und Schwellenländern [...] investieren, weil dort eine Reduktion 
der Emissionen von $\mathrm{CO}_{2}$ zu deutlich geringeren Kosten möglich ist“ und so „Technologietransfer" und „Exportoffensive“ verbunden werden können (FDP 28.05.2004: 10238). Durch diese Verknüpfung von erneuerbaren Energien mit Forderungen nationaler Interessenpolitik finden somit - wie soeben exemplarisch belegt - von Anfang an auch neokoloniale Elemente Einzug in den „Energiewende“-Diskurs. Was für mich im Rahmen des Forschungsdesigns Anlass war, postkoloniale Perspektiven in die Theoriebildung mit einzubinden (vgl. Kapitel 3.2.2).

Im Zusammenhang mit der von Bundeskanzler Gerhard Schröder einberufenen internationalen Konferenz „renewables2004“ verstärkt sich die Bedeutungsgenerierung erneuerbarer Energien über eine ,besondere Rolle‘ Deutschlands in der Welt im Laufe der 15. Legislaturperiode. Auffällig ist dabei, dass vor allem im Kontext der Thematisierung der internationalen Rolle Deutschlands nun häufiger der Begriff „Energiewende“ verwendet wird, während er in anderen Debatten kaum explizit auftaucht, wie in Kapitel 5.1.2 gezeigt wurde. Demnach spielt „die Konstruktion der Story-Line einer positiv belegten deutschen ,Vorreiterrolle‘ für die Bedeutungsgenerierung von „Energiewende“ von Anfang an eine besondere Rolle. Die Konferenz „renewables2004“ wird direkt mit einer Stärkung dieser Vorreiterrolle verbunden. So würden die 1000 Delegierten ,,aus über 100 Staaten nach Bonn kommen, um diese in Deutschland vollzogene Energiewende zu besichtigen“ (GRÜNE 28.05.2004: 10237). Bereits zuvor habe „eine Parlamentarierdelegation der pazifischen Inselstaaten“ bei einem Besuch in Berlin „die dringende Bitte gerade an uns Deutsche“ gerichtet, „beim Klimaschutz nicht nachzulassen. Wir seien eines der wenigen positiven Beispiele in der Welt“ (SPD 28.05.2004: 10247). „Wir sollten stolz darauf sein, hierzu eine avantgardistische Position einnehmen zu können“ (SPD 28.05.2004: 10241). Mit der deutschen Vorbildfunktion steht der Anspruch der Globalisierung der „Energiewende“ in direkter Verbindung. Die „Energiewende [könne] aber nur nachhaltig sein, wenn sie global ist“" (SPD 28.05.2004: 10234). Der Fokus liegt dabei auf den sogenannten Entwicklungsländern als Handlungsfelder:

„Entwicklungsländer dürfen und wollen nicht die Fehler wiederholen, die die Industrieländer bisher bei ihrer Energieversorgung gemacht haben, denn das hält unser Globus nicht aus [...]. Es gibt also keine Alternativen zu erneuerbaren Energien und zur Steigerung ihrer Effizienz. Außerdem bringt der Einsatz erneuerbarer Energien riesige Vorteile für Entwicklungsländer mit sich“ (SPD 28.05.2004: 10234).

Der erneuerbare Energiebereich biete einen Ansatzpunkt, um den „Zusammenhang zwischen globalen Entwicklungsproblemen und globalen Umweltproblemen“ anzugehen (SPD 28.05.2004: 10241). Deshalb wolle die Bundesregierung vermehrt in erneuerbare Energien in (sogenannten) Entwicklungsländern investieren (GRÜNE 28.05.2004: 10238).

In der großen Koalition der 16. Legislaturperiode etabliert sich die komplexitätsreduzierende Erzählung einer deutschen Vorreiterrolle im Zusammenhang mit Klimaschutz und erneuerbaren Energien weiter: „Deutschland wird weiterhin seine führende Rolle im Klimaschutz wahrnehmen“ (Koalitionsvertrag 2005: 65). Artikuliert wird dabei neben einer Vorbildfunktion auch die wirtschaftliche Position Deutschlands im internationalen Kontext: „Deutschland ist Weltmeister beim Ausbau der erneuerbaren Energien“ (SPD 06.06.2008: 17330); „Das deutsche EEG gilt in der Welt 
als Modell und Vorbild dafür, wie man erneuerbare Energien im Strombereich fördern kann“ (CDU 06.06.2008: 17742). Die CDU betont, „,dass es auf der Welt kein Industrieland gibt, das eine derartig positive energiepolitische Bilanz hat wie wir in Deutschland. Darauf können wir in der Großen Koalition stolz sein“ (CDU 02.07. 2009: 25690). Es wird eine deutsche Technologieführerschaft im Bereich erneuerbarer Energien konstruiert, aus der sich der Anspruch ableitet, diese insbesondere in sogenannten Entwicklungs- und Schwellenländern zu verbreiten: „Mit den Exportinitiativen ,Erneuerbare Energien “ und ,Energieeffizienz' unterstützt die Bundesregierung gezielt deutsche Unternehmen und die weltweite Verbreitung deutscher Spitzentechnologie, gerade auch in Entwicklungs- und Schwellenländern“ (CDU 02.07. 2009: 25690). Die Legitimität der Verbindung wirtschaftlicher Interessen mit Entwicklungszusammenarbeit wird dabei als quasi-natürlich vorausgesetzt: „Energieaußenpolitik ist vor allem auch Entwicklungspolitik“ und „Energieaußenpolitik [ist] insbesondere auch Wirtschaftsförderung und Wirtschaftspolitik" (CDU 02.07.2009: 25697). Dennoch sei Entwicklungspolitik nicht „Mittel zum Zweck“ (SPD 02.07. 2009: 25697). Um die positive Rolle Deutschlands für die Entwicklungszusammenarbeit im Bereich der erneuerbaren Energien hervorzuheben, wird immer wieder auf hohe Summen verwiesen, die investiert werden: „In dem vorgesehenen Zeitraum von 2003 bis 2007 wurden in der bilateralen Zusammenarbeit insgesamt 1,3 Milliarden Euro für erneuerbare Energien zugesagt. Ich finde, das kann sich sehen lassen (SPD 02.07.2009: 25698). ${ }^{64}$

Die komplexitätsreduzierende Erzählung einer ,deutschen Vorreiterrolle' bei den erneuerbaren Energien wird auch in der 16. Legislaturperiode von einer breiten Mehrheit im Bundestag artikuliert. Erneut wird die deutsche Technologieentwicklung mit einer Aufwertung der deutschen Rolle im internationalen Kontext äquivalenziert: „Die ganze Welt schaut staunend auf Deutschland, wo sich in kürzester Zeit eine [...] industrielle Entwicklung für Solarzellen, Windkraft und Biogas entwickelt hat“ (GRÜNE 06.06.2008: 17737). Die FDP möchte „,den Weg für deutsche Firmen in ausländische Märkte politisch [...] begleiten“ (FDP 02.07.2009: 25692). Eine Rolle für eine solche Begleitung spielt dabei das Projekt ,Desertec ${ }^{65 ،}$, auf das sich sämtliche Fraktionen im Deutschen Bundestag positiv beziehen und das - neben seiner Funktion für die Entwicklungszusammenarbeit - mit einer „Sicherstellung des Wohlstandes“ in Deutschland äquivalenziert wird (FDP 02.07.2009: 25692).

\section{Versus ungerechte Ressourcenverteilung und interessengeleitete Politik}

LINKE und GRÜNE fordern die Story-Line einer deutschen Vorreiterrolle im Energiebereich kritisch heraus, indem sie auf eine global ungerechte Ressourcenverteilung hinweisen sowie eine von wirtschaftlichen Interessen geleitete Politik kritisieren und somit die Brüche im Diskurs hervorheben.

64 Dabei wird aber nicht erwähnt, dass es sich überwiegend um Kredite handelt.

65 Unter dem Namen DESERTEC wird die Vision verfolgt überwiegend Solarstrom in den Wüstenregionen Nordafrikas zu produzieren und von dort in die Verbrauchszentren, auch nach Europa, zu übertragen (www.desertec.org). 
Vor dem Hintergrund einer gerechteren Ressourcenverteilung müsse Deutschland seinen Energieverbrauch einschränken, um den weltweiten Nachfragedruck zu mindern. Das funktioniere nicht, „wenn wir als ein Land mit einem erheblichen Energiebedarf - pro Kopf liegt er weit über dem Weltdurchschnitt - so tun, als könnten uns die anderen egal sein und als müssten wir hauptsächlich schneller als die anderen Länder sein“ (GRÜNE 02.07.2009: 25689). „Es kann nicht sein, dass die entwickelten Länder immer noch über 50 oder 60 Prozent des Gases und Öles für 15 Prozent der Weltbevölkerung beanspruchen“ (GRÜNE 02.07.2009: 25689). Die LINKE kritisiert die deutsche Energiepolitik als interessengeleitet. So sei die „deutsche Energieaußenpolitik [...] damals von SPD und Grünen militarisiert worden“ (LINKE 02.07.2009: 25694). „Die Bundesregierung betreibt Aufrüstung, weil sie fossile Energiequellen und die Transportwege sichern will“" (LINKE 02.07.2009: 25694). Auf den Klimawandel und die Ressourcenverknappung reagiere die NATO mit atomarer Aufrüstung. Dabei blieben „Frieden, Menschenrechte und eine sichere und nachhaltige Versorgung mit Energie“ „auf der Strecke“ (LINKE 02.07.2009: 25694). Die LINKE plädiert dafür, ,energietechnologisches Wissen mit den Ländern des Südens, zum Beispiel den Ländern Afrikas, vorbehaltlos“ zu teilen und erneuerbare Energien zum „Bestandteil einer Friedens- und Entwicklungspolitik“ zu machen (LINKE 02.07.2009: 25695).

Die Artikulation einer deutschen, Vorreiterrolle ' beim Klimaschutz und den erneuerbaren Energien hat sich etabliert und wird auch im Koalitionsvertrag als gegeben vorausgesetzt: „Unser Ziel ist es [...] Deutschlands Vorreiterrolle beim Klimaschutz beizubehalten“ (Koalitionsvertrag 2009: 26). Man wolle „die Technologieführerschaft bei den Erneuerbaren Energien ausbauen“ (Koalitionsvertrag 2009: 27). Mit seinem Energiekonzept setze Deutschland „für den Ausbau der erneuerbaren Energien und die Reduzierung von $\mathrm{CO}_{2}$ die im weltweiten Vergleich für ein Industrieland ehrgeizigsten Zielvorgaben“ (17/3050: 1). Auch in den Redebeiträgen zum gleichzeitig mit der Laufzeitverlängerung verabschiedeten Energiekonzept wird eine deutsche Vorreiterrolle artikuliert: „Wir sind dort weltweit an der Spitze und einzigartig“ (CDU 28.10.2010: 7168). Das Energiekonzept soll ein „Leitkonzept“ sein, das „Nachahmer in Europa und weltweit“ findet (FDP 28.10.2010: 7174). Es sei das „größte Modernisierungsprogramm für eine gesamte Volkswirtschaft“, „weltweit ein Prototyp“ (FDP 28.10.2010: 7201). Im Zusammenhang mit der Laufzeitverlängerung soll „die effizienteste, die klimaverträglichste und die wettbewerbsfähigste Energieversorgung [...], die es weltweit in einem Industrieland gibt", verwirklicht werden (CDU 28.10.2010: 7178).

Vor „Fukushima“" wird so die Laufzeitverlängerung mit einer international vorbildhaften, klimaverträglichen und wettbewerbsfähigen Energieversorgung unter dem Ziel des Umstiegs auf erneuerbare Energien äquivalenziert. Das Ereignis „Fukushima“ kann in dieser diskursiven Struktur aber nicht verarbeitet werden - die Kernenergie konterkariert die internationale Vorbildfunktion. Die Artikulation einer starken Rolle Deutschlands dient nun dazu, die Kurskorrektur weg von der Kernenergie zu rechtfertigen, „Fukushima“ diskursiv einzubinden und seine dislozierende Wirkung zu überwinden. Wurde vor „Fukushima“ bezweifelt, dass ein vollständiger Umstieg auf erneuerbare Energien auf absehbare Zeit ohne Kernenergie gelingen könne 
wird dies nun unter Zuhilfenahme nationaler Narrative und Mythen sowie der Berufung auf ein nationales Gemeinschaftsgefühls revidiert. Die deutsche Vorreiterrolle, die zuvor bereits mit Klimaschutz und erneuerbaren Energien äquivalenziert wurde, wird nun im Diskurs über die „Energiewende“ zu einem entscheidenden Moment, um ihre Machbarkeit zu vermitteln:

„Welches Land, wenn nicht unser Land, sollte dazu die Kraft haben? Deutschland hat schon so manches Mal gezeigt, was es kann, was in ihm steckt, und hat schon ganz andere Herausforderungen bewältigt [...]. Deshalb sind wir überzeugt: Deutschland hat das Potenzial und die Kraft für eine neue Architektur unserer Energieversorgung [...]. Wir können als erstes Industrieland der Welt die Wende zum Zukunftsstrom schaffen. Wir sind das Land, das für neue Technik, Pioniergeist und höchste Ingenieurkunst ${ }^{66}$ steht. Wir sind das Land der Ideen, das Zukunftsvisionen mit Ernsthaftigkeit, Genauigkeit und Verantwortung für zukünftige Generationen Wirklichkeit werden lässt [...]“( Angela Merkel 09.06.2011: 12963f.).

„[...E]s ist erstmalig und deshalb bislang einmalig, dass sich ein großes Industrieland bereit erklärt, eine solche technologisch-wirtschaftliche Revolution durchzuführen“ (CDU 30.06.2011: 13370). Auch „im Ausland“ erkenne man: „Wenn es ein Land schaffen kann, dann ist es Deutschland“ (CDU 30.06.2011: 13370). Die „Energiewende“ sei ein „Leitprojekt für den Klimaschutz in Europa. Andere Länder schauen auf uns, um zu sehen, wie wir es in unserem hochindustrialisierten Land schaffen, dieses große Projekt ohne Wohlfahrtsverluste zu stemmen“ (FDP 13.06.2013: 31292). Auch SPD und GRÜNE artikulieren eine deutsche Vorreiterrolle, bzw. das Bild einer starken Nation, die die „Energiewende“ ermögliche (z.B.: SPD 30.06. 2011: 13372). Deutschland sei nicht nur Vorreiter bei der „Energiewende“, sondern stehe auch ,an der Schwelle, im 21. Jahrhundert Vorreiter für die Green Economy zu sein“ (GRÜNE 30.06.2011: 13382).

Durch die Konstitution einer nationalen Gemeinschaft als handelndes Subjekt, wird der zuvor bestehende Konflikt über die „Energiewende“ zu verdecken versucht: „Die Deutschen machen sich ans Werk. Es wird gut für unser Land sein, weil wir alle zusammenstehen“ (CDU 30.06.2011: 13371). Die „Energiewende“ wird zum „nationale[n] Gemeinschaftswerk“ (CDU 30.06.2011: 13368) - häufig werden die Worte „wir“" und „unser“ verwendet. Dabei wird explizit auch die Opposition in dieses „Wir“ integriert. Damit verbunden wird aber auch ein konsensualer Anspruch, die Opposition solle ,jetzt endgültig über Ihren Schatten springen“ und „,begreifen, dass jetzt dieses nationale Werk in Deutschland losgeht" (CDU 30.06.2011: 13368). Aber auch SPD und GRÜNE appellieren im Zusammenhang mit einer deutschen Vorreiterrolle an ein kollektives ,Wir' und stärken dadurch diese Story-Line: „Jetzt schaut die Welt auf uns [...]. Wir haben die Verantwortung, zu zeigen, dass der Umbau funktioniert" (GRÜNE 30.06.2011: 13381). Die LINKE fordert die Konstruktion ei-

66 Das Element des, deutschen Ingenieurs' spielt für die Vermittlung der Machbarkeit der „Energiewende“ eine besondere Rolle und zeigt sich in mehreren Zitaten: „Das sind die 140000 Ingenieure unseres Landes, die das als ihr Projekt ansehen [...]. Diese Forscher, Ingenieure, Wissenschaftler machen dabei mit. Das macht unser Land stark“ (CDU 30.06. 2011: 13369). 
nes vermeintlichen Konsenses über eine nationale Gemeinschaft als Initiatorin der „Energiewende“ heraus: Der einzige Grund warum der „Atomausstieg“ „zuerst in Deutschland und nicht in Frankreich oder Polen“ gelinge, sei, dass „es in Deutschland eine ungeheuer starke Antiatombewegung gibt, die jetzt einen Erfolg feiert, für den sie jahrzehntelang gekämpft hat"“ (LINKE 09.06.2011: 12969).

Auch im Koalitionsvertrag von CDU, CSU und SPD der 18. Legislaturperiode wird im Zusammenhang mit der „Energiewende“ auf eine vermeintliche deutsche Vorbildfunktion verwiesen (Koalitionsvertrag 2013: 9). Der deutsche Führungsanspruch bezieht sich dabei auch auf die Europäische Union. Es sei notwendig die „Energiewende“ im europäischen Zusammenhang zu denken, „damit Deutschland auch langfristig Motor eines wettbewerbsfähigen Wirtschafts- und Industriestandorts Europa bleibt" (Koalitionsvertrag 2013:42).

Die internationale Vorbildfunktion (,Wir wollten doch beispielhaft sein $[\ldots]^{\text {“ }}$ (SPD 10.04.2014: 2434)) wird in der 18. Legislaturperiode weiter als eine Motivation für die „Energiewende“ artikuliert: „Wir sind mit der Energiewende angetreten, um $\mathrm{zu}$ zeigen [...], dass eine hochentwickelte Volkswirtschaft wie die deutsche es schafft, sich von nuklearer, langfristig aber auch von fossiler Energieversorgung zu befreien, ohne dabei ihren wirtschaftlichen Erfolg zu gefährden“" (SPD 27.06.3014: 3932). Es gehe auch darum „Nachahmer“ zu finden (SPD 01.06.2016: 16979).

\subsubsection{Strominfrastruktur als zentrale Herausforderung der „Energiewende“}

Der Ausbau der Strominfrastruktur im Sinne eines Netzausbaus für erneuerbare Energien wird vor 2007 (BMU 2007: 12) kaum thematisiert. Die große Koalition der 16. Legislaturperiode verabschiedet dann 2009 das Energieleitungsausbaugesetz EnLAG zum beschleunigten Netzausbau und Netzumbau (vgl. auch CDU 02.07. 2009: 25872). Aber erst in der 17. Legislaturperiode wächst die Bedeutung der (Netz-)Infrastruktur für die Bedeutungsgenerierung erneuerbarer Energien im Bundestag (17/3049: 10). Die FDP bezeichnet neben der Bereitstellung von Speichern die Netzentwicklung als „Dreh- und Angelpunkt des gesamten Umbaus“ (FDP 28.10. 2010: 7201).

Trotz dieser späten Entwicklung spielt diese Story-Line im „Energiewende“Diskurs der 17. und 18. Legislaturperiode eine zentrale Rolle, denn das zu langsame Voranschreiten des Netzausbaus wird zunehmend als zentrales Hindernis für den Umbau der Energieversorgung konstituiert. Die Regierungskoalition verknüpft dies aber nicht in erster Linie mit einer eigenen politischen Verantwortung, sondern weist auf ambivalente Weise die Verantwortung den Befürworter*innen einer „Energiewende“ zu: Verantwortlich seien auch „diejenigen, die im Plenum und in den Ausschüssen die erneuerbaren Energien und deren Ausbau vollmundig befürworten“, aber wenn es um den Netzausbau gehe ,als Erste gegen diese Infrastrukturprojekte wären und den Protest vor Ort organisieren würden“ (CDU 28.10.2010: 7168).

Auch in der 18. Legislaturperiode wird dem Netzausbau eine hohe Relevanz beigemessen. Neben der Problematisierung der Speicherung erneuerbarer Energie (Koalitionsvertrag 2013: 41), wird zunehmend der Knotenpunkt ,Digitalisierung ' mit „Energiewende“ verknüpft, ohne dies jedoch mit konkreten politischen Inhalten zu 
verbinden: „Die anstehende nächste Phase der Digitalisierung betrifft in besonderem Maße die Infrastrukturen: Erfolgsfaktor der Energiewende ist die Digitalisierung der Energieversorgung“ (Koalitionsvertrag 2013: 97).

Der Netzausbau wird im Zusammenhang mit mangelnder Akzeptanz artikuliert, wodurch die Regierungskoalition die politische Verantwortung in ein Außen verschiebt: „Aufgrund der hohen Dringlichkeit des Netzausbaus für das Gelingen der Energiewende ist eine breite Akzeptanz der Bevölkerung notwendig, die heute noch in vielen Fällen nicht gegeben ist" (Koalitionsvertrag 2013: 42). Die fehlende Akzeptanz wird als zentrales Problem bei der Umsetzung der „Energiewende“ konstituiert: „Es gibt einen enormen Aufwand bei der Netzausbauplanung im Einklang mit den Bürgerinnen und Bürgern“ (SPD 01.06.2016: 16987). Es seien „gerade einmal 9 Prozent der Leitungen [...] fertiggestellt“ (CDU 01.06.2016: 16984).

Nachdem die Verantwortung für einen zu langsamen Netzausbau diskursiv in ein Außen verschoben wurde, wird dieser im nächsten Schritt als ein Moment konstituiert, das es notwendig mache, den Ausbau der erneuerbaren Energien ebenfalls zu verlangsamen: „Nur dann, wenn die Netze vorhanden sind, darf der Ausbau der erneuerbaren Energien in dem Maße weiter betrieben werden" (CDU 01.06.2016: 16976). Weil der der Ausbau der erneuerbaren Energien zu schnell voranschreite, passen die „Netzausbauzahlen und die Ausbauzahlen bei den erneuerbaren Energien [...] nicht mehr zueinander“ (CDU 01.06.2016: 16984). Es sei eine „Synchronisierung" erforderlich (CDU 01.06.2016: 16979). Durch diese fehlende Synchronisierung komme es zu „Netzengpässen“ und erneuerbare Energien müssten abgeregelt werden - gleichzeitig können Kohle- und Gaskraftwerke wegen der fehlenden Netzstabilität nicht abgeschaltet werden (SPD 01.06.2016: 16981f.). Der fehlende Netzausbau wird als ein zentrales Hindernis der „Energiewende“ konstruiert: „Die Erneuerbaren [...] helfen uns aber überhaupt nicht, wenn der Netzausbau nur schleppend vorangeht, wenn der Strom also nicht dorthin gebracht wird, wo er gebraucht wird“ (CDU 01.06.2016: 16988). Hier zeigt sich wie über eine Story-Line, die den Netzausbau als zentrale Herausforderung der „Energiewende“ konstituiert und gleichzeitig die Verantwortung in ein Außen verweist, politische Praktiken gerechtfertigt werden, die den Ausbau erneuerbarer Energien verlangsamen.

\section{Versus konventionelle Stromproduktion erfordert überdimensionierten Netzausbau}

Vor allem die LINKEN stellen die Zentralität des Netzausbaus für die „Energiewende“ in Frage und verweist damit auf Brüche in den Artikulationen der Regierungskoalition. Die LINKE argumentiert, der ,überdimensionierte[...] Netzausbau“ sei nur notwendig, weil die Bundesregierung sich nicht von „100 Prozent konventioneller Erzeugung trennen“" wolle (LINKE 01.06.2016: 16985). ${ }^{67} \mathrm{Die}$ LINKE lehnt „,den massiven Ausbau der Übertragungsnetze und der Gleichspan-

67 Nach dieser Argumentation ist der Netzausbau nur notwendig, weil durch die konventionellen Energieträger zu viel Strom im Netz sei. Stattdessen müssten mehr Kohlekraftwerke abgeschaltet werden und statt Offshore-Windenergie vermehrt dezentrale Technologien eingesetzt werden. 
nungsleitungen“ ab. Die hohen Kosten dieses Ausbaus (30 Milliarden) seien „eine Umverteilung des Geldes von Verbraucherinnen und Verbrauchern hin zu den Aktionären" der Übertragungsnetzbetreiber. Sie fordert stattdessen den Kohlestrom zu reduzieren und vermehrt Speicher und Biomasse einzusetzen (LINKE 01.06. 2016: 16986).

\subsubsection{Rolle der Bürger*innen im Kontext von Akzeptanz und Konsens}

Die Rolle der Bürger*innen wird im Kontext von „Energiewende“ bzw. erneuerbare Energien wird zwischen der 14. und 16. Legislaturperiode selten artikuliert. Im Bedeutungszusammenhang mit ,dezentral' werden die Bürger*innen als Investor*innen beschrieben: „Dieses Gesetz wird nicht ohne die Bürger umgesetzt werden können. Es handelt sich um dezentrale Anlagen, die dezentrale Investoren brauchen“ (SPD 25.02.2000: 8437). Die Einführung erneuerbarer Energie entspreche zudem dem Willen der Bürger*innen: „80 bis 90 Prozent der Bürger sagen dort, dass sie sich erneuerbare Energien wie die Solarenergie und die Geothermie wünschen; sie wünschen sich nicht Kernenergie und Kohle, sondern den Umstieg auf erneuerbare Energien“ (GRÜNE 25.02.2000: 8442).

In der 17. Legislaturperiode wird die Rolle der Bürger*innen als Element in Verbindung mit einem Umstieg der Energieversorgung dann häufiger artikuliert. Im Energiekonzept 2010 wird zum Beispiel der „Akzeptanz“ ein hoher Stellenwert beigemessen (17/3049: 18), wobei den Bürger*innen eher eine passive Rolle zugewiesen wird. „Der Umbau zu einer nachhaltigen Energieversorgung“ könne „nur gelingen, wenn die künftige Energiepolitik für die Bürgerinnen und Bürger verständlich und nachvollziehbar ist" (17/3049: 18).

Gleichzeitig mit der Laufzeitverlängerung der Atomkraftwerke zeigt sich hier der Versuch einen energiepolitischen Konsens zu konstruieren und diesen mit der Forderung nach ,Akzeptanz' zu verbinden. So wolle die Bundesregierung ,mit den Wirtschafts- und Umweltverbänden und mit allen interessierten gesellschaftlichen Gruppen nach Wegen suchen, wie der energiepolitische Konsens über die zukünftige Energiepolitik verbreitert werden kann“" (17/3049: 18).

\section{Versus Spaltung statt Konsens durch Laufzeitverlängerung}

GRÜNE, LINKE (LINKE 28.10.2010: 7175) und SPD heben hervor, dass der vermeintliche energiepolitische Konsens ein konstruierter sei, und dass die Einbindung von Bürger*innen von der Regierungskoalition nicht ernst gemeint sei: „die Laufzeiten verlängern und dann einen Pakt ${ }^{68}$ machen! Die Bürger sind doch nicht blöd!“ (GRÜNE 28.10.2010: 7173). „Hunderttausende von Menschen“ würden gegen die Laufzeitverlängerung demonstrieren, was die Regierung nicht inte-

68 Gemeint ist hier der Vorschlag der FDP in der Debatte um die Laufzeitverlängerung mit den Bürger*innen „,einen nationalen Pakt für neue Netze“ (FDP 28.10.2010: 7173) einzugehen. 
ressiere. „Sie spalten die Gesellschaft, obwohl sie sich in diesem Punkt schon einig war“ (SPD 28.10.2010: 7170). Die Oppositionsfraktionen unter GRÜNE, LINKE und SPD zeigen so auf, wie die Bürger*innen in der Entscheidung zur Laufzeitverlängerung einerseits in ein energiepolitisches Außen gedrängt werden, ihre Artikulationen in der Entscheidung zur Laufzeitverlängerung also nicht berücksichtigt werden, während sie gleichzeitig artikulatorisch in einen scheinbaren Konsens eingebunden werden.

Nach „Fukushima“ verstärken sich die Versuche der Regierungskoalition, die Bürger*innen artikulatorisch in den vermeintlichen energiepolitischen Konsens zu integrieren. Insgesamt wird nach „Fukushima“ der Möglichkeitsraum, der sich für marginalisierte Positionen im Falle von Dislokationen (wie hier „Fukushima“) für eine Reartikulation öffnet, sichtbar: Die Position der Regierungskoalition für die Laufzeitverlängerung wird mit ihrem ,Anderen“ konfrontiert (der von sozialen Bewegungen stets benannten Gefahr eines atomaren Unfalls) und kann dies nicht länger verdecken. ${ }^{69}$ Um die Dislokation zu überwinden, müssen Zugeständnisse gemacht werden. Bereits unmittelbar nach „Fukushima“ betont Angela Merkel, dass ihr die „breite Unterstützung und Akzeptanz in der Gesellschaft“ „besonders wichtig“ sei (Angela Merkel 17.03.2011: 10887). Sie verspricht, ,natürlich auch gesellschaftliche Gruppen“ einzubeziehen: „Wirtschaft, Gewerkschaften, Umweltverbände, Kirchen“ (Angela Merkel 17.03.2011: 10886). Durch die diskursive Integration der Bürger*innen in ein kollektives ,Wir' sollen die Differenzen über die „Energiewende“ verdeckt und durch die Anrufung einer gemeinsamen Identität überlagert werden: „Wir alle, Regierung und Opposition, Bund, Länder und Kommunen, die Gesellschaft als Ganzes, jeder Einzelne, wir alle gemeinsam können, wenn wir es richtig anpacken, bei diesem Zukunftsprojekt ethische Verantwortung mit wirtschaftlichem Erfolg verbinden“ (Angela Merkel 09.06.2011: 12964). Als konstitutives Außen dienen dabei alle, die aus dem hegemonial artikulierten Konsens - verbunden mit der durch die Regierungskoalition festgelegten „Energiewende“ - ausbrechen. So mahnt die Bundeskanzlerin den „Kreislauf - hier dagegen und dort dagegen“ zu durchbrechen - es könne nicht sein, dass man einerseits einen schnellen Ausstieg aus der Kernenergie fordere und ,auf der anderen Seite aber eine Protestaktion nach der anderen gegen den Netzausbau“ starte (Angela Merkel 09.06.2011: 12961). Die Artikulation eines kollektiven ,Wir", von dem die Bürger*innen genauso Teil sind wie die Bundesregierung, verdeckt gleichzeitig die Rolle der Bürger*innen für die Entscheidung zur „Energiewende“. Gleichzeitig wird von der Regierungskoalition versucht, das dislozierende Ereignis von „Fukushima“ derart zu überwinden, dass ehemals kritisch positionierte Forderungen in die eigene Äquivalenzkette integriert werden - wie in Kapitel 5.1.3 beschrieben, kommt es zu einer Ausbreitung der hegemonialen Formation. So zeigt sich die CDU in der Debatte über den erneuten Atomausstieg nach „Fukushima“ „überzeugt, dass die Menschen in diesem Lande bei diesem Projekt der Energiewende und der neuen Energiepolitik voll dabei sind. Es ist zuallererst ein

69 Es wird dabei auch deutlich wie die Bürger*innen den Diskurs im Bundestag mit beeinflussen. 
Bürgerprojekt, das heute in Gang gesetzt wird ([...] Ulrich Kelber [SPD]: Das haben die Bürger gegen Sie durchgesetzt!)“, ,,alle Streitigkeiten [...] in den Grundfragen“ seien damit beseitigt (CDU 30.06.2011: 13369).

\section{Versus „Energiewende“ als Erfolg der Bürger*innen}

SPD, GRÜNE und LINKE verweisen auf die Differenz zwischen der Politik der schwarz-gelben Koalition und den für eine „Energiewende“ aktiven Bürger*innen. Sie kritisieren deren artikulatorische Vereinnahmung durch die schwarz-gelbe Koalition: „Die Wahrheit ist: Die Bürgerinnen und Bürger haben dies gegen Sie und Ihre Regierungskoalition durchgesetzt“ (SPD 30.06.2011: 13371). „Dies ist ein Erfolg der Anti-AKW-Bewegung und der Umweltverbände [...]. Frau Bundeskanzlerin, wenn Sie sich bei denen schon nicht entschuldigen wollen [...], so finde ich, dass Sie sich heute bei diesen Menschen für die Nachhilfe hätten bedanken sollen, die sie Ihnen erteilt haben“ (GRÜNE 09.06.2011: 12974). Die GRÜNEN heben hervor, dass diese Bewegungen stets in einem Gegensatz zur Regierungspolitik standen: „Ich bin heute stolz darauf - und auch ein bisschen gerührt -, was eine Bewegung, die früher diskriminiert und kriminalisiert wurde, alles geschafft hat" (GRÜNE 30.06.2011: 13382). ${ }^{70}$

In der 18. Legislaturperiode ebben die Bedeutungskämpfe, die sich nach „Fukushima“ insbesondere in Bezug auf die Anti-Atom-Bewegung, die „Energiewende“ und den Atomausstieg ergaben, allmählich ab. Die Artikulation der Rolle der Bürger*innen reduziert sich nun meist auf den Kontext von Akzeptanz und Konfliktvermeidung. So sollen die Bürger*innen in die „Energiewende“ eingebunden werden, damit sie zukünftig Proteste unterlassen: „Der eigene Hund macht keinen Lärm - er bellt nur“ (CDU 01.06.2016: 16991). Dies gilt insbesondere beim Netzausbau: „Für den Ausbau der Stromnetze muss bei den betroffenen Anliegern um Akzeptanz geworben werden“ (Koalitionsvertrag 2013: 42). Zudem werde ein „Kompetenzzentrum Naturschutz und Energiewende ${ }^{71 ، ~}$ eingerichtet, das der Konfliktvermeidung diene und Debatten versachlichen solle (Koalitionsvertrag 2013: 44). Die Verabschiedung eines Gesetzes zur Förderung von Mieterstrom gegen Ende der Legislaturperiode solle ebenfalls der Akzeptanz der „Energiewende“ dienen: „Bei der Energiewende ist aber auch Akzeptanz wichtig [...]. Nicht nur Hauseigentümer sollten davon profitieren, sondern wir als Sozialdemokraten meinen, dass auch Mieterinnen und Mieter vergleichbare Möglichkeiten haben müssen, diese Energiewende zu nutzen“ (SPD 29.06.2017: 24987).

Insgesamt zeigt sich nach „Fukushima“ besonders anschaulich, wie die Bürger*innen als Subjekte im Diskurs einerseits Einfluss auf den Diskurs im Bundestag üben (können) $)^{72}$ und andererseits darauf folgende (bundes)politische Praktiken wie-

70 Auch die GRÜNEN artikulieren gleichzeitig eine Einheit zwischen ihrer Politik und der Bürger*innenbewegungen, indem sie sich in diese mit einbeziehen (,Wir alle - ich habe es am Anfang gesagt - haben unser Land verändert“ [GRÜNE 30.06.2011: 13382]).

71 www.naturschutz-energiewende.de

72 Es sei hier auf die großen Demonstrationen nach „Fukushima“ verwiesen. 
derum direkten Einfluss auf ihre Lebenswelt üben, Bürger*innen also - wenn auch möglicherweise marginalisierter - Teil des Bundestags-Diskurses sind. Die Konstitution der Rolle der Bürger*innen im Kontext von Akzeptanz und die damit verbundenen Externalisierungsprozesse werden in Kapitel 6.4 nochmals aufgegriffen.

\section{Versus Bedrohung der Bürger*innenenergie durch EEG-Novellierungen}

GRÜNE und LINKE heben dagegen immer wieder eine aktive Rolle der Bürger*innen für die „Energiewende“ hervor und arbeiten heraus, wie diese aktive Rolle durch die politische Praktiken im Bundestag immer wieder marginalisiert werde. Insbesondere werden hier die Novellierungen des EEG 2014 und 2016/17 genannt: Die Regierung wolle „das weitere Engagement und Investitionen dieser Akteure abwürgen“, indem sei kleine Bürger*innenenergieprojekte unter $18 \mathrm{MW}$ nicht von der Ausschreibungspflicht befreie (GRÜNE 01.06.2016: 16974). ${ }^{73}$ Das Motto der schwarz-roten Regierung sei: „Nehmt es den Bürgern, gebt es den Konzernen“ (GRÜNE 29.06.2017: 24991). Sie mache eine Politik gegen die Mehrheit, die wolle, „dass die erneuerbaren Energien noch stärker ausgebaut werden“ und der Kohleausstieg beschlossen werde (GRÜNE 01.06.2016: 16975).

Auch die LINKE kritisiert, die große Koalition blockiere mit ihrem Ausschreibungsmodell im EEG die Bürgerenergie und ,schanz[e] das Geschäft mit Erneuerbaren-Strom internationalen Fonds und Konzernen zu“ (LINKE 01.06.2016: 16985). Das gefährde „massiv eine [...] dezentrale Stromerzeugung“ (LINKE 27.06.2014 3934f.). Gegen Ende der Legislaturperiode kritisiert die LINKE die Regierungskoalition habe „die erneuerbaren Energien zu einem Spiel- und Experimentierfeld für Spekulanten gemacht“ (LINKE 29.06.2017: 24988), was im Gegensatz zu einer von Bürger*innen gestalteten „Energiewende“ stehe. Zwar zeige sich bei den Ausschreibungen „eine hohe Beteiligung von sogenannten Bürgerenergiegesellschaften“. Dabei handele es sich aber vermutlich nur noch um ,windige Konstruktionen von Rechtsanwaltsbüros der großen Projektierer“ (LINKE 29.06.2017: 24988). ${ }^{74}$

73 Die GRÜNEN berufen sich dabei auf die Empfehlungen der EU-Wettbewerbskommissarin Windenergieanlagen bis maximal $18 \mathrm{MW}$ von der Ausschreibungspflicht zu befreien. Stattdessen sind nur Wind- und Solarenergieanlagen bis zu einer De-minimis Grenze von 750kwp von der Ausschreibungspflicht befreit. Solaranlagen unter dieser Grenze können weiterhin eine feste Einspeisevergütung in Anspruch nehmen.

74 Bürgerenergiegesellschaften werden im EEG 2016/2017 Sonderregelungen gewährt. Diese Sonderregelungen werden von anderen Gesellschaften genutzt, indem sie sich der Definition von Bürgerenergieprojekten im EEG (z.B. mindestens 10 Privatpersonen als Anteilseigner*innen) anpassen. Ein solcher „Missbrauch“ wird auch von der Bundesnetzagentur bestätigt: „Der überwiegende Teil der Bürgerenergiezuschläge geht an Gesellschaften, aus deren Geboten ersichtlich wird, dass sie zumindest organisatorisch einem einzelnen Projektierer zuzuordnen sind“ (www.bundesnetzagentur.de). 


\subsubsection{Wissenschaft als Schlüssel zum Gelingen der „Energiewende“}

Der Stellenwert von externem Wissen erhöht sich nach „Fukushima“ deutlich, sodass auch die Rolle der Wissenschaft für eine gelungene „Energiewende“ als Story-Line in den Fokus rückt. Wobei zunächst die Äquivalenzierung mit dem Knotenpunkt ,Wissenschaft‘ in Bezug auf die Entscheidung der schwarz-gelben Regierung zur Verlängerung der Laufzeiten zur Entpolitisierung dieses gesetzgeberischen Vorgangs beitragen soll (z.B. FDP 17.03.2011: 10895). So ei ein technisches Versagen unerwartbar gewesen, da der Betrieb von Kernkraftwerken auf wissenschaftlichen Grundlagen erfolge: „Die unfassbaren Ereignisse in Japan lehren uns, dass etwas, was nach allen wissenschaftlichen Maßstäben für unmöglich gehalten wurde, doch möglich werden konnte [...]“" (Angela Merkel 17.03.2011: 10884). Bei der ,Neubewertung“ der Atomenergie wird dann der Wissenschaft eine herausragende Rolle zugewiesen, die sich in der Einbeziehung der externen Kommission, „Ethikkommission Sichere Energieversorgung“, materialisiert. Die Kommission stellt in ihrem Bericht unter dem Titel „Deutschlands Energiewende - ein Gemeinschaftswerk für die Zukunft“ Atomausstieg und „Energiewende“ in ein äquivalentes Verhältnis und schlägt gleichzeitig gesetzgeberische Maßnahmen vor. Dieser Bericht spielt in den Bundestagsdebatten nach „Fukushima“ eine wichtige Rolle und wird als Teil des Diskurses um „Energiewende“ betrachtet. Erst nach Vorlage des Berichtes der Kommission beschließt der Bundestag den schrittweisen Ausstieg aus der Atomenergie. Die Arbeit der Kommission spielt somit für die Legitimation der politischen Entscheidung zum „Atomausstieg“ und zur „Energiewende“ eine große Rolle:

„Dass es bei diesem kontrovers diskutierten Thema gelungen ist, den Sachverstand von Wissenschaft, Wirtschaft und Technik und den Sachverstand der breiten Gesellschaft und der Politik zu bündeln und in konkretes politisches Handeln umzusetzen, ist eine großartige Leistung der Bundeskanzlerin und dieser Bundesregierung“" (CSU 09.06.2011: 12971).

Die wissenschaftliche Begleitung, nicht nur der politischen Prozesse bei der „Energiewende“ unmittelbar nach „Fukushima“, erhält in den nachfolgenden Debatten einen höheren Stellenwert. ${ }^{75}$ Es solle ein jährliches „Monitoring“ zur „Energiewende“ eingeführt werden, das die Zielerreichung kontrolliere, und das von einer unabhängigen Expert*innenkommission begleitet werde. Die Notwendigkeit eines Monitorings wird mit der hohen Komplexität der „Energiewende“ begründet und wird als Bestandteil der Regierungserklärung zum Atomausstieg nach „Fukushima“ artikuliert: „Es ist ja wahr: Es scheint einer Quadratur des Kreises nahezukommen, all das schaffen zu wollen, was wir uns vorgenommen haben. Deshalb ist ein fünfter Punkt zwingend und unerlässlich: die Einrichtung eines lückenlosen Monitoringprozesses“ (Angela Merkel 09.06.2011: 12963). Über den „Fortschrittsbericht“ und das „Monitoring“ sollen Probleme bei der „Energiewende“ lösbar werden: „Deshalb wollen wir

75 Krick (2018) untersucht die Rolle der hohen Anzahl an Expert*innenkommissionen in der Deutschen Energiewende-Politik, die sie im Rahmen von ,Konsens-Management‘ der Bundesregierung klassifiziert. 
diesen jährlichen Fortschrittsbericht. Wir wollen ihn, um dann nachjustieren zu können, und zwar nicht beim Enddatum des Ausstiegs, sondern bei dem, was auf diesem Weg noch notwendig ist und wo blockiert wird“ (CSU 09.06.2011: 12973).

Dabei wird der Energieforschung eine besondere Rolle zugewiesen: „Energieforschung ist der Schlüssel zum Gelingen der Energiewende“ (CDU 13.06.2013: 31546). Die Technologieorientierung im Rahmen der Story-Line ,Wissenschaft als Schlüssel zum Gelingen der „Energiewende““ wird dabei in eine übergeordnete Erzählung von ,Wachstum und Wohlstand“ eingeordnet: „Zukunftstechnologien sind für uns ein wesentlicher Bestandteil der Energiewende. Wir haben die Energieforschung zum zentralen Baustein unserer Technologiestrategie und damit zum Garanten für Wachstum und Wohlstand gemacht" (CDU 13.06.2013: 31547). Demnach überrascht es nicht, dass die Story-Line über die Rolle von Wissenschaft und Forschung eine zunehmend verwertungsorientierte Ausrichtung erhält, die sich im Diskurs auch während der 18. Legislaturperiode weiter festigt. So solle die Energieforschung „konsequent auf die Energiewende ausgerichtet“ werden, wobei „Forschungsergebnisse [...] zügig in Form von innovativen und marktfähigen Produkten verwertet werden“ müssen (Koalitionsvertrag 2013: 25f.). Dabei liege der Fokus auf „,intelligente[n] Lösungen insbesondere in den Bereichen Energieeffizienz, Energieeinsparung, Erneuerbare Energien und Versorgungssysteme“ (Koalitionsvertrag 2013: 25) und weniger auf sozialen und ökologischen oder Querschnittsbereichen. Dies sei auch für den „exportorientierten Technologiestandort[...] Deutschland“ von Bedeutung“ (Koalitionsvertrag 2013: 26). Hier zeigt sich auch die mitunter enge Verknüpfung mit der Story-Line ,Deutschland als Vorreiter'. Die Rolle von Wissen und Technologie für die Erzählung von Nation betrachte ich in Kapitel 6.4 genauer.

Was die Überprüfung politischer Maßnahmen durch externe Expert*innenkommissionen betrifft, so spielen diese auch in der 18. Legislaturperiode weiterhin eine Rolle für die Legitimation politischer Entscheidungen. So solle zum Beispiel ein „Nationaler Aktionsplan Energieeffizienz“ von einer „unabhängigen Expertenkommission“ in „einem jährlichen Monitoring“ überprüft werden (Koalitionsvertrag 2013: 37). Die Ergebnisse dieser Kommissionen werden allerdings in den Debatten selten aufgegriffen (z.B.: GRÜNE 10.04.2014: 2449).

\section{Versus Verlagerung politischer Verantwortung und Verengung der Energieforschung}

Aus der Opposition wird vor allem in der 17. Legislaturperiode im Zuge der Einsetzung der Ethikkommission eine Verschiebung politischer Verantwortung aus wahltaktischen Gründen kritisiert und somit die Ambivalenzen in der Anrufung von Wissenschaft hervorgehoben: „Deutschland braucht keine Regierung, die [...] Kommissionen einberuft, nur um über Landtagswahlen hinwegzukommen [...]. Deutschland braucht ein selbstbewusstes Parlament, das seine Aufgabe wahrnimmt“ (SPD 24.03.2011: 11301). Die LINKE verweist zudem auf einen Widerspruch zwischen wissenschaftlicher Expertise und Regierungspolitik. So würden wissenschaftliche Ressourcen, z.B. beim Umweltbundesamt durch die „dauernden Angriffe [...] gegen das Erneuerbare-Energien-Gesetz“ vor allem der FDP gebunden und „,verschleudert“. Die Ressourcen wären vielmehr nötig gewesen, um den Umbau des Energieversorgungssystems zu planen (LINKE 13.06.2013: 31294). 
Darüber hinaus wird eine Verengung des Energieforschungsprogramms kritisiert: Die „Tragweite und Komplexität der Energiewende“ spiegele sich nicht im Energieforschungsprogramm der Bundesregierung wider (SPD 13.06.2013: 31584). Die GRÜNEN weisen darauf hin, dass „die interdisziplinäre Forschung zu sozialwissenschaftlichen und technischen Fragen einer Energiewende mit ihren dezentralen Strukturen [...] in der Hochschullandschaft eher ab- als ausgebaut" werde (GRÜNE 13.06.2013: 31550f.). Auch die LINKE fordert eine Ausweitung der Energieforschung über rein ökonomische und technologische Fragen hinaus. Die Politik müsse sich fragen, wie eine Energieforschung aussehen könne, „die die Herausforderung der Energiewende meistert? Es geht also um die Unterstützung für einen Prozess des strukturellen Umbaus unserer Energieversorgung - um eine Transformation und damit auch um Transformationsforschung" (LINKE 13.06.2013: 31549). Dazu gehören auch die „Rahmenbedingungen der Energiewende“, z.B. wie „Nachwuchsförderung und Berufsausbildung [...] auf eine dezentrale Energieversorgung eingestellt werden“ können oder die wissenschaftliche Begleitung der „Rekommunalisierung von Netzen und Erzeugern“. Zudem müsse erforscht werden wie ,diese Transformation ohne soziale Härten, sondern in einem gerechten Verteilungsmodus“" gestaltet werden könne“ (LINKE 13.06.2013: 31550). Die LINKE fordert somit den hegemonialen Diskurs einer marktorientierten und auf ökonomische Verwertbarkeit ausgerichteten „Energiewende“ im Bereich der Forschung heraus und bringt zum ersten Mal ,Transformation“ in die Bedeutungsgenerierung von „Energiewende“ mit ein.

\subsubsection{Die ,großen Vier' als Repräsentanten des herkömmlichen Energiesystems}

In den energiepolitischen Debatten werden die großen vier Energiekonzerne (gemeint sind RWE, E.ON, EnBW und Vattenfall) immer wieder als die ,großen Vier ${ }^{6}$ bezeichnet und erscheinen somit als einzelner Akteur innerhalb des Diskurses. Sie werden häufig mit einer affirmativen Energiepolitik im Gegensatz zu einem Umstieg auf erneuerbare Energien, bzw. zu einer „Energiewende“, assoziiert. Während sich die bisher identifizierten Story-Lines zwischen der 14. und 18. Legislaturperiode über verschiedene politische Spektren entwickeln, wird die hier vorliegende Einordnung der Energiekonzerne überwiegend vom linken politischen Spektrum artikuliert (SPD, GRÜNE, PDS/LINKE) und weist eine eher kritische Positionierung zur hegemonialen Formation auf (die wie bereits mehrfach betont nicht zwingend mit den Fraktionsgrenzen identisch ist).

Bereits in der 15. Legislaturperiode werfen SPD und GRÜNE den sogenannten ,Monopolisten “ - wie die ,großen Vier' ebenfalls bezeichnet werden - vor, die Förderung erneuerbarer Energien als Vorwand für ungerechtfertigte Preiserhöhungen auszunutzen und sie damit zu diskreditieren: „Fakt ist: Die Stromkonzerne haben im letzten Jahr mehr auf die Strompreise umgelegt, als tatsächlich eingespeist wurde. Ursache dafür war der heiße Sommer. Die Stromkonzerne hätten die Strompreise also am Anfang des Jahres mit dem Hinweis auf das EEG senken und nicht erhöhen müssen“ (GRÜNE 09.09.2004: 11247). In der 16. Legislaturperiode zeigt sich der Dissens über die Rolle der Energiekonzerne auch innerhalb der großen Regierungs- 
koalition. Vor allem GRÜNE, LINKE und z.T. SPD verorten sich kritisch gegenüber den innerhalb der hegemonialen Formation verorteten für das herkömmliche Energiesystem stehenden Energiekonzernen, die, von Profitgier getrieben, an der konventionellen Energieerzeugung festhalten, um ihre Monopolstellung zu bewahren, und aus diesem Grund die erneuerbaren Energien torpedieren. So argumentiert die SPD, die „Fotovoltaik“ werde angegriffen, weil „Firmen wie Eon und RWE“ aufgrund der dezentralen Erzeugung damit „kein Geld verdienen können“ (SPD 06.06.2008: 17731). Die GRÜNEN verweisen auf einen Vorwurf der EU-Kommission gegen E.ON, der zeige, dass „der Strommarkt wegen der Dominanz der Energiekonzerne nicht funktionier[e]“: „Eon hat Kraftwerke gedrosselt oder abgeschaltet, um das Stromangebot zu verringern und den Börsenpreis für Strom zum eigenen Nutzen in die Höhe zu treiben ${ }^{76 ، ~(G R U ̈ N E ~ 02.07 .2009: ~ 25877) . ~ I m m e r ~ w i e d e r ~ w i r d ~ d e r ~ V o r-~}$ wurf der direkten Einflussnahme durch die Konzerne auf die Bundespolitik erhoben:

„Wirksame Maßnahmen der EU-Kommission gegen die Energiekonzerne zur Eindämmung der Monopolwirtschaft werden von der Bundesregierung gezielt verhindert. Erst vor kurzem hat sie einen Vorschlag Brüssels zur Zerschlagung des Stromkartells zu Fall gebracht - ganz nach dem Wunsch von Eon, RWE, Vattenfall und EnBW“ (LINKE 02.07.2009: 25876).

Der Dissens über die Rolle der großen Energiekonzerne verstärkt sich im Vorfeld der Bundestagswahl 2009, bei der es um eine „Richtungsentscheidung“ gehe (SPD 02.07.2009: 25880). Ein potenzieller Wahlgewinn von CDU, CSU und FDP wird dabei mit einem Gewinn der großen Energiekonzerne äquivalenziert:

„Wollen wir die eingeleitete Energiewende und das Jobwunder bei den erneuerbaren Energien weiterführen, oder setzen sich die Atomkonzerne RWE, Eon, Vattenfall und EnBW durch und würgen die Energiewende ab, stoppen den Ausbau der erneuerbaren Energien und vernichten dadurch die Arbeitsplätze bei den erneuerbaren Energien, und das nur, weil man mit einem abgeschriebenen Atomkraftwerk jeden Tag 1 Million Euro verdienen kann? Die Wählerinnen und Wähler haben die Wahl zwischen Gemeinwohl und den Interessen der Energiekonzerne.“ (SPD 02.07.2009: 25880)

Die schwarz-gelbe Koalition wird im Zuge des Dissenses über die Laufzeitverlängerung der 17. Legislaturperiode zur Repräsentantin der Energiekonzerne erhoben, die Entscheidungen in deren Profitinteresse treffe: „Sie haben ein paar Lastwagen mit Geld in Bewegung gesetzt [...]. Die Lkw fahren nacheinander vier Adressen ab. Die vier großen Dinosaurier der Energiewirtschaft bekommen, je nachdem, wie sich die Strompreise entwickeln, zwischen 40 und 100 Milliarden Euro zugeschustert“ (SPD 28.10.2010: 7169). „Hinterher können Sie sagen: Wir haben vier Konzerne reich und Millionen Menschen arm gemacht“ (LINKE 28.10.2010: 7176). „Die Macht der Energiekonzerne wird somit noch weiter gestärkt“ (LINKE 28.10.2010: 7196). Das schwäche auch die Stadtwerke und die Investitionen in erneuerbare Energien: „Sie enteignen sie zugunsten von Eon, RWE und Co“ (GRÜNE 28.10.2010: 7178)). Die

76 „Leider hat die EU-Kommission das Verfahren gegen Eon gegen einen Vergleich eingestellt“(GRÜNE 02.07.2009: 25877). 
LINKEN sprechen von „Klientelpolitik“, die „die Gesellschaft spaltet“ und bei der „[v]ier Konzerne [...] gewinnen, und Millionen und Abermillionen Menschen [...] verlieren“ (LINKE 28.10.2010: 7175). Teile der Bundesregierung seien mit Kernkraftlobbyisten eng verbandelt (GRÜNE 24.03.2011: 11293). Der Bundeswirtschaftsminister wird als „Bundesmonopolminister“ bezeichnet (SPD 28.10.2010: 7173).

Es wird zudem mehrfach artikulatorisch auf einen Widerspruch zwischen Absprachen mit Energiekonzernen und demokratischen politischen Entscheidungen abgezielt: „Es bedarf keines mit den Energiekonzernen abgestimmten energiepolitischen Gesamtkonzepts, sondern politischer Entscheidungen. Auf der politischen Ebene entscheidet sich, ob der Energiewechsel, den die Gesellschaft vollzieht, beschleunigt wird“ (SPD 28.10.2010: 7185). Dagegen sei durch das alleinige Aushandeln der Verträge mit den Konzernen die Politik ,entmachtet“" worden (LINKE 28.10.2010: 7175). „Die Atompläne der Bundesregierung gefährden, wie ich versucht habe nachzuweisen, die Demokratie“ (LINKE 28.10.2010: 7176).

Nach „Fukushima“ versucht vor allem die schwarz-gelbe Regierungskoalition die ,großen Vier“ in einen nun neu zu schließenden Konsens über die „Energiewende“ diskursiv zu integrieren und ihnen dabei eine zentrale Rolle zuzuweisen. So begrüßt die CDU den Wandel in der Haltung des Konzerns E.ON, der gegen den Atomausstieg gewesen sei, aber nun die „Energiewende“ zu einer „riesigen Chance“ erkläre und die Energiewirtschaft sich ,an die Spitze“ der Bewegung stelle (CDU 30.06. 2011: 13368f.). Die ,großen Vier' sollen nun nicht mehr für das herkömmliche Energiesystem stehen, sondern als Teil der hegemonialen Formation in die Äquivalenzkette um „Energiewende“ integriert werden. Hier wird deutlich, wie sich durch eine solche Reartikulation politische Praktiken konstituieren, die sich später in entsprechenden Energieerzeugungs- und versorgungsstrukturen materialisieren: So kritisieren die GRÜNEN, die Regierungskoalition wolle durch die Novellierung des EEG und das darin enthaltene Ausschreibungsdesign die Akteursvielfalt bei der „Energiewende“ zu Gunsten der „Energieoligopole“ beschädigen (GRÜNE 01.06.2016: 16974). Auch die LINKEN führen den Paradigmenwechsel im EEG hin zu Ausschreibungen und „Markteinführung“ auf die „Lobbyarbeit“ der großen vier Stromkonzerne zurück, die „um ihre Marktmacht bangen“ (LINKE 27.06.2014: 3940). So werde auch Windkraft auf See nur deshalb so stark gefördert, weil dabei Bürger*innen nicht teilhaben können, sondern große Konzerne und Akteur*innen wie „Goldman Sachs, RWE, Vattenfall, Eon, der Staat Dänemark und Siemens“ verdienen (LINKE 01.06.2016: 16985). „Als Linke werden wir weiter gegen die Marktmacht von RWE, Eon, Vattenfall und EnBW und für eine Stromwirtschaft in Bürgerhand kämpfen“ (LINKE 27.06.2014: 3941). Durch die Integration der ,großen Vier“ in die Äquivalenzkette um „Energiewende“, die nach „Fukushima“ Teil der hegemonialen Formation wird, wird die kritische Positionen, welche die ,großen Vier" als Gegner der „Energiewende“ konstituierte, weiter marginalisiert, da die antagonistische Grenze zwischen Hegemonie und Gegen-Hegemonie verschwimmt ${ }^{77}$, wie in Kapitel 5.1.3 gezeigt wurde.

77 Da die Forderung einer „Energiewende“ nun sowohl Teil des hegemonialen als auch Teil des gegenhegemonialen Diskurses ist, befindet sie sich in einem Spannungsfeld zwischen 


\section{Versus Demokratisierung der Energieversorgung}

Vor allem die LINKE stellt insbesondere nach „Fukushima“ dem Einfluss der vier Energiekonzerne (LINKE 30.06.2011: 13378) die Forderung einer Demokratisierung der Energieversorgung entgegen. Die Macht der vier Konzerne, die „sich die Bundesrepublik Deutschland feudal aufgeteilt haben“ “ (LINKE 24.03.2011: 11285), erfordere eine demokratische Kontrolle durch Preisregulierung: „Wieder geht es um die Frage der Zuständigkeit der Politik und der Demokratie. Sie begreifen eine einfache Tatsache nicht: Der Bundestag wird demokratisch gewählt; die Atomlobby wird nicht gewählt“ (LINKE 24.03.2011: 11285). Die Politik müsse die Kraft entwickeln, den „Konzernlobbyisten“ zu widerstehen „und den Vorrang der demokratischen Institutionen zu sichern“ (LINKE 17.03.2011: 10898). Ein „Energiekonzept der Zukunft“ müsse mit „unabhängigen Wissenschaftlerinnen und Wissenschaftlern, Umweltverbänden und kommunalen Energieversorgern erarbeitet werden“ (LINKE 17.03.2011: 10898). Einigungen dürften nicht mit der „Atomlobby“ ausgehandelt werden, sondern seien demokratisch zu erzielen - das sei auch der Fehler von rot-grün gewesen (LINKE 24.03.2011: 11283). Die Politik, nicht die Konzerne, müssten wieder für die Daseinsvorsorge zuständig sein, das sei eine Frage der Demokratie (LINKE 09.06.2011: 12970). So können Entscheidungen vor Ort demokratisch getroffen werden: „Wenn Sie alles privatisiert haben, hat der Bürgermeister nichts mehr zu entscheiden, weder hinsichtlich der Energiepreise noch hinsichtlich der Wasserpreise oder der Mieten [...]. (Volker Kauder [CDU/CSU]: Wir wollen keine Situation wie in der DDR!)“ (LINKE 24.03.2011: 11284). Daher sollen auch die Stromnetze wieder in öffentliche Hand überführt werden: „Wenn die Stromnetze nicht in öffentlicher Hand sind, dann ist die Politik auch nicht zuständig. Wenn die Politik nicht zuständig ist, dann ist auch die Demokratie nicht zuständig“ (LINKE 24.03.2011: 11284). Die LINKE fordere daher in letzter Konsequenz ,eine Zerlegung“ und „eine Rekommunalisierung“ der vier Konzerne (LINKE 30.06.2011: 13378).

\subsection{FANTASMATISCHE NARRATIVE IM KONTEXT DES DISKURSES UM „ENERGIEWENDE“}

Dieses Kapitel zielt auf die ,großen sinnstiftenden Erzählungen“ hinter den StoryLines, also auf die Kräfte hinter den Bedeutungssystemen, ab. Fantasmatische Narrative spielen eine Rolle bei der Verdeckung der Nicht-Naturgegebenheit sowie der Entpolitisierung sozialer Praktiken. Im Rahmen des in Kapitel 4.2.3 beschriebenen Analyseverfahrens wurden auf Grundlage der als zentral identifizierten Story-Lines drei fanstasmatische Narrative herausgearbeitet, die für die Bedeutungsgenerierung von „Energiewende“ als maßgeblich erachtet werden. Im Folgenden werden diese Narrative dargestellt, mitsamt ihrer glücksverheißenden Dimension, d.h. der kommenden Erfüllung, auf die sie verweisen (Glynos/Howarth 2007: 147f.). Zuvor wer-

Hegemonie und Gegen-Hegemonie und kann nicht mehr als zentrale Forderung für eine ausschließlich kritisch positionierte populare Äquivalenzkette stehen. 
den die in Bezug auf die Erfüllung der Glücksverheißung relevanten Hindernisse/Gefahren für das jeweilige Narrativ beschrieben sowie die Katastrophenszenarien, die im Rahmen der schreckensverheißenden Dimension der Narrative projiziert werden, sollten die Hindernisse/die Gefahren nicht überwunden werden können. Aus der zeitlichen Dimension der Glücksverheißung in Verbindung mit dem Verhältnis zwischen interner und externer Verortung des Hindernisses/der Gefahr lassen sich die Narrative in ihrem Verhältnis zur politischen Praxis klassifizieren (vgl. Kapitel 4.2.3). Somit zeigt sich auch, ob sie eher auf einen Wandel sozialer Praktiken gerichtet sind oder diesen eher verhindern.

\subsection{1 Ökologische Modernisierung}

\section{Entwicklung des Narrativs}

Das fantasmatische Narrativ der ,ökologischen Modernisierung taucht zunächst unter der rot-grünen Regierungskoalition der 14. und 15. Legislaturperiode auf. Trotz der Differenzen in den Positionierungen, bspw. bezüglich des Stellenwertes von Umweltpolitik, zeigt sich zunächst eine Diskurskoalition aus SPD und GRÜNEN in der Frage der Energiepolitik. Mit Beginn der großen Koalition verliert das Narrativ in der 16. Legislaturperiode allerdings an Bedeutung. Mit der Regierungsbeteiligung in der großen Koalition verändert die SPD ihre Diskursposition und artikuliert kaum noch Forderungen vor dem Hintergrund einer ökologischen Modernisierung. Die direkte Referenz auf ökologische Modernisierung nimmt ab (vgl. Abbildung 13).

Abbildung 13: Verteilung absoluter Häufigkeiten von ökologisch* Modernisierung* über Legislaturperioden (GRÜNE, SPD)

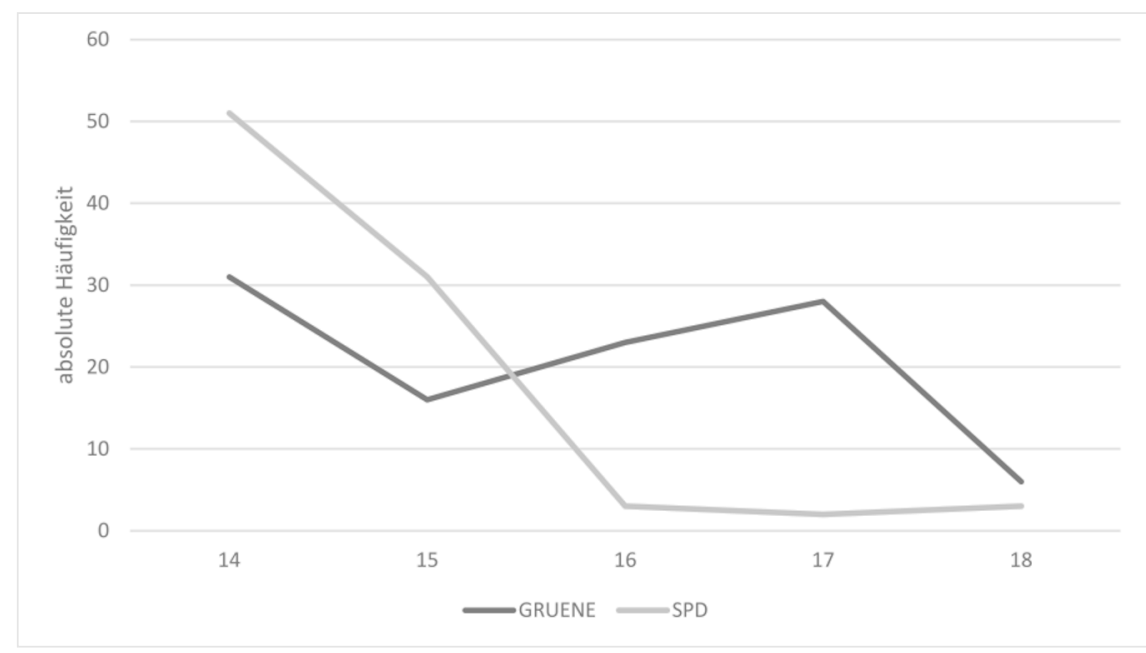

Quelle: eigene Darstellung

In der 17. und 18. Legislaturperiode setzt sich diese Tendenz fort: Sowohl von SPD als auch von GRÜNEN werden nur noch einzelne Forderungen im Kontext ökologischer Modernisierung aufgegriffen. In der 18. Legislaturperiode wird sie als glücks- 
verheißende Dimension von beiden kaum noch angesprochen, während das Kernproblem des Klimawandels ebenfalls kaum noch Thema ist.

\section{Hindernisse/Gefahren und schreckensverheißende Dimension}

Die schreckensverheißende Dimension des Narrativs begründet sich vor allem im Klimawandel durch Treibhausgasemissionen, woraus die Notwendigkeit einer ökologischen Modernisierung als glücksverheißendens Gegenszenario abgeleitet wird. Die angenommenen Ursachen und Folgen des Klimawandels liegen den Plenardebatten meist implizit zugrunde und werden selten explizit benannt; Wenn, dann fließen Elemente wie Ressourcenknappheit, Verteilungskämpfe, Kriege oder Naturkatastrophen in den Diskurs mit ein (z.B.: GRÜNE 25.02.2000: 8441). Im Vorfeld der renewables2004 Konferenz werden die Katastrophenszenarien konkreter artikuliert: Pazifische Inselstaaten werden ,in wenigen Jahrzehnten verschwunden sein“, der „Anstieg der Temperaturen“ erfolge schneller ,als erwartet“, „weder Fauna noch Flora“ können sich so schnell anpassen (SPD 28.05.2004: 10247).

„Die Eisschmelze von Gletschern und an den Polen geht schneller vonstatten und übertrifft alle Erwartungen. Der Meeresspiegel könnte [...] durchaus sprunghaft ansteigen. [...] Dem Süden der Welt, aber auch dem Mittelmeerraum und dem Süden der USA drohen verstärkte Dürren. Dem Norden der Welt drohen verheerende Hochwasser“ (SPD 28.05.2004: 10247).

Es werde daher zu „Flüchtlingsströmen“ kommen (SPD 06.06.2008: 17744). Im Koalitionsvertrag der 15. Legislaturperiode ist von der ,große[n] Flutkatastrophe“ (gemeint ist das Elbe-Hochwasser) die Rede, die den Handlungsbedarf ,auf erschreckende Weise vor Augen geführt“ habe (Koalitionsvertrag 2002: 10). Als ein „denkbares Szenario“ (aber „wohl nicht das wahrscheinlichste“) wird auf den Film „The Day after Tomorrow" rekurriert, der von einer abrupten Klimakatastrophe erzählt (GRÜNE 28.05.2004: 10237).

Die Hindernisse, die es zur Abwendung dieser mit dem Klimawandel in Verbindung gebrachten Katastrophen zu beseitigen gelte, werden nur teilweise intern - also innerhalb der politischen/ökonomischen Strukturen - verortet. Forderungen nach Anpassungen im ökonomischen System werden deshalb nicht im Rahmen eines Narrativs über eine Transformation artikuliert. Ursachen werden so eher im Konsum, der Produktionsweise, der Nachfrage nach Energie oder der Atomenergie, u.a., ausgemacht, ohne dass die Funktionsweisen des Wirtschaftssystems oder die Erzählung von ,Wachstum und Wohlstand“ als Ganzes in Frage gestellt werden: „Wenn wir jetzt nicht handeln, wenn wir nicht auf erneuerbare Energien und bessere Energieeffizienz setzen, geht uns auf allen Kontinenten, aber auch gerade uns in Europa irgendwann im wahrsten Sinne des Wortes die Luft aus“ (SPD 28.05.2004: 10234). Globale Machtverhältnisse spielen in der Betrachtung der Ursachen des Klimawandels eine untergeordnete Rolle. Die Forderung nach einer Änderung der Konsumund Produktionsweise wird daher auch in Bezug auf sogenannte Entwicklungsländer artikuliert. Diese dürfen nicht die Fehler der Industrieländer wiederholen, „denn das hält unser Globus nicht aus. Der Klimawandel würde sich dann noch weiter beschleunigen“" (SPD 28.05.2004: 10234).

$\mathrm{Ab}$ der 16. Legislaturperiode wird über das Katastrophenszenario des Klimawandels (gesellschaftliche Krisen, die mit dem Energiesystem verbundenen Ursachen 
und Folgen des Klimawandels, etc.) in Zusammenhang mit der Notwendigkeit einer ökologischen Modernisierung und der Umstellung des Energiesektors auf erneuerbare Energien kaum noch debattiert. Das wurde bereits anhand der Ermangelung entsprechender Äquaivalenzketten in Bedeutungszusammenhang zu „Energiewende“ im Rahmen des computerbasierten diskursanlytischen Verfahrens augenscheinlich und hat sich nun auch bei der qualitativen Verfeinerung der Diskursanalyse bestätigt.

Statt der Probleme im zu emmisionsreichen wirtschaftlichen Energiesektor wird nun durch die jeweiligen Oppositionsfraktionen hauptsächlich die entsprechende Regierungspolitik als Gefahr für eine „Energiewende“ konstituiert, wobei ein Scheitern der „Energiewende“ selbst zur Schreckensverheißung wird (vgl. z.B. die Konstitution einer „Konterrevolution gegen die Energiewende“ (GRÜNE 01.06.2016: 16974)).

\section{Glücksverheißende Dimension}

Die glücksverheißende Dimension des Narrativs der ,ökologischen Modernisierung‘ ist in ihrer zeitlichen Verortung ambivalent. Einerseits wird eine zukünftig ökologischere Wirtschaftsweise verheißen: Wichtige Artikulationen in diesem Zusammenhang sind „nachhaltiges“ „wirtschaftliches Wachstum“, „technischer Fortschritt“, „Innovation“, „umweltbewusstes Verhalten“, „ressourcensparende“ „energiesparende und umweltschonende“ Produkte und Technologien sowie entsprechende „Produktionsverfahren“ als „Schlüssel für künftigen Wohlstand und für hohe Wettbewerbsfähigkeit", „Verbilligung von Arbeit“ und dadurch Überwindung von Arbeitslosigkeit, Unabhängigkeit von Energieimporten, „massenhafter Einsatz“ von „unerschöpflichen“" erneuerbaren Energien - und dadurch auch verbesserte Chancen auf ,internationalen Märkten“ -, neue „Exportmöglichkeiten“ sowie eine erneuerbare Energien Branche, in der es „brummt“, etc. (z.B. Koalitionsvertrag 1998/2002, SPD/GRÜNE 25.11.1999, 25.02.2000, 14.12.2001, 28.05.2004). Die Verheißung beinhaltet demnach im Kern das Versprechen, eine Stärkung der Volkswirtschaft mit einer ökologischeren Wirtschaftsweise zu verbinden. Durch die Schaffung neuer Wirtschaftssektoren im Umweltbereich sollen Arbeitsplätze entstehen: „Umwelt schafft Arbeit“ (Koalitionsvertrag 2002: 37). Der Emissionshandel solle „Investitionen anreizen [...] und damit zu einer Jobmaschine“" werden (SPD 28.05.2004: 10250). Durch die erneuerbaren Energien gebe es ein Job- und ein „Gründungswunder“ (SPD 06.06.2008: 17730). Dabei bedient sich die glücksverheißende Dimension überwiegend der Story-Lines die erneuerbare Energien als Wirtschaftsfaktor konstituiert und eine Marktorientierung zur Bedingung der Energiepolitik macht.

Diese Verknüpfung von Ökologie und Ökonomie bewirkt andererseits, dass die im Rahmen der glücksverheißenden Dimension artikulierten Forderungen letztlich auf einen Erhalt der jetzigen Lebensumstände, des jetzigen Wohlstandes, gerichtet sind: „Lebensqualität und eine intakte Umwelt“ sollen ,auch für unsere Kinder und Enkel" bewahrt werden (Koalitionsvertrag 2002: 10).

Mit der ökologischen Modernisierung als Narrativ werden auch nationale Fantasien bedient. Deutschland könne eine weltweite Vorreiterrolle einnehmen, die international eine ökologischere Wirtschaftsweise befördere. Deutschland könne so Entwicklungszusammenarbeit mit Exportförderung verbinden (z.B. GRÜNE 28.05. 2004: 10237f.). Der Einsatz erneuerbarer Energien verspreche „riesige Vorteile für Entwicklungsländer“ (SPD 28.05.2004: 10234). Er leiste „einen Beitrag zur Armutsbekämpfung, wirkt dem Klimawandel entgegen und macht alle Volkswirtschaften, 
die der Industrie- und der Entwicklungsländer, unabhängiger vom Ö1““ (SPD 28.05. 2004: 10234). Auf diese Weise werden Umwelt- und Entwicklungsprobleme gleichzeitig gelöst (SPD 28.05.2004: 10241). Eingebunden in das Narrativ der ,ökologischen Modernisierung' wird der Knotenpunkt ,Deutschland' in einem hegemonialen Selbstverständnis selbst zur Verheißung einer glücklichen Zukunft erhoben. (Neo)koloniale Erzählmuster werden so im „Energiewende“-Diskurs fixiert, wie ich in Kapitel 6.4 zeige.

Auch über die Artikulation von Effizienz - sowohl in Bezug auf Kosten als auch in Bezug auf Energieeinsparung durch Technik - wird das zugrundeliegende Narrativs der ,ökologischen Modernisierung ' mit Bedeutung aufgeladen. Damit in Verbindung steht die Verheißung der Lösung von Umweltproblemen und größerer Umweltverträglichkeit durch technischen Fortschritt sowie einer kostengünstigen und -gerechten Energieversorgung, die gleichzeitig effizient und umweltverträglich sei sowie von „Ölpreiserhöhungen“ unabhängig mache (SPD 09.09.2004: 11244). Dadurch werde ,gleiche[r] Lebenskomfort bei sinkendem Energieverbrauch“ möglich (SPD 02.07.2009: 25874). Erneuerbare Energien versprechen eine unendliche Ressourcenverfügbarkeit, die mehr oder weniger umsonst sei: „Denn die Sonne schickt uns keine Rechnung“ (GRUENE 28.05.2004: 10245). „Dieser Überfluss schont unsere Umwelt, schafft Frieden und fördert Entwicklung und Sicherheit“ (SPD 25.08.2004: 10235). „Eine industrielle Technikrevolution für erneuerbare Energien gehört damit zu den Überlebensstrategien der Menschheit“" (GRÜNE 06.06.2008: 17737). Der technische Fortschritt taucht dabei als zentrales Motiv in gleich mehreren Äquivalenzbeziehungen auf, z.B. mit Energieeffizienz, ,Deutschland als Vorreiter' oder mit Wachstum und Wohlstand. Die „Energiewende“ als „Modell der Zukunft“ wird dabei konkret dem „Atomausstieg“ als „Konzept der Vergangenheit“ gegenüber gestellt (GRÜNE 14.12.2001: 20724).

Innerhalb der Story-Line, welche eine Marktorientierung als Bedingung von Energiepolitik konstituiert, wird die Verheißung artikuliert, durch steuerndes Eingreifen gegenwärtige ökologische Herausforderungen zu lösen, ohne dabei grundlegende Veränderungen im Wirtschaftssystem und der Gesellschaftsordnung vorzunehmen. Die verfahrenspolitische Umsetzung orientiert sich in diesem Sinne am Setzen von Marktanreizen. So solle beispielsweise über eine durch die Ökosteuer als Steuerungsinstrument initiierte Preiserhöhung die Nachfrage nach Energie gesenkt werden, ohne dabei die energieintensive Industrie zu belasten (Koalitionsvertrag 1998: 12). Vor allem auch das diskursiv als ,Markteinführungsprogramm“ verortete EEG ist als solches Steuerungsinstrument mit dem politischen Ziel der Förderung erneuerbarer Energien angelegt: Es solle

„eine dynamische Entwicklung in Gang gesetzt [werden], die privates Kapital mobilisiert, die Nachfrage nach Anlagen zur Erzeugung von Strom aus erneuerbaren Energien steigert, den Einstieg in die Serienproduktion ermöglicht, zu sinkenden Preisen führt, die wirtschaftliche Konkurrenzfähigkeit erneuerbarer Energien verbessert und ihre stärkere Marktdurchdringung zur Folge hat“"(14/2776: 1).

„Fukushima“ verorte ich in Bezug auf das fantasmatische Narrativ der ,ökologischen Modernisierung' nicht in der gefahrenverheißenden Dimension, da sich mit ihm nicht nur ein Katastrophenszenario verbindet, sondern auch die Einlösung der Verheißung 
der ökologischen Modernisierung im Energiebereich: „Jetzt kann niemand mehr infrage stellen, dass Deutschland die Energiewende will[...]. Jetzt geht es in Richtung Nachhaltigkeit“ (GRÜNE 30.06.2011: 13381). Nach „Fukushima“ erscheint die „Energiewende“ auf der politischen Verfahrensebene als vermeintlich durchgesetzt. Die begrifflichen Bedeutungskämpfe nehmen allerdings wie gezeigt rasant zu, wobei die glücksverheißende Dimension des Narrativs der ,ökologischen Modernisierung im Zuge dieser Kämpfe um Bedeutungsaufladung des „Energiewende“-Begriffs nur noch selten oder implizit artikuliert wird. Während die SPD in der 18. Legislaturperiode an der Regierung beteiligt ist, konzentrieren sich die GRÜNEN auf die Kritik an der Regierungspolitik, die die „Energiewende“ zunichtemache - ohne jedoch ein grundsätzliches Gegenprogramm, eine ,andere Utopie‘ oder eine Alternative zu präsentieren, die über technokratisch-managementorientierte ${ }^{78}$ Differenzen hinausgeht und mit grundsätzlich alternativen Glücksversprechen verbunden ist.

\section{Implizit geteilte Annahmen und Klassifizierung}

Den mit dem Narrativ der ,ökologischen Modernisierung ‘ verbundenen Artikulationsmustern liegen implizit geteilte Annahmen über Modernisierung, Klimaschutz, den Markt, Wachstum, Wohlstand, Wettbewerb, technologischen Fortschritt, Effizienz etc. zu Grunde. Diese sind aus Sicht derjenigen politischen Akteur*innen, die sie auf Artikulationsebene in die Bedeutungsaufladung von „Energiewende“ einbringen, größtenteils positiv konnotiert und bilden die ideellen Grundlagen ihrer politischen Praxis in Bezug auf ökologische Modernisierung ab. Die Referenz auf die damit verbundenen Konzepte erfolgt meist implizit, d.h. die zugrundeliegende politische Positionierung wird nicht explizit artikuliert. Auf diese Weise wird bewusst oder unbewusst deren nicht-Naturgegebenheit verdeckt und ihr hegemonialer Anspruch reproduziert. So resultiert bspw. aus der Referenz auf die Wettbewerbslogik das ebenso unhinterfragte Ziel auf dem „Weltmarkt“ „auch auf diesem Feld [der erneuerbaren Energien] in Zukunft eine Spitzenposition ein[zu]nehmen“" (SPD 25.02.2000: 8428). Die Ausrichtung der politischen Praxis auf diese Maxime des Wettbewerbs und die Dominanz des Marktes gegenüber politischen Entscheidungsprozessen erscheinen so quasi-natürlich.

Es wird somit deutlich, dass die mit dem Narrativ, ökologische Modernisierung verbundenen Story-Lines auf den Erhalt marktorientierter ökonomischer Strukturen abzielen, indem Narrative oder diskursive Muster über ,Wachstum und Wohlstand“, die Marktorientierung als Voraussetzung von „Energiewende“ oder die Bedeutung von Technik naturalisiert werden. Die ökonomischen Strukturen sollen durch Gesetzesreformen lediglich ökologischer ausgerichtet werden - die politischen Praktiken bewegen sich dabei in einem teilweise durch Ambivalenzen geprägten Spannungsfeld zwischen Marktorientierung und gesetzlich initiierten Markteingriffen. Augenscheinlich wird im Zuge der vorliegenden Diskursanalyse die Einbindung einer nationalen komplexitätsreduzierende Erzählung von ,Deutschland als Vorreiter ${ }^{6}$ in den

78 Als technokratisch-managementorientiert werden im Folgenden politische Praktiken bezeichnet, die sich auf Grundlage technokratischer Wertvorstellungen auf eine technologische und ökonomische Steuerung innerhalb gegebener, bzw. idealisierter marktwirtschaftlicher Strukturen beschränken. 
„Energiewende“-Diskurs. Methodisch hat sich dabei vor allem die Vorarbeit durch die computerbasierte Datenanalyse bewährt, welche das quantitative Ausmaß der mit der Story-Line in Verbindung stehenden Artikulationen aufgezeigt und so erst für die qualitative Analyse in den Fokus gerückt hat. Sowohl in der quantitativen Erhebung als auch in der qualitativen Analyse hat sich außerdem bestätigt, dass soziale und ökonomische Verhältnisse (außer der ökonomischen Thematisierung von Arbeitsplätzen), globale Machtverhältnisse oder gesellschaftliche Naturverhältnisse eher selten adressiert und so dem ,Außen` ökologischer Modernisierung zugewiesen werden.

Politische Praktiken, die sich im Kontext des Narrativs der ,ökologischen Modernisierung' zeigen, können in Anlehnung an Glynos/Howarth (2007) als reformistisch klassifiziert werden; zwar wird verfahrenspolitisch eine Änderung politischer Praktiken angestrebt, die zentralen Gefahren werden aber nicht oder nur teilweise intern, also im Wirtschafts- oder Gesellschaftssystem, verortet. Aufgrund der quasi-natürlichen Konstruktion der Markt- und der Wettbewerbslogik, des Wohlstandsmodells sowie von Fortschritt, verweist das Narrativ in seiner glücksverheißenden Dimension bezüglich der ökonomischen Verhältnisse sogar auf eine eher beharrende Wirkung. Mit den artikulierten Forderungen wird keine langfristige Zukunftsperspektive eröffnet und sie zielen weitestgehend auf Erhalt des Status Quo, bspw. bezüglich des Wohlstands, ab.

\subsubsection{Marktwirtschaftliche Energiepolitik}

\section{Entwicklung des Narrativs}

In der 14. und 15. Legislaturperiode bildet sich eine konservativ-liberale Diskurskoalition aus CDU, CSU und FDP heraus, die für ,mehr Marktwirtschaft' in der Energiepolitik argumentiert und die rot-grüne Politik als Gefahr für eben diese konstituiert. Mit Beginn der großen Koalition der 16. Legislaturperiode verschwimmen die Grenzen dieser Diskurskoalition mit der rot-grünen Diskurskoalition zunehmend. Die CDU und die CSU plädieren zwar weiterhin für eine marktwirtschaftliche Energiepolitik, grenzen sich dabei aber von der FDP ab, bspw. indem sie sich positiv auf das EEG beziehen. Diese Entwicklung wurde bereits in der Analyse der Story-Lines aufgezeigt. Gleiches gilt für die Annäherung der Artikulationsmuster von SPD und CDU/CSU während der 16. Legislaturperiode. Beide Fraktionen artikulieren nun Motive des fantasmatischen Narrativs ,ökologische Modernisierung', während gleichzeitig eine marktwirtschaftliche Einordnung an Stellenwert gewinnt. Die Orientierung an Marktwirtschaftlichkeit im Rahmen von Energiepolitik tritt in der 17. Legislaturperiode unter der schwarz-gelben Koalition noch weiter hervor. Nach „Fukushima“ verschwimmen die Differenzen zwischen den fantasmatischen Narrativen ,ökologische Modernisierung‘ und ,marktwirtschaftliche Energiepolitik‘ zunehmend.

\section{Hindernisse/Gefahren und schreckensverheißende Dimension}

Im Gegensatz zum fantasmatischen Narrativ der ,ökologischen Modernisierung، spielen der Klimawandel samt seiner Ursachen und Folgen für die schreckensverheißende Dimension im Narrativ der ,marktwirtschaftlichen Energiepolitik‘ größtenteils 
keine Rolle und werden nicht artikuliert. Vor allem noch in der 14. und 15. Legislaturperiode wird der politische Klimaschutz und die mit ihm in Zusammenhang gebrachte rot-grüne Energiepolitik durch die konservativ-liberale Opposition (CDU, CSU, FDP) als Hindernis bzw. Gefahr für eine erfolgreiche deutsche Wirtschaftspolitik stilisiert: So wird das Verhältnis der $\mathrm{CO}_{2}$-Einsparmöglichkeiten Deutschlands gegenüber dem „Zuwachs an $\mathrm{CO}_{2}$-Emissionen“ „,in den Vereinigten Staaten, in Russland oder auch in China" kritisch hinterfragt und so nationale Klimaschutzpolitik sowie damit zusammenhängend die eigene Verantwortung im Hinblick auf den Klimawandel generell in Frage gestellt (CDU 28.05.2004: 10247). Der Atomausstieg gefährde die wirtschaftliche Entwicklung und die Wettbewerbsfähigkeit, die Preise steigen, Arbeitsplätze fallen weg, Forschung und Technik werden reduziert (CDU 25.11.1999: 6657, 14.12.2001: 20725). Dass Deutschland durch den Atomausstieg wieder mehr auf fossile Energieträger aus dem Ausland angewiesen sei, führe zu großen Problemen (FDP 09.09.2004: 11229).

Das fantasmatische Narrativ der ,marktwirtschaftlichen Energiepolitik‘ zielt somit auf eine Gefahr ab, die zwar durchaus die Ausrichtung der Energiepolitik betrifft, dennoch aber extern, in einer ,Ideologie' der staatlichen Eingriffe und Regulierungen verortet wird: Wenn erneuerbare Energien vom „Marktgeschehen“ abgekoppelt und sich nicht dem „Wettbewerb“ stellen, werde die Energieversorgung zu teuer (z.B. CDU 25.02.2000: 8430). Die rot-grüne Bundesregierung richte durch ihr Vorgehen bei Gesetzesinitiativen ein „beispielloses Chaos“ an (FDP 28.05.2004: 10239). Durch ihren „Dirigismus“ verursache sie „einen hohen Finanzaufwand“ (FDP 09.09.2004: 11258). Auch die Energiepolitik der LINKEN wird in diesem Zusammenhang als Schreckensszenario für die wirtschaftliche Entwicklung und die Versorgungssicherheit konstituiert, immer wieder wird sie direkt oder indirekt zu einer rückwärtsgewandten, ,sozialistischen“ Bedrohung stilisiert: Ihnen wäre es am liebsten, wenn der „Stromverbrauch staatlich regulier[t]“ würde, wenn „,das Rad der Geschichte zurück[ge]dreh[t]“" würde“, entweder direkt oder indirekt wollen sie die ,Verstaatlichung“ (CDU 02.07.2009: 25871), im schlimmsten Fall führe diese ,ineffiziente Basarökonomie“ „zum Zusammenbruch der Stromversorgung“ (FDP 02.07.2009: 25875). „Wir wollen keine Situation wie in der DDR! ${ }^{79 ، “}$ (CDU 24.03.2011: 11284). Eine Politik, wie sie von der LINKEN gefordert werde, vernichte Arbeitsplätze: „Sie machen doch ernsthaft keine Industriepolitik. Sie möchten doch genau ein Modell haben, bei dem es ausschließlich darum geht, ein Volk von Hartz-IV-Empfängern zu produzieren, von Menschen, die der Staat zu versorgen hat ${ }^{80 ،}$ (FDP 29.03.2012: 20291).

Marktwirtschaftliche Zielsetzungen werden in einen Widerspruch zu umweltpolitischen Zielsetzungen und damit auch vor allem zur Politik der GRÜNEN artikuliert. Der Niedergang des Industriestandortes Deutschland wird als Katastrophenszenario entworfen. Die rot-grüne Regierungskoalition habe „das Kyoto-Protokoll zum Vorwand für eine Politik genommen, die den Industriestandort Deutschland stark gefähr-

79 Bei dem Zitat handelt es sich um einen Zwischenruf von Volker Kauder (CDU) zur Forderung der LINKEN nach „Fukushima“ die Energieversorgung zu dezentralisieren und kommunalisieren.

80 Das Zitat bezieht sich auf die Forderungen der Linken zur Rettung der Solarindustrie 2012. 
det“ (CDU 28.05.2004: 10250). Das sei auch eine Entscheidung ,gegen Arbeitsplätze“ (CDU 28.05.2004: 10253). Um ,[i] reichen, würde die Bundesregierung den Schaden der Industrie absichtlich in Kauf nehmen: „Wir hatten bei Ihnen gelegentlich durchaus den Eindruck, dass die Vorstellung für Sie nicht unangenehm wäre, wenn es in Deutschland bestimmte Industriezweige nicht mehr geben würde“ (CDU 28.05.2004: 10236).

In der 16 Legislaturperiode verändern sich im Zuge einer Annäherung zwischen SPD, CDU und CSU die Artikulationsmuster des Narrativs ,marktwirtschaftliche Energiepolitik', wodurch das Katastrophenszenario nur noch in abgeschwächter Form artikuliert wird. So beziehen CDU und CSU nun stärker auch die Folgekosten des Klimawandels als Gefahr für die Wirtschaft (z.B.: CDU 06.06.2008: 17741) in die schreckensverheißende Dimension des Narrativs mit ein und rechtfertigen damit ihre nun positive Haltung zum EEG. Andererseits verbinden sie erneuerbare Energien weiterhin mit der Gefahr einer mangelnden Versorgungssicherheit (CDU 02.07.2009: 25699). Auch die FDP sieht in den erneuerbaren Energien weiterhin eine Gefahr für die Versorgungssicherheit (FDP 02.07.2009: 25875) und somit für den Industriestandort Deutschland. Gleichzeitig grenzen sich CDU, CSU und FDP hinsichtlich der Gefahrenanalyse nun voneinander ab, denn die FDP sieht das Hindernis vor allem im ,größten Preistreiber“, dem Staat, den sie mit „Wettbewerb“ kontrastiert (FDP 02.07.2009: 25876). Sie kritisiert, die Bundesregierung habe mit dem EEWärmeG keinen „Markt für die erneuerbare Energien im Wärmebereich“ geschaffen, sondern übe „Zwang und Kontrolle über die Bürger aus“ (FDP 06.06.2008: 17731). Die CDU verbindet das EEG nun nicht mehr direkt mit ,Planwirtschaft‘ und ,Sozialismus', stellt die Marktwirtschaft aber weiterhin einer sozialistischen Bedrohung gegenüber: „Der Spruch ,Freiheit statt Sozialismus!‘ stimmt trotzdem!“ (CDU 06.06.2009: 17740).

Mit Beginn der 17. Legislaturperiode bindet auch die an der Regierung beteiligte FDP die Notwendigkeit eines Umbaus der „heutigen Energieversorgungsstrukturen“ in ihre Artikulationsmuster mit ein - allerdings in Zusammenhang mit der Verlängerung der Laufzeiten der Atomenergie als „Brückentechnologie“ (17/3049: 2). Die Notwendigkeit dieses Umbaus leite die Koalition vor allem aus der „weltweit steigende[n] Energienachfrage“, die zu „steigenden Energiepreisen“ führe, während gleichzeitig „die Abhängigkeit [...] von Energieimporten“ steige, ab (17/3049: 2). ,Klimaschutz' als Motiv wird nun endgültig in das Narrativ ,marktwirtschaftlicher Energiepolitik“ integriert und wird als „zentrale Voraussetzungen“ gesehen, „dass Deutschland auch langfristig ein wettbewerbsfähiger Industriestandort bleibt" (17/ 3049: 2). Politische Maßnahmen, die auf Klimaschutz abzielen, werden somit nicht mehr überwiegend als Gefahr gekennzeichnet, sondern artikulatorisch in die Wettbewerbslogik einer 'marktwirtschaftlichen Energiepolitik' eingebunden, wobei ökologische und gesellschaftliche Bereiche den ökonomischen Zielsetzungen untergeordnet werden.

Die marktwirtschaftliche Einbindung als oberste Maxime erfolgreicher Energiepolitik ändert sich auch nach „Fukushima“ nicht. CDU, CSU und FDP passen zwar ihre Artikulationsmuster bezüglich der Atomenergie an und befürworten nun eine „Energiewende“, die als notwendig akzeptiert wird. Dennoch wird weiterhin ein Verlust der wirtschaftlichen Stabilität durch die „Energiewende“ als Katastrophenszenario aufrechterhalten. Der Fokus des Narrativs ,marktwirtschaftlicher Energiepolitik“ 
wird in der schreckensverheißenden Dimension so bereits kurz nach „Fukushima“ erneut auf die Risiken einer „Energiewende“ gerichtet, anstatt auf die Risiken der konventionellen Energieerzeugung (Klimawandel, atomare Unfälle) hinzuweisen:

„Alle, die zweifeln, wie wir als großes Industrieland in zehn Jahren ohne Kernenergie auskommen wollen, ohne gleichzeitig die Klimaschutzziele zu riskieren, ohne Arbeitsplätze in der energieintensiven Industrie zu gefährden, ohne das Steigen der Strompreise in das sozial nicht mehr Erträgliche in Kauf zu nehmen, ohne gefährliche Stromausfälle zu provozieren, ohne dass andere Länder um uns herum denselben Weg einschlagen, alle, die solche Fragen stellen, sind keine Ideologen, keine Ewiggestrigen, keine Spinner, denn sie stellen wichtige Fragen“ (Angela Merkel 09.06.2011: 12963).

Als Hindernis für eine erfolgreiche Energiepolitik wird nun erneut die rot-grüne Vorgängerregierung herangezogen. Diese habe die Probleme, „die das Erreichen einer vernünftigen Energieversorgung nach sich zieht“ (FDP 30.06.2011: 13396) nicht angegangen. „Ökologie und Ökonomie“ seien ,in der Vergangenheit gegeneinander aus[gespielt]“ worden (CDU 30.06.2011: 13403), was aus dieser Perspektive ein als natürlich erachtetes Primat des Ökonomischen vor dem Ökologischen impliziert, verbunden mit der Annahme, die Priorisierung unter rot-grün sei eine gegensätzliche gewesen. In der Bewertung des Hindernisses für eine erfolgreiche „Energiewende“ ist somit am sichtbarsten eine Differenz zwischen den beiden Narrativen ,ökologische Modernisierung' und ,marktwirtschaftliche Energiewende' auszumachen. Während im Rahmen der ,ökologischen Modernisierung ' Gefahren zumindest in Teilen wenn auch nicht überwiegend - intern, also in der Struktur des Energiesektors, verortet werden, so erscheinen sie im Rahmen ,marktwirtschaftlicher Energiepolitik' rein extern in Form des Schreckgespenstes der staatlichen Regulierung.

Entsprechend ist auch das Katastrophenszenario ein anderes. Im Narattiv der ,marktwirtschaftlichen Energiepolitik' bleiben bei den Artikulationen im Rahmen der schreckensverheißenden Dimension die Folgen des Klimawandels außen vor. Stattdessen dient das Katastrophenszenario der ,Deindustrialisierung ' als Rechtfertigung einer wirtschaftsorientierten Politik, bspw. zur Befreiung der energieintensiven Unternehmen von der EEG-Umlage oder der Kürzung der Solarförderung im EEG 2012. So seien in der energieintensiven Industrie ,[h]underttausende von Arbeitsplätzen“ durch einen drohenden Anstieg der Strompreise gefährdet (CSU 09.06.2011: 12973). Es drohe die „Verlagerung“ dieser Betriebe sowie die Einschränkung derer Wettbewerbsfähigkeit in einem ,schleichenden Prozess“ (CDU 29.03.2012: 20281). „[W]ir wollen den Umbau der Energieversorgung[...]. Wir wollen aber eines nicht: die Industrie aus diesem Land treiben und damit Zigtausende Arbeitsplätze aufs Spiel setzen“ (CDU 29.03.2012: 20282). Auch die FDP bedient immer wieder das Katastrophenszenario der „Deindustrialisierung“: „Ich sage ganz klar: Was die FDP, aber auch die Koalition hier im Deutschen Bundestag nicht mitmachen werden, ist eine Politik der Deindustrialisierung“"(FDP 29.03.2012: 20284).

Auch die SPD artikuliert in der 18. Legislaturperiode verstärkt innerhalb der Gefahrendimension des marktwirtschaftlichen Narrativs. Konstituierte die SPD noch in der 17. Legislaturperiode zu umfangreiche Befreiungen der energieintensiven Industrie von der EEG-Umlage als Gefahr für die „Energiewende“, so argumentiert sie nun: Bereits heute gingen ,die Investitionen in energieintensiven Branchen deutlich zu- 
rück[...] und [...] Arbeitsplätze verl[oren]“ (SPD 27.06.2014: 3933). Dabei greift auch sie auf das Bedrohungsszenario einer „Deindustrialisierung“ zurück: „Diese Koalition und dieser Minister lassen Deindustrialisierung in Deutschland nicht $\mathrm{zu}^{\text {“ }}$ (SPD 27.06.2014: 3939f.). Eine Abschaffung der Subventionen der energieintensiven Industrie bedrohe den Export und die Wettbewerbsfähigkeit der deutschen „Industrienation“ (SPD 27.06.2014: 3995). Der Katastrophenhorizont wird zudem durch die Artikulation des fehlenden Netzausbaus erweitert. In diesem Zusammenhang wird nun der Knotenpunkt „Ausbaukorridor“ verwendet, der einen zu schnellen Ausbau und eine damit verbundene „Kostenexplosion“ verhindern soll (z.B.: SPD 10.04. 2014: 2433; Koalitionsvertrag 2013: 38). Die „Energiewende“ wird im Zusammenhang mit einer marktwirtschaftlichen Einordnung somit überwiegend als Ausgangspunkt für das Katastrophenszenario der ,Deindustrialisierung' betrachtet, während die im Narrativ der ,ökologischen Modernisierung` artikulierten Ursachen ihrer Notwendigkeit im Rahmen einer schreckensverheißenden Dimension im Narrativ ,marktwirtschaftlicher Energiepolitik‘ nicht vorkommen.

\section{Glücksverheißende Dimension}

Ein erfolgsversprechender und glücksverheißender Weg zum Ausbau erneuerbarer Energien wird von CDU/CSU und FDP bereits ab der 14. und 15. Legislaturperiode marktwirtschaftlich verortet. „Marktwirtschaft“ bedeute „Effizienz“ und „Kostensenkung“ (FDP 25.02.2000: 8443). Wenn die erneuerbaren Energien nach den Regeln des Marktes organisiert werden, könne es eine Zukunftstechnologie werden (CSU 25.02.2000: 8440). Die glücksverheißende Dimension wird dabei unter der Voraussetzung einer effizienten Ressourcenallokation eröffnet. Es sei demzufolge sinnvoller, Sonnenenergie in Entwicklungsländern zu fördern, da erneuerbare Energien dort effizienter eingesetzt werden könnten (CSU 25.02.2000: 8440), so können Technologietransfer und „Exportoffensive für erneuerbare Energien aus Deutschland“ verbunden werden (FDP 28.05.2004: 10238). Dieser Fokus auf die Verbindung von Energieaußenpolitik, Entwicklungspolitik und Wirtschaftsförderung als glücksverheißende Perspektive verfestigt sich in der 16. Legislaturperiode.

Die Atomenergie wird dabei zunächst als Teil der glücksverheißenden Dimension marktwirtschaftlicher Energiepolitik betrachtet. Durch „technischen Fortschritt“ sollen die Sicherheitsprobleme der Atomenergie gelöst werden und die Transmutation/Kernfusion gelingen (FDP 14.12.2001: 20715). Gleichzeitig diene Atomenergie dem Klimaschutz, weshalb der „Energiemix nach wie vor die Kernenergie mit einschließen wird" (CDU 28.05.2004: 10237). Auch in der 16. Legislaturperiode bleiben CDU, CSU und FDP bei dieser Argumentation und grenzen sich dadurch von der SPD ab.

Im Zuge des Wandels der Artikulationsmuster der CDU/CSU in der 16. Legislaturperiode wird das EEG in die glücksverheißende Dimension marktwirtschaftlicher Energiepolitik integriert. Dies gelingt, indem das EEG zum Bestandteil der ,Sozialen Marktwirtschaft' erklärt wird, die analog zu anderen politischen Diskursen in Kontrast $\mathrm{zu}$,Sozialismus` konstruiert wird, und wirtschaftliche und soziale Versprechen miteinander verbindet: 
wirtschaft und andere Formen des Kollektivismus ab. Darum haben wir auch begonnen, den Energiemarkt in Deutschland so zu formen, dass auch auf ihm die soziale Marktwirtschaft gilt. Nur so ist eine konkurrenzfähige und sozialverträgliche Energieversorgung auf Dauer zu erreichen“ (CDU 02.07.2009: 25872f.).

In der 16. Legislaturperiode wird darüber hinaus das Motiv der ,Nachhaltigkeit' in den „Energiewende“-Diskurs eingeführt. Statt einer ,ökologischen Modernisierung“, die mit der rot-grünen Bundesregierung verbunden wird, artikulieren CDU/CSU und SPD im Koalitionsvertrag 2005 nachhaltiges Wirtschaften als gemeinsame Zielsetzung. Nachhaltigkeit solle ,zum Motor“ für „die weltweite Vermarktung von Zukunftstechnologien“ und die „Erhöhung der Energie- und Ressourcenproduktivität und damit der Wettbewerbsfähigkeit der deutschen Volkswirtschaft" werden (Koalitionsvertrag 2005: 17f.). Auch im Zusammenhang mit dem Narrativ einer ,marktwirtschaftlichen Energiepolitik' tritt also wieder das Motiv der ,Vorreiterrolle ' verbunden mit nationalen Standortvorteilen zum Vorschein. Der Ausbau erneuerbarer Energien und die Erhöhung der Effizienz „,im Rahmen eines breiten Energiemix“ solle die Wettbewerbsfähigkeit stärken, Energiepreise senken, Unternehmen und Verbraucher*innen entlasten und gleichzeitig zum „Schutz der Erdatmosphäre und der Umwelt“" beitragen (Koalitionsvertrag 2005: 65). Die Grenzen zur glücksverheißenden Dimension ,ökologischer Modernisierung' verschwimmen hier, da in beiden Narrativen auf dieselben Story-Lines zurückgegriffen wird.

Dieser Trend verstärkt sich in der 17. und 18. Legislaturperiode insbesondere in Bezug auf die glücksverheißende Dimension weiter. In der schwarz-gelben Koalition der 17. Legislaturperiode verheißt die Atomenergie als „Brückentechnologie“ den „Weg ins regenerative Zeitalter“ (17/3049). Atomenergie wird so als Teil des „Umbaus der Energieversorgungsstrukturen“ (17/3049) zu erneuerbaren Energien gedacht. Dabei wird teilweise die Glücksverheißung des Narrativs der ,ökologischen Modernisierung“ artikulatorisch angeeignet: „Wir wollen den Wettbewerb und eine marktwirtschaftliche Orientierung auf den Energiemärkten stärken. Damit sichern wir nachhaltige wirtschaftliche Prosperität, zukunftsfeste Arbeitsplätze, Innovationen und die Modernisierung unseres Landes“ (17/3049: 2). Das EEG wird als Erfüllung dieser marktwirtschaftlich orientierten Verheißung betrachtet, denn es habe „massives Wachstum in allen Bereichen der erneuerbaren Energien erzeugt", die sich zu „einem Treiber für Innovation und die Modernisierung der Energieinfrastruktur“ entwickeln (17/3049: 4). Im Koalitionsvertrag und im Energiekonzept ist von einer „,ideologiefreie[n], technologieoffene[n] und marktorientierte[n] Energiepolitik“ die Rede (17/3049: 2; Koalitionsvertrag 2009: 26). Dabei wird „ideologiefrei“ mit „marktorientiert“ und „technologieoffen“ äquivalenziert, wobei ,technologieoffen“ implizit auf die Kernenergie verweist.

Als zentrales Element markwirtschaftlich orientierter Bedeutungsgenerierung von Energiepolitik wird im Koalitionsvertrag die ,wirtschaftliche Vernunft ${ }^{\star}$ artikuliert: Für eine „wirtschaftlich vernünftig[e]“ Gestaltung sei noch ,zeitlich befristet die Kernenergie“" notwendig (17/3050: 8). Die ,Befähigung' zur wirtschaftlichen Vernunft ist als Element zu betrachten, das sich die schwarz-gelbe Regierungskoalition identitätsstiftend in Abgrenzung zur Opposition selbst zuschreibt. Dieses Selbstverständnis wird zur Legitimierung der Durchsetzung eigener politischer Forderungen herangezogen. Gleichzeitig erfolgt die einseitige Artikulation eines vermeintlichen 
Konsenses in Bezug auf energiepolitische Ziele: Die „wirtschaftliche Vernunft“, durch die sich „die FDP und die Union“ von der Opposition unterscheide, befähige diese zur „Erreichung der ökologischen Ziele, die wir gemeinsam haben“ (FDP 28.10.2010: 7187). Hier zeigt sich die entpolitisierende Wirkung des Narrativs durch die versuchte Naturalisierung dieser spezifischen Sichtweise als ,ideologiefrei` deutlich. Gleichzeitig wird die Grundlage für die hegemoniale kurze Zeit später stattfindende Aneignung von „Energiewende“ in das Narrativ ,marktwirtschaftlicher Energiepolitik' durch diese artikulatorische Praxis gelegt.

Dass die Forderung nach erneuerbaren Energien sowohl den hegemonialen als auch den gegen-hegemonialen Diskursraum tangiert wurde bereits in Kapitel 5.1.3 erläutert und wird hier bei der Verschmelzung der Narrative um ,ökologische Modernisierung' und ,marktwirtschaftliche Energiepolitik' in ihrer glücksverheißenden Dimension deutlich. Diese wird im Diskurs nach „Fukushima“ nahezu vollendet, in dem die Regierungskoalition den Ausstieg aus der Kernenergie als Forderung in ihr Artikulationsmuster rund um eine marktwirtschaftlich organisierte „Energiewende“ integriert. Der Ausstieg aus der Kernenergie wird als „Chance“ für die deutsche Wirtschaft interpretiert und somit Teil der Glücksverheißung ,marktwirtschaftlicher Energiepolitik، (FDP 09.06.2011: 12968). Die Energiepolitik wird zum wirtschaftlichen „Modernisierungsprogramm“ erklärt (FDP 09.06.2011: 12986). Sie wird gleichzeitig mit dem Versprechen einer deutschen Vorreiterrolle und der Stärkung von Deutschland als ,Exportnation“ verknüpft, einem Motiv, das genauso dem Narrativ ,ökologischer Modernisierung' zugrunde liegt. Bei der Bedeutungsgenerierung von „Energiewende“ stehen marktwirtschaftliche Versprechen noch weiter im Vordergrund: „Dieser Einstieg wird in erheblichem Maße anlagesuchendes Kapital nach Deutschland ziehen. Das ist ein neues Konjunkturprogramm, und zwar ein marktwirtschaftliches“ (FDP 09.06.2011: 12976). Der Erfolg der erneuerbaren Energien und der „Energiewende“ wird an die Bedingung der marktwirtschaftlichen Ausrichtung geknüpft, weshalb „das Erneuerbare-Energien-Gesetz nach und nach zu einem Marktordnungsgesetz“ zu machen sei (CDU 29.02.2012: 2306). Ziel sei es „Wachstum so zu organisieren, dass wir nicht die Lebensgrundlagen der nächsten Generationen aufzehren“" (CDU 30.06.2011: 13370).

Auch in der 18. Legislaturperiode steht weiterhin die Artikulation von „Energiewende" als wirtschaftliches Modernisierungsprogramm, das ökologische mit ökonomischen Zielen vereinbar mache, im Mittelpunkt. Die glücksverheißenden Dimensionen ,ökologischer Modernisierung ‘ und ,marktwirtschaftlicher Energiepolitik' sind nun weitgehend identisch und werden in ihrer Artikulation nun auch von der SPD mitgetragen. „Sie [die Energiewende] schützt Umwelt und Klima, macht uns unabhängiger von Importen, sichert Arbeitsplatze und Wertschöpfung in Deutschland.“ (Koalitionsvertrag 2013: 36). Ziel der Politik sei „die Dekarbonisierung der deutschen Wirtschaft und der deutschen Energieversorgung voranzutreiben und 80 Prozent $\mathrm{CO}_{2}$-Emissionen bis 2050 einzusparen“ (CDU 27.06.2014: 3941). Auch in der 18. Legislaturperiode liegt der Fokus weiter auf der marktwirtschaftlichen Organisation sowie auf technischem Fortschritt (vgl. z.B. SPD 01.06.2016: 16989), während über die ökologische Dimension aber kaum mehr gesprochen wird.

Ein zentrales Diskurselement sind die Novellierungen des EEG 2014 und 2016/ 2017, die u.a. durch das Ausschreibungsdesign zu „mehr Markt und mehr Wettbewerb“ (CDU 27.06.2014: 3935) führen sollen. Das EEG habe sich damit in einer 
„vernünftigen Weise [...]“ (CDU 27.06.2014: 3935) verändert, die „Energiewende“ werde ,wieder auf ein festes Fundament“ gestellt (SPD 27.06.2014: 3932), es gehe auch darum „,vernünftige wirtschaftliche Strukturen“ zu erhalten (SPD 01.06.2016: 16978). Auch hier wird auf das Element der ,Vernunft‘ zurückgegriffen, um marktwirtschaftliche Instrumente zur Deregulierung im Bereich der erneuerbaren Energien zu rechtfertigen und zu ihrer Naturalisierung beizutragen. Die marktwirtschaftliche Orientierung der „Energiewende“ wird mit zahlreichen Glücksverheißungen aufgeladen, wie zum Beispiel „Ausbaukorridore“ für erneuerbare Energien verbunden mit „Planungs- und Versorgungssicherheit“ (SPD 10.04.2014: 2433) sowie „Berechenbarkeit“" (SPD 27.06.2014: 3932). Diese werden unter anderem mit Artikulationen wie „Kostenexplosionen“ (SPD 10.04.2014: 2433) und „Überförderung“ (SPD 27.04.2014: 3932) in Differenz zur bisherigen - als weniger marktwirtschaftlich markierten - Energiepolitik positioniert. Die vormals mit der „Energiewende“ verbundene Forderung nach Klimaschutz gerät in diesen Debatten in den Hintergrund. Sie wird nur noch indirekt als Ergebnis einer industrie- und marktorientierte Politik artikuliert: Um „Klimaschutz, Sicherung von Arbeitsplätzen und wirtschaftliche[n] Erfolg“ vereinbar zu machen, sei ,die energieintensive Industrie vor einer steigenden EEG-Umlage zu schützen“ (SPD 27.06.2014: 3932). Das Ende der „Zeit der Technologieförderung“" erneuerbarer Energien (SPD 27.04.2014: 3932) wird dadurch in der glücksverheißenden Dimension ,marktwirtschaftlicher Energiepolitik“ verortet. Deren hegemonialer Status innerhalb des „Energiewende“-Diskurses wird weiter gefestigt, in dem Forderungen nach mehr Marktwirtschaft immer wieder naturalisiert werden, so wie von der CDU gegen Ende der Legislaturperiode: Dass die „Euphorie“ für die „Energiewende“ „verflogen“ sei und die „Deutschen“ „ein nüchterneres Verhältnis zu den erneuerbaren Energien entwickelt“ haben, wertet sie als Erfolg. Es gehe den Menschen jetzt darum, die „finanziellen Vorteile“ zu nutzen und um „Unabhängigkeit durch die Eigenversorgung. Für die deutsche Volkswirtschaft wird sich das auszahlen“ (CDU 29.06.2017: 24992). Diese Naturalisierung soll durch die Konstruktion einer nationalen Identität in Bezug auf die „Energiewende“ weiter gefestigt werden.

\section{Implizit geteilte Annahmen und Klassifizierung}

Den mit dem fantasmatischen Narrativ der marktwirtschaftlichen Energiepolitik in Verbindung stehenden Artikulationsmustern liegen implizit geteilte und positiv konnotierte Annahmen über Marktwirtschaft, Vernunft, Wachstum, Wohlstand, Wettbewerb, technologischen Fortschritt, Effizienz etc. zu Grunde, die die politischen Praktiken prägen und als quasi-naturgegeben vorausgesetzt werden. Es zeigt sich dabei eine starke Überschneidung in den Artikulationsmustern von ,ökologischer Modernisierung' und ,marktwirtschaftlicher Energiepolitik', die sich wie gezeigt im zeitlichen Verlauf nahezu vereinheitlicht haben. Unterschiede gibt es am ehesten noch in der schreckensverheißenden Dimension der beiden Narrative. Während im Narrativ der ,ökologischen Modernisierung ‘ zumindest in ihren Ursprüngen noch die unmittelbaren Ursachen und Folgen von Klimawandel artikuliert werden, so wird in der Perspektive des marktwirtschaftlichen Narrativs das Katastrophenszenario von der Angst vor Deindustrialisierung bestimmt.

Leichte Differenzen zwischen den beiden fantasmatischen Narrativen sind auch in ihrer Beschreibung der Gefahren und Hindernisse für eine gelungene Energiepoli- 
tik auszumachen. Unter dem Narrativ ,ökologischer Modernisierung' wird u.a. auch eine zu ressourcenintensive Produktionsweise in den Blick genommen. Im Narrativ ,marktwirtschaftlicher Energiepolitik' wird eine von Sozialismus oder Ideologie geleitete Politik - im Gegensatz zur positiven Konnotation von Marktwirtschaft werden die Begriffe negativ besetzt - zur Hauptgefahr erklärt. Eine marktwirtschaftliche Ausrichtung wird zur Grundlage und zum Ziel jeglicher politischer Praxis stilisiert. Durch die Konstituierung als ideologiefrei und vernünftig erscheint Marktwirtschaft als alternativlos. Ökologische und soziale Aspekte von Energiepolitik werden abgesehen vom Arbeitsplatz-Argument außen vor gelassen. Die Gefahr wird eher extern, in einer ,Ideologie' der staatlichen Regulierung gesehen. Der zeitliche Bezug des Narrativs reduziert sich durch den Fokus auf die Ökonomie überwiegend auf die Gegenwart - politische Praktiken sind auf den Erhalt eines ökonomisch definierten Wohlstandes sowie wirtschaftlicher Stabilität gerichtet. Eine Zukunftsperspektive eröffnet sich am ehesten in der Einbindung der Story-Line von ,Deutschland als Vorreiter' sowie in der vereinzelten Nennung konkreter $\mathrm{CO}_{2}$-Reduktionsziele in einem bestimmten zeitlichen Korridor. Da diese jedoch nicht in eine umfassendere $\mathrm{Zu}$ kunftsperspektive eingebunden werden, haben die vereinzelten Artikulationen mit Zukunftsperspektive für die glücksverheißende Dimension des Narrativs insgesamt keinen hohen Stellenwert.

Die überdurchschnittlich hohe diskursive Verbreitung des fantasmatischen Narrativs ,marktwirtschaftliche Energiepolitik' belegt, dass es Teil der hegemonialen Formation ist, was auf die Dominanz marktwirtschaftlich orientierter Deutungsmuster innerhalb dieser Formation verweist. ${ }^{81}$ Wie in Kapitel 5.1.3 zeigt sich hier erneut, dass es der hegemonialen Formation in besonderer Weise gelingt, ihre eigenen inneren Grenzen zu verschieben und den politischen Raum neu zu definieren: Das Narrativ ,marktwirtschaftliche Energiepolitik' passt sich schnell an neue Gegebenheiten wie „Fukushima“ - an und bindet diese marktwirtschaftlich ein. So wird verhindert, dass Dislokationen zur Quelle , anderer' politischer Praktiken (Glynos/Howarth 2007: 147) werden können.

Politische Praktiken, die sich im Kontext des Narrativs ,marktwirtschaftliche Energiepolitik` zeigen - können in Anlehnung an Glynos/Howarth (2007) von ihrer Ausrichtung her als beharrend klassifiziert werden, da sich der zeitliche Bezug ihrer Glücksverheißung überwiegend auf die Gegenwart fokussiert. Durch ihre schnelle Anpassung an neue Gegebenheiten und die Vereinnahmung der Artikulationsmuster des*r politischen Gegner*in können sie in der Praxis teilweise eine reformistische Wirkung entfalten, die aber auf den Erhalt, bzw. die Ausbreitung der hegemonialen Formation gerichtet ist, deren marktwirtschaftliche Orientierung als alternativlos dargestellt wird. Da die Haupthindernisse einer erfolgreichen marktwirtschaftlichen Energiepolitik extern in einer ,Ideologie‘ der Regulierung bis hin zu ,Sozialismus' verortet werden, stärkt das die Einordnung der entsprechenden politischen Praktiken in ihrer Ausrichtung sowie der Wirkrichtung des marktwirtschaftlichen Narrativs im Spektrum zwischen reformistisch bis beharrend.

81 Dies führe ich im folgenden Kapitel 5.4 genauer aus. Vgl. dazu auch Fußnote 94. 


\subsubsection{Sozial-ökologischer Umbau}

\section{Entwicklung des Narrativs}

Die LINKE bzw. zunächst die PDS thematisiert eine „Energiewende“ vor dem Hintergrund eines umfassenderen gesellschaftlichen Umbaus. In der 14. Legislaturperiode wird dabei der Begriff des ,ökologischen Umbaus` verwendet, der gemeinsam mit sozialpolitischen Themen artikuliert wird. In der 16. Legislaturperiode spricht die LINKE dann vermehrt von ,sozial-ökologischem Umbau', was die Notwendigkeit einer Gleichzeitigkeit von ökologischer und gesellschaftspolitischer Transformation hervorhebt. In Abgrenzung zu einer ökologischen Modernisierung zielt der von PDS und später der LINKEN artikulierte ökologische, bzw. sozial-ökologische Umbau auf eine gemeinsame Betrachtung ökonomischer und sozialer Strukturen ab und ist nicht marktwirtschaftlich ausgerichtet. Ein sozial-ökologischer Umbau in diesem Sinne wird von anderen Fraktionen eher selten adressiert ${ }^{82}$ und teilweise auch explizit abgelehnt. Aufgrund der geringen Redezeiten von PDS und später der LINKEN, der isolierten Diskursposition sowie der relativ geringen Involvierung ${ }^{83}$ in den Diskurs, ist die diskursive Verbreitung gering - das fantasmatische Narrativ bleibt marginalisiert.

\section{Hindernisse/Gefahren und schreckensverheißende Dimension}

Die Ursachen sozialer und ökologischer Krisen werden im Kontext der Marktorientierung politischer Praktiken und in diesem Zusammenhang auch in der Durchsetzung von Profit- und Konzerninteressen, die in einen Gegensatz zu Demokratie gestellt werden, beschrieben. Die Hindernisse/Gefahren für „Energiewende“ werden demnach innerhalb der ökonomischen Struktur - also intern - verortet:

Denken Sie nur an die Entwicklung in den letzten Tagen und Wochen im Energie- und Telekommunikationssektor! Überall zeigt sich: Hemmungsloser Markt ist nicht nur blind gegenüber gesellschaftlichen Bedürfnissen, er stärkt auch nicht die Kreativen und die Fleißigen, sondern stets nur die Mächtigen. Kurzfristige Wohlstandsgewinne werden so teuer erkauft" (PDS 25.11.1999: 6654).

Von einer marktorientierte Steuerung - im Gegensatz zu einer demokratischen Steuerung - von Maßnahmen (z.B. des Emissionshandels) sowie von fehlendem politischen Eingreifen und Liberalisierung (z.B. der Abschaffung der Strompreisaufsicht) profitieren nach Ansicht der LINKEN vor allem Großunternehmen, während die Strompreise für Privatpersonen steigen. Das sei ein „Feldzug gegen die Verbraucherinnen und Verbraucher" (LINKE 02.07.2009: 25876).

Die Priorisierung ökonomischer vor ökologischen und sozialen Interessen, wie sie auch durch die rot-grüne Bundesregierung erfolge, wird als krisenverursachend konstituiert: „Im Streit ,Umwelt kontra Wirtschaft‘ blieb der Umweltminister zweiter

82 In einigen Fällen greifen die GRÜNEN eine sozial-ökologische Transformation auf (z.B. GRÜNE 03.07.2014: 4298), oder artikulieren ebenfalls umwelt- und sozialpolitische Themen gemeinsam.

83 Gemeint ist die vergleichsweise geringe relative Häufigkeit, mit der PDS und später die LINKE an dem Diskurs um „Energiewende“ teilnehmen. 
Sieger“ (PDS fraktionslos ${ }^{84}$ 28.05.2004: 10252). Die rot-grüne Regierung mache nur vordergründig Umweltpolitik, habe in Wirklichkeit den Umweltetat gekürzt und schaffe soziale Ungerechtigkeit (PDS 25.11.1999: 6748). Vor diesem Hintergrund wird im Narrativ des ,sozial-ökologischen Umbaus“ ein Katastrophenszenario eröffnet, welches die Gefahr zeitlich in der Gegenwart verortet. Die Regierungskoalition rede die „Klimakatastrophe“ klein und biete auch mit dem Emissionshandel keinen Lösungsansatz: „Wenn wir auch gern anderes glauben und die Bundesregierung anderes predigt: Das Problem der drohenden Klimakatastrophe steht weiter vor uns bzw. schwebt über der Welt. Der Klimaschutz stagniert seit Jahren, jedenfalls gemessen an den $\mathrm{CO}_{2}$-Emissionen“ (PDS fraktionslos 28.05.2004: 10252).

Die Beschreibung interner Ursachen des Klimawandels, wie zum Beispiel die „weltweite Verbrennung fossiler Energieträger“ als „Hauptursache des Klimawandels“ (LINKE 02.07.2009: 25694), wird über die 16. Legislaturperioden hinweg als Ausgangspunkt für die Artikulation konkreter Folgen des Klimawandels im Rahmen einer schreckensverheißenden Dimension genommen:

„Die Folgen [...] sind heute Trinkwassermangel und Ernteausfälle weltweit. Für Millionen von Menschen bedeutet das Hunger, Elend und Heimatlosigkeit. Viele Regionen der Welt treiben von Krise zu Krise. Konflikte verschärfen sich, und der Kampf um Wasser und Ressourcen gehört in vielen Ländern, zum Beispiel in vielen Ländern Afrikas, und Gaszusagen gegen Waffenlieferungen“" (LINKE 02.07.2009: 25694).

Die politische Priorisierung wirtschaftlicher Interessen verschlimmere die Situation, so reagiere die Bundesregierung mit Aufrüstung, um sich die Transportwege für ihre Energiequellen zu sichern, z.B. in Libyen. Dadurch bleiben „Frieden, Menschenrechte und eine sichere und nachhaltige Versorgung mit Energie“" auf der Strecke (LINKE 02.07.2009: 25694). Hervorzuheben ist hierbei, dass die schreckensverheißende Dimension durch Ausweitung der Erzählperspektive auf den globalen Süden einen Gegenwartsbezug erhält.

Auch nach „Fukushima“ bleibt die LINKE bei einer internen Gefahrenverortung in Bezug auf ihre Vorstellung einer „Energiewende“ im Rahmen des sozialökologischen Umbaus und zielt in ihrer Kritik auf die in ihren Augen Profit- und Marktorientierung der Energiepolitik der Bundesregierung ab: „Während die Bürgerinnen und Bürger über die EEG-Umlage die Energiewende finanzieren müssen, wird bei der Industrie Geld damit verdient ${ }^{85 ، ~(L I N K E ~ 30.06 .2011: ~ 13390) . ~ D a s ~ G a n z e ~ s e i ~}$ eine „gigantische Umverteilungsmaschine“ (LINKE 29.03.2012: 20277). Wenn sich daran nichts ändere, „dann wird der sozial-ökologische Umbau scheitern“ (LINKE 29.03.2012: 20277). Auch die LINKE bemüht das Katastrophenszenario der ,Deindustrialisierung', allerdings aus Perspektive der Solarindustrie. In deren Niedergang spiegele sich die ungerechte, interessengeleitete und profitorientierte Politik der Regierungskoalition. Im Osten Deutschlands drohe ,eine zweite Deindustrialisierungs-

84 Die PDS ist in der 15. Legislaturperiode nicht als Fraktion, sondern nur über Direktmandate vertreten.

85 Gemeint ist hier, dass die energieintensiven Unternehmen von den strompreissenkenden Effekten der erneuerbaren Energien profitieren, aber keine EEG-Umlage bezahlen. 
welle“, die „für die Menschen vor Ort eine Katstrophe“ wäre und „auch das Vertrauen in die Politik nachhaltig zerstören“ würde (LINKE 13.06.2013: 31587). Das nütze nur den „Stromgroßkonzernen“ und der Atomindustrie, denen sich die Koalition verpflichtet fühle, während sie „die Solarindustrie am ausgestreckten Arm verhungern“ lasse (LINKE 13.06.2013: 31587).

Die LINKE betrachtet auch die marktorientierten Novellierungen des EEG 2014 und 2016/2017 in der 18. Legislaturperiode als Hindernisse für die „Energiewende“, welcher sie im Verständnis ihres Narrativs des sozial-ökologischen Umbaus Bedeutung zuweist. Unter Rückgriff auf die Story-Line, welche die ,großen Vier' als Repräsentanten des herkömmlichen Energiesystems konstituiert, kritisiert sie politische Praktiken, die nach ihrer Auffassung Konzerninteressen bedienen („Lex RWE“) (LINKE 27.06.2014: 3934), und die im Sinne der Profitinteressen das weitere Betreiben von Kohlekraftwerken ermöglichen (LINKE 01.06.2016: 16977). Die Novellierung des EEG 2016/17 wird von Seiten der LINKEN als Gefahr für die Bürger*innenenergie konstituiert, weil sie „das Geschäft mit Erneuerbaren-Strom internationalen Fonds und Konzernen zu[schanze]“ (LINKE 01.06.2016: 16985) und Bürgerenergiegesellschaften durch ,windige Konstruktionen von Rechtsanwaltsbüros der großen Projektierer“ (LINKE 29.06.2017: 24988) ersetzt werden.

\section{Glücksverheißende Dimension}

Die PDS skizziert in der 14. und 15. Legislaturperiode eine positive Vision für einen ,ökologischen Umbau' und benennt dafür aus ihrer Sicht erforderliche politische Maßnahmen. Insgesamt müssten „32 Milliarden DM an ökologisch schädlichen Subventionen“ abgebaut werden und in einen „ökologischen Umbau“ fließen. Im Kohlebergbau wären „alternative Arbeitsplätze“ zu schaffen (PDS 25.11.1999: 6749). Die Mittel sollten quer über alle Haushalte, „beispielsweise für die Altbausanierung, für eine ökologische Verkehrswende, für die Förderung erneuerbarer Energien sowie für die Umweltforschung und internationale Klimaschutzmaßnahmen verwendet“ werden (PDS 25.11.1999: 6749). Letztlich erfordere der „ökologische Umbau“ aber eine Abkehr vom „Wachstumsmodell“ insgesamt, da auch technischer Fortschritt den zunehmenden Energiekonsum nicht auffangen könne (PDS 25.02.2000: 8436). Zudem sei ein sofortiger Atomausstieg notwendig, anders als im Rahmen des ,Atomkonsenses“ im Verständnis der Bundesregierung vorgesehen (PDS 14.12.2001).

Insgesamt fällt auf, dass in der glücksverheißenden Dimension das Narrativ des ,sozial-ökologischen Umbaus' relativ unspezifisch erscheint und der sozial-ökologische Umbau sowohl als Narrativ selbst, als auch als zukünftiges Ziel seiner Verheißung in Erscheinung tritt. Artikulationen zielen dabei oft auf spezifische politische Maßnahmen in Form einer Änderung politischer Praktiken in der Gegenwart ab. Erneuerbare Energien werden dabei als ein wichtiger Bestandteil des ökologischen Umbaus gesehen. Das EEG sei „eines der besten Gesetze im Umweltbereich“ (PDS 27.06.2002: 24775). Allerdings seien mehr Maßnahmen zum Energiesparen zu treffen (PDS 25.02.2000: 8436). Fossile Energien müssten durch eine, richtige ${ }^{\text {86 }}$ Ökosteuer verteuert werden. Zudem müsse der Strom-, Wärme- und Verkehrsbereich

86 Wie bereits ausgeführt wurde, kritisiert die PDS die Ökosteuer der rot-grünen Bundesregierung als sozial ungerecht und ökologisch wirkungslos. 
viel mehr betrachtet werden (PDS 25.02.2000: 8436). In der 16. Legislaturperiode fordert die LINKE eine ,radikale Energiewende hin zu erneuerbaren Energien“ (LINKE 02.07.2009: 25694), wodurch die „Energiewende“ im Verständnis des sozial-ökologischen Umbaus ebenfalls im Rahmen einer glücksverheißenden Dimension unter einem zeitlichen Zukunftsbezug positiv verortet wird. Eine Vollversorgung mit erneuerbaren Energien sei bis 2040 machbar (LINKE 02.07.2009: 25695).

Die mit der Story-Line ,Deutschland als Vorreiter“ verbundene Glücksverheißung spielt im Narrativ des ,sozial-ökologischen Umbaus' keine Rolle, stattdessen wird das internationale friedenspolitische Potenzial der erneuerbaren Energien im Sinne einer Verhinderung von Kriegen um Ressourcen in den Vordergrund gestellt. Das technologische Wissen müsse dabei mit Schwellen- und Entwicklungsländern geteilt werden (LINKE 02.07.2009: 25694). Auch in der 18. Legislaturperiode bleibt die LINKE bei diesen Forderungen (z.B. LINKE 01.06.2016: 16986).

Mit der Forderung nach einer Demokratisierung des Energiesektors als Teil eines sozial-ökologischen Umbaus projiziert die LINKE vor allem in der 16. und 17. Legislaturperiode eine weitere glücksverheißende Perspektive für die Zukunft, wiederum unterlegt mit gegenwartsbezogenen politischen Forderungen: Spekulationen sollen verboten, das Stromgeschäft zurück „,in die Hände der Stadtwerke“ gelegt, die Monopolwirtschaft beendet, ein Verbraucherbeirat institutionalisiert und die Kontrolle des Stromhandels in öffentliche Hand übertragen werden (LINKE 02.07.2009: 25876). Die Demokratisierung umfasse auch, dass die Stromnetze ,in öffentlicher Hand“ seien, und somit die Politik und „die Demokratie“ dafür ,zuständig“ (LINKE 24.03.2011: 11284). Ebenso wird „eine Dezentralisierung und Kommunalisierung“ der Energieversorgung gefordert, die Politik solle ,für die öffentliche Daseinsvorsorge zuständig“" sein (LINKE 24.03.2011: 11284). Im Zusammenhang mit der Verheißung der Demokratisierung des Energiemarktes kommt erneut ein Rückgriff auf die Story-Line der ,großen Vier“ zum Tragen. Die ,Zerlegung und, soweit es geht, eine Rekommunalisierung“ der großen Energiekonzerne wird gefordert (LINKE 30.06. 2011: 13378). Politik müsse von Lobbyismus unabhängig sein (LINKE 17.03.2011: 10898), damit Einigungen demokratisch erzielt werden können. Dabei spiele auch die Wissenschaft eine Rolle: Es müsse ein „Energiekonzept der Zukunft“ mit „unabhängigen Wissenschaftlerinnen und Wissenschaftlern, Umweltverbänden und kommunalen Energieversorgern erarbeitet werden“" (LINKE 17.03.2011: 10898).

\section{Implizit geteilte Annahmen und Klassifizierung}

Den mit dem fantasmatischen Narrativ des ,sozial-ökologischen Umbaus ‘ verbundenen Artikulationsmustern liegen implizit geteilte und positiv besetzte Annahmen über Umbau, Demokratisierung, sozial, ökologisch, sozial-ökologisch, etc. zu Grunde. Der Rahmen des Narrativs umfasst auch Annahmen über Marktwirtschaft, Wettbewerb, Liberalisierung oder Wachstum, die aber negativ konnotiert sind. Diese werden eher explizit artikuliert, um aus dem Feld der Gegen-Hegemonie heraus die Annahme ihrer Naturgegebenheit herauszufordern. Dennoch bleibt das Narrativ des ,sozialökologischen Umbaus“ im Rahmen des „Energiewende“ - Diskurses marginal und es gelingt nur in geringem Umfang die Bedeutungsaufladung von „Energiewende“ etwa im Hinblick auf eine Dezentralisierung des Strommarktes zu beeinflussen.

Die Hindernisse für den sozial-ökologischen Umbau als glücksverheißende Vision werden dabei intern verortet: Zum einen in der marktwirtschaftlichen Orientierung 
und der zunehmenden Privatisierung öffentlicher Daseinsvorsorge, zum anderen in der Ausrichtung der Politik an den (Profit-)Interessen der Wirtschaft, bzw. der Großunternehmen (die in einem Gegensatz zu den Interessen der Bürger*innen und zur Demokratie gestellt werden). Der gesellschaftliche Ist-Zustand ist daher negativ konnotiert, die glücksverheißende Dimension ist auf die Zukunft gerichtet. Der sozialökologische Umbau verweist auf eine zukünftige ,andere‘ Gesellschaftsordnung, auch wenn deren Gestaltung in vielen Teilen implizit bleibt. Stattdessen werden vielfach Forderungen, die auf eine verfahrenspolitische Ebene abzielen, artikuliert. Insgesamt bleiben die Konturen eines sozial-ökologischen Umbaus auch aufgrund der geringen diskursiven Verbreitung unscharf.

Die implizite Annahme globaler Ungleichverteilung, welche im Narrativ des ,sozial-ökologischen Umbaus` und teilweise auch dem der ,ökologischen Modernisierung` zu Tage tritt, ermöglicht es im Rahmen der schreckensverheißenden Dimension einen Gegenwartsbezug herzustellen und Konsequenzen des Klimawandels im globalen Süden sichtbar zu machen. Aber auch bezüglich dieser Dimension bleibt die diskursive Wirkung des Narrativs marginalisiert und wird vom hegemonialen Katastrophenszenario der ,Deindustrialisierung‘ überlagert.

Politische Praktiken, die sich im Kontext des Narrativs des ,sozial-ökologischen Umbaus' zeigen, sind in Anlehnung an Glynos/Howarth (2007) von ihrer Ausrichtung her als transformativ einzustufen, da die Hindernisse für die positive $\mathrm{Zu}$ kunftsperspektive ausschließlich system-intern - in dem Fall in der ökonomischen Struktur des Energiesektors - beschrieben werden. In der zeitlichen Perspektive der glücksverheißenden Dimension wird durch das Nennen verfahrenspolitischer Maßnahmen jedoch überwiegend ein Gegenwartsbezug hergestellt, wodurch im Rahmen des Narrativs auch als reformistisch ausgerichtet zu wertende politische Praktiken abgebildet werden. Deren Wirkung wird allerdings in der Intention als transformativ, auf ein nur ansatzweise skizziertes Zukunftsprojekt des sozialökologischen Umbaus ausgerichtet, dargestellt.

\subsection{ZUSAMMENFÜHRUNG UND DISKUSSION: POST-POLITIK DER „ENERGIEWENDE“}

In Kapitel 5.1.2 (Kollokationsanalyse) habe ich die regelmäßigen Differenzbeziehungen von „Energiewende“, herausgearbeitet und in Kapitel 5.1.3 die Entwicklung dieser Muster im Kontext der Klassifizierung von Forderungen und somit von Hegemonie diskutiert und zusammengeführt. In Kapitel 5.2 und 5.3 habe ich durch Analyse von Story-Lines komplexitätsreduzierende Erzählungen von „Energiewende“ nachgezeichnet, die Bedeutungskämpfe analysiert und schließlich durch Benennen und Beschreiben der fantasmatischen Narrative den Rahmen des „Energiewende“ - Diskurses auf der Ebene der Fantasie sichtbar gemacht. Bereits in der computerbasierten Analyse, welche die oberste Diskursebene adressiert, deutet sich eine Tendenz zur Reduktion des politischen Diskurses über erneuerbare Energien auf technologisch und ökonomisch orientierte Themenfelder an. Diese Tendenz festigt sich in den fol- 
genden beiden Analyseschritten, die auf die mittlere Ebene der Artikulationsmuster (Story-Lines) sowie auf die unterste Diskursebene der zugrunde liegenden Narrative abzielen. Demnach werden insbesondere verfahrenspolitische, technokratische und managementorientierte politische Praktiken mit „Energiewende“ in Verbindung gebracht. Erik Swyngedouw $(2015,2010,2011)$ zeigt, inwiefern der Klimawandel und die mit ihm zusammenhängenden Politikbereiche anfällig für post-politische Repräsentationen sind (vgl. auch Kenis/Mathijs 2014: 148). Dies werde ich nun in einer Diskussion anhand einiger Beispiele, die nach ihrem chronologischen Auftreten im Diskursverlauf geordnet werden, am „Energiewende“-Diskurs vertiefen, dadurch die Ergebnisse von Kapitel 5 zusammenführen und so die Relevanz post-politischer Repräsentationen für diese Ergebnisse herausarbeiten.

\section{Einführung von „Energiewende“ in den Diskurs als vor-politisches Element}

In der computerbasierten Analyse (Kapitel 5.1) wird deutlich, dass der Diskurs um „Energiewende“ in der 14. sowie 15. Legislaturperiode überwiegend von der rotgrünen Bundesregierung initiiert wird, aber schwach ausgeprägt ist und „Energiewende" im parlamentarischen Raum kaum mit Bedeutung aufgeladen wird. In Kapitel 5.1.3 habe ich gezeigt, dass „Energiewende“ vor „Fukushima“ kaum als Identifikationsprinzip kritischer Forderungen bedient wird - eine Politisierung von „Energiewende“ findet kaum statt, der diskursive Raum um „Energiewende“ bleibt unbestimmt. Von der rot-grünen Bundesregierung wird meist eine explizite Artikulation von „Energiewende“ vermieden, auch weil es innerhalb der Regierungskoalition differente Positionen gibt und eine grundsätzliche Wende in der Energiepolitik nicht als Konsens erscheint (vgl. Kapitel 5.2.1). Der Atomausstieg wird zwar von der rotgrünen Bundesregierung der 14. und 15. Legislaturperiode als „Einstieg in eine andere Energiepolitik“ interpretiert (vgl. z.B.: SPD 25.11.1999: 6742). Nur selten wird aber explizit gemacht, auf welche politische Praktiken eine ,andere Energiepolitik“ genau abzielt - ein Energiekonzept legt die rot-grüne Regierung nicht vor. Der Ausbau erneuerbarer Energien wird isoliert von „Energiewende“ als Moment im Diskurs fixiert, wobei die Diskussion darüber überwiegend ohne Einbettung in ein energiepolitisches Gesamtkonzept erfolgt. Aufgrund und im Sinne dieser mangelnden Bedeutungsgenerierung und somit nicht stattfindenden Politisierung von „Energiewende“ in der 14. und 15. Legislaturperiode spreche ich hier von einer vor-politischen „Energiewende“. Die „Energiewende“ hat den parlamentarischen Raum noch nicht oder noch kaum erreicht. ${ }^{87}$

Gleichzeitig dominieren in den mit „Energiewende“ verbundenen Themenbereichen wie erneuerbare Energien oder Klimaschutz sowie dem fantasmatischen Narrativ ,ökologischer Modernisierung' bereits in der 14. und 15. Legislaturperiode postpolitische Artikulationen. Das heißt, dass der Diskurs um erneuerbare Energien größtenteils auf einer verfahrenspolitischen Ebene verbleibt ohne naturalisierte Strukturen in Frage zu stellen. Umweltpolitische Bezüge zeigen sich in der Kollokationsanalyse (vgl. Kapitel 5.1.2) erneuerbarer Energien überwiegend im Knotenpunkt „Klima-

87 Die Bezeichnung, vor-politisch' bezieht sich also rein auf den parlamentarischen Raum. Innerhalb sozialer Bewegungen würde die Analyse sicherlich anders ausfallen. 
schutz", während andere ökologische Aspekte nicht adressiert werden. Das fantasmatische Narrativ der ,ökologischen Modernisierung“ stellt die Energiepolitik nicht grundsätzlich in Frage, sondern zielt vor allem auf ein ökologisch regulierendes Eingreifen in die Marktwirtschaft ohne an grundsätzlichen Strukturen von Wirtschaftsund Gesellschaftsordnung anzusetzen, weswegen die politischen Praktiken, die sich aus dem Narrativ ableiten, als reformistisch klassifiziert wurden. Als glücksverheißende Zukunftsperspektive dient das Versprechen, die Stärkung der Volkswirtschaft mit einer ökologischeren Wirtschaftsweise zu verbinden. Dabei stehen marktwirtschaftlich-technische Bereiche im Vordergrund (vgl. Kapitel 5.3.1). Die Bedeutung der Technologie erneuerbarer Energien als Wirtschaftsfaktor für die gesamte Volkswirtschaft ist die argumentative Grundlage für die Rechtfertigung ihrer Förderung und daher eine wichtige Story-Line (vgl. Kapitel 5.2.3). Das Ziel der Förderung wird dabei ebenfalls von Anfang an marktorientiert eingebettet, das EEG als Marktanreizprogramm konstituiert (vgl. Kapitel 5.2.4). Insgesamt zeigt sich eine technokratisch-managementorientierte Ausrichtung, ökologischer Modernisierung ' unter dem Motto: „we have to change radically, but within the contours of the existing state of the situation" (Swyngedouw 2015: 4). Eine solche Politik ist von einem konsensualen Charakter geprägt, der sich auch in der breiten Zustimmung über alle Fraktionen zeigt, die in der 14. und 15. Legislaturperiode bezüglich der Förderung erneuerbarer Energien herrscht. Differenzen zeigen sich überwiegend in der verfahrenspolitischen Umsetzung der Förderung (vgl. z.B. CSU 25.02.2000: 8440; Kapitel 5.2.2) ${ }^{88}$

Der Klimawandel mit seinen Auswirkungen wird dabei zum Katastrophenszenario stilisiert, aus dem die Notwendigkeit einer ökologischen Modernisierung abgeleitet wird (vgl. Kapitel 5.3.1). Die Folgen des Klimawandels werden explizit allerdings nur an wenigen Stellen benannt, zum Beispiel in Form von Katastrophenszenarien (z.B. SPD 28.05.2004: 10247) (vgl. Kapitel 5.3.1). Hier wird eine apokalyptische Bedrohung skizziert, die die Dringlichkeit des Handelns in den Mittelpunkt stellt: „Wenn wir jetzt nicht handeln [...] geht uns [...] im wahrsten Sinne des Wortes die Luft aus“ (SPD 28.05.2003: 10234; vgl. Kapitel 5.3.1). Eine Zentralität von Angst kann allerdings zu einer Beschränkung des politischen Raums führen:

„The point is that when fear becomes the overwhelming sentiment, the space for asking fundamental political questions about our current society is strongly restrained. This situation can then be manipulated to impose an apparently broad consensus concerning a set of technocratic and market-driven measures“ (Kenis/Mathijs 2014: 152).

Dem schreckenserzeugenden Katastrophenszenario des Klimawandels wird andererseits keine positive Vision einer ,anderen Zukunft', einer , anderen Gesellschaft ${ }^{\star}$ entgegengestellt. Die glücksverheißende Dimension des fantasmatischen Narrativs ,ökologischer Modernisierung' zielt auf einen Erhalt der jetzigen Lebensumstände (vgl. Kapitel 5.3.1). Swyngedouw (2010: 219) spricht im Anschluss an Derrida (1992: 66)

88 Ein Dissens besteht zwar bezüglich des „Atomausstiegs“, den CDU, CSU und FDP als Gefahr für den „Standort Deutschland“ konstruieren (vgl. z.B.: CDU 14.12.2001: 20711; vgl. Kapitel 5.2.3), aber auch dieser wird - wie oben dargestellt von der rot-grünen Koalition nicht zwingend mit einem grundsätzlichen Wandel der Energiepolitik verbunden. 
von ,purer Negativität“. Gleichzeitig werden die Ursachen des Klimawandels in den Debatten kaum explizit genannt und nicht mit möglichen strukturellen Ursachen, bspw. innerhalb des ökonomischen Systems, kontextualisiert. So werden selbst dann, wenn von Klimaschutz oder Klimawandel die Rede ist, meist kaum politische Inhalte oder Strukturen adressiert.

Gleichzeitig scheint die Feststellung der Existenz des Problems ,Klimawandel Konsens zwischen allen im Zeitraum der Untersuchung im Bundestag vertretenen politischen Fraktionen zu sein. Die Bedeutung der Forderungen ,Klimaschutz' und ,erneuerbare Energien' bleibt zwischen den äquivalentiellen Fronten zwischen Befürwortung und Ablehnung einer „Energiewende“ somit unbestimmt (Laclau 2005: 132; vgl. Kapitel 5.1.3), sie sind nicht in eine starke kritische Äquivalenzkette eingebunden. Der Klimawandel erscheint so als Problem , an sich‘. Durch diese Externalisierung des Konfliktes um Klimaschutz auf ein „sozial entkörpertes [eig. Übersetzung]", da nicht im Kontext seiner sozial-ökologischen Verursachung thematisierten, $\mathrm{CO}_{2}$ erscheinen alle Akteur*innen in diesem Kampf vereint - es kommt zu einer „pseudo-Politisierung [eig. Übersetzung]“ (Kenis/Mathijs 2014: 151). Dies zeigt sich bspw. in der Diskussion um den Emissionshandel in der 15. Legislaturperiode, der prinzipiell breite Befürwortung findet und mit dem der Klimaschutz „effizient“ gemacht werden soll (GRÜNE 28.05.2004: 10237) ohne grundsätzliche ökonomische Strukturen zu verändern. Swyngedouw (2015: 5) argumentiert, dass es gerade die konsensuale Konstruktion von Klimaschutz sei, die für einen Entpolitisierungsprozess stehe. So werde einerseits das Ökologische, repräsentiert durch das Klima, politisch mobilisiert, während gleichzeitig die Sorge um das Klima die politische Dimension dadurch außer Kraft setze, dass die Mobilisierung ohne grundsätzliches - über eine verfahrenspolitische Ebene hinausgehendes - politisches Ziel erfolge (ebenda: 2). Die strukturellen, systembedingten Ursachen für den Klimawandel - geschweige denn anderer ökologischer Probleme - werden nicht thematisiert. Diese Tendenz der Entpolitisierung des Diskursgegenstandes lässt sich anhand der drei Analyseschritte für den „Energiewende“ - Diskurs nachzeichnen, wobei sie sich mit fortschreitendem Analyseprozess verstetigt. Nach Swyngedouw (2011: 258f.) bleibe die Natur somit letztlich ,extern'; das ,Andere' des Politischen - der politische Gehalt von ,Natur' werde geleugnet. Es handele sich um einen Vorgang der Entpolitisierung par excellance.

Stattdessen zeigt sich in der Analyse der Story-Lines eine Dominanz marktwirtschaftlicher, auf technischen Fortschritt sowie globalen Wettbewerb gerichteten Erzähl- und Deutungsmuster. So wird mit dem Emissionshandel, der Ökosteuer, dem EEG und anderen politischen Maßnahmen nach möglichst wirtschaftsfördernden (vgl. Kapitel 5.2.3), marktwirtschaftlich orientierten (vgl. Kapitel 5.2.4) oder ,preisgünstigsten“ (SPD 28.05.2004: 10247) Lösungen gesucht. Während eine Politik des Politischen den Klimawandel als Krisensymptom des ,Normalen“ sehen und die diesbezügliche Differenz in den politischen Fantasien herausarbeiten würde, bestehe der hegemoniale politische Diskurs auf eine Interpretation von Klimawandel als Anomalie des Systems, der durch ,eine Mobilisierung der inneren Dynamiken und Logiken des System, welches das Problem ursprünglich hervorgerufen habe [eig. Übersetzung]“, vorgebeugt werden solle (Swyngedouw 2011: 268f.). So werden die sozial-ökologischen Verhältnisse und Prozesse, durch die der Klimawandel verursacht werde, radikal verleugnet (Swyngedouw 2010: 222f.). 
Ein weiterer entpolitisierender Faktor des aufkommenden „Energiewende“Diskurses folgt aus seiner globalen Einordnung (vgl. Kapitel 5.2.6). So scheint zwischen der 14. und 16. Legislaturperiode „Energiewende“ vor allem dann relevant zu werden, wenn ein internationaler Kontext im Fokus steht, bspw. im Vorfeld der Renewables2004 Konferenz ${ }^{89}$ (vgl. Kapitel 5.1.2). Dabei wird die politische Verantwortung globalisiert (vgl. z.B. SPD 28.05.2004: 10234). Eine „Energiewende“ erscheint so als Projekt, das vor allem global eingeführt werden muss - und zwar am besten mit deutscher Technologie und deutschem Wissen (vgl. Kapitel 5.2.6). Die Notwendigkeit einer globalen „Energiewende“ wird aus dem Klimawandel sowie dem wachsenden Ressourcenverbrauch als universale humanitäre Bedrohung abgeleitet. ,Die Menschen' werden dabei nicht als heterogene Subjekte konstituiert, sondern als universale Opfer (Swyngedouw 2010: 221): „denn wegen der Emissionen und des Wettlaufs um knappe fossile Ressourcen gibt es für alle Menschen auf diesem Globus nur eine gemeinsame Zukunft“ (SPD 28.05.2004: 10234). Dabei werden konstitutive soziale Differenzen verschwiegen. Das universale politische Subjekt ,Mensch“ wird im Kontext eines antagonistischen Kampfes Klima vs. Mensch (Swyngedouw 2010: 221) bestimmt - alternative mögliche sozial-ökologische Konstellationen bleiben so außerhalb der Betrachtung, da jede andere antagonistische Spaltung verdeckt wird. Es scheinen zwar nicht alle Menschen im gleichen Ausmaß vom Klimawandel betroffen und für ihn verantwortlich, doch bleibt die Menschheit letztlich in ihrer grundsätzlichen Betroffenheit und Verantwortung vereint:

„Bisher hat ein Drittel der Welt, 2 Milliarden Menschen, keinen Zugang zu moderner Energie. [...]. Dabei ist aber eines klar: Entwicklungsländer dürfen und wollen nicht die Fehler wiederholen, die die Industrieländer bisher bei ihrer Energieversorgung gemacht haben, denn das hält unser Globus nicht aus“ (SPD 28.05.2004: 10234).

Letztlich wird durch die Gegenüberstellung Klima vs. Mensch die Mensch/Natur Dichotomie reproduziert (Swyngedouw 2011: 268f.; Smith 2008: 245) und vorherrschende gesellschaftliche Naturverhältnisse perpetuiert, was in Kapitel 6 in Bezug auf den Gesamtdiskurs noch genauer betrachtet wird. Globale Machtverhältnisse werden - hier zwischen ,Entwicklungsländern` und Industrieländern - naturalisiert und somit verdeckt. Das Verdecken des politischen Gehalts dieser Verhältnisse trägt zur Entpolitisierung des gesamten Diskurses bei. Auch dies wird in Kapitel 6.4 noch genauer betrachtet.

\section{Vermischung der fantasmatischen Narrative, ökologischer Modernisierung“ und ,marktwirtschaftlicher Energiepolitik}

Nachdem „Energiewende“ unter der rot-grünen Regierungskoalition also einerseits kaum politisiert wurde und andererseits gleichzeitig in den mit ihr in Verbindung gesetzten Themenbereichen und Forderungen post-politische Vorstellungen dominieren, verschwindet sie in der 16. Legislaturperiode fast gänzlich aus den bundespolitischen Debatten. Die große Koalition knüpft aber vielfach an die Artikulationsmus-

89 Die Anzahl der Vorfälle von „Energiewende“ in dieser Debatte ist die höchste der gesamten 15. Legislaturperiode (vgl. Tabelle 4 in Kapitel 4.2.2). 
ter/Story-Lines und Forderungen des Narrativs der ,ökologischen Modernisierung، an. Allerdings spricht sie dabei nicht explizit von ökologischer Modernisierung, sondern setzt die erneuerbaren Energien in den Kontext eines ,breiten Energiemixes“ und verwendet dabei den Begriff der ,Nachhaltigkeit' (vgl. Kapitel 5.2.1). So wird das zentrale Versprechen des fantasmatischen Narrativs ,ökologischer Modernisierung ' - die Vereinbarkeit von (markt)wirtschaftlichen und ökologischen Zielen -von der CDU/CSU durch Einbindung in die eigenen Äquivalenzketten angeeignet. Erneuerbare Energien sollen zum Bestandteil ,Sozialer Marktwirtschaft' werden (CDU 02.07.2009: 25872).$^{90}$ Spätestens in der 16. Legislaturperiode wird deutlich, dass sich die fantasmatischen Narrative ,ökologische Modernisierung' und ,marktwirtschaftliche Energiepolitik' hinsichtlich ihrer verfahrenspolitischen, technokratisch-managementorientierten Ausrichtung politischer Praktiken aneinander angleichen. Sie unterscheiden sich überwiegend im Stellenwert, der umweltpolitischen Themen innerhalb der auf Verfahrenspolitik beschränkten Dimensionen des Glücks zugewiesen wird, und in ihren Katastrophenszenarien (Folgen des Klimawandels vs. Deindustrialisierung) (vgl. Kapitel 5.3). Aufgrund der abnehmenden Artikulation ,ökologischer Modernisierung' (vgl. Abbildung 13) sowie der Aneignung von Artikulationsmustern durch das marktwirtschaftliche Narrativ, vermischen sich die fantasmatischen Narrative zunehmend.

In der 17. Legislaturperiode greift dann auch die FDP den Kern des Versprechens ,ökologischer Modernisierung ‘ - die Vereinbarkeit von ökologischen und (markt)wirtschaftlichen Zielen - auf. Dabei werden von der schwarz-gelben Koalition auch die wirtschaftlichen Gefahren, die vom Klimawandel ausgehen, hervorgehoben, während ökologische und soziale Krisenszenarien weiterhin ausgeblendet werden. Klimaschutz sei notwendig, um den Industriestandort nicht in seiner Wettbewerbsfähigkeit zu gefährden (17/3049: 2; vgl. Kapitel 5.3.2). Zur Rechtfertigung der Laufzeitverlängerung bindet die schwarz-gelbe Regierungskoalition Forderungen, die mit „Energiewende“ (z.B. „Umbau unseres Energieversorgungssystems“ (CDU 28.10. 2010: 7168)) und ,ökologischer Modernisierung“ (,das größte Modernisierungsprogramm für eine gesamte Volkswirtschaft“ (FDP 28.10.2010: 7201)) in Verbindung stehen in ihre Äquivalenzketten ein. Mit der Kernenergie als ,Brückentechnologie“ wird der Anschein erweckt, dass Klima und Wirtschaft auf einmal gerettet werden können (vgl. auch Swyngedouw 2011: 270f.). Die schwarz-gelbe Koalition durchbricht dabei die antagonistische Grenze zwischen Befürwortung und Gegnerschaft

90 Dennoch kommt es im Vorfeld der Bundestagswahl 2009 zumindest kurzzeitig zu einer Repolitisierung des Diskurses um „Atomausstieg“ und damit verbunden der Energiepolitik. Mit der CDU und der CSU sind zwei Parteien an der Regierung, die weiterhin offiziell erklären, den „Atomausstieg“ rückgängig machen zu wollen. GRÜNE und LINKE und im Vorfeld der Wahl auch die SPD konstituieren darüber hinaus zunehmend die, großen vier Energiekonzerne“ als Gefahr für den „Atomausstieg“ sowie für eine nachhaltige Energiepolitik. CDU/CSU und FDP werden dabei in ihrer Politik mit den Interessen dieser Konzerne äquivalenziert (vgl. z.B. SPD 02.07.2009: 25880). Dabei wird das Bild eines vermeintlichen Konsenses über den Ausbau der erneuerbaren Energien, das noch zu Beginn der großen Koalition der 16. Legislaturperiode auch von der SPD bedient wurde, durchbrochen (vgl. Kapitel 5.2.10). 
einer „Energiewende“ gezielt (vgl. Kapitel 5.1.3, Abbildung 11) und verschiebt diskursive Elemente über diese Grenze hinweg (vgl. auch Nonhoff 2006: 234).

In der Äquivalenzierung von ,,ideologiefrei“, „,marktorientiert“ und „technologieoffen“ (17/3050: 8) zeigt sich die entpolitisierende Wirkung des fantasmatischen Narrativs ,marktwirtschaftlicher Energiepolitik' deutlich (vgl. Kapitel 5.3.2). Diese wird durch die Konstruktion eines vermeintlichen (nationalen) Konsenses verstärkt: Die Energiepolitik als „Lebensader unserer Gesellschaft“ sollte „kein Streitthema“ sein, sondern ein gemeinsames Thema, ,weil wir dem Land zu dienen haben“ (CDU 28.10.2010: 7178). Eine Politisierung der Debatte durch die Opposition wird so als ,ideologisch “ und interessengeleitet delegitimiert, während die Prämissen der schwarz-gelben Politik naturalisiert werden. Letztlich wird eine Differenz zu den Zielsetzungen der Opposition bestritten: „Ich glaube sogar - weil wir so viel streiten und weil es hier in dieser Debatte so einen großen Streitgestus gibt -, dass das in Wahrheit ein Konsens in diesem Haus ist, dass wir das alle wollen" (CDU 28.10. 2010: 7178).

\section{Entpolitisierende Diskursmuster nach „Fukushima“}

„Fukushima“ ist eine Dislokation für diesen Diskurs, da es die Verknüpfung von ,technologieoffen', ,ideologiefrei' und ,Vernunft' unterminiert. Durch Reartikulation, d.h. durch die Herstellung neuer diskursiver Verknüpfungen, gelingt aber die Einbindung von „Energiewende“ in die hegemoniale Formation, wie in Kapitel 5.1.3 gezeigt wurde. Dabei lassen sich im Laufe der Analyseschritte im Wesentlichen drei Deutungsmuster ausmachen, die darauf zielen, das Postulat der Ideologiefreiheit für die eigene Politik nach „Fukushima“ zu erhalten, bzw. wiederherzustellen.

Erstens: „Fukushima“ wird als die erste nukleare Katastrophe konstituiert, die auf unerwartbares technisches Versagen (nicht auf menschliches) zurückzuführen (z.B. FDP 09.06.2011: 12967) und wissenschaftlich nicht vorhersehbar gewesen sei (Angela Merkel 17.03.2011: 10884). Die Ursache für die Dislokation wird so in einem ,Außen` gesucht, die Laufzeitverlängerung ihrem politischen Zusammenhang entzogen: Die Ursache von „Fukushima“ liege in einem technischen Versagen, das unabhängig von den politischen Akteur*innen zu bewerten sei und nun zu einer ,neuen Lage' führe: „Wenn das so ist, wenn also in einem so hoch entwickelten Land wie Japan das scheinbar Unmögliche möglich, das absolut Unwahrscheinliche Realität wurde, dann verändert das die Lage“ (Angela Merkel 17.03.2011: 10884f.). Um dieser ,neuen Lage' gerecht zu werden, wird in der Folge Expert*innen für energiepolitische Entscheidungen eine herausragende Rolle zugewiesen (vgl. Kapitel 5.2.9). Die Möglichkeit eines technischen Versagens in einem hochindustrialisierten Land erfordere eine Neubewertung unter wissenschaftlichen Gesichtspunkten. Diese Neubewertung erfolgt zunächst durch die ,Ethikkommission Sichere Energieversorgung ${ }^{6}$. Es erfolgt also eine Verschiebung aus dem Bereich des Politischen in die Wissenschaft. So erscheint die Entscheidung zum Atomausstieg in Verbindung mit der „Energiewende" als wissenschaftliche und weniger als politische Frage. Wissenschaftliche Expertise wird zur Garantie und Grundlage für die ,richtige“ politische Entscheidung erhoben (Swyngedouw 2010: 217). Die wissenschaftliche Neubewertung führt im nächsten Schritt zur Stilisierung der „Energiewende“ als ,neuer Konsens“.

Zweitens: Die „Energiewende“ wird als nationaler Konsens konstruiert: „Insofern ist es richtig, gemeinsam in einem gesellschaftlichen Konsens, mit der Ethik-Kom- 
mission und allen beteiligten gesellschaftlichen Gruppen, den Beschluss zu fassen, nach 2022 auf die Kernenergie zu verzichten“ (FDP 09.06.2011: 12967). Als handelndes Subjekt wird eine konstruierte nationale Gemeinschaft eingesetzt („Die Deutschen“ (CDU 30.06.2011: 13371); „Wir alle“ (Angela Merkel 09.06.2011: 12963)). Nach „Fukushima“ trägt der nationale Mythos, der nun mit „Energiewende“ verbunden wird (Angela Merkel 09.06.2011: 12963f.) dazu bei, Gegner*innen der „Energiewende“ zu integrieren - die identitätsstiftende Funktion der „Energiewende“ für „Deutschland“ gewinnt nun an Bedeutung (vgl. Kapitel 5.1.3). Gerade dadurch, dass die Knotenpunkte „Deutschland“ und „Energiewende“ offen sind für verschiedene Projektionen der politischen Fraktionen und ihrer jeweiligen Positionen, entsteht eine konsenserzeugende, entpolitisierende Wirkung (vgl. Kapitel 5.1.3; 5.2.6). Es wird eine gesellschaftliche Einigkeit konstruiert, bestehende Konflikte werden verdeckt und so eine Schließung des Diskurses verheißen (vgl. z.B. CDU 30.06. 2011: 13369). Hier wird also bereits kurz nach „Fukushima“ der Dissens über die grundsätzliche Gestaltung der „Energiewende“ aus dem vermeintlich konsensualen politischen Raum gedrängt. „Energiewende“-Politik wird auf eine verfahrenspolitische Ebene innerhalb gegebener Strukturen reduziert.

Drittens: Was innerhalb dieses, ,neuen Konsenses' als ,richtig' gilt, soll nicht durch ,Ideologie', sondern durch ,Vernunft' bestimmt werden. Während das Energiekonzept von schwarz-gelb ,vernünftig[...]“ sei, habe die rot-grüne Bundesregierung bei ihrem „Ausstiegsbeschluss einfach nur Ihre Ideologie befriedigt“ (FDP 09.06.2011: 12967). Wie zuvor die Kernenergie wird nun „Energiewende“ in einer Äquivalenzkette mit ,Vernunft', ,Marktorientierung' und ,Ideologiefreiheit' reartikuliert und so ihre marktorientierte Einbindung naturalisiert ${ }^{91}$ (vgl. Kapitel 5.2.4): „Das zeigt, wie weit Sie vom Markt, von der Realität und von ökonomischer Vernunft entfernt sind, meine Damen und Herren [...]. Wir treiben die Energiewende voran mit wirtschaftlicher Vernunft und sozialer Verantwortung“ (CDU 29.03.2012: 20307).

\section{Ausgrenzung des Ökologischen und des Sozialen aus dem diskursiven Raum nach „Fukushima“}

Die Probleme ,Klimawandel‘ und ,Atomausstieg‘ werden im Rahmen der „Energiewende“ zur ökonomischen Chance uminterpretiert, während Machtverhältnisse, z.B. zwischen Geschlechtern, Klassen und Weltregionen oder Produktionsverhältnisse aus dem politischen Raum gedrängt werden. Bereits in Kapitel 5.1.3 wurde gezeigt, dass

91 Politische Forderungen, die nicht mit einem solchen Verständnis der „Energiewende“ kompatibel sind, werden als, ideologisch', ,unwirtschaftlich“, ,emotional“ oder ,sozialistisch` abgespalten und abgewertet. Dies wird beispielsweise deutlich, als die LINKE 2012 fordert, die Befreiung der energieintensiven Industrie von der EEG-Umlage zu begrenzen: „Bei den ideologischen Ergüssen und sozialistischen Ausarbeitungen Ihrerseits fällt es manchmal schwer, gelassen zu bleiben, [...]. Meine Damen und Herren, ich weiß, dass Sie Probleme mit dem demokratischen Rechtsstaat und dem demokratischen System haben. Aber nicht Sie entscheiden über Recht und Unrecht; [...] Darüber entscheidet auch kein ZK oder Politbüro, sondern dieses Haus [...]. Meine Damen und Herren, wir haben es nicht nötig, uns mit solchen Leuten auf Anti-Marktwirtschafts-Debatten einzulassen“ (CDU 29.03.2012: 20292f). 
relativ schnell eine Begrenzung des diskursiven Raumes gelingt, was sich in der weiteren Analyse in der ökonomischen Ausrichtung der Story-Lines zeigt und durch Aussagen wie „Energiepolitik ist Wirtschaftspolitik“ (CSU 13.06.2013: 31584) reproduziert wird (vgl. Kapitel 5.2.3). Nonhoff (2007: 188) bezeichnet eine solche hegemoniale Strategie als „superdifferenzielle Grenzziehung“, die dazu führe, dass „,einzelne diskursive Elemente oder ganze Diskursregionen aus der Zugehörigkeit zu einem bestimmten diskursiven Raum verbannt [werden], indem ihre Differenz in gewisser Weise ,verstärkt" wird“. In diesem Fall werden bspw. „Sozial- und Arbeitsmarktpolitik“ (CSU 13.06.2013: 31584) explizit aus dem diskursiven Raum der Energiepolitik ausgeschlossen. Mit dieser Strategie wird die Ausbildung von „Energiewende“ als diskursivem Gegenstand grundlegend geprägt und die „Voraussetzung für die Möglichkeit von hegemonialer Praxis“ geschaffen (Nonhoff 2007: 188), die „Energiewende“ als ein (markt)wirtschaftspolitisches Feld konstituiert. ${ }^{92}$

Vor diesem Hintergrund erklärt sich auch, weshalb die vermeintlich hohen Kosten der „Energiewende“ eine zunehmend zentrale Rolle spielen, während sozialökologische Themenbereiche und Handlungsfelder im Hintergrund bleiben (vgl. Kapitel 5.2.5; vgl. auch Kapitel 5.1.2). Zudem erfolgt implizit eine diskursive Reduktion von „Energiewende“ auf den Strombereich. Darüber hinausgehende Bereiche wie die Wärmeversorgung oder der Verkehrsbereich werden vergleichsweise selten adressiert - eine energiepolitische Wende in diesen Bereichen scheint mit marktwirtschaftlichen Zielen schwieriger vereinbar zu sein. So erklärt die CDU mobilitätspolitische Ziele nicht gegen die Industrie durchsetzen zu wollen, denn es gehe ,nicht gegen den Markt, es geht nur mit dem Markt“" (CDU 13.06.2013: 31303).

Solche Grenzziehungen werden von den Oppositionsfraktionen nur unzureichend herausgefordert: Obwohl sich SPD und GRÜNE in einigen verfahrenspolitischen Positionen deutlich von der schwarz-gelben Regierungskoalition abgrenzen (z.B. Ausbauziele, Förderhöhe, Gestaltung der Einspeisevergütung), werden grundsätzliche marktwirtschaftliche Zielsetzungen von ihnen kaum in Frage gestellt und soziale sowie ökologische Themen in Verbindung mit „Energiewende“ zu selten gesetzt.

\section{Etablierung eines ,technokratisch-managementorientierten Ökokonsenses“}

In der 18. Legislaturperiode, in der die große Koalition das Ziel der Marktorientierung mit den Novellierungen des EEG offensiv weiter verfolgt, etabliert sich die marktwirtschaftliche Einbindung von „Energiewende“ weiter (vgl. Kapitel 5.2.4). Obwohl GRÜNE und LINKE die jeweilige Regierungspolitik kritisieren, bleibt die Artikulation einer ,anderen“ „Energiewende“ weitgehend aus. Nach „Fukushima“ werden grundlegende Glücks- und Katastrophenszenarien des fantasmatischen Narrativs ,ökologischer Modernisierung' auch von den GRÜNEN kaum noch bedient. Ihre Kritik an der Regierungspolitik beschränkt sich überwiegend auf die verfahrenspolitische Ebene. Die fantasmatischen Narrative ,ökologischer Modernisierung und ,marktwirtschaftlicher Energiepolitik` gehen damit in einem gemeinsamen ,technokratisch-managementorientierten Ökokonsens` auf, indem die Herausarbeitung von

92 Dies zeigt sich gegen Ende der 17. Legislaturperiode bspw. in der strikten Ablehnung der ,Rettung' der Solarindustrie (vgl. Kapitel 5.2.3). 
grundsätzlicher Differenz zwischen den Narrativen aufgegeben wird (vgl. Abbildung 14). ${ }^{93}$ Der ,technokratisch-managementorientierte Ökokonsens' kann nun als gemeinsames fantasmatisches Narrativ einer hegemonialen marktwirtschaftlichen Formation gewertet werden. ${ }^{94}$ Dieser ,Ökokonsens ${ }^{6}$ basiert zwar auf umweltpolitischen Forderungen, indem umweltpolitische Artikulationsmuster diskursiv angeeignet werden, gleichzeitig werden diese Forderungen aber permanent aus dem Bereich des Politischen in den Hintergrund gedrängt. Ihre Erfüllung wird der marktorientierten Verheißung des Erhalts von ,Wachstum und Wohlstand' untergeordnet.

Auch anhand der Debatte über den Ausbau der Netzinfrastruktur in der 17. und 18. Legislaturperiode lässt sich verdeutlichen, wie der Diskursrahmen durch den ,technokratisch-managementorientierten Ökokonsens“ determiniert wird. Die Netzinfrastruktur wird als „Dreh- und Angelpunkt“ (FDP 28.10.2010: 7201) der „Energiewende“ konstituiert. Die Planung der „Energiewende“ wird zum technischen Infrastrukturprojekt stilisiert. Die Debatte darüber orientiert sich zunehmend an großen Energie-Produktionszentren, bspw. im Rahmen von Offshore-Windenergie. Diskurse, die danach fragen, wie sozial-ökologische Anliegen mit technischen Herausforderungen integriert werden können, bleiben marginal (z.B. LINKE 01.06.2016: 16985f.; vgl. Kapitel 5.2.7).

Gleichzeitig wird der Netzausbau in der 18. Legislaturperiode zunehmend als Problem der „Energiewende“ konstituiert - er könne nicht mit dem Ausbau Schritt halten (vgl. Kapitel 5.2.7). Mit Artikulationen wie ,Überförderung` oder ,Ausbaukorridor' wird ein verlangsamter Umstieg auf erneuerbare Energien gefordert (vgl. Kapitel 5.2.2), die Artikulationen von „Energiewende“ durch SPD, CDU und CSU sind zunehmend von Ambivalenzen geprägt (vgl. Kapitel 5.3.2). So wird die „Energiewende" selbst Teil der schreckensverheißenden Dimension, indem bspw. der Eindruck erweckt wird, sie sei zu teuer, verursache eine „Kostenexplosion“ (z.B.: SPD 10.04.2014: 2433; Koalitionsvertrag 2013: 38) und schade der Wirtschaft (vgl. Kapitel 5.2.5; 5.3.2). Die SPD fordert vor dem Hintergrund des Katastrophenszenarios einer „Deindustrialisierung“ (SPD 27.06.2014: 3939f.) eine wirtschaftsorientierte „Energiewende“-Politik. Sie gibt in der 18. Legislaturperiode die Differenz zu wirt-

93 Dies bedeutet nicht, dass von den Akteur*innen, die innerhalb dieser Muster artikulieren, dieselben Interessen verfolgt werden. Es geht hier lediglich darum die diskursiven Muster in ihrer Wirkung zu betrachten und zu klassifizieren (vgl. dazu auch Kapitel 7.5). Es handelt sich also lediglich um einen scheinbaren Konsens, der durch eine Aneignung ökologisch orientierter Artikulationsmuster auf der einen Seite und eine fehlende Herausarbeitung der Differenz auf der anderen Seite erzeugt wird. Auch wenn es sich also nicht um einen ,tatsächlichen Konsens‘ im Sinne eines Konsenses über politische Ziele oder Interessen handelt, entsteht im Diskurs der Anschein und mindestens teilweise auch die Wirkung eines solchen.

94 In Kapitel 5.1.3 habe ich gezeigt, dass sich die hegemoniale Formation, welche ich über ihre Abgrenzung zur „Energiewende“ definiert habe, nach „Fukushima“ den Knotenpunkt „Energiewende“ artikulatorisch aneignet. Dadurch ergibt sich eine (auch bezüglich der in ihr wirkenden Akteur*innen) erweiterte hegemoniale Formation, die sich vor allem durch die regelmäßige marktwirtschaftliche Einbindung von „Energiewende“ auszeichnet und, die ich daher hier als hegemoniale marktwirtschaftliche Formation bezeichne. 
schaftsliberalen Positionen - und somit wie gezeigt auch das von ihr mitinitialisierte Narrativ einer, ökologischen Modernisierung - weitgehend auf und schließt sich dem Diskurs einer konsensualen, ,vernünftigen“ „Energiewende“ im Gegensatz zu „,ideologischen Kampfparolen“ an (SPD 01.06.2016 16979; vgl. Kapitel 5.2.3). Hier zeigt sich: Die diskursive marktwirtschaftliche Einbindung von „Energiewende“, die einerseits als Lösung präsentiert wird, bietet gleichzeitig die Grundlage für ihre Delegitimation. Anstatt sozial-ökologischer Krisen oder den Folgen des Klimawandels, bestimmen mit der auf diese Weise ,sozial-ökologisch entbetteten“ „Energiewende“ selbst in Verbindung gebrachte Risiken, bspw. in Form einer Bedrohung für die Wirtschaft, das Katastrophenszenario. ,Andere“ Perspektiven auf die „Energiewende“, werden als "sozialistische[...] Industriepolitik“ (CSU 13.06.2013: 31585), „wie in der DDR“ (CDU 24.03.2011: 11284) delegitimiert (vgl. Kapitel 5.3.2) und als extern verortete Gefahr für eine marktwirtschaftliche Energiepolitik herangezogen.

\section{Abbildung 14: Vermischung der fantasmatischen Narrative}

,ökologische Modernisierung ' und , marktwirtschaftliche Energiepolitik ‘ im ,technokratisch-managementorientierten Ökokonsens ‘

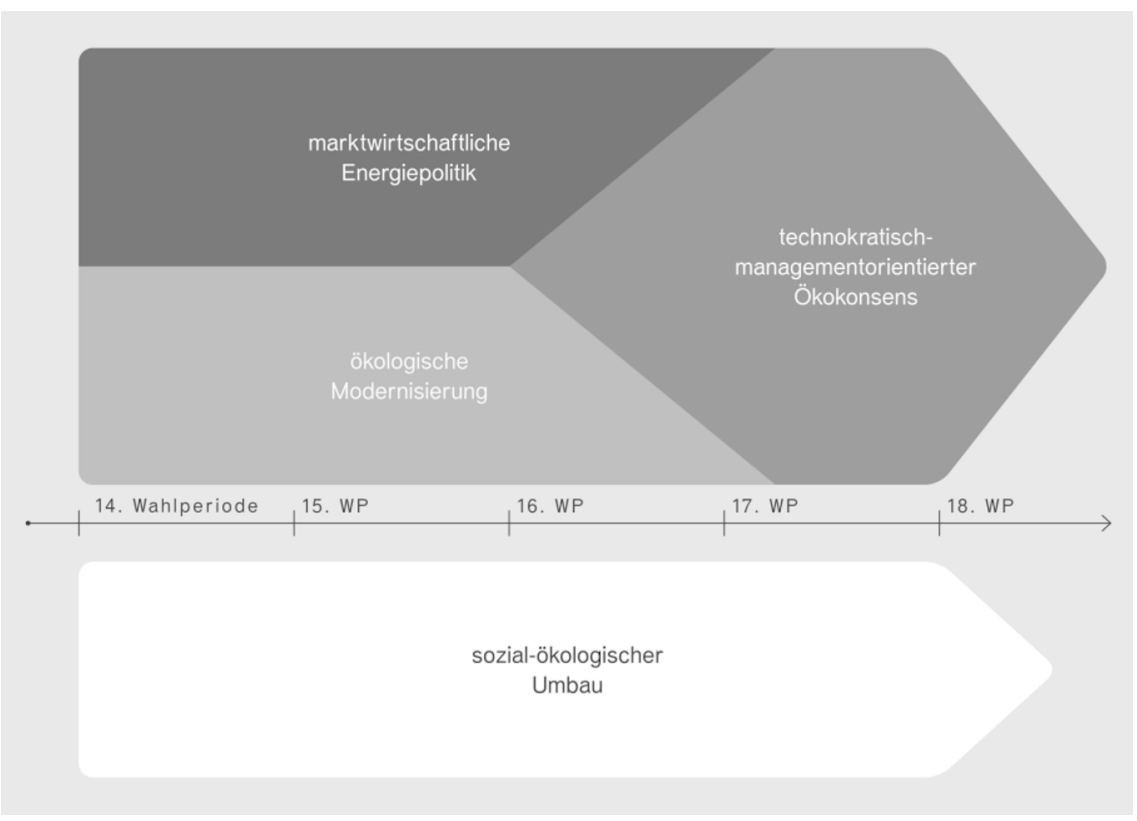

Quelle: eigene Darstellung

\section{Schlussfolgerungen}

Insgesamt zeigt sich in den Debatten zur „Energiewende“ nach „Fukushima“ ein Post-Politisierungsprozess, der sich mit Swyngedouw (2010: 216) als „Kolonisierung des Politischen durch die Verfahrensebene [eig. Übersetzung]“ bezeichnen lässt. Die politische Lenkung zentriert sich auf das technische und wirtschaftliche Management sowie die Verwaltung der „Energiewende“, wobei bestehende Verhältnisse im Bereich des Sozialen, der Produktion oder des Sozial-Ökologischen nicht angetastet werden (vgl. auch Swyngedouw 2015: 5). „This post-political frame is structured 
around the perceived inevitability of capitalism and a market economy as the basic organizational structure of the social and economic order, for which there is no alternative" (Swyngedouw 2010: 215). Wenn nach Glynos/Howarth (2007) die politische Realität der Fantasie bedarf, um sich zu konstituieren, und - wie nach „Fukushima“ eine große politische Mehrheit (aus Teilen von CDU, CSU, FDP, SPD und zum Teil auch GRÜNEN ${ }^{95}$ ) innerhalb eines fantasmatischen Narrativs artikuliert, welches die politische Realität aus einer spezifischen Perspektive heraus beschreibt - hier als technokratisch-managementorientierter Ökokonsens bezeichnet -, dann zeigt dies, dass die Naturalisierung dieser spezifischen politischen Realität gelungen ist, bei gleichzeitiger Verdeckung der Nicht-Naturgegebenheit sozialer Realität sowie der politischen Dimension ihrer Praktiken (vgl. Glynos/Howarth 2007: 145). Das verdeutlicht: Die entpolitisierende Wirkung des technokratisch-managementorientierten Ökokonsenses ist ein Symptom seiner Hegemonialität. Der Diskurs um „Energiewende" zielt demnach nicht (mehr) in erster Linie auf die Umsetzung umweltpolitischer Forderungen, sondern auf die Ausbreitung und den Erhalt der hegemonialen marktwirtschaftlichen Formation. „Energiewende“ entspricht nun in etwa dem, was Laclau (2007: 31) als „leeren Signifikanten“ bezeichnet - ein Signifikant, der kein Signifikat (mehr) hat. Die differentielle Identität von „Energiewende“ wurde von einer konsensorientierten Diskursformation aufgegeben, „um die rein äquivalentielle Identität eines gemeinschaftlichen Raumes als solches zu repräsentieren“ (Laclau 2002: 72). „Energiewende“ wurde nach „Fukushima“ zu einer umfassenden Forderung erhoben, mit dem Ziel den Bruch in den Artikulationen der hegemonialen Formation, die bis „Fukushima“ am alten Energiesystem festgehalten hatte, zu verdecken und wurde zur Einschreibungsfläche für überwiegend technokratisch-managementorientierte politische Praktiken, die letztlich mit einer Ausbreitung der hegemonialen Formation verbunden waren. Wie bei Laclau (2002: 74) ist zumindest für die Zeit nach „Fukushima“ die Präsenz des leeren Signifikanten „Energiewende“ „die eigentliche Bedingung für Hegemonie“.

Politische Entscheidungsfindung erscheint zunehmend als Frage von Expert*innenwissen und nicht als Ergebnis politischer Positionierung (Swyngedouw 2010: 225f.). Die Debatten drehen sich zum großen Teil um die Art der Technologie, den Zeitpunkt ihrer Einsetzung oder die Höhe ihrer Förderung. Die Natur wird dabei zwar auf unpolitische Weise in den Raum des Politischen eingeführt (ebenda: 216). Dies wird auch dadurch deutlich, dass gesellschaftliche Naturverhältnisse oder Annahmen über die Natur den Debatten über die „Energiewende“ permanent zu Grunde liegen, ja sogar ihr Ausgangspunkt sind, aber so gut wie nie explizit genannt werden - von Natur wird nicht gesprochen und wenn, dann findet eine Reduktion auf Klimaschutz statt (vgl. Kapitel 5.1.3). Die eigentliche politische Angelegenheit aber - die sozial-ökologische Krise - wird auf ein Terrain außerhalb der Debatte verlagert (vgl. Swyngedouw 2010: 217). Das eigentlich Politische wird aus dem Politischen extrahiert. Die Folgen des Klimawandels in ihrer schreckensverheißenden Dimension ver-

95 Wie bereits in Kapitel 5.1.3 verdeutlicht, sind die Fraktionsgrenzen nicht immer mit den Grenzen diskursiver Formationen identisch. So brechen bspw. die GRÜNEN und in einigen Fällen auch die SPD immer wieder aus dem technokratisch-managementorientierten Ökokonsens aus, indem sie sozial-ökologische Themen in den Blick holen. 
schwinden zunehmend aus den Debatten - möglicherweise, weil zentrale Herausforderungen des Klimaschutzes mit der beschlossenen „Energiewende“ zunächst als gelöst gelten, möglicherweise aber auch, weil ihre konkrete Benennung den Raum für die Herausarbeitung von Differenz zu weit öffnen würde und somit die auf Konsens ausgerichtete politische Praxis gefährden könnte. ${ }^{96}$ In Bezug auf die „Energiewende" hat die marktwirtschaftliche hegemoniale Formation umweltpolitische Forderungen nicht nur anerkannt, sondern konnte auch die Überzeugung etablieren, dass sie innerhalb der Marktwirtschaft bearbeitet werden können. Umweltpolitische Forderungen aus der Bevölkerung - z.B. aus der Anti-Atom-Bewegung - wurden so im Rahmen der marktwirtschaftlichen Hegemonie in den Diskurs aufgenommen und gleichzeitig auch für marktwirtschaftliche Interessen mobilisiert (vgl. auch Swyngedouw 2010: 223f.). Letztlich werden so sozial-ökologische Probleme nicht gelöst, sondern durch eine Relegitimation gegenwärtiger (westlicher) Lebensstile und vorherrschender politischer Interessen verstärkt (vgl. auch Brand u.a. 2009: 12) ${ }^{97}$ Im Zuge ihrer Integration in die hegemoniale marktwirtschaftliche Formation verbessert sich auch das „Image“ von Umweltschützer*innen (SPD 09.09.2004: 11256), die nun nicht mehr als politische Gegner*innen bekämpft werden. Sie seien nun nicht mehr die „Miesmacher, Müsliesser“ sondern „die Wegbereiter zu neuem Optimismus in Wirtschaft und Gesellschaft“ (SPD 09.09.2004: 11256).

Der Staat werde so zu einem Verfahrensakteur, der innerhalb eines neoliberalen Konsenses die Bedürfnisse des Marktes bediene und bei dem Regierungsführung auf die Verfahrens- und Verwaltungsebene reduziert werde, auf welcher der Staat vermeintlich gemeinsam mit Expert*innen agiere (Swyngedouw 2010: 227). Innerhalb dieser Sphäre des Nicht-Konfliktiven, innerhalb dieses technokratisch-managementorientierten Regelungssystems, kann quasi alles diskutiert werden, ist Dissens erlaubt, sind auch Positionswechsel möglich. ${ }^{98}$ Was diesen Rahmen aber überschreitet, erscheint „hoffnungslos aus der Zeit gefallen [eig. Übersetzung“ (vgl. z.B. den DDRVorwurf gegenüber der LINKEN) (Swyngedouw 2011: 267), unvernünftig und/oder unverantwortlich (vgl. Kapitel 5.3.2).$^{99}$ An einer inhaltlichen, d.h. über den Vorwurf der ,Rückständigkeit` hinausgehenden, Auseinandersetzung mit konkurrierenden Vi-

96 Die relative Häufigkeit von Klimawandel* im Gesamtkorpus ist für die 16. Legislaturperiode am höchsten.

97 Dass dieser Schein nicht dauerhaft aufrechterhalten werden kann, sondern durch die sozialökologische Krise, durch die „Spuren ihres Ausschlusses“ (vgl. Mouffe 2000: 147) permanent disloziert wird, zeigt sich in gegenwärtig erstarkenden Protesten gegen die Klimaschutz-Politik.

98 Deutlich wird dies auch in den wechselnden Positionierungen der großen Fraktionen, v.a. CDU/CSU und SPD.

99 Durch ihre Abweichung vom konsensualen, technokratisch-marktwirtschaftlichen Konsens erscheint die LINKE nicht als gleichwertige, respektable Diskurspartnerin, da ihre Positionen nicht als ,vernünftig' und somit nicht, verantwortungsvoll' gelten. Vor dem Hintergrund dieser Abwertung erscheint ein Ignorieren ihrer inhaltlichen Positionen legitim, eine politische Auseinandersetzung darüber geradezu niveaulos: „Meine Damen und Herren, wir haben es nicht nötig, uns mit solchen Leuten auf Anti-Marktwirtschafts-Debatten einzulassen“ (CDU 29.03.2012: 20292f). 
sionen sozial-ökologischer Zukünfte besteht im Rahmen der hegemonialen Formation kein Interesse, da die Alternativlosigkeit marktwirtschaftlicher Einbindung in Frage gestellt würde. So bleibt eine inhaltlich-politische Auseinandersetzung aus und die Fantasie eines sozial-ökologischen Umbaus unscharf. Die mit dieser Abweichung von der Norm verbundene soziale Ächtung verdeutlicht nicht nur, wie Ansichten, die den technokratisch-managementorientierten, bzw. marktwirtschaftlichen Konsens verlassen und alternative sozial-ökologische Arrangements in den Blick holen, zum Schweigen gebracht werden, es offenbart auch den beharrenden Kern dieses Konsenses (vgl. auch Swyngedouw 2010: 228). Denn vorherrschende soziale Verhältnisse, Produktionsverhältnisse und gesellschaftliche Naturverhältnisse sollen eben gerade nicht verändert werden.

Die Aufgabe einer pluralistischen demokratischen Politik bestehe nach Mouffe darin, die „Spuren der Macht und des Ausschlusses“ ins Zentrum zu rücken, sie sichtbar zu machen und somit in das Politische wiedereinzuführen (Mouffe 2000: 149). Dies sei ein unendlicher Prozess, denn der Antagonismus könne nicht ausgelöscht werden. Aber seinen verschiedensten Formen sollte in einem pluralistischen System Raum gegeben werden, sodass sich Identifikationsmöglichkeiten um ,wirkliche Alternativen' herum bieten und die gegenwärtige post-politische Vorstellung von Alternativlosigkeit gesprengt werden könne (Mouffe 2000: 149). Aus einem solchen Anspruch heraus seien demokratische Räume als Grundlage und Bedingung für ,andere' sozial-ökologische Arrangements zurückzuerobern, sozial-ökologische Zukünfte sollten positiv artikuliert und benannt werden sowie anerkannter Gegenstand von Konflikt werden (Swyngedouw 2011: 273). Das Politische am Umgang mit Natur, an den gesellschaftlichen Naturverhältnissen, an der Spaltung des Sozialen müsse sichtbar gemacht werden (ebenda). Die Ausschlüsse des hegemonialen Konsenses können so zum Ansatzpunkt von Repolitisierung werden. Solche Ansatzpunkte werden im folgenden Kapitel herausgearbeitet und mit dem Vorsorgenden Wirtschaften gleichzeitig in den Kontext von möglichen ,Alternativen“ im Hinblick auf Transformation gestellt. 



\section{Dekonstruktion Teil II:}

\section{Der „Energiewende“-Diskurs im Bundestag aus Perspektive Vorsorgenden Wirtschaftens}

Im vorigen Kapitel habe ich den Diskurs um „Energiewende“ dekonstruiert, indem ich seine Bedeutungsgenerierung anhand regelmäßiger Differenzbeziehungen aufgezeigt, anhand von Story-Lines komplexitätsreduzierende Erzählungen innerhalb des Diskurses identifiziert sowie zugrunde liegende fantasmatische Narrative herausgearbeitet habe. Es wurde deutlich, dass eine vor „Fukushima“ kaum politisierte „Energiewende“ nach „Fukushima“ schnell entpolitisiert und in eine hegemoniale marktwirtschaftliche Formation eingebunden wurde (vgl. Kapitel 5.4). Zweitens hat sich gezeigt, dass Diskurse, die sich gegen diese hegemoniale Formation richten, stark marginalisiert sind. Die Artikulation einer grundlegend , anderen' Energiewende findet dementsprechend kaum statt.

In Kapitel 4.3 wurde das Vorsorgende Wirtschaften als kritisch-emanzipatorische Analyseperspektive operationalisiert. Mithilfe der analytischen Funktion Vorsorgenden Wirtschaftens werden im Folgenden die Eigenheiten und Ausschlüsse des „Energiewende“-Diskurses aus dieser kritischen Perspektive herausgearbeitet. Dies dient der Positionierung für einen vorsorgenden, transformativen „Energiewende“Diskurs. Denn durch das Sichtbarmachen seiner Ausschlüsse und die Bewertung der Ausschluss-Mechanismen zeigen sich Ansatzpunkte für eine Repolitisierung des Diskurses sowie für emanzipatorische, nicht-externalisierende Gestaltungsperspektiven (vgl. auch Biesecker/von Winterfeld 2015: 5).

Das folgende Kapitel gliedert sich anhand der in Kapitel 3 vorgestellten und in Kapitel 4.3 anhand von Analyseheuristiken operationalisierten Prinzipien und Kriterien Vorsorgenden Wirtschaftens.

\subsection{VORSORGENDE „ENERGIEWENDE“?}

In Kapitel 3.2.1 wurde Vorsorge als Handlungsprinzip Vorsorgenden Wirtschaftens eingeführt und mit einem transformativen Verständnis von Zeitlichkeit in Beziehung gesetzt (vgl. Kapitel 3.1.1). Im Folgenden analysiere ich, inwiefern sich das Handlungsprinzip der Vorsorge in den Debatten um die „Energiewende“ und erneuerbare 
Energien widerspiegelt und welche Vorstellungen von Zeit dabei dominieren. Dabei gehe ich chronologisch nach den Legislaturperioden vor.

Wie im vorigen Kapitel 5 herausgearbeitet wurde, basiert das Narrativ der ,ökologischen Modernisierung', wie es zunächst den Artikulationen der rot-grünen Bundesregierung der 14. und 15. Legislaturperiode zu Grunde liegt, auf dem Glauben an technischen Fortschritt für die Lösung ökologischer Probleme. Dieser Glaube an technischen Fortschritt erscheint allerdings nicht als unbegrenzt - so führt gerade die Einsicht, dass die Probleme bei der Atomenergie eben nicht durch technischen Fortschritt lösbar erscheinen, zur Forderung des Atomausstiegs. Die Risiken von Technologien kommen in den Blick, führen aber nicht zu einer grundsätzlichen Technik- oder Fortschrittskritik, sondern zur Vorstellung einer ,anderen', eben ,moderneren', technologischen Entwicklung, welche die ,alten` Risiken beseitige. In diesem Zusammenhang spielen Energieeffizienz und erneuerbare Technologien eine besonders wichtige Rolle. Die ökologische Frage gewinnt als Frage im energiepolitischen Diskurs an Gewicht - sie wird bis hin zur Überlebensfrage (vgl. Kapitel 5.3.1) erklärt; Umweltauswirkungen, vor allem als Folgen des Klimawandels, erhalten zeitweise Einzug in den Diskurs. Allerdings wird Naturbeherrschung nicht grundsätzlich in Frage gestellt, sie wird überhaupt gar nicht erst thematisiert. Der Fokus der politischen Debatten wird auf die Symptome und Manifestationen der ökologischen Krise gerichtet, nicht auf deren strukturellen Ursachen (Krüger 2015: 104). Im Narrativ der ,ökologischen Modernisierung' vermischen sich die Zeitvorstellung gegenwärtiger Zukunft und zukünftiger Gegenwart (vgl. Kapitel 3.1.1): Einerseits geht es um die Frage, wie Umweltprobleme auch für die Zukunft gelöst werden können; dabei geht es auch um intergenerationelle Gerechtigkeit, bspw. dass zukünftige Generationen für die durch die Subventionierung konventioneller Energie entstehenden Kosten bezahlen müssen (SPD 25.02.2000: 8438f; vgl. Kapitel 5.2.5) - hier zeigt sich die Zeitvorstellung zukünftiger Gegenwart, die danach fragt, was wir für die Zukunft tun können. Andererseits werden ökologische und soziale Probleme durch den Fokus auf technologische Lösungen und technischen Fortschritt immer wieder in die Zukunft verschoben (vgl. Kapitel 5.2.1), wobei sich die Zeitvorstellung gegenwärtiger Zukunft zeigt, die danach fragt, was die Zukunft für uns tun kann (Adam 2013: 123). Insgesamt kommt die Frage nach dem Zeithorizont, nach der Zukunft, in den Debatten eher selten auf. Zwar verweist der Begriff Modernisierung implizit auf die $\mathrm{Zu}$ kunft, beschränkt sich aber auf den Bereich der Ökonomie und der Technologien, auch wenn er im Kontext des Narrativs einer ,ökologischen Modernisierung' artikuliert wird. Die Frage, in welchem Zeitrahmen was modernisiert werden soll, und welche konkreten politischen Ziele es dafür gibt, bleibt zudem außen vor.

So ersetzt das Narrativ einer ,ökologischen Modernisierung' anfangs die Debatte um eine „Energiewende“, die mit konkreteren Zielen im Energiebereich verbunden sein könnte. Nicht nur Teile der Opposition (CDU,CSU, FDP) sehen einen vollständigen Umstieg auf erneuerbare Energien skeptisch (CDU 09.09.2004: 11254), auch innerhalb der Regierung besteht dazu keine Einigkeit. „Zukunft“ ist zwar in der 14. Legislaturperiode eine Kollokation von „Energiewende“ (vgl. Kapitel 5.1.2), die Referenz auf die Zukunft bleibt aber meist unkonkret. Zukünftige Generationen spielen häufig nur implizit eine Rolle, es wird der Eindruck erweckt, ihre Interessen würden über eine marktorientierte Modernisierung automatisch verwirklicht. Durch die Marktorientierung gehen langfristige Perspektiven im Kontext einer glücksverhei- 
ßenden Dimension verloren. Das Narrativ der ,ökologischen Modernisierung ' zielt mit den Zielsetzungen von Wachstum und Wohlstandserhalt eher auf eine Optimierung kommodifizierter Zeit im kapitalistischen Produktionsprozess ab, als darauf, lebendige Zeiten und Produktionszyklen der Natur in den Blick zu nehmen. Statt der Adressierung krisenhafter gesellschaftlicher Naturverhältnisse und ihrer Ursachen, steht die Einführung von erneuerbaren Energien als Technologie (vgl. Kapitel 5.1.2), als Produktions- und Wirtschaftsfaktor, in der Gegenwart und der nahen Zukunft im Fokus (vgl. Kapitel 5.2.3). Die sozialen und ökologischen Kontexte und Auswirkungen entsprechender politischer Praktiken außerhalb des Marktes werden kaum einbezogen, hierarchisch strukturierte gesellschaftliche Naturverhältnisse werden dadurch reproduziert (vgl. Kapitel 6.4). Umweltpolitiken werden ökonomischen Zielsetzungen wie der Verbesserung der internationalen Wettbewerbsfähigkeit untergeordnet. Es wird ein Sachzwang zur „Erzielung eines ökologisch-ökonomischen Doppelnutzens“ (Jänicke 1988: 23) suggeriert (vgl. auch Krüger 2015: 100f.): Ökologische Ziele erscheinen nur dann legitim, wenn sie auch einen ökonomischen Nutzen erbringen.

Diese, die Ausgrenzung sozialer und ökologischer Aspekte bewirkende Artikulationsweise schreibt sich in der 15. Legislaturperiode fort. Zwar wird „Energiewende“ durch die Erwähnung im Koalitionsvertrag innerhalb eines eigenen Unterkapitels unter ,ökologischer Modernisierung' zunächst ein höherer Stellenwert beigemessen. Es wird auch auf Generationengerechtigkeit verwiesen - die „Energiewende“ solle helfen „Lebensqualität und eine intakte Umwelt auch für unsere Kinder und Enkel zu bewahren“ (Koalitionsvertrag 2002: 10). Darüber hinaus spiegelt sich der Stellenwert der „Energiewende“ im Koalitionsvertrag aber nicht in Form von Artikulationen in den Debatten wider, in denen „Energiewende“ weiterhin kaum als Begriff vorkommt und Generationengerechtigkeit nur marginal thematisiert wird (vgl. 5.1.2). Eine Bedürfnisreflexion im Rahmen von Suffizienz spielt kaum eine Rolle, Energiesparen soll überwiegend über technologische Einsparungen erfolgen: „Die neue Bundesregierung wird sich gemäß ihrem Grundsatz ,Vorrang der Einsparung vor der Erzeugung' mit einem breiten Maßnahmenbündel der Förderung von Einspartechnologien widmen, nicht zuletzt auch angesichts der großen Exportchancen“ (Koalitionsvertrag 1998: 15). Darüber, dass umweltpolitische Zielsetzungen der Energiepolitik über marktwirtschaftlich orientierte Instrumente erreicht werden können, herrscht unter den in der 15. Legislaturperiode im Bundestag vertretenen Fraktionen anscheinend Einigkeit - wenn sich auch die Ansichten darüber unterscheiden welche Markteingriffe notwendig sind (vgl. Kapitel 5.2.4). Über marktwirtschaftliche Instrumente wie den Emissionshandel sollen bspw. „,vorsorgender Umweltschutz mit Wirtschaftswachstum und Arbeitsplatzsicherung vereinbar" gemacht werden (CDU 28.05.2004: 10236).

Auch während der Regierungszeit der großen Koalition in der 16. Legislaturperiode liegt die Vorstellung eines ökologisch-ökonomischen Doppelnutzens den Artikulationen um erneuerbare Energien weiter zu Grunde. Von einer „Energiewende“ ist kaum noch die Rede (vgl. 5.1.2), in einem „breiten Energiemix“ sollen wirtschaftliche und ökologische Anliegen vereint werden (Koalitionsvertrag 2005: 65). Im Unterschied zur 14. und 15. Legislaturperiode werden die Risiken fossiler EnergieTechnologien noch stärker ausgeblendet, ihre Integration in einen „breiten Energiemix" wird als ökonomischer Sachzwang dargestellt, ohne den eine saubere, sichere und gleichzeitig soziale Energieversorgung nicht möglich wäre (vgl. z.B. CDU 
06.06.2008: 17741; vgl. Kapitel 5.2.1). Dennoch fließen immer wieder Elemente ,vorsorgenden Handelns' in den Diskurs mit ein: So werden die Kosten der erneuerbaren Energien in Relation zu den Folgekosten des Klimawandels gesetzt (vgl. z.B. CDU 06.06.2008: 17741; SPD 06.06.2008: 17744). ${ }^{1}$ Hier zeigt sich vereinzelt die Zeitvorstellung zukünftiger Gegenwart, in der Weise, dass Folgen des Klimawandels in der Zukunft durch ein Handeln in der Gegenwart vermieden werden sollen (vgl. Kapitel 5.2.5). Solche vorsorgenden Perspektiven bleiben aber auch in der 16. Legislaturperiode marginal. Überwiegend fokussieren sich die Debatten zur Energiepolitik auf marktwirtschaftliche Auswirkungen und technologischen Fortschritt - langfristige Perspektiven geraten dabei aus dem Blick. ,Nachhaltigkeit‘ wird als politisches Ziel gesetzt und erweckt zunächst den Eindruck einer Anschlussfähigkeit für vorsorgende Perspektiven. Allerdings stehen auch im Zusammenhang mit Nachhaltigkeit ökonomische Ziele im Vordergrund: Eine Nachhaltigkeit praktizierende, ,ambitionierte Umweltpolitik“ soll zum Motor für die „Vermarktung von Zukunftstechnologien“ und „die Wettbewerbsfähigkeit der deutschen Wirtschaft" werden (Koalitionsvertrag 2005: 17f.). Dieser Auffassung des Begriffes ,Nachhaltigkeit“, in dem marktökonomische Ziele hierarchisch übergeordnet sind (vgl. Kapitel 6.4), liegt eine neoliberale Zeitvorstellung zugrunde, in der der Blick auf die Zukunft durch die Marktutopie verstellt wird. Gemäß dieser Annahme führe alleine marktwirtschaftlicher Wettbewerb zu Fortschritt sowie Nachhaltigkeit und wird somit für die Problemlösung als alternativlos betrachtet, weshalb alle anderen demokratischen Organisationsformen des Marktes als ,Sozialismus‘ oder ,Kollektivismus` abgelehnt werden (vgl. z.B. CDU 02.07.2009: 25872; Kapitel 5.4).

Das zeigt sich auch zu Beginn der 17. Legislaturperiode in der Debatte um die Laufzeitverlängerung. Zwar wird mit dem „Weg in das Zeitalter erneuerbarer Energien“ auf eine zukünftige erneuerbare Energieversorgung verwiesen. Allerdings soll die Kernenergie eine „Brücke“ in diese Zukunft darstellen (17/3049). Mögliche soziale und ökologische Folgen werden von der schwarz-gelben Regierungskoalition ausgeblendet. Die Kernenergie solle vor allem eine Zeit ,überbrücken', innerhalb derer technischer Fortschritt sich entwickele, bis bspw. Carbon Capture and Storage $\mathrm{CCS}^{2}$ eine klimaneutrale Braunkohleverstromung ermögliche (Koalitionsvertrag 2009: 28; 17/3049: 9) oder die Kernfusion erforscht sei (Koalitionsvertrag 2009: 34). Dem liegt eine „Grundüberzeugung der Moderne“ zugrunde - nämlich, dass wissenschaftlich-technische Naturbeherrschung $\mathrm{zu}$ gesellschaftlichem Fortschritt führe (Becker/Jahn 2006: 66). Mittels technischen Fortschritts und Modernisierung solle Deutschland bei „hohem Wohlstandsniveau eine der energieeffizientesten und umweltschonendsten Volkswirtschaften der Welt werden“ (17/3049: 2). Dieser Modernisierungsprozess wird in einen Gegensatz zu einem „Verzichtsprozess“ gestellt (CDU 28.10.2010: 7182). Daraus lässt sich ein negativ konnotiertes Verständnis von Suffizienz im Sinne von Verzicht ableiten, was im Sinne des artikulierten Ziels, das Wohlstandsniveau gemessen am Bruttosozialprodukt durch eine Steigerung der Energieeffizienz zu erhalten, nicht in Betracht gezogen wird (CDU 28.10.2010:

1 So argumentiert die SPD ,für die Zukunft unserer Kinder und Enkelkinder [seien] 3 oder 5 Euro im Monat verdammt preiswert“" (SPD 06.06.2008: 17744).

2 Abspaltung und Speicherung von $\mathrm{CO}_{2}$. 
7167; vgl. Kapitel 5.3.2). Mit der Laufzeitverlängerung um 12 Jahre solle nicht nur das Klima geschützt, sondern auch Geld eingespart werden ${ }^{3}$ - eine kommodifizierte Zeit wird dabei hierarchisch über lebendige Zeit gestellt, indem von der Kernenergie beschädigte soziale und ökologische Lebensprozesse und Bedürfnisse (außerhalb des Klimaschutzes - bzw. Klimaschutz reduziert auf $\mathrm{CO}_{2}$ Einsparung) ausgeblendet werden. ,Klimaschutz“ als „Lebensgrundlage“ wird dabei als Oberziel politischer Praktiken benannt, die über Marktorientierung und ,Modernisierung' auf die Vereinigung wirtschaftlicher Ziele mit dem Ziel der „Zukunftssicherung“ abzielen (CDU 28.10. 2010: 7179; 7182). Wie bei Benjamin (2010: 19ff.) (vgl. Kapitel 3.1.1) wird durch die damit verbundene Vorstellung eines „unabschließbare[n]“ und „unaufhaltsame[n]" Fortschritts der Eindruck einer homogenen und leeren Zeit erweckt.

Mit „Fukushima“ wird die mangelhafte Fehlerfreundlichkeit und Bedachtsamkeit sowie das fehlende Bewusstsein innerhalb der hegemonialen Formation ${ }^{4}$ für die ökologische und soziale Mitwelt sichtbar. Die damit verbundene Vorstellung einer absoluten und immer rationaleren Naturbeherrschung wird durch „Fukushima“ derart herausgefordert, dass die LINKE von einem „Zivilisationsbruch in der Geschichte des industriell-kapitalistischen Zeitalters" spricht (LINKE 17.03.2011: 10896). Der Glaube an den technischen Fortschritt als Lösung aller Probleme wird durch „Fukushima“ disloziert (vgl. Angela Merkel 17.03.2011: 10884f.). Ein dreimonatiges Moratorium solle dazu dienen, die „Energiewende“ zu beschleunigen, die jetzt nach „Fukushima“ - eine zukünftig , andere“ Energieversorgung verspricht und auf eine Sorge um die Zukunft verweist (Angela Merkel 17.03.2011: 10884f.). Die hegemoniale neoliberale Vorstellung von Zeitlichkeit wird für kurze Zeit brüchig, indem die Auswirkungen vergangener politischer Entscheidungen auf die Gegenwart und auch auf die Zukunft sichtbar werden - es deutet sich an, dass es keine leere und offene Zukunft gibt. Vor allem die Opposition weißt kritisch darauf hin, dass die Risiken der Kernenergie bereits zuvor bekannt waren (vgl. Kapitel 5.2.1; vgl. z.B. SPD 09.06.2011: 12965). Die Regierungskoalition sieht sich gezwungen, den Glauben an eine absolute und immer rationalere Naturbeherrschung anzupassen und die Risiken von Technologien verstärkt in den Blick zu nehmen. Dennoch wird der Glaube an Naturbeherrschung nicht gänzlich aufgegeben. Die Risikobewertung und Folgenabschätzung von Technologien bei der Naturbeherrschung werden aber zumindest vorübergehend stärker einbezogen, wenn auch in ihrer Betrachtung der Politik ausgelagert in einem wissenschaftlichen Expert*innengremium. Auch wenn Risikobewusstsein an Bedeutung gewinnt, so kann Vorsorge als politische Perspektive sich nicht durchsetzen, da die Krisenhaftigkeit gesellschaftlicher Naturverhältnisse nicht in den Blick kommt: „Fukushima“ wird diskursiv als nicht objektiv vorhersehbares Ereignis, als ,Anomalie“ und nicht als Krisensymptom herrschender Verhältnisse konstituiert. „Energiewende“ wird so marktwirtschaftlich eingeordnet, vorsorgende Aspekte politischer Praktiken geraten wieder aus dem Blick (vgl. Kapitel 5.4).

3 Vgl. z.B.: „Das ist ein Lastwagen voller Geld, der verbrannt wird. Wir wollen diesen Lastwagen voller Geld nicht verbrennen, sondern wir wollen das Geld für den schnelleren Umbau unseres Energieversorgungssystems nutzen“ (CDU 28.10.2010: 7168).

4 Welche ich bis zu diesem Zeitpunkt über ihre Abgrenzung zur „Energiewende“ und ihren Bezug zum herkömmlichen Energiesystem definiert habe (vgl. Kapitel 5.1.3). 
Die „Energiewende“ wird im Koalitionsvertrag von CDU//CSU und SPD der 18. Legislaturperiode mit dem Ziel formuliert, den Weg in eine nachhaltige Industriegesellschaft zu ebnen (Koalitionsvertrag 2013: 36). Dieser Weg solle noch marktwirtschaftlicher (Koalitionsvertrag 2013: 39) und rationaler gestaltet werden (vgl. z.B. CDU 27.06.2014: 3935). Die politische Perspektive verschiebt sich weiter von der Lösung gegenwärtiger und zukünftiger sozial-ökologischer Krisen auf die marktwirtschaftliche Ausrichtung in der Gegenwart, durch die eine ,automatische" Lösung aller Probleme suggeriert wird. Die „Energiewende“ wird weiterhin als „Technologieprojekt" und ,Wirtschaftsfaktor' konstituiert (CDU 29.06.2017: 24990), ihr sozialökologischer Kontext wird ausgeblendet (vgl. Kapitel 5.2.1). Auch die Fokussierung der Debatte auf die gegenwärtigen vermeintlich zu hohen Kosten der „Energiewende" verstellt den Blick auf die Zukunft und lenkt von den transformativen Potenzia$l^{5}{ }^{5}$ einer „Energiewende“ ab. Anstatt die Potenziale einer „Energiewende“ für vorsorgende politische Praktiken in den Mittelpunkt der Debatte zu stellen, wird sie von der Regierungskoalition zunehmend mit einem wirtschaftlichen Katastrophenszenario in Verbindung gebracht („Deindustrialisierung“ (vgl. z.B. SPD 27.06.2014: 3939f.) vgl. Kapitel 5.3.2). Dabei werden hauptsächlich die Bedürfnisse großer Industriezweige in den Blick genommen (wie der energieintensiven Industrie), während kleinere Branchen wie die Solarindustrie für ihre Zukunft selbstverantwortlich gemacht werden (vgl. Kapitel 5.2.3). GRÜNE und LINKE bezeichnen die zunehmende Ausrichtung auf die großen Unternehmen als „Konterrevolution der alten, dreckigen Energiewirtschaft" (GRÜNE 01.06.2016: 16974) und heben damit die beharrende bis reaktionäre Wirkung dieser politischen Praktiken hervor, die sie als „Bestandschutz“ für die Kohlewirtschaft werten (GRÜNE 01.06.2016: 16974). Sie verweisen auf zukünftige Auswirkungen, wie das Verfehlen der Klimaziele (LINKE 29.06.2017: 24987f.).

Insgesamt erscheint der Status vorsorgender Perspektiven auf die „Energiewende“ innerhalb der untersuchten Plenardebatten nur als marginal, während neoliberale Vorstellungen von Zeitlichkeit im Gegensatz zu transformativen Vorstellungen von Zeitlichkeit dominieren. Der sozial-ökologische Kontext der „Energiewende“ wird größtenteils ausgeblendet, die Debatten beschränken sich inhaltlich überwiegend auf technologische und ökonomische Fragen. Die Marktökonomie wird als Sachzwang präsentiert und auch als Lösungsansatz für überwiegend nicht artikulierte ökologische Probleme. Dass diese Marktwirtschaft in ihrer neoliberalen Ausrichtung krisenhafte gesellschaftliche Naturverhältnisse verstärkt und verursacht, in dem sie die Produktivität der Natur und des sozial weiblichen abspaltet (vgl. Kapitel 3.2), wird ausgeblendet. Anstatt sozial-ökologische Krisenphänomene zu problematisieren, wird die Frage nach einer möglichst marktorientierten Gestaltung zur wesentlichen Herausforderung für Energiepolitik stilisiert. Dabei zeigt sich die von Rilling (2014: 34f.) beschriebene (vgl. Kapitel 3.1.1) ,neoliberale Transformation der Zeitlichkeitskultur“ in Form einer „Reduktion auf die Unmittelbarkeiten des Gegenwärtigen“.

5 Auf diese wurde in Kapitel 1 verwiesen. 


\subsection{KOOPERATIVE „ENERGIEWENDE“?}

Auf Kooperation als Prinzip Vorsorgenden Wirtschaftens wurde in Kapitel 3.2.1 bereits eingegangen. Im ökonomischen Handlungsraum bezeichnet kooperieren die gemeinsame Ausführung einer ökonomischen Tätigkeit (Biesecker/Kesting 2003: 180). Die Frage, wie diese Gemeinsamkeit gestaltet ist, hat jedoch großen Einfluss darauf, ob eine Kooperation tatsächlich als Kooperation im Sinne Vorsorgenden Wirtschaftens gelten kann oder nicht. Verschiedene Typen von Kooperation ${ }^{6}$ wurden in Kapitel 3.2.1 vorgestellt. Im Folgenden analysiere ich, welche Vorstellungen des wirtschaftlichen, sozialen und politischen Zusammenwirkens in den Debatten identifiziert werden können, ob diese eher konkurrenz-/wettbewerbs- oder kooperationsbasiert sind und auf welche Typen von Kooperation Bezug genommen wird. Außerdem wird das Einbeziehen der gesellschaftlichen Naturverhältnisse im Sinne der in Kapitel 3 ausgeführten Kategorie der (Re)Produktivität in den „Energiewende“ - Diskurs überprüft.

Auch das in seiner Wirkung als reformistisch klassifizierte Narrativ der ,ökologischen Modernisierung', das sich im Kontext der politischen Praktiken der rot-grünen Regierung in der 14. und 15. Legislaturperiode zeigt, setzt eher an einem konkurrenzund wettbewerbsbasierten als an einem kooperativen Ökonomieverständnis an. Zukünftige Generationen sowie ökologische Fragen werden zwar stärker als bisher in die politische Entscheidungsfindung eingebunden, auch sie werden aber marktökonomisch eingeordnet. Der Erhalt und die Verbesserung der Wettbewerbsfähigkeit sind stets ein Ziel umweltorientierter energiepolitischer Maßnahmen, ökologische Krisen werden zur Chance uminterpretiert, die Ökologie der Ökonomie als vorgelagert betrachtet: Durch die Bekämpfung des Klimawandels über die Förderung erneuerbarer Energien solle die internationale Wettbewerbsfähigkeit der deutschen Wirtschaft gesteigert werden (vgl. Kapitel 5.2.3). Über die Ökosteuer, deren Einnahmen nicht für ökologische Zwecke eingesetzt werden, sondern um die Lohnnebenkosten zu senken, solle die Wettbewerbsfähigkeit der Unternehmen erhöht werden (vgl. z.B. Koalitionsvertrag 1998: 12; vgl. Kapitel 5.2.1); Wettbewerb wird also als Ziel und Mittel politischer Praktiken zugleich formuliert. Dabei wird auch in dem zumindest in seinen Ansätzen auf Sorge für die zukünftige Gegenwart ,Anderer' ausgerichteten Narrativ der ,ökologischen Modernisierung‘ Natur nicht im Sinne von (Re)Produktivität als ,Kooperationspartnerin“ in ökonomisches Handeln mit einbezogen. Eine Vermittlung zwischen Arbeits- und Naturproduktivität (Biesecker/Hofmeister 2006; Biesecker/Hofmeister 2013a) ist nicht erkennbar.

Im Spannungsfeld zwischen Kooperation und marktwirtschaftlicher Konkurrenz stellen sich die Artikulationen zur Implementierung erneuerbarer Energien unter dem Narrativ der ,ökologischen Modernisierung' ambivalent dar. Einerseits ist die Artikulation ,erneuerbarer Energien' stark durch die Story-Line determiniert, welche die Marktwirtschaft als Bedingung für erneuerbare Energiepolitik konstituiert. Andererseits schlägt sich dies in den politischen Praktiken insofern zunächst nicht wieder, als dass das EEG im Kern nicht als (rein) marktwirtschaftliches Instrument angelegt wird, sondern über feste Einspeisevergütungen als Förderinstrument für erneuerbare 
Energien. Dass sich erneuerbare Energien im EEG nicht „,dem Wettbewerb [...] stellen müssten“ (CDU 25.02.2000: 8430), wird von CDU/CSU und FDP als Grund angeführt, dieses zunächst abzulehnen (vgl. Kapitel 5.2.4). Zwar wird die Bedeutung des EEGs als Markteinführungsinstrument betont, gleichzeitig argumentiert aber die SPD, dass erneuerbare Energien ,nicht nach dem traditionellen Bewertungsmuster von Wettbewerb eingeführt werden“ könnten (SPD 25.02.2000: 8439; vgl. Kapitel 5.2.4). Entsprechend materialisiert sich das EEG außerhalb der Bundestagsdebatten in Elementen verständiger Kooperation, indem es bspw. Privatpersonen ${ }^{7}$ und Bürger*innengenossenschaften, die auf demokratische Entscheidungsfindung ausgerichtet sind und nicht in erster Linie profitorientiert ${ }^{8}$ wirtschaften, Gestaltungsmacht zuweist und ihnen über feste Einspeisevergütungen die Teilhabe am Energieproduktionsprozess ermöglicht (Amri-Henkel/Hofmeister 2018). Gesellschaftliche Asymmetrien werden allerdings kaum benannt. In den Debatten um das EEG wird das Bild eines (männlichen) Eigenheimbesitzers (GRÜNE 29.03.2012: 20203) gezeichnet, dem die Rolle des Investors (SPD 25.02.2000: 8437) in erneuerbare Energien zugewiesen wird, während seine Funktion im gesellschaftlichen Gestaltungsprozess der „Energiewende" oder als möglicherweise aktive*r Konsument*in kaum bestimmt wird (vgl. Kapitel 5.2.8). Es erfolgt im politischen Diskurs hier also kaum eine Einbeziehung der „,menschlichen Tätigkeiten und [der] Naturleistungen [...] in das Ökonomische“ (Biesecker/Hofmeister 2013a: 154) im Sinne von (Re)Produktivität. Die Elemente verständiger und vorsorgend-verantwortlicher Kooperation, die durch das EEG ermöglicht werden, werden in den Debatten von der Regierungskoalition nicht angesprochen/explizit gemacht, während marktökonomische Legitimationen im Vordergrund stehen.

In der 16. Legislaturperiode nimmt die Ausrichtung des EEG auf Wettbewerb zu und die Vergütungssätze werden 2009 mit der Begründung der internationalen Wettbewerbsfähigkeit verringert - schließlich sei die ,,ausländische Konkurrenz [...] aus den Startblöcken heraus“ (vgl. CDU 06.06.2008: 17742; vgl. Kapitel 5.2.4). Energiepolitische Maßnahmen im Hinblick auf die im Koalitionsvertrag 2013 bemühte ,Nachhaltigkeit' werden auch in der 16. Legislaturperiode nur insofern als akzeptabel betrachtet, als sie die Wettbewerbsfähigkeit nicht einschränken und gleichzeitig einen ökonomischen Nutzen erbringen (vgl. z.B. BMU 2007: 4). So gelte es, die energieintensive Industrie durch Kostensteigerungen ,in ihrer internationalen Wettbewerbsfähigkeit nicht zu beeinträchtigen“ (Koalitionsvertrag 2005: 85).

Zukünftige Generationen als berechtigte Anspruchsgruppe und Kooperationspartnerinnen im Verständnis Vorsorgenden Wirtschaftens finden in den politischen Entscheidungsprozessen zwar vereinzelt Erwähnung, werden aber kaum berücksich-

7 Natürlich kann die Teilhabe von Privatpersonen am Energieproduktionsprozess auch strategisch motiviert, also eigennutzorientiert sein. Ich spreche hier von ,Elementen` verständiger Kooperation, da die Verschiebung von Machtasymmetrien durch das EEG die Teilhabe zuvor vom Produktionsprozess ausgeschlossener Personengruppen immerhin ermöglicht.

8 Eine ausschließliche Gewinnorientierung für Energiegenossenschaften ist in Deutschland durch das Genossenschaftsgesetz ausgeschlossen. Gewinn dient der Erfüllung des Förderauftrags nach $\S 1 \mathrm{GenG}$. 
tigt. Umweltpolitische Fragen bleiben marginal (vgl. Kapitel 5.1.2). Das Konkurrenzprinzip - auf volkswirtschaftlicher Ebene verkörpert im Wettbewerbsprinzip steht im Vordergrund politischer Handlungsorientierung. Asymmetrien (bspw. in Form zu hoher Strompreise durch Spekulation) zu Ungunsten der Verbraucher*innen werden abgestritten: Die Märkte seien „,von echten physischen Interessen [und nicht von Spekulation] getrieben“ (CDU 02.07.2009: 25871). Die LINKEN fordern eine demokratische Koordination, bzw. Kontrolle des Strommarktes durch eine Strompreisbehörde (LINKE 02.07.2009: 25876), was von den anderen Fraktionen überwiegend mit dem Argument des Wettbewerbs abgelehnt wird. So argumentieren die GRÜNEN eine solche Behörde sei durch ihre monopolartige Stellung ,der natürliche Feind des Fortschritts“ (GRÜNE 02.07.2009: 25877). Sie fordern stattdessen „,fairen Wettbewerb“ (GRÜNE 02.07.2009: 25877) (vgl. Kapitel 5.2.4).

Zivilgesellschaftliche Akteur*innen werden in den Entscheidungsprozess der Laufzeitverlängerung der Atomkraftwerke in der 17. Legislaturperiode trotz zahlreicher Demonstrationen ${ }^{9}$ nicht nur nicht eingebunden, sondern größtenteils ignoriert (sie werden lediglich von der Opposition erwähnt). ${ }^{10}$ Gleichzeitig wird im Energiekonzept eine aktivere Beteiligung innerhalb eines Dialogforums „nachhaltige Energieversorgung" für die Zukunft in Aussicht gestellt, um den energiepolitischen Konsens zu ,verbreitern“ (17/3049: 18). Dabei werden die Konflikthaftigkeit des Energiekonzeptes und die breite gesellschaftliche Ablehnung der Kernenergie verdeckt, indem eine generelle Kooperationsbereitschaft der Bundesregierung suggeriert wird. Im Gegensatz zu zivilgesellschaftlichen Akteur*innen werden die Energieversorgungsunternehmen aktiv in die Vereinbarungen zur Laufzeitverlängerung und zur Kernbrennstoffsteuer einbezogen, die zwischen der Bundesregierung und den Unternehmen im Vorfeld in zunächst geheimen Verträgen getroffen werden (vgl. z.B. GRÜNE 28.10.2010: 7160f.; LINKE 28.10.2010: 7175; GRÜNE 28.10.2010: 7189). ${ }^{11}$ In diesem Vorgehen erscheinen die Profitinteressen der Unternehmen als berechtigt - im Gegensatz zu nichtökonomischen Interessen anderer Anspruchsgruppen oder Interessen von kleineren Unternehmen wie Stadtwerken. Auch durch das NichtEinbeziehen zivilgesellschaftlicher Akteur*innen und bspw. Umweltverbänden entfällt eine Vermittlung zwischen sozial-ökologischen Belangen und dem Ökonomischen im Sinne von (Re)Produktivität. Als legitime Interessen im Entscheidungspro-

9 Beispielsweise demonstrieren im September 2010 zwischen 40.000 und 100.000 Menschen in Berlin gegen die Laufzeitverlängerung (www.zeit.de - Proteste).

10 Die Mehrheit der deutschen Bevölkerung ist zu diesem Zeitpunkt laut einer Umfrage von TNS Emnid im Auftrag der ZEIT gegen eine Laufzeitverlängerung von mehr als 10 Jahren. So lehnten 48 Prozent der Deutschen eine Verlängerung der Laufzeiten der Kernkraftwerke generell ab, 29 Prozent wollen eine Verlängerung um höchstens 10 Jahre (www.zeit.de Laufzeitverlängerung).

11 Zudem kritisiert die Opposition, die Bundesregierung habe für ihre Interessenvertretung in den Verhandlungen einen Atomkraftlobbyisten beauftragt: „Sie, Umweltminister Röttgen, lagen in der Nacht, in der die Vereinbarung mit den Konzernen unterschrieben wurde, im Bett. Die Feder der Regierung führte der bekennende Atomlobbyist Hennenhöfer. Freunde unter sich beim Aushandeln der Revolution zurück ins 20. Jahrhundert!“ (GRÜNE 28.10.2010: 7189). 
zess zur Laufzeitverlängerung konstituiert die Regierungskoalition ausschließlich wirtschaftliche Interessen, deren Berücksichtigung als Sachzwang dargestellt wird bspw. der Erhalt von Arbeitsplätzen im konventionellen Energiebereich (vgl. Kapitel 5.2.1). Andere politische Positionen gegen Atomenergie werden als illegitim konstituiert, die Verweigerung der Kooperation durch die Opposition als „Zukunftsverweigerung und Verantwortungsverweigerung“ (CDU 28.10.2010: 7179). Die Kooperation, wie sie von der schwarz-gelben Koalition eingefordert wird, wird demnach nicht mit einer zivilgesellschaftlichen Teilhabe an Entscheidungsprozessen verbunden, ist also nicht als gleichberechtigte Kooperation zu verstehen, sie basiert auf einem herrschaftlich-autoritären Anspruch, der sich aus einer Unterordnung unter eine naturalisierte marktwirtschaftliche Ideologie ableitet.

Das Ereignis „Fukushima“ holt die nichtmarktlichen Akteur*innen insofern in den Blick, als sich die Vorbehalte zahlreicher zivilgesellschaftlicher Akteur*innen gegenüber der Atomenergie als berechtigt erweisen. Die Regierungskoalition versucht nun die nichtmarktlichen, zivilgesellschaftlichen Akteur*innen in einen neuen vermeintlich kooperativen Konsens mit einzubeziehen. In einem ersten Schritt wird die „Ethikkommission Sichere Energieversorgung“ einberufen, als deren Aufgabe es beschrieben wird, ,die Energiewende auf einen breiten gesellschaftlichen Konsens zu stellen" (www.bundesregierung.de - Ethikkommission). Mitglied sind überwiegend Vertreter*innen aus Wissenschaft und Politik, aber auch aus Wirtschaft, Gewerkschaft und Kirche. Weitere Interessensgruppen (z.B. Umweltverbände, Wirtschaftsverbände, Energieversorgungsunternehmen, Jugendverbände) werden im Rahmen der Kommissionsarbeit angehört. Eine über die Arbeit in der Kommission hinausgehende Einbindung von Akteur*innen in Entscheidungsprozesse wird allerdings kaum diskutiert und lediglich von der Opposition eingefordert. ${ }^{12}$ Bürger*innen spielen in den Bundestagsdebatten um die „Energiewende“ weiterhin eine untergeordnete Rolle (vgl. Kapitel 5.1.2), ihrer Einbindung scheint mit Abschluss der Kommission, deren Diskussion sich in den Bundestagsdebatten überwiegend auf den Atomausstieg beschränkt, genüge getan. Gleichzeitig wird die Gesamtgesellschaft sprachlich in den ,neuen“ Konsens eines kollektiven „Wir“ einbezogen, verbunden mit dem Appell, zukünftigen Protest zu unterlassen (Angela Merkel 09.06.2011: 12961). So soll nicht nur der Eindruck geweckt werden, die Regierungskoalition teile das Anliegen einer „Energiewende“ mit den Bürger*innen und anderen zivilgesellschaftlichen Akteur*innen, es wird auch eine verständigungsorientierte Kooperation mit allen gesellschaftlichen Gruppen suggeriert. Dieser ist aber ein herrschaftlich-autoritärer Charakter zu attestieren, da unterschiedliche Standpunkte nicht anerkannt bzw. abgestritten werden und eine politische Auseinandersetzung darüber verweigert wird. ${ }^{13}$

Eine Vermittlung zwischen Arbeits- und Naturproduktivität findet auch nach „Fukushima“ nicht statt, da die Regierungskoalition die Artikulation des Katastrophenszenarios einer „Deindustrialisierung“ aufrechterhält (FDP 24.03.2011: 11286) und so weder die sozial-ökologische Krise noch potenziell transformative sozial-

12 So fordern die LINKEN die kooperative Erarbeitung eines neuen Energiekonzeptes, in das verschiedene Interessensgruppen einbezogen werden (LINKE 17.03.2011: 10898).

13 Vgl. z.B. die Aussage der CDU, dass ,alle Streitigkeiten [...] in den Grundfragen“ damit beseitigt seien (CDU 30.06.2011: 13369). 
ökologische Arrangements in den Blick kommen (vgl. Kapitel 5.4). Das EEG wird weiter sozial-ökologisch entbettet, indem es ,so wirtschaftsfreundlich und industriefreundlich“ gemacht werden solle, ,wie es noch nie war“ (CDU 30.06.2011: 13370), während sozial-ökologische Sichtweisen ausgeblendet werden (vgl. Kapitel 5.4). Die Elemente verständiger und vorsorgend-verantwortlicher Kooperation, die durch das EEG ermöglicht wurden und stets im Schatten der Debatten verblieben, werden nun zunehmend zurückgedrängt. ${ }^{14}$ Durch die Novellierungen des EEG 2014 und 2016/17 und dem damit verbunden „Systemwechsel hin zu Ausschreibungen“ (CDU 01.06.2016: 16984) wird das Konkurrenzprinzip als handlungskoordinierendes Prinzip der „Energiewende“ weiter gestärkt (vgl. Kapitel 5.2.4). Preise sollen künftig durch Wettbewerb und nicht mehr durch das Gesetz festgelegt werden. Zugrunde liegt die Annahme, dass die Teilnehmenden eines solchen Bieterverfahrens rational und eigennutzorientiert handeln. Für Bürger*innenenergiegesellschaften werden diese ökonomischen Prämissen genauso vorausgesetzt wie für Energieversorgungsunternehmen. Asymmetrien werden zwar insofern berücksichtigt, dass für Bürger*innenenergiegesellschaften besondere Bedingungen gelten. Die Teilnahme am Bieterverfahren erfordert aber ein hohes $\mathrm{Ma} ß$ an strategischem und marktfokussiertem Handeln, im Gegensatz zu kommunikativem oder vorsorgendem Handeln (vgl. Biesecker/Kesting 2003: 177) und ist daher für profitorientierte Unternehmen attraktiver als für größtenteils ehrenamtlich arbeitende Bürger*innenenergiegesellschaften. Strategische Akteur*innen, die auf Grundlage einer eigennutzorientierten ökonomischen Rationalität arbeiten sind daher im Vorteil - kooperative Eigentumsformen werden zurückgedrängt. ${ }^{15}$ Es kommt zu einer Machtverschiebung von herkömmli-

14 Die neuen strukturellen Rahmenbedingungen begünstigen eher eine strategische Handlungsorientierungen, da Anlagenbetreiber im Gegensatz zur bisherigen festen Einspeisevergütung nun als aktive Marktakteur*innen im Wettbewerb gesehen werden, die durch die sich nach dem Börsenstrompreis richtende „Marktprämie“ auf Preissignale reagieren sollen. Dass dies bei fluktuierenden erneuerbaren Energien überhaupt nicht möglich ist, solange keine Speichermöglichkeiten bestehen, wird dabei ebenso ausgeblendet wie die Tatsache, dass das Strommarktmodell, welches den Börsenstrompreis bestimmt, auf fossile Energien ausgerichtet ist (Schomerus/Henkel 2012: 19).

15 Diese Einschätzung bestätigt sich bei einer genaueren Betrachtung der Zahlen aus der Datenbank für Bürgerenergie, die an der Leuphana Universität Lüneburg geführt wird. So zeigt sich zwischen 2009 und 2013 ein Aufschwung in den Neugründungen von Bürger*innenenergiegesellschaften (darunter vor allem auch Genossenschaften), der hauptsächlich den rechtlichen Rahmenbedingungen des EEG geschuldet ist. Seit 2014 ist die Anzahl der neu gegründeten Energiegenossenschaften jedoch deutlich gesunken, die Anzahl an Löschungen angestiegen. Gleichzeitig sind die Neugründungen von Bürger*innenenergiegesellschaften in anderen Rechtsformen wie der GmbH \& Co KG gestiegen. Dies liegt auch an einer Verschiebung der EEG-Förderung weg von PV hin zu Windenergie. Es kam zu deutlichen Verschiebungen in der Zusammensetzungen des Bürger*innenenergiesektors (Kahla u.a. 2017: 13ff.). Kahla u.a. (2017) beschreiben den Unterschied zwischen den beiden Rechtsformen im Bürger*innenenergiebereich wie folgt: „(Viele) Energiegenossenschaften entstehen trotz der vorhandenen Gründungsunterstützungsstrukturen eher emergent; d.h. die Gründungsprozesse von Energiegenossenschaf- 
chen größtenteils auf Privatpersonen basierenden Bürger*innenenergiegesellschaften zu strategischen, von Unternehmen initiierten, vermeintlichen Bürger*innenenergiegesellschaften (vgl. Kapitel 5.2.8).

Insgesamt werden in den Debatten um die „Energiewende“ sowie erneuerbare Energien kooperative Vorstellungen des Zusammenwirkens marginalisiert und die Gestaltung der Energiepolitik marktwirtschaftlichen Prinzipien unterworfen. Machtasymmetrien im Wettbewerb werden bis auf wenige Ausnahmen (bspw. der Verweis auf die Macht der , großen Vier', vor allem durch SPD, GRÜNE und LINKE) nicht artikuliert. Es dominiert die implizite Annahme von gleichen Ausgangsbedingungen, eines Wettbewerbs unter Gleichen. Normative, sozial-ökologische Handlungsorientierungen geraten aus dem Blick. Dies führt zu einer diskursiven Verfestigung der gesellschaftlichen Naturverhältnisse, in denen die Natur der Wettbewerbslogik unterworfen wird (Krüger 2015: 101; Görg 2003: 140). ${ }^{16}$ Natur wird somit nicht als gleichberechtigte Akteurin in einem ökonomischen Kooperationsprozess gefasst, sondern wird nutzenorientiert angeeignet und als Mittel zum Zweck betrachtet. Arbeit wird nur im Sinne von Erwerbsarbeit adressiert, Sorgearbeit ist kein Gegenstand der Debatten. Kooperative, sozial-ökologische, geschweige denn (re)produktive politische Praktiken werden so verunmöglicht.

\subsection{AM GUTEN LEBEN ORIENTIERTE „ENERGIEWENDE“?}

In Kapitel 3.2.1 wurde Orientierung am für das gute Leben Notwendigen als handlungsleitendes Prinzip einer vorsorgenden Wirtschaftsweise eingeführt und zur Orientierung an monetären, rein marktorientierten Prinzipien abgegrenzt. Im Folgenden analysiere ich, welche handlungsleitenden Prinzipien sich in den untersuchten Debatten um Energiepolitik identifizieren lassen und welche Zielsetzungen und Wohlstandsvorstellungen damit verbunden werden.

Ein handlungsleitendes Prinzip des Narrativs der ,ökologischen Modernisierung‘ der 14. und 15. Legislaturperiode ist nicht unbedingtes Wachstum um jeden Preis, sondern ein Wachstum, welches mit ökologischen Zielvorstellungen vereinbar sein soll. Neben ökonomischen Zielen kommt auch der Erhalt der natürlichen Lebensgrundlagen als Lebensbedürfnis in den Blick. Reine Gewinnmaximierung wird nicht zur alleinigen Zielsetzung ökologischer Modernisierung erklärt: So werden überwiegend profitorientierte Motivationen wie bspw. der ,großen Vier‘ auch von der Regie-

ten sind im Vergleich zu den übrigen Bürgerenergiegesellschaften als eher nicht zentral gesteuert zu bezeichnen. Im Fall von GmbH und Co. KGs stehen meist Initiatoren in Form von Projektentwicklern, Flächeninhabern oder Ankerinvestoren bereit, die den Gründungsprozess der Bürgerenergiegesellschaft strukturieren. Im Gegensatz dazu sind in Energiegenossenschaften ehrenamtliche Gremienstrukturen anzutreffen, deren Motivation zu einem Großteil durch Altruismus erklärt werden muss“ (Kahla u.a. 2017: 25).

16 Auch wenn die oben dargestellten Effekte des EEG für verständige und vorsorgendverantwortlicher Kooperation außerhalb des Parlaments zum Teil andere gesellschaftliche Naturverhältnisse ermöglichen oder aufscheinen lassen (bspw. in Energiegenossenschaften, vgl. Amri-Henkel/Hofmeister (2018)). 
rungskoalition kritisiert. Diese würden die erneuerbaren Energien ablehnen, weil sich damit „kein Geld verdienen“ ließe (SPD 06.06.2008: 17731; vgl. Kapitel 5.2.10). Eine gemeinwohlorientierte im Gegensatz zu einer profitorientierten Ausrichtung wird aber nicht auf die Ökonomie als Ganzes übertragen. Es wird keine grundsätzliche Kritik an den ökonomischen Zielsetzungen und Voraussetzungen von Wirtschaftswachstum geübt, so wird Wachstum nicht direkt mit Ressourcenverbrauch oder Treibhausgasemissionen in Beziehung gesetzt. Vielmehr liegt die implizite Prämisse zu Grunde, dass Wachstum und Ökologie keine grundsätzlichen Gegensätze darstellen, sondern miteinander in Einklang zu bringen seien, wenn ein ,anderes', ökologischeres Wachstum angestrebt werde (vgl. auch Krüger 2015: 107) ${ }^{17}$ : So solle der nachhaltige „Erhalt der natürlichen Lebensgrundlagen“ gleichzeitig „Gerechtigkeit und Wachstum“ sichern (Koalitionsvertrag 2002: 7; vgl. Kapitel 5.2.1). Umgekehrt wird davon ausgegangen, dass Naturzerstörung dem Wirtschaftswachstum schade. Beidem liegt keine (re)produktive Perspektive im Sinne einer Vermittlung von Ökologie und Ökonomie zugrunde, sondern es dominieren, wie bereits gezeigt, marktökonomieorientierte Story-Lines. Im fantasmatischen Narrativ ,ökologischer Modernisierung' werden so Forderungen aus der Umweltbewegung mit der Forderung des Wirtschaftswachstums äquivalenziert, wodurch letztlich eine Voraussetzung für die Ausbreitung einer hegemonialen marktwirtschaftlichen Formation geschaffen wird. So beziehen sich bereits in der 14. und 15. Legislaturperiode CDU, CSU, GRÜNE und SPD - wenn auch in unterschiedlicher Weise - auf ein ökologischeres Wachstum, ${ }^{18}$ was auf die beginnende Vermischung der fantasmatischen Narrative ,ökologischer Modernisierung' und ,marktwirtschaftlicher Energiepolitik' in einem technokratisch-managementorientierten Ökokonses verweist. Dagegen fordert die PDS eine Abkehr vom Wachstumsmodell ${ }^{19}$ und kritisiert die Blindheit des Marktes ,gegenüber gesellschaftlichen Bedürfnissen“ (PDS 25.11.1999: 6654).

In der 16. Legislaturperiode wird die Wachstumsdynamik des Sektors erneuerbarer Energien wird mythenhaft aufgeladen (SPD 06.06.2008: 17730; vgl. Kapitel 5.2.3). Ökonomische Zielsetzungen werden dabei im Koalitionsvertrag mit den ,sozialen Anliegen der Menschen im Sinne des nachhaltigen Wirtschaftens" verbunden (Koalitionsvertrag 2005: 65). In den Debatten um die Energiepolitik spielen diese dann allerdings kaum mehr eine Rolle (vgl. auch Kapitel 5.1.2). Anstatt Energiepolitik an einer Orientierung an sozial-ökologischen Bedürfnissen oder gar am für das gute Leben Notwenigen auszurichten, geht es vielfach darum, international eine Vor-

17 Vgl. z.B.: „Unsere Politik der Energiewende bringt mehrfach Dividende: Sie ist gut für Umwelt und Wirtschaft und sie schafft Arbeitsplätze“ (SPD 27.06.2002: 24781).

18 Vgl. z.B.: „Eine ökonomische Grundwahrheit ist, dass nur technischer Fortschritt nachhaltiges Wachstum begründen kann“ (CDU 24.02.2005: 14980). „Mehr Wohlstand für alle ist nur durch nachhaltiges Wirtschaftswachstum erreichbar“ (CSU 07.11.2002: 464). „Der Emissionshandel soll Impulse für ein nachhaltiges Wachstum geben“ (GRÜNE 16.01. 2004: 7664).

19 Vgl. z.B.: „Ich denke, hier gibt es technisch-technologische Grenzen. Langfristig ist das Wachstumsmodell, welches auch die rot-grüne Koalition hochhält, eine Sackgasse“ (PDS 25.02.2000: 8436). 
reiterposition im Bereich erneuerbarer Energien einzunehmen ohne das eigene Wohlstandsmodell in Frage zu stellen (vgl. Kapitel 5.2.6).

Aus einer kritischen Positionierung heraus thematisiert die LINKE in der 16. Legislaturperiode die „Energiewende“ im Kontext von sozialen Bedürfnissen, wie Sozialstandards bei Arbeitsplätzen (LINKE 06.06.2008: 17736) oder Frieden (LINKE 02.07.2009: 25694).

In der 17. Legislaturperiode wird der Stellenwert von Wachstum als Zweck politischer Praktiken bereits durch den Titel des Koalitionsvertrags verdeutlicht: „Wachstum. Bildung. Zusammenhalt" (Koalitionsvertrag 2009). Dabei wird weiter an der Vorstellung ökologischen Wachstums festgehalten: So solle der Ressourcenverbrauch durch Energieeffizienz derart reduziert werden, dass der gleiche „Anteil am Bruttosozialprodukt mit nur der Hälfte der Energie produzier[t]“ werden kann (CDU 28.10.2010: 7167). Der Energiebereich diene der Sicherung einer „nachhaltige[n] wirtschaftliche Prosperität“ (17/3049: 2). Gleichzeitig treten ökologische Zielsetzungen von Wachstum in den Hintergrund: Das EEG wird von schwarz-gelb vor allem positiv gesehen, weil es ein „,massives Wachstum“ im Sektor erneuerbarer Energien verursacht habe und dadurch zum Treiber für „die Modernisierung der Energieinfrastruktur" wurde (17/3049: 4). Als Akteur*innen werden überwiegend private Unternehmen gesehen, weshalb deren wirtschaftliche Interessen Eingang in politische Zielsetzungen finden, während die (Lebens-)Bedürfnisse anderer Akteur*innen ausgeblendet werden (FDP 28.10.2010: 7173; vgl. Kapitel 5.2.4). Durch den Fokus auf marktwirtschaftliche und technologische Zielsetzungen kommen die Auswirkungen der Laufzeitverlängerung auf die Lebensbedingungen in den Reden der Regierungskoalition gar nicht erst in den Blick. Gleichzeitig kritisiert die Opposition die Verlängerung der Laufzeiten als rein profitorientiert (vgl. Kapitel 5.2.10).

Durch die Nuklearkatastrophe von „Fukushima“ gerät der Widerspruch der Kernenergie mit grundlegenden Lebensbedürfnissen in den Blick (z.B. Gesundheit, intakte Lebensgrundlagen, etc.). Mit der Artikulation von „Energiewende“ soll dieser Widerspruch überwunden werden. Sie wird implizit zum Leitprojekt für nachhaltiges Wachstum in einem Industrieland erhoben. Ziel sei es, die „Energiewende“ „ohne Wohlfahrtsverluste zu stemmen“ (FDP 13.06.2013: 31292) (vgl. Kapitel 5.2.6). Wachstum bleibt Ziel und Voraussetzung der „Energiewende ${ }^{20 ، ،}$ (vgl. Kapitel 5.4), während die Verbindung der Energiepolitik zu sozial-ökologischen Lebensbedürfnissen weiterhin aus den politischen Debatten externalisiert bleibt (vgl. z.B. CSU 13.06.2013: 31584; vgl. Kapitel 5.4). Wachstumsorientierte Zielsetzungen von „Energiewende“ werden dabei nicht nur von den Regierungsparteien CDU, CSU und FDP artikuliert, sondern teilweise auch von SPD und GRÜNEN. ${ }^{21}$

20 So machen laut FDP die „,erhöhten Wachstumszahlen“ „,den zugegeben riskanten Weg dieser Energiewende“ leistbar (FDP 30.06.2011: 13396).

21 Vgl. z.B.: „Wir sind mit der Energiewende angetreten, um zu zeigen [...], dass eine hochentwickelte Volkswirtschaft wie die deutsche es schafft, sich von nuklearer, langfristig aber auch von fossiler Energieversorgung zu befreien, ohne dabei ihren wirtschaftlichen Erfolg zu gefährden“ (SPD 27.06.3014: 3932). Vgl. z.B.: Deutschland steht „an der Schwelle, im 21. Jahrhundert Vorreiter für die Green Economy zu sein“ (GRÜNE 30.06.2011: 13382). 
Da eine Einbettung der „Energiewende“ in Grundfähigkeiten, bzw. sozial-ökologische Bedürfnisse kaum erfolgt, erscheint eine marktökonomische Ausrichtung insgesamt als Selbstzweck und übergeordnetes Ziel.

Die Vorstellung ,ökologischen Wachstums‘ wird durch die Ausbreitung der hegemonialen marktwirtschaftlichen Formation im Zusammenhang mit dem Narrativ des technokratisch-managementorientierten Ökokonsenses zwar gestärkt, andererseits treten ökologische Zielsetzungen eines solchen Wachstums immer weiter in den Hintergrund. So sind vor allem Kosten-Nutzen Kriterien in den Debatten um die „Energiewende“ der 18. Legislaturperiode zentral. Die Nennung ökologischer Zusammenhänge der „Energiewende“ bleibt auf wenige Ausnahmen beschränkt (bspw. die Vermeidung von „Nutzungskonkurrenzen mit dem Arten- und Naturschutz“ bei der Bioenergie (Koalitionsvertrag 2013: 54; Kapitel 5.1.2). Eine „Energiewende“ erscheint nur so lange legitim, als sie ihren ökonomischen Zweck nicht gefährdet. ${ }^{22}$

Insgesamt lässt sich schließen, dass mit Aufkommen des Narrativs der ,ökologischen Modernisierung' neben ökonomischen Zielsetzungen ökologische Zwecke des Wirtschaftens zwar Einzug in den Diskurs erhalten. Allerdings wird Ökonomie auch hierbei keine rein (lebens)dienende Funktion zugeschrieben, sondern sie wird immer gleichzeitig selbst als Zweck betrachtet. Die Frage, wie Aushandlungsräume für eine am guten Leben orientierte Energiepolitik geschaffen werden können, ist kein politisches Thema. Im Gegenteil, die Notwendigkeit dafür kommt gar nicht erst in den Blick, weil das auf monetärer Wertmessung beruhende Wohlstandsmodell und das daraus abgeleitete Ziel des Wirtschaftswachstums unhinterfragt bleiben. Die Frage der Lebensdienlichkeit der Energiepolitik scheint mit „Fukushima“ zwar kurzzeitig auf, erscheint aber mit der „Energiewende“ vermeintlich beantwortet. Obwohl die „Energiewende“ mindestens implizit mit der Sinn- und Legitimationsfrage von Wirtschaften in Verbindung steht (z.B. Erhalt von natürlichen Lebensgrundlagen, Generationengerechtigkeit) und dafür auch unabhängig der vorliegenden Ergebnisse Potenziale bietet, werden diese Fragen in den Debatten nach „Fukushima“ permanent aus dem Politischen gedrängt und durch marktökonomische Zielsetzungen ersetzt. Die „Energiewende“ als soll als Teil der glücksverheißenden Dimension des technokratisch-managementorientierten Ökokonsens der Marktökonomie zum Erfolg verhelfen (oder diese mindestens nicht behindern). Die Frage nach dem Wozu der „Energiewende“ wird in den Debatten eher mit Wachstum, Effizienz oder der internationalen Reputation Deutschlands beantwortet, als mit dem guten Leben - quantitativer Wohlstand, bemessen an Wirtschaftswachstum, erscheint als Effekt einer marktorientierten „Energiewende“. Durch den Fokus auf am Markt geäußerte Präferenzen, kommen vermeintlich private Bedürfnisse oder die Versorgungswirtschaft nicht in den Blick.

22 Vgl. z.B.: Es gehe ,nicht nur um den Ausbau der erneuerbaren Energien auf Teufel komm raus, sondern auch darum, [...] vernünftige wirtschaftliche Strukturen“ zu erhalten (SPD 01.06.2016: 16978). 


\subsection{EXTERNALISIERUNG ALS PRINZIP IM DISKURS UM ,ENERGIEWENDE“}

In Kapitel 3.2.2 wurde Externalisierung als Prinzip als Kriterium Vorsorgenden Wirtschaftens beschrieben und die theoretischen Parallelen zur Diskurstheorie von Laclau/Mouffe (2015) aufgezeigt. ${ }^{23}$ Die Externalisierungsstrukturen im Diskurs um „Energiewende“ werden im Folgenden zur besseren Strukturierung des Kapitels anhand von im Diskurs identifizierten hierarchisch strukturierten Dichotomien herausgearbeitet, innerhalb derer sich Abgrenzungs-/Abspaltungs-, Abwertungs- und Aneignungsprozesse zeigen.

\section{Kultur/Natur}

Becker/Jahn (2006) bezeichnen die Natur-Kultur-Unterscheidung als geschlechtlich kodierte ,zentrale Ordnungskategorie des hegemonialen westlichen Denkens“ (Becker/Jahn 2006: 227). ${ }^{24}$ Unabhängig der Ergebnisse der vorliegenden Arbeit bieten erneuerbare Energien zweifellos Potenziale für die Untergrabung dieser Dichotomie. So findet mit den erneuerbaren Energien eine graduelle Vereinigung von Schutz und Nutzung sowie Erhalten und Gestalten von Natur statt: bspw. durch die Vermittlung der Vermeidung von Ausbeutung fossiler Ressourcen sowie von Treibhausgasemissionen mit der Nutzung von Naturleistungen für die Energieproduktion.

Die vorliegende Analyse legt bisher allerdings den Rückschluss nahe, dass der „Energiewende“-Diskurs im Bundestag nicht vermittelnd, sondern verwertungsorientiert ausgerichtet ist und mit weiteren Ausschlussprozessen einhergeht.

So wird Natur in den Debatten kaum artikuliert - wenn, dann wird sie passiv, als etwas zu Schützendes konstituiert, während ihre ständige Nutzung abgespalten und ausgeblendet wird. Gleichzeitig wird Natur auf Klima reduziert, wodurch Klimaschutz als einziges umweltpolitisches Ziel politischer Praktiken im Rahmen erneuerbarer Energien und „Energiewende“ erscheint. Dies wird bspw. in der Kollokationsanalyse deutlich, in der „Naturschutz“ lediglich in der 14. Legislaturperiode als Knotenpunkt der Äquivalenzkette um „Energiewende“ auftaucht, während sich in der 15., 17. und 18. Legislaturperiode die ökologische Dimension auf „Klimaschutz“ reduziert. Darunter werden aber lediglich naturwissenschaftlich messbare und ökono-

23 Ebenso wie Biesecker/von Winterfeld (2014) für die Beschreibung von Externalisierungsstrukturen gehen auch Laclau/Mouffe (2015) von dualistischen Trennungsstrukturen aus, die für Identitäten konstitutiv und hierarchisch strukturiert seien. „Externalisierung als Prinzip bedeutet zunächst, dass etwas zum Außen gemacht werden muss, das dann als Abgespaltenes angeeignet werden kann. [...] Es findet sich überall dort, wo Menschen als nicht Zugehörige be- und vernutzt und wo Natur als ,frei` verfügbare, dem Wertvollen äuBere Ressource verbraucht wird“ (Biesecker/von Winterfeld 2014: 11).

24 Mit der Natur/Kultur Dichotomie einher gehen weitere hierarchisch strukturierte Dichotomien, bspw. Schutz/Nutzung, Statik/Dynamik, Erhalten/Gestalten oder Bewerten/Verwerten. 
misch handelbare Treibhausgaskonzentrationen einbezogen - weitere Kollokationen mit Bezug auf Natur kommen nicht vor ${ }^{25}$ (vgl. Kapitel 5.1.2).

Da die Ökonomie als überwiegendes Betätigungsfeld erscheint, findet eine implizite Reduktion der menschlichen Lebenswelt, der Kultur, auf das Ökonomische statt. Gleichzeitig wird Natur meist selbstverständlich als statisch vorhandenes Naturkapital vorausgesetzt, sie wird ökonomisch verwertet, aber nicht bewertet. So wird bspw. der „Erfolg“ durch erneuerbare Energien und „Energiewende“ hauptsächlich als ökonomischer Erfolg adressiert, während der Anteil von und die Folgen für die Natur ausgeblendet werden (vgl. Kapitel 5.1.2). Dieses Verhältnis zwischen Ökonomie und Natur zeigt sich bereits in den Debatten im Rahmen des Narrativs der ,ökologischen Modernisierung' in der 14. und 15. Legislaturperiode. So sollen unter dem Begriff der ,ökologischen Modernisierung ' Ökologie und Ökonomie zwar vermittelt werden (vgl. z.B. Koalitionsvertrag 1998: 1), aber gleichzeitig wird diese ,Modernisierung“ in erster Linie ökonomischen Zielsetzungen untergeordnet (vgl. Kapitel 5.2.1). Immer wieder scheinen in der Folge teilweise vermittelnde, nicht grundsätzlich dichotome Naturverständnisse auf, bspw. wenn Natur als „Lebensgrundlage“ benannt wird (vgl. z.B. Koalitionsvertrag 2002: 7). Durch den Fokus auf marktorientierte Lösungen werden aber die Produktivitäten und Produktionszyklen der Natur ausgeblendet, Natur wird als passives Objekt marktorientierter Politik abgewertet. Bereits im Begriff, ökologische Modernisierung' spiegeln sich auch die gesellschaftlichen Naturverhältnisse der sogenannten Moderne, in der von Gesellschaft und Natur als getrennten Sphären ausgegangen wird, wider. Die ökologische Krise wird daher nicht als Krisensymptom der Moderne aufgefasst, sondern vielmehr wird von einer Lösung ökologischer Probleme durch ,eine ökologische Modernisierung der Moderne“ ausgegangen, in der Wachstum und Entwicklung ökologisch angepasst werden (Krüger 2015: 112).

Das EEG als politische Praxis im Rahmen des Narrativs ,ökologische Modernisierung' zielt nicht explizit auf eine Organisation erneuerbarer Energien nach marktwirtschaftlichen Prinzipien ab. Es materialisiert sich außerhalb des Bundestags auch in einer nicht-vermarktungsorientierten Vermittlung ${ }^{26}$ von Erhalten und Gestalten, von Schutz und Nutzung, Natur und Kultur. Diese Dimension des EEG bleibt in den Debatten im Bundestag allerdings unbeleuchtet. Im Mittelpunkt steht die Markteinführung von erneuerbaren Energien als Technologie - das EEG wird zum „Marktanreizprogramm“ interpretiert und dem Zweck der „Markteinführung“ erneuerbarer Energien untergeordnet (vgl. Kapitel 5.1.2). Diese werden somit dem ökonomischtechnologischen Bereich zugeordnet (vgl. Kapitel 5.1.2). Die ,automatische‘ ökologische Wirkung der Technologie wird als Annahme mit globalem Geltungsanspruch getroffen: Ohne „Klimaschutz“ mit politischen Inhalten zu füllen, wird gleichzeitig der Eindruck erzeugt, die ökologische Wirkung deutscher Klimapolitik entstehe über den Export erneuerbarer Energien quasi von selbst (vgl. Kapitel 5.2.6). Hier zeigt

25 Eine Ausnahme ist die 16. Legislaturperiode, in der die Debatte um „Energiewende“ aber marginal ist und Kollokationen in diesem Bereich hauptsächlich von der LINKEN gesetzt werden.

26 Bspw. in nicht gewinnorientierten Genossenschaften, durch nicht gewinnmotivierte private Nutzung etc. 
sich deutlich der instrumentelle Aspekt von Externalisierung: Das Abgespaltene wird für die Kapitalverwertung gebraucht.

Die Vorstellung eines dichotomen Verhältnisses zwischen Natur und Ökonomie dominiert die in Verbindung mit „Energiewende“ stehenden Story-Lines: Die Natur wird als das ,Andere' des Marktes betrachtet. Anstatt eine Transformation der Marktökonomie anzustreben, die ein erneuerndes Gestalten durch und mit Natur ermöglicht, wird die Marktökonomie, welche die Natur abspaltet, nicht hinterfragt.

Durch den Fokus auf das technologisch-messbare werden umweltpolitische Inhalte so stark auf Klimaschutz - im Sinne von Reduktion der $\mathrm{CO}_{2}$ Emissionen - reduziert, dass dieser in der 17. Legislaturperiode genutzt werden kann, um für die Laufzeitverlängerung von Atomkraftwerken zu argumentieren (vgl. Kapitel 5.2.1). Durch die Abspaltung sämtlicher ökologischer Folgen von Atomkraft und ihrer Unterordnung unter die Profitrationalität ${ }^{27}$ wird Kernenergie mit dem Ziel des Klimaschutzes artikulatorisch auf dem „Weg in das Zeitalter erneuerbarer Energien“ in einen „dynamischen Energiemix“ integriert (17/3049).

Diese hegemoniale Artikulation erfährt durch „Fukushima“ eine Dislokation: Die ökologischen Folgen der Kernenergie werden sichtbar und somit für kurze Zeit auch die Kultur/Natur Dichotomie. Der Glaube an die technologische Beherrschbarkeit von Natur wird herausgefordert. Der Begriff „Energiewende“ wird nun verwendet, um die Dislokation zu überwinden und die Trennungsstruktur zwischen Natur und Ökonomie wieder zu verdecken (vgl. z.B. CDU 30.06.2011: 13403). Diese Reartikulation in einer Äquivalenzkette mit „Energiewende“ ist jedoch nicht als Internalisierung von Natur zu bewerten, sondern nach Biesecker/von Winterfeld (2014: 14) als „abspaltendes Einbeziehen“ im Rahmen der sich nun ausbreitenden und Schließung verheißenden hegemonialen marktwirtschaftlichen Formation um „Energiewende“. Durch Aufgehen des Narrativs „ökologische Modernisierung“ im fantasmatischen Narrativ der hegemonialen Formation, das ich als technokratisch-managementorientierten Ökokonsens bezeichnet habe, wird Natur nahezu vollständig aus den Dimensionen der Fantasie ausgeschlossen. Ökologische Krisen über den nuklearen Unfall hinaus werden externalisiert und als Gefahr für eine auf Erhalt von Wohlstand ausgerichtete Energiepolitik ausgeblendet (vgl. Kapitel 5.4).

In dieser Weise wird die Natur/Kultur-Dichotomie in den Debatten um „Energiewende“ nach „Fukushima“ nicht nur fortgeschrieben, sie festigt sich sogar: Durch die Artikulation von „Energiewende“ wird die Lösung ökologischer Probleme suggeriert, die aber de facto gar nicht Gegenstand der Debatten sind, sondern permanent aus dem Politischen gedrängt werden.

Der hegemoniale Externalisierungsprozess in Bezug auf die Kultur/Natur Dichotomie kann auch durch das fantasmatische Narrativ ,sozial-ökologischer Umbau“ nicht entscheidend herausgefordert werden, was seiner marginalisierten Diskursposition zuzuschreiben ist. Aufgrund der wenigen Artikulationen, die diesem Narrativ zugeordnet werden konnten, kann darüber hinaus aktuell noch nicht beurteilt werden, ob in ihm die Abspaltung und Abwertung von Natur aus dem Ökonomischen aufgehoben wird.

27 Vgl. z.B. „Wir wollen diesen Lastwagen voller Geld nicht verbrennen“ (CDU 28.10.2010: $7168)$. 


\section{Öffentlich/Privat}

Die Dichotomie öffentlich/privat spielt für die feministische Analyse eine wichtige Rolle, da sie aus der Verknüpfung von Männlichkeit mit Öffentlichkeit und der Verschiebung des Weiblichen ins Private hervorgeht. Das Private wird dabei als Residualkategorie generiert und abgewertet, als das, was das Öffentliche nicht ist. Das Private entspricht also hier dem Externen. Gleichzeitig erfolgt eine implizite hierarchische Bewertung. „Durch ihre Zuordnung zur Privatsphäre [...] werden die Lebensund Arbeitszusammenhänge von Frauen weitgehend unsichtbar gemacht, ihre Erfahrungen, Interessen, Organisations- und Aktionsformen als nicht politikwürdig ausgeschlossen“ (Wischermann 2003: 23).

Wie bereits herausgearbeitet wurde, zeigt sich in den untersuchten Plenardebatten eine Reduktion des Öffentlichen auf das Ökonomische, welche als hauptsächliches Betätigungsfeld erscheint. Die Ökonomie wird zwar der Gesellschaft zugeordnet (soll Arbeitsplätze schaffen etc.), soziale Themen werden aber insbesondere in der Fokussierung auf das Arbeitsplatz-Argument auf den ökonomischen Bereich reduziert (vgl. z.B. Kapitel 5.2.3), nur Erwerbsarbeit wird gesehen. Der Blickes auf das ,Soziale" wird dadurch verengt. Soziale Themen, die sich nicht in der Perspektive auf (Markt)Ökonomie verarbeiten lassen, werden implizit dem privaten Bereich zugeordnet und im Zuge dieses Externalisierungsprozesses kaum artikuliert - so ist von Sorgearbeit keine Rede. Dies wird bereits in der Kollokationsanalyse deutlich, in der sich kaum Differenzbeziehungen zeigen, die auf den sozialen Bereich zielen (vgl. Kapitel 5.1.2). Die Ausgrenzung des Sozialen aus dem sichtbaren öffentlichökonomischen Bereich hat wie oben dargestellt auch eine geschlechtshierarchische Dimension, da der öffentliche Bereich bedingt bspw. durch gesellschaftliche Arbeitsteilung immer noch eher männlich konnotiert ist, während Frauen eher dem privaten Bereich zugeordnet werden, wie die feministische Wissenschaft seit den 1970er Jahren herausgearbeitet hat (vgl.z.B. Bock/Duden 1976; Fraser 1996; Lerner 1991). Damit verwoben sind weitere Dichotomisierungsprozesse: Akteur*innen des öffentlich-ökonomischen Bereichs werden bspw. eher als aktiv konstituiert, Akteur*innen des Privaten eher als passiv (vgl. z.B. die Rolle der Bürger*innen in Kapitel 5.2.8 ).

Die Trennungsstruktur zwischen öffentlich und privat manifestiert sich bereits in den energiepolitischen Debatten im Rahmen des Narrativs ,ökologische Modernisierung' in der 14. und 15. Legislaturperiode. Privatpersonen werden dabei auf ihre Funktion als ökonomische Akteur*innen, meist Konsument*innen oder Investor*innen, reduziert (vgl. Kapitel 5.2.1). In dieser Rolle werden sie zwar in den Bereich des öffentlich-Ökonomischen einbezogen, aber gleichzeitig abspaltend dem Privaten zugeordnet und somit als passiv konstituiert. Die Möglichkeit einer aktiven Konsument*innenfunktion, bei der die Bürger*innen aus eigener Fähigkeit zur Verantwortung heraus nachhaltigen Konsum praktizieren, wird nicht artikuliert. Eine derartiges Handeln aus „Sorge und Vorsorge für sich und für andere“ heraus würde bspw. dem Menschenbild des Vorsorgenden Wirtschaftens entsprechen (Theoriegruppe Vorsorgendes Wirtschaften 2000: 30). Im „Energiewende“ - Diskurs dominieren aber selbst im Narrativ der ,ökologischen Modernisierung ' diskursive Muster, die das Bild von nutzenmaximierenden Konsument*innen zeichnen, die durch veränderte Nachfrage scheinbar, automatisch` auf Marktsignale des öffentlich-ökonomischen Bereichs, wie bspw. Preisänderungen, reagieren. Demnach zielen die als reformistisch klassifizierten politischen Praktiken darauf ab, über marktanreizinitiierte 
Verhaltensänderungen einen Beitrag der Konsument*innen zur ,ökologischen Modernisierung' zu erwirken. Als Beispiel ist die sogenannte Ökosteuer zu nennen, die mit dem Ziel eingeführt wird, „marktwirtschaftliche Anreize für [...] ein umweltbewußtes Verhalten der Verbraucherinnen und Verbraucher" zu setzen (Koalitionsvertrag 1998: 11). Dass die Einnahmen aus der Steuer nicht für ökologische Maßnahmen, sondern für Kosteneinsparungen der Industrie eingesetzt werden (nämlich die Senkung der Lohnnebenkosten (Koalitionsvertrag 1998: 12)), ist als weiteres Indiz für eine Abwertung des Ökologischen und des Sozialen gegenüber dem Marktwirtschaftlichen zu werten. Die sozialen Auswirkungen einer marktorientierten ökologischen Modernisierungspolitik unter dem Motto ,Arbeit verbilligen, Ressourcen verteuern $^{28 ،}$ (SPD 25.11.1999: 6740) werden kaum hinterfragt - die Konsequenzen für den privaten Bereich durch die Verteuerung des Konsums, u.a. für die Sorgearbeit, bleiben überwiegend im Dunkeln. Dem öffentlich-Ökonomischen werden unter dem Primat von Wachstum andere in den Bereich des Privaten verschobene Ziele untergeordnet.

Deutlich wird eine Ausgrenzung des Sozialen aus dem Bereich des öffentlichÖkonomischen auch in den Debatten um die Befreiung der energieintensiven Industrie von der EEG-Umlage in der 16. Legislaturperiode. Während die Auswirkungen des Strompreises auf die Industrie problematisiert werden, werden die Auswirkungen dieser Befreiung auf private Haushalte lediglich von der jeweiligen Opposition adressiert (vgl. Kapitel 5.2.5). Neben ihrer Rolle als Konsument*innen wird den privaten Haushalten spätestens ab der 17. Legislaturperiode hauptsächlich die Aufgabe zugewiesen, die „Energiewende“ zu akzeptieren. Akzeptanz als Ergebnis eines Bewertungsprozesses enthält eine aktive Komponente und birgt über entsprechende Einbeziehung und Beteiligungsmöglichkeiten die Chance einer aktiveren Rolle von Bürger*innen. Schweizer-Ries u.a. (2011: 140ff.) beschreiben eine aktive und eine passive Dimension des Akzeptanzbegriffes, wobei die aktive Dimension aktives Engagement und Unterstützung beinhalte, während die passive Dimension nur auf Befürwortung beruhe. Die in den Debatten um „Energiewende“ adressierte Akzeptanz zielt dabei eher auf einen passiven Akzeptanzbegriff: Bürger*innen sollen die „Energiewende" befürworten und sich nicht dagegen wehren (vgl. z.B. Angela Merkel 09.06.2011: 12961). Dies beinhaltet auch eine fordernde Haltung an die Bürger*innen in einen vermeintlichen energiepolitischen Konsens einzustimmen (vgl. Kapitel 5.2.8), was bspw. beim Thema Netzausbau in den Debatten der 17. und 18. Legislaturperiode eine besondere Rolle spielt (vgl. Kapitel 5.2.7). Dabei wird die mangelnde Akzeptanz als hauptsächlich mitverantwortlich für den zu langsamen Netzausbau dargestellt und die Verantwortung für das langsame Voranschreiten der „Energiewende“ ins Private verschoben, während strukturelle Ursachen wie das Festhalten an konventionellen Kraftwerken trotz massiver Überkapazitäten (www.unendlich-viel-energie.de - verfehlte Ausbauziele) lediglich von der Oppositi$\mathrm{on}^{29}$ thematisiert werden (vgl. Kapitel 5.2.7). Das ins Privaten verschobene Soziale

28 Vgl. z.B.: „Die Kosten für den Faktor Arbeit werden gesenkt. Im Gegenzug wird der Verbrauch von Energie und Rohstoffen verteuert“ (SPD 25.11.1999: 6740).

29 Vgl. z.B.: „Das Falscheste ist, eine neue Fertigung mit 100 Prozent Leistung aufzubauen und die alte Fertigung mit kompletter Kapazität zu erhalten“(LINKE 01.06.2016: 16985). 
erscheint so als Gefahr bzw. Hindernis für die „Energiewende“, während das öffentlich-Ökonomische in Verbindung mit einem technologieorientierten Fortschrittsglauben als wertvoll erscheint.

Politische Willensbekundungen der Bürger*innen scheinen nur erwünscht insofern sie dem vermeintlichen energiepolitischen Konsens entsprechen. Während vor „Fukushima“ einerseits die massiven Proteste von Bürger*innen gegen die Laufzeitverlängerung ignoriert werden (vgl. Kapitel 5.2.8), wird andererseits Akzeptanz für einen „energiepolitischen Konsens“ eingefordert (17/3049: 18). Nach „Fukushima“ werden dagegen eben diese gegen Atomkraft protestierenden Bürger*innen in einen ,neuen Konsens` einbezogen (Angela Merkel 17.03.2011: 10886f.), jedoch ohne ihnen eine aktive Rolle bei der politischen Gestaltung von „Energiewende“ zuzuweisen und ohne ihren Beitrag zu diesem ,neuen Konsens' zu thematisieren. Dieses Einbeziehen ist demnach als ,abspaltendes Einbeziehen` zu bewerten, was sich dadurch verstärkt, dass die Bürger*innen gemeinsam mit der Bundesregierung in ein kollektives „Wir“ eingebunden werden - verbunden mit einem Appell weitere Protestaktionen zu unterlassen (Angela Merkel 09.06.2011: 12961ff.).

Wie sich an den Protesten gegen die Laufzeitverlängerung und vor allem nach „Fukushima“ ablesen lässt, hat die aktive Rolle der Bürger*innen bspw. im Rahmen der Anti-Atombewegung zur Bedeutungsgenerierung von „Energiewende“ im Bundestag zumindest indirekt beigetragen und sich in den folgenden politischen Praktiken auch materialisiert. Die vorliegende Diskursanalyse legt allerdings nahe, dass diese aktive Rolle in den Debatten um „Energiewende“ im Bundestag meist ausgeblendet wird und außerhalb einiger Artikulationen durch die jeweilige Opposition unsichtbar bleibt. Dieser Trennungsprozess, durch den die Bürger*innen aus den politischen Entscheidungen zur „Energiewende“ extrahiert und ins Private verschoben werden, während sich das politische Betätigungsfeld auf das Ökonomische beschränkt, ist Symptom einer sich ausbreitenden hegemonialen marktwirtschaftlichen Formation im „Energiewende“-Diskurs (vgl. Kapitel 5.1.3 und 5.4). Politische Praktiken im Rahmen ,marktorientierter Energiepolitik' folgen der Annahme, dass Innovationen und technische Verbesserungen ausschließlich durch Wettbewerb und Marktanreize (wie Absenkung der Fördersätze) entstehen (CDU 06.06.2008: 17742). Gesellschaftliche Faktoren oder andere Motivationen außerhalb von Gewinnorientierung werden ausgeblendet (vgl. Kapitel 5.3.2). Auch die Bewertung des „Erfolgs“ der „Energiewende“ wird als hauptsächlich abhängig von ökonomischen und technologischen Faktoren konstituiert, während private Haushalte in der Bewertung kaum eine Rolle spielen (vgl. Kollokationsanalyse zu „Erfolg“ in Kapitel 5.1.2). Ihr Anteil am „Erfolg“ der Energiewende bleibt im Dunkeln.

Allerdings geht die Ausbreitung der hegemonialen marktwirtschaftlichen Formation ab der 17. Legislaturperiode auch mit verstärkten Kämpfen um die Zuweisungen zum öffentlichen und privaten Bereich einher. Dies zeigt sich bspw. durch den gestiegenen Signifikanzwert der Kollokationen „Bürgerinnen“ und „Bürger“ in der 18. Legislaturperiode (vgl. Kapitel 5.1.2). Im Zuge der Novellierungen des EEG in der 18. Legislaturperiode droht sich die den Bürger*innen im Diskurs zugeschriebene Rolle in der politischen Praxis weiter zu materialisieren. GRÜNE und LINKE kritisieren, dass durch das veränderte Ausschreibungsdesign hauptsächlich große Konzerne zu Akteur*innen der „Energiewende“ werden (vgl. z.B. LINKE 27.06.2016: 16985). Durch den hohen Aufwand der Teilnahme an Ausschreibungen, seien diese 
für Bürger*innenenergieprojekte, die sich oberhalb einer von Ausschreibungen befreiten Erzeugungsgrenze befinden, kaum noch handhabbar (vgl. Kapitel 5.2.8). Im Zuge des Dissenses über die Rolle der Bürger*innenenergie wird diese verstärkt Gegenstand politischer Praktiken, wobei sie in hegemonialer Aneignung in die marktwirtschaftliche Formation einbezogen wird. ${ }^{30}$ Blieb die Bürger*innenenergie zuvor im Schatten des Privaten, wird sie nun dem Öffentlich-Ökonomischen zugeordnet und droht ohne gleichzeitige Umgestaltung der hier vorherrschenden Machtstrukturen zu verschwinden (vgl. z.B. GRÜNE 01.06.2016: 16974; vgl. Kapitel 5.2.8).

Die Dichotomie öffentlich/privat kann hier auch im Kontext von Geschlecht als Strukturkategorie (Hofmeister u.a. 2013b: 47f.; 62ff.) interpretiert werden, denn es konnte gezeigt werden wie im „Energiewende“-Diskurs die Abgrenzung und Abwertung des Sozialen produziert und reproduziert wird und so die gesellschaftlichen Bedingungsgefüge mit hervorgebracht werden, in denen über die Kategorie Geschlecht als Platzanweiserin das als sozial Weibliches Markierte aus dem Politischen verbannt und ins Private verwiesen wird.

\section{Produktiv/Reproduktiv}

Die Dichotomien öffentlich/privat sowie Natur/Kultur sind mit der Dichotomie produktiv/reproduktiv verwoben: Als produktiv gilt vor dem Hintergrund hegemonialer Gesellschafts- und Naturverhältnisse das öffentlich-Ökonomische, während die dem Privaten zugewiesene als sozial weiblich markierte Produktivität und die Leistungen der Natur als reproduktiv abgespalten werden. Dies manifestiert sich im Rahmen der vorliegenden Diskursanalyse bspw. dadurch, dass der „Energiewende“, bzw. den erneuerbaren Energien, immer dann und nur solange ein hoher Stellenwert beigemessen wird, wie sie aus Perspektive markwirtschaftlicher Diskursmuster als produktiv eingeordnet werden. Energie gilt dabei als „Schlüsselfaktor“ für die Wirtschaft (SPD 27.06.2002: 24776). Ob eine umfassende das Soziale und Ökologische integrierende „Energiewende“ stattfindet oder nicht, erscheint vor dem Hintergrund ,erneuerbarer Energien als Wirtschaftsfaktor` zunächst irrelevant (vgl. Kapitel 5.2.3). Gleichzeitig wir die Produktivität erneuerbarer Energien mythenhaft aufgeladen, mehrfach ist von ,Wundern“ die Rede („Jobwunder“, „Gründungswunder“) (SPD 06.06.2008: 17730). Produktivität wird auf ,warenförmige Arbeit (Erwerbsarbeit) und Kapital“ reduziert (Biesecker/Hofmeister 2006: 133) und nur das wird inwertgesetzt. Die Betonung einer solchen Produktivität erneuerbarer Energien wird in der 17. Legislaturperiode als Begründung herbeigezogen, um den Kurswechsel der schwarz-gelben Regierung nach „Fukushima“ zu legitimieren. Es wird nun von „Energiewende“ gesprochen, während dabei erneuerbare Energien weiterhin überwiegend als Produktionsfaktor adressiert werden. Dessen Inwertsetzung im Rahmen einer „Energiewende“ wird nun auch von CDU, CSU und FDP als internationale „Chance“ gesehen (vgl. FDP 09.06.2011: 12968; vgl. Kapitel 5.2.3).

30 Vgl. z.B.: „Es ist doch so, dass die Fakten insoweit eindeutig sind, dass [...] wir jetzt an einem Punkt sind, an dem die erneuerbaren Energien den Systemwechsel schaffen müssen und auch schaffen werden, nämlich von dem bewährten System des EEG hin zu einem System mit Wettbewerb und Marktwirtschaft“ (CDU 01.06.2016: 16990). 
Das vermeintlich Reproduktive, die sozial weibliche Produktivität und die Naturproduktivität, wird vom vermeintlich Produktiven abgespalten und kommt als Element in den Debatten kaum vor - die Ökonomie erscheint als „Durchflussökonomie“ (Biesecker/Hofmeister 2006: 133). Marktorientierte Instrumente wie der Emissionshandel nehmen zwar Naturleistungen zum Teil in den Blick und scheinen die Dichotomien zwischen Be- und Verwerten sowie Schutz und Nutzung teilweise zu überwinden, indem sie $\mathrm{CO}_{2}$ bewerten. Allerdings wird auch dabei das lineare Modell der „Durchflussökonomie“ nicht durchbrochen, da sich der Preis an Angebot und Nachfrage bemisst und die naturale Produktion wiederum ausgeblendet wird. Es wird davon ausgegangen, dass der Emissionshandel automatisch zu „Umweltschutz“ führe (CDU 28.05.2004: 10236) ohne das Verhältnis von Preis zum Aufwand naturaler (Re)Produktion zu betrachten. Dabei bieten die erneuerbaren Energien die Chance, Naturproduktivität sichtbar zu machen, da sich die Hybridität von erneuerbarer Energie als ,NaturKulturProdukt‘ (vgl. Biesecker/Hofmeister 2006: 147ff.) aufdrängt. Diese Hybridität scheint im Diskurs aber nur an wenigen Stellen durch („Denn die Sonne schickt uns keine Rechnung" (GRUENE 28.05.2004: 10245)“). Gleichzeitig wird scheinbar von einer unendlichen Ressourcenverfügbarkeit ausgegangen (vgl. z.B. SPD 25.08.2004: 10235), wodurch der Anteil der ,Natur' an der Produktion der Solarmodule oder anderer Anlagen, und verbunden damit die Endlichkeit der verfügbaren Ressourcen, ausgeblendet werden.

Ebenso selten wie Naturproduktivität wird sozial weibliche Produktivität adressiert, wie bspw. die Produktivität der ins Private verwiesenen Sorgearbeit. Private energieverbrauchende vermeintliche Konsumtion kommt in ihren produktiven Tätigkeitsformen (bspw. in Form von Wäsche waschen oder Kochen) nicht in den Blick und wird als passive Handlung beschrieben, die durch Preissignale gesteuert werde (s.o., Ökosteuer). Gleichzeitig wird ein großer Teil ökologischer Verantwortung in diesen privaten Konsumbereich verschoben, da staatliche Eingriffe in den marktwirtschaftlichen Produktionsbereich unerwünscht sind und mitunter sogar zur wesentlichen Gefahr für und gleichzeitig durch die „Energiewende“ stilisiert werden. Vor diesem Hintergrund wird im Diskurs an die „Eigenverantwortung“ und „Vernunft“ der Konsument*innen appelliert. ${ }^{31}$

Mit der diskursiven Ausgrenzung der Produktivität vermeintlicher Konsumtion, zum Beispiel in Form einer aktiven auf „Sorge und Vorsorge für sich und für andere“ (Theoriegruppe Vorsorgendes Wirtschaften 2000: 30) ausgerichteten Konsument*innenrolle, geht das Ausblenden der Produktivität des Privaten im Energiebereich einher. Der aktive Anteil, den Haushalte sowohl am Energieverbrauch als auch der -produktion innehaben, wird größtenteils nicht thematisiert, obwohl die „Energiewende" Chancen bietet, die Dichotomie zwischen Produktion und vermeintlicher Konsumtion auf Haushaltsebene zu überwinden, indem die Haushalte nicht mehr nur scheinbar passive Konsument*innen sondern auch Produzent*innen von Energie sein können (Prosumer*innen). Auch auf diese Prosumtion zeichnet sich aber eine sozial

31 Vgl. z.B.: „Dabei setzt die Bundesregierung auf Vernunft und Eigenverantwortung von Wirtschaft und Bürgern und nicht auf mehr Bürokratie“ ... „Unternehmer und [...] Verbraucher“ sollen „bisher ungenutzte Potentiale im Bereich Energieeffizienz aus eigenem Antrieb“ erschließen (17/3049: 6). 
männliche Perspektive ab, indem als Produzent dann der „Familienvater“ genannt wird (GRÜNE 29.03.2012)). Eine mögliche Prosument*innenfunktion der Haushalte wird insgesamt aber kaum in den Blick genommen. ${ }^{32}$ Ein Aufbrechen der Dichotomie produktiv/reproduktiv ließe sich bspw. anhand von Modellen angehen, bei denen Mieter*innen an der Stromproduktion beteiligt sind. Tatsächlich können Mieter*innen durch Einführung des Mieterstromgesetzes 2017 stärker und aktiver an der Konsumtion von erneuerbarem Strom teilhaben - sie können selbst entscheiden, ob sie den Strom aus der häuslichen Solaranlage beziehen oder nicht. Allerdings haben sie meist keinen Anteil an der Stromproduktion, die in der Hand des*r Hausbesitzer*in bleibt (vgl. Kapitel 5.2.8). ${ }^{33}$ Vom Mieterstromgesetz profitieren aufgrund der gesetzlichen Bedingungen - neben den Mieter*innen ${ }^{34}$ - hauptsächlich Hauseigentümer*innen, die bereits zahlreiche Wohneinheiten besitzen sowie Energieversorgungsunternehmen, die die Anlagen betreiben, wenn der bürokratische Aufwand für den*die Vermieter*in zu hoch ist.

Weitere Chancen für eine aktive Konsument*innenrolle im Rahmen der „Energiewende“ werden im Diskurs gar nicht erst abgebildet. So könnten bspw. Haushalte innerhalb von sogenannten Microgrids ${ }^{35}$ auf intelligente Weise so verknüpft werden, dass nicht die Nachfrage an ein zentrales Angebot angepasst werden müsste, also sich der private Stromverbrauch nach dem öffentlichen Angebot richten müsste, sondern stattdessen eine beiderseitige Anpassung auf lokaler Ebene erfolgen würde. Nachbar*innen könnten untereinander innerhalb ihrer lokalen Gemeinschaften mit Strom handeln, wodurch auch Konsument*innen ohne eigene Solaranlage lokal produzierten Strom erwerben könnten und so mehr Entscheidungsmacht erhielten (Mengelkamp u.a. 2018: 207f.). Stattdessen soll in der politischen Praxis die Anpassung aber zukünftig über ,nachfrageseitiges Lastmanagament“ innerhalb von weiter zentral gesteuerten „Smart Grids“ erfolgen (17/3049:11). Über „Anreize in den Stromtarifen" sollen Konsument*innen ihre Nachfrage an das zentrale Angebot anpassen (17/3049:11). Zwar erhielten Konsument*innen eine begrenzte Entscheidungsmacht, ihren Stromverbrauch zeitlich an die Stromproduktion anzupassen, diese Anpassung wäre aber einseitig nachfragebasiert und würde über sogenannte ,Smart Meters' zentral gesteuert. Es wäre also eine Anpassung der Lebensgewohnheiten und somit des vermeintlich reproduktiven Bereiches an die Stromproduktion notwendig, was die hierarchische Strukturierung der Dichotomie produktiv/reproduk-

32 Die Buchstabenfolge Prosumer* taucht im gesamten Korpus in Bezug auf Energie lediglich drei Mal auf.

33 Darüber hinaus kommen laut einer Studie des BMWi aufgrund verschiedener Bedingungen nur maximal ca. 18\% der Mietwohnungen, insgesamt 3,8 Millionen Haushalte, für Mieterstrom in Frage (Koepp u.a. 2017: 82f.). Bspw. lohnt sich Mieterstrom nur bei einer höheren Anzahl von Wohnungen innerhalb eines Hauses. Weitere Einflussfaktoren sind der hohe bürokratische Aufwand, Sanierungsstand, Baujahr und Eigentumsverhältnisse (ebenda).

34 Die Strompreise für Mieterstrom müssen laut Gesetz um mindestens 10\% niedriger sein als ortsübliche Strompreise.

35 Microgrids sind Kleinststromnetze, die in der Regel mit dem zentralen Netz verbunden sind, aber auch autark funktionieren. 
tiv und somit eine Aneignung des vermeintlich Reproduktiven durch das vermeintlich Produktive erneut reproduzieren würde.

Ebenso wie die Dichotomie öffentlich/privat kann auch die Dichotomie produktiv/reproduktiv im Kontext von Geschlecht als Strukturkategorie (Hofmeister u.a. 2013b: 47f.; 62ff. ) interpretiert werden. Es konnte gezeigt werden wie im „Energiewende"-Diskurs im Bundestag die Abspaltung des vermeintlich Reproduktiven diskursiv reproduziert wird, indem dieses vermeintlich Reproduktive kein Gegenstand politischer Debatten ist und somit die Voraussetzungen für dessen Aneignung innerhalb politischer Praktiken geschaffen werden - die Auswirkungen dieser politischen Praktiken auf das Abgespaltene werden nicht betrachtet. Dementsprechend werden vorherrschende strukturelle, geschlechtlich kodierte Machtverhältnisse reproduziert.

\section{Zentral/Dezentral}

In der sich außerhalb des Bundestags materialisierenden „Energiewende“ zeigen sich veränderte gesellschaftliche Naturverhältnisse vor allem auch mit Blick auf die räumlichen Strukturen. „So werden die im fossilen Energiesystem dominanten zentralen Raumbeziehungen tendenziell durch dezentrale Produktionsstrukturen ersetzt“ (Amri-Henkel u.a. 2017: 16). Während eine zentrale Organisation der Energieversorgung weitgehend in den Händen privater großer Unternehmen liegt (also dem öffentlichen Bereich zugeordnet ist), ist die Akteur*innenvielfalt bei einer dezentralen Organisation wesentlich größer, da vermehrt kleinere Produzent*innen wie private Haushalte eine Rolle spielen. Die zentrale Organisation des Energiesystems bleibt in den politischen Debatten allerdings weitgehend unhinterfragt, liegt implizit zu Grunde, während die materiell bereits stattfindende Dezentralisierung durch erneuerbare Energien im Dunkeln bleibt. Die Kollokation „dezentral“ spielt für die Bedeutungsgenerierung von „Energiewende“ kaum eine Rolle und taucht zum ersten Mal in der 18. Legislaturperiode auf. Sie wird allerdings ausschließlich von der Opposition verwendet und bleibt dadurch in ihrer Bedeutung marginal (vgl. Kapitel 5.1.2). Auch der Ausbau der Netzinfrastruktur (vgl. Kapitel 5.2.7) erfolgt unter der Annahme großer Stromerzeugungszentren auf See und in Küstenregionen, ist also eher auf eine zukünftige zentrale Organisation ausgerichtet. Dies spiegelt sich entsprechend in den Artikulationen im Diskurs wider. Potenziale für eine Dezentralisierung durch die „Energiewende“ werden dadurch verdeckt und ins Außen des „Energiewende“Diskurses verwiesen.

\section{Rational/Emotional - Objektiv/ldeologisch}

Die Binarisierung von Gefühl und Vernunft sowie deren geschlechtliche Kodierung ist ein zentraler Aspekt der Geschlechterforschung. Geschlechterdiskurs und Gefühlsdiskurs können als zeitgleich grundlegend für die Herausbildung des bürgerlichkapitalistischen Staates und für die patriarchale Herrschaft betrachtet werden. Im kapitalistischen Rationalisierungsprozess werden nur bestimmte als männlich kodierte Emotionen als nützlich und berechtigt gewertet, und somit als produktiv konstituiert ${ }^{36}$

36 „Die Kontrolle von Leidenschaften und ihre Kanalisation in Interessen ist Teil eines Gefühlsdispositivs, mit dem sich das Bürgertum beste Bedingungen zu seiner Reproduktion schuf. Das Gefühlsdispositiv ist insofern »produktiv« und nicht zuvörderst repressiv, weil 
- der Rest werde der Natur und den Frauen zugewiesen (Sauer 1997: 9f.). Die geschlechtliche Kodierung des bürgerlichen Gefühlsdiskurses hat auch eine räumliche Dimension, indem weibliche Emotionen in den privaten Bereich verschoben werden, während Rationalität als vermeintlich männliche Eigenschaft sachliches, regelgeleitetes Entscheiden ermöglicht und dem öffentlichen Raum zugewiesen wird (ebenda: 10). (Sozial weibliche) Emotionalität wird zum ,Außen` des Politischen, sie wird als Gefahr für den politischen Raum konstituiert. Dieser Dichotomisierungsprozess zwischen Rationalität und Emotionalität zeigt sich deutlich in den Debatten zur „Energiewende“. Dabei wird Rationalität als handlungsleitendes Prinzip mit Objektivität verbunden, während politische Positionen der Gegner*innen als ideologisch, irrational und vermeintlich emotional abgewertet werden (vgl. Kapitel 5.4) - die Dichotomie rational/emotional wird auf diese Weise mit der Dichotomie objektiv/ideologisch verbunden. Vermeintlich rationale politische Positionen werden so naturalisiert, während andere, davon abweichende Positionen, als unsachlich gewertet werden. Gleichzeitig wird Vernunft, also Rationalität, im Sinne des bürgerlich-kapitalistischen Verwertungsprozesses auf marktökonomische ,Vernunft ‘ reduziert - ohne dies explizit zu machen. Als vernünftig gilt, was gut für die Wirtschaft ist (vgl. z.B. SPD 09.09. 2004: 11256; vgl. Kapitel 5.2.3). Diese Dichotomisierungsprozesse zwischen rational und emotional sowie objektiv und ideologisch zeigen sich besonders deutlich anhand der Debatte um die Laufzeitverlängerung der 17. Legislaturperiode, schreiben sich aber auch nach „Fukushima“ fort (vgl. Kapitel 5.4). Durch die Äquivalenzierung von ,wirtschaftlicher Vernunft', ,Ideologiefreiheit', ,Marktorientierung' und ,Technologieoffenheit“ (17/3050; 17/3049) vor „Fukushima“" entsteht eine antagonistische Zweiteilung des diskursiven Raumes. Das antagonistische Außen, das ,Andere“, bleibt unbenannt, wird aber implizit als ,emotional', ,unsachlich', ,irrational' und ,unwirtschaftlich' abgewertet. Eine Energiepolitik ohne Kernenergie wird so zunächst implizit diesem ,Anderen' zugeordnet, wird zum ,ideologischen“ und ,parteipolitische[n] Kampfthema“ erklärt (CDU 28.10.2010: 7179). „[W]irtschaftliche Vernunft", die CDU, CSU und FDP den anderen Fraktionen absprechen, sei Voraussetzung für die Erreichung ökologischer Ziele (FDP 28.10.2010: 7187).

In Kapitel 5.4 wurde gezeigt wie die Dislokation „Fukushima“ mit der Aneignung von „Energiewende“ durch eine sich ausbreitende hegemoniale marktwirtschaftliche Formation um den ,technologisch-managementorientierten Ökokonsens überwunden wurde: Die „Energiewende“ wird nicht mehr diskursiv im Außen verortet, sondern wird vor dem Hintergrund einer ,neuen Lage‘ in die Äquivalenzkette um ,Vernunft' und ,Objektivität‘ integriert und nun ihrerseits von ,Emotionalität‘ und ,Ideologie" abgegrenzt. Gleichzeitig wird die Ursache für die Katastrophe in „Fukushima“" als nicht objektiv vorhersehbar konstruiert (Angela Merkel 17.03.2011: 10884f.). Die „Emotionalität dieser Debatte“ nach „Fukushima“ sei daher nicht gerechtfertigt (FDP 17.03.2011: 10895), die Opposition sei „hysterisch“, wobei „hysterisch“ im genannten Beispiel explizit auf eine weibliche Vorrednerin abzielt, um de-

es zunächst einmal die regulierte »leidenschaftslose« Realisierung von ökonomischen Interessen in einem »gefühlsfreien« Raum erlaubte“. Gier, Habsucht und Gewinnsucht waren Emotionen, die im Kapitalisierungsprozess nutzbringend eingesetzt werden konnten (Sauer 1997: 9). 
ren Beitrag gegenüber der als ,Norm“ deklarierten ,Vernunft‘ abzuwerten. ${ }^{37}$ Die „Energiewende“ als Teil des ,neuen Konsenses“ solle dabei in Abgrenzung zu früheren Ansätzen der rot-grünen Bundesregierung, die „nur ihre Ideologie befriedigt“ habe, „vernünftig[...]“ sein (FDP 09.06.2011: 12967). Rationalität als vermeintliche ,Entpersönlichung، von Herrschaft solle die Berechenbarkeit politischer Handlungsabläufe suggerieren (Sauer 1997: 12): Während die Opposition von ,glauben“ spreche und „,von der Realität [...] wenig Ahnung“ habe, rede die CDU von „Fakten“ (CDU 29.03.2012: 20304). Der Prozess einer vermeintlichen „Versachlichung“ der „Energiewende“ erscheint hier als „Störfreimachung“ (vgl. Sauer 1997: 12) durch Zurückdrängung nicht-marktwirtschaftlicher Positionen und Emotionen. Politische Positionen, die nicht mit einem Verständnis von „Energiewende“ unter der StoryLine ,Marktorientierung als Bedingung von Energiepolitik' kompatibel sind, werden dem ,Anderen' zugewiesen und als ,ideologisch', ,unwirtschaftlich', ,irrational', ,emotional‘ oder ,sozialistisch“ abgespalten und abgewertet ${ }^{38}$ (vgl. Kapitel 5.4). Untermauert wird das Postulat einer vermeintlich objektiven Sicht auf die „Energiewende" durch die vermehrte Einberufung von Expert*innenkommissionen - beginnend mit der ,Ethikkommission Sichere Energieversorgung‘. Letztlich wird dies zur Legitimation politischer Entscheidungen angeführt- ohne, dass auf die Ergebnisse etwaiger Kommissionen zwangsläufig politische Konsequenzen folgen müssen (vgl. Kapitel 5.2.9).

Sieht sich die SPD noch in der 17. Legislaturperiode selbst mit dem Ideologievorwurf konfrontiert, ändert sie in der Regierungskoalition der 18. Legislaturperiode ihre Diskursposition und wertet die Kritik der Opposition selbst als ,irrational', ,ideologisch“ (SPD 01.06.2016: 16979) und ,emotional“ (,aufgeregt“ (SPD 10.04.2014: 2443)), bzw. „schrill ${ }^{39 ،}$ ab. Ein „nüchterneres“ im Gegensatz zu einem ,emotionalen“ Verhältnis zur „Energiewende“ („Die Euphorie ist verflogen“) wertet die CDU gegen Ende der 18. Legislaturperiode als positiv für die „deutsche Volkswirtschaft“ (CDU 29.06.2017 24992). Emotionalität erscheint hier als Störfaktor für die „Energiewende“, eine Gefahr für die politische Debatte über sie und ihre marktwirtschaftliche Entwicklung.

Analog zur Dichotomie rational/emotional zeigten sich auch die Dichotomien öffentlich/privat sowie produktiv/reproduktiv analytisch fruchtbar, um die Geschlech-

37 „Es ist klug, in diesem Zusammenhang nicht panikhaft und hysterisch zu agieren, sondern die Dinge sachlich und richtig zu analysieren und dann vernünftig zu entscheiden. [...] Frau Höhn, mit den Worten ,panikhaft" und ,hysterisch“ habe ich auch Sie gemeint" (CSU 24.03.2011: 11300).

38 Vgl. z.B.: „Bei den ideologischen Ergüssen und sozialistischen Ausarbeitungen Ihrerseits fällt es manchmal schwer, gelassen zu bleiben, [...]. Meine Damen und Herren, ich weiß, dass Sie Probleme mit dem demokratischen Rechtsstaat und dem demokratischen System haben. Aber nicht Sie entscheiden über Recht und Unrecht; [...] Darüber entscheidet auch kein ZK oder Politbüro, sondern dieses Haus [...]. Meine Damen und Herren, wir haben es nicht nötig, uns mit solchen Leuten auf Anti-Marktwirtschafts-Debatten einzulassen“ (CDU 29.03.2012: 20292f).

39 Vgl. z.B.: „Gott sei Dank kümmert sich die Energiewende nicht um solche schrillen Reden“ (SPD 01.06.2016: 16981). 
terperspektive auf „Energiewende“ zu vervollständigen. Diese Externalisierungsprozesse stehen für eine Ausgrenzung des dem weiblichen zugeschriebenen Sozialen aus dem öffentlichen Politischen in Verbindung mit einer Abwertung des als reproduktiv abgewerteten Sozialen und Ökologischen. Eine Vermittlung zwischen ,Innen“ und ,Außen` im Rahmen der Kategorie der (Re)Produktivität findet nicht statt. Wie bereits dargestellt zeigt sich in diesen Dichotomien Geschlecht als gesellschaftliche Strukturkategorie. Darüber hinaus kann insbesondere die Dichotomie rational/ emotional auch im Kontext von Geschlecht als Prozesskategorie (,doing gender ${ }^{6}$ ) interpretiert werden. ,Doing gender' fragt danach wie Geschlecht in sozialen Prozessen reproduziert und hervorgebracht, also hergestellt wird (West/Zimmermann 1987). Mit der Abwertung speziell weiblicher Rednerinnen als ,hysterisch', wird nicht nur die Bedeutung wiederholt, die Emotionalität als Ausdruck weiblicher Natur festschreibt, sondern gleichzeitig auch das soziale Arrangement gerechtfertigt, welches eben diese Emotionalität aus dem politischen Raum verbannt. Die Selbstverständlichkeit, mit der eine vermeintliche Sachlichkeit/Rationalität als einzig legitimer Modus politischer Debatten festgeschrieben wird, verdeckt dessen (sozial männliche) Konstruktion und verunmöglicht die Frage nach dem geschlechtlich kodierten Herstellungsmodus dieser Aufteilung (vgl. auch Gildemeister 2008: 137).

\section{Natur- und Technikwissenschaft/Geisteswissenschaft}

Die Dichotomien Natur/Kultur sowie öffentlich/privat spiegeln sich auch in einer Spaltung der Wissenschaft in Naturwissenschaften auf der einen und Geisteswissenschaften auf der anderen Seite, die nicht nur methodisch, sondern auch institutionell abgegrenzt sind, wider. „Sie scheinen sich auf getrennte Bereiche in der realen Welt zu beziehen: auf die anorganische und die organische Natur einerseits, auf Kultur und Gesellschaft andererseits“ (Becker/Jahn 2006: 110). Die Geisteswissenschaften werden dabei gegenüber den Naturwissenschaften, die als objektiv gelten, abgewertet. Analog zu den bisher bereits analysierten Dichotomien, spielen in den Debatten zur „Energiewende“ Natur- und Technikwissenschaften eine deutlich größere Rolle als Sozialwissenschaften. Dabei wird eine Verwertungsorientierung der Wissenschaft deutlich $^{40}$, vor deren Hintergrund die Sozialwissenschaften aus dem Blickfeld geraten (vgl. Kapitel 5.2.9). Während Ergebnisse sozialwissenschaftlicher Forschung - mit Ausnahme der Akzeptanzforschung - häufig nicht direkt als marktökonomisch verwertbar in Betracht gezogen werden, wird die Erforschung der Natur und der Technik als Grundlage für die Ausbeutung der Natur herangezogen, durch die Akkumulation also erst möglich wird. Technologische Energieforschung - personifiziert durch den ,deutschen Ingenieur “ - solle Garant „für Wachstum und Wohlstand" sein und dem Export dienen (CDU 13.06.2013: 31547; CDU 30.06.2011: 13369).

Gesellschaftswissenschaftliche Themen, die zum Beispiel auf soziale Folgen des Klimawandels abzielen, werden wie gezeigt im Diskurs größtenteils überhaupt nicht benannt, die integrativen Potenziale sozial-ökologischer Forschung werden nicht

40 Vgl. z.B.: „Forschungsergebnisse“ zur „Energiewende“ sollen ,zügig in Form von innovativen und marktfähigen Produkten verwertet werden“ müssen (Koalitionsvertrag 2013: 25f.). 
gesehen. Umweltprobleme werden im Hinblick auf ihre technische Lösbarkeit betrachtet, während ihre sozialen und ökonomischen Ursachen und Wirkungen unbenannt bleiben. Die GRÜNEN kritisieren daher eine mangelnde interdisziplinäre Ausrichtung (GRÜNE 13.06.2013: 31550f.), die LINKEN fordern eine Ausweitung der Energieforschung zur Transformationsforschung (LINKE 13.06.2013: 31549) (vgl. Kapitel 5.2.9). Diese Forderungen bleiben marginalisiert, da sich auch in der Bezugnahme auf die Wissenschaft das Narrativ des ,technokratisch-managementorientierten Ökokonsenses` als Teil der hegemonialen marktwirtschaftlichen Diskursformation durchsetzt.

\section{Neokoloniale und nationale Externalisierung als Prinzip im Diskurs um „Energiewende“}

Wie in 3.2.2 dargelegt, zeigte sich Externalisierung als Prinzip im Zuge der Analyse deutlich auch in Form nationaler und neokolonialer Externalisierung, sodass eine Erweiterung der Theorie und Methodik notwendig wurde. Neokoloniale und nationale Externalisierung als Prinzip verweisen darüber hinaus auf die Kultur/Natur Dichotomie sowie die Verwobenheit von Geschlechterverhältnissen mit globalen rassistischen Ausbeutungsstrukturen und anderen intersektionalen Ausschließungsprozessen, wie im Folgenden deutlich gemacht wird.

Im vorliegenden Unterkapitel zeige ich anhand der in Kapitel 3.2.2 dargestellten Theorie, wie sich Formen des ,Othering sowie der Erzeugung von Subalternität, auch im Querschnitt mit hegemonialem Wissen und (neo)kolonialen Vorstellungen von Zeitlichkeit, in den energiepolitischen Debatten manifestieren. Darüber hinaus wird die Bedeutung der mit nationalen Motiven aufgeladenen Story-Line ,Deutschland als Vorreiter' im Zusammenhang mit energiepolitischen Praktiken und der Entwicklung des „Energiewende“ - Diskurses insgesamt analysiert.

Im Diskurs über „Energiewende“ wird das ,Andere“ auf vielfältige Weise produziert. ,Othering' manifestiert sich in den energiepolitischen Debatten ab der 14. Legislaturperiode unter anderem in der Dimension des ,Worldings' (des Weltenmachens). Dabei steht zum einen die Konsolidierung eines ,deutschen Selbst‘ im Mittelpunkt. So wird die Einführung erneuerbarer Energien von Anfang an mit einer deutschen Sonderrolle und einer internationalen Vorbildfunktion verknüpft (vgl. Kapitel 5.2.6). Zum anderen werden , andere‘ Länder, allen voran sogenannte Entwicklungsländer, von diesem konsolidierten Selbst als ,Vorbild‘ ausgehend gleichzeitig als unterlegen konstituiert. Es wird der Anschein erweckt, dass sie darauf angewiesen seien, sich am deutschen Vorbild zu orientieren und sie scheinbar die deutsche „Energiewende“ geradezu hoffnungsvoll erwarten. ${ }^{41}$ Dieses ebenso nationale wie (neo)koloniale diskursive Muster begründet sich auf einem ,Worlding“ in Verbindung mit der hegemonialen westlichen Wissensordnung. So wird im Rahmen der Story-Line ,Deutschland als Vorreiter' das Wissen über eine nachhaltige Energiepolitik als etwas ,Eigenes“ konstituiert, während die ,Anderen“ dieses Wissen mehr oder weniger passiv übernehmen. Diese Perspektive findet beispielsweise im Selbst-

41 Vgl. z.B.: „Ich bin mir ganz sicher, dass viele internationale Augen auf dieses Gesetz schauen werden und viele Erwartungen und Hoffnungen damit verbunden sind" (SPD 25.02.2000: 8437). 
verständnis deutscher Parlamentarier im Hinblick auf renewabales2004 Konferenz ihren Ausdruck. Durch ihr Wissen über die „Energiewende“ sprachen sie sich im Vorfeld der Konferenz die Befähigung zu, den ,Anderen“ „die Augen zu öffnen“, „zu zeigen, was wirklich möglich ist“ (SPD 28.05.2004: 10240).

Im nächsten Schritt zeigt sich in der Story-Line ,Deutschland als Vorreiter ‘ der Anspruch auf eine Globalisierung der „Energiewende“, wobei der Fokus dieser Globalisierung implizit auf die sogenannten Entwicklungsländern gelegt wird. Hier zeigt sich die Überschneidung von Wissen und Macht, bzw. was nach Spivak (1985: 255f.) als „epistemische Gewalt“ bezeichnet werden kann: „Entwicklungsländer dürfen und wollen nicht die Fehler wiederholen, die die Industrieländer bisher bei ihrer Energieversorgung gemacht haben, denn das hält unser Globus nicht aus [...]“ (SPD 28.05. 2004: 10234). Deutlich wird hier auch eine paternalistische Haltung: Der vermeintliche Wissensvorsprung wird nicht nur als Legitimation dafür herangezogen, sogenannten Entwicklungsländern die Art und Weise ihrer Entwicklung vorzuschreiben, ohne dabei die tatsächlich zu diesem Zeitpunkt existierende eigene Energieversorgung zu hinterfragen ${ }^{42}$, er soll auch als Grundlage dienen für eine Beurteilung darüber, welche Energieversorgung für die ,anderen' Länder am besten $\mathrm{sei}^{43}$, ohne deren Bedürfnisse anzuhören. Der erneuerbare Energiebereich ermögliche eine gemeinsame Lösung von ,globalen Entwicklungsproblemen und globalen Umweltproblemen“ (SPD 28.05.2004: 10241). Eine deutsche „Energiewende“, die physisch-materiell faktisch zu diesem Zeitpunkt kaum vorhanden ist, wird international zur Norm erhoben.

Hier wird zum einen augenscheinlich, was Bhabha (1994: 142) als disjunktive Temporalität der Moderne bezeichnet (vgl. Kapitel 3.2.2) - nämlich das Ausblenden der gewaltvollen Ursprünge dieser sogenannten ,Entwicklungsprobleme', die sich in neokolonialen Machtverhältnissen weiter fortschreiben, bei gleichzeitiger Betonung eines westlichen Fortschritts- und Rationalitätsnarrativs (Fortschritt durch westliche Technologie erneuerbarer Energien). Zum anderen zeigt sich auch die von Spivak (1985) beschriebene Kompliz*innenschaft zwischen westlicher Wissensformation und Wirtschaftsinteressen (Castro Varela/Dhawan 2015: 193): Denn aus der ,eigenen' Erkenntnis über Fortschrittspotenziale für Entwicklungsländer durch erneuerbare Energien, wird direkt die Notwendigkeit abgeleitet, dort vermehrt zu ,investieren“ (GRÜNE 28.05.2004: 10238). Dabei wird weder benannt, dass die Artikulation von ,Investitionen“ überwiegend auf Kredite sowie auf Exportförderung abzielt, noch werden Abhängigkeitsverhältnisse, die damit in Verbindung stehen, reflektiert. Es wird sogar eine Verantwortung konstruiert, die Deutschland als „Exportland“ zu tragen habe, um die erneuerbaren Energien „dort“ - „,in der Dritten Welt“ - „,wirksam werden zu lassen“" (SPD 25.02.2000: 8438). Investitionen, die sich in ihrem materiellen Gehalt überwiegend als Kredite oder Zinssubventionen darstellen, werden als fi-

42 So wird beispielsweise der Eindruck vermittelt, als sei die „Energiewende“ in Deutschland bereits ,vollzogen“ (GRÜNE 28.05.2004: 10237). Dagegen betrug der Anteil erneuerbarer Energien am Primärenergieverbrauch zu diesem Zeitpunkt (2004) lediglich 4,5\% und am Bruttostromverbrauch 9,4\% (www.erneuerbare-energien.de).

43 Vgl. z.B.: „Außerdem bringt der Einsatz erneuerbarer Energien riesige Vorteile für Entwicklungsländer mit sich“ (SPD 28.05.2004: 10234). 
nanzielle „Zusagen“ konstruiert (SPD 02.07.2009: 25698) und erscheinen so als vermeintlich bedingungslose Hilfe, die mit einer Aufwertung der eigenen moralischen Position verbunden wird. ${ }^{44}$ Während das ,Eigene' also als technologisch fortschrittlich, verantwortungsbewusst und darüber hinaus als moralisch konsolidiert wird, erscheint das ,Andere` von dieser Position des Selbst aus als hilfsbedürftig, rückständig, nicht eigenständig, sondern von „deutscher Spitzentechnologie“ (CDU 02.07. 2009: 25690) abhängig ${ }^{45}$ und gleichzeitig räumlich betrachtet weit entfernt („,dort“ (SPD 25.02.2000: 8438)). Das ,Eigene“ hilft - dem ,Anderen“ wird geholfen.

So wird gleichzeitig das Zeichen der ,Dritten Welt‘ vernebelt (vgl. Kapitel 3.2.2), indem die machtvolle Herstellung dieser Einteilung der Welt nicht benannt wird, während über Exportförderung und Kreditvergaben neokoloniale Abhängigkeitsverhältnisse gestärkt werden. Über die moralische Rechtfertigung von Exportförderung und insbesondere ab der 17. Legislaturperiode auch von Rohstoffsicherung (17/3049: 18) durch Herstellung eines Zusammenhangs mit Entwicklungszusammenarbeit werden Wirtschaftsinteressen verdeckt ${ }^{46}$ oder legitimiert. ${ }^{47}$ Dabei ist es vor allem die vermeintliche Attraktivität aus marktwirtschaftlicher Perspektive, die von Anfang an zu einer breiten Zustimmung zur Förderung des Exportes erneuerbarer Energien in Verbindung mit Entwicklungszusammenarbeit führt (vgl. Kapitel 5.2.6). ${ }^{48} \mathrm{Im} \mathrm{Zu}$ sammenhang zwischen Wissensordnung und Wirtschaftsinteressen, wie er sich in der Exportförderung zeigt, wird es darüber hinaus erforderlich, Wissen als das ,Eigene“ zu reproduzieren und zu erhalten. Das technologische Wissen wird selbst als Kapital im Wirtschaftsprozess betrachtet. Dagegen fordert die LINKE „energietechnologisches Wissen mit den Ländern des Südens, zum Beispiel den Ländern Afrikas, vorbehaltlos“ zu teilen (LINKE 02.07.2009: 25695). ${ }^{49}$

44 Vgl. z.B.: „In dem vorgesehenen Zeitraum von 2003 bis 2007 wurden in der bilateralen Zusammenarbeit insgesamt 1,3 Milliarden Euro für erneuerbare Energien zugesagt. Ich finde, das kann sich sehen lassen“ (SPD 02.07.2009: 25698).

45 Vgl. z.B.: „Mit den Exportinitiativen „Erneuerbare Energien“ und „Energieeffizienz“ unterstützt die Bundesregierung gezielt deutsche Unternehmen und die weltweite Verbreitung deutscher Spitzentechnologie, gerade auch in Entwicklungs- und Schwellenländern“ (CDU 02.07.2009: 25690).

46 Vgl. z.B.: „Unser politikfeldübergreifender Ansatz bedeutet nach unserem Verständnis nämlich nicht, dass Entwicklungspolitik Mittel zum Zweck wird“ (SPD 02.07.2009: 25697).

47 Vgl. z.B.: „Energieaußenpolitik ist vor allem auch Entwicklungspolitik“ und „EnergieauBenpolitik insbesondere auch Wirtschaftsförderung und Wirtschaftspolitik“ (CDU 02.07. 2009: 25697).

48 So argumentiert die CSU Deutschland solle die Technologie „dort einsetzen, wo sie viel mehr und viel effizienter zum Klimaschutz beitragen kann [...]“ (CSU 25.02.2000: 8440) und die FDP möchte ,in Entwicklungs- und Schwellenländern [...] investieren, weil dort eine Reduktion der Emissionen von $\mathrm{CO}_{2}$ zu deutlich geringeren Kosten möglich ist“ und so „Technologietransfer“ und „Exportoffensive“ verbunden werden können (FDP 28.05.2004: 10238).

49 In dieser Forderung wird die Beanspruchung des technologischen Wissenskapitals für das ,Selbst‘ zwar überwunden, die Zuordnung des Wissens zum ,Eigenen` bleibt aber erhalten. 
Wie sich hier bereits andeutet, zeigt sich in den Debatten zur Energiepolitik nicht nur die Konsolidierung des eigenen deutschen Selbst als das ,Normale', von dem aus das ,Andere“ der sogenannten Entwicklungsländer als unterlegen (,Worlding') konstituiert wird. Die Subjekte des ,Anderen“ werden auch gleichzeitig als statisch, passiv und moralisch unterlegen herabgewürdigt (zweite Dimension des ,Othering'). Dies wird beispielsweise in der Rolle, die den , anderen` Parlamentarier*innen bei der renewables2004 Konferenz zugewiesen wird, deutlich: Sie kommen nach Bonn, „um diese in Deutschland vollzogene Energiewende zu besichtigen" (GRÜNE 28.05. 2004: 10237). Die Parlamentarier*innen aus anderen Staaten, vor allem aus sogenannten Entwicklungsländern, erscheinen dabei als passiv, unentwickelt, rückstän$\operatorname{dig}^{50}$ aber beeinfluss- und formbar (ihnen werden somit vermeintlich weibliche Eigenschaften zugeschrieben) - während die als aktiv und rational geltenden deutschen Parlamentarier*innen scheinbar von einem besonders privilegierten Punkt aus die Welt erklären und zur Nachahmung ermutigen. ${ }^{51}$ Es zeigt sich deutlich, wie die westliche hegemoniale Wissensordnung das Selbst- und Fremdbild prägt. Vor dem Hintergrund der Zuweisung von Technologie und Wissen zum ,Eigenen', erscheint das ,Andere“ als vermeintlich schwach, im Gegensatz zum starken ,Eigenen“: „Der Entwicklungsminister Gerd Müller hat [...] den Startschuss für das Projekt ,Grüne Bürgerenergie für Afrika' gegeben. [...] Ein Solarunternehmer aus Kamerun hat auf diesem Kongress gesprochen. Der Schlusssatz seiner Rede war: Für uns ist alles, was aus Deutschland kommt, stark" (CDU 29.06.2017: 24992). Dabei zeigt sich auch, wie diese Abwertungsstruktur für die deutsche Volkswirtschaft nutzbar gemacht werden kann. ${ }^{52}$

Vor dem Hintergrund der Annahme dieser hegemonialen Wissensordnung wird der ,deutsche Ingenieur' zur Personifikation von Produktivität, Wissen und Rationalität erhoben. Nicht nur Bewohner*innen von sogenannten Entwicklungsländern werden zur Antithese dieser Eigenschaften angeführt, sondern sie wird auch auf sogenannte ,orientalische' Länder übertragen, deren wirtschaftliche Entscheidungsträger als unkontrollierbar oder gar ,verrückt“ konstituiert werden: „Lieber deutsche Ingenieure als verrückte Derwische in Nahost als Garanten unserer Energieversorgung!“ (FDP 09.09.2004: 11229). Zudem wird das Wort ,Basar' als Metapher für vermeintliche Ineffizienz und Unkontrollierbarkeit orientalischer Märkte im Gegen-

50 Vgl. z.B.: „Ich habe einen ziemlich guten Überblick über das, was in den Ländern auf den verschiedenen Kontinenten passiert. In Deutschland sind die Koalitionsparteien in dieser Frage deutlich weiter als die Oppositionsparteien. Die Oppositionsparteien sind in dieser Frage aber durchaus weiter als manche sozialdemokratischen Parteien in anderen Ländern“ (SPD 28.05.2004: 10242).

51 Vgl. z.B.: „Wir wollen die anderen Parlamentarier motivieren, positive Beispiele nachzuahmen, sie ermutigen, die Initiativen auch von sich aus zu ergreifen“ (SPD 28.05.2004: 10240).

$52 \mathrm{Zu}$ der Bemerkung des Solarunternehmers aus Kamerun fügt die CDU hinzu: „Wir haben ein derart großes Vertrauenskapital bei den erneuerbaren Energien und der Energiewende, das es für unsere Volkswirtschaft zu nutzen gilt“" (CDU 29.06.2017: 24992). 
satz zur westlichen Marktökonomie bemüht. ${ }^{53}$ Sowohl bei ,Basar` als auch bei ,Derwisch` handelt es sich um generalisierende Repräsentationen des ,Orients` (Said 1979: 231), die hier dazu verwendet werden, um gegnerische politische Positionen abzuwerten. Das orientalische Stereotyp dient hier analog zu Said (1979: 7) dem vermeintlich vernunftgeleiteten und hoch entwickelten ,deutschen Selbst ${ }^{6}$ als sein minderwertiges Gegenbild.

Anhand des durch die CDU angeführten Beispiels des Solarunternehmers aus Kamerun, lässt sich im Ansatz nachvollziehen, wie Subalternität ${ }^{54}$ als Position der radikalen Differenz zum westlichen ,Selbst' produziert wird. Während der als männlich gekennzeichnete Solarunternehmer als Mitglied einer vermeintlichen ,Elite“ seines Landes immerhin indirekt adressiert wird, werden subalterne Frauen oder Angehörige ,unterer Klassen', Menschen die in keiner Weise Zugang zu einer herrschenden ,Elite“ haben, in den Debatten nicht erwähnt. Gleichzeitig bewegt sich selbst das diskursiv erzeugte Bild des Solarunternehmers innerhalb der westlichen Wissensordnung, die seinen Status im Diskurs und die Bewertung seines Handelns determiniert und nach der ihm keine Möglichkeit ,autonom` zu wissen und somit zu sprechen zugestanden wird. Elemente von Subalternität tauchen auch in der Personifikation des ,verrückten Derwischs“ als männlicher Repräsentant einer ,fremden“ ,orientalischen“ ,Elite` auf. Er wird antithetisch dem männlichen „deutschen Ingenieur“ gegenüber gestellt. Alles dazwischen verbleibt im Dunkeln: Auf der einen Seite die nicht sozial männlichen, nicht-technologieorientierten Beiträge zu einer deutschen Energieversorgung, die im hegemonial männlichen Diskurs ebenfalls abgespalten werden. Auf der anderen Seite subalterne Subjekte (z.B. Frauen), die der ohnehin bereits abgewerteten männlichen Position der ,orientalischen“ ,Elite" noch weiter untergeordnet werden. Die Orientalität überschreibt dabei jede andere Eigenschaft: „An Oriental man was first an Oriental and only second a man“ (Said 1979: 231). Rassismus, Sexismus und Klassismus wirken ineinander.

Die Bedeutung des „Energiewende“-Diskurses für die Konsolidierung eines ,deutschen Selbst', und umgekehrt das Bemühen nationaler narrativer Muster zur Begründung der "Energiewende“ nach „Fukushima“ (vgl. Kapitel 5.4), ist vollumfänglich erst im Laufe der Diskursanalyse augenscheinlich geworden. Während der Auswertung des Datenmaterials ergab sich daher die Notwendigkeit, die Verknüpfungen zwischen erneuerbaren Energien und „Energiewende“ mit Erzählungen über Nation genauer zu betrachten, was wie beschrieben auch eine theoretische Erweiterung des Kriterienrahmens des Vorsorgenden Wirtschaftens und eine entsprechende Anpassung der Analyseheuristik erforderte. Mithilfe dieser Erweiterung lassen sich Kontinuitäten der europäischen Aufklärung in Verbindung mit nationalen und neokolonialen Motiven in den energiepolitischen Debatten im Bundestag nachzeichnen,

53 Vgl. z.B. die Bemerkung der FDP, die Preisaufsicht sei „,nichts anderes als ineffiziente Basarökonomie“, die für den Wettbewerb eine „Katastrophe“ wäre und Arbeitsplätze „,vom Markt [...]feg[e]“ (FDP 02.07.2009: 25875).

54 Um Subalternität im Diskurs um „Energiewende“ genauer zu untersuchen, sind weitere Forschungen nötig. Hier wäre es sicher notwendig nicht nur Debatten aus dem deutschen Parlament zu betrachten, sondern auch internationale Dokumente/Vorgänge, bspw. aus der Entwicklungszusammenarbeit. 
z.B. anhand der Annahme ,der Privilegierung des bürgerlichen männlichen Subjekts als universelles Subjekt der Vernunft" (Castro Varela/Dhawan 2015: 202) gegenüber dem ,Anderen“, wie sie bspw. in der Gegenüberstellung von ,deutschem Ingenieur und ,verrücktem Derwisch' (s.o.) projiziert wird. Im Rahmen der Story-Line ,Deutschland als Vorreiter' werden ,deutsche' Technologie und das damit verbundene Wissen zu erneuerbaren Energien als „Symbole eines wünschenswerten Fortschritts“ (Castro Varela/Dhawan 2015: 38) gedeutet (s.o.). Im „Energiewende“ Diskurs erscheinen dabei ,Fortschritt' und ,Rationalität' als Produkte deutscher Aufklärung. Um diese Verknüpfung aufrechtzuerhalten, wird zum einen jeglicher $\mathrm{Zu}$ sammenhang mit (neo)kolonialen Machtverhältnissen ausgeblendet und zum anderen die Umsetzung der „Energiewende“ innerhalb Deutschlands diskursiv mit einem gewissen ,Sendungsbewusstsein“ verbunden. ${ }^{55}$ Es wird das Bild von „denen“ gezeichnet, die ,unserem“, deutschen Vorbild“ folgen und dadurch Entwicklung erfahren (Castro Varela/Dhawan 2015: 87). ${ }^{56}$

Infolge der Debatten um die renewables2004 Konferenz verstetigt sich die StoryLine ,Deutschland als Vorreiter“ im Verlauf des „Energiewende“-Diskurses als Moment nationaler Identität, das schließlich auch den konservativen und liberalen Fraktionen einen positiven Bezug auf das EEG ermöglicht. ${ }^{57}$ Die ,Entwicklungsprobleme“ (s.o.) , anderer' Länder werden als Mangel konstruiert und gleichzeitig als Legitimation für Deutschland, globale Verantwortung durch Export zu übernehmen, herangezogen. Das Vordringen deutscher Unternehmen und deutscher Spitzentechnologie in die ,unentwickelte“ Welt wird so (erneut) als „Triumph der Wissenschaft und Rationalität" (Castro Varela/Dhawan 2015: 38) und somit der Aufklärung über das Unwissen stilisiert:

„Nun ist es unsere Aufgabe, Impulse zu setzen. Im Rahmen dieser Konferenz müssen wir auf-
zeigen, welche Möglichkeiten die erneuerbaren Energien tatsächlich bieten. Für deren Einsatz
gibt es nicht nur Umweltgründe [...] sondern auch entwicklungspolitische Gründe. Viele Län-
der der Dritten Welt sitzen mittlerweile in der Falle der fossilen Energien [...]. Hier liegt die

55 Vgl. z.B.: „Wir sind mit der Energiewende angetreten, um zu zeigen [...], dass eine hochentwickelte Volkswirtschaft wie die deutsche es schafft, sich von nuklearer, langfristig aber auch von fossiler Energieversorgung zu befreien, ohne dabei ihren wirtschaftlichen Erfolg zu gefährden“ (SPD 27.06.3014: 3932). Vgl. z.B.: „Die ganze Welt schaut staunend auf Deutschland, wo sich in kürzester Zeit eine [...] industrielle Entwicklung für Solarzellen, Windkraft und Biogas entwickelt hat" (GRÜNE 06.06.2008: 17737).

56 Dieser Zusammenhang wird ab der 16. Legislaturperiode hauptsächlich von den LINKEN und teilweise auch von den GRÜNEN herausgefordert, deren Positionen aber marginalisiert bleiben. Bspw. heben die GRÜNEN hervor, dass die „entwickelten Länder immer noch über 50 oder 60 Prozent des Gases und Öles für 15 Prozent der Weltbevölkerung beanspruchen“ (GRÜNE 02.07.2009: 25689). Die LINKEN heben die strategischen Interessen in der internationalen Zusammenarbeit hervor: „Die Bundesregierung betreibt Aufrüstung, weil sie fossile Energiequellen und die Transportwege sichern will“ (LINKE 02.07.2009: 25694).

57 Vgl. z.B.: „Das deutsche EEG gilt in der Welt als Modell und Vorbild dafür, wie man erneuerbare Energien im Strombereich fördern kann“ (CDU 06.06.2008: 17742). 
große Chance durch erneuerbare Energien [...]. Wir sollten stolz darauf sein, hierzu eine avantgardistische Position einnehmen zu können“ (SPD 28.05.2004: 10241).

Die Story-Line ,Deutschland als Vorreiter' wird dabei eng mit dem Motiv ,Deutschland als Exportnation“ im Bereich erneuerbarer Energien verknüpft (vgl. z.B. FDP 09.06.2011: 12968), was eine Konsolidierung kapitalistischer Interessen im Kontext einer nationalen Erzählung von „Energiewende“ zeigt.

Die wichtige Rolle ,erneuerbarer Energien“ in der Konstruktion nationaler Identität, zeigt sich auch anhand der Debatte um die Laufzeitverlängerung 2010: So betont die Regierungskoalition dabei ebenfalls die internationale Vorbildfunktion Deutschlands ${ }^{58}$ im Bereich erneuerbarer Energien, während die Verlängerung der Laufzeiten der Kernkraftwerke als ,Brücke“ artikuliert wird. Es ist also nicht die „Energiewen$\mathrm{de}^{\text {" }}$ als Idee, sondern insbesondere die erneuerbaren Energien als Technologie, die bereits vor „Fukushima“ auch aufgrund ihrer Funktion für die nationale Identitätskonstruktion breite Anerkennung findet. Nach „Fukushima“ wird „Energiewende“ in die Konstruktion nationaler Identität integriert. Dies wird auch durch die signifikante Verbindung von „Energiewende“ und „Deutschland“ ab der 17. Legislaturperiode deutlich (vgl. Kapitel 5.1.2). Dabei ermöglichen die bereits zuvor mit erneuerbaren Energien verknüpften Bilder deutscher ,Stärke' und einer deutschen ,Vorbildfunktion“ die Aneignung des Begriffs „Energiewende“ für die nationale Erzählung in besonderer Weise: „Wenn es ein Land schaffen kann, dann ist es Deutschland“ (CDU 30.06.2011: 13370). ${ }^{59}$ Die deutsche „Energiewende“ wird zum internationalen „Leitprojekt für den Klimaschutz" erklärt, an dem sich andere Länder orientieren (FDP 13.06.2013: 31292). Erneut wird diese ,Vorbildfunktion“ auch mit einer internationalen moralischen Verantwortung verbunden. ${ }^{60}$ Durch die Berufung auf eine konstruierte nationale Vergangenheit werden die Risse in der Gegenwart verdeckt (vgl. Bhabha 1994: 142), die durch die mit „Fukushima“ zu Tage geförderten Inkohärenz ${ }^{61}$ sichtbar wurden. Besonders deutlich zeigt sich dies in Angela Merkels Regierungserklärung zum Atomausstieg im Juni 2011:

„Deutschland hat schon so manches Mal gezeigt, was es kann, was in ihm steckt, und hat schon ganz andere Herausforderungen bewältigt: die Einführung der sozialen Marktwirtschaft, weltweit in dieser Form einmalig; die Vollendung der deutschen Einheit, historisch ohne Vorbild; aus der weltweiten Finanz- und Wirtschaftskrise stärker herausgekommen, als wir in sie hineingegangen sind, und $-\mathrm{ja}$, auch das - besser als die meisten anderen [...]“ (Angela Merkel 09.06.2011: 12963f.).

58 Vgl. z.B.: „Wir sind dort weltweit an der Spitze und einzigartig“ (CDU 28.10.2010: 7168).

59 Vgl. z.B.: „Welches Land, wenn nicht unser Land, sollte dazu die Kraft haben?“ (Angela Merkel 09.06.2011: 12963f.).

60 Vgl. z.B.: „Jetzt schaut die Welt auf uns [...]. Wir haben die Verantwortung, zu zeigen, dass der Umbau funktioniert“ (GRÜNE 30.06.2011: 13381).

61 Bspw. das Sichtbarwerden einer nicht-nachhaltigen, möglicherweise nicht-vorbildhaften, da auf Atomenergie basierenden Energieversorgung. 
Die diskursive Verknüpfung von „Energiewende“ mit der Erzählung von Nation trägt dazu bei, die Kohärenz im energiepolitischen Diskurs nach „Fukushima“ zumindest scheinbar wiederherzustellen. So wird die neue identitäre Erzählung von „Energiewende“ auch zur Erzählung von nationaler Gemeinschaft und Kultur: „Wir sind das Land, das für neue Technik, Pioniergeist und höchste Ingenieurkunst steht. Wir sind das Land der Ideen, das Zukunftsvisionen mit Ernsthaftigkeit, Genauigkeit und Verantwortung für zukünftige Generationen Wirklichkeit werden lässt [...]“ (Angela Merkel 09.06.2011: 12963f.). Die Nation erscheint hier zeitlos und eins. Die Ambivalenzen, die sich durch „Fukushima“ zeigten und das Konfliktive in den historischen Entscheidungen zur Atomenergie offenbarten, werden durch die Berufung auf eine nationale Gemeinschaft verdeckt. ${ }^{62}$ Dabei wird die Performanz, die Veränderbarkeit der Erzählung der Nation (vgl. Bhabha 1990; Castro Varela/Dhawan 2015: 257f.) deutlich: Bei Konfrontation mit mangelnder Kohärenz eignet sich die nationale Identität neue Erzählungen (hier: die „Energiewende“) an, wodurch sich Ausschließungsprozesse verschieben. Das Beharren der Erzählung der Nation auf Gleichzeitigkeit, wird u.a. daran sichtbar, dass die Regierungskoalition die Entscheidung zur Atomenergie als Fehler kollektiviert, in die Vergangenheit verschiebt, ihren eigenen politischen Anteil leugnet und die Entscheidung damit entpolitisiert: „In den 60er-Jahren ist ein kollektiver Fehler begangen worden - übrigens im Einvernehmen der großen Parteien -, nämlich die Entscheidung, maßgeblich auf Atomenergie zu setzen“ (CDU 30.06.2011: 13383). ${ }^{63}$ Die politische Auseinandersetzung mit diesen Fehlern wird dann durch den Verweis dies sei eine „Historikerdebatte“, man solle sich „stärker dem Ausblick als dem Rückblick widmen“ (CSU 30.06.2011: 13392) delegitimiert. Die nationale Gemeinschaft als Basis energiepolitischer Entscheidungen kann nur auf der Grundlage des Dementierens von Heterogenität und Uneinigkeit konstruiert werden. Sie beruht damit parasitär auf dem Ausschluss von Vielfalt. Es wird an ein nationales ,Wir' (vgl. Kapitel 5.2.6) als Basis einer nationalen Einigkeit und Einstimmigkeit appelliert:

„Aber man muss auch ein Gespür dafür haben, dass es jetzt nicht nur darum geht, recht zu haben und in einzelnen Punkten auf seiner Meinung zu bestehen [...], sondern man muss auch

62 Auch die Entscheidung zur „Energiewende“ erscheint nun als Verdienst der nationalen Gemeinschaft, während der Anteil von zivilgesellschaftlichen Protesten wie der AntiAtombewegung verdeckt wird. Die LINKE hebt dies hervor: „Warum - das ist doch eine spannende Frage - gelingt das zuerst in Deutschland und nicht in Frankreich oder Polen? Ich kann Ihnen sagen, warum: Weil es in Deutschland eine ungeheuer starke Antiatombewegung gibt, die jetzt einen Erfolg feiert, für den sie jahrzehntelang gekämpft hat“ (LINKE 09.06.2011: 12969).

63 Interessant ist hier, dass eine Politisierung dieses Fehlers (hier in Bezug auf eine Rede des Abgeordneten der LINKEN Gregor Gysi) direkt im nächsten Satz durch eine Abwertung der Kritik daran delegitimiert wird: „Herr Gysi, Sie und Ihr System hatten mit kollektiven Irrtümern ja viel zu tun; denn Sie haben immerhin 40 Jahre lang versucht, darauf eine Republik zu gründen [...]. Insofern war es sehr beeindruckend, wie Sie sich hier hingestellt haben“(CDU 30.06.2011: 13383). 
begreifen, dass jetzt dieses nationale Werk in Deutschland losgeht [...]. Sie sollten jetzt endgültig über Ihren Schatten springen“ (CDU 30.06.2011: 13368).

In der Erzählung von nationaler Gemeinschaft und Kultur sowie im Appell an Einigkeit zeigt sich deutlich die pädagogische Dimension des nationalen Narrativs: Die Historizität der Nation wird behauptet, aber ihre Ambivalenz gleichzeitig verdrängt die Konfliktivität in der Geschichtlichkeit von „Energiewende“, die sich im Zusammenhang mit den Protesten gegen Atomkraft und für erneuerbare Energien seit den 70er Jahren und nach „Fukushima“ sowie gegen die Laufzeitverlängerung 2010 zeigt, wird durch die Berufung auf eine nationale Einheit verdeckt. So erscheint die „Energiewende“ im Bundestag letztlich als enthistorisierte „Energiewende“.

Im Zuge der nationalen und neokolonialen Externalisierungsprozesse, die sich über den „Energiewende“-Diskurs hinweg entfalten, lassen sich wie auch anhand der zuvor analysierten Dichotomien die hegemoniale Gesellschafts- und Naturverhältnisse nachzeichnen. Die Auslagerung von Sozialem und Ökologischem aus dem unter rein ökonomischen Kriterien betrachteten Politischen wird durch die Konstruktion nationaler Identität weiter verstärkt und in ihrer neokolonialen Dimension vertieft. Insgesamt wurde deutlich, dass in Bezug auf die aufgezeigten Dichotomien in der hegemonialen Diskursformation keine aussichtsreichen Ansätze für Vermittlung bspw. im Sinne der Kategorie der (Re)Produktivität aufgezeigt werden.

\subsection{POTENZIALE FÜR EINE HERRSCHAFTSÄRMERE ZUKUNFTSGESTALTUNG IM DISKURS UM ,ENERGIEWENDE“}

In Kapitel 3.2.2 wurde ,Potenziale für eine herrschaftsärmere Zukunftsgestaltung ‘ als weiteres Kriterium Vorsorgenden Wirtschaftens eingeführt. Es fragt in dieser Arbeit vor allem nach den Potenzialen, die sich im energiepolitischen Diskurs im Bundestag für eine herrschaftsärmere Zukunftsgestaltung zeigen, wozu es in Hinblick auf den Umgang mit Externalisierungen bereits im vorausgehenden Kapitel erste Rückschlüsse gab. Dies wird nun mit der Frage nach Gerechtigkeit ${ }^{64}$ - als Legitimation von politischen Praktiken, die auf eine herrschaftsärmere Zukunftsgestaltung zielen im Kontext des Ansatzes von ,Affirmation“ und ,Transformation' nach Fraser (2001: 47ff.) sowie der Frage nach Eigentum (Biesecker/von Winterfeld 2011) verbunden.

In Kapitel 5.3.1 wurden die politischen Praktiken, die sich im Kontext des fantasmatischen Narrativs, ökologische Modernisierung' zeigen, als reformistisch ausgerichtet klassifiziert, jedoch wurde wegen einer strukturell externen Verortung der Hindernisse/Gefahren auf eine beharrende Wirkung bezüglich ökonomischer Strukturen verwiesen. Im Rahmen der in Kapitel 5.3.2 erfolgten Klassifizierung wurden politischen Praktiken im Kontext des Narrativs ,marktwirtschaftliche Energiepolitik sowohl in Bezug auf die externe Gefahrenverortung als auch auf die am Status-Quo orientierte Glücksverheißung eine beharrende Ausrichtung attestiert und reformisti-

64 Für den begrifflichen Umgang mit ,Gerechtigkeit` in der vorliegenden Arbeit vgl. Fußnote 43 in Kapitel 3. 
sche Ansätze nur insofern erkannt, als dass auf Veränderung ausgerichtete Praktiken insbesondere aufgrund der ,neuen Lage“ nach „Fukushima“ angeeignet werden. Eine gemeinsame Betrachtung politischer Praktiken im Rahmen der beiden Narrative in Bezug auf ihre Wirkung im Spannungsfeld zwischen Transformation, Reform und Beharrung macht insofern Sinn, als dass sie, wie in Kapitel 5.4 gezeigt, spätestens in der zweiten Hälfte der 17. Legislaturperiode im gemeinsamen Narrativ eines ,technologisch-managementorientierten Ökokonsenses` aufgehen. Da weder zuvor noch danach das parallel verlaufende fantasmatische Narrativ ,sozial-ökologischer Umbau' aufgrund seiner marginalisierten Diskursposition die Ausrichtung politischer Praktiken entscheidend beeinflusst, bleibt es in der folgenden Analyse über den emanzipatorischen Gehalt dieser politischen Praktiken weitestgehend außer Betracht.

Sowohl das Narrativ ,ökologische Modernisierung' als auch das Narrativ ,markwirtschaftliche Energiepolitik' setzen an einem affirmativen - im Gegensatz zu einem transformativen - Umgang mit Ungerechtigkeit an, was sich in Bezug auf Anerkennung zum Beispiel an einem fehlenden Entgegenwirken gegen Externalisierung zeigt (vgl. Kapitel 6.4). Politische Praktiken, die sich im Kontext der Narrative zeigen, zielen nicht auf die Veränderung der Ursachen sozial-ökologischer Krisenphänomene in den kapitalistischen Produktionsverhältnissen, sondern auf eine Abschwächung der ökologischen Folgen dieser Verhältnisse vor allem durch technologische Verbesserungen im Produktionsprozess, auch wenn zumindest anfangs innerhalb des Narrativs ,ökologische Modernisierung ' interne Hindernisse in den Produktionsverhältnissen thematisiert werden. Der herrschaftlichen Strukturierung gesellschaftlicher Verhältnisse sowie gesellschaftlicher Naturverhältnisse mitsamt der zugrundeliegenden Externalisierungsstrukturen, die mit der letztlich marktökonomischen Ausrichtung politischer Praktiken verbunden ist, wird aber nicht entgegengewirkt. Exemplarisch werden nun für den Energiebereich einige Instrumente affirmativer Gerechtigkeitspolitiken analysiert, um zu überprüfen, inwiefern sie sich als geeignet erweisen, Herrschaft und Ungerechtigkeit abzubauen, bzw. inwiefern sie Ungerechtigkeiten sogar noch verstärken. Politische Praktiken, die auf Transformation ausgerichtet sind, ließen sich im Rahmen der Diskursanalyse außerhalb einer marginalisierten Position nicht ausmachen, weswegen die Bewertung bezüglich transformativer Umverteilung oder Anerkennung hier zwangsläufig in den Hintergrund rückt.

\section{Ökosteuer}

Ein Beispiel für affirmative Gerechtigkeitspolitik im Kontext des Narrativs ,ökologischer Modernisierung ' ist die Ökosteuer. Sie birgt zunächst das Potenzial, affirmative Umverteilung mit transformativer Anerkennung zu verbinden, da sie an der Überwindung von Externalisierungen ansetzt: Externe Kosten durch die ökologischen Auswirkungen des (Energie)Produktionsprozesses sollen internalisiert werden. Gleichzeitig können so umweltschädliche externe Effekte des Produktionsprozesses monetär und somit ökonomisch sichtbar gemacht werden, was im Idealfall zu einer höheren Anerkennung von Naturleistungen führen kann. Allerdings wird die Einführung der Ökosteuer im Bundestag nicht nur mit der Internalisierung externer Effekte („Naturverbrauch“; SPD 03.03.1999: 1835f.) gerechtfertigt, sondern in erster Linie mit der Senkung der Sozialversicherungsbeiträge, für die die Einnahmen aus der 
Ökosteuer verwendet werden. ${ }^{65}$ Naturleistungen kommen so in den Debatten eher selten in den Blick, der Anerkennungseffekt wird konterkariert. Eine Vermittlung zwischen Arbeits- und Naturproduktivität im Sinne von (Re)Produktivität findet so gerade nicht statt. Stattdessen werden die Preise der ,Faktoren“ Naturverbrauch“ und „Arbeit“ (SPD: 03.03.1999: 1835f.) im Rahmen einer marktwirtschaftlichen KostenNutzen-Rechnung optimiert. Hier zeigt sich nach Biesecker/von Winterfeld (2014: 4), dass die Externalisierung „nicht mittels Internalisierung aufgelöst werden“ kann, weil das ökonomische und politische System nicht ohne die Ausbeutung des Wertlosen - in dem Fall der Natur - funktioniere. Da die Einnahmen aus der Ökosteuer kaum für umweltpolitische Zwecke eingesetzt werden, wird ein möglicher sozialökologischer Umverteilungseffekt unterlaufen. Die PDS kritisiert zudem eine ,soziale[...] Schieflage“ (PDS 25.11.1999: 6748): Während private Haushalte mit geringem Einkommen prozentual am höchsten belastet werden, sollen Unternehmen, die durch ihre Produktionsweise ökologische Schäden mit verursachen, durch die Steuer sogar entlastet werden. Energieintensive Unternehmen werden überwiegend von der Ökosteuer befreit und auch kleinere Unternehmen sollen im Saldo durch die Senkung der Lohnnebenkosten von der Steuer profitieren. ${ }^{66}$ Ökologische Auswirkungen spielen in den Argumentationen zur Ökosteuer kaum eine Rolle. Der Versuch, aktiv mit Externalisierung umzugehen, wird auf halbem Wege abgebrochen, weswegen ihre Wirkung auf Anerkennungsebene affirmativ bleibt. Auch bezüglich der Umverteilung bleibt die Wirkung, wie beschrieben, affirmativ, wenn überhaupt von einer Umverteilung im Sinne der Verschiebung von Eigentum von oben nach unten gesprochen werden kann. Vielmehr wird der Ökosteuer ein umgekehrter Effekt attestiert. ${ }^{6768}$

65 Vgl. z.B.: „Als vor über 10 Jahren über Ökosteuern diskutiert wurde, war die verbreitete Meinung, man brauche das ganze Geld für die ökologischen Wohltaten. So ähnlich hat es auch Frau Merkel heute Nachmittag gesagt. Das ist aber ein Denkfehler. Damit bekommt man nicht das notwendige Paket, auf Grund dessen sich auch die Arbeitnehmerseite voll mit diesem Reformprojekt identifizieren kann. Es ist, wie Herr Minister Lafontaine richtig ausgeführt hat, in einer Situation eines Überschusses von Arbeit, einer hohen Arbeitslosigkeit, und eines eigentlich knappen Gutes Natur über alle Parteigrenzen hinweg erforderlich, die Kosten des Faktors Arbeit zu senken und die Kosten des Faktors Naturverbrauch zu erhöhen“ (SPD 03.03.1999: 1835f.). Vgl. z.B.: „Die Mittel der Ökosteuer werden zur Senkung des Rentenbeitrags verwandt, der im Jahre 2000 von jetzt 19,5 Prozent auf 19,3 Prozent sinkt [...].Das ist durchaus einen Beifall wert, denn wir losen damit ein weiteres Wahlversprechen ein: die Senkung der Lohnnebenkosten“ (SPD 25.11.1999: 6670). Vgl. z.B.: „Wir folgen einer Logik, indem wir eine der Hauptbelastungen der Unternehmen durch eine sinnvolle Maßnahme, nämlich die ökologische Steuerreform, verringern“ (SPD 03.03.1999: 1838). Vgl. z.B.: „Ja, er hat gesagt: Endlich wurde die Arbeitskraft verbilligt, endlich wurde etwas getan, um die Ressourcen zu besteuern. Damit werde eine Wende eingeleitet“" (GRÜNE 25.11.1999: 6747).

66 So bezeichnen die GRÜNEN die Ökosteuer als „das größte Entlastungsprogramm, das es bei den Lohnnebenkosten gibt" (GRÜNE 09.09.2004: 11253).

67 Die PDS kritisiert: „Abgesehen von der sozialen Schieflage der rotgrünen Konstruktion, ist das Paket in umwelt- wie haushaltspolitischer Hinsicht eine Katastrophe. Die Ökosteuer schafft keine zusätzliche Finanzierungsgrundlage für den ökologischen Umbau, weil deren 


\section{Erneuerbare Energien Gesetz (EEG)}

Ähnlich wie die Ökosteuer bietet auch die Einführung des EEG das Potenzial, auf Anerkennungsebene transformative Wirkung zu entfalten, in Verbindung mit einer affirmativen Umverteilungspolitik. Denn zum einen gerät durch die erneuerbaren Energien (Sonne, Wind, Wasser) Naturproduktivität in den Blick, zum anderen werden Produktionsmittel durch den Einspeisevorrang und die feste Einspeisevergütung von wenigen großen Unternehmen, die überwiegend konventionelle Energie produzieren, zu vielen kleinen Produzent*innen erneuerbarer Energien umverteilt. Dadurch werden zahlreiche kleine Akteur*innen in den Produktionsprozess einbezogen, Herrschafts-Eigentum in Form von monopolisierter Energieproduktion wird zurückgedrängt. Bei einer konsequenten Umsetzung einer solchen Umverteilungspolitik unter Aufbrechen der Dichotomie zentral/dezentral im Zuge einer grundliegenden Umstrukturierung des Energiesektors, würde das EEG auf Umverteilungsebene sogar transformative Wirkung entfalten. Zudem werden die Rechte zukünftiger Generationen anerkennend einbezogen, was den transformativen Charakter auf Anerkennungsebene durch Zugrundelegung eines intergenerationellen Gerechtigkeitsverständnisses stärkt: Die Förderung erneuerbarer Energien diene auch „dazu, die Subvention des herkömmlichen Energieverbrauchs mit seinen Umweltschäden durch die nächsten Generationen, die diese Umweltschäden ,abbezahlen " müssen“ zu beenden (SPD 25.02.2000: 8438f.). Bezüglich der Externalisierung von Umweltschäden ist also zunächst in der Formulierung der politischen Praktiken ein Entgegenwirken erkennbar. Allerdings zeigen sich solche Artikulationen in den Debatten um das EEG eher selten, es wird dagegen im Kontext des Narrativs ,marktwirtschaftliche Energiepolitik vor allem mit den marktökonomischen Potenzialen argumentiert (vgl. z.B. Kapitel 5.2.3), was auch im Rahmen des Narrativs ,ökologische Modernisierung ‘ eine Rolle spielt. Die Förderung erneuerbarer Energien wird als „Schlüsselfaktor für die Entwicklung gerade der deutschen Wirtschaft“ (SPD 27.06.2002: 24776) dargestellt. So wird nicht nur die Chance vertan gesellschaftliche Naturverhältnisse, oder gar deren herrschaftliche Strukturierung, zu adressieren, sondern auch die Veränderung der Energieproduktionsstrukturen durch erneuerbare Energien stärker hervorzuheben. Die somit zunächst noch als affirmativ zu kennzeichnenden Umverteilungsprozesse im Rahmen des EEG werden allerdings spätestens mit den Novellen 2014 und 2016/2017 weiter abgeschwächt, worauf ich an späterer Stelle noch näher eingehe.

Einnahmen aus den Energiesteuern fast vollständig für die Senkung der Lohnnebenkosten verwendet werden“ (PDS 25.11.1999: 6748).

68 Dies bestätigt sich auch in zwei Studien des DIW, die dieses Anfang 2019 als Bilanz zum 20 jährigen Bestehen der Ökosteuer veröffentlicht: „Die vor 20 Jahren in Kraft getretene ökologische Steuerreform hat ihre Ziele - die Entlastung der Rentenversicherung und eine bessere Energieeffizienz - nur zum Teil erreicht. Sie generiert Steuereinnahmen, die bis heute das Rentensystem entlasten. Sie hat allerdings nicht wie gewünscht dazu geführt, dass der Energieverbrauch und somit die Treibhausgasemissionen in Deutschland nachhaltig sinken. [...] Weil die Ausgaben für Energie in ihrem Budget schwerer wiegen und sie kaum von Beitragssenkung und Rentenerhöhung profitieren, sind einkommensschwache Haushalte relativ von der Ökosteuer mehr betroffen als Haushalte mit mittleren oder hohen Einkommen“ (www.diw.de - Ökosteuer). 
Auch auf Anerkennungsebene bleibt die Wirkung des EEG folglich eine affirmative, da spätestens im Rahmen des ,technologisch-managementorientierten Ökokonsenses ‘ Artikulationen, die unter dem Narrativ der ,ökologischen Modernisierung' noch auf das Aufbrechen etwa der Dichotomie zentral/dezentral oder durch Einbeziehen der Naturproduktiviät der Dichotomie produktiv/reproduktiv abzielten, im Diskurs ausbleiben. Daran zeigt sich, dass affirmative politische Praktiken, z.B. im Rahmen affirmativer Umverteilungsmaßnahmen, weniger zum Aufbrechen von Dichotomien auf Anerkennungsebene geeignet sind und diesbezüglich eine eher beharrende Wirkung entfalten (vgl. auch Fraser 2001: 52f.). Dies wird unter Verweis auf das ,Umverteilungs-Anerkennungs-Dilemmas‘ nach Fraser (2001: 27) später ebenfalls anhand des Beispiels der EEG-Novellen von 2014 und 2016/2017 weiter verdeutlicht.

\section{Emissionshandel}

Auch die Einführung des Emissionshandels als Instrument der EU-Klimapolitik in der 15. Legislaturperiode (und seine Anpassung in der 16. und 17. Legislaturperiode) ist ein Beispiel dafür, dass eine affirmative Umverteilungspolitik auf Anerkennungsebene keine transformative Wirkung entfaltet, auch wenn diese in der ursprünglichen Intention artikuliert wird. Diese zielt ähnlich wie bei der Ökosteuer auf die Internalisierung externer Effekte $\mathrm{ab}$ - in diesem Fall durch eine Bepreisung von $\mathrm{CO}_{2}$ - und somit auf die Einbeziehung von Natur in ökonomische Prozesse. Der Emissionshandel hat das Potenzial, Naturleistungen (z.B. den Abbau von $\mathrm{CO}_{2}$ ) sichtbar zu machen und dadurch deren Anerkennung zu steigern sowie gleichzeitig die Einnahmen aus dem Verkauf der Zertifikate für die Erneuerung bzw. Wiederherstellung von Natur zu verwenden. Somit wird potenziell nicht nur die Klimaschädlichkeit von Produktionsweisen sichtbar, sondern gleichzeitig können Gewinne aus klimaschädlicher Produktion abgeschöpft und umverteilt werden, wobei neben dem Umverteilungsaspekt auch der Anreiz zur $\mathrm{CO}_{2}$-neutralen Produktion im Vordergrund steht. Allerdings zeigen sich in der Konstruktion und Wirkung des Emissionshandel zahlreiche Aspekte, die sowohl den transformativen Potenzialen im Hinblick auf Anerkennung als auch den Potenzialen für affirmative Umverteilung zuwider laufen. So ist zunächst die Schaffung von Privateigentum an $\mathrm{CO}_{2}$ für den Handel am Markt notwendig. Es zeigt sich auch hier, dass hierarchisch strukturierte gesellschaftliche Naturverhältnisse nicht durch Internalisierung des Externen in Form eine Bepreisung überwunden werden können. Stattdessen wird Gemeinschaftsgut privatisiert und private Eigentumsrechte, Herrschafts-Eigentum, werden ausgedehnt (Biesecker/von Winterfeld 2011: 137). Dieses Privateigentum wird dann in Form von Luftverschmutzungsrechten an Unternehmen ausgegeben. Die Einbindung der Luftverschmutzungsrechte erfolgt im Zuge marktorientierter Artikulationsmuster (,gemeinsam noch mehr auf den Markt setzen“ (SPD 28.05.2004: 10248f.)) und soll gemäß dieses marktwirtschaftlichen Verständnisses zu einer optimalen Verteilung des Eigentums führen. ${ }^{69}$ Diese Marktorientierung des Emissionshandels bildet sich in den entsprechenden StoryLines (vgl. Kapitel 5.2.3 und 5.2.4) nicht nur in den Artikulationen von rot-grün ab,

69 Vgl. z.B.: „Veraltete Anlagen müssen dann zukaufen und neue Anlagen können, weil sie effizienter sind, Zertifikate am Markt verkaufen und haben so einen Vorteil im Emissionshandel“" (SPD 28.05.2004: 10249). 
sondern auch von CDU/CSU und FDP. ${ }^{70}$ Jedoch werden die Zertifikate in der ersten Phase zu großen Teilen nicht verkauft, sondern an die Unternehmen auf Grundlage von im Vorhinein und zu Beginn großzügig kalkulierten erwarteten Emissionen verschenkt. ${ }^{71}$ Die LINKE kritisiert den Effekt auf der Umverteilungsebene: „Die Sache ist doch die, dass die Kraftwerksbetreiber Milliarden an leistungslosen Extraprofiten einfahren, weil ihnen 91 Prozent der Emissionsrechte ${ }^{72}$ geschenkt werden, sie aber den Handelspreis der Zertifikate auf den Strompreis umlegen“ (LINKE 02.07.2009: 25881). Durch die emissionshandelsbedingte Erhöhung der Strompreise verdienen auch Anlagenbetreiber, die nicht emissionshandelspflichtig sind, wie Betreiber von Atomkraftwerken (vgl. auch Brand u.a. 2013: 2). Die LINKE rechnet mit ca. 18 Milliarden Euro an Extragewinnen bis 2012. ${ }^{7374}$ „Das ist ein Skandal, angesichts klam-

70 Vgl. z.B.: Es gehe „um nicht weniger als die Umstellung in der Umweltpolitik von der bisherigen reinen Ordnungspolitik hin zu einem marktwirtschaftlichen Instrument" (FDP 28.05.2004: 10239). Vgl. z.B.: „Meine sehr geehrten Damen und Herren, bei der Umsetzung des Emissionshandels hat die Union besonderen Wert darauf gelegt, dass der Aspekt, dass vorsorgender Umweltschutz mit Wirtschaftswachstum und Arbeitsplatzsicherung vereinbar ist, in den Vordergrund gestellt wird. sind, dass es gelungen ist, im TreibhausgasEmissions-handelsgesetz einen Passus zu verankern, der für neu zu gründende Unternehmen ebenso wie für Betriebserweiterungen hinreichend Emissionsberechtigungen vorsieht“ (CDU 28.05.2004: 10236).

71 Die Anzahl der ausgegebenen Zertifikate soll dann jährlich reduziert werden. Bemessen wird die Anzahl der ausgegebenen Zertifikate am sogenannten ,Cap', einer festgelegten Emissionsobergrenze, die Emissionen zu einem knappen Gut machen soll. 2019 beträgt der Lineare Reduktionsfaktor der ausgegebenen Zertifikate (,Cap-Absenkung“) jährlich 1,74\% (BMU 2018: 2).

72 In der ersten Phase von 2005-2007 wurden beinahe 100\% der Zertifikate kostenlos ausgegeben. Das Zitat bezieht sich auf die zweite Phase (2008-2012), in der ca. 9\% der Zertifikate versteigert wurden (www.umweltbundesamt.de - Emissionshandel).

73 Vgl. z.B.: „So kommt eine im Juni 2008 vorgelegte Studie des Öko-Instituts im Auftrag des WWF Deutschland zu dem Ergebnis, dass diese Extragewinne rund 35,5 Milliarden Euro, also rund 7 Milliarden Euro pro Jahr betragen. Dabei wurde ein $\mathrm{CO}_{2}$ Zertifikatepreis von 25 Euro angesetzt. Nun liegt momentan der Preis aufgrund der tiefen Wirtschaftskrise nur bei 13 Euro. Das kann sich schnell ändern, aber selbst wenn wir mit diesem Wert rechnen, kommen wir in einem Überschlag auf wenigstens 18 Milliarden Euro Extraprofite bis 2012. Ich meine, das sind ganz erkleckliche Sümmchen. Mir würde eine Menge einfallen, was man damit bezahlen könnte. Die Bundesregierung hat es jedoch bislang strikt abgelehnt, in irgendeiner Form die Windfall Profits zu besteuern. Es gibt bislang keine Hinweise darauf, dass die Bundesregierung die in anderen Ländern diskutierte Besteuerung dieser leistungslosen Zusatzgewinne wenigstens einmal thematisiert oder rechtlich geprüft hat" (LINKE 02.07.2009: 25881f.).

74 Eine 2011 vom Öko-Institut im Auftrag des WWF durchgeführte Studie (Öko-Institut 2011) bestätigt diese Einschätzung nachträglich: „Da der $\mathrm{CO}_{2}$-Preis im Bereich der Stromerzeugung auf den Strompreis umgelegt wird, konnten die Stromerzeuger im Zeitraum von 2005 bis 2012 umfangreiche Zusatzerträge realisieren. Dies zeigt eine aktuelle Untersuchung des Öko-Instituts im Auftrag des WWF Deutschland. Insgesamt haben die Stromer- 
mer Kassen und Hartz IV!“ (LINKE 02.07.2009: 25881f.). So wirke der Emissionshandel als „Gelddruckmaschine für Energiekonzerne“ (Brouns/Witt 2008 zit. in Biesecker/von Winterfeld 2011: 137). Durch die Unterwerfung unter die Nutzenmaximierungs-Rationalität ist zudem auf Anerkennungsebene nicht von einem Entgegenwirken zur Kultur/Natur Dichotomie auszugehen: „Vielmehr wird durch diese Form der Schaffung von Herrschafts-Eigentum die Ökonomisierung der Natur weitergetrieben“ (Biesecker/von Winterfeld 2011: 140). Brand u.a. (2013a: 2) schließen für den Emissionshandel:

„Durch den Emissionshandel wird Klimaschutz abhängig von Marktbewegungen und auch von Marktmacht, hinter denen nicht primär das Interesse steht, das Klima zu schützen. Vielmehr ist es umgekehrt: Die Marktbewegungen sind Resultat von Interessen, die den ,Klimaschutz a als Mittel nutzen, um Geld zu machen, ohne zum Klimaschutz beizutragen“ (Brand u.a. 2013a: 2).

Durch die leistungslosen Extraprofite (sog. ,windfall profits“ (Helbig 2010)) wird die angestrebte affirmative Umverteilung in ihr Gegenteil verkehrt. ${ }^{7576}$ Auf Anerkennungsebene wird zudem die bestehende hierarchische Strukturierung gesellschaftlicher Naturverhältnisse reproduziert, da das zunächst durch Bepreisung zu internalisieren intendierte Naturprodukt - hier in Form von Rechten an $\mathrm{CO}_{2}$-Emissionen - in Unterordnung zur industriellen Energieproduktion kostenlos angeeignet wird.

\section{Atomausstieg und Laufzeitverlängerung}

Aspekte affirmativer Gerechtigkeitspolitik zeigen sich auch im Atomausstiegsbeschluss der 14. Legislaturperiode: Ohne die Energieversorgungsstrukturen grundle-

zeuger so zwischen 35,6 und 38 Milliarden Euro Mehreinnahmen verbuchen können. Die Unternehmen der energieintensiven Industrie erzielten Erträge von rund 840 Millionen Euro" (www.oeko.de - Zusatzgewinne).

75 Es deutet sich nun allerdings eine Veränderung im Emissionshandel an, die den negativen Auswirkungen entgegenwirken soll. Ob dadurch Potenziale für den Klimaschutz erreicht werden, wird sich zeigen. So tritt Anfang 2019 eine Reform des Emissionshandels in Kraft, die bereits 2018 zu starken Preiserhöhungen der Emissionszertifikate führt. Die zuvor sehr niedrigen Preise boten kaum einen Anreiz für die Einsparung von Emissionen. Der Zertifikate-Überschuss soll nun schneller als bisher abgebaut werden. „Mit dieser Reform soll der Emissionshandel ab 2020 endlich Wirkung entfalten für den Klimaschutz. Denn bisher war der Emissionshandel aufgrund eines Überangebotes an Zertifikaten kein wirksames Klimaschutzinstrument [...]“(Agentur für Erneuerbare Energien b 2018). Zwar wird bereits seit 2013 ein Großteil der ausgegebenen Zertifikate versteigert und nicht mehr verschenkt, allerdings werden Zertifikate an Unternehmen, die durch „Abwanderung von Industrieproduktion oder vorgelagerten Anlageinvestitionen in das nicht vom Emissionshandel regulierte Ausland (sogenanntes Carbon Leakage)“ (www.bmwi.de-Emissionshandel) betroffen sein könnten, weiterhin kostenfrei ausgegeben (BMU 2018: 5).

76 Auf die Beförderung neokolonialer Strukturen durch den seit der zweiten Phase des Emissionshandels (2008) möglichen außereuropäischen Ausgleich von Emissionen in sogenannten Entwicklungsländern im Rahmen des Clean Development Mechanismus CDM gehe ich an dieser Stelle nicht ein (vgl. dazu Dietz/Brunnengräber 2008). 
gend zu ändern werden die Rechte zukünftiger Generationen an den „natürlichen Lebensgrundlagen“ (Koalitionsvertrag 1998: 1) anerkannt und in die politische Entscheidungsfindung einbezogen. ${ }^{77}$ Mit dem Beschluss zur Laufzeitverlängerung der 17. Legislaturperiode wird dieses Entgegenwirken gegen die Externalisierung von Natur sowie von zukünftigen Generationen jedoch konterkariert: Die Rechte zukünftiger Generationen an den natürlichen Lebensgrundlagen in Bezug auf die Folgen der Atomenergie werden ausgeblendet, ebenso wie die Naturleistungen, die für die Bereitstellung, den Abbau und die Entsorgung hochradioaktiver Ressourcen notwendig sind. Auf Anerkennungsebene werden somit bestehende Externalisierungen verstärkt, wobei Natur weiterhin aus den ökonomischen Prozessen ausgelagert und abgewertet wird. Auf Umverteilungsebene kann im Kontext der politischen Praktiken der Laufzeitverlängerung von einer Ausdehnung von Herrschafts-Eigentum ausgegangen werden, da vorherrschende zentrale Eigentumsstrukturen der Energieproduktion gestärkt werden. So kritisieren LINKE, GRÜNE und SPD dass den ,großen Vier' ein großer Teil der zusätzlichen Gewinne ${ }^{78}$ durch die Laufzeitverlängerung der Atomenergie überlassen werde (SPD 28.10.2010: 7169; LINKE 28.10.2010: 7176; GRÜNE 28.10.2010: 7178) - während die sozial-ökologischen Auswirkungen der Laufzeitverlängerung vergesellschaftet werden (vgl. Kapitel 5.2.10). Zwar soll ein Teil dieser Gewinne durch eine Kernbrennstoffsteuer abgeschöpft werden, diese sei aber nicht ausreichend, da sie zeitlich befristet sei und die Konzerne dagegen klagen könnten (SPD 28.10.2010: 7185). „Keiner von uns weiß, wie die Auseinandersetzung endet [...]. Das will ich Ihnen vorher gesagt haben, weil Sie eine so leichtfertige Politik im Interesse der Konzerne machen“ (LINKE 28.10.2010: 7176). ${ }^{79}$

Diese Entwicklung im Zusammenhang mit den politischen Praktiken der Laufzeitverlängerung fällt mit der Etablierung des Narrativs ,technokratisch-managementorientierten Ökokonsenses‘ zusammen: Denn in diesem Rahmen werden auch Artikulationsmuster, die ursprünglich zur Begründung transformativ oder reformistisch ausgerichteter politischer Praktiken herangezogen wurden, angeeignet. ${ }^{80}$ Die

77 Vgl. z.B.: „Wegen ihrer großen Sicherheitsrisiken mit der Gefahr unübersehbarer Schäden ist die Atomkraft nicht zu verantworten“ (Koalitionsvertrag 1998: 15).

78 Die LINKE spricht von Zusatzgewinnen zwischen 67 und 127 Milliarden Euro (LINKE 28.10.2010: 7176). Auch die Strompreise würden durch die Atomenergie nicht billiger, da der Preis über die Grenzkosten der teureren fossilen Kraftwerke bestimmt werde. Die Differenz seien Profite, das „sacken die Konzerne ein“ (LINKE 28.10.2010: 7196).

79 Die Brennstoffsteuer wird tatsächlich 2016 nicht verlängert und nachträglich als verfassungswidrig eingestuft. Die Gelder müssen wie hier von der Opposition befürchtet zurückbezahlt werden. Das Bundesverfassungsgericht stellt im April 2017 fest: „Da sich die Kernbrennstoffsteuer nicht dem Typus der Verbrauchsteuer im Sinne des Art. 106 GG zuordnen lässt, fehlte dem Bundesgesetzgeber die Gesetzgebungskompetenz für den Erlass des Kernbrennstoffsteuergesetzes (KernbrStG)“ (www.bundesverfassungsgericht.de). Die Bundesregierung muss 6,3 Milliarden Euro zurückzahlen (www.faz.net - Brennelementesteuer).

80 So begründet die CDU bspw. das Energiekonzept mit der Laufzeitverlängerung folgendermaßen: „Das ist eine Revolution im Prozess. Das ist eine grundlegende Umgestaltung un- 
herrschaftliche Strukturierung gesellschaftlicher Naturverhältnisse wird so weiter verdeckt, einer herrschaftsärmeren Zukunftsgestaltung wird entgegengewirkt.

\section{EEG-Novellen 2012, 2014 und 2016/2017}

Nach „Fukushima“ ist in Zusammenhang mit „Energiewende“ von einem „tiefgreifenden Umbau unserer Energieversorgung“ (Angela Merkel 09.06.2011: 12961) die Rede. Dass dieser „Umbau“ allerdings nicht auf ökonomische Strukturen abzielt, wird schnell deutlich: Die „Energiewende“ solle an den Markt angepasst werden, nicht umgekehrt (z.B. FDP 29.03.2012: 20308). Der „Umstieg“ solle nach den Leitlinien herkömmlicher Marktrationalität gestaltet werden (vgl. Kapitel 5.2.4): „Diesem Ziel dient die Novelle des Erneuerbare-Energien-Gesetzes“ (Angela Merkel 09.06.2011: 12962). Die politischen Praktiken zur „Energiewende“ der Mehrheitsgruppe können im Kontext des fantasmatischen Narrativs ,marktwirtschaftlicher Energiepolitik' interpretiert werden. Entsprechend entfalten diese politischen Praktiken in Bezug auf ökonomische Strukturen eher eine beharrende Wirkung, wie in Kapitel 5.3.2 gezeigt wurde. Gleichzeitig zeigt sich in Bezug auf das EEG nach „Fukushima“ eine von Fraser (2001: 52) beschriebene Logik affirmativer Maßnahmen: So führt das EEG als Mechanismus affirmativer Umverteilung zu einer öffentlich sichtbaren ständigen Erhöhung der EEG-Umlage, d.h. der Kosten, die auf den Strompreis umgelegt werden. Die erneuerbaren Energien (und mit ihnen die vielen kleinen, gegensätzlich zu ,den großen Vier' verorteten, Produzent*innen) erscheinen dadurch als besonders hilfsbedürftig, als Empfänger*innen einer besonderen Behandlung. So haftet ihnen das Stigma der vermeintlichen Privilegierung an in Verbindung mit dem Vorwurf, dass sie zu teuer seien. ${ }^{81}$ Die FDP spricht beispielsweise von der „gemütliche[n] Hängematte der Einspeisevergütung“, die ,abgehangen“ werden müsse (FDP 29.03.2012: 20308). ${ }^{82}$ Fraser (2001: 52) bezeichnet diese „stigmatisierende Anerkennungsdynamik“ als „praktischen Anerkennungseffekt“ affirmativer Umverteilung. Übertragen auf die „Energiewende“ impliziert dies eine soziale Abwertung erneuerbarer Energien. Politische Praktiken, deren Ziel ursprünglich „der Ausgleich von Ungerechtigkeiten in der Verteilung" war, schaffen im Endeffekt „Ungerechtigkeiten in den Anerkennungsbeziehungen“ (ebenda): Während die gesellschaftlichen Kosten der konventionellen Energie im „Energiewende“ - Diskurs kaum thematisiert werden, werden die erneuerbaren Energien unter Rückgriff auf eine komplexitätsreduzierende Story-Line, welche die Kosten in den Mittelpunkt stellt (vgl. Kapitel 5.2.5), als zu teuer dargestellt und im Rahmen des Narrativs ,marktwirtschaftliche Energiepolitik‘ zur Gefahr für eine erfolgreiche Volkswirtschaft (vgl. Ka-

seres Landes. Wir führen sie durch, weil wir glauben, dass sie dem Klimaschutz dient, und Klimaschutz ist unsere Lebensgrundlage“ (CDU 28.10.2010: 7179).

81 „Glauben Sie denn, dass die Verbraucherinnen und Verbraucher bereit wären, doppelt so viel zu bezahlen, obwohl das nicht durch die Marktpreise gerechtfertigt ist? Wir müssen die Kosten der Energiewende im Blick behalten“ (CDU 29.03.2012: 20305).

82 Interessant ist hier auch die begriffliche Analogie zum vielfach bemühten Bild der, sozialen Hängematte', die Ausdruck desselben Effektes affirmativer Umverteilungsmaßnahmen durch die Sozialversicherungssysteme ist. 
pitel 5.2.4) stilisiert. ${ }^{83}$ Den Kosten durch Zerstörung der Lebensgrundlagen wird gleichzeitig in der schreckensverheißenden Dimension des Narrativs keine Aufmerksamkeit geschenkt und Kosten durch Subventionen konventioneller Energieträger werden durch die jeweilige Mehrheitsgruppe im Parlament ausgeblendet (vgl. Kapitel 5.3.2).

Durch die einseitige Orientierung der Kostendebatte auf die EEG-Umlage als Finanzierungsinstrument erneuerbarer Energien scheint neben dem stigmatisierenden Effekt die Ausdehnung von Herrschafts-Eigentum verdeckt und begünstigt zu werden: So kritisieren vor allem LINKE und GRÜNE (vgl. z.B. GRÜNE 29.03.2012: 20286; LINKE 24.03.2011: 11308), dass der Börsenstrompreis (auch) durch die strompreissenkenden Effekte erneuerbarer Energien ${ }^{84}$ gesunken sei - stärker als die EEG-Umlage angestiegen sei. Dennoch würden die Unternehmen die EEG-Umlage als Begründung für Preiserhöhungen heranziehen. ${ }^{85}$ „Das heißt, das Ganze ist eine Gelddruckmaschine“ (LINKE 30.06.2011: 13390). Dadurch finde eine Umverteilung von Privatpersonen zu Energieversorgungsunternehmen und energieintensiver Industrie statt, die von der Umlage befreit ist. ${ }^{86}$ Preiserhöhungen, die aus Profitinteresse erfolgen, werden so den erneuerbaren Energien zugeschrieben, die stigmatisierende Anerkennungsdynamik wird durch die Profitrationalität der Marktökonomie verstärkt. Diese Dynamik in den Debatten um erneuerbare Energien schafft die Voraussetzungen dafür, das EEG - und somit das Aufbrechen der Dichotomie zentral/ dezentral - als Instrument zum Abbau von Ungerechtigkeit durch affirmative Umverteilung zu delegitimieren. Die EEG Novelle 2012 ist bereits als erste Konsequenz dieser Delegitimation zu werten, da die Grundlage zur Abschaffung der festen Ein-

83 Vgl. z.B.: „Die Debatte über die Verteilung der EEG-Umlage lenkt von dem Problem ab, dass sie inzwischen zu einer massiven Belastung geworden ist. Wir können doch nicht so tun, als ob die Steigerung der EEG-Umlage in den letzten Jahren kein Problem gewesen wäre [...]. Deswegen glaube ich nicht, dass die Industriebefreiungen das Problem sind, sondern eine in den letzten Jahren drastisch gestiegene EEG-Umlage“ (SPD 10.04.2014: 2435).

84 „Beispielsweise führt eine hohe Einspeisung von Windenergie zu einer Verringerung der nötigen Residuallast, welche durch teurere konventionelle Kraftwerke, wie Gas- oder Ö1kraftwerke gedeckt werden muss“" (Schomerus/Henkel 2012: 27). Daher haben erneuerbare Energien eine strompreissenkende Wirkung.

85 Diese Einschätzung wird durch eine Studie des Umweltbundesamtes aus dem Jahr 2011 bestätigt. Darin heißt es: „Den Anstieg der EEG-Umlage im Jahr 2011 um rund 1,5 Cent/kWh gegen- über 2010 nutzten viele Stromversorger als Argument für starke Strompreiserhöhungen. Diese Argumentation ist jedoch falsch, denn der Erhöhung der EEGUmlage stehen erhebliche Kostensenkungen an anderer Stelle gegenüber, vor allem bei den Strombeschaffungskosten. $\mathrm{Zu}$ verdanken ist dies auch dem Ausbau der erneuerbaren Energien, der zu einem Rückgang der Preise an der Strombörse führte“ (Umweltbundesamt 2011: 9).

86 „Es ist eine Umverteilung von den Kleinen zu den Großen, die hier stattfindet“ (LINKE 01.06.2016: 16986). Es könne nicht sein, „dass die privaten Verbraucher zahlen und am Ende nur die Industrie profitiert. Das hat nichts mit Kostengerechtigkeit zu tun“ (GRÜNE 10.04.2014: 2441). 
speisevergütung gelegt wird, von der vor allem Kleinproduzent*innen profitieren (Schomerus/Henkel 2012: 19; vgl. Kapitel 6.2). Auch hier wird zumindest der Status von Herrschafts-Eigentum, als Kleinproduzent*innen ausschließendes Eigentum großer Unternehmen gestärkt.

Die Novellierungen des EEG der 18. Legislaturperiode schwächen dessen Wirkungen in Richtung affirmativer Gerechtigkeit weiter ab, indem es immer mehr an marktwirtschaftliche Rationalität angepasst wird (,mehr Markt und mehr Wettbewerb" (CDU 27.06.2014: 3935)). Diese Abgabe politischer Gestaltungsmacht an den Markt wird als , vernünftig ' konstituiert. ${ }^{87}$ Gleichzeitig verstärkt sich in der 18 . Legislaturperiode die ,stigmatisierende Anerkennungsdynamik' in Bezug auf erneuerbare Energien - in Verbindung mit dem Katastrophenszenario der ,Deindustrialisierung ‘ wird immer wieder das Bild einer Bedrohung für den deutschen Wirtschaftsstandort durch die „Energiewende“ erzeugt (vgl. Kapitel 5.2.3 und 5.3.2). Es ist von einer „Last“, die man sich „aufgeladen“ (CDU 10.04.2014: 2439) habe die Rede oder von „drastische[n] Fälle[n] von Überförderung“ (SPD 27.04.2014: 3932; vgl. Kapitel 5.2.5). Ob sich Herrschafts-Eigentum durch das Ausschreibungsdesign im EEG 2016/2017 langfristig weiter ausbreitet, bleibt abzuwarten. Es deutet sich aber bereits an, dass die Teilnahme kleinerer Akteur*innen erschwert ist und sich Bürger*innenenergiegesellschaften vermehrt zu profitorientierten Unternehmen wandeln, in denen komplexe Eigentumsstrukturen privater Unternehmen die Teilhabe von Bürger*innen ersetzen (vgl. Kapitel 5.2.8).

Ein Ansatz affirmativer Umverteilung und affirmativer Anerkennung lässt sich in der 18. Legislaturperiode am ehesten bei der Einführung des Mieterstromgesetzes erkennen (vgl. Kapitel 5.2.8). Die Mieter*innen profitieren und partizipieren am Ende jedoch nur passiv von und an den erneuerbaren Energien. Zwar sinken im Rahmen eines Mieter*innenstrommodells die Strompreise für sie, die Stromproduktion bleibt aber in der Hand der Hausbesitzer*innen - Eigentumsverhältnisse bleiben unangetastet (vgl. Kapitel 5.2.8).

\section{Energetische Gebäudesanierung}

Aber nicht nur im Zuge der EEG-Novellen wird nach „Fukushima“ die „Energiewende“ für die Stärkung von herrschaftlichen Eigentumsstrukturen genutzt. Durch die einseitige Fokussierung des Diskurses auf den Bereich der Marktökonomie werden Gerechtigkeitsfragen zunehmend in das ,Außen“ der „Energiewende“ gedrängt. So wird 2013 eine Änderung im Mietrecht beschlossen, die der „Energiewende“ im Wärmebereich dienen soll, indem die Hürden für eine energetische Sanierung gesenkt werden (Koalitionsvertrag 2009: 28; vgl. auch Kapitel 5.1.2). Dabei werden die Kosten von Sanierungen einseitig auf die Mieter*innen umgelegt. ${ }^{88}$ Darüber hinaus

87 Vgl. z.B.: „Heute ist für mich eine Premiere: Ich diskutiere über das EEG, ohne dass mir dabei gleich das Messer in der Tasche aufgeht [...]. Genau genommen habe nicht ich mich verändert, sondern das EEG hat sich verändert, und zwar in einer vernünftigen Weise $[\ldots]^{\text {“ }}$ (CDU 27.06.2014: 3935).

88 Dies wird von der Opposition kritisiert: Vgl. z.B.: „Unter dem Vorwand der notwendigen energetischen Sanierung verschieben Sie mit dem vorliegenden Entwurf eines Mietrechtsänderungsgesetzes alle Lasten auf die Schultern der Mieterinnen und Mieter [...]“ 
werden sogar zusätzliche langfristige Profite für die Vermieter*innen generiert, da die Mieterhöhung von 11\% der Sanierungskosten pro Jahr ( 5559 BGB 2013) auch über die vollständige Abbezahlung der Sanierungskosten hinaus Bestand haben darf. ${ }^{89}$ Dass energiepolitische Praktiken, die sich im Kontext des Narrativs des ,technokratisch-managementorientierten Ökokonsenses` zeigen, eine Festigung bestehender Externalisierungsstrukturen bewirken können, lässt sich hier beispielhaft aufzeigen. „Wir wollen die Eigentümer ermutigen, ihre Miethäuser und Mietwohnungen energetisch auf den aktuellen Stand zu bringen. Damit leisten wir in der Rechtspolitik unseren Beitrag zur Energiewende“" (FDP 13.12.2012: 26286). Während der Fokus auf dem als aktiv konstituierten, dem Ökonomischen zugewiesenen Eigentümer liegt, erscheinen die Mieter*innen im Gegensatz zum aktiven Eigentümer-Investor eher als passiv. Die Änderung des Mietrechtes soll bewirken, dass auch sie ihren Beitrag zur „Energiewende“ leisten - ohne, dass sie an Entscheidungen über Sanierungen beteiligt werden. ${ }^{90}$ Der Grundsatz von Eigentum, das verpflichtet, wird dabei ausgeblendet und mit dem Eigentum an Wohnraum zusammenhängende Machtverhältnisse werden nicht artikuliert - so erscheint die Finanzierung durch die Mieter*innen sogar als ,gerecht":

„Die Reform des Mietrechtes ist ein wichtiger Baustein der Energiewende [...]. Deswegen brauchen wir Rahmenbedingungen, die Eigentümer nicht von Investitionen abhalten [...]. Natürlich stellt das eine Belastung der Mieter dar. Aber wir können unsere ehrgeizigen Klimaschutzziele nur erreichen, wenn alle an einem Strang ziehen. Das ist eine gesamtgesellschaftliche Aufgabe, deren Lasten gerecht verteilt werden müssen. Daran müssen alle mitwirken. Deswegen ist es, so glaube ich, gerechtfertigt, dass auch Mieter hier ihren Beitrag zum Gelingen der Energiewende leisten“ (CDU 13.12.2012: 26290f.).

Politische Praktiken affirmativer Umverteilung werden hier in ihr Gegenteil verkehrt: So ziele die Gesetzesreform explizit darauf die Rechte der Vermieter*innen zu Lasten der Mieter*innen zu stärken, denn durch vergangene Reformen seien Mieterrechte ,immer weiter aufgebaut“ worden, es sei „eine Schieflage“ entstanden, die nun

(LINKE 13.12.2012: 26291f.). Vgl. z.B.: „Sie versuchen unter dem Vorwand der Energiewende, Mieterinnen- und Mieterrechte abzubauen“ (GRÜNE 13.12.2012: 26293).

89 Diese Änderung im Mietrecht erfolgte 2013 mit dem §559 BGB und ermöglichte umfassende Mietsteigerungen. Laut §559 BGB (2013) kann der Vermieter 11\% p.a. der Sanierungskosten für die Wohneinheit auf den Mieter durch Mieterhöhung umlegen. Folglich sind nach ca. 9 Jahren die Sanierungskosten durch Mieterhöhung vollständig gedeckt. Da die Mieterhöhung aber dauerhaft gilt, stellen die 11\% p.a. der Sanierungskosten ab dann für den*die Vermieter*in einen Reingewinn dar. Seit Januar 2019 wurde diese Umlage auf $8 \%$ reduziert. Zudem darf sich die Miete nun innerhalb von 6 Jahren nicht mehr um mehr als 3 Euro je Quadratmeter Wohnfläche erhöhen ( $\$ 559$ BGB 2019).

90 Vgl. z.B.: „Ihnen [den Mieter*innen] erlegen wir auf, diese Sanierungsmaßnahmen zu dulden [...] und für die Dauer von drei Monaten die Miete nicht zu mindern; denn [...] wenn in einem Mehrfamilienhaus 5, 10 oder 20 Mieter die Miete mindern, dann ist das schon ein gewaltiges Hindernis für den Eigentümer bei der Durchführung dieser Modernisierung“ (FDP 13.12.2012: 2686f.). 
„wieder ins Lot zu bringen“ sei, indem die „Anreize für Investitionen“ erhöht werden (FDP 13.12.2012: 2686). ${ }^{91}$

\section{Bewertung}

Insgesamt materialisieren sich transformative Ansätze, die bei der Bedeutungsgenerierung von „Energiewende" abgesehen vom marginalisierten Narrativ des ,sozialökologischen Umbaus“ überwiegend im Kontext des Narrativs, ökologische Modernisierung' artikuliert werden, nur unzureichend in Form politischer Praktiken. Vor dem Hintergrund der dieser Arbeit zu Grunde liegenden sozial-ökologischen Forschungsperspektive konnten hierarchisch strukturierte gesellschaftliche Naturverhältnisse sowie Verteilungs- und Anerkennungsverhältnisse, die auch unter rot-grün nur wenig adressiert werden, sichtbar gemacht werden. Analog zur nachgezeichneten Wirkrichtung des ,technokratisch-managementorientierten Ökokonsenses ' (vgl. Kapitel 5.4), ist die Wirkung politischer Praktiken im Rahmen von „Energiewende“ nach „Fukushima“ auch mit dem Ansatz von ,Affirmation' und ,Transformation“ nach Fraser (2001) eher als beharrend ${ }^{92}$ einzustufen. Vor dem Hintergrund einer dominierenden Marktrationalität etablieren sich somit keine politischen Praktiken, die auf den Abbau von Herrschaft abzielen. Solche Effekte, die sich mit dem EEG in der Perspektive von Transformation zeigten, werden nach „Fukushima“ eher zurückgedrängt. Eine herrschaftsärmere Zukunftsgestaltung ist insgesamt kaum als Objekt politischer Praktiken im Rahmen von „Energiewende“ nach „Fukushima“ erkennbar.

Aspekte transformativer Umverteilung und Anerkennung vor dem Hintergrund der dieser Arbeit zugrundeliegenden Perspektive werden ab der 17. Legislaturperiode überwiegend von GRÜNEN und LINKEN artikuliert. Bereits ab der 14. Legislaturperiode artikuliert die PDS und später die LINKE Forderungen im Kontext des Narrativs ,sozial-ökologischer Umbau', wobei Potenziale für transformative Umverteilung und Anerkennung sichtbar werden. In diesem Kontext werden die zugrunde liegenden Produktions- (bzw. das „Wachstumsmodell“) (PDS 25.02.2000: 8436), Verteilungs- (z.B. LINKE 29.03.2012: 20277) und Teilhabeverhältnisse (vgl. die Forderung nach Demokratisierung, z.B. LINKE 24.03.2011: 11284) als Hindernis für die Bewältigung sozialer und ökologischer Krisen adressiert. Insgesamt bringen sich aber PDS und LINKE (mit Ausnahme der 16. Legislaturperiode) quantitativ betrachtet relativ wenig in den Diskurs ein (vgl. Abbildung 7). Dies kann man als Hinweis deuten, dass die herrschaftliche Strukturierung gesellschaftlicher Naturverhältnisse und deren Verwobenheit mit Gesellschaftsverhältnissen kein Kernthema der LINKEN, bzw. möglicherweise innerhalb der LINKEN marginalisiert ist. Das ist aber kein Gegenstand der vorliegenden Untersuchung.

91 Der Berliner Mieterverein e.V. kommt in einer empirischen Kurzstudie über 200 Maßnahmen im Berliner Mietwohngebäudebestand 2017 zu dem Schluss, dass über das Gesetz abgedeckte Modernisierungsmaßnahmen zu einem ,durchschnittliche[n] Mietanstieg um 2,44 $€ / q m$ bzw. 186,37 € absolut im Monat“ führen, was ,gemessen an der durchschnittlichen ortsüblichen Vergleichsmiete im Mietspiegel 2015 einen Anstieg von fast $42 \%$ “ bedeutet. Die Senkung der Heizkosten stehe dazu in keinem Verhältnis (Wild 2017: 15).

92 Beharrung ist hier nicht dasselbe wie Affirmation, da Praktiken affirmativer Umverteilung und Anerkennung nach obiger Einordnung eher als reformistisch einzustufen wären. 



\section{Fazit: Die bundespolitische „Energiewende“ im Kontext marktwirtschaftlicher Beharrung}

Ausgehend von der obersten Diskursebene der lexikalischen Elemente, über die Ebenen der zugrundeliegenden komplexeren Verknüpfungen innerhalb von Story-Lines und fantasmatischen Narrativen, bis hin zur Anwendung einer kritisch-emanzipatorischen Analyseperspektive Vorsorgenden Wirtschaftens wurde der Forschungsgegenstand der „Energiewende“ als bundespolitisches Transformationsprojekt umfangreich dekonstruiert. Zur Beantwortung der Forschungsfragen werden nun abschließend die Ergebnisse zusammengeführt unter Bezugnahme auf die der Arbeit zugrundeliegende Forschungsperspektive, mit der ich mich eingangs auf Grundlage des Vorsorgenden Wirtschaftens, der Sozialen Ökologie sowie der Bezugnahme auf die poststrukturalistische Diskurstheorie nach Laclau/Mouffe (2015) innerhalb einer kritischen feministischen Transformationsforschung positioniert habe. Darüber hinaus erfolgt ein Ausblick auf gegenwärtige und mögliche zukünftige Entwicklungen sowie ein Verweis auf weiteren Forschungsbedarf (Kapitel 7.3). Die theoretischen Schlussfolgerungen, die aus der vorliegenden Arbeit für die Transformations- und Diskursforschung gezogen werden können, fasse ich in Kapitel 7.4 zusammen. Abschließend unterziehe ich Methodik und Ergebnisse meiner Arbeit einer kritischen Reflexion (Kapitel 7.5).

\subsection{BEANTWORTUNG DER FORSCHUNGSFRAGEN ÜBER ZENTRALE ZEITABSCHNITTE}

Die Ergebnisse der vorliegenden Arbeit lassen sich über drei Zeitabschnitte zusammenfassen, innerhalb derer für den Diskurs um „Energiewende“ zentrale Entwicklungen identifiziert werden konnten:

1. 14. und 15. Legislaturperiode: Vorpolitische „Energiewende“ im Kontext des Narrativs ,ökologischer Modernisierung،

2. 16. und 17. Legislaturperiode vor „Fukushima“: Zunehmende Vermischung der fantasmatischen Narrative ,ökologische Modernisierung' und ,marktwirtschaftliche Energiepolitik“ 
3. 17. und 18. Legislaturperiode nach „Fukushima“: Entpolitisierung von „Energiewende“ im Rahmen des ,technokratisch-managementorientierter Ökokonsens“ und Zurück-drängen zentraler Errungenschaften in Bezug auf Transformation

Die der Arbeit zugrunde liegenden Forschungsfragen (vgl. Kapitel 1.1) werden im Folgenden zunächst über diese Zeitabschnitte differenziert beantwortet. Im zweiten Schritt (Kapitel 7.2) folgt daraus eine Antwort für die gesamte Arbeit:

(1) Welche Bedeutung(en) hat „Energiewende“ im Bundestag im Zeitverlauf?

(2) Kann die „Energiewende“ vor dem Hintergrund dieser Bedeutung(en) aus diskurstheoretischer, kritisch-emanzipatorischer Perspektive vorsorgenden Wirtschaftens als ein bundespolitisches Transformationsprojekt gewertet werden?

\section{4. und 15. Legislaturperiode}

In Kapitel 5.1 habe ich gezeigt, dass „Energiewende“ von der rot-grünen Regierungskoalition kaum mit Bedeutung aufgeladen wurde. Eine parlamentarische Debatte über „Energiewende“ fand nicht in einem nennenswerten Umfang statt. Weder Atomausstieg noch erneuerbare Energien wurden zwingend mit „Energiewende“ in Verbindung gebracht. Die von der rot-grünen Regierungskoalition mit „Energiewende“ verbundenen Knotenpunkte wurden in Kapitel 5.1.3 nach Laclau (2005: 74ff.) überwiegend als demokratische Forderungen klassifiziert, d.h. sie treten nur vereinzelt zusammen auf - „Energiewende“ ist kein starkes Identifikationsprinzip dieser Forderungen. Gleichzeitig werden Forderungen wie ,Klimaschutz', ,Effizienz‘ oder ,erneuerbare Energien“ von allen Fraktionen geteilt, auch von Gegner*innen der „Energiewende“, sie stehen also als flottierende Forderungen im „Spannungsfeld zwischen Hegemonie und Gegen-Hegemonie“ (Bedall 2014: 62). Während ein kritischer „Energiewende“-Diskurs also schwach ausgeprägt ist, beziehen sich alle Fraktionen positiv auf die Technologie erneuerbarer Energien sowie auf Effizienz. Im Gegensatz zu „Energiewende“ ist der Diskurs über erneuerbare Energien bereits stark ausgeprägt. Die hier ausgetragenen politischen Kämpfe beschränken sich allerdings überwiegend auf technologische und marktwirtschaftliche Aspekte sowie auf die verfahrenspolitische Gestaltung im Feld der Energie (vgl. Kapitel 5.1.2). Grundsätzliche darüber hinausgehende Differenzen, die bspw. eine strukturelle Ebene adressieren, werden selten artikuliert.

In Kapitel 6 habe ich gezeigt, dass sich in den politischen Praktiken im Kontext des Narrativs ,ökologischer Modernisierung', in dem sich die Energiepolitik unter der rot-grünen Regierungskoalition der 14. und 15. Legislaturperiode entfaltet, vor allem im Zusammenhang mit der Einführung des EEGs Aspekte identifizieren lassen, die in einigen Ansatzpunkten eine transformative Wirkung im Sinne des Vorsorgenden Wirtschaftens entfalten bzw. zur Veränderung gesellschaftlicher Naturverhältnisse geeignet erscheinen: Zum Beispiel die Ermöglichung einer Bürger*innenbeteiligung an der Energieproduktion erneuerbarer Energien, die damit verbundene Subversion der Dichotomie Produktion/Konsumtion durch Verbrauch der selbst hergestellten Energie, eine damit einhergehende Dezentralisierung und ein verstärktes Sichtbarwerden „der raum- und zeitlichen Kontextgebundenheit“ des Energiesystems [...] (Amri-Henkel u.a. 2017: 17). Allerdings sind diese materialisierten Effekte poli- 
tischer Praktiken kaum Gegenstand von Bundestagsdebatten und werden auch nicht unter der Forderung einer „Energiewende“ subsumiert (vgl. Kapitel 5.1.3 und 6). Veränderte gesellschaftliche Naturverhältnisse, wie sie sich im Zuge der „Energiewende" außerhalb des Bundestags zeigen (vgl. Kapitel 1) entstehen somit als Nebeneffekt, werden aber in den Plenardebatten nicht thematisiert und bleiben innerhalb des Bundestags unsichtbar.

Stattdessen erfolgt unter rot-grün eine überwiegend marktwirtschaftliche Einordnung energiepolitischer Praktiken. Dabei wird der Ökonomie auch im Kontext des Narrativs ,ökologischer Modernisierung ' nicht in erster Linie eine lebensdienende Funktion zugeschrieben, sondern sie wird immer gleichzeitig selbst als Zweck betrachtet (vgl. Kapitel 6.3). In Kapitel 5.4 habe ich gezeigt, dass sich die fantasmatischen Narrative ,ökologische Modernisierung' und ,marktwirtschaftliche Energiepolitik' im Laufe der Zeit immer mehr vermischen. Dies ist auch vor dem Hintergrund zu bewerten, dass sowohl erneuerbare Energien als auch „Energiewende“ unter der rot-grünen Regierungskoalition innerhalb komplexitätsreduzierender Erzählungen (Story-Lines; vgl. Kapitel 5.2), überwiegend marktwirtschaftlich eingeordnet wurden. In einer auf diese Weise als alternativlos konstituierten Marktwirtschaft, lässt sich möglicherweise auch eine Erklärung dafür identifizieren, dass „Energiewende“ in der 14. und 15. Legislaturperiode kaum politisiert wurde: Denn für die Ausbreitung einer popularen, kritisch positionierten Äquivalenzkette um „Energiewende“ wäre mit Laclau (2005: 74ff.) eine Verbindung mit weitergehenden sozial-ökologischen Forderungen, bzw. Kämpfen gegen den Status Quo erforderlich gewesen (vgl. Kapitel 5.1.3), deren gesellschaftsverändernde Zielsetzungen die herkömmliche Marktrationalität möglicherweise disloziert hätten, bzw. den Raum für die Herausarbeitung von Differenz geöffnet und so die alternativlose Konstitution von Marktwirtschaft gefährdet hätten. ${ }^{1}$

Über den Umfang des Umstiegs auf erneuerbare Energien herrschte innerhalb der rot-grünen Regierungskoalition zudem kein Konsens. Es bestand also insgesamt kein ausreichendes Interesse daran, „Energiewende“ zur Repräsentantin eines Politikwechsels zu machen. Die Diskussionen beschränkten sich daher überwiegend auf einzelne politische Maßnahmen, wie auf den Ausstieg aus der Kernenergie, die Förderung erneuerbarer Energien als Technologie, technologische Verbesserungen, bspw. durch Energieeffizienz, oder der Veränderung von Verbraucher*innenverhalten, bspw. durch die Ökosteuer. Diese politischen Praktiken wurden selten in einen politischen Zusammenhang gesetzt und wenn, dann meist nicht unter der Forderung „Energiewende“, sondern des Klimaschutzes, aber ohne Hindernisse für die Realisierung dieser Forderung intern der ökonomischen Struktur zu verorten (vgl. Kapitel 5.1 sowie 5.3.1). Die Artikulationsmuster im Rahmen des Narrativs ,ökologischer Modernisierung' bewegen sich überwiegend auf einer technokratisch-managementorientierten Verfahrensebene (vgl. Kapitel 5.4). Zwar werden die Risiken von Technologien, wie bspw. der Atomenergie, verstärkt benannt, dies führt allerdings nicht

1 Dies bedeutet nicht, dass es innerhalb der GRÜNEN oder auch der SPD solche Positionen, zur Verbindung von „Energiewende“ mit weitergehenden Forderungen, nicht gegeben hätte, allerdings konnten sie sich möglicherweise nicht soweit durchsetzen, dass sie innerhalb der Regierungskoalition im Bundestag ,zur Sprache kommen` konnten. 
zu einer grundsätzlichen Technologie- oder Fortschrittskritik, im Gegenteil: Vorsorge wird im Rahmen von ,ökologischer Modernisierung' überwiegend eindimensional durch den Glauben an technischen Fortschritt besetzt, während andere Möglichkeiten wie Suffizienz nicht in den Blick kommen (vgl. Kapitel 6.1). Die sozial-ökologische Krise wird so nicht als Symptom der Moderne aufgefasst, sondern vielmehr wird von einer Lösung ökologischer Probleme durch „eine ökologische Modernisierung der Moderne" ausgegangen, in der Wachstum und Entwicklung ökologisch angepasst werden (Krüger 2015: 112). In Kapitel 5.4 habe ich gezeigt, wie Natur im Rahmen des Narrativs der ,ökologischen Modernisierung` zwar politisch mobilisiert, aber letztlich aus dem Politischen extrahiert wird. Der politische Gehalt von Naturverhältnissen bleibt unsichtbar, die system-internen Ursachen für die sozial-ökologische Krise werden nicht benannt. Auf diese Weise wird eine parlamentarisch noch nicht politisierte „Energiewende“ über ihre Verknüpfungen mit marktwirtschaftlich orientierten Story-Lines im Rahmen des Narrativs ,ökologischer Modernisierung ‘ von vorne herein mit post-politischen Repräsentationen verbunden. Vor diesem Hintergrund wird das fantasmatische Narrativ ,ökologischer Modernisierung ' und die mit ihm in Verbindung stehenden politischen Praktiken in ihrer Wirkrichtung als reformistisch bis beharrend klassifiziert (vgl. Kapitel 5.3.1).

Dennoch tauchen bei der Analyse der Wirksamkeit der entsprechenden politischen Praktiken, vor dem Hintergrund des Spannungsfeldes zwischen ,Affirmation“ und Transformation' nach Fraser (2001), vereinzelt reformistische bis transformative Aspekte auf. Auf Umverteilungsebene findet zum Beispiel im Rahmen des EEGs eine Umverteilung von Produktionsmitteln von Groß- zu Kleinproduzent*innen statt. Diese Umverteilung wird allerdings in der Weiterentwicklung des Gesetzes verbunden mit stärkerer Marktorientierung abgeschwächt. Auf Anerkennungsebene sind Ansätze der Internalisierung externer Effekte bspw. durch die Ökosteuer erkennbar. Aber auch diese werden durch die letztlich marktorientierte Ausrichtung konterkariert, da die Steuer zur Verbilligung des Faktors Arbeit verwendet wird und auf die Entlastung von Unternehmen zielt, und somit letztlich nicht zur Vermittlung zwischen Arbeits- und Naturproduktivität im Sinne einer sozial-ökologischen Transformation beiträgt. Auch aus Geschlechterperspektive wird die hierarchische Trennungsstruktur zwischen öffentlich und privat, produktiv und reproduktiv nicht aufgehoben, sondern ständig (wieder-)hergestellt, indem Energiepolitik als wirtschaftspolitisches Feld konstituiert wird, soziale Themen in den Debatten kaum vorkommen und Privatpersonen auf ihre Konsument*innenrolle reduziert werden, die gleichzeitig aber als passiv konstituiert wird (vgl. Kapitel 6.4). Geschlecht wirkt hier als soziale Strukturkategorie.

Obwohl die „Energiewende“ auf nationaler politischer Ebene unter rot-grün kaum mit Bedeutung gefüllt wurde, über ihre Ausgestaltung innerhalb der Regierungskoalition kein Konsens bestand und sie physisch-materiell zu diesem Zeitpunkt mit einem Anteil erneuerbarer Energien am Primärenergieverbrauch von nur 4,5\% (www.erneuerbare-energien.de) noch am Beginn stand, wird sie gleichzeitig zum internationalen Vorbild erklärt. Bereits in der 15. Legislaturperiode spielt die so als fortschrittlich konstituierte deutsche „Energiewende“ eine Rolle in der Konsolidierung des deutschen Selbst, von dem aus sogenannte Entwicklungsländer als rückständig abgewertet werden. Vor dem Hintergrund der Annahme westlicher Wissenshegemonie dominiert die Auffassung, dass mit ,deutscher Spitzentechnologie“ 
im Feld erneuerbarer Energien globale Umwelt- und Entwicklungsprobleme gleichzeitig gelöst werden können. Globale Machtverhältnisse und ihre Ursprünge werden so verdeckt, während Wirtschaftsinteressen zum Beispiel durch Exportförderung gleichzeitig legitimiert werden (vgl. Kapitel 6.4).

\section{Ebene der lexikalischen Elemente}

„Energiewende“ wird im Gegensatz zu erneuerbaren Energien in der 14. und 15. Legislaturperiode kaum mit Bedeutung aufgeladen. Die identifizierten Knotenpunkte sind entsprechend schwach ausgeprägt. Die von rot-grün artikulierten Forderungen sind nach Laclau (2005) überwiegend als demokratisch und flottierend einzustufen, d.h. sie sind nicht geeignet diskursiv Gegen-Hegemonie zu einer sich von „Energiewende“ abgrenzenden hegemonialen Diskursformation zu begründen. Flottierende Forderungen, wie ,Klimaschutz' oder ,erneuerbare Energien“ werden mit der hegemonialen Formation geteilt.

\section{Ebene der komplexeren Verknüpfungen und quasi-transzendentale Ebene (Story-Lines, fantasmatische Narrative)}

Die Wirkrichtung des fantasmatischen Narrativs ,ökologischer Modernisierung und der politischen Praktiken, die sich in seinem Kontext zeigen, ist wegen des system-externen Ansetzens - außerhalb ökonomischer Strukturen - der verfahrenspolitisch ausgerichteten Maßnahmen sowie dem geringen Zukunftsbezug der dominierenden Glücksverheißung, die auf Erhalt des jetzigen Wohlstands zielt, als reformistisch bis beharrend zu klassifizieren.

\section{Ebene des Vorsorgenden Wirtschaftens}

Bei der Analyse anhand der Handlungsprinzipien (Vorsorge, Kooperation, Orientierung am für das gute Leben Notwendigen) sowie der weiteren Kriterien (Externalisierung als Prinzip, Potenziale für eine herrschaftsärmere Zukunftsgestaltung) Vorsorgenden Wirtschaftens zeigten sich vereinzelt Aspekte politischer Praktiken, die im Sinne des Vorsorgenden Wirtschaftens als transformativ eingestuft werden können, bspw. kommen Generationengerechtigkeit oder die Risiken der Atomenergie verstärkt in den Blick. Allerdings wird ein aktiver Umgang mit Externalisierung, bspw. bei der Ökosteuer, nicht konsequent umgesetzt, da letztlich eine marktwirtschaftliche Einordnung politischer Praktiken dominiert. So werden Externalisierungsstrukturen und bestehende hierarchische gesellschaftliche Naturverhältnisse reproduziert oder gefestigt.

Die fehlende Politisierung von „Energiewende“ bei gleichzeitigem Dominieren post-politischer Vorstellungen innerhalb des energiepolitischen Diskurses, die sich in der Naturalisierung der marktwirtschaftlichen Einordnung politischer Praktiken manifestieren, wirkt einer Transformation im Sinne des Vorsorgenden Wirtschaftens entgegen.

\section{6. und 17. Legislaturperiode vor „Fukushima“}

In der 16. Legislaturperiode ziehen sich vor allem die GRÜNEN weiter aus dem Diskurs um „Energiewende“ zurück (vgl. Kapitel 5.1). Die LINKE tritt mit der Forderung einer ,radikalen „Energiewende“ 
verbindet diesen mit weitergehenden sozial-ökologischen Forderungen (vgl. Kapitel 5.1.2). Das sich im Kontext dieser Artikulationen entfaltende fantasmatische Narrativ des ,sozial-ökologischen Umbaus“ bleibt aber in den Bedeutungskämpfen um „Energiewende" marginal. Gleichzeitig findet ein diskursiver Anpassungsprozess innerhalb einer breiten parlamentarischen Mehrheit statt: Während das fantasmatische Narrativ ,ökologischer Modernisierung ‘ zunehmend in den Hintergrund tritt (vgl. Kapitel 5.3.1), greifen CDU, CSU und ab der 17. Legislaturperiode auch FDP zunehmend dessen Artikulationsmuster auf und eignen sich so das zentrale Versprechen der glücksverheißenden Dimension des Narrativs - die Vereinbarkeit ökologischer und ökonomischer Ziele - an. Während die GRÜNEN die Differenz zu diesen Artikulationen über verfahrenspolitische Unterschiede hinaus nur wenig herausarbeiten, gibt die SPD die Differenz weitestgehend auf und artikuliert selbst nicht mehr im Kontext des Narrativs, ökologischer Modernisierung'. Die fantasmatischen Narrative ,ökologische Modernisierung ' und ,marktwirtschaftlicher Energiepolitik' vermischen sich bereits zu diesem Zeitpunkt zunehmend im Hinblick auf einen sich abzeichnenden ,technokratisch-managementorientierten Ökokonsens'. Im Rahmen dieses Anpassungsprozesses treten ökologische Ziele weiter hinter marktwirtschaftliche Ziele zurück (vgl. Kapitel 5.4; Abbildung 14). Vor dem Hintergrund einer weiteren Dethematisierung ökologischer Ziele erscheint ein „breiter Energiemix“ aus erneuerbaren und konventioneller Energien nicht in einem Widerspruch zur Vorstellung von einer ,nachhaltigen Energieversorgung“(BMU 2007: 4; vgl. Kapitel 5.2.1).

In der 17. Legislaturperiode rechtfertigt die schwarz-gelbe Regierungskoalition die Laufzeitverlängerung ebenfalls über Artikulationsmuster, die bereits auf das aufkommende Narrativ des ,technokratisch-managementorientierten Ökokonsenses“ hindeuten: Die bereits zuvor beobachtbare Bedeutungs-Reduktion von Natur auf Klima, vor dem Hintergrund marktwirtschaftlich ausgerichteter Diskursmuster, ermöglicht das Einbeziehen der Laufzeitverlängerung in die Glücksverheißung von Klimaschutz bei gleichzeitiger Modernisierung der Volkswirtschaft durch technologischen Fortschritt (vgl. Kapitel 5.1.3). Die Natur/Kultur-Dichotomie wird durch die Abspaltung sämtlicher ökologischer Folgen reproduziert und im Vergleich zu den vorigen Legislaturperioden weiter gestärkt. Nicht erst - aber in besonderer Weise durch die Laufzeitverlängerung als politische Maßnahme wird das Vorsorgeprinzip konterkariert.

In der zunehmenden Priorisierung ökonomischer Ziele im Rahmen ökologisch orientierter Artikulationsmuster - auch innerhalb der Äquivalenzkette um ,Nachhaltigkeit ${ }^{6}$ in der 16. Legislaturperiode - zeigen sich neoliberale Zeitvorstellungen. Im damit verbundenen Verständnis von Fortschritt wird marktwirtschaftlicher Wettbewerb zum entscheidenden Kriterium für erfolgreiche Energiepolitik erhoben und zur Voraussetzung für die Lösung ökologischer Probleme in der Zukunft erklärt. Die Konstitution der Kernenergie als ,Brückentechnologie“ in der 17. Legislaturperiode steht repräsentativ für diesen Fortschrittsglauben, denn mit der Kernenergie solle die Zeit ,überbrückt‘ werden, in der technischer Fortschritt den Klimawandel durch Geoingeneering oder die Energieversorgung durch die Kernfusion löse (vgl. Kapitel 6.1). Der sozial-ökologische Kontext von Ökonomie ist im Rahmen dieses Fortschrittsverständnisses nicht Gegenstand der Debatten. Eine Vermittlung zwischen Arbeits- und Naturproduktivität im Sinne des Vorsorgenden Wirtschaftens findet entsprechend nicht statt. 
In Kapitel 5.4 wurde gezeigt, dass die Artikulationen im Kontext der Laufzeitverlängerung durch deren Konstitution als ,ideologiefrei ‘ eine entpolitisierende Wirkung entfalten. Die damit verbundenen post-politischen und post-demokratischen Vorstellungen sind aus Perspektive des Vorsorgenden Wirtschaftens nicht mit dem Prinzip der Kooperation vereinbar: Während die Interessen nichtmarktlicher Akteur*innen, bspw. der Anti-Atom-Bewegung, als illegitim be- und als ,ideologisch ‘ abgewertet werden, werden die Profit- und Marktinteressen der Konzerne als berechtigt konstituiert und entsprechend in den Entscheidungsprozess eingebunden. Gleichzeitig wird von den übrigen Akteur*innen kritikfreie Zustimmung eingefordert (vgl. Kapitel 6.2).

Entgegen der Handlungsprinzipien des Vorsorgenden Wirtschaftens wird allein „wirtschaftliche Vernunft“ (FDP 28.10.2010: 7187), über die auch ökologische Ziele erreicht werden sollen, zum handlungsleitenden Prinzip stilisiert. Der sich aus diesem neoliberalen Verständnis von wirtschaftlicher Vernunft ableitenden Profitlogik dienen ökologische Ziele lediglich als Mittel zu ihrer Legitimation: „Wir wollen diesen Lastwagen voller Geld nicht verbrennen, sondern wir wollen das Geld für den schnelleren Umbau unseres Energieversorgungssystems nutzen“ (CDU 28.10.2010: 7168). Emotionalität wird dabei als das ,Andere' dieser wirtschaftlichen Vernunft verortet. Alles was nach marktrationaler Wettbewerbslogik nicht als ,vernünftig' erscheint, wird als ,unsachlich` und ,irrational' abgewertet und aus dem Diskurs ausgegrenzt. Dass diese Dichotomisierung zudem als geschlechtshierarchisch einzustufen ist und Geschlecht dabei sowohl als soziale Strukturkategorie, als auch als Prozesskategorie wirksam wird, wurde in Kapitel 6.4 gezeigt. Mit der Abweichung von der zur Norm stilisierten marktwirtschaftlichen Rationalität wird somit eine soziale Ächtung verbunden, die als herrschaftlicher Gestus zu werten ist, um herausfordernde Positionen zu marginalisieren.

Durch die derartige Ausgrenzung kritischer Sichtweisen manifestiert sich ein vermeintlicher Konsens, der sich über Abspalten bzw. maximal ,abspaltendes Einbeziehen' des ,Anderen' und somit in der hegemonialen Aufhebung von grundsätzlichem Dissens konstituiert. Ökologische Ziele werden nur scheinbar verfolgt - sie werden von der hegemonialen marktwirtschaftlichen Formation zwar artikulatorisch angeeignet, bleiben aber in großen Teilen gegenstandslos (vgl. Kapitel 5.4). Hier zeigt sich der beharrende Charakter des sich unter Dominanz des Narrativs ,marktwirtschaftlicher Energiepolitik ${ }^{\star}$ zunehmend abzeichnenden ,technokratisch-managementorientierten Ökokonsenses‘. Politische Praktiken, die sich auf dieser Grundlage entfalten, zielen nicht auf Veränderung gesellschaftlicher Naturverhältnisse ab. Stattdessen werden transformative Artikulationen und Diskursmuster, die andere sozialökologische Arrangements in den Blick holen, abgewertet und durch Delegitimation aus dem Politischen verdrängt.

\section{Ebene der lexikalischen Elemente}

Eine Bedeutungsgenerierung von „Energiewende“ findet in der 16. und zu Beginn der 17. Legislaturperiode weiterhin kaum statt. Im Kontext des marginalisierten Narrativs , sozial-ökologischer Umbau' artikuliert die LINKE zunehmend populare Forderungen, die aber (auch quantitativ) nicht ausreichen, um ein bedeutsames Feld der Gegen-Hegemonie zu eröffnen. 


\section{Ebene der komplexeren Verknüpfungen und quasi-transzendentale Ebene (Story-Lines, fantasmatische Narrative)}

Es zeichnet sich eine zunehmende Dominanz marktökonomisch orientierter StoryLines ab, wobei ökologisch orientierte Artikulationsmuster aus dem Narrativ, ökologische Modernisierung ' durch Teile von CDU, CSU und später der FDP angeeignet werden. Im Zuge dieser Aneignung zeichnet sich ein ,technokratischmanagementorientierter Ökokonsens' bereits ab. In diesem Rahmen aufgegriffene Artikulationen vormaliger Gegner*innen - wie der nun positive Bezug auf das EEG - bergen einerseits Potenziale für als reformistisch zu klassifizierende politische Praktiken (vgl. auch Kapitel 5.3). Andererseits sind vor dem Hintergrund der externen Gefahrenverortung, der gegenwartsbezogenen Glücksverheißung (Erhalt von Wohlstand und Wachstum) sowie der Abwertung transformativer Artikulationen zunehmen als beharrend zu klassifizierende politische Praktiken erwartbar.

\section{Ebene des Vorsorgenden Wirtschaftens}

Auch bei der Analyse anhand der Handlungsprinzipien (Vorsorge, Kooperation, Orientierung am für das gute Leben Notwendigen) sowie der weiteren Kriterien (Externalisierung als Prinzip, Potenziale für eine herrschaftsärmere Zukunftsgestaltung) Vorsorgenden Wirtschaftens zeigen sich kaum noch Aspekte politischer Praktiken, die im Sinne des Vorsorgenden Wirtschaftens als transformativ eingestuft werden können. Im Gegenteil wird bspw. durch die Laufzeitverlängerung das Vorsorge-Prinzip konterkariert, eine Ausbreitung von Herrschafts-Eigentum der großen Energieversorger befördert und die Externalisierung des Sozial-Ökologischen gestärkt.

Im energiepolitischen Diskurs der 16./des Beginns der 17. Legislaturperiode zeigen sich überwiegend als beharrend zu klassifizierende politische Praktiken. Eine „Energiewende“ ist kein politisches Ziel.

\section{7. und 18. Legislaturperiode nach „Fukushima“}

Der „Energiewende“ - Diskurs nach „Fukushima“ als dislozierendem Ereignis, steht im Zeichen der Entpolitisierung von „Energiewende“ im Rahmen des ,technokratisch-managementorientierten Ökokonsenses ‘ und dem Zurückdrängen zentraler Errungenschaften in Bezug auf Transformation. Wie die Verschiebung demokratischer Forderungen aus dem Feld der Gegen-Hegemonie ins Feld der Hegemonie zeigt, breitet sich die hegemoniale Formation, die sich zuvor noch über eine Abgrenzung von „Energiewende“ auszeichnete, nun aus. Noch im Zuge der Laufzeitverlängerung wurden diese Forderungen unter Äquivalenzierung von ,Ideologiefreiheit' und ,Vernunft' durch die hegemoniale Formation, auch in Bezug auf Kernenergie, abgewertet und aus dem Diskurs ausgegrenzt. Nun werden durch die Dislokation „Fukushima“ für kurze Zeit mögliche sozial-ökologische Folgen des herkömmlichen Energiesystems sichtbar und können im energiepolitischen Diskurs nicht weiter ignoriert werden - auch als Ergebnis des außerparlamentarischen Drucks durch die Zivilgesellschaft. Über die Konstitution von „Fukushima“ als ,Anomalie“, als wissenschaftlich nicht vorhersehbares Ereignis, das eine ,Neubewertung“ erfordere, wird „Energiewende“ nun im Zusammenhang mit einem Atomausstieg als Grundlage eines neuen nationalen energiepolitischen Konsenses präsentiert. Dabei wird der vorherige Be- 
schluss zur Laufzeitverlängerung durch die Betonung einer ,neuen Lage und die Reartikulation von „Energiewende“ seinem politischen Zusammenhang entzogen (vgl. Kapitel 5.4) und somit auch eine Grundlage für die Entpolitisierung von „Energiewende" gelegt.

Mit „Fukushima“ kommen zwar Aspekte von Vorsorge, wie die Unmöglichkeit von absoluter und immer rationalerer Naturbeherrschung oder die mangelnde Fehlerfreundlichkeit des Energiesystems, kurzzeitig in den Blick. Allerdings kann sich eine vorsorgende Perspektive im Diskurs nicht durchsetzen, da „Fukushima“ eben nicht als Folge interner Gefahren konstituiert wird und die sozial-ökologische Krise als Katastrophenszenario in der schreckensverheißenden Dimension von der dominierenden Diskursformation ausgeblendet wird (vgl. Kapitel 6.1). Dies bildet sich auch in der Analyse der steigenden diskursiven Ausbreitung der Artikulationen von und um „Energiewende“ nach „Fukushima“ ab. Den Gruppen, die einer „Energiewende“ und einem Atomausstieg zuvor kritisch gegenüber standen, gelingt eine schnelle Integration in ihre Äquivalenzketten, was durch die schwache Bedeutungsgenerierung im parlamentarischen Raum vor „Fukushima“ begünstigt wird (vgl. Kapitel 5.1). Da sich die hegemoniale Formation bereits vor „Fukushima“ auch ökologische Artikulationsmuster zunehmend angeeignet hat, gelingt eine schnelle Einbindung von „Energiewende" in überwiegend marktwirtschaftlich ausgerichtete Deutungsmuster, ich spreche daher von einer hegemonialen marktwirtschaftlichen Formation nach „Fukushima“. Artikulationen im Rahmen einer vorsorgenden Perspektive werden dabei schnell wieder in den Hintergrund gedrängt. Statt „Energiewende“ mit transformativen Artikulationsmustern im Rahmen des ,sozial-ökologischen-Umbaus“ mit Bedeutung aufzuladen, wird sie zum Leitprojekt für ein ökologischeres Wachstum geformt. Wachstum wird im Rahmen des nach „Fukushima“ endgültig etablierten ,technokratisch-managementorientierten Ökokonsenses“" sowohl zum Zweck als auch zum Mittel einer marktwirtschaftlichen „Energiewende“ erklärt (vgl. Kapitel 6.3).

Auch aufgrund der geringen Politisierung vor „Fukushima“ erscheint eine superdifferenzielle Eingrenzung des „Energiewende“-Diskurses auf technologisch-marktwirtschaftlich orientierte politische Praktiken nicht widersprüchlich (vgl. Kapitel 5.1.3 und 5.4). Die „Energiewende“ wird zwar basierend auf umweltpolitischen Forderungen mit Bedeutung aufgeladen und ihre diskursive Einbindung wird hervorgehoben, gleichzeitig werden diese Forderungen aber permanent aus dem Politischen gedrängt und den marktorientierten Forderungen zu „Energiewende“ untergeordnet, weswegen aus kritisch-emanzipatorischer Forschungsperspektive von einem ,abspaltenden Einbeziehen“ gesprochen werden kann (vgl. Kapitel 5.4). Darüber hinaus sind mit „Energiewende“ verbundene Knotenpunkte (z.B. Erfolg) nach „Fukushima“ häufig außergewöhnlich interpretationsoffen, d.h. sie werden kaum mit spezifischen politischen Forderungen äquivalenziert. Letztlich gelingt es der hegemonialen marktwirtschaftlichen Formation das Postulat der ,Ideologiefreiheit‘ für ihre Politik nach „Fukushima“ wiederherzustellen (vgl. Kapitel 5.4) und „Energiewende“ aus sozialökologischer Perspektive an Bedeutung zu ,entleeren' und somit zu entpolitisieren.

Ein noch im Kontext von ,ökologischer Modernisierung' erkennbares Entgegenwirken gegen Externalisierungsprozesse, als Voraussetzung für einen kritischemanzipatorischen „Energiewende“-Diskurs, der eine zukunftsorientierte Glücksverheißung über eine grundlegend ,andere“ „Energiewende“" umfasst, findet nach „Fukushima“ kaum statt bzw. erfolgt (überwiegend durch GRÜNE und LINKE initi- 
iert) lediglich im Rahmen des weiterhin marginalisierten Narrativs ,sozial-ökologischen Umbau' (vgl. Kapitel 5.1.3). Die sich im Zuge der politischen Praktiken rund um das EEG entfaltende Subversion der Dichotomie öffentlich/privat, wird nach „Fukushima“ nur kurzzeitig vertieft. Als Reaktion auf die zahlenmäßig mächtigen Proteste gegen Atomenergie werden kritische nicht-marktliche Akteur*innen von der Bundesregierung zwar kurzzeitig in den politischen Entscheidungsprozess eingebunden, diese Einbindung findet mit dem Abschluss der Beratungen im Rahmen der Ethikkommission aber ein schnelles Ende. Dabei trägt auch die Verlagerung von Verantwortung von Politik auf Wissenschaft zur Entpolitisierung des Diskurses bei (vgl. Kapitel 5.2.9). Die aus der Zivilgesellschaft eingebrachten Forderungen zur Energiepolitik werden diskursiv durch Betonung eines vermeintlichen Konsenses eingebunden. Der gleichzeitige Apell, die dem nun wieder Privaten zugeordneten Proteste zu unterlassen, legt allerdings auch hier den Rückschluss nahe, dass es sich um ein ,abspaltendes Einbeziehen' handelt.

Es wird in der Folge deutlich, dass das sich im Kontext des Narrativs des ,technokratisch-managementorientierten Ökokonsenses' Potenziale für beharrende bis reaktionäre politische Praktiken abzeichnen. Diese materialisieren sich in den Novellierungen des EEG 2014 und 2016/2017, die große Energiekonzerne begünstigen und somit zentrale Eigentumsstrukturen wieder stärken. Die Bürger*innenenergie, die vor dem Hintergrund der dieser Arbeit zugrunde liegenden Forschungsperspektive als eine zentrale Errungenschaft der „Energiewende“ im Hinblick auf Transformation zu werten ist, wird hingegen wieder zurückgedrängt (vgl. Kapitel 6.2). In diesem Kontext intensivieren sich andererseits Deutungs-Kämpfe um Bürger*innenenergie, Trennungsstrukturen zwischen öffentlich und privat werden kurzzeitig sichtbar und verschieben sich: Existierte die Bürger*innenenergie zuvor im Schatten des Privaten, wird sie im Ausschreibungsdesign dem öffentlich-Ökonomischen zugeordnet und droht ohne gleichzeitige Umgestaltung der hier vorherrschenden Machtverhältnisse im Zuge eines ,abspaltenden Einbeziehens` zu verschwinden (vgl. Kapitel 6.4).

Es wurde gezeigt, dass die Aufhebung von Dissens - und somit Entpolitisierung - ein Kernelement des ,technokratisch-managementorientierten Ökokonsenses ‘ und somit auch der diesem Narrativ zugrunde liegenden hegemonialen marktwirtschaftlichen Formation ist (vgl. Kapitel 5.4). Die herrschaftliche Wirkung einer solchen vermeintlich konsensualen Diskursformation begründet sich demnach in der Negierung von Heterogenität und Vielfalt und bildet sich auch in einer identitären Erzählweise von „Energiewende“ als Erzählung einer nationalen Gemeinschaft und Kultur ab. Die Konstruktion eines nationalen ,Wirs “ wird so zu einem zentralen Moment zur Überwindung der Dislokation „Fukushima“. Im Rahmen der Story-Line ,Deutschland als Vorreiter' werden Bilder deutscher ,Stärke' mit nationalen Mythen sowie nationalen Wirtschaftsinteressen verbunden, um deren Durchsetzung auf internationaler Ebene über das Motiv der deutschen ,Vorbildfunktion` zu legitimieren. Externalisierungen, die aus (neo)kolonialer Perspektive bereits im Gründungsmythos von ,Nation“ auszumachen sind, werden auch in Bezug auf „Energiewende“ verdeckt. Aus dieser Perspektive erscheint „Energiewende“ letztlich enthistorisiert, was eine reproduzierende Wirkung auf neokoloniale Machtverhältnisse nahe legt (vgl. Kapitel 6.4).

Gegen Ende der 17. und in der 18. Legislaturperiode sind die Artikulationen der Regierungskoalitionen zunehmend durch Ambivalenzen geprägt. „Energiewende“ wird nicht als Notwendigkeit vor dem Katastrophenszenario einer sozial-ökolo- 
gischen Krise diskutiert, sondern ihre marktwirtschaftliche Einbindung rückt zunehmend in den Fokus. In diesem Zusammenhang wird die „Energiewende“ zunehmend selbst zur Gefahr stilisiert: Vor dem Hintergrund des Katastrophenszenarios der ,Deindustrialisierung ' und der Story-Line zu ihren ,hohen Kosten“ wird sie im Gegensatz zu einer möglichen mit ihr verbundenen Glücksverheißung selbst verstärkt Teil der schreckensverheißenden Dimension (vgl. Kapitel 5.2 und 5.3). Über die damit einhergehende ,stigmatisierende Anerkennungsdynamik' (Fraser 2001: 52) (vgl. Kapitel 3.2.3), erfolgt eine Abwertung der erneuerbaren Energien gegenüber dem konventionellen Energiesektor. Während die gesellschaftlichen Kosten der konventionellen Energie nicht thematisiert werden, erscheinen die erneuerbaren Energien in diesem Kontext permanent als zu teuer. Zwar entfalten die transformativen Potenziale des EEG auch in der 17. und 18. weiter Wirkung auf der Umverteilungsebene auBerhalb des Bundestags (indem bspw. der Ausbau dezentraler erneuerbarer Energien weiter voranschreitet ${ }^{2}$ ), allerdings werden diese Effekte zunehmend abgeschwächt. Über die Ausnutzung der stigmatisierenden Anerkennungsdynamik werden erneuerbare Energien trotz ihrer strompreissenkenden Wirkung als Rechtfertigung für Preiserhöhungen angeführt, während die feste Einspeisevergütung, von der vor allem Kleinproduzent*innen profitieren, schrittweise reduziert wird. Unter Anwendung des von Fraser (2001) beschriebenen Ansatzes von ,Affirmation“ und ,Transformation“ lässt sich als Folge der stigmatisierenden Anerkennungsdynamik schließlich auch auf Umverteilungsebene eine beharrende Wirkung politischer Praktiken konstatieren und somit trotz voranschreitendem Ausbau dezentraler erneuerbarer Energieinfrastruktur eine Stärkung zentraler Eigentumsstrukturen (vgl. Kapitel 6.5). Unter dem Vorwand der „Energiewende“ im Wärmebereich kommt es aus der zugrunde liegenden Forschungsperspektive zu einer umgekehrten Umverteilung, indem die Stärkung der Rechte von Immobilieninvestor*innen in Verbindung mit dauerhaften, über die Sanierungskosten hinausgehenden, Mietsteigerungen als ,gerecht ${ }^{\star}$ konstituiert wird (CDU 13.12.2012: 26290f.). Dabei zeigt sich, wie sich die beharrenden bis reaktionären politischen Praktiken der hegemonialen marktwirtschaftlichen Formation außerhalb des Bundestags materialisieren ermöglicht (vgl. Kapitel 6.5).

\section{Ebene der lexikalischen Elemente}

Nach „Fukushima“ steigt die Anzahl der Artikulationen von und um „Energiewende“ schlagartig. In der Bedeutungsgenerierung spielen aber verstärkt marktwirtschaftlich und technologisch orientierte Knotenpunkte eine Rolle, während aus sozial-ökologischer Perspektive „Energiewende“ an Bedeutung entleert wird. Vormalig kritisch positionierte, demokratische Forderungen werden nun von der hegemonialen Formation angeeignet.

2 Zwar schreitet der Ausbau der erneuerbaren Energien materiell weiter voran, was weiterhin mit transformativen Potenzialen verbunden ist. Dieser Ausbau erfolgt aber weitestgehend auf Grundlage des unter rot-grün beschlossenen EEGs und geht kaum mit ,neuen“ politischen Ansätzen einher. 


\section{Ebene der komplexeren Verknüpfungen und quasi-transzendentale Ebene (Story-Lines, fantasmatische Narrative)}

Ein Post-Politisierungsprozess im Energiebereich erreicht nach „Fukushima“ seinen Höhepunkt, indem es der hegemonialen marktwirtschaftlichen Formation gelingt, „Energiewende“ auf einer technokratisch-managementorientierten Verfahrensebene zu kolonisieren, für ihre marktwirtschaftlichen Interessen zu mobilisieren und damit letztlich dem Politischen zu entziehen. Die Naturalisierung marktwirtschaftlicher Strukturen schreitet so voran, während „Energiewende“ vor dem Katastrophenszenario der ,Deindustrialisierung' auf ambivalente Weise bald selbst zur Gefahr stilisiert wird. Die sozial-ökologische Krise verschwindet hingegen aus der schreckensverheißenden Dimension. Vor dem Hintergrund einer nationalen Erzählung komplettiert sich aus (neo)kolonialer Perspektive die hegemoniale Formation unter der Identität des nationalen ,Wir‘. Der Begriff „Energiewende“ wird im parlamentarischen Diskurs zwar verwendet, um „Fukushima“ als Dislokation zu überwinden, bleibt aber bezüglich der Potenziale einer Übersetzung in ,neue“ - aus sozial-ökologischer Perspektive als transformativ zu klassifizierende - politische Praktiken weitgehend gegenstandslos.

\section{Ebene des Vorsorgenden Wirtschaftens}

Die Natur/Kultur Dichotomie und andere Externalisierungsstrukturen werden fortgeschrieben. Durch den Fokus auf die ,Kosten der „Energiewende““ entfaltet sich letztlich eine stigmatisierende Anerkennungsdynamik, was zu einer Abwertung der erneuerbaren Energien gegenüber den konventionellen Energien führt. Trotz reformistischer Potenziale, die sich zum Beispiel vor dem Hintergrund des erneuten Atomausstiegs abbilden, bleibt die Wirkung politischer Praktiken in dieser Phase der „Energiewende“ eher beharrend. Der Begriff „Energiewende“ suggeriert eine Lösung sozial-ökologischer Probleme, die aber de facto gar nicht Gegenstand der Debatten sind, sondern durch den Fokus auf die Marktökonomie permanent aus dem Politischen gedrängt werden.

Handlungsprinzipien des Vorsorgenden Wirtschaftens haben vor dem Hintergrund dieses post-politischen Diskurses keine Chance, eine materiell-symbolische Wirkung im Sinne von Transformation in politischen Praktiken zu entfalten.

\subsection{SCHLUSSFOLGERUNGEN FÜR DEN GESAMTEN BETRACHTUNGSZEITRAUM}

Mit dem analytischen Durchlaufen der verschiedenen Ebenen der Dekonstruktion wurde die Entwicklung von „Energiewende“ aus dem Bereich des Vor-(Bundes-)Politischen in der Zeit vor „Fukushima“ in den Bereich des Post-Politischen bis zum Ende des Betrachtungszeitraums nachgezeichnet. Da in dem als ,vor-politisch“ klassifizierten Betrachtungszeitraum eine Bedeutung von „Energiewende“ kaum generiert wurde und die „Energiewende“ als Projekt bundespolitischer Gesetzgebung nur aus einer marginalisierten Position heraus adressiert wurde, kann von einer „Energiewende" als von einer Mehrheit getragenem bundespolitischem Projekt also über- 
haupt erst in Bezug auf den Betrachtungszeitraum nach „Fukushima“ gesprochen werden.

In einer weiteren Dekonstruktion des Diskurses um „Energiewende“ wurde auf den Ebenen der Story-Lines und der zugrunde liegenden fantasmatischen Narrative die Wirkrichtung der sich auf Grundlage der Narrative materialisierenden politischen Praktiken analysiert. Diese wurde, wie anhand der Operationalisierung der Diskursanalyse dargestellt, überwiegend nicht als transformativ klassifiziert. In einer weiteren Ebene der Dekonstruktion wurde aus der Perspektive des Vorsorgenden Wirtschaftens die Wirkung der identifizierten politischen Praktiken in Bezug auf die Handlungsprinzipien sowie die weiteren Kriterien Vorsorgenden Wirtschaftens analysiert. In Bezugnahme auf die vorausgehenden Ebenen der Dekonstruktion ist daraus die Schlussfolgerung abzuleiten, dass sich im nachgezeichneten diskursiven Rahmen von „Energiewende“ nach „Fukushima“ überwiegend energiepolitische Praktiken materialisieren, welche in ihrer Wirkrichtung im Spannungsfeld reformistisch-beharrend-reaktionär zu verorten sind. Vor dem Hintergrund der dieser Arbeit zugrunde liegenden Forschungsperspektive kann daher nicht von einer „Energiewende“ als bundespolitischem Transformationsprojekt gesprochen werden. Im Folgenden möchte ich kurz zusammenführen, wie es zu einer Festigung beharrender Strukturen nach „Fukushima“ kam und mit welchen Machtverhältnissen diese in Verbindung stehen.

Ein besonderer Fokus der Dekonstruktion liegt auf dem sichtbar machen von hierarchischen Externalisierungsstrukturen. Das ,abspaltende Einbeziehen' des zuvor und auch weiterhin marginalisierten und abgewerteten ,Anderen " wird besonders im zunehmenden Vermischen der fantasmatischen Narrative ,ökologische Modernisierung ‘ und ,marktwirtschaftliche Energiepolitik' ab der 16. Legislaturperiode deutlich, bis hin zu ihrer Verschmelzung im hegemonialen, technokratisch-managementorientierten Ökokonsens' in der 17. Legislaturperiode. Dabei wird deutlich, dass nicht nur die konservativ-liberalen Fraktionen an dieser Entwicklung beteiligt sind, sondern dass auch GRÜNE und SPD durch die Aufgabe bzw. die fehlende Herausarbeitung von Differenz die Herausbildung der hegemonialen marktwirtschaftlichen Diskursformation begünstigten. Diese Diskursentwicklung schafft die Voraussetzungen dafür, dass „Energiewende“ nach „Fukushima“ in die Deutungsmuster des ,technokratisch-managementorientierten Ökokonsenses“ integriert werden kann. Zugeständnisse, wie der Atomausstieg, erfolgen aber nur insoweit sie für die Überwindung der dislozierenden Wirkung von „Fukushima“ und somit für die Aufrechterhaltung und Erneuerung der hegemonialen Formation notwendig sind. Hendrik Sander kommt in seiner historisch-materialistischen Policy-Analyse der Energiepolitik der 17. Legislaturperiode zu einem ähnlichen Schluss:

\footnotetext{
„Der neue Atomkonsens diente zwar nur dazu, die Krisenphänomene selektiv zu bearbeiten. Er spielte aber sogar eine organische Rolle bei der Erneuerung von Herrschaft im Rahmen des deutschen Kapitalismusmodells, indem die zeitweise politische Konfrontation produktiv zur Reorganisation der neoliberalen Hegemonie genutzt wurde. Die erfolgreiche Befriedung des Atomkonflikts hatte gewissermaßen einen kathartischen Effekt, so dass die Herrschaftsarchitektur nach Fukushima stabiler war als zuvor" (Sander 2016: 259).
} 
Die Anpassungsfähigkeit der hegemonialen marktwirtschaftlichen Diskursformation verdeutlicht sich dabei im „Energiewende“-Diskurs in besonderer Weise. Durch die Aneignung ökologischer Artikulationsmuster innerhalb des ,technokratisch-managementorientierten Ökokonsenses ${ }^{\text {' }}$ ist eine Einbindung weiterer ökologischer Forderungen jederzeit möglich - sollten bspw. bestimmte Forderungen aus der zivilgesellschaftlichen Umweltbewegung (wieder) an Stärke gewinnen. Damit ist eine wichtige Voraussetzung für den Erhalt der hegemonialen Formation erfüllt (Laclau/Mouffe 2015: 18). Wie in Kapitel 5.4 dargestellt, zielen die Artikulationen von „Energiewende" nicht (mehr) in erster Linie auf die Umsetzung umweltpolitischer Forderungen, sondern auf die Ausbreitung und den Erhalt der hegemonialen marktwirtschaftlichen Formation. „Energiewende“ wird zum ,leeren Signifikanten“, der darauf zielt die „rein äquivalentielle Identität eines gemeinschaftlichen Raumes als solches zu repräsentieren“" (Laclau 2002: 72).

Ein weiterer Schwerpunkt der vorliegenden Diskursanalyse ist ausgehend von der Forschungsfrage in der Analyse des Spannungsverhältnisses zwischen Beharrung und Transformation auszumachen. Dabei wird auf allen Ebenen der Dekonstruktion augenscheinlich, dass unter Anwendung der für die jeweiligen Analyseebenen relevanten Kriterien zur Identifikation transformativer Potenziale und Effekte diese nur wenig erkennbar sind. Daraus ist ein Widerspruch zu den Erwartungen, die zivilgesellschaftliche Akteur*innen bspw. im Bereich der Bürger*innenenergie scheinbar mit „Energiewende“ verbinden, abzuleiten (vgl. Kapitel 1). Obwohl die Umstellung der Stromproduktion auf erneuerbare Energien auch nach „Fukushima“ materiell weiter voranschreitet und als Teil der diskursiven Konsensbildung erscheint, artikuliert eine breite Mehrheit im Parlament das Verhältnis zwischen erneuerbaren Energien und konventioneller Energie nicht als ,Systemkonflikt‘ (vgl. Kapitel 5.2.4) und verortet Hindernisse für eine erfolgreiche Umstellung auf erneuerbare Energien demnach nicht Energiesystem-intern. So können die Effekte dieses Konfliktes ${ }^{3}$ im Zusammenhang mit der im Rahmen der Analyse beschriebenen stigmatisierenden Anerkennungsdynamik von den großen Energiekonzernen genutzt werden, um durch Strompreiserhöhungen Herrschafts-Eigentum auszudehnen (vgl. Kapitel 6.5). Daraus lässt sich ableiten, dass einer transformativen Energiepolitik vor dem Hintergrund des Analysegegenstandes insbesondere auch die system-externe Verortung von Gefahren für ihr Gelingen entgegensteht, oder umgekehrt: Die Weigerung der jeweiligen parlamentarischen Mehrheiten, system-interne Ursachen für sozial-ökologische Krisen, die wiederum selbst ausgeblendet werden, anzuerkennen. Mit der „Energiewende“ ist es der hegemonialen marktwirtschaftlichen Formation gelungen, ein großes potenziell auf Transformation ausgerichtetes Projekt aus sozial-ökologisch orientierten zivilgesellschaftlichen Bewegungen für verfahrenspolitische Prozesse im Bundestag zu mobilisieren und gleichzeitig sozial-ökologisch und politisch an Bedeutung zu entleeren.

In Kapitel 5.1 wurde darüber hinaus gezeigt, dass sich der diskursive Raum um „Energiewende“ auf den Strom- und in etwas geringerem Umfang auch auf den Wärmebereich beschränkt. Die hegemoniale marktwirtschaftliche Formation hat eben

3 Bspw. ein regelmäßiger Stromüberschuss durch erneuerbare Energien sowie strompreissenkende Effekte, s.o. 
kein Interesse daran die Artikulation von „Energiewende“ von sich aus auf andere Kontexte auszuweiten, deren Umstellung auf erneuerbare Energien möglicherweise marktwirtschaftlichen Interessen zuwider laufen könnte. So werde eine „Energiewende" im Verkehrsbereich nicht verfolgt, denn mobilitätspolitische Veränderungen gehen „nicht gegen den Markt, es geht nur mit dem Markt“ (CDU 13.06.2013: 31303).

Biesecker/von Winterfeld (2016: 36) kommen in ihrer Betrachtung des Energiekonzeptes der Bundesregierung zu folgendem Schluss:

\begin{abstract}
„Zusammengefasst und in erster Näherung liegt unseres Erachtens die Regenerationsvergessenheit [der Energiewende] darin, dass sich die Energiewende auf einen Ausstieg aus der Kernenergie und auf eine Umstellung auf erneuerbare Energien unter Beibehaltung der gewohnten Produktions- und Verteilungsstrukturen sowie der Nutzungsgewohnheiten beschränkt“" (Biesecker/von Winterfeld 2016: 36)
\end{abstract}

Vor dem Hintergrund meiner diskurstheoretischen Forschungsperspektive konnte ich zeigen, dass diese Reduktion des Begriffes „Energiewende“ mit seiner Integration in die Artikulationsmuster des ,technokratisch-managementorientierten Ökokonsenses “ erfolgte und mit einer Ausbreitung der hegemonialen marktwirtschaftlichen Formation verbunden war. Dies führte nicht nur zu einer Regenerationsvergessenheit der „Energiewende“ selbst, sondern auch zu einer Stärkung beharrender Strukturen. Denn die „Energiewende“ ist auch ein Maßstab dafür wie Nachhaltigkeitsthemen politisch umgesetzt werden. Nach „Fukushima“ ist es einer politischen Mehrheit gelungen die Deutungshoheit über die Einbindung ökologischer Forderungen in den bundespolitischen Diskurs zu erlangen - und zwar auf marktwirtschaftliche Weise. Somit führte die „Energiewende“ nach „Fukushima“ nicht nur zu einer Festigung und Ausbreitung der marktwirtschaftlichen Hegemonie, sondern auch damit zusammenhängender gesellschaftlicher Naturverhältnisse.

Diese Ausbreitung der hegemonialen marktwirtschaftlichen Formation wirkt sich in vielfältiger Weise auf Machtverhältnisse aus, bzw. ist mit Machtverhältnissen verwoben:

Dies betrifft ökonomische Machtverhältnisse - in Kapitel 6 wurde gezeigt wie zentrale Eigentumsstrukturen nach „Fukushima“ gestärkt wurden, wie die Rolle der Kleinproduzent*innen geschwächt und wie sozialpolitische Fragen ins Private verwiesen wurden.

Dies betrifft (neo)kolonialen Machtverhältnisse - in Kapitel 6.4 wurde gezeigt, wie sogenannte Entwicklungsländer im „Energiewende“-Diskurs als das ,Andere“ des fortschrittlichen, nationalen Selbst abgewertet werden, wie damit Wirtschaftsinteressen konsolidiert werden und die Geschichtlichkeit globaler Machtverhältnisse verdeckt wird. Über die Konstitution von Deutschland als ,Vorreiter' wird nicht nur der deutsche Anteil an der globalen Klimakrise vernebelt, es entsteht auch der Eindruck, dass bereits ausreichend für die „Energiewende“ getan werde.

Dies betrifft aber auch Geschlechterverhältnisse, die sich ebenso wie (neo)koloniale Machtverhältnisse im Diskurs um „Energiewende" auf vielfältige Weise manifestieren. Dies zeigt sich zum einen darin, worüber überhaupt diskutiert wird, was im Diskurs sichtbar wird. In Kapitel 6.4 habe ich gezeigt, dass die Ökonomie und technologische Fragen dem Öffentlichen zugewiesen werden, während soziale Themen 
außerhalb der Ökonomie dem Privaten zugeordnet werden und im „Energiewende“Diskurs mit wenigen Ausnahmen nicht vorkommen. Während Energieunternehmen von der Politik als aktive Gestalter der „Energiewende“ adressiert und eingebunden werden, werden Bürger*innen auf Haushaltsebene als passiv konstituiert. Ihre Rolle wird überwiegend in Äquivalenz zu Konsum und Akzeptanz artikuliert, während eher selten auf ihre produktive Rolle für die „Energiewende“ abgezielt wird und wenn, dann stets im Kontext starker Bedeutungskämpfe.

Zum anderen werden geschlechtshierarchische Dichotomisierungsprozesse auch dazu verwendet, bestimmte Diskurspositionen zu delegitimieren: In Kapitel 6.4 wurde entsprechend herausgearbeitet, wie über die Abwertung sozial weiblicher Emotionalität gegenhegemoniale Forderungen delegitimiert werden und transformative Perspektiven (z.B. als ,irrational', ,hysterisch` oder ,rückständig') sozial geächtet werden. Aus feministischer Perspektive zeigt sich daran deutlich, wie sich eine auf die Abwertung sozialer Weiblichkeit ausgerichtete sprachliche Argumentation in sozial männlichen politischen Praktiken materialisiert. Ein auf solche Weise geschlechtshierarchisch strukturierter Diskurs bietet vor dem Hintergrund der zugrunde liegenden Forschungsperspektive keine transformativen Potenziale, auf Grundlage derer sich (vor)sorgende politische Praktiken entfalten können, die transformativ auf eine Vermittlung zwischen produktiv und reproduktiv hinwirken, stattdessen folgt eine Abspaltung des sozial Weiblichen aus dem Öffentlichen ins Private. Die LINKE und in einigen Fällen auch die GRÜNEN bringen mit Artikulationen im Rahmen des Narrativs ,sozial-ökologischer Umbau' zwar alternative Perspektiven ein, diese bleiben aufgrund einer fehlenden politischen Auseinandersetzung sowie der relativ geringen Involvierung der LINKEN aber marginalisiert.

Insgesamt lässt sich vor dem Hintergrund der zugrunde liegenden Forschungsperspektive aus der Dekonstruktion des „Energiewende“ - Diskurses schlussfolgern, dass die „Energiewende“, wie sie im Bundestag konstituiert wird, nicht nur als regenerationsvergessen bezüglich ihrer natürlichen Grundlagen zu bewerten ist, sondern, dass es sich auch um eine neokoloniale, männliche, enthistorisierte und marktökonomische Strukturen stabilisierende „Energiewende“ handelt. Eine bundestagspolitische „Energiewende“, die in dem kritisch-dekonstruktiv sichtbar gemachten Ausmaß, Machtstrukturen und -verhältnisse ignoriert, die aus sozial-ökologischer Perspektive als Ursachen bestehender Krisen zu sehen sind, reproduziert bestehende Ungerechtigkeiten.

\subsection{AUSBLICK UND WEITERER FORSCHUNGSBEDARF}

Mouffe (2007: 7f.) arbeitet in ihrem Buch „Über das Politische“ heraus, inwiefern gegenwärtig vorherrschende Vorstellungen über Gesellschaftsverhältnisse von Konsens geprägt sind, verbunden mit der Behauptung, grundsätzliche gesellschaftliche Konflikte in einer vermeintlich „,freien Welt“ überwinden zu können. Sie spricht von einem ,post-politischen Zeitgeist“, den sie für „,von Grund auf verfehlt“ hält und als „Ursprung vieler gegenwärtiger Probleme“ demokratischer Institutionen betrachtet (ebenda). So interpretiert sie das Erstarken des ,Rechtspopulismus' im Kontext des Mangels an Identifikationsmöglichkeiten um ,wirkliche Alternativen'. Rechtspopulistische Parteien seien in manchen Ländern die einzigen, die den Konsens der ,Mit- 
te', bzw. der großen Parteien, herausfordern (Mouffe 2000: 150). Als Ergebnis der vorliegenden Diskursanalyse verorte ich den „Energiewende“-Diskurs im Deutschen Bundestag ebenfalls im Rahmen dieses ,post-politischen Zeitgeists‘. Vor diesem Hintergrund und in Verbindung mit der Einschätzung von Chantal Mouffe, ließe sich der „Energiewende“-Diskurs auch im Kontext des erstarkenden ,Rechtspopulismus“ analysieren. Ergebnisse des Projektes „Energiekonflikte - Akzeptanzkonflikte und Gerechtigkeitsvorstellungen in der Energiewende", das innerhalb der Forschung für nachhaltige Entwicklungen FONA des BMBF von 2013 bis 2017 durchgeführt wurde, legen eine Verbindung zwischen Gegnerschaft zur „Energiewende“ und ,Rechtspopulismus' nahe:

„Wir haben aufdecken können, dass es strukturelle Affinitäten zwischen dem Rechtspopulismus der AfD einerseits und dem Protest gegen Energiewende-Projekte andererseits gibt (vgl. Eichenauer u.a. 2018): Es geht gegen ein scheinbar ,alternativloses‘ Projekt von ,denen da oben' (in Berlin), das ja immerhin von einer CDU/FDP-Regierung beschlossen, von CDU/SPD- Regierungen weitergeführt und von den Grünen ohnehin gewollt wird“ (Reusswig u.a. 2017: 58).

Eine bundesweite Erhebung hat ergeben, dass 44\% der „Energiewende“-Gegner*innen AfD Wähler*innen seien (Eichenauer u.a. 2018: 639). Die Wissenschaftler*innen des BMBF-Projektes schlussfolgern, dass es gerade nicht inhaltliche Übereinstimmungen in der Energiepolitik sind, die die „Energiewende“-Gegner*innen zu AfD-Wähler*innen werden lassen, sondern, dass es die auch in der vorliegenden Arbeit identifizierten post-politischen Repräsentationen ${ }^{4}$ des Diskurses sind, welche die AfD - wie ihr Name suggeriert - mit alternativen Identifikationsmöglichkeiten herausfordert. Diese sind im Energiebereich geprägt von Polarisierung, Anti-Elitarismus und Anti-Intellektualismus (ebenda: 644ff.). Aus Sicht der Forscher*innen ist dies zum einen besorgniserregend, da der AfD aus der „Kritik an der Energiewende ein zunehmendes Wählerpotenzial erwachsen“ könnte, zum anderen, da die AfD mit ihrem potenziellen politischen Einfluss die „Energiewende“ stoppen oder zurückdrängen könnte (ebenda: 641). Für eine ausführlichere Betrachtung von „Energiewende“ im Kontext von Rechtspopulismus sei auf Radtke u.a. (2019) verwiesen.

Selbstverständlich bilden die sich (auch) in der Energiepolitik manifestierenden post-politischen Tendenzen nur eine von mehreren Erklärungsmöglichkeiten für das Erstarken des Rechtspopulismus. Eine weitere Ursache ist auch darin auszumachen, dass sich eine breite Diskursformation über fast alle Fraktionen im Bundestag hinweg, seit dem Erstarken der AfD und der als ,Flüchtlingskrise' konstituierten Migrationsbewegungen ab 2015, zunehmend rechtspopulistische Artikulationsmuster angeeignet hat und damit insgesamt der Diskurs nach rechts verschoben wurde. Auch hier zeigen sich post-politische Strategien, die auf die Aufhebung, bzw. die Verdeckung von Dissens - in diesem Fall mit den Protestierenden von rechts zielten (vgl. auch

4 Genannt werden hier bspw. die Konstruktion als ,alternativlos', die „Energiewende“ als technokratisches Projekt sowie die Verwissenschaftlichung der „Energiewende“. 
Ruhose 2019: 35ff.). ${ }^{5}$ Gleichzeitig gerieten Artikulationen zu „Energiewende“ und ,Klimaschutz' durch die dominante Thematisierung von ,Migration“ im Zuge von Bundestags-Debatten in den Hintergrund, wodurch sich der Raum für grüne und linke gegenhegemoniale Artikulationen in diesem Bereich öffnete. ${ }^{6}$ Außerparlamentarisch wird dieser Raum von erneut erstarkenden ökosozialen Bewegungen wie ,Fridays for Future‘, ,Extinction Rebellion` oder dem Bündnis ,Ende Gelände‘ besetzt. Welchen Erfolg diese Bewegungen bzw. welchen Einfluss sie auch auf den „Energiewende“-Diskurs im Bundestag entfalten werden, ist noch offen. Aktuell deutet sich aber an, dass die Regierungskoalition erneut versucht durch Zugeständnisse und Aufgreifen ökologischer Artikulationsmuster ein ,abspaltendes Einbeziehen“ dieser Bewegungen in die marktwirtschaftliche Formation zu erreichen. Als Beispiel für ein solches Zugeständnis kann zum einen der sogenannte ,Kohlekompromiss“ gewertet werden, mit dem die 2019 präsentierten Ergebnisse der von der Bundesregierung im Juni 2018 eingesetzten Kommission ,Wachstum, Strukturwandel und Beschäftigung ' bezeichnet werden. Diese sogenannte ,Kohlekommission', an der neben politischen Parteien auch Forschungsinstitute, Arbeitgeber*innen- und Industrieverbände, Umweltverbände, NGOs, Kirchen und Gewerkschaften beteiligt waren, empfiehlt, neben umfangreichen Maßnahmen zum Strukturwandel in den Kohleregionen, einen Kohleausstieg bis zum Jahr 2038 (BMWi 2019). Die ,Fridays for Future'Bewegung kritisiert allerdings einen Kohleausstieg 2038 als zu spät und inkompatibel mit dem Pariser Klimaabkommen (www.fridaysforfuture.de - Forderungen).

In Reaktion auf den durch die regelmäßigen Demonstrationen von ,Fridays for Future‘ erzeugten Druck, erfolgten weitere Zugeständnisse, die im Herbst 2019 in die „Eckpunkte für das Klimaschutzprogramm 2030“, das sogenannte Klimapaket, mündeten (Bundesregierung 2019). Das Paket umfasst Maßnahmen in den Bereichen Bauen und Wohnen, Verkehr, Land- und Forstwirtschaft, Industrie, Energiewirtschaft, Abfallwirtschaft, Forschung und Entwicklung sowie eine Bepreisung von $\mathrm{CO}_{2}$. Zum ersten Mal werden darin vielfältige politische Praktiken in verschiedenen Sektoren vom Kabinett gebündelt auf den Weg gebracht. Das Paket wird von ,Fridays for Future“ aber als unzureichend und ,,politische Bankrotterklärung" kritisiert (www.fridaysforfuture.de - offener Brief). Auffällig ist zum einen, dass das Schlagwort „Energiewende“ in den Formulierungen im Kontext des Klimapakets keine besondere Rolle mehr spielt, die Klimamaßnahmen in den verschiedenen Sektoren werden also nicht unter der Forderung einer „Energiewende“ subsumiert. Die Forderung „Energiewende“ wird somit weiterhin kaum auf andere Bereiche über den Strombereich hinaus ausgeweitet. Zum anderen zeigt sich deutlich, dass sich Artiku-

5 Diese diskursive Aneignung rechtspopulistischer Artikulationsmuster hat eine andere Qualität als vorherige diskursive Aneignungen, denn sie macht diskriminierende, menschenverachtende rechte Rhetorik sagbar, womit sich in der hegemonialen Diskursformation nicht nur post-politische, sondern auch explizit antidemokratische Potenziale verfestigen.

6 Diese Tendenzen zeigten sich innerhalb des vorliegenden Untersuchungszeitraumes, in dem die AfD noch nicht im Bundestag vertreten war, im Energiebereich erst in Ansätzen. $\mathrm{Ob}$ die deutliche Abnahme der Artikulation von „Energiewende*“ von 924 Vorfällen im Jahr 2014 auf 348 bzw. 381 Vorfälle 2015, bzw. 2016 im Kontext dieser Diskursverschiebung zu interpretieren ist, wäre genauer zu untersuchen (vgl. Kapitel 5.1.1). 
lationsmuster aus den früheren „Energiewende“-Debatten im Bundestag - zum Teil wortidentisch - wiederholen, z.B.: „Klimaschutz gibt es nicht zum Nulltarif“ (www.bundesregierung.de - Klimaschutzprogramm). Die Deutungsmuster der hegemonialen marktwirtschaftlichen Formation schreiben sich fort und werden auf die ,neuen` Forderungen übertragen. Dies zeigt sich unter anderem in der Begründung der Bundesregierung für das Klimapaket:

„Aus volkswirtschaftlicher Sicht ist das Klimaschutzprogramm 2030 für Deutschland daher nicht nur sinnvoll, um höhere Schadens- und Anpassungskosten und den drohenden notwendigen Zukauf von Emissionszuweisungen aus dem Ausland bei Zielverfehlung zu vermeiden. Es ist auch deshalb geboten, weil es sowohl durch direkte Förderung von Forschung und Entwicklung als auch durch Marktanreize dazu beiträgt, dass Deutschland seine Stellung als innovativer Leitanbieter und Leitmarkt für klimafreundliche Technologien ausbaut und damit ein positiver Impuls für Wachstum und Wohlstand gesetzt wird. $\mathrm{CO}_{2}$-neutrale Technologien ,made in Germany ' werden einen wichtigen Beitrag für den weltweiten Klimaschutz liefern und Deutschlands Exportkraft als Spitzentechnologieland weiter stärken“ (Bundesregierung 2019: 2).

Ob eine Einbindung von ,Fridays for Future ${ }^{67}$ oder anderer Bewegungen gelingt, in welchem Umfang die hegemoniale Formation sich für Zugeständnisse öffnet, ob dies wie nach „Fukushima“ letztlich zu einem weiteren Erstarken der hegemonialen marktwirtschaftlichen Formation führt oder ob die sozialen Bewegungen auf der Differenz bestehen und sich somit zwangsweise weiter politisieren, bleibt im Hinblick auf noch bevorstehende Kämpfe um Hegemonie und Gegen-Hegemonie offen.

Vor dem Hintergrund der derart beschriebenen (möglichen) Weiterentwicklung des „Energiewende“ - Diskurses bieten sich auch Ansatzpunkte für weiterführende Forschung in Bezug auf Transformation im Bereich der Nachhaltigkeitswissenschaften. In der vorliegenden Arbeit wurde deutlich, dass es zur Umsetzung einer vorsorgenden „Energiewende“ der transformativen Nachhaltigkeitswissenschaft bedarf, die an den Widersprüchen und Ausschlüssen der derzeitigen „Energiewende“ ansetzt, die die Notwendigkeit einer „Energiewende“ im Kontext der multiplen Krise betrachtet und „Energiewende“ sozial-ökologisch einbettet. Hier eröffnet sich vielfältiges Forschungspotenzial, bspw. im Hinblick darauf wie eine solche „Energiewende“ in den einzelnen Handlungsfeldern gestaltet werden könnte. Bspw. stellt sich hier die Frage, wie über technokratisch-managementorientierte, auf eine verfahrenspolitische Ebene fokussierte politische Praktiken hinausgegangen werden kann, oder genauer: Wie könnten transformative politische Praktiken gestaltet sein und welche Voraussetzungen brauchen sie? So konstatieren auch Radtke/Czada (2018: 69), dass ,[ü]bliche Strategien der Problemvereinfachung - wie sie das einseitig auf Kapazitätserweite-

7 Der Versuch der Regierungskoalition, die Forderungen von ,Fridays for Future“ einzubinden und sich deren Artikulationsmuster anzueignen, zeigt sich im Herbst 2019 bildlich, als die CDU mit dem Beschluss des Klimapakets durch das Kabinett ihr Titelbild beim Kurznachrichtendienst ,twitter' ändert, mit dem Hashtag \#cduforfuture versieht und dabei den mit den ,Friday for Future“ Demonstrationen verbundenen Slogan „Es gibt keinen Planeten B“ verwendet. Gleichzeitig ist am Konrad Adenauer Haus der Slogan „Monday to Friday for Future“"zu lesen (www.twitter.de - CDU). 
rung bzw. Zubau ausgerichtete EEG von Anfang an darstellt" an ihre Grenzen stoßen. Dahingehend ist es eine Aufgabe der Energieforschung eigene Wege zu gehen und sich nicht auf die von den Parteien in bundespolitischen Debatten benannten Problemfelder der „Energiewende“ zu beschränken. So kritisiert auch Neukirch (2018: 2), dass die Schwerpunkte in der Energieforschung teilweise so gesetzt werden, „dass in der Gesamtinterpretation der Ergebnisse durch Politik und Gesellschaft gerade jene Argumente der Etablierten Koalition untermauert werden, welche von dieser zur Verlangsamung der Energiewende eingesetzt werden“. Dies betreffe die Akzeptanzforschung, die Forschung zu Protesten gegen Stromtrassen und Windparks oder die wirtschaftswissenschaftliche Energieforschung, die sich häufig auf die Kosten der Energiewende konzentriere (ebenda). Vor dem Hintergrund der vorliegenden Forschungsperspektive im Hinblick auf die Ergebnisse der Analyse, braucht es also eine Energieforschung, welche nicht innerhalb der Story-Lines und Narrative der hegemonialen marktwirtschaftlichen Formation agiert, bzw. diese zur Grundlage hat oder deren Prämissen als objektiv gegeben voraussetzt. Im Gegenteil, braucht es eine Energieforschung, welche diese herausfordert und alternative Perspektiven eröffnet. Aus einer Geschlechterperspektive stellt sich dabei auch die Frage, wie eine Transformation im Energiebereich so gestaltet werden kann, dass sie mit einer Transformation der Geschlechterverhältnisse einhergeht und nicht beharrend auf diese wirkt.

Im Hinblick auf eine Verbindung von Transformations- und Diskursforschung für die „Energiewende“ zeigt sich weiterer Forschungsbedarf bezüglich der Frage nach dem transformativen Potenzial sozialer Praktiken im Rahmen von „Energiewende“, d.h. der Frage, wie sich der Diskurs um „Energiewende“ im Bereich des Sozialen manifestiert und materialisiert. ${ }^{8}$ Es ist zu erwarten, dass transformative Potenziale sich hier deutlicher zeigen. Forschungen in diesem Bereich könnten einerseits zur weiteren Operationalisierung des materiellen Diskursbegriffs nach Laclau/Mouffe (2015) beitragen und andererseits Ansatzpunkte für transformative Politiken aufzeigen.

In der Verbindung von Transformations- und Diskursforschung liegt darüber hinaus weiterer Forschungsbedarf nicht nur darin, die Folgen erstarkender rechtspopulistischer Diskurse für Klima- und Transformationsdiskurse aufzuzeigen, sondern auch zu erforschen, wie rechtspopulistischen Diskursen in diesem Bereich entgegengewirkt werden kann.

Darüber hinaus wurde in der vorliegenden Arbeit deutlich, dass die Schärfung einer post-, bzw. dekolonialen Perspektive Vorsorgenden Wirtschaftens weiterer Forschungen bedarf. Dies ist notwendig, um globale Machtverhältnisse und rassistische Ausbeutungsstrukturen aufzudecken und nicht zu reproduzieren. In Bezug auf die „Energiewende“ hieße die Anwendung einer dekolonialen Perspektive bspw. danach zu fragen wie dekoloniale politische Praktiken der „Energiewende“ gestaltet sein könnten. In Bezug auf die Energieforschung hieße dies auch zunächst dem Forschungsbereich eigene neokoloniale Muster aufzudecken und zu hinterfragen.

8 Selbstverständlich gibt es bereits zahlreiche Forschungen zu den transformativen Potenzialen der „Energiewende“, jedoch wenige diskurstheoretische Arbeiten und noch weniger Arbeiten, die einen materiellen Diskursbegriff wie den von Laclau/Mouffe (2015) zugrunde legen. 
Auch im Bereich der Politischen Ökonomie, insbesondere der Frage nach den Eigentumsverhältnissen bedarf das Vorsorgende Wirtschaften weiterer Spezifizierung. Dies verweist auch auf die Notwendigkeit der Schärfung eines Gerechtigkeitsverständnisses.

\subsection{RÜCKBINDUNG AN DIE THEORIE: ANSATZPUNKTE ZUR ÜBERWINDUNG DES POST-POLITISCHEN}

Aus der dieser Arbeit zu Grunde liegenden Forschungsperspektive heraus, wäre eine Repolitisierung von „Energiewende“ - und der Debatte über ,Klimaschutz“ insgesamt - wünschenswert, um die Ausschlüsse gegenwärtiger politischer Praktiken sichtbar zu machen. Nur so kann eine Debatte über ,Alternativen` jenseits naturalisierter marktwirtschaftlicher Lösungen entstehen, so kann post-politischen Tendenzen entgegengewirkt werden und es können - im Gegensatz zu rechtspopulistisch konstruierten Identitäten - nicht parasitär auf Ausschluss beruhende Identifikationsmöglichkeiten jenseits marktwirtschaftlicher Hegemonie geschaffen werden. Vor dem Hintergrund der oben beschriebenen Mechanismen sozialer Ächtung gegenhegemonialer Diskursformationen, erweist sich dies sicher als schwierig - zumal im Kontext eines ,post-politischen Zeitgeists' bereits Politisierung an sich als populistisch, da zu radikal, zu different und somit illegitim erscheinen kann. Kenis/Mathijs (2014) kommen in ihrer Diskursstudie zu den Politisierungsbestrebungen der NGO Climate Justice Action CJA zu einem solchen Schluss: Es zeige sich, dass sich andere klimapolitisch aktive Menschen gerade wegen der Politisierung des Diskurses durch CJA von der NGO distanzierten. „This brings us to a paradoxical observation. Establishing a cleavage between one's own ideology and existing discourses is a crucial ingredient for repoliticization, but it can lead to minorization or an inability to gather people beyond the strongly convinced and politicized activists" (ebenda: 155). Ein Problem liege also unter anderem darin, dass gleichzeitig für alternative Gesellschaftsmodelle und gegen Post-Politik gekämpft werden müsse, ohne der Einbindung einer kritischen Masse entgegenzuwirken (vgl. auch ebenda).

Im Umgang mit einer derart identifizierten Problemlage zeigt sich das Potenzial der Verbindung von Diskurs- und Transformationstheorie deutlich: Die Diskurstheorie hilft, post-politische Diskursstrukturen aufzudecken und ihre Ausschlüsse aufzuzeigen. Mithilfe eines Forschungsdesigns, das in der Operationalisierung Diskursund Transformationstheorie zusammenführt, können wie in der vorliegenden Arbeit die Wirkweisen (post)politischer Praktiken dekonstruiert werden. Die Transformationstheorie bietet im Kontext der Ausschlüsse gegenwärtiger gesellschaftlicher Machtverhältnisse Anknüpfungspunkte für nicht auf hierarchischen Ausschluss beruhende Identifikationen, wie sie in der vorliegenden Arbeit aus Perspektive des Vorsorgenden Wirtschaftens angedeutet wurden. Die Diskurstheorie wiederum stellt Werkzeuge für diskursive Strategien zur Verfügung, die für einen transformativen Aktivismus genutzt werden können, um erfolgreich eine kritische Masse einzubinden. Derartige theoretische Verknüpfungen können sich nicht nur als hilfreich erweisen, um Lösungen für die sozial-ökologische Krise zu erforschen, sondern auch um 
rechtspopulistischen Tendenzen im Diskurs über gesellschaftliche Herrschaftsverhältnisse entgegenzuwirken.

Der Wissenschaft kommt in Diskursen um Transformation eine wichtige Rolle zu: Aus der dieser Arbeit zugrunde liegenden sozial-ökologischen Perspektive ist es nicht nur Aufgabe der Wissenschaft, die Folgen des Klimawandels zu erforschen, sondern auch die sozial-ökologische Krise in ihrer Vielfältigkeit - auch bezüglich ihrer strukturellen Ursachen zu benennen. Eine solche Wissenschaft verlässt zwangsweise das Terrain des vermeintlich Unpolitischen, da sie durch das Sichtbarmachen interner Krisenursachen außerhalb der naturalisierten und somit scheinbar unpolitischen hegemonialen marktwirtschaftlichen Formation agiert. Um gegenwärtige Beharrungstendenzen zu überwinden, braucht es also auch eine Politisierung der Wissenschaft. Welche Rolle dafür die gegenwärtige ,Scientists for Future' Bewegung (www.scientists4future.org) spielt, ist noch offen. Aus den Ergebnissen der vorliegenden Arbeit lassen sich insbesondere drei Ansatzpunkte für eine Repolitisierung von „Energiewende“ und Transformation ableiten, von denen die ersten beiden ebenso wie in der vorliegenden Arbeit - als Ansatzpunkte für eine kritische Transformationsforschung gesehen werden können:

1. Post-Politik sichtbar machen: Der erste Ansatzpunkt liegt darin, die Post-Politik der „Energiewende“ unter der derzeitigen hegemonialen Formation sichtbar zu machen. Post-politische Praktiken der „Energiewende“ wurden in Kapitel 5.4 umfassend aufgearbeitet. Eine Repolitisierung des Diskurses müsste demnach an der herrschaftskritischen Dekonstruktion ansetzen und aufzeigen, wie „Energiewende" marktwirtschaftlich eingebunden wird, wie diese Einbindung naturalisiert wird und welche Ausschlüsse und Ausbeutungsstrukturen dadurch entstehen welche diskursiven Mechanismen also am Werk sind. So würde die beharrende, eben nicht nachhaltige bzw. transformative Wirkung einer derart im hegemonialen Verständnis konzipierten „Energiewende“ sichtbar.

2. Differenz herausarbeiten: Ein weiterer Ansatzpunkt baut darauf auf und zielt darauf $\mathrm{ab}$, „Energiewende“ streitbar zu machen, indem einer post-politischen „Energiewende“ eine explizit ,andere“ „Energiewende“ mit transformativem Potenzial entgegen gestellt wird. Es ginge also mit Laclau/Mouffe (2015) darum, die Differenz herauszuarbeiten, die Ausschlüsse der hegemonial marktwirtschaftlichen „Energiewende“ in einer ,anderen“ „Energiewende“ zu integrieren und das transformative Potenzial dieses ,Anderen“ zu verdeutlichen. Die Kombination von Diskurs- und Transformationstheorie kann dabei helfen, Trennungsstrukturen besser zu identifizieren. Gleichzeitig wird die Möglichkeit zu einer politischen Positionierung eröffnet, wodurch - wie zum Beispiel im Rahmen des Vorsorgenden Wirtschaften - Ansatzpunkte für eine ,andere“ „Energiewende“ aufgezeigt werden können. Die Differenz der bisherigen bundespolitischen Umsetzung von „Energiewende“ zu einer vorsorgend angelegten „Energiewende“ wurde in Kapitel 6 herausgearbeitet. Vor diesem Hintergrund wurde die affirmative Wirkung in der Materialisierung des post-politischen „Energiewende“ - Diskurses durch entsprechend beharrende bis reaktionäre politische Praktiken herausgearbeitet. Die Verknüpfung von Transformations- und Diskurstheorie hilft also auch, dem mate- 
riellen Anspruch des Diskursbegriffes nach Laclau/Mouffe (2015) analytisch gerecht zu werden.

3. Äquivalenzkette ausweiten: Dies führt unmittelbar zum nächsten Ansatzpunkt: Mit einer Integration des ,Anderen“ wäre mit Laclau/Mouffe (2015) eine Ausbreitung der Äquivalenzkette um „Energiewende“ auf andere gesellschaftliche Kämpfe verbunden - eine Voraussetzung für den Erfolg kritischer Diskurse (vgl. Kapitel 4.2.1). Mit der Perspektive Vorsorgenden Wirtschaftens könnte der „Energiewende“-Diskurs grundlegend verschoben werden: Nicht die Frage, wie eine „Energiewende“ marktwirtschaftlich eingebunden werden kann oder welche marktökonomischen Ziele mit einer „Energiewende“ verbunden werden können, stünde im Mittelpunkt der Artikulationen; sondern die Frage, wie eine „Energiewende" sozial-ökologisch und (re)produktiv, d.h. auf die Erneuerung der sozialen und ökologischen Lebensgrundlagen gerichtet, eingebunden und wie eine diesem Zweck dienende Ökonomie gestaltet werden kann.

Das bislang Ausgeschlossene würde zum grundlegenden Bestandteil der Artikulation von „Energiewende“.9 Bspw. wären innerhalb eines vorsorgenden „Energiewende“-Diskurses das Private und das (Re)produktive Bestandteil der Äquivalenzkette, da den Haushalten eine aktive Rolle in der Energieproduktion zugewiesen würde, bzw. die Ermöglichung einer solchen Rolle eingefordert würde. Die Produktivität der im Haushalt stattfindenden vermeintlich konsumtiven Tätigkeiten (z.B. Kochen) käme in den Blick. Die Einbindung von Naturleistungen in den Produktionsprozess von Energie würde sichtbar gemacht. Eine tatsächlich erneuerbare Energieproduktion in diesem Sinne wäre für ihre naturalen Voraussetzungen und Folgen nicht blind. Statt der Interessen strategisch agierender marktlicher Akteur*innen, stünden gesellschaftliche Bedürfnisse im Mittelpunkt, wodurch auch die geschlechtshierarchische gesellschaftliche Arbeitsteilung in den Blick käme und die Erwerbsfixierung politischer Entscheidungen untergraben würde. Die Forderung einer vorsorgenden „Energiewende“ bietet somit das Potenzial der Verknüpfung mit vielfältigen gesellschaftlichen Kämpfen, wie öko-aktivistischen Kämpfen, Feminismus, Kämpfen um Umverteilung, gewerkschaftlichen Kämpfen (bspw. im Rahmen von Strukturwandel), Kämpfen für Bürger*innenenergie, Kämpfen für Menschenrechte, postkolonialen Kämpfen, Kämpfen für Naturschutz oder anti-kapitalistischen Kämpfen.

Eine solche Verbreiterung/Ausweitung der Kämpfe um „Energiewende“, wie sie im dritten Ansatzpunkt beschrieben ist, muss gesellschaftspolitisch geleistet werden. Allerdings trägt gerade eine als kritische Transformationswissenschaft verstandene Nachhaltigkeitswissenschaft eine Verantwortung dafür, Entpolitisierungstendenzen entgegen zu wirken sowie den eigenen Standpunkt zu verdeutlichen und zu verteidigen. Die Bedeutung dieser Verantwortung zeigt sich gerade vor dem Hintergrund ei-

9 Wie eine solche „Energiewende“ genau auszusehen hätte, wäre Ergebnis eines gesellschaftlichen Aushandlungsprozesses und kann nicht wissenschaftlich bestimmt werden. Die hier genannten Punkte sollen nur Beispiele liefern. 
nes erstarkenden Rechtspopulismus. Eine kritische Nachhaltigkeitsforschung, die auf die Transformation gesellschaftlicher Naturverhältnisse zielt, müsste, ebenso wie die Geschlechterforschung, auf die Aufdeckung von Dichotomisierungsprozessen, von Ausschlüssen und Abwertungen und somit auf Herrschaftskritik gerichtet sein (Hofmeister u.a. 2013: 45f.). Eine solche Wissenschaft ist zwangsweise immer politisch. Denn: „Das sichtbar zu machen geschieht nicht interesselos, sondern mit dem Ziel, Herrschaftsverhältnisse zu unterlaufen und sie schließlich im Interesse des Abgespaltenen und Abgewerteten zu verändern“ (ebenda: 45). In diesem Sinne bedarf es vor allem nicht einer Wissenschaft, die unter Vorhaltung eines vermeintlichen Objektivitätsanspruches in dieser Arbeit aufgezeigte nicht-nachhaltige, post-politische Vorstellungen, wie das Postulat von ,Ideologiefreiheit', reproduziert und somit letztlich den hegemonialen Diskurs stärkt.

\subsection{KRITISCHE REFLEXION}

Abschließend möchte ich die Verbindung von Theorie, Methodik und Analyse in der vorliegenden Arbeit noch einmal kritisch reflektieren und etwaige, durch die Vorgehensweise entstandene Blindstellen sichtbar machen.

Im Rahmen der Dekonstruktion hat sich die Verbindung der Diskurstheorie nach Laclau/Mouffe (2015) mit den Handlungsprinzipien des Vorsorgenden Wirtschaftens mitsamt ihrer im Theoriekapitel beschriebenen konzeptionellen Erweiterung als aussagekräftig erwiesen. Unter Zuhilfenahme des materiellen Diskursbegriffs nach Laclau/Mouffe (2015) wurde sich schrittweise über die Ebenen der Dekonstruktion an die Materialisierungen politischer Praktiken der „Energiewende“ angenähert. Die Offenheit des Diskursbegriffs ermöglichte dabei auf allen Analyseebenen eine Vermittlung zwischen Sprache und Materialität. Dabei konnte der Kritik an der Diskurstheorie in Bezug auf ihre politische Erklärkraft durch Verknüpfung mit den normativ angelegten Kriterien des Vorsorgenden Wirtschaftens entgegengewirkt werden. Umgekehrt hat sich in der Operationalisierung die Diskurstheorie als methodische Bereicherung für das Konzept des Vorsorgenden Wirtschaftens erwiesen, da die Analyseheuristik verfeinert werden konnte und dadurch Aspekte von Herrschaft mit dem materiell-symbolisch angelegten Diskursbegriff frühzeitiger und teilweise überhaupt erst aufgedeckt werden konnten. Methodisch bewährt hat sich auch das Einbeziehen der Rolle der Fantasie nach Glynos/Howarth (2007). Anhand der Identifikation und Einordnung fantasmatischer Narrative lässt sich die Blindheit der hegemonialen Diskursformation für strukturelle Krisenursachen nachvollziehen und begründen. Eine (neo)koloniale und nationale Externalisierung als Prinzip wurde durch die Verknüpfung von Vorsorgendem Wirtschaften mit der Diskurstheorie überhaupt erst sichtbar und konnte im Rahmen des retroduktiven Forschungsdesigns noch in Erweiterung der Kriterien Vorsorgenden Wirtschaftens in die Analyseheuristik aufgenommen werden. Was das Sichtbarmachen von Geschlechterverhältnissen betrifft, so haben sich Diskurstheorie und Vorsorgendes Wirtschaften dahingehend ergänzt, dass das Vorsorgende Wirtschaften vor dem Hintergrund feministischer Theoriebildung den Blick auf die Geschlechterverhältnisse und geschlechtshierarchisch strukturierte Dichotomien lenkt. Auch gesellschaftliche Naturverhältnisse konnten mit dem Vorsorgenden Wirtschaften tiefergehend in den Blick genommen werden. Einem zentralen Dilem- 
ma feministischer Theoriebildung, dem Verhältnis zwischen Materialität und Diskurs, konnte mit dem materiell-symbolisch angelegten Diskursbegriff von Laclau/ Mouffe (2015) entgegengewirkt werden. Um allerdings die Materialisierungen politischer Praktiken wie des EEGs genauer zu untersuchen, wäre eine weitere Datenerhebung, bzw. Recherche außerhalb von Bundestagsprotokollen notwendig, die nicht Gegenstand der vorliegenden Arbeit war. Eine Verknüpfung zu diesen Daten erfolgte in Kapitel 6 daher nur in Annäherungen.

Auch die Methodenkombination aus quantitativer, computerbasierter und qualitativer Analyse hat sich im Nachhinein als sinnvoll erwiesen. So deuteten sich zentrale Diskursentwicklungen bereits in der computerbasierten Analyse an und konnten qualitativ dann tiefergehend in den Blick genommen werden. Dies gilt sowohl für die Bedeutung einzelner Knotenpunkte für den Diskurs (z.B. die Relevanz des Knotenpunktes „Deutschland“), als auch für zeitliche Entwicklungen. Die zeitliche Entwicklung des „Energiewende“-Diskurses in seiner quantitativen Bedeutung (z.B. kaum Vorfälle vor „Fukushima“) hätte ohne die computerbasierte Analyse in dieser Form nicht nachvollzogen werden können. Auch die Plenarprotokolle für die qualitative Analyse konnten über die Computeranalyse zielgenauer ausgewählt werden. Dennoch muss kritisch hinterfragt werden, inwiefern computerbasierte, quantitative Methoden bestimmte technokratische, auf Rationalität, Effizienz und vermeintliche Objektivität gerichtete Vorgehensweisen in der Wissenschaft reproduzieren und somit zur Stärkung post-politischer Tendenzen innerhalb der Wissenschaft beitragen. Ich habe versucht diese Wirkung in der vorliegenden Arbeit kritisch zu reflektieren und durch eine Einbettung in ein umfangreiches, quantitatives und qualitatives Forschungsdesign aufzuheben.

Durch den Fokus der vorliegenden Untersuchung auf Bundestagsdebatten konnten externe Einflussfaktoren auf den Diskurs nicht, oder nur indirekt erfasst werden. Solche Einflussfaktoren liegen dem Diskurs implizit zu Grunde. Zu nennen sind hier für den Untersuchungszeitraum z.B. diverse Entscheidungen auf EU-Ebene, die Finanzkrise, der Kosovo Krieg, Reaktionen der GRÜNEN Wähler*innenschaft auf deren Regierungspolitik oder Wechsel in Ministerämtern, wie z.B. die Übernahme des Wirtschaftsministeriums im Jahr 2003 durch Wolfgang Clement (SPD). Durch meinen diskursorientierten Ansatz, der sich auf Plenarprotokolle fokussierte, wurde in der vorliegenden Arbeit die Rolle einzelner Akteur*innen weniger betrachtet. Wie eingangs im Forschungsstand (vgl. Kapitel 1) beschrieben wurde, war eine solche akteurszentrierte Perspektive bereits Gegenstand anderer Forschungsarbeiten.

Meine diskurstheoretische Vorgehensweise, die auf eine Klassifikation der Wirkrichtung politischer Praktiken und fantasmatischer Narrative im Spannungsfeld zwischen Beharrung und Transformation gerichtet war, führt darüber hinaus dazu, dass zugrunde liegende Interessen einzelner Akteur*innen nicht immer sichtbar werden. So können innerhalb des von mir klassifizierten ,technokratisch-managementorientierten Ökokonsenses ' die Interessen von grünen, sozialdemokratischen, konservativen und liberalen Akteur*innen nur unzureichend differenziert werden. So bedienen diese Akteur*innen zwar einerseits ähnliche Artikulationsmuster, es ist aber davon auszugehen, dass sie dies vor dem Hintergrund unterschiedlicher Interessen tun: So könnte ein Teil dieser Akteur*innen ökologische Artikulationsmuster jederzeit wieder aufgeben, sobald dies für den eigenen Machterhalt nicht mehr erforderlich ist - während diese Artikulationsmuster für andere Akteur*innen, wie die 
GRÜNEN, Grundlage politischen Handelns sind. Eine solche Differenzierung war nicht Gegenstand der vorliegenden Analyse, da sie sich auf die Wirkrichtung diskursiver Muster konzentrierte. Für eine solche Differenzierung wäre eine tiefergehende Untersuchung, ggf. eine Kontextualisierung mit Parteiprogrammen, ggf. Expert*inneninterviews und somit weitere Forschungen notwendig. 


\section{Literatur}

Acosta, Alberto; Brand, Ulrich (2018): Radikale Alternativen: Warum man den Kapitalismus nur mit vereinten Kräften überwinden kann. München: oekom verlag.

Adam, Barbara (1998): Timescapes of modernity: The environment and invisible hazards. London [u.a.]: Routledge.

Adam, Barbara (2006): Leere und Gelebte Zeit - Über den Umgang mit Zukunft. Tutzing: Vortrag zur Zeitakademie des Tutzinger Projekts „Ökologie der Zeit““. Text abrufbar unter: http://www.cardiff.ac.uk/socsi/futures/conf_ba_tutzing11050 6.pdf (Zugriff am 7.9.2017).

Adam, Barbara (2013): Sustainability through a temporal lens: Time, future, process. In: Netzwerk Vorsorgendes Wirtschaften (Hrsg.): Wege vorsorgenden Wirtschaftens. Marburg: Metropolis-Verlag, 115-130.

Adam, Barbara; Groves, Chris (2007): Future matters: action, knowledge, ethics. Leiden [u.a.]: Brill.

Adorno, Theodor W. (1984): Fortschritt. In: Philosophie und Gesellschaft: fünf Essays. Stuttgart: Reclam, 94-118.

AK Postwachstum (2016): Wachstum - Krise und Kritik: Die Grenzen der kapitalistisch-industriellen Lebens-weise. Frankfurt, New York: Campus Verlag.

Althusser, Louis (1977): Ideologie und ideologische Staatsapparate: Aufsätze zur marxistischen Theorie. Hamburg [u.a.]: VSA.

Amigo-Jorquera, Catalina; Guerrero-González, María José; Sannazzaro, Jorgelina; Urquiza-Gómez, Anahí (2019): Does energy poverty have a female face in Chile? In: Tapuya: Latin American Science, Technology and Society, 2 (1), 378-390.

Amri-Henkel, Andrea (2020): Skizzen eines (re)produktiven Ansatzes radikaler Demokratie - Vermittlungen von (Re)Produktivität und der Laclau/Mouffe'schen Diskurstheorie. In: Mölders, Tanja; Thiem, Anja; Katz, Christine (Hrsg.): Nachhaltigkeit (re)produktiv denken: Pfade kritischer sozial-ökologischer Wissenschaft. Opladen, Berlin, Toronto: Barbara Budrich, 218-226.

Amri-Henkel, Andrea; Biesecker, Adelheid; Breitenbach, Sarah; Hofmeister, Sabine; Lenz, Christoph; Moths, Katharina (2017): Nachhaltig transformativ? Wie Geschlechterperspektiven die Transformationsdebatte/n zu transformieren vermögen.... Text abrufbar unter: https://wupperinst.org/fa/redaktion/downloads/projec ts/TraVo_Nachhaltig_transformativ.pdf (Zugriff am 30.8.2017).

Amri-Henkel, Andrea; Hofmeister, Sabine (2018): Energiegenossenschaften im Kontext einer sozial-ökologischen Transformation der Ökonomie. In: Holstenkamp, 
Lars; Radtke, Jörg (Hrsg.): Handbuch Energiewende und Partizipation. Wiesbaden: Springer VS, 317-330.

Angermüller, Johannes (2005): Sozialwissenschaftliche Diskursanalyse in Deutschland: Zwischen Rekonstruktion und Dekonstruktion. In: Keller, Reiner; Hirseland, Andreas; Schneider, Werner; Viehöver, Willy (Hrsg.): Die diskursive Konstruktion von Wirklichkeit : zum Verhältnis von Wissenssoziologie und Diskursforschung. Konstanz: UVK, 23-48.

Ashcroft, Bill; Griffiths, Gareth; Tiffin, Helen (2004): Post-colonial studies: the key concepts. London [u.a.]: Routledge.

Avelino, Flor; Grin, John; Pel, Bonno; Jhagroe, Shivant (2016): The politics of sustainability transitions. In: Journal of Environmental Policy and Planning, 18 (5), 557-567.

Baker, Paul (2006): Using corpora in discourse analysis. London: Continuum.

Baker, Paul (2016): The shapes of collocation. In: International Journal of Corpus Linguistics, 21 (2), 139-164.

Barthes, Roland. (1987): S/Z. 1. Aufl. Frankfurt a. M.: Suhrkamp.

Barthes, Roland (2010): Die Lust am Text. 1. Aufl. Berlin: Suhrkamp.

Bauriedl, Sybille (2015): Eurozentrische Weltbürgerbewegung. Zum WBGU-Sondergutachten Klimaschutz als Weltbürgerbewegung. In: GAIA, 24 (1), 13-16.

Bauriedl, Sybille; Wichterich, Christa (2014): Ökonomisierung von Natur, Raum, Körper. Feministische Perspektiven auf sozialökologische Transformationen. In: Rosa Luxemburg Stiftung. Reihe Analysen, Berlin. Text abrufbar unter: https:// www.rosalux.de/fileadmin/rls_uploads/pdfs/Analysen/Analysen_Oekonomisieru ng.pdf (Zugriff am 17.2.2020).

Becker, Egon (1999): Sozial-ökologische Transformation: Anmerkungen zur politischen Ökologie der Nachhaltigkeit. In: Neue Ansätze zur Entwicklungstheorie, 50-59.

Becker, Egon; Hummel, Diana; Jahn, Thomas (2011): Gesellschaftliche Naturverhältnisse als Rahmenkonzept. In: Groß, Matthias (Hrsg.): Handbuch Umweltsoziologie. Wiesbaden: Springer VS, 75-96.

Becker, Egon; Jahn, Thomas (2000): Sozial-ökologische Transformationen. Theoretische und methodische Probleme transdisziplinärer Nachhaltigkeitsforschung. In: Brand, Karl-Werner (Hrsg.): Nachhaltigkeit und Transdisziplinarität. Berlin, 6884.

Becker, Egon; Jahn, Thomas (2006): Soziale Ökologie: Grundzüge einer Wissenschaft von den gesellschaftlichen Naturverhältnissen. Frankfurt, New York: Campus Verlag.

Bedall, Philip (2014): Climate Justice vs. Klimaneoliberalismus?: Klimadiskurse im Spannungsfeld von Hegemonie und Gegen-Hegemonie. Bielefeld: transcript.

Benjamin, Walter (2010): Über den Begriff der Geschichte. 1. Aufl. Berlin: Suhrkamp.

Bhabha, Homi K. (1990): Nation and narration. London [u.a.]: Routledge.

Bhabha, Homi K. (1994): The location of culture. London [u.a.]: Routledge.

Biesecker, Adelheid (1994): Wir sind nicht zur Konkurrenz verdammt. In: BuschLüty, Christiane; Jochimsen, Maren; Knobloch, Ulrike; Seidl, Irmi (Hrsg.): Vorsorgendes Wirtschaften: Frauen auf dem Weg zu einer Ökonomie der Nachhaltigkeit. Politische Ökologie: Sonderheft 6, 28-32. 
Biesecker, Adelheid (1996): Kooperation, Netzwerk, Selbstorganisation - Prinzipien für eine faire und vorsorgende Ökonomie. In: Biesecker, Adelheid; Grenzdörffer, Klaus (Hrsg.): Kooperation, Netzwerk, Selbstorganisation: Elemente demokratischen Wirtschaftens. Pfaffenweiler: Centaurus-Verlags-Gesellschaft, 9-22.

Biesecker, Adelheid; Breitenbach, Sarah; von Winterfeld, Uta (2015): Vorsorgendes Wirtschaften und transformative Gesellschaftsverträge. Text abrufbar unter: https://wupperinst.org/uploads/tx_wupperinst/TraVo_Gesellschaftsvertraege.pdf (Zugriff am 30.8.2017).

Biesecker, Adelheid; Breitenbach, Sarah; von Winterfeld, Uta (2016): Transdisziplinäre Erzählungen. Text abrufbar unter: https://wupperinst.org/fa/redaktion/down loads/projects/TraVo_Transformative_Erzaehlungen.pdf (Zugriff am 13.9.2017).

Biesecker, Adelheid; Gottschlich, Daniela (2012): Vorsorgendes Wirtschaften. In: Brand, Ulrich; Lösch, Bettina; Opratko, Benjamin; Thimmel, Stefan (Hrsg.): ABC der Alternativen 2.0: von Alltagskultur bis Zivil-gesellschaft. Hamburg: VSA, 320-321.

Biesecker, Adelheid; Hofmeister, Sabine (2006): Die Neuerfindung des Ökonomischen: ein (re)produktions-theoretischer Beitrag zur sozial-ökologischen Forschung. München: oekom verlag.

Biesecker, Adelheid; Hofmeister, Sabine (2013a): (Re)Produktivität als Kategorie vorsorgenden Wirtschaftens. In: Netzwerk Vorsorgendes Wirtschaften (Hrsg.): Wege Vorsorgenden Wirtschaftens. Marburg: Metropolis-Verlag, 137-159.

Biesecker, Adelheid; Hofmeister, Sabine (2013b): Zur Produktivität des «Reproduktiven». Fürsorgliche Praxis als Element einer Ökonomie der Vorsorge. In: Feministische Studien, 31 (2), 240-252.

Biesecker, Adelheid; Hofmeister, Sabine (2015): (Re)Produktivität als ein sozialökologisches ,Brückenkonzept‘ ${ }^{\star}$ In: Katz, Christine; Heilmann, Sebastian; Thiem, Anja; Moths, Katharina; Koch, Lea; Hofmeister, Sabine (Hrsg.): Nachhaltigkeit anders denken: Veränderungspotenziale durch Geschlechterperspektiven. Wiesbaden: Springer VS, 77-95.

Biesecker, Adelheid; Hofmeister, Sabine; Amri-Henkel, Andrea; Breitenbach, Sarah; Saave-Haarnack, Anna (2019): (Re)Produktivität - eine Vermittlungskategorie für Vorsorgendes Wirtschaften. In: Knobloch, Ulrike (Hrsg.): Ökonomie des Versorgens: feministisch-kritische Wirtschaftstheorien im deutsch-sprachigen Raum. Weinheim: Beltz Juventa, 120-138.

Biesecker, Adelheid; Kesting, Stefan (2003): Mikroökonomik: Eine Einführung aus sozial-ökologischer Perspektive. München: Oldenbourg.

Biesecker, Adelheid; Mathes, Maite; Scurrell, Babette; Schön, Susanne (Hrsg.) (2000): Vorsorgendes Wirtschaften: auf dem Weg zu einer Ökonomie des guten Lebens. Bielefeld: Kleine.

Biesecker, Adelheid; von Winterfeld, Uta (2005): Es gibt keine „richtige“ Nachhaltigkeit im „falschen“ Denken: Nachhaltigkeit und Existenzsicherung. In: Politische Ökologie 94 (3), 75-77.

Biesecker, Adelheid; von Winterfeld, Uta (2011): Nachhaltige Feministische Einsprüche. Die Blockierung nachhaltiger Entwicklungen durch klassische Rationalitätsmuster. In: GENDER, 3 (2), 129-144.

Biesecker, Adelheid; von Winterfeld, Uta (2013a): Es geht nicht allein. Vorsorgendes Wirtschaften braucht neue Gesellschaftsverträge. In: Netzwerk Vorsorgendes 
Wirtschaften (Hrsg.): Wege vorsorgenden Wirtschaftens. Marburg: MetropolisVerlag, 385-402.

Biesecker, Adelheid; von Winterfeld, Uta (2013b): Geld, Wachstum und gutes Leben. In: Netzwerk Vorsorgendes Wirtschaften (Hrsg.): Wege vorsorgenden Wirtschaftens. Marburg: Metropolis-Verlag, 257-276.

Biesecker, Adelheid; von Winterfeld, Uta (2013c): Alte Rationalitätsmuster und neue Beharrlichkeiten: Impulse zu blinden Flecken der Transformationsdebatte. In: GAIA, 22 (3), 160-164.

Biesecker, Adelheid; von Winterfeld, Uta (2014): Extern? Weshalb und inwiefern moderne Gesellschaften Externalisierung brauchen und erzeugen. Working Paper der DFG-KollegforscherInnengruppe Postwachstumsgesellschaften, Jena. Text abrufbar unter: http://www.kolleg-postwachstum.de/sozwgmedia/dokumente/Wor kingPaper/wp2_2014.pdf (Zugriff am 30.8.2017).

Biesecker, Adelheid; von Winterfeld, Uta (2015): Positionspapier 1: Zum Gesellschaftsvertrag in vorsorgenden Perspektiven. Text abrufbar unter: http://www.vor sorgendeswirtschaften.de/fileadmin/netzwerk-wirtschaften/Zum_Gesellschaftsver trag_in_vorsorgenden_Perspektiven.pdf (Zugriff am 4.10.2017).

Biesecker, Adelheid; von Winterfeld, Uta (2016): Wie regenerativ ist die Energiewende tatsächlich? In: GAIA, 25(1), 34-37.

Binswanger, Hans-Christoph (1998): Dominium und Patrimonium - Eigentumsrechte und -pflichten unter dem Aspekt der Nachhaltigkeit. In: Held, Martin; Nutzinger, Hans-Gerd (Hrsg.): Eigentumsrechte verpflichten: Individuum, Gesellschaft und die Institution Eigentum. Frankfurt a. M. [u.a.]: Campus Verlag, 126-142.

Blaette, Andreas (2017): GermaParl. Corpus of Plenary Protocols of the German Bundestag. R Data Package (v1.0.4). Available from: https://doi.org/10.5281/ zenodo.1312551.

Blaette, Andreas (2018): Using Data Packages to Ship Annotated Corpora of Parliamentary Protocols: The GermaParl R Package. Text abrufbar unter: http://lrecconf.org/workshops/lrec2018/W2/pdf/15_W2.pdf.

BMU (2018): Die Reform des EU-Emissionshandels für die 4. Handelsperiode (2021-2030). Text abrufbar unter: https://www.bmu.de/fileadmin/Daten_BMU/ Download_PDF/Emissionshandel/eu-emissionshandel_reform_bf.pdf (Zugriff am 9.1.2019).

Bock, Gisela; Duden, Barbara (1976): Arbeit aus Liebe — Liebe als Arbeit. Zur Entstehung der Hausarbeit im Kapitalismus. Frauen und Wissenschaft, Berlin: Courage-Verlag.

Book, Carina; Huke, Nikolai; Klauke, Sebastian; Tietje, Olaf (2019): Alltägliche Grenzziehungen. Das Konzept der ,imperialen Lebensweise', Externalisierung und exklusive Solidarität. Münster: Westfälisches Dampfboot.

Bourdieu, Pierre (1982): Die feinen Unterschiede: Kritik der gesellschaftlichen Urteilskraft. 1. Auflage. Frankfurt a. M.: Suhrkamp.

Brand, Karl-Werner (Hrsg.) (2017): Die sozial-ökologische Transformation der Welt. Frankfurt, New York: Campus Verlag.

Brand, Ulrich (2012): Sozial-ökologische Transformation. In: Brand, Ulrich; Lösch, Bettina; Opratko, Benjamin; Thimmel, Stefan (Hrsg.): ABC der Alternativen 2.0. Hamburg: VSA, 270-271. 
Brand, Ulrich (2014): Sozial-ökologische Transformation als gesellschafts-politisches Projekt. In: Kurswechsel, 2, 7-18.

Brand, Ulrich (2016): „Transformation“ as a new critical orthodoxy: The strategic use of the term ,transformation“ does not prevent multiple crises. GAIA, 25 (1), 23-27.

Brand, Ulrich; Lötzer, Ulla; Müller, Michael; Popp, Michael (2013a): Big Business Emissionshandel. In: Rosa Luxemburg Stiftung (Hrsg.): Standpunkte, 3.

Brand, Ulrich; Pühl, Katharina; Thimmel, Stefan (Hrsg.) (2013b): Wohlstand - Wie anders? Linke Perspektiven. In: Rosa Luxemburg Stiftung (Hrsg.): Manuskripte, 5. Berlin.

Brand, Ulrich; Wissen, Markus (2011): Die Regulation der ökologischen Krise: Theorie und Empirie der Transformation gesellschaftlicher Naturverhältnisse. In: Österreichische Zeitschrift für Soziologie, 36 (2), 12-34.

Brand, Ulrich; Wissen, Markus (2017): Imperiale Lebensweise: Zur Ausbeutung von Mensch und Natur in Zeiten des globalen Kapitalismus. München: oekom verlag.

Brangsch, Lutz; Dellheim, Judith; Spangenberg, Joachim H; Otto Wolf, Frieder (Hrsg.) (2012): Den Krisen entkommen: Sozialökologische Transformation. Berlin: Karl Dietz Verlag.

Brie, Michael (Hrsg.) (2014a): Futuring: Perspektiven der Transformation im Kapitalismus über ihn hinaus. Münster: Westfälisches Dampfboot.

Brie, Michael (2014b): Transformation des Reichtums - Reichtum der Transformationen: Eine Vier-in-einem Perspektive. In: Brie, Michael (Hrsg.): Futuring: Perspektiven der Transformation im Kapitalismus über ihn hinaus. Münster: Westfälisches Dampfboot, 194-241.

Brie, Michael (2014c): Vorwort. In: Brie, Michael (Hrsg.): Futuring: Perspektiven der Transformation im Kapitalismus über ihn hinaus. Münster: Westfälisches Dampfboot, 7-11.

Brie, Michael (2015a): Beiträge zur kritischen Transformationsforschung - ein erster Überblick über den Diskussionsstand. In: Brie, Michael (Hrsg.): Mit Realutopien den Kapitalismus transformieren? Hamburg: VSA, 7-32.

Brie, Michael (Hrsg.) (2015b): Lasst uns über Alternativen reden. Beiträge zur kritischen Transformations-forschung. Hamburg: VSA.

Brie, Michael (Hrsg.) (2015c): Mit Realutopien den Kapitalismus transformieren? Hamburg: VSA.

Brie, Michael (2015d): Polanyi neu entdecken: das hellblaue Bändchen zu einem möglichen Dialog von Nancy Fraser und Karl Polanyi. Hamburg: VSA.

Brie, Michael; Reißig, Rolf; Thomas, Michael (Hrsg.) (2016): Transformation: Suchprozesse in Zeiten des Umbruchs. Berlin [u.a.]: LIT Verlag.

Brodocz, Andre (2003): Das Ende der politischen Theorie? Über die Rechtfertigung der Demokratie und die Ironie ihrer Unmöglichkeit. In: Bonacker, Thorsten; Brodocz, Andre; Noetzel, Thomas (Hrsg.): Die Ironie der Politik: über die Konstruktion politischer Wirklichkeiten. Frankfurt, New York: Campus Verlag, 52-64.

Brouns, Bernd; Witt, Uwe (2008): Klimaschutz als Gelddruckmaschine. In: Altvater, Elmar; Brunnengräber, Joachim (Hrsg.): Ablasshandel gegen Klimawandel. Marktbasierte Instrumente in der globalen Klima-politik und ihre Alternativen. Reader des Wissenschaftlichen Beirats von Attac. Hamburg: VSA, 67-87. 
Brownhill, Leigh; Turner, Terisa E. (2009): Women and Abuja Declaration for Energy Sovereignity. In: Eco-sufficiency \& Global Justice. Women Write Political Ecology, 230-250.

Brunnengräber, Achim (2014): Eine Weltbürgerbewegung ohne Realitätsbezug. Zum WBGU-Gutachten Klima-schutz als Weltbürgerbewegung. In: GAIA, 23 (4), 306-308.

Bundesministerium für Wirtschaft und Energie (BMWi) (2019): Kommission „Wachstum, Strukturwandel und Beschäftigung“: Abschlussbericht. Text abrufbar unter: https://www.bmwi.de/Redaktion/DE/Downloads/A/abschlussberichtkommission-wachstum-strukturwandel-und-beschaeftigung.pdf?_blob=publica tionFile (Zugriff am 28.10.2019).

Bundesregierung (2019): Eckpunkte für das Klimaschutzprogramm 2030. Text abrufbar unter: https://www.bundesregierung.de/resource/blob/975232/1673502/76 8b67ba939c098c994b71c0b7d6e636/2019-09-20-klimaschutzprogramm-data.pdf ?download=1 (Zugriff am 28.10.2019).

Bundestag (Hrsg.) (2013): Schlussbericht der Enquete-Kommission „Wachstum, Wohlstand, Lebensqualität - Wege zu nachhaltigem Wirtschaften und gesellschaftlichem Fortschritt in der Sozialen Marktwirtschaft". Band 1419. Bonn: Bundeszentrale für politische Bildung.

Burke, Paul J.; Dundas, Guy (2015): Female Labor Force Participation and Household Dependence on Biomass Energy: Evidence from National Longitudinal Data. In: World Development, 67, 424-437.

Burkhart, Corinna; Schmelzer, Matthias; Treu, Nina (Hrsg.) (2017): Degrowth in Bewegung(en): 32 alternative Wege zur sozial-ökologischen Transformation. München: oekom verlag.

Busch-Lüty, Christiane; Jochimsen, Maren; Knobloch, Ulrike; Seidl, Irmi (Hrsg.) (1994): Vorsorgendes Wirtschaften: Frauen auf dem Weg zu einer Ökonomie der Nachhaltigkeit. In: Politische Ökologie, Sonderheft 6.

Butler, Judith (1991): Das Unbehagen der Geschlechter. Frankfurt a. M.: Suhrkamp.

Butler, Judith (1993): Bodies that matter: on the discursive limits of „sex“. New York [u.a.]: Routledge.

Butler, Judith (1995): Körper von Gewicht: die diskursiven Grenzen des Geschlechts. Berlin: Berlin-Verlag.

Butler, Judith (1997): Das Ende der Geschlechterdifferenz? In: Huber, Jörg; Heller, Martin (Hrsg.): Konturen des Unentschiedenen. Basel: Stromfeld, 25-43.

Butler, Judith (1998): Weitere Reflexionen zu Hegemonie und Gender. In: Marchart,

Oliver (Hrsg.): Das Undarstellbare der Politik: zur Hegemonietheorie Ernesto Laclaus. Wien: Turia + Kant, 254-257.

Butler, Judith (2016): Hass Spricht: zur Politik des Performativen. 5. Aufl. 2006. Frankfurt a. M.: Suhrkamp.

Butler, Judith; Laclau, Ernesto (1998): Gleichheiten und Differenzen. Eine Diskussion via E-mail. In: Marchart, Oliver (Hrsg.): Das Undarstellbare der Politik: zur Hegemonietheorie Ernesto Laclaus. Wien: Turia + Kant, 238-253.

Butler, Judith; Scott, Joan Wallach (Hrsg.) (1992): Feminists theorize the political. New York, NY [u.a.]: Routledge.

Candeias, Mario (2010): Passive Revolutionen vs. sozialistische Transformation. In: Rosa Luxemburg Stiftung (Hrsg.): Papers. Text abrufbar unter: https://www.rosa 
lux.de/fileadmin/rls_uploads/pdfs/rls_papers/rls-paper-Candeias_2010.pdf (Zugriff am 10.10.2017).

Candeias, Mario (2013): Grüne Transformation. In: Rosa Luxemburg Stiftung (Hrsg.): Analysen. Text abrufbar unter: http://www.rosalux-nyc.org/wp-content/ files_mf/analysis_green_transformationdeu.pdf(Zugriff am 1.9.2017).

Castro Varela, María do Mar; Dhawan, Nikita (2015): Postkoloniale Theorie: Eine kritische Einführung. Bielefeld: transcript.

Chappin, Emile J.L.; Ligtvoet, Andreas (2014): Transition and transformation: A bibliometric analysis of two scientific networks researching socio-technical change. In: Renewable and Sustainable Energy Reviews, 30, 715-723.

Chatterjee, Partha (1986): Nationalist thought and the colonial world: a derivative discourse. University of Minnesota Press.

Child, Michael; Breyer, Christian (2017): Transition and transformation: A review of the concept of change in the progress towards future sustainable energy systems. In: Energy Policy, 107, 11-26.

Clancy, Joy; Roehr, Ulrike (2003): Gender and energy: is there a Northern perspective? In: Energy for Sustainable Development, 7 (3), 44-49.

Crenshaw, Kimberle (1989): Demarginalizing the Intersection of Race and Sex: A Black Feminist Critique of Antidiscrimination Doctrine, Feminist Theory and Antiracist Politics. University of Chicago Legal Forum, 1, 139-167.

Critchley, Simon (1998): Dekonstruktion - Marxismus - Hegemonie. Zu Derrida und Laclau. In: Machart, Oliver (Hrsg.): Das Undarstellbare der Politik : Zur Hegemonietheorie Ernesto Laclaus. Wien: Turia + Kant, 193-208.

Czada, Roland; Radtke, Jörg (2018): Governance langfristiger Transformationsprozesse. Der Sonderfall „Energiewende“. In: Radtke, Jörg; Kersting, Norbert (Hrsg.): Die Energiewende in Deutschland - Politikwissenschaftliche Perspektiven. Wiesbaden: Springer VS, 45-75.

Dash, Madhusmita; Behera, Bhagirath; Rahut, Dil Bahadur (2018): Understanding the factors that influence household use of clean energy in the Similipal Tiger Reserve, India. In: Natural Resources Forum, 42 (1), 3-18.

Dellheim, Judith; Krause, Günter (Hrsg.) (2008): Für eine neue Alternative: Herausforderungen einer sozial-ökologischen Transformation. Rosa Luxemburg Stiftung. Berlin: Karl Dietz Verlag.

Demirović, Alex (2014): Transformation und Ereignis: Zur Dynamik demokratischer Veränderungsprozesse der kapitalistischen Gesellschaftsformation. In: Brie, Michael (Hrsg.): Futuring: Perspektiven der Trans-formation im Kapitalismus über ihn hinaus. Münster: Westfälisches Dampfboot, 419-435.

Dernbach, Beatrice (2015): Energiewende - ein politisch besetzter Begriff. In: Jahrbuch für christliche Sozial-wissenschaften, 56, 23-35.

Derrida, Jacques (1972): Die Schrift und die Differenz. 1. Aufl. Frankfurt a. M.: Suhrkamp.

Derrida, Jacques (1974): Grammatologie. 1. Aufl. Frankfurt a. M.: Suhrkamp.

Derrida, Jacques (1988): Randgänge der Philosophie. 1. Aufl. Wien: Passagen Verlag.

Derrida, Jacques (1992): Of an Apocalyptic Tone Recently Adopted in Philosophy. In: Coward, Harold G.; Foshay, Toby (Hrsg.): Derrida and negative theology. Albany, N.Y.: State University of New York Press, 25-72. 
Derrida, Jacques (1995): Marx' Gespenster: der verschuldete Staat, die Trauerarbeit und die neue Internationale. Frankfurt a. M.: Fischer-Taschenbuch-Verlag.

Derrida, Jacques (2003): Schurken: zwei Essays über die Vernunft. 1. Aufl. Frankfurt a. M.: Suhrkamp.

Diaz-Bone, Rainer; Schneider, Werner (2008): Qualitative Datenanalysesoftware in der sozialwissenschaftlichen Diskursanalyse: Zwei Praxisbeispiele. In: Keller, Reiner; Hirseland, Andreas; Schneider, Werner; Viehöver, Willy (Hrsg.): Handbuch Sozialwissenschaftliche Diskursanalyse. 2, Forschungspraxis. Wiesbaden: VS Verl. f. Sozialwissenschaften, 491-530.

Ding, Wenguang; Wang, Lijun; Chen, Baoyu; Xu, Luan; Li, Haoxu (2014): Impacts of renewable energy on gender in rural communities of north-west China. In: Renewable Energy, 69, 180-189.

Distelhorst, Lars (2007): Umkämpfte Differenz: hegemonietheoretische Perspektiven der Geschlechterpolitik mit Butler und Laclau. Berlin: Parodos.

Dörre, Klaus (2009): Die neue Landnahme. Dynamiken und Grenzen des Finanzmarktkapitalismus. In: Dörre, Klaus; Lessenich, Stephan; Rosa, Hartmut (Hrsg.): Soziologie - Kapitalismus - Kritik: eine Debatte. Frankfurt a. M.: Suhrkamp, 2186.

Dörre, Klaus; Rosa, Hartmut; Becker, Karina; Bose, Sophie; Seyd, Benjamin (2019): Große Transformation? Zur Zukunft moderner Gesellschaften. In: Sonderband des Berliner Journals für Soziologie. Wiesbaden: Springer VS.

Duden, Barbara (1993): Die Frau ohne Unterleib: Zu Judith Butlers Entkörperung*: Ein Zeitdokument. In: Feministische Studien, 2, 24-33.

Dunning, Ted (1993): Accurate Methods for the Statistics of Surprise and Coincidence. In: Computational linguistics, 19 (1), 61.

Dzudzek, Iris; Glasze, Georg; Mattissek, Annika; Schirmel, Henning (2009): Verfahren der lexikometrischen Analyse von Textkorpora. In: Glasze, Georg; Mattissek, Annika (Hrsg.): Handbuch Diskurs und Raum. Theorien und Methoden für die Humangeographie sowie die sozial- und kulturwissenschaftliche Raumforschung. Bielefeld: transcript.

Eichenauer, Eva; Reusswig, Fritz; Meyer-Ohlendorf, Lutz; Lass, Wiebke (2018): Bürgerinitiativen gegen Windkraftanlagen und der Aufschwung rechtspopulistischer Bewegungen. In: Kühne, Olaf; Weber, Florian (Hrsg.): Bausteine der Energiewende. Wiesbaden: Springer VS, 633-651.

EIGE (2012): Review of the implementation in the EU of area K of the Beijing platform for action: Women and the Environment: Gender Equality and Climate Change. Text abrufbar unter: https://op.europa.eu/en/publication-detail/-/publica tion/9ef701cd-3c76-48a7-8739-eb1fc126ffa7 (Zugriff am 29.2.2020).

Exner, Andreas; Held, Martin; Kümmerer, Klaus (Hrsg.) (2016): Kritische Metalle in der Großen Transformation. Kritische Metalle in der Großen Transformation, Wiesbaden: Springer VS.

Fairclough, Norman (1995): Critical discourse analysis : the critical study of language. 6. Aufl. Harlow [u.a.]: Longman.

Feldman, Martha S.; Sköldberg, Kaj; Brown, Ruth Nicole; Horner, Debra (2004): Making Sense of Stories: A Rhetorical Approach to Narrative Analysis. In: Journal of Public Administration Research and Theory, 14 (2), 147-170. 
Flämig, Dieter; De Maiziére, Lothar (Hrsg.) (2016): Weiter Denken: von der Energiewende zur Nachhaltigkeits-gesellschaft. Berlin, Heidelberg: Springer Vieweg.

Flaute, Markus; Großmann, Anett; Lutz, Christian; Nieters, Anne; Aretz, Astrid; Gährs, Swantje; Madlener, Reinhard; Oberst, Christian (2018): Prosumer-Haushalte und ihr Beitrag zur Transformation des Energiesystems und der Gesellschaft. In: Die Energiewende der Bürger stärken. Marburg: Metropolis-Verlag, 167-189.

Flügel-Martinsen, Oliver (2017): Die Kontingenz der demokratischen Gesellschaft. Zum demokratietheoretischen Gehalt von Ernesto Laclaus Hegemonietheorie. In: Marchart, Oliver (Hrsg.): Ordnungen des Politischen: Einsätze und Wirkungen der Hegemonietheorie Ernesto Laclaus. Wiesbaden: Springer VS, 13-32.

Forschungsverbund „Blockierter Wandel?“ (Hrsg.) (2007): Blockierter Wandel? Denk- und Handlungsspielräume für eine nachhaltige Regionalentwicklung. München: oekom verlag.

Foucault, Michel (1974): Die Ordnung der Dinge: eine Archäologie der Humanwissenschaften. 1. Aufl. Frankfurt a. M.: Suhrkamp.

Foucault, Michel (1976): Mikrophysik der Macht: über Strafjustiz, Psychiatrie und Medizin. Berlin: Merve Verlag.

Foucault, Michel (1978): Dispositive der Macht: über Sexualität, Wissen und Wahrheit. 1.Aufl. Berlin: Merve Verlag.

Foucault, Michel (1986): Sexualität und Wahrheit: Erster Band: Der Wille zum Wissen. 1.Aufl. Frankfurt a. M.: Suhrkamp.

Fraser, Nancy (1996): Öffentlichkeit neu denken. Ein Beitrag zur Kritik real existierender Demokratie. In: Scheich, Elvira (Hrsg.): Vermittelte Weiblichkeit: feministische Wissenschafts- und Gesellschaftstheorie. 1. Aufl. Hamburg: Hamburger Ed., 151-182.

Fraser, Nancy (2001): Die halbierte Gerechtigkeit: Schlüsselbegriffe des postindustriellen Sozialstaats. Frankfurt a. M.: Suhrkamp.

Fraune, Cornelia (2015): Gender matters: Women, renewable energy, and citizen participation in Germany. In: Energy Research \& Social Science, 7, 55-65.

Geels, Frank W. (2014): Regime Resistance against Low-Carbon Transitions: Introducing Politics and Power into the Multi-Level Perspective. In: Theory, Culture \& Society, 31 (5), 21-40.

Giacovelli, Sebastian (Hrsg.) (2017): Die Energiewende aus wirtschaftssoziologischer Sicht. Die Energiewende aus wirtschaftssoziologischer Sicht, Wiesbaden: Springer VS.

Giddens, Anthony (1988): Die Konstitution der Gesellschaft: Grundzuege einer Theorie der Strukturierung. Frankfurt a. M. [u.a.]: Campus Verlag.

Gildemeister, Regine (2008): Doing Gender: Soziale Praktiken der Geschlechterunterscheidung. In: Becker, Ruth; Kortendiek, Beate (Hrsg.): Handbuch Frauenund Geschlechterforschung. 3. Aufl. VS Verlag für Sozialwissenschaften, 137145.

Glaser, Barney G.; Strauss, Anselm L. (1980): The discovery of grounded theory: Strategies for qualitative research. 11. Aufl. New York: Aldine.

Glasze, Georg (2008): Vorschläge zur Operationalisierung der Diskurstheorie von Laclau und Mouffe in einer Triangulation von Lexikometrischen und Interpretativen Methoden. In: Historical Social Research, 33 (1), 185-223. 
Glasze, Georg (2009): Handbuch Diskurs und Raum : Theorien und Methoden für die Humangeographie sowie die sozial- und kulturwissenschaftliche Raumforschung. Bielefeld: transcript.

Glasze, Georg; Mattissek, Annika (2009a): Die Hegemonie- und Diskurstheorie von Laclau und Mouffe. In: Glasze, Georg; Mattissek, Annika (Hrsg.): Handbuch Diskurs und Raum: Theorien und Methoden für die Humangeographie sowie die sozial- und kulturwissenschaftliche Raumforschung. Bielefeld: transcript, 153180.

Glasze, Georg; Mattissek, Annika (2009b): Diskursforschung in der Humangeographie: Konzeptionelle Grundlagen und empirische Operationalisierungen. In: Glasze, Georg; Mattissek, Annika (Hrsg.): Handbuch Diskurs und Raum. Bielefeld: transcript, 11-60.

Glasze, Georg; Shadia, Husseini; Mose, Jörg (2009): Kodierende Verfahren in der Diskursforschung. In: Glasze, Georg; Mattissek, Annika (Hrsg.): Handbuch Diskurs und Raum: Theorien und Methoden für die Humangeographie sowie die sozial- und kulturwissenschaftliche Raumforschung. Bielefeld: transcript, 293-314.

Glynos, Jason; Howarth, David (2007): Logics of Critical Explanation in Social and Political Theory. London: Routledge.

Göllinger, Thomas; Gaschnig, Hannes (2016): Die Energiewende zwischen Pfadmodifikation und „Großer Transformation“. In: Unternehmen und ökologische Herausforderung aus systemorientierter Perspektive, 2, 39-76.

Görg, Christoph (1999): Gesellschaftliche Naturverhältnisse. Münster: Westfälisches Dampfboot.

Görg, Christoph (2003): Regulation der Naturverhältnisse: zu einer kritischen Regulation der ökologischen Krise. Münster: Westfälisches Dampfboot.

Gottschlich, Daniela (2017): Kommende Nachhaltigkeit: Nachhaltige Entwicklung aus kritisch-emanzipatorischer Perspektive. Baden-Baden: Nomos.

Gottschlich, Daniela; Katz, Christine (2016): Sozial-ökologische Transformation braucht Kritik an den gesellschaftlichen Naturverhältnissen - Zur notwendigen Verankerung von Nachhaltigkeitsforschung in feministischer Theorie und Praxis. In: Soziologie und Nachhaltigkeit SuN; Beiträge zur sozial-ökologischen Transformationsforschung, 2 (3), 1-18.

Graf, Antonia; Sonnberger, Marco; Ruddat, Michael (2018): Transformation gestalten oder verwalten? In: Holstenkamp, Lars; Radtke, Jörg (Hrsg.): Handbuch Energiewende und Partizipation. Wiesbaden: Springer VS, 485-505.

Gramsci, Antonio (1991-2006): Gefängnishefte: kritische Gesamtausgabe, Bd. 1-10. Hamburg [u.a.]: Argument-Verlag.

Grasselt, Nico (2016): Die Entzauberung der Energiewende: Politik- und Diskurswandel unter schwarz-gelben Argumentationsmustern. Wiesbaden: Springer VS.

Gründinger, Wolfgang (2017): Drivers of Energy Transition - How Interest Groups Influenced Energy Politics in Germany. Wiesbaden: Springer VS.

Haas, Tobias (2017): Die politische Ökonomie der Energiewende Deutschland und Spanien im Kontext. Energiepol. Wiesbaden: Springer VS.

Habermas, Jürgen (1985): Die neue Unübersichtlichkeit. Frankfurt a. M.: Suhrkamp.

Hajer, Maarten A. (1997): The politics of environmental discourse : ecological modernization and the policy process. Oxford [u.a.]: Clarendon Press. 
Hajer, Maarten A. (2004): Argumentative Diskursanalyse. Auf der Suche nach Koalitionen, Praktiken und Bedeutung. In: Keller, Reiner; Hierseland, Andreas; Schneider, Werner; Viehöder, Willy (Hrsg.): Handbuch Sozialwissenschaftliche Diskursanalyse: Band 2 Forschungspraxis. Wiesbaden: VS Verlag für Sozialwissenschaften, 271-298.

Hanke, Gerolf; Best, Benjamin (2013): Die Energiewende aus wachstumskritischer Perspektive. In: Radtke, Jörg; Hennig, Bettina (Hrsg.): Die deutsche „Energiewende" nach Fukushima. Marburg: Metropolis-Verlag.

Haraway, Donna (1988): Situated Knowledges: The Science Question in Feminism and the Privilege of Partial Perspective. In: Feminist Studies, 14 (3), 575-599.

Helbig, Eike (2010): Windfall Profits im europäischen Emissionshandel. BadenBaden: Nomos.

Hemmati, Minu; Röhr, Ulrike (2009): Engendering the climate-change negotiations: experiences, challenges, and steps forward. In: Gender and Development, 17 (1), 19-32.

Hermwille, Lukas (2016): The role of narratives in socio-technical transitions - Fukushima and the energy regimes of Japan, Germany, and the United Kingdom. In: Energy Research and Social Science, 11, 237-246.

Hilpert, Martin; Gries, Stefan Th. (2009): Assessing frequency changes in multistage diachronic corpora: Applications for historical corpus linguistics and the study of language acquisition. In: Literary and Linguistic Computing, 24 (4), 385-401.

Hofmeister, Sabine (2008): Verwildernde Naturverhältnisse: Versuch über drei Formen der Wildnis. In: Das Argument, 279, 813-826.

Hofmeister, Sabine; Adam, Barbara (2000): Vorsorgendes Wirtschaften in Zeiten. Zur Bedeutung von Zeitvielfalt für eine Ökonomie der Vorsorge. In: Biesecker, Adelheid; Mathes, Maite; Schön, Susanne; Scurrell, Babette (Hrsg.): Vorsorgendes Wirtschaften: auf dem Weg zu einer Ökonomie des guten Lebens. Bielefeld: Kleine, 238-248.

Hofmeister, Sabine; Immler, Hans (1998): Natur als Grundlage und Ziel der Wirtschaft: Grundzüge einer Ökonomie der Reproduktion. Opladen: Westdt. Verl.

Hofmeister, Sabine; Katz, Christine (2011): Naturverhältnisse. Geschlechterverhältnisse. Nachhaltigkeit. In: Groß, Matthias (Hrsg.): Handbuch Umweltsoziologie. Wiesbaden: VS Verlag für Sozialwissenschaften, 365-398.

Hofmeister, Sabine; Katz, Christine; Mölders, Tanja (Hrsg.) (2013a): Geschlechterverhältnisse und Nachhaltigkeit: die Kategorie Geschlecht in den Nachhaltigkeitswissenschaften. Berlin, Toronto: Verlag Barbara Budrich.

Hofmeister, Sabine; Katz, Christine; Mölders, Tanja (2013b): Grundlegungen im Themenfeld Geschlechterverhältnisse und Nachhaltigkeit. In: Hofmeister, Sabine; Katz, Christine; Mölders, Tanja (Hrsg.): Geschlechterverhältnisse und Nachhaltigkeit. Die Kategorie Geschlecht in den Nachhaltigkeits-wissenschaften. Berlin, Toronto: Budrich, 33-76.

Hofmeister, Sabine; Mölders, Tanja; Deininger, Michaela; Kapitza, Katharina (2019): Für welche ,Natur/en' sorgen wir? Kritisch feministische Perspektiven auf aktuelle Care-Debatten im sozial-ökologischen Kontext. In: GENDER - Zeitschrift für Geschlecht, Kultur und Gesellschaft, 11 (1-2019), 125-139.

Hofmeister, Sabine; Scurrell, Babette (2016): Die ,Energielandschaft‘ als StadtLandschaft. Die Transformationsgeschichte einer Region in sozial-ökologischer Per- 
spektive'. In: Hofmeister, Sabine; Kühne, Olaf (Hrsg.): StadtLandschaften: Die neue Hybridität von Stadt und Land. Wiesbaden: Springer VS, 187-214.

Holstenkamp, Lars; Radtke, Jörg (Hrsg.) (2018): Handbuch Energiewende und Partizipation. Handbuch Energiewende und Partizipation, Wiesbaden.

Hombach, Bodo (1991): Semantik und Politik. In: Liedtke, Frank; Wengeler, Martin; Böke, Karin (Hrsg.): Begriffe besetzen: Strategien des Sprachgebrauchs in der Politik. Opladen: Westdt. Verlag, 34-43.

Howarth, David (2000): Discourse. Buckingham: Open University Press.

Huber, Joseph (2001): Allgemeine Umweltsoziologie. Wiesbaden: Westdt. Verlag.

Jäger, Siegfried (2012): Kritische Diskursanalyse : eine Einführung. Münster: Unrast.

Jäger, Siegfried; Zimmermann, Jens (2010): Lexikon kritische Diskursanalyse: eine Werkzeugkiste. Münster: Unrast-Verlag.

Jahn, Thomas (2005): Soziale Ökologie, kognitive Integration und Transdisziplinarität. In: Technikfolgenabschätzung - Theorie und Praxis, 14 (2), 32-38.

Jahn, Thomas; Wehling, Peter (1998): Gesellschaftliche Naturverhältnisse - Konturen eines theoretischen Konzepts. In: Brand, Karl-Werner (Hrsg.): Soziologie und Natur. Opladen, New York: Budrich, 75-96.

Jänicke, Martin (1988): Ökologische Modernisierung: Optionen und Restriktionen präventiver Umweltpolitik. In: Simonis, Udo E. (Hrsg.): Präventive Umweltpolitik. Frankfurt a. M. [u.a.]: Campus Verlag, 13-26.

Jensen, Sune Q. (2011): Othering, identity formation and agency. In: Qualitative Studies, 2 (2), 63-78.

Joas, Fabian; Pahle, Michael; Flachsland, Christian (2014): Die Ziele der Energiewende : Eine Kartierung der Prioritäten. In: ifo Schnelldienst, ifo Institut - Leibniz-Institut für Wirtschaftsforschung an der Universität München, 67 (9), 6-11.

Joas, Fabian; Pahle, Michael; Flachsland, Christian; Joas, Amani (2016): Which goals are driving the Energiewende? Making sense of the German Energy Transformation. In: Energy Policy, 95, 42-51.

Jochimsen, Maren; Knobloch, Ulrike; Seidl, Irmi (1994): Vorsorgendes Wirtschaften: Konturenskizze zu Inhalt und Methode einer ökologischen und sozialverträglichen Ökonomie. In: Busch-Lüty, Christiane; Jochimsen, Maren; Knobloch, U1rike; Seidl, Irmi (Hrsg.): Vorsorgendes Wirtschaften: Frauen auf dem Weg zu einer Ökonomie der Nachhaltigkeit. Politische Ökologie: Sonderheft 6, 6-11.

Kanning, Helga (2013): Genderspezifische Ansätze zur Energiewende. In: Hofmeister, Sabine; Katz, Christine; Mölders, Tanja (Hrsg.): Geschlechterverhältnisse und Nachhaltigkeit. Die Kategorie Geschlecht in den Nachhaltigkeitswissenschaften. Berlin, Toronto: Budrich, 262-266.

Kanning, Helga; Mölders, Tanja; Hofmeister, Sabine (2016): ,Gendered Energy“ Analytische Perspektiven und Potenziale der Geschlechterforschung für eine sozial-ökogische Gesatltung der Energiewende im Raum. In: Raumforschung und Raumordnung, 74 (3), 213-227.

Keller, Reiner (2011): Wissenssoziologische Diskursanalyse Grundlegung eines Forschungsprogramms. 3. Auflage. Wiesbaden: VS Verlag für Sozialwissenschaften.

Keller, Reiner; Hirseland, Andreas; Schneider, Werner; Viehöver, Willy (Hrsg.) (2005): Die diskursive Konstruktion von Wirklichkeit : zum Verhältnis von Wissenssoziologie und Diskursforschung. Konstanz: UVK. 
Kenis, Anneleen; Bono, Federica; Mathijs, Erik (2016): Unravelling the (post-)political in Transition Management: Interrogating Pathways towards Sustainable Change. In: Journal of Environmental Policy \& Planning, Routledge, 18 (5), 568584.

Kenis, Anneleen; Mathijs, Erik (2014): Climate change and post-politics: Repoliticizing the present by imagining the future? In: Geoforum, Pergamon, 52, 148-156.

Klein, Dieter (2014): Doppelte Transformation. In: Futuring: Perspektiven der Transformation im Kapitalismus über ihn hinaus. Münster: Westfälisches Dampfboot, 101-125.

Klein, Josef (1991): Kann man „Begriffe besetzen“? Zur linguistischen Differenzierung einer plakativen politischen Methapher. In: Liedtke, Frank; Wengeler, Martin; Böke, Karin (Hrsg.): Begriffe besetzen: Strategien des Sprachgebrauchs in der Politik. Opladen: Westdt. Verlag, 44-69.

Kleinhückelkotten, Silke; Neitzke, H-Peter (2016): Berechnung individueller ProKopf-Verbräuche natürlicher Ressourcen nach Konsumbereichen. In: Umweltbundesamt (Hrsg.): Texte 39/2016. Dessau-Roßlau.

Knobloch, Ulrike (2013): Versorgen-Fürsorgen-Vorsorgen. Normative Grundlagen einer Sorgeökonomie als allgemeine Wirtschaftstheorie und die Ethik des Vorsorgenden Wirtschaftens. In: Netzwerk Vorsorgendes Wirtschaften (Hrsg.): Wege vorsorgenden Wirtschaftens. Marburg: Metropolis-Verlag, 21-42.

Knobloch, Ulrike; von Winterfeld, Uta (2018): Anmerkungen zu strukturellen Hintergründen des Gerechtigkeitsbegriffs: Was heißt hier gerecht? In: Politische Ökologie, 154, 134-137.

Koch, Lea M.; Roth, Stephanie (2015): ,Ich sehe was, was Du nicht siehst ${ }^{\text {- Poten- }}$ ziale einer feministisch-postkolonialen Perspektive für den genderorientierten Nachhaltigkeitsdiskurs. In: Katz, Christine; Heilmann, Sebastian; Thiem, Anja; Moths, Katharina; Koch, Lea; Hofmeister, Sabine (Hrsg.): Nachhaltigkeit anders denken. Wiesbaden: Springer VS, 43-60.

Koepp, Marcus; Krampe, Leonard; Schalle, Heidrun (2017): Mieterstrom: Rechtliche Einordnung, Organisationsformen, Potenziale und Wirtschaftlichkeit von Mieterstrommodellen. Text abrufbar unter: http://www.bhw-energie.de/ (Zugriff am 19.10.2018).

Köhlin, Gunnar; Sills, Erin O.; Pattanayak, Subhrendu K.; Wilfong, Christopher (2011): Energy, Gender and Development: What are the Linkages? Where is the Evidence? In: Policy Research working paper. World Bank, The World Bank, WPS 5800.

Kopatz, Michael (2013): Energiewende - aber fair! : wie sich die Energiezukunft sozial tragfähig gestalten lässt. München: oekom verlag.

Kopatz, Michael (2015): Sozial- und Suffizienzpolitik als Teil der Energiewende. In: Jahrbuch für Christliche Sozialwissenschaften, 56, 61-71.

Krause, Florentin; Bossel, Hartmut; Müller-Reissmann, Karl-Friedrich (1980): Energie-Wende: Wachstum und Wohlstand ohne Erdöl und Uran. O.O.: Umwälz.

Krick, Eva (2018): Ensuring social acceptance of the energy transition. The German government's 'consensus management' strategy. In: Journal of Environmental Policy and Planning, 20 (1), 64-80.

Kropp, Cordula (2002): „Natur“: soziologische Konzepte, politische Konsequenzen. Opladen: Leske und Budrich. 
Krüger, Timmo (2015): Das Hegemonieprojekt der ökologischen Modernisierung: Die Konflikte um Carbon Capture and Storage (CCS) in der internationalen Klimapolitik. Bielefeld: transcript.

Lacan, Jacques (1973): Schriften/1. Olten: Walter.

Laclau, Ernesto; Mouffe, Chantal (2015): Hegemonie und radikale Demokratie : zur Dekonstruktion des Marxismus. 5. Aufl. Wien: Passagen Verlag.

Laclau, Ernesto (1990): New Reflections on The Revolution of Our Time. London [u.a.]: Verso.

Laclau, Ernesto (2000): Power and Social Communication. In: Ethical Perspectives, 7 (2-3), 139-145.

Laclau, Ernesto (2002): Emanzipation und Differenz. Wien [u.a.]: Turia und Kant.

Laclau, Ernesto (2004): Glimpsing the Future. In: Critchley, Simon; Marchart, Oliver (Hrsg.): Laclau: A critical reader. Routledge, 279-328.

Laclau, Ernesto (2005): On Populist Reason. Paperback ed. London [u.a.]: Verso.

Laclau, Ernesto (2007): Ideologie und Post-Marxismus. In: Nonhoff, Martin (Hrsg.): Diskurs, radikale Demokratie, Hegemonie: zum politischen Denken von Ernesto Laclau und Chantal Mouffe. Bielefeld: transcript, 25-40.

Lang, Eva (1994): Den Fortschrittsbegriff erweitern. In: Busch-Lüty, Christiane; Jochimsen, Maren; Knobloch, Ulrike; Seidl, Irmi (Hrsg.): Vorsorgendes Wirtschaften: Frauen auf dem Weg zu einer Ökonomie der Nachhaltigkeit. Politische Ökologie: Sonderheft 6, 47-50.

Lang, Eva (2000): Entwurf einer Politik Vorsorgenden Wirtschaftens. In: Biesecker, Adelheid; Mathes, Maite; Schön, Susanne; Scurrell, Babette (Hrsg.): Vorsorgendes Wirtschaften: auf dem Weg zu einer Ökonomie des guten Lebens. Bielefeld: Kleine, 215-224.

Lang, Eva (2004): Vorsorgendes Wirtschaften und aktivierender Staat. In: Jochimsen, Maren A.; Kesting, Stefan; Knobloch, Ulrike (Hrsg.): Lebensweltökonomie. Bielefeld: Kleine, 327-342.

Lauber, Volkmar; Jacobsson, Staffan (2016): The politics and economics of constructing, contesting and restricting socio-political space for renewables - The German Renewable Energy Act. In: Environmental Innovation and Societal Transitions, 18, 147-163.

Lazar, Michelle M (2007): Feminist Critical Discourse Analysis: Articulating a Feminist Discourse Praxis. In: Critical Discourse Studies, 4 (2), 141-164.

Leggewie, Claus; Messner, Dirk; Schlacke, Sabine (2015): Und doch: Klimaschutz als Weltbürgerbewegung. In: GAIA, 24 (1), 10-12.

Leipprand, Anna (2017): From conflict to consensus? Discourses on German Energy Transition. Berlin. Text abrufbar unter: https://www.reiner-lemoine-stiftung.de/ pdf/dissertationen/Dissertation-Anna_Leipprand.pdf.

Leipprand, Anna; Flachsland, Christian; Pahle, Michael (2017): Energy transition on the rise: discourses on energy future in the German parliament. In: Innovation: The European Journal of Social Science Research, 30 (3), 283-305.

Lerner, Gerda (1991): Die Entstehung des Patriarchats. Frankfurt a. M. [u.a.]: Campus Verlag.

Lessenich, Stephan (2016): Neben uns die Sintflut: die Externalisierungsgesellschaft und ihr Preis. Bonn: Bundeszentrale für politische Bildung. 
Lessenich, Stephan (2018): Externalisierung als soziale Praxis - Wachstum als Lebensform. In: Zeitschrift für Wirtschafts- und Unternehmensethik, 19 (3), 423428.

Link, Jürgen (2005): Warum Diskurse nicht von „personalen Subjekten“ ausgehandelt werden. Von der Diskurs-zur Interdiskurstheorie. In: Keller, Reiner; Hirseland, Andreas; Schneider, Werner; Viehöver, Willy (Hrsg.): Die diskursive Konstruktion von Wirklichkeit : zum Verhältnis von Wissenssoziologie und Diskursforschung. Konstanz: UVK, 77-100.

Loorbach, Derk; Frantzeskaki, Niki; Avelino, Flor (2017): Sustainability Transitions Research: Transforming Science and Practice for Societal Change. In: Annual Review of Environment and Resources, Annual Reviews, 42 (1), 599-626.

Luxemburg, Rosa (1981): Die Akkumulation des Kapitals. Berlin: Dietz.

Mahat, Ishara (2011): Gender, energy, and empowerment: a case study of the Rural Energy Development Program in Nepal. In: Development in Practice, 21 (3), 405-420.

Marchart, Oliver (Hrsg.) (1998a): Das Undarstellbare der Politik: zur Hegemonietheorie Ernesto Laclaus. Wien: Turia + Kant.

Marchart, Oliver (1998b): Einleitung: Undarstellbarkeit und ontologische Differenz. In: Marchart, Oliver (Hrsg.): Das Undarstellbare der Politik: zur Hegemonietheorie Ernesto Laclaus. Wien: Turia + Kant, 7-22.

Marchart, Oliver (1998c): Gibt es eine Politik des Politischen? Démocratie à venir betrachtet von Clausewitz aus dem Kopfstand. In: Marchart, Oliver (Hrsg.): Das Undarstellbare der Politik: zur Hegemonietheorie Ernesto Laclaus. Wien: Turia + Kant, 90-122.

Markard, Jochen; Raven, Rob; Truffer, Bernhard (2012): Sustainability transitions: An emerging field of research and its prospects. In: Research Policy, 41 (6), 955967.

Marshall, Mipsie; Ockwell, David; Byrne, Rob (2017): Sustainable energy for all or sustainable energy for men? Gender and the construction of identity within climate technology entrepreneurship in Kenya. In: Progress in Development Studies, 17 (2), 148-172.

Matinga, Margaret N.; Gill, Bigsna; Winther, Tanja (2019): Rice Cookers, Social Media, and Unruly Women: Disentangling Electricity's Gendered Implications in Rural Nepal. In: Frontiers in Energy Research, 6.

Mautz, Rüdiger (2017): Der Kampf um die postfossile Energiewende. In: Brand, Karl-Werner (Hrsg.): Die sozial-ökologische Transformation der Welt: Ein Handbuch. Frankfurt, New York: Campus Verlag, 189-215.

Mautz, Rüdiger; Byzio, Andreas; Rosenbaum, Wolf (2008): Auf dem Weg zur Energiewende; die Entwicklung der Stromproduktion aus erneuerbaren Energien in Deutschland; eine Studie aus dem Soziologischen Forschungsinstitut Göttingen (SOFI). Text abrufbar unter: https://opacplus.bsb-muenchen.de/metaopac/search? $\mathrm{db}=100 \&$ View $=$ default\&lokalkey $=12809362$.

Mayring, Philipp (1995): Qualitative Inhaltsanalyse: Grundlagen und Techniken. 5. Aufl. Weinheim: Beltz.

Mengelkamp, Esther; Notzeiten, Benedikt; Beer, Carolin; Dauer, David; Weinhardt, Christof (2018): A blockchain-based smart grid: towards sustainable local energy markets. In: Computer Science - Research and Development, 33, 207-214. 
Menghwani, Vikas; Zerriffi, Hisham; Dwivedi, Puneet; Marshall, Julian D.; Grieshop, Andrew; Bailis, Rob (2019): Determinants of Cookstoves and Fuel Choice Among Rural Households in India. In: EcoHealth, 16 (1), 21-60.

Morris, C.; Jungjohann, A. (2016): Energy democracy: Germany's energiewende to renewables. Cham: Palgrave Macmillan.

Mouffe, Chantal (1992): Feminism, Citizenship, and Radical Democratic Politics. In: Butler, Judith; Scott, Joan Wallach (Hrsg.): Feminists theorize the political. New York, NY [u.a.]: Routledge, 369-384.

Mouffe, Chantal (2000): Politics and Passions: the Stakes of Democracy. In: Ethical Perspectives, 7 (2-3), 146-150.

Mouffe, Chantal (2001): Feministische kulturelle Praxis aus anti-essentialistischer Sicht. In: Mouffe, Chantal; Trinks, Jürgen (Hrsg.): Feministische Perspektiven. Turia + Kant, 11-22.

Mouffe, Chantal (2007): Über das Politische: wider die kosmopolitische Illusion. Frankfurt a. M.: Suhrkamp.

Müller, Tadzio (2012): Von Energiekämpfen, Energiewenden und Energiedemokratie. In: Sozial-ökologische Transformation und Energiepolitik in Lateinamerika und Europa: Papers und Thesenpapiere für das internationale Seminar in Wien, 11.-14. Juli 2012.

Narr, Wolf-Dieter; von Winterfeld, Uta (Hrsg.) (2015): Niemands-Herrschaft: Eine Einführung in Schwierig-keiten, Herrschaft zu begreifen. Hamburg: VSA.

Netzwerk Vorsorgendes Wirtschaften (Hrsg.) (2013): Wege Vorsorgenden Wirtschaftens. Marburg: Metropolis-Verlag.

Netzwerk Vorsorgendes Wirtschaften; Gottschlich, Daniela; Knobloch, Ulrike; Mölders, Tanja; u.a. (2018): Was heißt hier gerecht? Perspektiven vorsorgend-transformativen Wirtschaftens: Thesen. Text abrufbar unter: https://www.vorsorgen deswirtschaften.de/wp-content/uploads/Gerechtigkeitsthesen-190327.pdf (Zugriff am 8.1.2020).

Neukirch, Mario (2018): Die Energiewende in der Bundesrepublik Deutschland (1974-2017) - Reform, Revolution, oder Restauration? Makroperspektive auf einen Dauerkonflikt. In: Sozialpolitik.CH, 1.

Nkrumah, Kwame (1965): Neo-Colonialism: The Last Stage of Imperialism. London: Nelson.

Nonhoff, Martin (2006): Politischer Diskurs und Hegemonie: Das Projekt »Soziale Marktwirtschaft«. Bielefeld: transcript.

Nonhoff, Martin (2007): Politische Diskursanalyse als Hegemonieanalyse. In: Nonhoff, Martin (Hrsg.): Diskurs - radikale Demokratie - Hegemonie. Zum politischen Denken von Ernesto Laclau und Chantal Mouffe. Bielefeld: transcript, 173194.

Nowotny, Helga (1989): Eigenzeit: Entstehung und Strukturierung eines Zeitgefühls. 2. Aufl. Frankfurt a.M.: Suhrkamp.

Di Nucci, Maria Rosaria; Brunnengräber, Achim (Hrsg.) (2014): Im Hürdenlauf zur Energiewende: Von Transformationen, Reformen und Innovationen. Wiesbaden: Springer VS.

Nünning, Ansgar; Nünning, Vera (2002): Neue Ansätze in der Erzähltheorie. Trier: Wiss. Verlag. 
Nussbaum, Martha C. (1992): Human Functioning and Social Justice: In Defense of Aristotelian Essentialism. In: Political Theory, 20, 202-246.

Nussbaum, Martha C. (1999): Gerechtigkeit oder das gute Leben. Frankfurt a. M.: Suhrkamp.

Nussbaum, Martha C. (2006): Frontiers of justice: disability, nationality, species membership. Cambridge [u.a.]: Belknap Press of Harvard Univ. Press.

O'Hara, Sabine (2000): Vorsorgendes Wirtschaften in einer sorglosen Welt. In: Biesecker, Adelheid; Matthes, Maite; Schön, Susanne; Scurrell, Babette (Hrsg.): Vorsorgendes Wirtschaften. Auf dem Weg zu einer Ökonomie des Guten Lebens. Bielefeld: Kleine, 225-237.

Ogwumike, Fidelis O.; Ozughalu, Uche M. (2014): Interactions among Poverty, Access to Modern Energy Sources, and Gender in Nigeria. In: The Journal of Developing Areas, 48 (4), 225-241.

Öko-Institut (2011): Zusatzerträge von ausgewählten deutschen Unternehmen und Branchen im Rahmen des EU-Emissionshandelssystems: Analyse für den Zeitraum 2005-2012.

Opratko, Benjamin (2012): Revolution I. In: Brand, Ulrich; Lösch, Bettina; Opratko, Benjamin; Thimmel, Stefan (Hrsg.): ABC der Alternativen 2.0. Hamburg: VSA, 248-249.

Pateman, Carole (1988): The sexual contract. Stanford [u.a.]: Polity.

Peirce, Charles S. (1967): Schriften. Frankfurt a. M.: Suhrkamp.

Polanyi, Karl (1995): The Great Transformation: politische und ökonomische Ursprünge von Gesellschaften und Wirtschaftssystemen. 1. Aufl. [Frankfurt a. M.]: Suhrkamp.

Ptak, Ralf (2008): Soziale Marktwirtschaft und Neoliberalismus: ein deutscher Sonderweg. In: Butterwegge, Christoph; Lösch, Bettina; Ptak, Ralf (Hrsg.): Neoliberalismus: Analysen und Alternativen. Wiesbaden: VS Verlag für Sozialwissenschaften, 69-90.

pwc (2014): Frauen in der Energiewirtschaft. Text abrufbar unter: www.pwc.de (Zugriff am 29.2.2020).

Radtke, Jörg (2016): Bürgerenergie in Deutschland: Partizipation Zwischen Gemeinwohl und Rendite. Wiesbaden: Springer VS.

Radtke, Jörg (2018): Energiedemokratie durch Bürgerenergie? Die Grenzen finanzieller Bürgerbeteiligung. In: GAIA, 27 (3), 284-286.

Radtke, Jörg; Canzler, Wert; Schreurs, Miranda; Wurster, Stefan (Hrsg.) (2019): Energiewende in Zeiten des Populismus. Wiesbaden: Springer VS.

Radtke, Jörg; Hennig, Bettina (2013): Die deutsche „Energiewende“ nach Fukushima: Der wissenschaftliche Diskurs zwischen Atomausstieg und Wachstumsdebatte. Marburg: Metropolis-Verlag.

Radtke, Jörg; Kersting, Norbert (Hrsg.) (2018): Die Energiewende in Deutschland Politikwissenschaftliche Perspektiven. Wiesbaden: Springer VS.

Räty, Riitta; Carlsson-Kanyama, Annika (2009): Comparing energy use by gender, age and income in some European countries. Stockholm. Text abrufbar unter: https://www.compromisorse.com/upload/estudios/000/101/foir2800.pdf (Zugriff am 29.2.2020).

Räty, Riitta; Carlsson-Kanyama, Annika (2010): Energy consumption by gender in some European countries. In: Energy Policy, 38 (1), 646-649. 
von Redecker, Eva (2011): Zur Aktualität von Judith Butler: Einleitung in ihr Werk. Wiesbaden: VS Verlag für Sozialwissenschaften.

Reißig, Rolf (2014): Transformation - Ein spezifischer Typ sozialen Wandels: Ein analytischer und sozialtheoretischer Entwurf. In: Brie, Michael (Hrsg.): Futuring: Perspektiven der Transformation im Kapitalismus über ihn hinaus. Münster: Westfälisches Dampfboot, 50-100.

Reißig, Rolf (2015): Neue Transformation - eine theoretische Konzeptualisierung und gesellschaftspolitische Problematisieren. In: Brie, Michael (Hrsg.): Mit Realutopien den Kapitalismus transformieren? Hamburg: VSA, 107-144.

Reusswig, Fritz; Eichenauer, Eva; Heger, Ines; Meyer-Ohlendorf, Lutz; Fahrenkrug, Katrin; Melzer, Michael; Scheepmaker, Teike; Braun, Florian; Ott, Konrad; Franzke, Jochen; u.a. (2017): Projekabschluss-Bericht Energiekonflikte-Akzeptanzkriterien und Gerechtigkeitsvorstellungen in der Energiewende. Potsdam. Text abrufbar unter: http://www.transformation-des-energiesystems.de/sites/de fault/files/Energiekonflikte_Abschlussbericht.pdf (Zugriff am 18.1.2019).

Rilling, Rainer (2014): Transformation als Futuring. In: Brie, Michael (Hrsg.): Futuring: Perspektiven der Transformation im Kapitalismus über ihn hinaus. Münster: Westfälisches Dampfboot, 12-49.

Roe, Emery (1994): Narrative Policy Analysis: Theory and Practice. Durham: Duke University Press.

Rose, Jeff; Cachelin, Adrienne (2018): Critical sustainability: incorporating critical theories into contested sustainabilities. In: Journal of Environmental Studies and Sciences, 8 (4), 518-525.

Rosenkranz, Gerd (2012): Das sabotierte Jahrhundertprojekt. In: Blätter für deutsche und internationale Politik, 11, 101-110.

Ruhose, Fedor (2019): Die AfD im Deutschen Bundestag: Zum Umgang mit einem neuen politischen Akteur. essentials. Wiesbaden: Springer.

Ryan, Sarah E. (2014): Rethinking gender and identity in energy studies. In: Energy Research \& Social Science, 1, 96-105.

Saave-Haarnack, Anna; Dengler, Corinna; Muraca, Barbara (2019): Feminisms and Degrowth - Alliance or Foundational Relation? In: Global Dialogue, 9 (1), 29-30.

Said, Edward W. (1979): Orientalism. New York: Vintage Books.

Sander, Hendrik (2016): Auf dem Weg zum grünen Kapitalismus? Die Energiewende nach Fukushima. Berlin: Bertz+Fischer.

Sauer, Birgit (1997): Geschlecht, Emotion und Politik. In: Reihe Politikwissenschaft/Institut für Höhere Studien, Abt. Politikwissenschaft, 46, Text abrufbar unter: https://www.ssoar.info/ssoar/bitstream/handle/document/26393/ssoar-1997sauer-geschlecht.pdf? sequence $=1$ (Zugriff am 25.10.2018).

De Saussure, Ferdinand (1967): Grundfragen der allgemeinen Sprachwissenschaft. 2. Aufl. Berlin: de Gruyter.

Scheich, Elvira; Schultz, Irmgard; Forschungsgruppe Soziale Ökologie. (1989): Soziale Ökologie und Feminismus. Frankfurt a. M.: IKO-Verlag für Interkulturelle Kommunikation.

Scherer, Christiane (2014): Das menschliche und das gute menschliche Leben. In: Deutsche Zeitschrift für Philosophie, 41 (5), 905-920. 
Schlacke, Sabine; Kröger, James (2015): Die Energiewende - Herausforderungen für einen gestaltenden Staat. In: Jahrbuch für christliche Sozialwissenschaften, 56, 37-47.

Schmid, Eva; Pechan, Anna; Mehnert, Marlene; Eisenack, Klaus (2017): Imagine all these futures: On heterogeneous preferences and mental models in the German energy transition. In: Energy Research \& Social Science, 27, 45-56.

Schomerus, Thomas; Henkel, Andrea (2012): Die Marktprämie im EEG 2012 - eine erste Zwischenbilanz. In: EnergieRecht, 1, 13-21.

Schubert, Josef; Kurt, Daniel; Meyer, Thomas; Möst, Dominik (2015): Die Transformation des deutschen Energiesystems aus der Perspektive der Bevölkerung. In: Zeitschrift für Energiewirtschaft, 39 (1), 49-61.

Schultz, Irmgard; Hummel, Diana; Hayn, Doris (2006): Geschlechterverhältnisse. In: Becker, Egon; Jahn, Thomas (Hrsg.): Soziale Ökologie. Grundzüge einer Wissenschaft von den gesellschaftlichen Naturverhältnissen. Frankfurt, New York: Campus Verlag, 224-235.

Schumpeter, Joseph Alois (1965): Geschichte der ökonomischen Analyse: Band 1. Göttingen: Vandenhoeck \& Ruprecht.

Schwab-Trapp, Michael (2001): Diskurs als soziologisches Konzept: Bausteine für eine soziologisch orientierte Diskursanalyse. In: Keller, Reiner; Hirseland, Andreas; Schneider, Werner; Viehöver Willy (Hrsg.): Handbuch Sozialwissenschaftliche Diskursanalyse. 1, Theorien und Methoden. Opladen: Leske + Budrich, 261-284.

Schweizer-Ries, Petra; Rau, Irina; Hildebrand, Jan (2011): Akzeptanz- und Partizipationsforschung zu Energienachhaltigkeit. In: FVEE Themen, 138-144. Text abrufbar unter: http://www.fvee.de/fileadmin/publikationen/Themenhefte/th2011-2/ th2011_07_01.pdf (Zugriff am 24.10.2018).

Sikka, Tina (2019): Climate Technology, Gender, and Justice. Cham: Springer International Publishing.

Smith, Adam (1974): Der Wohlstand der Nationen. 3. Auflage. München: Deutscher Taschenbuch Verlag.

Smith, Anna-Marie (1998): Das Unbehagen der Hegemonie. Die politischen Theorien von Judith Butler, Ernesto Laclau und Chantal Mouffe. In: Marchart, Oliver (Hrsg.): Das Undarstellbare der Politik: zur Hegemonietheorie Ernesto Laclaus. Wien: Turia + Kant, 225-237.

Smith, Neil (2008): Uneven development: nature, capital, and the production of space. Athens, Georgia: University of Georgia Press.

Spitzner, Meike; Hummel, Diana; Stieß, Immanuel; Alber, Gotelind; Röhr, Ulrike (2020): Interdependente Genderaspekte der Klimapolitik. Dessau-Roßlau. Text abrufbar unter: http://www.umweltbundesamt.de/publikationen (Zugriff am 29.2. 2020).

Spivak, Gayatri Chakravorty (1985): The Rani of Sirmur: An Essay in Reading the Archives. In: History and Theory, 24 (3), 247-272.

Spivak, Gayatri Chakravorty (2011): Can the subaltern speak? Postkolonialität und Subalterne Artikulation. Unveränderter Nachdruck. Wien: Turia + Kant.

Spivak, Gayatri Chakravorty (1999): A Critique of Postcolonial Reason: Toward a History of the Vanishing Present. Cambridge [u.a.]: Harvard University Press. 
Staten, Henry (1986): Wittgenstein and Derrida. Lincoln [u.a.]: University of Nebraska Press.

Strauss, Anselm L.; Corbin, Juliet M. (1996): Grounded theory: Grundlagen qualitativer Sozialforschung. Weinheim: Beltz.

Šumič-Riha, Jelica (1998): Politik der Treue, Treue der Politik. In: Marchart, Oliver (Hrsg.): Das Undarstellbare in der Politik: Zur Hegemonietheorie Ernesto Laclaus. Wien: Turia + Kant, 132-158.

Sutterlütti, Simon; Meretz, Stefan; Rosa Luxemburg Stiftung (Hrsg.) (2018): Kapitalismus aufheben: eine Einladung, über Utopie und Transformation neu nachzudenken. Hamburg: VSA.

Swyngedouw, Erik (2010): Apocalypse Forever? Post-political Populism and the Spectre of Climate Change. In: Culture \& Society, 27 (3), 213-232.

Swyngedouw, Erik (2011): Depoliticized Environments: The End of Nature, Climate Change and the Post-Political Condition. In: Royal Institute of Philosophy Supplements, 69, 253-274.

Swyngedouw, Erik (2015): The Non-political Politics of Climate Change. In: ACME: An International Journal for Critical Geographies, 12 (1), 1-8.

Theoriegruppe Vorsorgendes Wirtschaften (2000): Zur theoretisch-wissenschaftlichen Fundierung Vorsorgenden Wirtschaftens. In: Biesecker, Adelheid; Mathes, Maite; Scurrell, Babette; Schön, Susanne (Hrsg.): Vorsorgendes Wirtschaften: auf dem Weg zu einer Ökonomie des guten Lebens. Bielefeld: Kleine, 27-70.

Thomas, Michael (2012): Der erfolgreiche Einstieg in die Energiewende und den sozialökologischen Umbau als Voraussetzung einer „großen Transformation“. In: LIFIS Online 28.06.2012, Text abrufbar unter: https://leibniz-institut.de/archiv/ thomas_28_06_12.pdf.

Torfing, Jacob (1999): New theories of discourse: Laclau, Mouffe, and Žižek. Oxford [u.a.]: Blackwell Publishers.

Umweltbundesamt (2011): Stromerzeugung aus erneuerbaren Energien - klimafreundlich und ökonomisch sinnvoll. Dessau-Roßlau.

Umweltbundesamt (2018): Transformative Umweltpolitik: Nachhaltige Entwicklung konsequent fördern und gestalten. Dessau-Roßlau.

Unmüßig, Barbara (2015): Die Rolle der Zivilgesellschaft in der Klimapolitik. In: GAIA, 24 (3), 160-163.

van Dijk, Teun A. (1992): Subtiler Rassismus in westlichen Parlamenten. In: Butterwegge, Christoph; Jäger, Siegfried (Hrsg.): Rassismus in Europa. Köln: BundVerlag, 200-212.

van Dijk, Teun A. (1997): Discourse as structure and process. Reprinted. London [u.a.]: SAGE.

Viehöver, Willy (2008): Die Wissenschaft und die Wiederverzauberung des sublunaren Raumes. Der Klimadiskurs im Licht der narrativen Diskursanalyse. In: Keller, Reiner; Hirseland, Andreas; Schneider, Werner; Viehöver, Willy (Hrsg.): Handbuch Sozialwissenschaftliche Diskursanalyse. 2, Forschungspraxis. Wiesbaden: VS Verl. f. Sozialwissenschaften, 233-270.

von Winterfeld, Uta (2007): Keine Nachhaltigkeit ohne Suffizienz: Fünf Thesen und Folgerungen. In: Vorgänge, 3, 46-54.

von Winterfeld, Uta (2012): Partizipieren reicht nicht, Klimawandel und demokratische Kultur. In: dynaklim-Publikationen, 32. 
Wamukonya, Njeri; Skutsch, Margaret (2002): Gender Angle to the Climate Change Negotiations. In: Energy \& Environment, 13 (1), 115-124.

WBGU (2011a): Factsheet Nr.4/2011: Transformation zur Nachhaltigkeit.

WBGU (2011b): Hauptgutachten: Welt im Wandel. Gesellschaftsvertrag für eine Große Transformation.

Weller, Ines (2004): Nachhaltigkeit und Gender: neue Perspektiven für die Gestaltung und Nutzung von Produkten. München: Ökom Verlag.

Weller, Ines (2012): Klimawandel, Konsum und Gender. In: Çağlar, Gülay; Castro Varela, María do Mar; Schwenken, Helen (Hrsg.): Geschlecht - Macht - Klima. Opladen [u.a.]: Verlag Barbara Budrich, 177-190.

Weller, Ines (2013): Konsum- und Lebensstile: Nachhaltiger Konsum, Lebensstile und Geschlechterverhältnisse. In: Hofmeister, Sabine; Katz, Christine; Mölders, Tanja (Hrsg.): Geschlechterverhältnisse und Nachhaltigkeit. Opladen: Budrich.

Weller, Ines; Röhr, Ulrike; Fischer, Karin; Böckmann, Melanie; Birk, Nanna (2016): Chancengerechtigkeit im Klimawandel. artec Forschungszentrum Nachhaltigkeit; GenderCC - Women for Climate Justice e.V. Bremen, Berlin.

West, Candace; Zimmermann, Don H. (1987): Doing Gender. In: Gender \& Society, 2 (1), 125-151.

Wischermann, Ulla (2003): Feministische Theorien zur Trennung von privat und öffentlich - Ein Blick zurück nach vorn. In: Feministische Studien, 1 (21), 23-34.

Wissen, Markus (2014): Ökologische Krise und „große Transformation“: Einführung in den Themenschwerpunkt. In: Österreichische Zeitschrift für Politikwissenschaft, 43, 49-54.

Wodak, Ruth; Chilton, Paul A. (Hrsg.) (2005): A new agenda in (critical) discourse analysis: theory, methodology, and interdisciplinary. Amsterdam [u.a.]: J. Benjamins.

Wodak, Ruth; Meyer, Michael (Hrsg.) (2009): Methods of critical discourse analysis. 2. Aufl. Los Angeles [u.a.]: SAGE.

Wöhl, Stefanie (2007): Die Subjekte der radikalen Demokratie: Institutionalisierte Differenzen und Barrieren gegenhegemonialer Artikulation. In: Nonhoff, Martin (Hrsg.): Diskurs, radikale Demokratie, Hegemonie : zum politischen Denken von Ernesto Laclau und Chantal Mouffe. Bielefeld: transcript, 139-158.

World Commission on Environment and Development (1987): Report of the World Commission on Environment and Development: Our Common Future. Text abrufbar unter: http://www.un-documents.net/our-common-future.pdf (Zugriff am 20.2.2018).

\section{Webseiten}

www.bmwi.de - EEG 2016: BMWi - Entwurf eines Gesetzes zur Einführung von Ausschreibungen für Strom aus erneuerbaren Energien und zu weiteren Änderungen des Rechts der erneuerbaren Energien (Erneuerbare-Energien-Gesetz EEG 2016). https://www.bmwi.de/Redaktion/DE/Downloads/G/gesetzentwurfausschreibungen-erneuerbare-energien-aenderungen-eeg-2016.html (Zugriff am 17.2.2020). 
www.bmwi.de - EEG 2017; wettbewerbliche Vergütung: EEG 2017: Wettbewerbliche Vergütung. http://www.bmwi.de/DE/Themen/Energie/Erneuerbare-Energien/ eeg-2017-wettbewerbliche-verguetung.html (Zugriff am 18.12.2016).

www.bmwi.de - EEG 2017: Die nächste Phase der Energiewende: Das EEG 2017. https:/www.bmwi.de/Redaktion/DE/Artikel/Energie/eeg-2017-start-in-die-naech ste-phase-der-energiewende.html (Zugriff am 17.2.2020).

www.bmwi.de - Energiepolitik: Ziele internationaler Energiepolitik. https://www. bmwi.de/Redaktion/DE/Artikel/Energie/internationale-energiepolitik-1.html (Zugriff am 11.11.2019).

www.bundesregierung.de - Energiewende: Presse- und Informationsdienst der Bundesregierung. https://www.bundesregierung.de/breg-de/themen/energiewende (Zugriff am 29.8.2019).

www.bundesregierung.de - Ethikkommission. https://www.bundesregierung.de/bregde/suche/ethikkommission-441116.

www.bundesregierung.de - Klimaschutzprogramm. https://www.bundesregierung.de /breg-de/themen/klimaschutz/klimaschutzprogramm-2030-1673578 (Zugriff am 28.10.2019).

www.bundestag.de/services/opendata (Zugriff am 22.8.2019).

www.bundestag.de - Geschäftsordnung: Deutscher Bundestag - Erläuterungen zur Geschäftsordnung. https://www.bundestag.de/parlament/aufgaben/rechtsgrundla gen/go_erl/gescho07-244670 (Zugriff am 30.8.2019).

www.bundesverfassungsgericht.de: Kernbrennstoffsteuergesetz mit dem Grundgesetz unvereinbar und nichtig. https://www.bundesverfassungsgericht.de/Shared Docs/Pressemitteilungen/DE/2017/bvg17-042.html (Zugriff am 25.9.2019).

www.desertec.org: Clean Power from the Deserts - DESERTEC Foundation. https:// www.desertec.org/concept-note/ (Zugriff am 24.9.2019).

www.dip21.bundestag.de. http://dip21.bundestag.de/dip21.web/br (Zugriff am 22.8. 2019).

www.diw.de - Ökosteuer: DIW Berlin: 20 Jahre Ökosteuer: finanz- und sozialpolitisch top, umweltpolitisch ein Flop. https://www.diw.de/de/diw_01.c.617690.de/ themen_nachrichten/20_jahre_oekosteuer_finanz_und_sozialpolitisch_top_umwe ltpolitisch_ein_flop.html (Zugriff am 16.10.2019).

www.duden.de

www.erneuerbare-energien.de: Erneuerbare Energien in Zahlen. https://www.erneuer bare-energien.de/EE/Navigation/DE/Service/Erneuerbare_Energien_in_Zahlen/E ntwicklung/entwicklung-der-erneuerbaren-energien-in-deutschland.html (Zugriff am 18.12.2018).

www.faz.net - Brennelementesteuer: Ungerechter Fiskus: Wieso die Kernbrennstoffsteuer nicht funktioniert hat. https://www.faz.net/aktuell/wirtschaft/wirtschaftspo litik/ungerechter-fiskus-wieso-die-kernbrennstoffsteuer-nicht-funktioniert-hat-15 051128.html (Zugriff am 27.2.2020).

www.fridaysforfuture.de - Forderungen. https://fridaysforfuture.de/forderungen/ (Zugriff am 28.10.2019).

www.fridaysforfuture.de - offener Brief: Offener Brief an die Bundesregierung. https://fridaysforfuture.de/offener-brief-klimakabinett/ (Zugriff am 28.10.2019). 
www.oeko.de - Zusatzgewinne. https://www.oeko.de/aktuelles/2011/zusatzertraegevon-ausgewaehlten-deutschen-unternehmen-und-branchen-im-rahmen-des-eu-em issionshandelss/ (Zugriff am 11.7.2019).

www.polmine.github.io (Zugriff am 21.8.2019).

www.polmine.sowi.uni-due.de (Zugriff am 1.12.2017).

www.rls.de: Kritische Transformationsforschung. http://ifg.rosalux.de/kritische-trans formationsforschung/.

www.scientists4future.org: Stellungnahme von Wissenschaftlerinnen und Wissenschaftlern zu den Protesten für mehr Klimaschutz. https://www.scientists4future. org/stellungnahme/stellungnahme-de/ (Zugriff am 29.2.2020).

www.spiegel.de: Interview mit Peter Ramsauer zur Energiewende. http://magazin. spiegel.de/EpubDelivery/spiegel/pdf/125966639 (Zugriff am 18.1.2018).

www.tei-c.org: TEI: Text Encoding Initiative (Zugriff am 21.8.2019).

www.transformation-des-energiesystems.de: Umwelt- und gesellschaftsverträgliche Transformation des Energie-systems (Zugriff am 13.11.2019).

www.umweltbundesamt.de - Emissionshandel. https://www.umweltbundesamt.de/da ten/klima/der-europaeische-emissionshandel\#textpart-1 (Zugriff am 11.10.2019). www.umweltbundesamt.de - Energieverbrauch: Energieverbrauch nach Energieträgern, Sektoren und Anwendungen. https://www.umweltbundesamt.de/daten/ener gie/energieverbrauch-nach-energietraegern-sektoren.

www.umweltbundesamt.de - erneuerbare Energien. https://www.umweltbundes amt.de/indikator-erneuerbare-energien\#textpart-1 (Zugriff am 25.11.2019).

www.umweltbundesamt.de - Transformation: Gesellschaft erfolgreich verändern. https://www.umweltbundesamt.de/themen/nachhaltigkeit-strategien-international es/gesellschaft-erfolgreich-veraendern (Zugriff am 12.11.2019).

www.umweltbundesamt.de - Treibhausgasemissionen: Emissionsquellen. https:// www.umweltbundesamt.de/daten/energie/energiebedingte-emissionen\#energiebe dingte-treibhausgas-emissionen (Zugriff am 20.2.2020).

www.unendlich-viel-energie.de - verfehlte Ausbauziele: Verfehlte Ausbauziele und hoher Stromexport: Was läuft in Deutschland schief? Agentur für Erneuerbare Energien. https://www.unendlich-viel-energie.de/themen/strom/verfehlte-ausbau ziele-und-hoher-stromexport (Zugriff am 18.10.2019).

www.vorsorgendeswirtschaften.de (Zugriff am 01.01.2020). www.zeit.de - Proteste: Demonstration in Berlin: Zehntausende protestierten gegen Atomkraft. https://www.zeit.de/politik/deutschland/2010-09/demonstration-atom energie-berlin (Zugriff am 20.11.2018). 



\section{Anhang}

Tabelle 26: Übersicht über zitierte Plenarprotokolle über Legislaturperioden; (Gesamtzahl: 124)

\begin{tabular}{|c|c|c|c|c|}
\hline 14. Lp & 15. Lp & 16. Lp & 17. Lp & 18. Lp \\
\hline 06.05 .1999 & 29.10 .2002 & 16.02 .2006 & 28.10 .2010 & 17.01.2014 \\
\hline 07.10 .1999 & 07.11 .2002 & 28.03 .2006 & 25.11 .2010 & 29.01 .2014 \\
\hline 25.11 .1999 & 03.12 .2002 & 06.04 .2006 & 17.03 .2011 & 31.01 .2014 \\
\hline 16.12 .1999 & 10.04 .2003 & 21.06 .2006 & 24.03 .2011 & 13.02 .2014 \\
\hline 25.02 .2000 & 21.05 .2003 & 08.03 .2007 & 12.05 .2011 & 19.03 .2014 \\
\hline 06.04 .2000 & 26.06 .2003 & 06.07 .2007 & 09.06.2011 & 10.04 .2014 \\
\hline 14.09 .2000 & 13.11 .2003 & 07.11 .2007 & 30.06 .2011 & 11.04 .2014 \\
\hline 13.10 .2000 & 16.01 .2004 & 10.04 .2008 & 04.07 .2011 & 08.05 .2014 \\
\hline 30.11 .2000 & 28.05 .2004 & 29.05 .2008 & 08.07.2011 & 21.05 .2014 \\
\hline 29.03 .2001 & 09.09.2004 & 06.06 .2008 & 07.09.2011 & 23.05 .2014 \\
\hline 21.06 .2001 & 24.09 .2004 & 26.06 .2008 & 22.09.2011 & 25.06 .2014 \\
\hline 12.10 .2001 & 02.12 .2004 & 18.12 .2008 & 19.10 .2011 & 26.06 .2014 \\
\hline 14.12.2001 & 16.02 .2005 & 19.03.2009 & 04.11 .2011 & 27.06 .2014 \\
\hline 25.01 .2002 & 17.02 .2005 & 02.07.2009 & 22.11 .2011 & 26.09 .2014 \\
\hline 28.02.2002 & 24.02 .2005 & & 24.11 .2011 & 06.11 .2014 \\
\hline 22.03 .2002 & & & 19.01 .2012 & 13.11 .2014 \\
\hline 16.05 .2002 & & & 08.02 .2012 & 04.12 .2014 \\
\hline \multirow[t]{13}{*}{27.06 .2002} & & & 08.03 .2012 & 29.01 .2015 \\
\hline & & & 22.03 .2012 & 05.02 .2015 \\
\hline & & & 29.03 .2012 & 26.03 .2015 \\
\hline & & & 24.05 .2012 & 24.04 .2015 \\
\hline & & & 14.06 .2012 & 08.05 .2015 \\
\hline & & & 11.09 .2012 & 22.05 .2015 \\
\hline & & & 14.09 .2012 & 02.07 .2015 \\
\hline & & & 26.09 .2012 & 03.12 .2015 \\
\hline & & & 27.09 .2012 & 18.12 .2015 \\
\hline & & & 17.10 .2012 & 29.01 .2016 \\
\hline & & & 18.10 .2012 & 15.04 .2016 \\
\hline & & & 20.11 .2012 & 29.04 .2016 \\
\hline & & & 22.11 .2012 & 01.06 .2016 \\
\hline
\end{tabular}




\begin{tabular}{|l|l|l|l|}
\hline & & 22.11 .2012 & 23.06 .2016 \\
& & 13.12 .2012 & 24.06 .2016 \\
& & 17.01 .2013 & 08.07 .2016 \\
& & 28.02 .2013 & 09.09 .2016 \\
& & 01.03 .2013 & 29.06 .2017 \\
& & 14.03 .2013 & \\
& & 15.03 .2013 & \\
& & 21.03 .2013 & \\
& & 18.04 .2013 & \\
& & 25.04 .2013 & \\
& & 16.05 .2013 & \\
& & 13.06 .2013 & \\
& &
\end{tabular}

Quelle: eigene Darstellung 


\section{Politikwissenschaft}

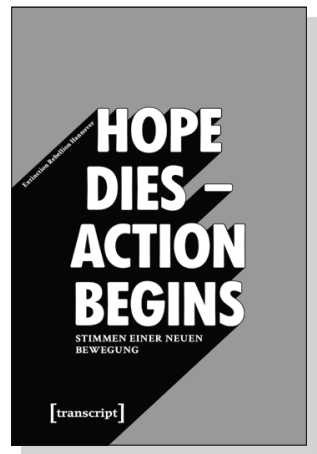

Extinction Rebellion Hannover

"Hope dies - Action begins":

Stimmen einer neuen Bewegung

2019, 96 S., kart.

7,99€ (DE), 978-3-8376-5070-9

E-Book: kostenlos erhältlich als Open-Access-Publikation, ISBN 978-3-8394-5070-3

EPUB: kostenlos erhältlich als Open-Access-Publikation, ISBN 978-3-7328-5070-9

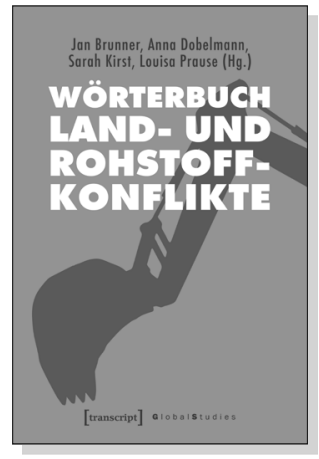

Jan Brunner, Anna Dobelmann,

Sarah Kirst, Louisa Prause (Hg.)

\section{Wörterbuch Land- und Rohstoffkonflikte}

2019, 326 S., kart., Dispersionsbindung, 1 SW-Abbildung 24,99€ (DE), 978-3-8376-4433-3

E-Book: 21,99 € (DE), ISBN 978-3-8394-4433-7

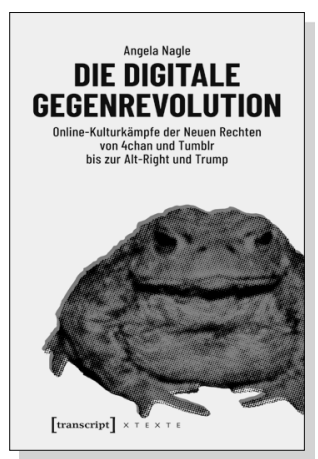

Angela Nagle

\section{Die digitale Gegenrevolution}

Online-Kulturkämpfe der Neuen Rechten

von 4chan und Tumblr bis zur Alt-Right und Trump

2018, 148 S., kart.

$19,99 €(D E), 978-3-8376-4397-8$

E-Book: 17,99 € (DE), ISBN 978-3-8394-4397-2

EPUB: $17,99 €$ (DE), ISBN 978-3-7328-4397-8 


\section{Politikwissenschaft}

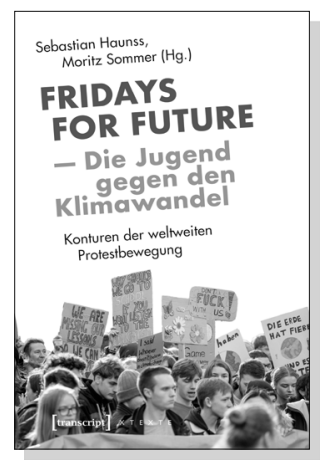

Sebastian Haunss, Moritz Sommer (Hg.)

Fridays for Future -

Die Jugend gegen den Klimawandel

Konturen der weltweiten Protestbewegung

Oktober 2020, 264 S., kart.

$22,00 €(D E), 978-3-8376-5347-2$

E-Book: kostenlos erhältlich als Open-Access-Publikation

PDF: ISBN 978-3-8394-5347-6

ISBN 978-3-7328-5347-2

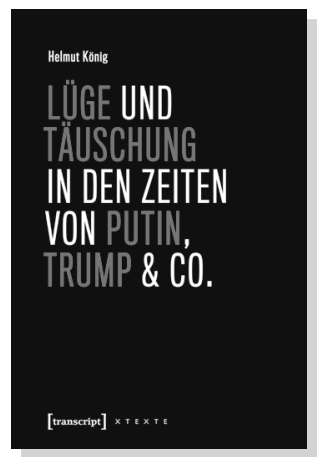

Helmut König

Lüge und Täuschung

in den Zeiten von Putin, Trump \& Co.

September 2020, 360 S., kart.

$29,50 €(D E), 978-3-8376-5515-5$

E-Book:

PDF: $26,99 €$ (DE), ISBN 978-3-8394-5515-9

EPUB: $26,99 €$ (DE), ISBN 978-3-7328-5515-5

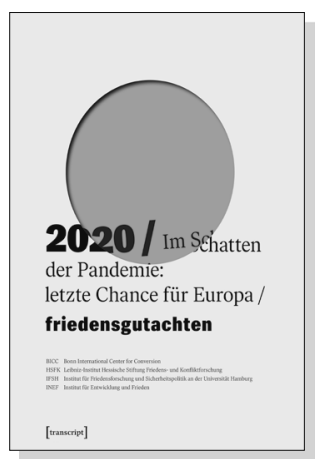

BICC Bonn International Center for Conversion, HSFK Leibniz-Institut Hessische Stiftung Friedens- und Konfliktforschung, IFSH Institut für Friedensforschung und Sicherheitspolitik an der Universität Hamburg, INEF Institut für Entwicklung und Frieden

\section{Friedensgutachten 2020}

Im Schatten der Pandemie: letzte Chance für Europa

Juni 2020, 160 S., kart., 33 Farbabbildungen

15,00€ (DE), 978-3-8376-5381-6

E-Book: kostenlos erhältlich als Open-Access-Publikation PDF: ISBN 978-3-8394-5381-0 